\title{
Ecologia e conservação dos cerrados, campos e florestas do Triângulo \\ Mineiro e Sudeste de Goiás
}
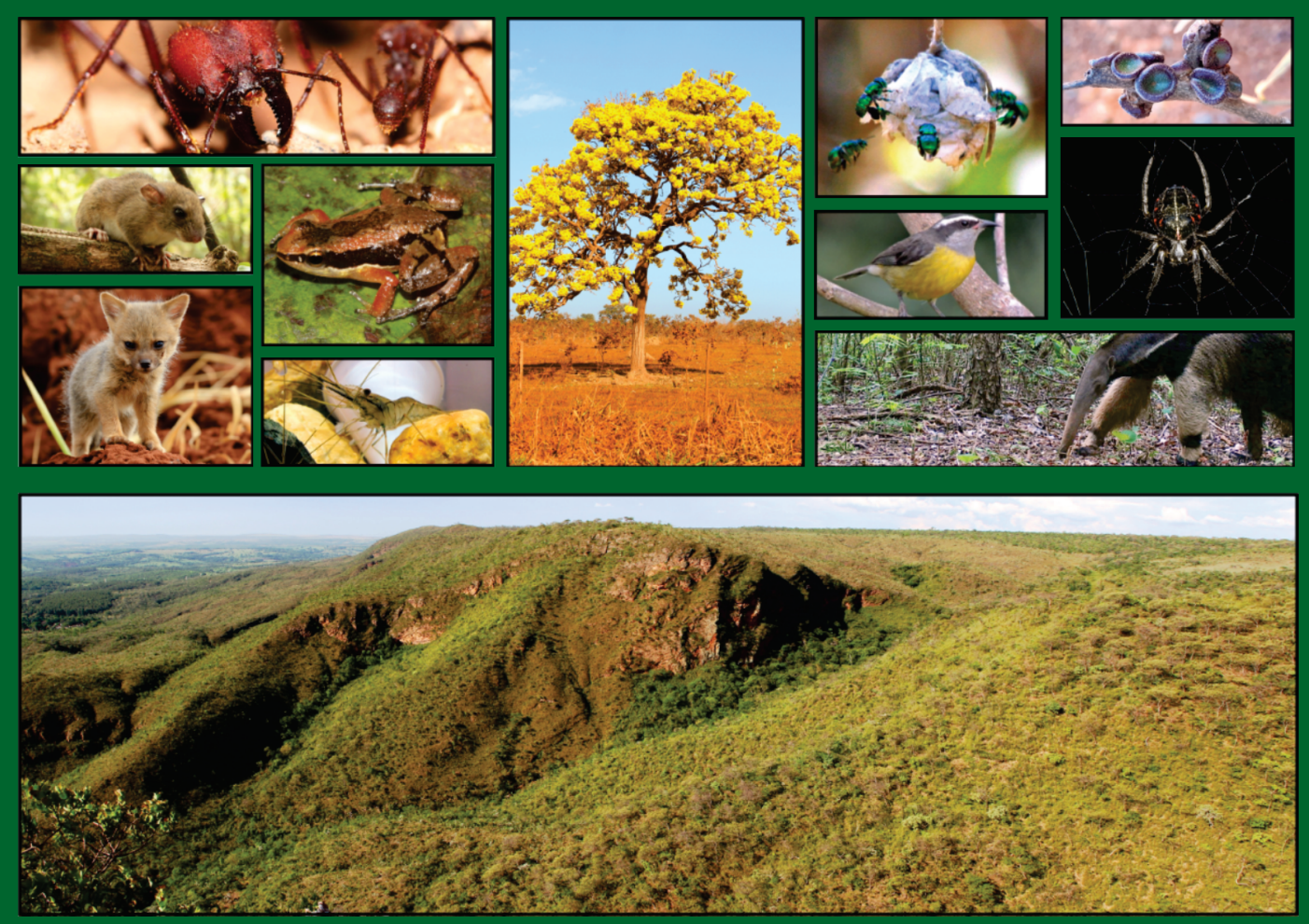

HERALDO L. VASCONGELOS

(Organizador) 


\section{HERALDO L. VASCONCELOS}

(Organizador)

\section{Ecologia e conservação dos cerrados, campos e florestas do Triângulo Mineiro e Sudeste de Goiás}




\title{
Capa e Revisão de Texto
}

Jonas B. Maravalhas

\section{Diagramação \\ Adriana Cardoso}

\section{Projeto Gráfico}

Regência e Arte Editora

\begin{abstract}
Apoio
Programa de Pesquisa Ecológica de Longa Duração (PELD-CNPq)

Curso de Pós-Graduação em Ecologia e Conservação dos Recursos Naturais, Universidade Federal de Uberlândia (UFU)

Fundação de Amparo à Pesquisa do Estado de Minas Gerais (FAPEMIG)
\end{abstract}

Dados Internacionais de Catalogação na Publicação (CIP) Sistema de Bibliotecas da UFU, MG, Brasil.

E19 Ecologia e conservação dos cerrados, campos e florestas do Triângulo Mineiro e Sudeste de Goiás [recurso eletrônico] / Heraldo L. Vasconcelos (organização). Uberlândia : Regência e Arte, 2020.

ISBN: 978-65-86084-16-0 (digital)

DOI: $10.14393 /$ UFU-978-65-86084-16-0

Disponível em: https://www.peldtriangulomg.com Inclui bibliografia.

Inclui ilustração

1. Ecologia. 2. Cerrados. 3. Biodiversidade - Conservação. I. Vasconcelos, Heraldo L., (org.).

CDU: 574 


\section{APRESENTAÇÃO}

O intuito deste livro é divulgar os resultados de pesquisas científicas sobre a ecologia e a conservação dos cerrados, campos e florestas da região do Triângulo Mineiro e Sudeste de Goiás. A maior parte destas pesquisas foi desenvolvida no âmbito do Programa de Pesquisa Ecológica de Longa Duração (PELD). O PELD é uma iniciativa do Conselho Nacional de Pesquisas e Desenvolvimento Científico (CNPq). Atualmente este programa financia pesquisas em 36 centros de estudo (os chamados "sítios") espalhados por todos os biomas brasileiros, sendo o sítio Triângulo Mineiro e Sudeste de Goiás (TMSG) um dos sítios que faz pesquisas ecológicas de longo prazo sobre a biodiversidade do Cerrado. O PELD dá apoio financeiro ao sítio TMSG desde 2012, porém parte dos estudos aqui apresentados tiveram início até mesmo antes desta data. São pesquisas que envolvem primariamente, mas não exclusivamente, docentes e discentes do Programa de Pós-Graduação em Ecologia e Conservação de Recursos Naturais da Universidade Federal de Uberlândia (UFU) em Minas Gerais. Além de apoio financeiro do CNPq, quer através do PELD ou de outros programas do $\mathrm{CNPq}$, os autores deste livro muitas vezes tiveram apoio de outras agências de fomento, como a Coordenação de Aperfeiçoamento de Pessoal de Nível Superior (CAPES) e a Fundação de Amparo à Pesquisa do Estado de Minas Gerais (Fapemig), ou até mesmo de empresas como a LD Celulose.

O sítio TMSG está situado em uma região já bastante afetada pelo desmatamento e degradação ambiental, ainda que esta seja uma região considerada como prioritária para a conservação de alguns grupos de plantas e animais do Cerrado. Há relativamente poucas unidades de conservação no Triângulo Mineiro e Sudeste de Goiás. Além disto, algumas destas têm tamanho reduzido ( $<500$ hectares) ou se apresentam em fase de regeneração, como é o caso do Parque Estadual de Pau Furado, criado em 2007 como uma medida de compensação pelos danos decorrentes da criação dos reservatórios da Usina Hidrelétrica Amador Aguiar, no rio Araguari. Parte da vegetação nativa que ainda resta em nossa região de estudos está situada dentro de propriedades privadas onde há pastagens para a criação de gado, cultivos agrícolas ou plantios de árvores. Em função disso, o TMSG desenvolve pesquisas não apenas em unidades de conservação e remanescentes de vegetação nativa, mas também nos agroecossistemas do entorno uma vez que estes são relevantes para o entendimento da ecologia, dinâmica e manutenção das populações animais que ocorrem na região.

Como em outras áreas do Brasil central, a vegetação nativa da região de estudos do TMSG inclui não apenas as vegetações savânicas mais típicas do bioma Cerrado, como o cerrado sensu stricto, mas também vegetações florestais (cerradão, matas decíduas e semidecíduas e matas de galeria) e campestres (campos úmidos e veredas). Assim, esta é uma região heterogênea, não só por ser composta por um mosaico de áreas naturais e manejadas, mas também pela própria heterogeneidade e estado de conservação da vegetação nativa. Como exemplificado em vários capítulos deste livro, esta heterogeneidade espacial e temporal é chave para descrever e entender os padrões de biodiversidade.

Vários grupos taxonômicos são estudados no âmbito do sítio PELD TMSG, incluindo-se plantas lenhosas e herbáceas, mamíferos, aves, anfíbios e vários grupos 
de invertebrados terrestres e aquáticos. Além de apresentar resultados das pesquisas específicas desenvolvidas com cada um destes grupos, o livro traz também informações sobre a história natural, importância e ameaças à conservação desses grupos. Nosso intuito é dar ao público em geral maior familiaridade com a biologia das plantas e animais do Cerrado. Desta forma, esperamos estimular uma maior conscientização sobre o valor e importância deste que é um dos biomas mais ameaçados do planeta. Esperamos também chamar a atenção sobre a importância da pesquisa científica básica e estimular a formação de uma nova geração de pesquisadores.

Boa leitura!

Heraldo L. Vasconcelos, Uberlândia, Minas Gerais

Agosto de 2020 


\section{AGRADECIMENTOS}

Agradecemos ao Conselho Nacional de Desenvolvimento Científico e Tecnológico - CNPq pelo apoio financeiro dado através de seu Programa de Pesquisa Ecológica de Longa Duração - PELD ao projeto "Padrões de biodiversidade e processos ecológicos em ecossistemas de Cerrado na região do Triângulo Mineiro e Sudeste de Goiás (sub-bacia do Rio Paranaíba)" (Processo CNPq 403733/2012-0 e 441225/20160 ). Apoio financeiro a este projeto de pesquisas também foi dado pela Fundação de Amparo à Pesquisa do Estado de Minas Gerais - FAPEMIG, pela Coordenação de Aperfeiçoamento de Pessoal de Nível Superior - CAPES e pela LD Celulose.

Agradecemos à Universidade Federal de Uberlândia - UFU e ao Programa de Pós-Graduação em Ecologia e Conservação de Recursos Naturais - PPGECRN pelo apoio logístico e suporte para o desenvolvimento dos trabalhos de campo na Reserva Ecológica do Panga. Aos gestores do Parque Estadual da Serra de Caldas Novas, do Parque Estadual do Pau Furado e da RPPN Galheiros pela permissão para condução das pesquisas de campo. Aos gestores do Parque Estadual da Serra de Caldas Novas pelo apoio para a realização do curso Ecologia de Campo do PPGECRN. Por fim, agradecemos a todos os alunos de graduação e pós-graduação da UFU que voluntariamente deram suporte eventual aos nossos trabalhos de campo. 



\section{LISTA DE AUTORES}

Adilson Quero, Programa de Pós-graduação em Ecologia e Conservação de Recursos Naturais, Universidade Federal de Uberlândia. E-mail: adilsonquero@gmail.com

Alan N. Costa, Instituto de Biologia, Universidade Federal de Uberlândia.

E-mail: alan.costa@ufu.br

Aline L. Nascimento, Programa de Pós-graduação em Ecologia e Conservação de Recursos Naturais, Universidade Federal de Uberlândia.

E-mail: aline.leles@hotmail.com

Ana Cláudia Garcia Barboza, Programa de Pós-Graduação em Ecologia e Conservação de Recursos Naturais, Universidade Federal de Uberlândia.

E-mail: pamores2@gmail.com

Ana P. de Faria, Ecology and Evolutionary Biology Department, University of Toronto, St George Campus. E-mail: anapdefaria@gmail.com

Ana Silvia F.P. Moreira, Instituto de Biologia, Universidade Federal de Uberlândia. E-mail: anasilviamoreira@gmail.com

Ariádine Cristine de Almeida, Instituto de Biologia, Universidade Federal de Uberlândia. E-mail: ariadinecalmeilda@ufu.br

Ariovaldo A. Giaretta, Instituto de Ciências Exatas e Naturais do Pontal (ICENP), Universidade Federal de Uberlândia, Ituiutaba. E-mail: aagiaretta@gmail.com

Bianca Bonami Rosa, Pós-graduação em Ecologia e Conservação de Recursos Naturais. Instituto de Biologia, Universidade Federal de Uberlândia.

E-mail: bianca.bonamirosa@gmail.com

Bianca M. Kotviski, Programa de Pós-graduação em Ecologia e Conservação de Recursos Naturais, Universidade Federal de Uberlândia.

E-mail: bianca_kotviski@hotmail.com

Camilla Queiroz Baesse, Laboratório de Ornitologia e Bioacústica, Universidade Federal de Uberlândia. E-mail: camillabaesse@gmail.com

Celine de Melo, Instituto de Biologia, Universidade Federal de Uberlândia.

E-mail: celinemelo@gmail.com

César Gómez-Hernández, Laboratório de Imunologia, Universidade Federal do Triângulo Mineiro-UFTM. E-mail: cesar_cgh@hotmail.com

Claire Pauline Röpke Ferrando, Programa de Pós-Graduação em Ecologia e Conservação de Recursos Naturais, Universidade Federal de Uberlândia.

E-mail: claireprf@gmail.com

Denis Coelho de Oliveira, Instituto de Biologia, Universidade Federal de Uberlândia. E-mail: denisoliveira@ufu.br 
Emilio M. Bruna, Department of Wildlife Ecology and Conservation, University of Florida. E-mail: embruna@ufl.edu

Felipe A. Meira, Programa de Pós-graduação em Ecologia e Conservação de Recursos Naturais, Universidade Federal de Uberlândia. E-mail: meirafa@hotmail.com

Fernanda C. Azevedo, Programa de Conservação Mamíferos do Cerrado/PCMC, Departamento de Ciências Biológicas, Universidade Federal de Catalão.

E-mail: cavalcantifer@yahoo.com

Frederico G. Lemos, Programa de Conservação Mamíferos do Cerrado/PCMC, Departamento de Ciências Biológicas, Universidade Federal de Catalão.

E-mail:lemos.pcmc@gmail.com

Filipe Ferreira de Deus, Pós-graduação em Ecologia e Conservação da Biodiversidade. Universidade Federal de Mato Grosso. E-mail:filipefdedeus@yahoo.com.br

Gabriel M. Xavier, Programa de Pós-graduação em Ecologia e Conservação de Recursos Naturais, Universidade Federal de Uberlândia. E-mail: gabriel.m.x@hotmail.com

Giuliano Buzá Jacobucci, Instituto de Biologia, Universidade Federal de Uberlândia. E-mail: jacobucci@ufu.br

Heraldo L. Vasconcelos, Instituto de Biologia, Universidade Federal de Uberlândia. E-mail: heraldo@ufu.br

Izabella L. Rigobello, Programa de Pós-graduação em Zootecnia, Universidade Estadual Paulista - UNESP, Campus de Jaboticabal. E-mail: iza_larosa@hotmail.com

Jamir A. Prado-Junior, Instituto de Biologia, Universidade Federal de Uberlândia. E-mail:jamirjunior@yahoo.com.br

Jaqueline V. Silva, Instituto de Biologia, Universidade Federal de Uberlândia.

E-mail: j.vazsilva@yahoo.com.br

Jessica Ferreira de Lima, Instituto de Biologia, Universidade Federal de Uberlândia. E-mail: jessica_11996@hotmail.com

Jonas B. Maravalhas, Instituto de Biologia, Universidade Federal de Uberlândia. E-mail:jmaravalhas@gmail.com

João Custódio F. Cardoso, Pós-graduação em Ecologia e Conservação de Recursos Naturais, Universidade Federal de Uberlândia. E-mail: jcfclg@gmail.com

Karine Rezende-Oliveira, Instituto de Ciências Exatas e Naturais do Pontal, Universidade Federal de Uberlândia. E-mail: karinerezende@ufu.br

Kátia G. Facure, Instituto de Ciências Exatas e Naturais do Pontal, Universidade Federal de Uberlândia. E-mail: katiafacure@ufu.br

Laura V. B. Silva, Instituto de Biologia, Universidade Federal de Uberlândia.

E-mail: laurabyo@gmail.com

Léo Correia da Rocha Filho, Instituto de Biologia, Universidade Federal de Uberlândia. E-mail: correiadarocha@yahoo.com.br 
Letícia Benavalli, Programa de Pós Graduação em Ecologia e Conservação de Recursos Naturais, Universidade Federal de Uberlândia. E-mail: lebenavalli@gmail.com

Lino A. Zuanon, Instituto de Biologia, Universidade Federal de Uberlândia.

E-mail: zuanonlino@gmail.com

Luma Astun Lopes, Programa de Pós Graduação em Ecologia e Conservação de Recursos Naturais, Universidade Federal de Uberlândia.

E-mail: lumaastun@gmail.com

Marcelo O. Gonzaga, Instituto de Biologia, Universidade Federal de Uberlândia. E-mail:mogonzaga@yahoo.com.br

Marco Miguel de Oliveira, Programa de Pós-Graduação em Imunologia e Parasitologia Aplicadas, Instituto de Ciências Biomédicas, Universidade Federal de Uberlândia, E-mail: marcomiguel03@gmail.com

Marina Calixto Cunha, Programa de Pós-Graduação em Ecologia e Conservação de Recursos Naturais, Universidade Federal de Uberlândia.

E-mail: marinaccunha@gmail.com

Mozart C. Freitas-Junior, Programa de Conservação Mamíferos do Cerrado/PCMC, Departamento de Ciências Biológicas, Universidade Federal de Catalão.

E-mail:mozart-bio@outlook.com

Natália Mundim Tôrres, Instituto de Biologia, Universidade Federal de Uberlândia. E-mail: natalia.torres@ufu.br

Natália Oliveira Leiner, Instituto de Biologia, Universidade Federal de Uberlândia. E-mail:naleiner@gmail.com

Norberto E. Oliveira-Neto, Programa de Pós-graduação em Ecologia e Conservação de Recursos Naturais, Universidade Federal de Uberlândia.

E-mail: norbertoemidio@gmail.com

Paola P. Raupp, Instituto de Biologia, Universidade Federal de Uberlândia.

E-mail:paola_raupp@hotmail.com

Paulo Eugênio Oliveira, Instituto de Biologia. Universidade Federal de Uberlândia. E-mail:poliveira@ufu.br

Paulo Vitor Alves Ribeiro, Laboratório de Ornitologia e Bioacústica, Universidade Federal de Uberlândia. E-mail: paulovitorbio@gmail.com

Pedro Henrique Pereira Gonçalves, Programa de Pós Graduação em Ecologia e Conservação de Recursos Naturais, Universidade Federal de Uberlândia.

E-mail:pedrohpg4@gmail.com

Pietro K. Maruyama, Instituto de Ciências Biológicas, Universidade Federal de Minas Gerais. E-mail: pietrokiyoshi@gmail.com

Rafael R. Moura, Laboratório de Ecologia e Zoologia, Universidade Estadual de Minas Gerais - Unidade Ituiutaba. E-mail: biorafaelrm@gmail.com

Raquel L. Carvalho, Instituto de Biologia, Universidade Federal de Uberlândia.

E-mail: raqueluly@gmail.com 
Renan B. Pitilin, Programa de Pós-graduação em Ecologia e Conservação de Recursos Naturais, Universidade Federal de Uberlândia. E-mail: pitilin_tj@hotmail.com

Renata de Moura Guimarães Souto, Instituto de Biologia, Universidade Federal de Uberlândia. E-mail: guimaraesrm@gmail.com

Rodrigo Cassimiro Rossi, Programa de Pós-Graduação em Ecologia e Conservação de Recursos Naturais, Instituto de Biologia, Universidade Federal de Uberlândia.

E-mail: crossirodrigo@gmail.com

Sergio F. Lopes, Departamento de Biologia, Universidade Estadual da Paraíba, Campina Grande, PB. E-mail: defarialopes@gmail.com

Solange Cristina Augusto, Instituto de Biologia, Universidade Federal de Uberlândia. E-mail: solange.augusto@ufu.br

Susana Faria Nalla, Instituto de Ciências Exatas e Naturais do Pontal, Universidade Federal de Uberlândia. E-mail: susana_nalla@hotmail.com

Talita A. Silva, Instituto de Ciências Exatas e Naturais do Pontal, Universidade Federal de Uberlândia. E-mail: bio.talitaalves@gmail.com

Thiago Henrique Azevedo Tosta, Instituto de Biologia, Universidade Federal de Uberlândia. E-mail: thenriquebio@gmail.com

Thiago R. Carvalho, Departamento de Biodiversidade e Centro de Aquicultura (CAUNESP), Universidade Estadual Paulista, campus de Rio Claro.

E-mail: carvalho.thiagoribeiro@gmail.com

Vagner S. Vale, Departamento de Engenharia Florestal, Universidade Estadual de Goiás, Ipameri. E-mail: vsvale@hotmail.com

Vanessa Fonseca Gonçalves, Escola de Educação Básica, Laboratório de Ornitologia e Bioacústica, Universidade Federal de Uberlândia. E-mail: vanessa.goncalves@ufu.br

Vinícius L.G. Brito, Instituto de Biologia. Universidade Federal de Uberlândia.

E-mail:viniciusduartina@gmail.com

Vitor A. Egêa, Graduação em Ciências Biológicas, Universidade Federal de Uberlândia. E-mail: vitor.egea@ufu.br

Vitor Campana Martini, Programa de Pós Graduação em Ecologia e Conservação de Recursos Naturais, Universidade Federal de Uberlândia.

E-mail: thenriquebio vitorcmartini@gmail.com

Vitor Carneiro de Magalhães Tolentino, Laboratório de Ornitologia e Bioacústica, Universidade Federal de Uberlândia. E-mail: vitorcarneiro12@yahoo.com.br 


\section{PARTE 1- BIODIVERSIDADE}

\section{CAPÍTULO 1}

Osítio ‘Triângulo Mineiro e Sudeste de Goiás' do Programa de Pesquisa Ecológica de Longa Duração do CNPq: ampliando o conhecimento do Cerrado.

Jonas B. Maravalhas, Jamir Prado-Junior, Paulo Eugênio Oliveira, Heraldo L. Vasconcelos

\section{CAPÍTULO 2}

A vegetação lenhosa: estrutura, diversidade e impactos antrópicos. .25

Jamir Prado-Junior, Norberto E. Oliveira-Neto, Sergio F. Lopes, Vagner S. Vale

\section{CAPÍTULO 3}

Ecologia de pequenos mamíferos não-voadores.

Rodrigo C. Rossi, Claire P.R. Ferrando, Marco M. de Oliveira, Natalia O. Leiner

\section{CAPÍTULO 4}

Ecologia de canídeos silvestres em agroecossistemas.

Kátia G. Facure, Frederico G. Lemos, Fernanda C. Azevedo, Bianca M. Kotviski, Mozart C. Freitas-Junior, Izabella L. Rigobello, Talita A. Silva, Susana Faria Nalla, César Gómez-Hernández, Karine Rezende-Oliveira

\section{CAPÍTULO 5}

Os mamíferos de médio e grande porte do Parque Estadual do Pau Furado.

Natália M.Tôrres, Letícia Benavalli, Luma A. Lopes, Vitor A. Egêa

\section{CAPÍTULO 6}

Diversidade e biomonitoramento de aves

Camilla Q. Baesse, Paulo V. A. Ribeiro, Vanessa F. Gonçalves, Vitor C. M. Tolentino,

Celine de Melo

\section{CAPÍTULO 7}

Diversidade, distribuição e conservação dos anfíbios anuros.

Thiago R. de Carvalho, Ariovaldo A. Giaretta

\section{CAPÍTULO 8}

Os macroinvertebrados aquáticos.

Giuliano B. Jacobucci, Renata M. G. Souto, Marina C. Cunha, Ana Cláudia G. Barboza, Ariádine C. Almeida

\section{CAPÍTULO 9}

As formigas: ecologia e história natural. 


\section{CAPÍTULO 10}

Abelhas das orquídeas (Euglossini): importância dos remanescentes florestais para a conservação da diversidade.

Solange C. Augusto, Thiago H. A. Tosta, Leo C. Rocha Filho

\section{CAPÍTULO 11}

Ecologia e diversidade de besouros escarabeíneos.

Raquel L. Carvalho, Lino A. Zuanon, Heraldo L. Vasconcelos

\section{CAPÍTULO 12}

Biologia e diversidade de galhas nos cerrados. .209

Vitor C Martini, Pedro HP Gonçalves, Denis C Oliveira

\section{PARTE 2 - ADAPTAÇÕES E PROCESSOS ECOLÓGICOS CAPÍTULO 13}

Ecologia e comportamento de aranhas.

Marcelo O. Gonzaga, Adilson Quero, Rafael R. Moura, Aline L. Nascimento, Felipe A. Meira, Renan B. Pitilin, Gabriel M. Xavier

\section{CAPÍTULO 14}

Ecofisiologia de plantas do Cerrado: sobrevivência em um ambiente com alta sazonalidade hídrica, pouca disponibilidade de nutrientes e sob a ação do fogo.

Ana Silvia F. P. Moreira, Ana Paula de Faria, Jessica F. de Lima

\section{CAPÍTULO 15}

Polinização e reprodução de plantas do Cerrado. 257 João C. F. Cardoso, Pietro K. Maruyama, Vinícius L.G. Brito, Bianca B. Rosa, Filipe de Deus, Paulo E. Oliveira

\section{CAPÍTULO 16}

Os insetos herbívoros e seu impacto sobre a vegetação.

Alan N. Costa, Laura V. B. Silva, Jaqueline V. Silva, Paola P. Raupp

\section{CAPÍTULO 17}

O processo de decomposição da serapilheira. 


\section{PARTE 1}

\section{BIODIVERSIDADE}

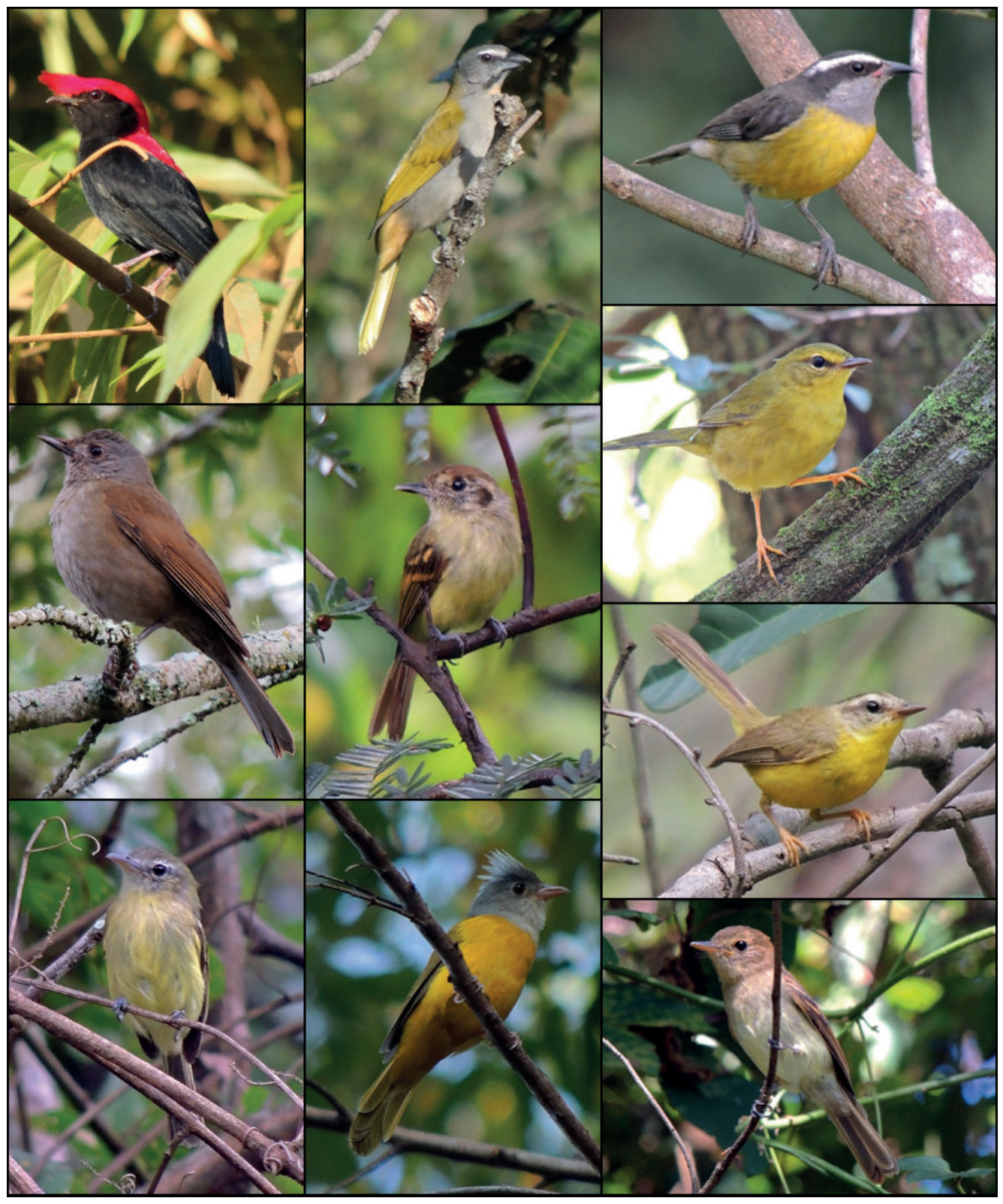





\title{
CAPÍTULO 1
}

\section{O SÍTIO 'TRIÂNGULO MINEIRO E SUDESTE DE GOIÁS' DO PROGRAMA DE PESQUISA ECOLÓGICA DE LONGA DURAÇÃO DO CNPQ: AMPLIANDO O CONHECIMENTO DO CERRADO}

\author{
Jonas B. Maravalhas \\ Jamir Prado-Junior \\ Paulo Eugênio Oliveira \\ Heraldo L. Vasconcelos
}

\section{O subestimado papel do Cerrado na conservação da biodiversidade}

Para a maioria da população, a imagem de biodiversidade está relacionada às florestas tropicais úmidas, como a Amazônia, representadas por seu dossel fechado composto por árvores com dezenas de metros de altura e um sub-bosque muito úmido e denso com as mais variadas espécies. Entretanto, dados recentes indicam que a diversidade de plantas no Cerrado é quase tão alta como na Amazônia, enquanto as taxas de endemismo são duas vezes maiores (33\% contra $15 \%)$. Essa elevada diversidade biológica tem sido descrita para outros grupos taxonômicos e contrasta com a ideia tradicional do Cerrado como um ambiente empobrecido ou limitado por estresses ambientais.

O domínio atual do Cerrado está localizado em sua maior parte no Planalto Central do Brasil, abrangendo uma área de quase dois milhões de $\mathrm{km}^{2}$ e 16 estados brasileiros, quando consideramos suas porções disjuntas. A composição da paisagem no Cerrado é marcada por grande variação de fitofisionomias, abrangendo desde formações vegetais campestres, com predomínio de espécies herbáceas e algumas espécies arbustivas, até formações florestais densas, dominadas por espécies arbóreas e com estrato herbáceo praticamente ausente (Figura 1). Usualmente são descritos 11 tipos principais de vegetação no Cerrado, enquadrados em formações florestais (floresta ciliar, floresta de galeria, florestas estacionais e cerradão), formações savânicas (cerrado sensu stricto, parque de cerrado, palmeiral e vereda) e formações campestres (campo sujo, campo limpo e campo rupestre). Entretanto, algumas subdivisões são descritas para algumas destas fitofisionomias (por exemplo, cerrado sensu stricto - a formação dominante subdividido em cerrado denso, cerrado típico, cerrado ralo e cerrado rupestre; florestas de galeria inundável e não-inundável; florestas estacionais semideciduais e deciduais). Nesses casos, alguns autores reconhecem até 25 fitofisionomias distintas para o Cerrado como um todo. Este complexo mosaico de fitofisionomias é condicionado por diversos fatores, incluindo especialmente o clima, as características físico-químicas do solo, a profundidade do lençol freático e a frequência de fogo, os quais atuam de forma simultânea, mas em diferentes escalas.

O Cerrado como conhecemos hoje não foi sempre assim. No período Quaternário houveram repetidos ciclos de mudanças climáticas, possivelmente 18 ciclos ao todo. 


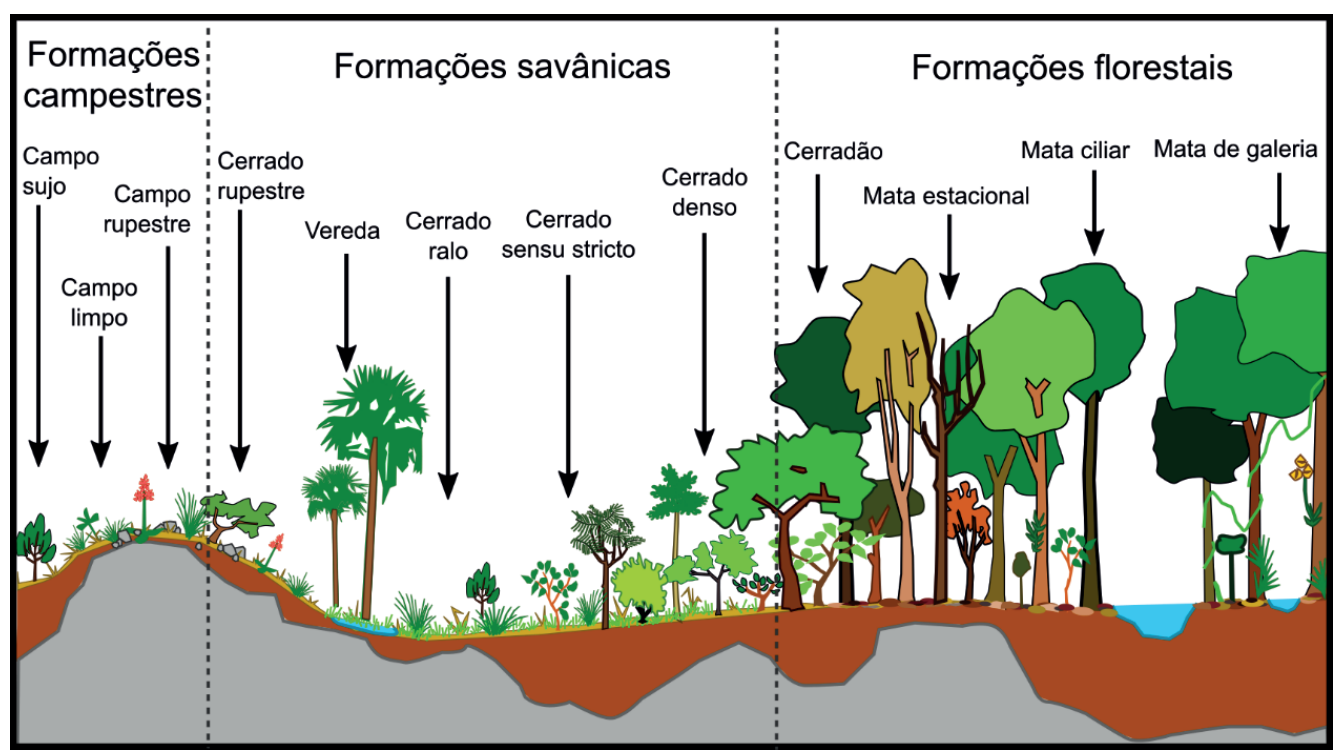

Figura 1. A composição da paisagem na região do Triângulo Mineiro e Sudeste de Goiás é marcada pela ocorrência de diversas fitofisionomias do Cerrado próximas umas às outras, o que aumenta a diversidade local de espécies de plantas e animais.

Nos máximos glaciais (com clima mais seco e frio), o domínio do Cerrado ficou mais restrito às latitudes mais baixas (ou seja, mais ao norte, avançando sobre a Amazônia), sendo que as áreas mais meridionais (ao sul) foram ocupadas por formações vegetais mais secas, como as da Caatinga e do Chaco. Nos períodos interglaciais, de climas mais amenos e úmidos, o Cerrado se expandiu e passou a ocupar áreas maiores. No último máximo glacial, há cerca de 10 mil anos, o Cerrado parece ter ficado restrito às áreas de planaltos mais centrais. Assim, grande parte das áreas hoje ocupadas pelo Cerrado foram dominadas por florestas de araucárias ou por vegetações mais semelhantes à Caatinga e ao Chaco. Desde então, as formações savânicas voltaram a se expandir e a ocupar as áreas mais ao sul e oeste (avançando sobre a Floresta Atlântica), e assim as formações outrora dominantes no Brasil Central ficaram restritas a pequenas áreas dentro do Cerrado. Estes ciclos envolvendo a retração e expansão das formações vegetais do Brasil (Cerrado, Caatinga e Florestas Amazônica e Atlântica) geraram processos de hibridação, especiação e vicariância que contribuíram para a alta biodiversidade na América do Sul como um todo. Também conhecida como Teoria dos Refúgios, as consequências destas mudanças climáticas no período Quaternário ajudam a entender o mosaico de paisagens no Brasil e os padrões de distribuição de espécies da flora e fauna nos diferentes domínios biogeográficos. Não à toa, o Cerrado hoje inclui várias sub-regiões que, apesar de serem semelhantes em sua ecologia e estrutura, possuem elementos florísticos muito diferentes (Figura 2). No caso das formações savânicas especificamente, há uma enorme diversidade beta de espécies de plantas lenhosas, ou seja, existe uma alta substituição de espécies de uma área para outra. 


\section{O Sítio PELD TMSG}

A região onde os estudos descritos neste livro foram conduzidos, no Triângulo Mineiro e Sudeste de Goiás (doravante "sítio" TMSG, uma das áreas de referência para a pesquisa ecológica no Brasil; http://cnpq.br/sitios-peld), apresenta temperaturas relativamente mais baixas do que outras partes do Cerrado. Além disso, ao contrário das áreas mais centrais do Cerrado, que se mantiveram relativamente estáveis durante o final do Quaternário, as áreas mais meridionais - que incluem o TMSG - parecem ter sido invadidas por florestas de araucárias e eram aparentemente muito mais secas e frias há 10 mil anos atrás. Além de formações típicas do Cerrado, o TMSG possui enclaves de Floresta Atlântica em áreas próximas aos grandes cursos d'água, como o Rio Paranaíba. Este rio faz parte da bacia hidrográfica do Paraná e está próximo ao limite da bacia do São Francisco, ambas de extrema importância socioeconômica no Brasil. A região de estudos do sítio TMSG (Figura 3) abrange 107 municípios, cuja área total corresponde a $136.784 \mathrm{~km}^{2}$, e onde residem quase três milhões de pessoas. $\mathrm{O}$ sítio TMSG está inserido em uma região de grande relevância estratégica, pois interliga diversos centros produtores da região Sudeste e Centro-Oeste do Brasil.

A maior parte do sítio TMSG se encontra no Planalto do Rio Paraná, porém ele também abrange porções dos planaltos de Goiânia, Distrito Federal, Central Brasileiro, bem como a totalidade do Planalto de Uberlândia. O sítio abrange ainda parte da Serra da Canastra e das Chapadas do Rio São Francisco. Possui um regime climático caracterizado por altas temperaturas durante todo o ano, bem como uma marcada estação seca durante o inverno. Há uma predominância de solos do tipo latossolo, que são solos profundos, com poucos nutrientes e de coloração avermelhada. Estes solos também são caracterizados pelo alto grau de intemperismo, $\mathrm{pH}$ ácido, elevado grau de drenagem hídrica e alto teor de alumino. 


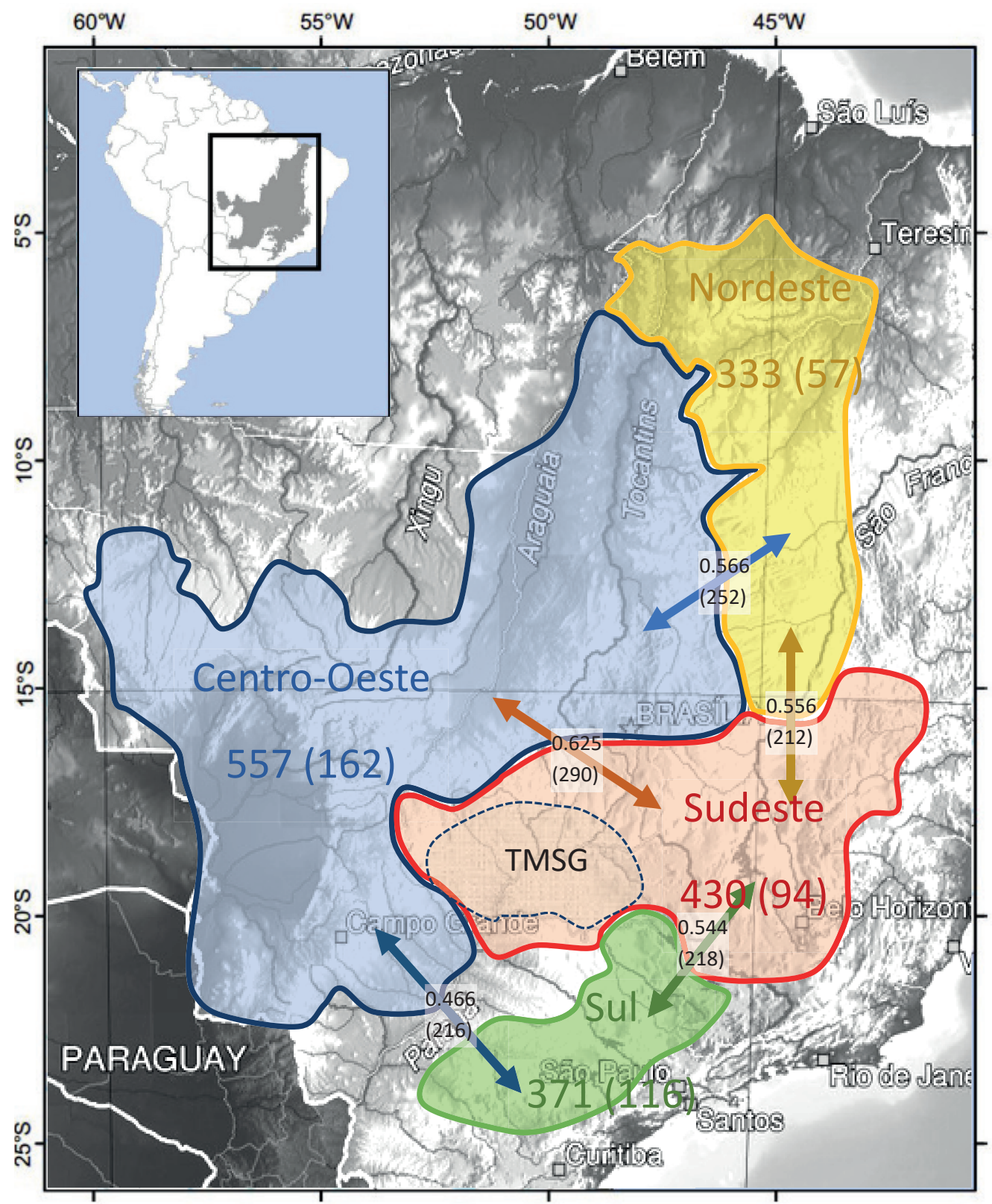

Figura 2. Regiões florísticas do Cerrado, relações e endemismos. O mapa mostra as quatro principais regiões florísticas do Cerrado com a riqueza de espécies de plantas lenhosas e o número de espécies endêmicas (entre parêntesis). Nas setas são mostradas as taxas de similaridade entre as regiões e o número de espécies compartilhadas (entre parêntesis). Os limites são baseados em Bridgewater et al. (2004) e Françoso et al. (2020). A região aproximada de abrangência do sítio PELD TMSG é limitada pela linha tracejada. 
Historicamente, o desenvolvimento da região do Triângulo Mineiro e Sudeste de Goiás foi marcado por diferentes momentos de relevância para a compreensão dos padrões atuais de ocupação da terra. Primeiramente, em meados do século XVII, expedições jesuítas exploraram a região para contatar e catequizar os povos indígenas presentes - principalmente das tribos Caiapós e Araxás, enquanto as expedições bandeirantes abriram estradas para conectar o estado de São Paulo com o de Goiás. Nesse primeiro momento, a mineração dessa e de outras áreas mais ao norte motivaram a ocupação do território, sendo que o pastoreio logo se desenvolveu para a subsistência dos colonos bem como dos tropeiros que cruzavam a região. O segundo momento está relacionado a construção de Brasília, que estimulou o crescimento da região, visto que esta interliga os centros urbanizados do litoral da região Sudeste com a futura capital. Por fim, o desenvolvimento de técnicas de neutralização da acidez características do solo do Cerrado permitiu o avanço da fronteira agrícola na região. A chegada do agronegócio, juntamente com a localização estratégica, explica o acelerado crescimento populacional e econômico do Triângulo Mineiro e Sudeste de Goiás.

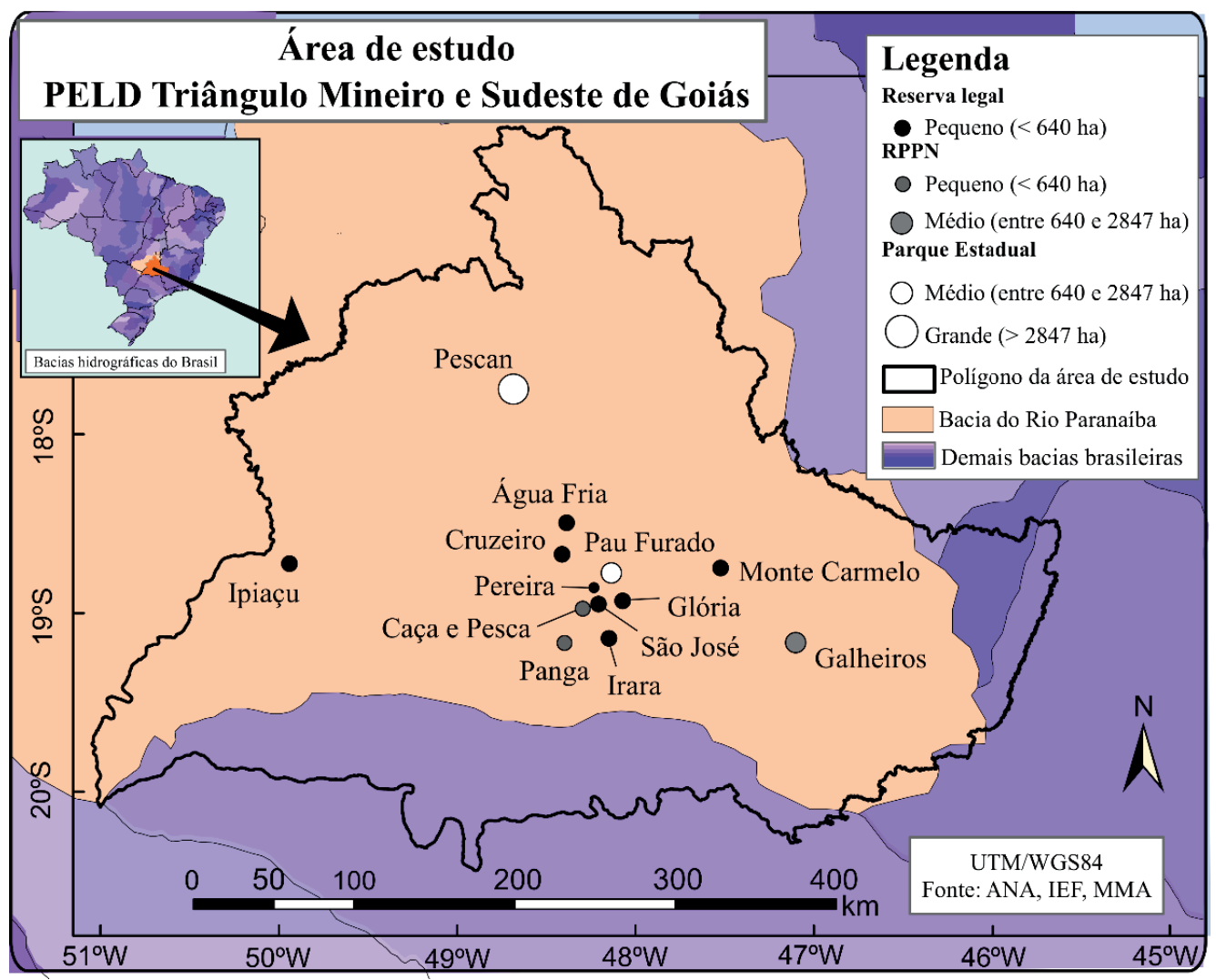

Figura 3. Área de estudos do sítio "Triângulo Mineiro e Sudeste de Goiás" (TMSG) do Programa Ecológico de Longa Duração (PELD-CNPq).

A região foi palco importante para os primeiros estudos sobre a flora e fauna no Brasil, tendo sido visitada no século XIX por naturalistas como Carl von Martius, Auguste de Saint-Hilaire e Eugenius Warming (autor de Lagoa Santa, o primeiro livro sobre a vegetação do Cerrado). As narrativas desses naturalistas, que exaltam a 
riqueza biológica do Brasil e descrevem as relações da biodiversidade com o clima, o solo e o próprio homem são, ainda hoje, de importância fundamental para a ecologia e botânica. Hoje, pouco mais de 100 anos depois dessas expedições, a situação da vegetação nativa no TMSG é muito diferente. As áreas naturais representam menos de $30 \%$ da área original e as taxas de desmatamento chegam a 2,5\% ao ano. Grande parte da vegetação nativa foi substituída por pastagens, cultivos e áreas urbanas. Da extensão total do sítio TMSG $\left(136.784 \mathrm{~km}^{2}\right), 37 \%$ é atualmente ocupada por pastagens com manejo, sendo, portanto, o principal uso da terra na região. Esta porcentagem se manteve relativamente estável entre os anos de 2000 e 2016. Já as áreas agrícolas cresceram em extensão ao longo do período avaliado: cobriam 24,5\% da área em 2000 e passaram para $34 \%$ em 2018 . Em contrapartida, a área ocupada por vegetação nativa decaiu de 34,5 para $25,5 \%$ (Figura 4), o que indica uma perda de $25 \%$ da área em pouco mais de uma década. Além disso, os dados mostram que, comparadas às áreas florestais, houve uma conversão proporcionalmente maior de áreas com fisionomia mais aberta, isto é, savanas e campos. O sítio TSMG também representa uma região bastante impactada por reservatórios artificiais de hidrelétricas. Embora os reservatórios artificiais forneçam importantes serviços sociais, como energia hidrelétrica e sistemas de irrigação, eles têm sido relacionados a diversos impactos socioambientais, como o aumento das emissões de gases do efeito estufa, doenças transmitidas por mosquitos e fragmentação de habitats.

Além das mudanças na vegetação outras alterações ambientais também têm sido notadas como evidenciado por um estudo recente no sítio TMSG. Neste, foram utilizadas técnicas de sensoriamento remoto para criar um polígono englobando as 10 micro-regiões onde estão situadas as áreas de estudo. Este polígono serviu como referência para a extração de dados oriundos de imagens de satélites disponíveis online. Em relação ao clima, não foram detectadas mudanças significativas na precipitação anual ao longo de 30 anos na região de estudo (Figura 4). Por outro lado, a temperatura máxima anual apresentou uma tendência de aumento no mesmo período: estava em torno de $30^{\circ} \mathrm{C}$ no final dos anos 80 e atualmente está cerca de $2,5^{\circ} \mathrm{C}$ mais alta (Figura 4). No ano de 2015, por exemplo, a média da temperatura máxima medida nas estações climatológicas da região foi de $34,5^{\circ} \mathrm{C}$. Embora os dados não permitam estabelecer uma relação de casualidade, a perda de vegetação nativa tem se mostrado um dos principais direcionadores das mudanças climáticas globais. A importância da vegetação no controle térmico envolve diversos processos, como o sequestro de carbono atmosférico por meio da fotossíntese (o que reduz o efeito estufa), a reflexão de boa parte da luz solar infravermelha de volta para a atmosfera (evitando que ela seja absorvida pelo solo), e a evapotranspiração, que envolve a remoção do calor do ar. Por fim, estes dados mostraram um aumento na incidência de focos de incêndios na região. Este aumento, observado em um período de apenas 13 anos, foi exponencial: em 2003 foram detectados 5.695 focos de incêndios, enquanto em 2018, o número de detecções foi de 17.378 (Figura 4).

Conforme visto anteriormente, a vegetação predominante nas paisagens do sítio TMSG é o cerrado sensu stricto, ou seja, uma formação savânica. Uma característica desse tipo vegetacional é a ocorrência frequente de queimadas. Na região do Cerrado o fogo ocorre naturalmente durante o início e o fim da estação seca, momento em que descargas elétricas agem como fontes de ignição, enquanto o combustível (matéria 
vegetal morta) encontra-se seco. Queimadas deste tipo costumam ocorrer em uma frequência variável, a cada dois anos ou em intervalos mais longos. A ocorrência de incêndios esporádicos e de baixa intensidade é importante para a manutenção da heterogeneidade estrutural típica do Cerrado, favorecendo a coexistência de plantas e animais com preferências ambientais distintas. $O$ fogo favorece o crescimento de gramíneas e elimina árvores que não possuem adaptações a queimadas, que são típicas de ambientes florestais e que poderiam excluir plantas da savana por serem competitivamente superiores. Dentre as adaptações das árvores do Cerrado ao fogo pode-se citar a grande espessura do súber - a casca da árvore, que promove um isolamento térmico para o caule - e os órgãos subterrâneos de reserva - que permitem uma rápida rebrota após a passagem do fogo. Com o aumento da presença humana e de fontes de ignição durante a estação seca, o regime fogo na região do Cerrado foi profundamente alterado. Com o combustível mais seco, há ocorrência de queimadas de grande intensidade e que atingem vastas áreas, inclusive formações florestais, com consequências desastrosas para a vegetação não adaptada ao fogo.

Um outro ponto preocupante para a conservação da biodiversidade do sítio TMSG é que as unidades de conservação de âmbito municipal, estadual ou federal são poucas e de tamanho relativamente reduzido. Assim, ao contrário de muitos outros sítios PELD, que concentram suas atividades em apenas uma reserva biológica de grande extensão, o sítio TMSG engloba várias áreas em diferentes paisagens da região de estudo. Fazem parte do TMSG cinco unidades de conservação: (i) o Parque Estadual da Serra de Caldas Novas, com 12.500 ha, (ii) o Parque Estadual do Pau Furado, com 2.200 ha, (iii) a Estação Ecológica de Galheiros, com 2.847 ha, (iv) a Reserva Ecológica do Panga, com 409 ha e (v) a RPPN do Clube Caça e Pesca, com 640 ha. Também fazem parte do sítio TMSG oito remanescentes de florestas estacionais semideciduais, de extensão variando entre 16 e 200 ha, localizadas em reservas legais ou áreas de preservação permanente de propriedades privadas (Figura 3). Nesse sentido, a composição da paisagem no sítio TMSG abrange um mosaico de fitofisionomias florestais e savânicas, possibilitando uma ampla gama de estudos com os mais diversos grupos biológicos, incluindo árvores, abelhas, aranhas, formigas, insetos galhadores, invertebrados aquáticos e mamíferos de pequeno, médio e grande porte. 

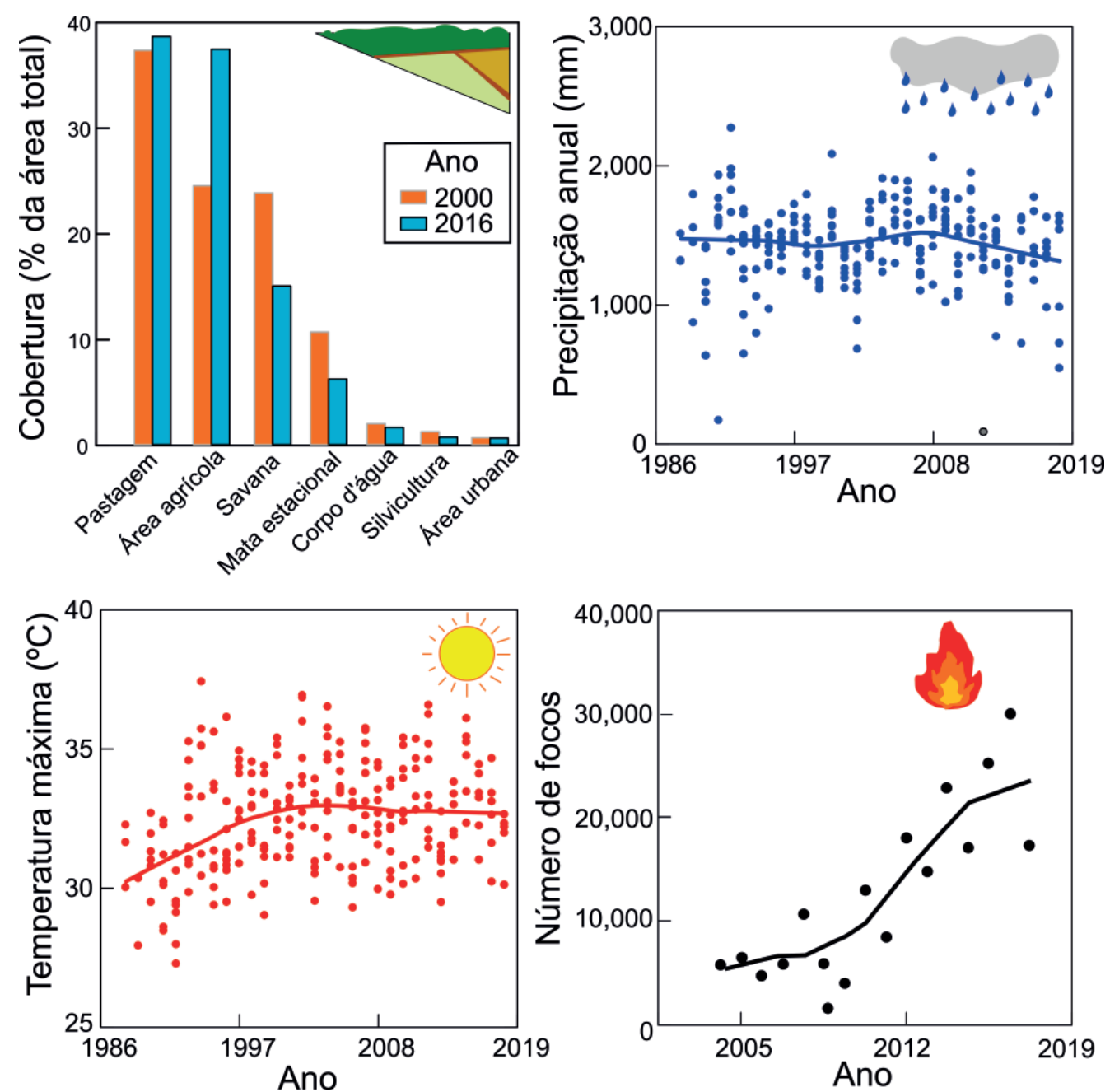

Figura 4. Mudanças temporais no uso da terra, no clima e no número de focos de incêndios no Triângulo Mineiro e Sudeste de Goiás. Acima a esquerda as mudanças na cobertura e uso da terra entre 2000 e 2016. Acima a direita, a variação na precipitação e abaixo a esquerda na temperatura máxima anual. Abaixo a direita o número de eventos de incêndio entre 2003 e 2018.

Os estudos desenvolvidos no sítio procuram, de forma ampla, expandir nosso conhecimento sobre a biodiversidade do Cerrado, os processos ecológicos que originaram essa biodiversidade, bem como as maneiras de proteger esse patrimônio para a posteridade. Nesse contexto, as pesquisas científicas realizadas no sítio TMSG oferecem uma oportunidade para atingir estes objetivos, visto que a região apresenta uma rica variedade de ambientes, uma alta diversidade de plantas e animais, e, ao mesmo tempo, altos níveis de conversão da vegetação nativa devido às intensas atividades econômicas e ao acelerado crescimento urbano. Grande parte do conhecimento sobre as relações entre biodiversidade e impactos antrópicos provém de estudos realizados em florestas úmidas. Contudo, estas relações são fundamentalmente diferentes entre ecossistemas que são limitados por diferentes recursos e que sofrem diferentes impactos. Por exemplo, o clima fortemente sazonal da região e as frequentes queimadas na estação seca impõem às espécies locais filtros ambientais muito diferentes dos 
observados na Amazônia e Mata Atlântica. Embora muitas das espécies da flora e da fauna regional possuam adaptações para lidar com a sazonalidade climática, regimes extremos de perturbação (secas muito prolongadas ou queimadas em intervalos muito curtos) podem levar a grandes perdas de biodiversidade e de produtividade desses ecossistemas. Para conservar é necessário, primeiro, conhecer. Portanto, os próximos capítulos deste livro irão apresentar o conhecimento oriundo de pesquisas científicas desenvolvidas no âmbito do sítio PELD TMSG.

\section{Para saber mais}

Bridgewater S, Ratter JA, Ribeiro JF (2004) Biogeographic patterns, $\beta$-diversity and dominance in the cerrado biome of Brazil. Biodiver Conserv 13:2295-2317 doi: 10.1023/B:BIOC.0000047903.37608.4c

Brito MA, Oliveira D, Mamede MA, Randing O, Lacerda FS (2020) Programa De Pesquisa Ecológica De Longa Duração - PELD/CNPq - Desafios da gestão, avanços e perspectivas. Oecologia Australis 24: 259-265 doi: 10.4257/oeco.2020.2402.02

Françoso RD, Dexter KG, Machado RB, Pennington RT, Pinto JRR, Brandão RA, Ratter JA (2020) Delimiting floristic biogeographic districts in the Cerrado and assessing their conservation status. Biodiver Conserv 29:1477-1500 doi: 10.1007/s10531-019-01819-3

Martins, HP (1998) Formação e desenvolvimento sócio-econômico do Triângulo Mineiro. Varia Historia, Belo Horizonte, 19, p.164-182

Pivello, VR (2011) The use of fire in the Cerrado and Amazonian rainforests of Brazil: past and present. Fire ecology, 7(1), 24-39.

Prado-Junior J, Maravalhas J, Tosta T, Augusto S, Araújo B, Rosa T, Vasconcelos HL (2020). Spatio-temporal changes in the structure of the ant, bee, and tree communities in the Brazilian Cerrado. Oecologia Australis 24:448-460 doi:10.4257/oeco.2020.2402.15 



\title{
CAPÍTULO 2
}

\section{A VEGETAÇÃO LENHOSA: ESTRUTURA, DIVERSIDADE E IMPACTOS ANTRÓPICOS}

\author{
Jamir Prado-Junior \\ Norberto E. Oliveira-Neto \\ Sergio F. Lopes \\ Vagner S. Vale
}

As plantas são a base das cadeias tróficas terrestres e regulam os diversos ciclos biogeoquímicos, desde a escala local dos ecossistemas até o equilíbrio climático global. Algumas árvores estão entre os maiores e mais antigos organismos do planeta, ajudando na compreensão das condições ambientais do passado e na previsão dos cenários climáticos futuros. $\mathrm{O}$ valor econômico dos serviços ecossistêmicos providos pelas comunidades vegetais é incalculável. O extrativismo vegetal produz componentes utilizados na construção civil, na produção de energia, em materiais de uso cotidiano na e indústria farmacêutica e alimentícia. A vegetação atua na formação, enriquecimento e estabilização do solo, além de abrigar e fornecer recursos para grande parte da biodiversidade do planeta.

A quantificação destes serviços ecossistêmicos tem ajudado na conservação das comunidades vegetais. Por exemplo, durante as crescentes ondas de calor nos centros urbanos, as diferenças de temperatura entre o centro da cidade e uma floresta urbana podem chegar a $10^{\circ} \mathrm{C}$. Este importante controle térmico está relacionado a vários processos das plantas, como o sequestro de carbono atmosférico através da fotossíntese, a reflexão da luz solar infravermelha e a evapotranspiração. Muitas cidades ao redor do mundo têm investido na arborização de seus centros urbanos para reduzir os custos crescentes com a regulação térmica artificial. Outro exemplo envolve os ganhos na produtividade agrícola em áreas próximas a remanescentes de vegetação nativa, seja pelo aumento da polinização cruzada e formação de sementes e frutos com maior valor econômico, ou pela redução de gastos com o controle de pragas.

Apesar de seu papel fundamental na sustentação da vida na Terra, o cenário atual das comunidades vegetais é alarmante. Mesmo com os crescentes esforços na recuperação de áreas naturais, o desmatamento e as pressões antrópicas crescem a cada ano, eventualmente levando espécies à extinção antes mesmo de conhecê-las. Estudos recentes indicam que talvez já tenhamos ultrapassado os limites de resiliência das comunidades vegetais, e as previsões para os próximos 50 anos são catastróficas.

Nesse sentido, os estudos sobre vegetação desenvolvidos pelo Programa de Pesquisas Ecológicas de Longa Duração (PELD) no sítio Triângulo Mineiro e Sudeste de Goiás (TMSG) têm buscado entender os padrões e processos ecológicos das comunidades arbóreas na região, em especial, das florestas estacionais (expostas à forte sazonalidade climática) e das comunidades savânicas (onde além da limitação hídrica, o fogo também tem um papel importante em sua estruturação). Neste capítulo, iremos discutir aspectos relacionados à estrutura, diversidade (taxonômica e funcional) e 
conservação dessas comunidades. Mais especificamente, nossos estudos têm procurado responder três perguntas centrais: (1) Qual a diversidade abrigada nos remanescentes de vegetação da região? (2) Como essa diversidade afeta a produtividade e os serviços ecossistêmicos dessas comunidades (por exemplo, o estoque e sequestro de carbono e a oferta de recursos para a fauna)? (3) Como os diferentes impactos antrópicos (fragmentação, mudanças climáticas, construção de reservatórios artificiais e alteração nos regimes de fogo) afetam a resiliência dessas comunidades?

\section{Estrutura e diversidade da flora na região do TMSG}

O Cerrado abriga cerca de 12.500 espécies de plantas, sendo que mais de 30\% dessa riqueza é endêmica ao bioma. Para compreender quanto dessa diversidade vegetal está representada no sítio PELD TMSG, compilamos os estudos florísticos realizados na região e as bases de dados de herbários virtuais do Programa REFLORA (http://www.reflora.jbrj.gov.br/) e da Rede SpeciesLink (http://www.splink.org.br/). Os resultados mostram que a região abriga cerca de 4.500 espécies de plantas, o que representa mais de um terço das espécies do Cerrado. Destas, 111 espécies estão sob algum grau de ameaça (45 são classificadas como vulneráveis, 54 como ameaçadas e 12 como criticamente ameaçadas) segundo a Lista Vermelha da International Union for Conservation of Nature (IUCN). Esta grande diversidade reflete a heterogeneidade ambiental da região, onde ocorrem todas as fitofisionomias do Cerrado, desde as formações abertas como as veredas e campos, formações de cerrado sensu stricto e suas variações quanto à densidade arbórea (cerrado ralo a cerrado denso), até as formações florestais como o cerradão, a floresta estacional semidecidual e decidual, e as florestas de galeria e ciliar.

As famílias com maior riqueza de espécies no sítio PELD TMSG são Fabaceae (484 espécies), Asteraceae (478), Poaceae (279), Rubiaceae (165), Melastomataceae (160) e Myrtaceae (145), que juntas representam 37\% das espécies compiladas. A grande diversidade dessas famílias também é usualmente encontrada em toda a extensão do Cerrado. Fabaceae é uma das famílias mais diversas do mundo, com grande representatividade em quase todos os hábitos (arbóreo, arbustivo e herbáceo) e inclui muitas das espécies fixadoras de nitrogênio. As famílias Asteraceae e Melastomataceae têm um de seus centros de biodiversidade no Cerrado, onde predominam as espécies herbáceo-arbustivas. Poaceae, uma família tradicionalmente herbácea, também tem grande importância no endemismo do Cerrado. Estas três famílias (Asteraceae, Melastomataceae e Poaceae) apresentam maior dominância nas fitofisionomias com menor cobertura arbórea, e ressaltam a importância dos estrato herbáceo-arbustivo no Cerrado. As famílias Rubiaceae e Myrtaceae possuem maior dominância de espécies arbóreo-arbustivas, e são caracterizadas por seu importante papel na oferta de alimento para a fauna.

O mosaico de fitofisionomias florestais e savânicas na região do PELD TMSG é marcado pelo domínio do Cerrado e a influência dos enclaves de Floresta Atlântica, próximos às grandes bacias hidrográficas da região (Rio Paranaíba, Rio Grande e Rio Araguari). Alguns autores consideram que as florestas estacionais no TMSG corroboram a Teoria dos Refúgios do Quaternário, quando houve a retração das florestas úmidas e a expansão das savanas no Brasil Central. Nesse caso, muitas destas florestas 
estacionais representariam refúgios da biodiversidade da Floresta Atlântica imersos em uma paisagem tipicamente de Cerrado. Entretanto, o que condiciona a coocorrência de ambas formações vegetais (florestal e savânica) em escala local e com estrutura e composição florística tão distintas ainda é um tema intrigante.

As condições climáticas estão entre os principais direcionadores das diferenças entre as formações vegetais em escala global, onde a maior disponibilidade hídrica usualmente está relacionada à ocorrência de florestas. Entretanto, as florestas estacionais e as savanas da região estão sob mesmo clima tropical de savana, com precipitação anual inferior a $1.600 \mathrm{~mm}$ por ano e um período seco (entre 4-6 meses) onde a precipitação mensal é inferior a $10 \mathrm{~mm}$. Por algum tempo acreditou-se que a fertilidade do solo poderia ser determinante na ocorrência desses dois tipos fitofisonômicos; porém, diversas florestas estacionais na região do PELD TMSG ocorrem em solos com baixa concentração de fósforo e potássio e alto teor de alumínio. Por outro lado, áreas de cerrado sensu stricto podem ocorrer em afloramentos basálticos e com ausência de alumínio, ou seja, em solos férteis. A ocorrência de queimadas parece atuar no equilíbrio entre espécies florestais e savânicas no Cerrado, mas algumas savanas protegidas do fogo há algumas décadas mantém sua estrutura e composição tipicamente savânica. $\mathrm{O}$ histórico de uso e atuais impactos antrópicos (como entrada de gado e corte seletivo de madeira) também influenciam a estrutura e composição de espécies da vegetação nessas áreas. Dessa forma, a composição da paisagem no TMSG é direcionada por múltiplos fatores que atuam simultaneamente, e a inclusão de variáveis bióticas (como interações entre espécies, herbivoria e ciclagem de nutrientes do solo pela decomposição da serapilheira) são fundamentais para a compreensão dos mosaicos de vegetação na região (Figura 1).

\section{Monitoramento de florestas estacionais}

O monitoramento de parcelas permanentes em florestas estacionais semideciduais tem ajudado a entender os padrões de estrutura e diversidade na região. A metodologia aplicada envolve a amostragem de todos os indivíduos arbóreos com diâmetro à altura do peito (DAP, medido a 1,30 $\mathrm{m}$ do solo) maior que $5 \mathrm{~cm}$ (Figura 2). As remedições ocorrem a cada cinco anos, onde são avaliadas as taxas de mortalidade, recrutamento e crescimento. A cobertura temporal dos períodos de monitoramento varia de cinco a 15 anos.

A densidade arbórea nessas florestas é de aproximadamente 1.000 indivíduos por hectare (entre 798 a 1.292 ind ha ${ }^{-1}$ ) e a área basal média é de 27,38 $\mathrm{m}^{2}$ ha $^{-1}$ (entre 15,14 a $45,78 \mathrm{~m}^{2} \mathrm{ha}^{-1}$ ). A riqueza de espécies varia entre 50 a 103 espécies por hectare. Os valores de densidade, área basal e riqueza de espécies dessas florestas são relativamente menores quando comparado a outras florestas estacionais semideciduais do sul e sudeste de Minas Gerais e de São Paulo, provavelmente devido aos períodos de seca mais intensos e prolongados na região do PELD TMSG. As taxas de dinâmica florestal estão próximas a $3 \%$ ao ano, superiores a outras florestas tropicas maduras (aproximadamente $1 \%$ ao ano), o que indica uma dinâmica mais acelerada nessas florestas. As variações entre os fragmentos parecem estar relacionadas ao tamanho do fragmento e ao seu grau de perturbação, com um aumento na proporção de espécies pioneiras e anemocóricas à medida que estes estressores são maiores (Tabela 1). 

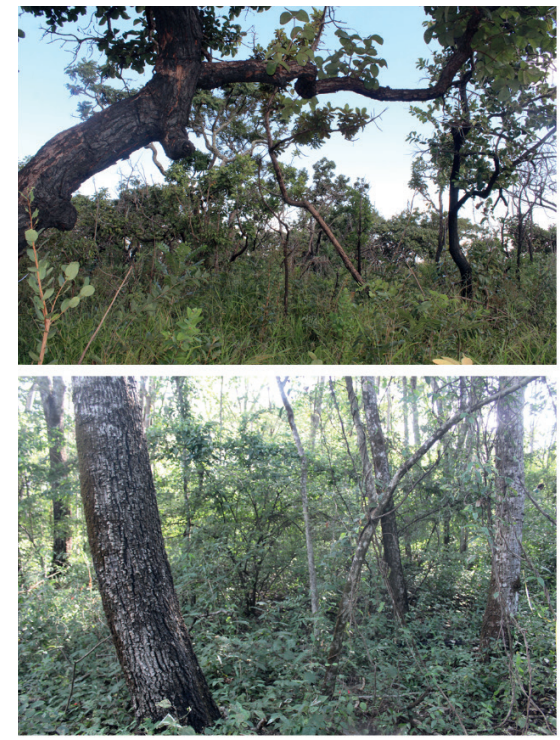

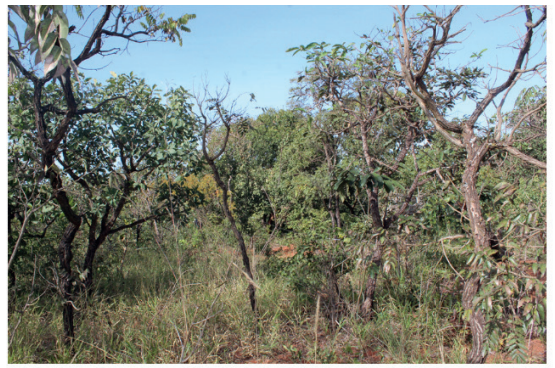

Figura 1. O mosaico de vegetações, formado por diferentes tipos de fitofisionomias é marcante na região do PELD TMSG. Comumente observa-se um gradiente de adensamento arbóreo, partindo de um cerrado sentido restrito com árvores esparsas e alta densidade de gramíneas em direção às fisionomias florestais, com árvores de grande porte e estrato arbustivo-herbáceas ralo ou ausente.

O estrato vertical e a distribuição dos diferentes grupos ecológicos entre os estratos verticais (sub-bosque, estrato intermediário e o dossel) também está relacionado aos estressores nesses fragmentos. O dossel dessas florestas é composto por indivíduos com altura igual ou superior a $13 \mathrm{~m}$, com maior dominância de espécies secundárias tardias, anemocóricas e decíduas em relação aos demais estratos. Em alguns fragmentos, as árvores emergentes atingem $30 \mathrm{~m}$ de altura. O sub-bosque é composto por indivíduos de até $9 \mathrm{~m}$ de altura e dominado por espécies sempre-verdes e com dispersão zoocórica. O estrato intermediário $(9-13 \mathrm{~m})$ é formado por um conjunto de espécies secundárias iniciais, mais susceptíveis à variação nas condições de luminosidade. As principais espécies em cada estrato são apresentadas na Tabela 2.
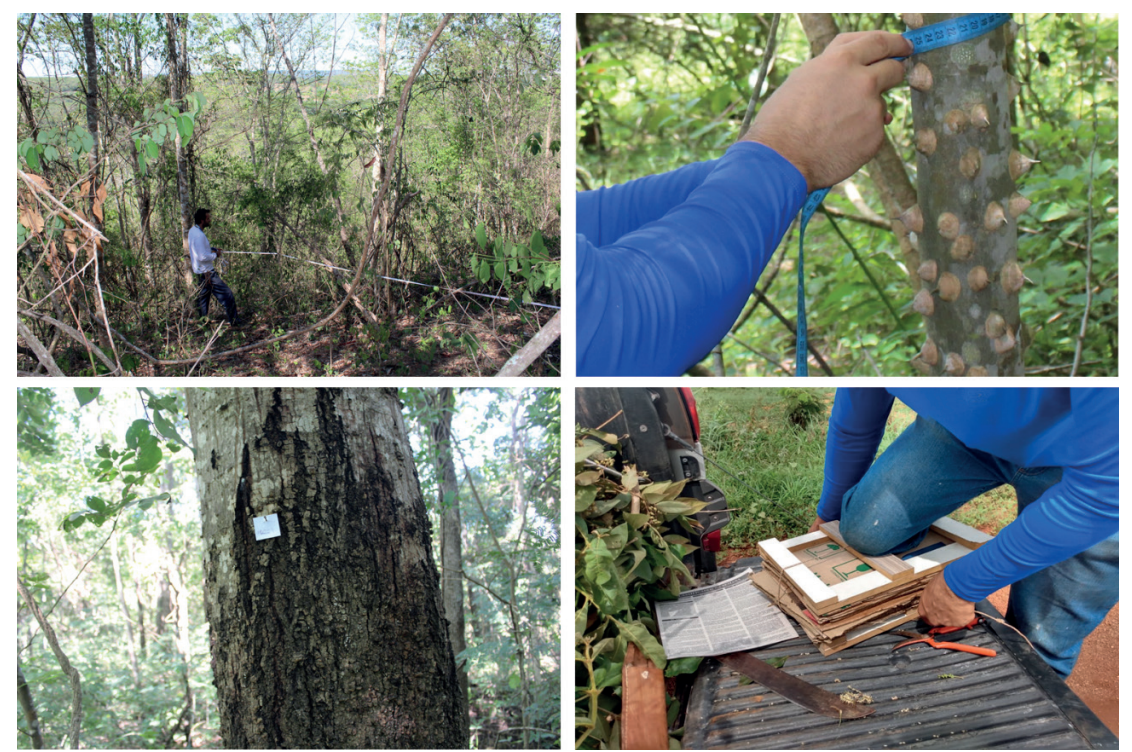

Figura 2. O monitoramento das parcelas permanentes é realizado em florestas estacionais da região do PELD TMSG. As árvores são marcadas com placas de alumínio para posterior remedição e o material botânico vegetativo/reprodutivo é coletado para posterior identificação das espécies. 
Tabela 1 - Parâmetros estruturais e de diversidade de dez fragmentos de floresta estacional semidecidual no TMSG. A classificação da intensidade de perturbação nos fragmentos foi realizada a partir de uma matriz de Leopold, considerando a frequência e intensidade de estressores como matriz de entorno, tamanho do fragmento, presença de gado, corte seletivo, lixo urbano e trilhas internas. $\mathrm{S}=$ Riqueza de espécies, $\mathrm{NI}=$ densidade arbórea por hectare, $\mathrm{AB}=$ área basal $\left(\mathrm{m}^{2}\right)$ por hectare, \% Pion e \% Ane $=$ porcentagem de indivíduos pertencentes a espécies pioneiras ou com dispersão anemocórica, respectivamente.

\begin{tabular}{llllllll}
\hline Fragmento & Perturbação & Tamanho & S & NI & AB & \%Pion & \%Ane \\
\hline AGU & 45 & 200 & 78 & 839 & 25,5 & 8,5 & 17,9 \\
PAN & 45 & 16 & 98 & 1292 & 21,7 & 23,1 & 28,5 \\
UBE & 48 & 70 & 88 & 805 & 45,8 & 3,5 & 23,0 \\
GLO & 74 & 30 & 86 & 976 & 26,2 & 5,6 & 24,4 \\
PER & 119 & 35 & 103 & 1144 & 26,8 & 6,9 & 24,3 \\
SJO & 119 & 20 & 88 & 1063 & 35,8 & 5,3 & 30,6 \\
IRA & 128 & 22 & 73 & 945 & 26,9 & 8,8 & 20,5 \\
MONT & 152 & 119 & 98 & 798 & 26,4 & 7,4 & 22,4 \\
IPI & 161 & 40 & 50 & 837 & 15,1 & 45,1 & 30,1 \\
CRU & 209 & 18 & 79 & 1233 & 23,5 & 19,2 & 34,2 \\
\hline Média & - & - & 242 & 993 & 27,4 & 13,34 & 25,6 \\
\hline
\end{tabular}

Tabela 2 - As 20 espécies com maior representatividade em cada estrato (dossel, intermediário e sub-bosque) nas florestas estacionais semideciduais do PELD TMSG.

\begin{tabular}{lll}
\hline Dossel & Intermediário & Sub-bosque \\
\hline Protium heptaphyllum & Casearia gossypiosperma & Cheiloclinium cognatum \\
Terminalia glabrescens & Duguetia lanceolata & Cordiera sessilis \\
Copaifera langsdorffi & Ixora brevifolia & Siparuna guianensis \\
Astronium nelson-rosae & Eugenia florida & Luehea grandiflora \\
Cryptocarya aschersoniana & Casearia grandiflora & Trichilia catigua \\
Aspidosperma discolor & Siphoneugena densiflora & Piptadenia gonoacantha \\
Hymenaea courbaril & Matayba guianensis & Campomanesia velutina \\
Apuleia leiocarpa & Heisteria ovata & Monteverdia floribunda \\
Pouteria torta & Cupania vernalis & Myrciaria glanduliflora \\
Virola sebifera & Sweetia fruticosa & Hirtella gracilipes \\
Ocotea corymbosa & Machaerium brasiliense & Chrysophyllum gonocarpum \\
Diospyros lasiocalyx & Unonopsis guatterioides & Guapira venosa \\
Tapirira obtusa & Casearia sylvestris & Coussarea hydrangeifolia \\
Machaerium villosum & Trichilia elegans & Celtis iguanaea \\
Cariniana estrellensis & Garcinia brasiliensis & Rhamnidium elaeocarpum \\
Vochysia magnifica & Chrysophyllum marginatum & Eugenia involucrata
\end{tabular}


Inga vera

Terminalia phaeocarpa

Simira sampaioana

Nectandra membranacea
Trichilia clausseni

Roupala montana

Faramea hyacinthina

Trichilia pallida
Coutarea hexandra

Galipea jasminiflora

Bauhinia ungulata

Eugenia ligustrina

\section{Visão funcional dos padrões de diversidade}

Estabelecer padrões e compreender seus mecanismos em comunidades vegetais com alta diversidade é uma tarefa difícil. A similaridade florística entre comunidades é fortemente influenciada pela distância geográfica, o que restringe os estudos a uma escala regional de comparação. Por exemplo, se agruparmos comunidades de diferentes regiões do Brasil com base em sua composição florística, os resultados refletirão muito mais sua proximidade geográfica que questões locais importantes como a perturbação. Além disso, comunidades com composição florística completamente distintas podem ser limitadas pelos mesmos recursos e apresentar interações bióticas e graus de conservação muito similares. Outro desafio envolve a baixa uniformidade na distribuição dos indivíduos entre as espécies, sendo a maioria das espécies locais representadas por poucos indivíduos. Por isso, muitos dos padrões já estabelecidos são baseados nas poucas espécies dominantes, enquanto grande parte da biodiversidade (representadas pelas muitas espécies localmente raras) acaba sendo ignorada devido a inviabilidade de incluí-las nas análises.

$\mathrm{Na}$ ecologia funcional, as comparações taxonômicas têm efeito reduzido, pois as espécies são avaliadas de acordo com suas características (traços) funcionais (Figura 3). Os traços funcionais são atributos com influência significativa na colonização, desenvolvimento ou sobrevivência de uma espécie. Eles refletem as adaptações à heterogeneidade ambiental, uso diferenciado de recursos e as interações ecológicas entre as espécies. Dessa forma, espécies filogeneticamente distantes podem possuir traços funcionais similares e, consequentemente, desempenhar as mesmas funções no ambiente. Por exemplo, Anadenanthera colubrina (angico) e Myracrodruon urundeuva (aroeira) pertencem a ordens diferentes (Fabales e Sapindales, respectivamente) mas apresentam muitos traços funcionais similares: são espécies de dossel, comuns em florestas estacionais, e que tem alta densidade de madeira e dispersão abiótica de sementes. Por outro lado, Hymenaea stigonocarpa (jatobá do cerrado), que também pertence à família Fabaceae, é uma espécie de cerrado, com densidade de madeira intermediária e dispersão mastocórica. Se imaginarmos três comunidade dominadas por uma das três espécies, as comunidades dominadas pelo angico ou aroeira serão muito mais próximas funcionalmente comparadas à comunidade dominada pelo jatobá do cerrado. A partir das análises funcionais, podemos não apenas comparar comunidades com composição florística totalmente distintas, mas também incluir as espécies raras nestas análises (Figura 3). O baixo número de indivíduos das espécies raras é combinado aos indivíduos de outras espécies funcionalmente similares, permitindo que os padrões e processos ecológicos avaliados cubram toda a diversidade de espécies. 


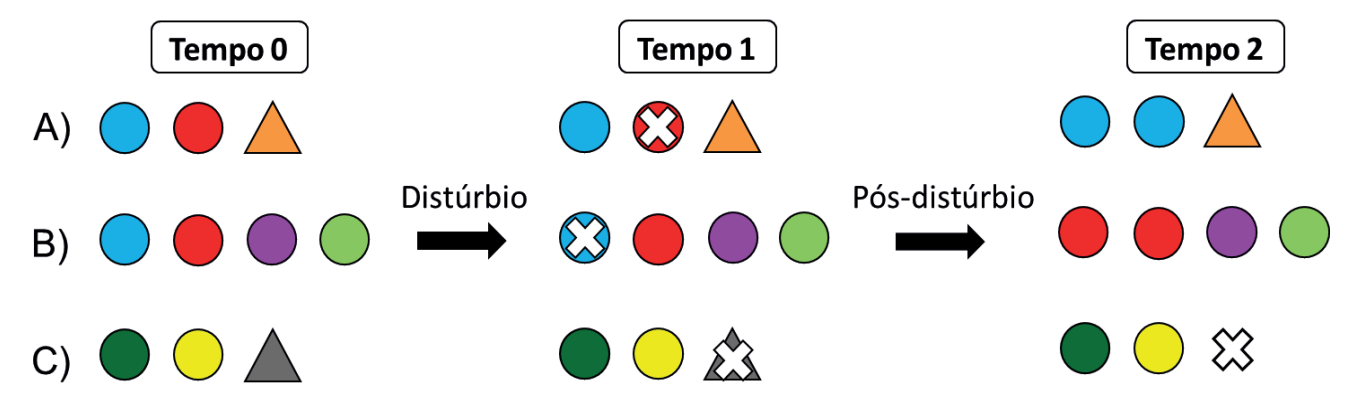

Figura 3. Esquema metodológico da análise funcional em comunidades vegetais. As cores das figuras geométricas representam diferentes espécies em três comunidades (A, B e C). A forma representa um traço funcional categórico (p. ex., tolerância ao sombreamento), onde círculos indicam espécies pioneiras e triângulos representam espécies não-pioneiras. No tempo 0, observa-se que as áreas A e B são mais próximas floristicamente do que a área C. Entretanto, a composição funcional das áreas A e C são similares, enquanto na área B não ocorrem espécies não-pioneiras. No tempo 1, as três comunidades sofreram algum distúrbio, o que resultou na perda de uma de suas espécies. No tempo 2 (pós-distúrbio), as comunidades A e $\mathrm{B}$ foram resilientes ao distúrbio, sendo que a espécie perdida em cada comunidade foi substituída por outra espécie do mesmo grupo funcional (redundância funcional). Já na comunidade C, a espécie localmente extinta era a única de seu grupo funcional, e dessa forma nenhuma outra espécie da comunidade consegue ocupar seu nicho na comunidade, o que gera perda de funções e resiliência.

\section{Diferenças nas relações de produtividade entre florestas úmidas e estacionais}

A produtividade de uma floresta pode ser avaliada por suas mudanças líquidas de biomassa ao longo dos anos. Essas mudanças líquidas são o resultado do ganho em biomassa pelo recrutamento de novas árvores e pelo crescimento das árvores sobreviventes, subtraídos da perda de biomassa pelas arvores mortas. Em um de nossos estudos, avaliamos como as mudanças na biomassa de florestas estacionais são afetadas por suas métricas de diversidade funcional e até que ponto essas relações são similares àquelas observadas em florestas úmidas. Observamos que o recrutamento de novas árvores é maior quando a comunidade é composta por espécies decíduas, o que tem implicações interessantes sobre a regeneração das florestas estacionais e os filtros ambientais criados pela fenologia foliar das espécies. O aumento de espécies decíduas no dossel aumenta a disponibilidade de luz no sub-bosque e favorece o estabelecimento de novas árvores na floresta. Estudos mostram que em comunidades vegetais com alta deciduidade foliar, as espécies de menor porte produzem folhas novas até um mês antes das árvores de dossel. Nesse sentido, elas aproveitam o período de dossel aberto para aumentarem suas taxas de crescimento nessa pequena janela temporal. Isto demonstra que apesar do dossel mais baixo e esparso, a luz é recurso limitante nas florestas estacionais e um direcionador de suas taxas de recrutamento. Embora esperássemos que a perda de biomassa fosse menor em comunidades com maior complementariedade de nichos, não encontramos nenhuma relação entre mortalidade e diversidade funcional.

Por fim, observamos que o crescimento em biomassa das florestas estacionais é maior quando elas são dominadas por espécies com maior densidade de madeira e menor área foliar específica, o que contrapõe o padrão de produtividade em florestas úmidas. Embora uma madeira mais densa exija um maior custo de produção de biomassa por volume de madeira (o que potencialmente reduz o crescimento da planta), a presença de vasos condutores mais estreitos permite a condutividade hidráulica durante a seca 
e assim minimiza o estresse hídrico. De forma similar, espécies com menor área foliar específica possuam menores taxas fotossintéticas líquidas, mas também menor taxa respiratória e transpiração, o que permite um melhor uso da água disponível. Dessa forma, as relações entre traços funcionais e produtividade parecem se diferir entre florestas úmidas e secas, onde as vantagens relacionadas à maior adaptação ao estresse hídrico aumentam a produtividade das florestas estacionais. Estes resultados têm implicações importantes para os padrões relacionados ao espectro econômico dos traços e para a compreensão da produtividade das florestas tropicais como um todo frente às mudanças climáticas.

\section{A influência dos traços varia ao longo da ontogenia das árvores}

Como discutido anteriormente, as relações entre os processos demográficos das espécies e seus traços funcionais refletem os mecanismos ligados à sua distribuição e sucesso em ambientes contrastantes. Um de nossos estudos demonstrou que essa influência é fortemente dependente do tamanho da árvore, ou seja, ela varia ao longo da ontogenia dos indivíduos. As condições ambientais mudam consideravelmente ao longo do desenvolvimento de uma árvore, especialmente para as espécies que atingem o dossel quando adultas. Quando jovens e localizadas no sub-bosque da floresta, as árvores estão sujeitas à uma baixa disponibilidade de luz e alta umidade relativa. À medida que atingem tamanhos maiores, a luz começa a ser mais abundante e a água passa a ser mais limitante (devido à maior distância entre as raízes e as folhas e ao aumento na evapotranspiração). Assim, traços funcionais que aumentam a captura de luz e a tolerância à sombra são mais importantes enquanto as árvores estão no subbosque, enquanto traços que incrementam a resistência ao estresse hídrico e a exposição ao vento aumentam a performance das árvores que atingem o dossel.

A arquitetura de copa tem influência sobre a dinâmica de crescimento das árvores menores (5-25 cm de diâmetro do tronco) mas essa relação desaparece quando elas atingem maior tamanho (Figura 4a). Em situação de maior sombreamento, as espécies com menor comprimento da copa (maior altura das primeiras folhas em relação à altura total) tem maiores taxas de crescimento. Como as porções mais baixas da copa estão expostas a maior auto sombreamento, adiar o desenvolvimento de ramos laterais permite o investimento em crescimento vertical para atingir regiões com maior disponibilidade de luz. Curiosamente, as espécies com maior largura de copa têm maior taxa de crescimento e menor mortalidade (trade-on) quando ainda têm pequeno porte. Isso indica que os custos do crescimento lateral de ramos e a maior chance de serem atingidas pela queda de outras árvores são compensados pela maior exposição à luz difusa quando estão no sub-bosque (Figura 4c,d). Ao contrário do comprimento de copa, uma maior área de copa não promove o auto sombreamento, o que pode justificar as relações inversas entre os dois tipos de arquitetura arbórea. Além disso, a ausência de trade-off quanto à largura de copa, ou seja, copas mais largas crescem mais e sobrevivem mais quando são jovens, pode ajudar a entender a dominância de algumas espécies em relação ao restante da comunidade. 

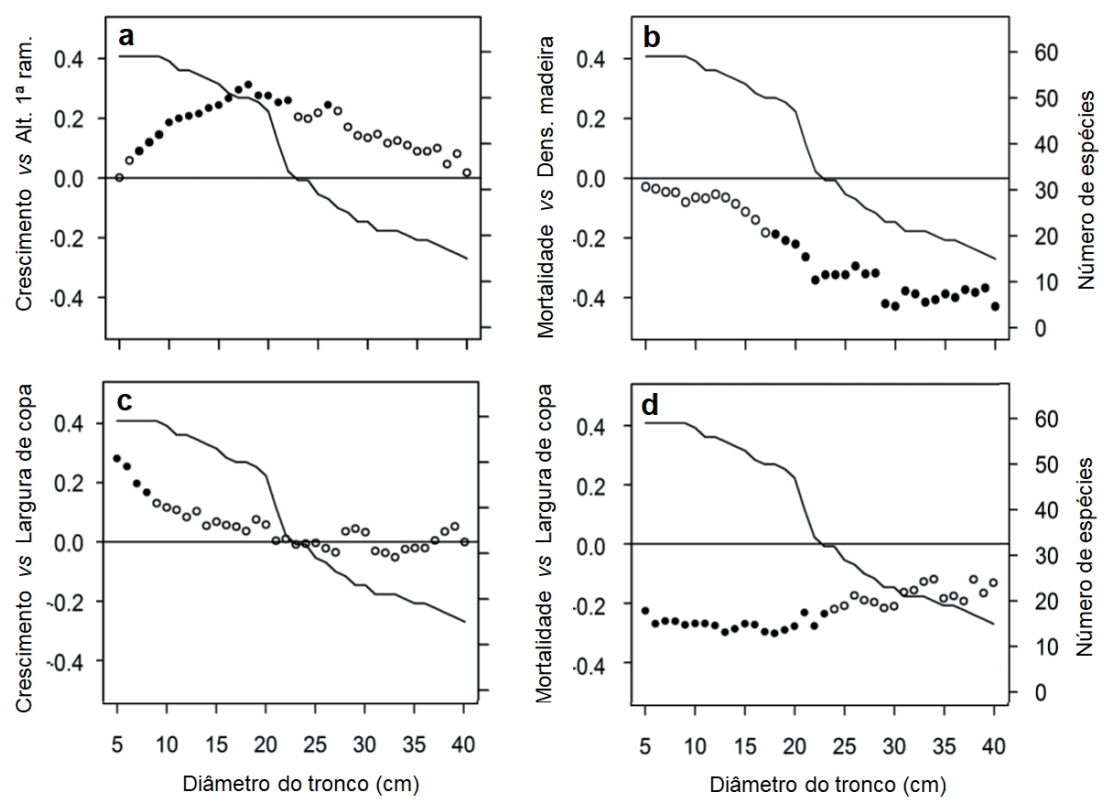

Figura 4. Mudanças dependentes do tamanho nos coeficientes de correlação entre os processos demográficos (crescimento e mortalidade) e a altura da primeira ramificação (a), densidade de madeira (b) e largura de copa (c, d) entre espécies de florestas estacionais com diferentes diâmetros do tronco (de 5 a 40 $\mathrm{cm})$. Círculos sólidos indicam correlações significativas $(\mathrm{p}<0,05)$ e círculos abertos indicam correlações não significativas $(\mathrm{p}>0,05)$. A linha mostra a redução no número de espécies com o aumento do diâmetro do tronco, de 59 espécies no menor diâmetro de referência $(5 \mathrm{~cm})$ a 15 espécies no maior diâmetro de referência. Adaptado de Prado-Junior et al. 2017.

Já a influência da densidade de madeira na taxa de mortalidade não é evidente entre as árvores de menor porte, mas torna-se significativa quando as árvores atingem maiores tamanhos (Figura $4 \mathrm{~b}$ ). Durante os longos períodos de estiagem, muitas árvores morrem por problemas relacionados à cavitação no xilema (isto é, a formação de bolhas de gás capazes de interromper o fluxo de água). A susceptibilidade à cavitação se torna maior à medida que a árvore atinge maior porte. Madeiras mais densas possuem vasos condutores mais estreitos (menos sensíveis à cavitação) e mais numerosos, permitindo que a embolia de um dos vasos seja superada já que muitas outras vias estão disponíveis para condução da água. Esses resultados evidenciam a influência dos traços (comprimento e largura de copa e densidade de madeira) na performance das espécies, mas também a dependência do tamanho da árvore. Dessa forma o tamanho das árvores deve ser incluído como uma importante fonte de variação na ecologia funcional para uma maior compreensão das relações entre os traços funcionais e as taxas demográficas das espécies.

\section{Impactos antrópicos na vegetação}

\section{Os reservatórios de usinas hidrelétricas e as florestas estacionais}

Os reservatórios de água das usinas hidrelétricas estão envolvidos não apenas na produção de energia, mas também em diversas atividades humanas como a irrigação agrícola, o abastecimento dos centros urbanos, a navegabilidade e a recreação. As represas são criadas a partir da construção de uma barragem, que interrompe o fluxo 
natural de um rio e inicia o alagamento da área à montante (Figura 5). Por muito tempo, a ideia de "energia limpa" provida pelas usinas hidrelétricas pareceu ser a solução para atender às crescentes demandas energéticas da população humana. Por não utilizarem a queima de combustíveis fósseis, como as usinas termoelétricas, as usinas hidrelétricas poderiam frear a emissão de gases do efeito estufa e solucionar o problema da constante diminuição nos estoques de combustíveis fósseis. Embora outras formas de energia renovável (como a energia solar e eólica) também sejam promissoras no controle das mudanças climáticas, sua geração de energia é muito menor comparada à das usinas hidrelétricas, sendo insuficientes para abastecer toda a população. A cada ano, diversos reservatórios artificiais são construídos em todo o mundo e, em muitos países como o Brasil, a energia hidrelétrica já representa a maior parte de toda a energia consumida.

No entanto, estes reservatórios têm sido relacionados a impactos ambientais significativos, como o aumento na emissão de outros gases do efeito estufa (como o metano que é gerado pela decomposição anaeróbica da matéria orgânica dentro dos reservatórios e é mais nocivo que o $\mathrm{CO}_{2}$ ), o aumento de doenças transmitidas por mosquitos, e a redução da migração e reprodução de peixes. Nas comunidades vegetais, os efeitos diretos dos reservatórios são facilmente visualizados pelo desmatamento das extensas áreas de inundação. No entanto, impactos indiretos e de longo prazo podem ocorrer na vegetação do entorno, que uma vez distante do curso de água antes do represamento, passam a se situar próximas à água (Figura 5). Esta nova condição ripária afeta o desempenho das espécies e, consequentemente, a sucessão natural dessas comunidades.

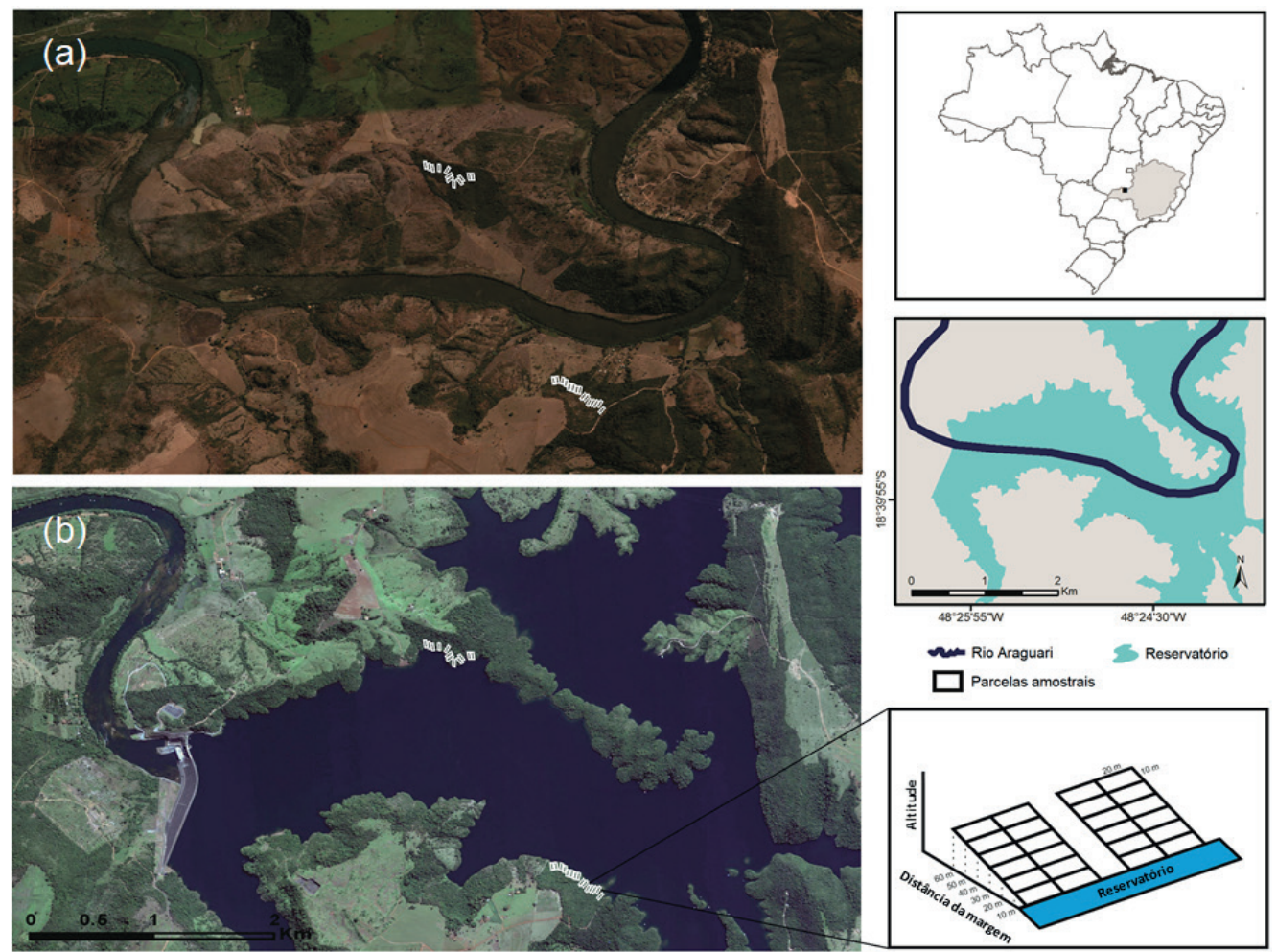

Figura 5. Florestas estacionais antes (a) e depois (b) da construção da barragem no Rio Araguari, entre os municípios de Uberlândia e Araguari, Brasil. As parcelas amostrais estavam localizadas a pelo menos $500 \mathrm{~m}$ do curso do rio antes da construção da barragem (a) e agora estão próximas (0-60m) à margem do reservatório (b). Figura adaptada de Raymundo et al. 2019. 
A maioria dos estudos que avaliaram o efeito da construção de reservatórios artificiais em comunidades vegetais foram conduzidos em regiões temperadas e em ecossistemas dominados por gramíneas e espécies herbáceo-arbustivas. No entanto, a maioria das barragens está localizada em regiões tropicais, cobertas por florestas de grande diversidade. Em um estudo pioneiro sobre esse tema no Brasil, o PELD TMSG tem monitorado algumas florestas estacionais afetadas por reservatórios artificiais desde 2005. As florestas estacionais estão entre as formações vegetais do Brasil mais afetadas por reservatórios, já que usualmente ocorrem em vales íngremes e com forte drenagem, condições favoráveis à construção de usinas hidrelétricas. Além disso, por estarem sob acentuada sazonalidade climática e abrigarem muitas espécies com características de resistência à seca, as florestas estacionais representam ecossistemas muito interessantes para avaliar como as mudanças na disponibilidade de água afetam a biodiversidade vegetal.

A criação do reservatório pertencente ao Complexo de Barragens Amador Aguiar ocorreu em 2006, inundando uma área de aproximadamente $45 \mathrm{~km}^{2}$. Antes da inundação, as florestas estavam a pelo menos $500 \mathrm{~m}$ do curso do rio original (Figura 5a) e, depois da inundação, estão localizadas à margem do reservatório (Figura 5b). Antes da construção da barragem, um estudo topográfico determinou a cota de inundação do reservatório e permitiu a implantação das parcelas amostrais em locais que ficariam entre 0-60 m de distância da água.

A umidade do solo aumenta consideravelmente após o represamento, criando um gradiente de umidade a partir da margem do reservatório. Nas parcelas mais próximas (entre 0 e $20 \mathrm{~m}$ do reservatório), esse aumento é de aproximadamente $20 \%$ na estação chuvosa e maior que $100 \%$ durante a estação seca. Por outro lado, essas mudanças não ocorrem nas parcelas mais distantes ( $>20 \mathrm{~m}$ ). Assim, a nova condição ripária na região mais próxima ao reservatório ameniza o déficit hídrico durante o período de estiagem nas florestas estacionais, aumentando a disponibilidade de água para as plantas ao longo de todo o ano (Figura 6).

Logo após a inundação do reservatório, a variação abrupta na umidade do solo promove uma alta mortalidade do estrato regenerativo da floresta, mas é acompanhada pela rápida colonização de novas espécies. Nos primeiros anos, as taxas de dinâmica florestal (recrutamento, mortalidade e crescimento) são superiores a $5 \%$ ao ano nas parcelas mais próximas ao reservatório, em contraste com os $2 \%$ observado nas parcelas mais distantes. Normalmente, florestas maduras apresentam taxas de dinâmica entre $0-2 \%$ ao ano. A taxa de mortalidade nas parcelas próximas ao reservatório é similar a mortalidade observada após incêndios florestais, furacões, grandes enchentes e tempestades, considerados os distúrbios mais intensos nas mudanças florestais. Entretanto, ao contrário destes distúrbios, os impactos causados pelos reservatórios são permanentes, indicando que essas florestas provavelmente não voltarão ao seu estado anterior ao reservatório. 

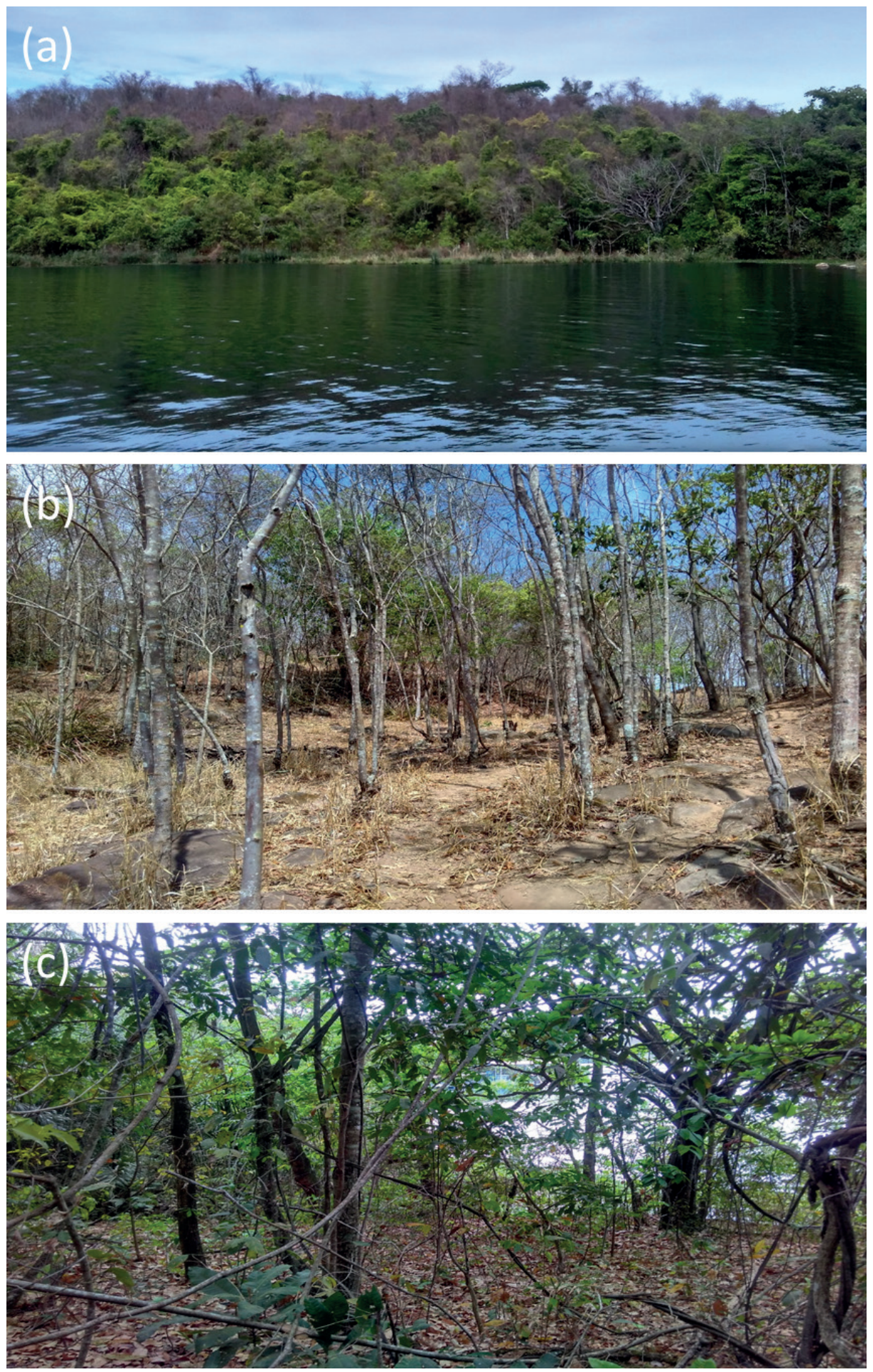

Figura 6. Floresta afetada por um reservatório artificial. O gradiente de umidade do solo é refletido pelas mudanças na deciduidade das árvores à medida que se distanciam da margem do reservatório (a). As diferenças na composição funcional das espécies dominantes da comunidade longe (b) e perto (c) do reservatório promovem grandes mudanças no microclima, regeneração e potenciais serviços ecossistêmicos entre as duas comunidades. 
Após 10 anos dessa nova condição, as mudanças líquidas na biomassa da comunidade ainda são nulas, onde o ganho em biomassa pelo recrutamento e os trechos da floresta mais próximos ao reservatório apresentam maior diversidade de espécies e maior diversidade funcional, principalmente pela colonização de novas espécies menos resistentes à seca. As espécies novas e as que aumentaram sua dominância na comunidade apresentam traços funcionais típicos de ambientes com alta disponibilidade de água, como baixa densidade de madeira e fenologia foliar sempre-verde (Figura 7). Com o aumento na disponibilidade de água, espécies com menor densidade de madeira são beneficiadas por possuírem maior condutividade hidráulica, aumentando suas taxas de crescimento. Espécies decíduas perdem suas folhas durante a estação seca para reduzir o déficit hídrico a um custo de reduzirem seu período de crescimento comparado às espécies sempre-verdes. Dessa forma, como a água não é mais limitante no ambiente próximo ao reservatório, essas novas estratégias funcionais aumentam o poder competitivo dessas novas espécies em relação às espécies que dominavam a comunidade antes da construção do reservatório (Figura 6).
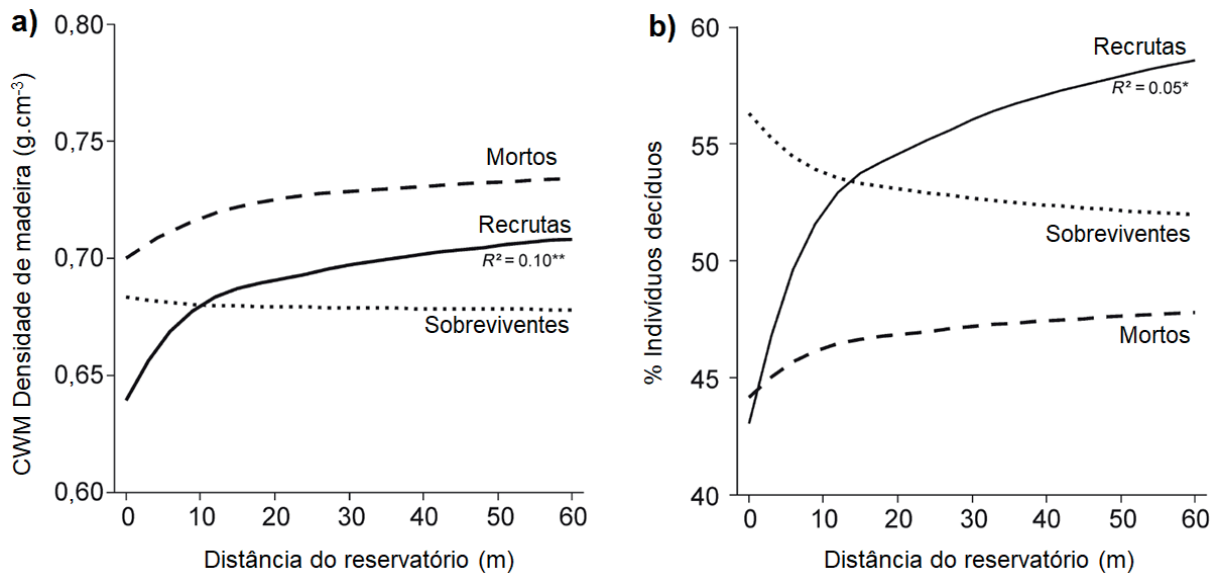

Figura 7. Relações entre a distância do reservatório e a média ponderada de densidade de madeira (a) e deciduidade (b) para cada grupo demográfico (sobreviventes, recrutas e mortos). Nota-se que as mudanças na comunidade são significativas apenas para as árvores recrutadas, que pertencem a espécies sempreverdes e com menor densidade de madeira. Figura adaptada de Raymundo et al. 2019.

As mudanças na diversidade e composição funcional da comunidade são mais evidentes nas árvores de menor porte (árvores recrutadas, Figura 7), provavelmente porque as árvores maiores possuem sistema radicular mais profundo e, portanto, são menos sensíveis às flutuações hídricas comuns às florestas estacionais. Isso indica que muitas das mudanças ocorrem no sub-bosque dessas florestas, sendo menos evidentes as mudanças que ocorrem no dossel. Apesar de representar uma fração pequena da biomassa florestal, o recrutamento de espécies funcionalmente diferentes da comunidade residente indica que as mudanças na estrutura e composição das florestas estacionais afetadas por reservatórios são duradouras e que devem se tornar cada vez mais significativas com ao longo dos anos. Atualmente, existem mais de 200 usinas hidrelétricas no Brasil, e muitas estão sendo projetadas. Compreender como elas afetam a vegetação do entorno fornece ferramentas para a conservação dessas áreas, inclusive sobre técnicas mais efetivas para a recuperação de áreas sem vegetação às margens dos reservatórios. 


\section{O paradoxo entre o fogo "bom" e "ruim" na estruturação das savanas}

Todos os anos, as queimadas ao redor do mundo atingem mais de 400 milhões de hectares (área equivalente à metade do Brasil). Entretanto, seus efeitos na estrutura e diversidade das comunidades variam consideravelmente, mesmo em formações vegetais intimamente ligadas ao fogo como as savanas. As queimadas são um importante direcionador da distribuição e endemismo das savanas, ocorrendo de forma natural muito antes da ocupação humana destas áreas. Elas são causadas principalmente por descargas elétricas, embora a combustão espontânea, atrito entre rochas ou da pelagem de alguns animais com a vegetação seca também podem provocar queimadas naturais. Os filtros ambientais criados pelos eventos de fogo natural contribuíram não apenas para a evolução de espécies tolerantes ao fogo, mas também de espécies dependentes do fogo em pelo menos um de seus processos de desenvolvimento, desde a quebra de dormência da semente até a produção de flores e frutos.

O papel do fogo na manutenção da coexistência entre gramíneas e espécies arbóreas nas savanas tem sido objeto de estudo há décadas. Muitas das espécies de gramíneas têm ciclo de vida anual, com rápido crescimento em biomassa no período chuvoso e morte no período seco, o que favorece a ocorrência de incêndios. Assim, é importante que a biomassa seca acumulada ao longo dos anos seja queimada para promover a ciclagem de nutrientes e o desenvolvimento da nova vegetação (Figura 8). O papel do fogo é particularmente importante nas savanas neotropicais. Em savanas africanas, a megafauna de herbívoros ajuda na manutenção do equilíbrio entre gramíneas e espécies arbóreas. O constante pastoreio e as movimentações das grandes manadas regulam o acúmulo de biomassa das gramíneas e evitam que a vegetação arbórea se adense. Com a extinção da megafauna nativa das savanas neotropicais, essa regulação passou a ser feita principalmente pelo fogo. 

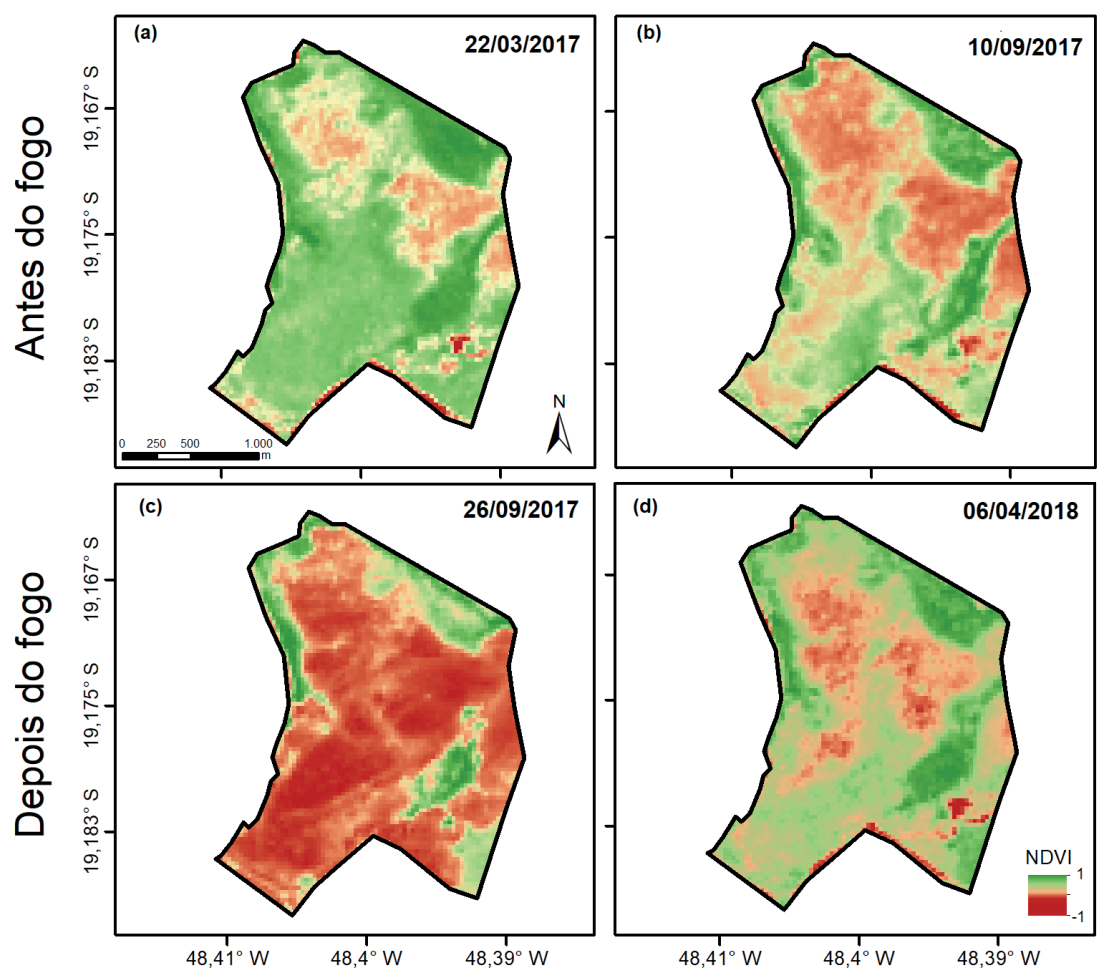

Figura 8. Efeito do fogo na vegetação da Reserva Ecológica do Panga, evidenciado pelas mudanças no Índice de Vegetação da Diferença Normalizada (NDVI) ao longo de um ano. Tons mais próximos ao verde indicam vegetação mais densa e tons mais próximos ao vermelho indicam solo mais exposto. (a) Final da estação chuvosa (março de 2017), onde grande parte da vegetação está com folhas; (b) Final da estação seca (setembro de 2017), cinco dias antes do fogo atingir a reserva. Nota-se que que muitas espécies estão sem folhas, principalmente nos trechos dominados pela vegetação savânica; (c) Final da estação seca (setembro de 2017), dez dias após a queimada. Com exceção das porções florestais da reserva, praticamente toda a vegetação foi queimada. (d) Final da estação chuvosa do ano seguinte após a queimada. Nota-se a redução na densidade da vegetação comparada à vegetação da reserva há um ano, mas a recuperação da cobertura vegetal é evidente após seis meses da passagem do fogo.

Curiosamente, as queimadas em áreas naturais ainda são vistas como desastres pela maioria da população. Por muito tempo, esse pensamento foi refletido em diversas políticas públicas e planos de manejo que procuraram suprimir qualquer foco de incêndio que atingisse as unidades de conservação. Estudos recentes têm contribuído para mudar esse paradigma, e mostram que a supressão do fogo nas savanas por um longo período pode levar à homogeneização dessas comunidades e substituição de muitas espécies savânicas por espécies florestais (e em alguns casos até à extinção local dessas espécies típicas). Além disso, quando a biomassa de gramíneas se acumula após longos períodos sem fogo, as queimadas são mais intensas, atingem temperaturas maiores e queimam não apenas as gramíneas, mas as copas das árvores mais altas. Nesse sentido, o manejo do fogo tem sido cada vez mais estimulado, onde queimadas periódicas e de baixa intensidade ajudam na conservação das savanas.

Em um de nossos estudos, avaliamos como um evento de fogo pode afetar áreas de cerrado em estágio inicial de sucessão. Após o abandono de uma pastagem, as árvores de grande porte remanescentes (chamadas de nucleadoras) ajudam na recuperação da vegetação do cerrado. Essas árvores alteram as condições ambientais sob a copa 
(aumentam a fertilidade do solo e reduzem a incidência luminosa direta, as variações de temperatura, o estresse hídrico e a biomassa de gramíneas), além de servir como poleiros naturais para a fauna dispersora de sementes. A facilitação ecológica promovida por essas árvores aumenta significativamente a colonização de novos indivíduos arbóreos e, consequentemente, acelera a sucessão vegetal no cerrado (Figura 9).

Entretanto, a flora colonizadora destes núcleos pode ser dominada por espécies florestais trazidas pelos pássaros que forrageiam na paisagem do entorno. Por possuírem taxas de crescimento mais rápidas que as espécies típicas de cerrado, em poucos anos as espécies florestais podem transformar esses núcleos de recuperação do cerrado em pequenas manchas florestais, sobrepondo a própria árvore nucleadora inicial. Embora seja difícil imaginar que um evento de fogo em uma comunidade composta por indivíduos tão jovens possa trazer algum benefício, mais uma vez o fogo nos mostra o quão complexo e importante é o seu papel nas savanas.
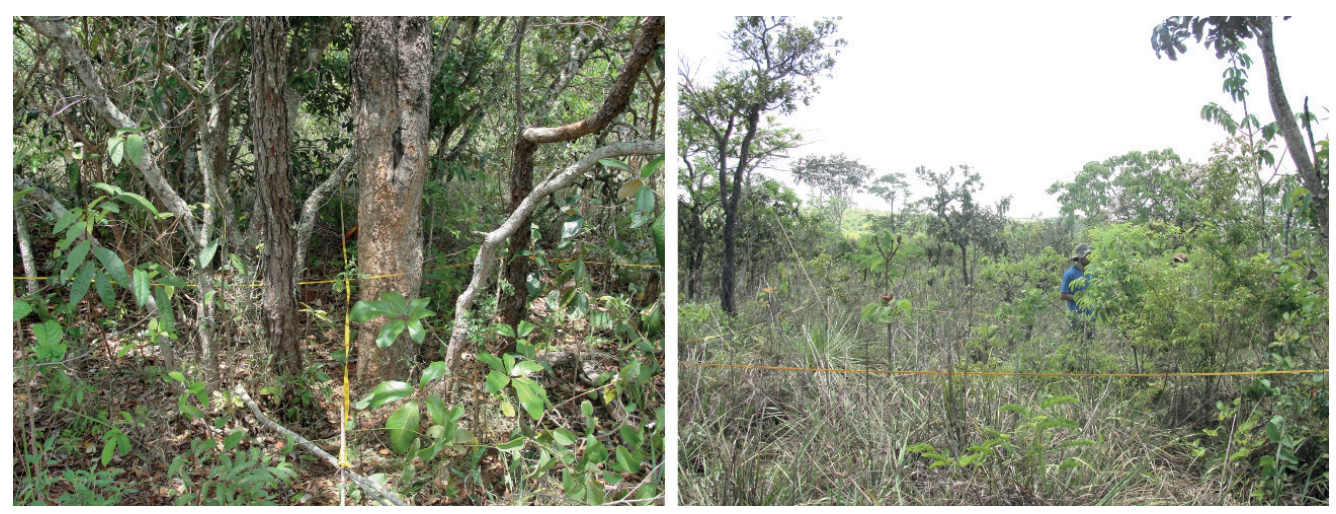

Figura 9. Comunidade de cerrado sob uma árvore nucleadora (à esquerda) e uma comunidade adjacente à árvore nucleadora (à direita). As alterações no microclima abaixo da copa aceleram o processo de sucessão no cerrado, auxiliando na recuperação de áreas degradadas. Fotos: Carolina Arantes.

Quando os núcleos passam por algum evento de fogo, existe uma redução de aproximadamente $25 \%$ na densidade de plantas, mas eles passam a ser dominados por espécies de cerrado e apresentam diversidade de espécies maior que núcleos não queimados. Como o sombreamento promovido pela árvore nucleadora reduz significativamente a biomassa de gramíneas abaixo da copa, o fogo que atinge os núcleos é de baixa intensidade e duração. Após o fogo, muitos dos indivíduos jovens de espécies savânicas que perderam a parte aérea podem rebrotar, retomando o processo de sucessão da comunidade.

Usando técnicas de sensoriamento remoto e dados de monitoramento da vegetação, alguns estudos no PELD TMSG tem ajudado a entender este controverso debate sobre o regime de fogo "ideal" nas savanas. A redução do estoque de biomassa acima do solo é inevitável quando as comunidades estão sujeitas a queimadas. Essas reduções podem variar desde $30-40 \%$ em comunidades com frequência de fogo quadrienal, até $75 \%$ em comunidades queimadas anualmente. Entretanto, quando avaliamos a biodiversidade como um todo, generalizações sobre o efeito positivo ou negativo do fogo precisam ser feitas com cautela. Quando a frequência de fogo não é alta ( $>4$ anos entre as queimadas), área queimadas podem apresentar maior diversidade funcional de traços vegetativos (densidade de madeira e área foliar específica), o que indica maior equilíbrio entre 
espécies com diferentes demandas por luz e resistência ao fogo e, consequentemente, maior complementariedade de nichos (Figura 10). Além disso, área com baixa frequência de fogo possuem os mesmos grupos funcionais de áreas conservadas, indicando que as funções ecológicas são mantidas mesmo após as queimadas.

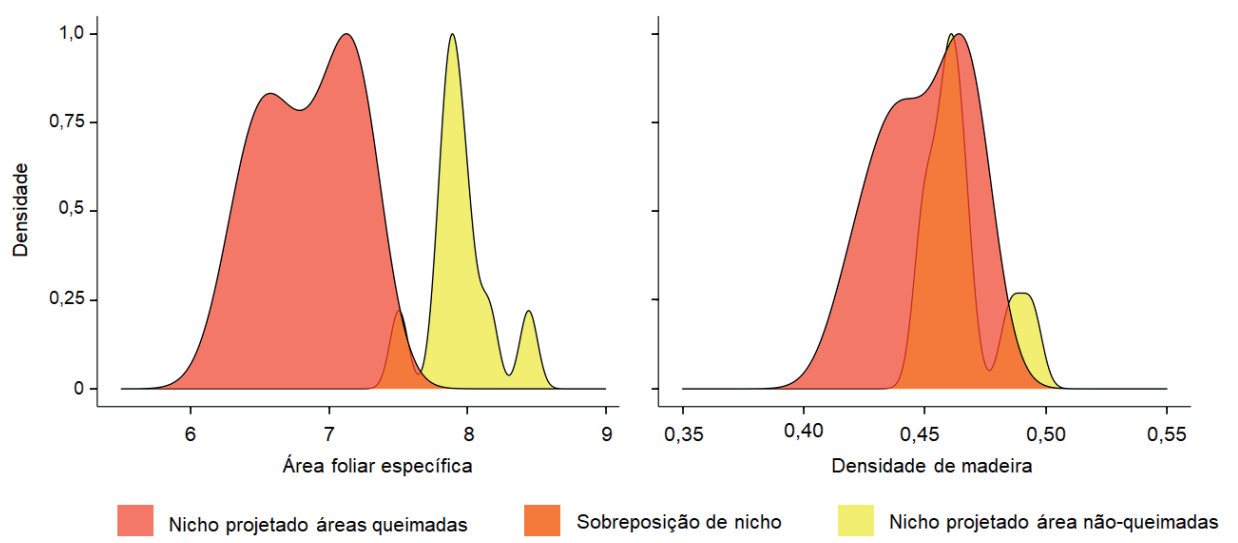

Figura 10. Nichos projetados para área foliar específica (a) e densidade de madeira (b) em duas comunidades com diferentes regimes de fogo. Uma comunidade com frequência de fogo quadrienal e outra com supressão de fogo por 10 anos. Observa-se que a amplitude de nichos dos dois traços é maior na área queimada, o que indica maior dispersão funcional e, consequentemente, maior complementariedade de nichos.

Por outro lado, não se pode dizer que todo evento de fogo beneficia as savanas. Nas últimas décadas, o aumento das atividades antrópicas e dos eventos de seca prolongada tem aumentado a frequência de fogo em muitas áreas naturais (em alguns casos até duas queimadas no mesmo ano). Surpreendentemente, o fogo ainda é muito usado no controle de capins exóticos e na preparação do solo para plantios em muitas propriedades no Brasil. A queima de entulhos em centros urbanos e o constante fogo às margens das rodovias são muitas vezes as fontes de ignição das queimadas catastróficas que atingem as áreas naturais. Uma das diferenças entre queimadas naturais e antrópicas está relacionado ao período do ano em que elas normalmente ocorrem. Os raios que atingem a vegetação seca e iniciam uma queimada natural são sucedidos pela chuva, que naturalmente maneja o fogo e evita que ele tome grandes proporções. Já a maioria das queimadas antrópicas ocorrem no final do período seco e podem queimar milhares de hectares de vegetação nativa em poucos dias, até que todo o combustível vegetal acabe. Mesmo apresentando diversas características de resistência ao fogo (como casca espessa e capacidade de rebrota pós-fogo), muitas espécies savânicas têm apresentado reduções significativas de suas populações. Assim como a supressão do fogo por longos períodos, a alta frequência de fogo tem levado à homogeneização e perda de espécies de muitas comunidades savânicas.

\section{O subestimado potencial do cerrado às margens de rodovias para conservação}

Embora as rodovias tenham um papel fundamental no desenvolvimento socioeconômico de um país, estudos indicam que elas estão associadas a graves problemas ambientais, tais como a fragmentação de habitas, o atropelamento da fauna e o acúmulo de resíduos sólidos. Ao longo das rodovias, faixas marginais de $15 \mathrm{~m}$ são 
restritas a qualquer tipo de uso (conhecidas como faixas não edificáveis ou de servidão), que usualmente são cobertas por vegetação nativa. Considerando-se a extensão da malha rodoviária que corta o domínio do Cerrado (superior a $100 \mathrm{mil} \mathrm{km}$ ) e sua faixa marginal de $15 \mathrm{~m}$ de cada lado, a área total de vegetação às margens das rodovias é superior a 300 mil ha. Essa área representa quase seis vezes toda a área protegida de Cerrado em unidades de conservação. Embora essas faixas marginais sejam consideradas Áreas de Preservação Permanente segundo a legislação, pouco se conhece sobre sua capacidade de resiliência, e quais os seus reais serviços ecossistêmicos (tais como a manutenção do estoque de biomassa, a oferta de recursos para a fauna e refúgio para a biodiversidade) comparados a outras áreas protegidas.

Os filtros ambientais que atuam na estrutura e diversidade da vegetação de cerrado às margens de rodovias (a partir daqui referido como CerMR) são mais intensos que em outras áreas. Por serem estreitas faixas de vegetação e com uma matriz de entorno coberta por pastagens ou culturas agrícolas, as comunidades de CerMR estão sob intenso estresse hídrico, maior frequência de fogo e constante lixiviação de nutrientes do solo (Figura 11). Compreender como essas condições afetam sua resiliência tem sido um dos objetivos de recentes pesquisas no PELD TMSG. Mais especificamente, procuramos responder às seguintes questões: I) quantas espécies arbóreas existem no CerMR e quanto elas representam da diversidade do Cerrado como um todo? II) quais as espécies mais abundantes e mais frequentes? III) as espécies arbóreas com maior dominância são as mesmas encontradas em áreas de Cerrado conservadas? IV) as espécies dominantes compartilham as mesmas características funcionais para superar os filtros ambientais (baixa disponibilidade de água e nutrientes e alta frequência de fogo)?

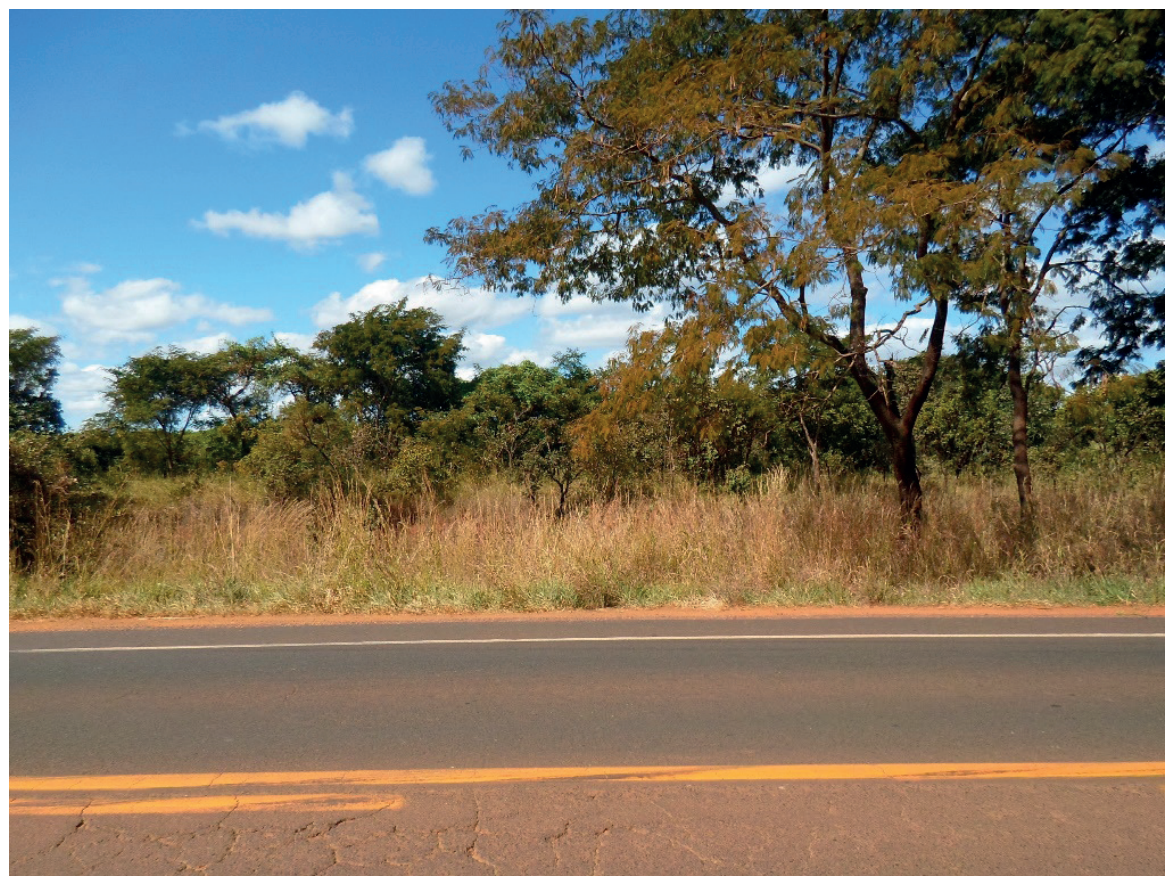

Figura 11. As áreas de cerrado às margens de rodovias são representadas por estreitas faixas de vegetação inseridas em uma matriz coberta por pastagens ou culturas agrícolas. Conhecer os potenciais serviços ecossistêmicos promovidos por essas áreas é de grande importância para a conservação do Cerrado como um todo. 
Os resultados preliminares mostram que a riqueza de espécies e a biomassa do CerMR equivalem a $70 \%$ e $50 \%$ dos valores encontrados em áreas protegidas, respectivamente. Se considerarmos sua grande extensão no Brasil, essas áreas demonstram um grande potencial para a conservação da biodiversidade. A composição funcional relacionada aos traços vegetativos (área foliar específica, espessura de casca e densidade de madeira) é similar entre o CerMR e as áreas protegidas (Figura 12), sendo que a variabilidade desses traços parece ser ainda maior no CerMR (provavelmente devido à ocorrência dos eventos extremos de fogo e lixiviação do solo em algumas áreas). Entretanto, quando avaliamos os traços reprodutivos das espécies, que refletem as potenciais interações com a fauna, as diferenças entre CerMR e as áreas protegidas são bem significativas (Figura 12). Nota-se maior dominância de espécies polinizadas e com sementes dispersas pelo vento, indicando perdas de serviços ecossistêmicos relacionados à fauna. A ausência de espécies com polinização e dispersão por vertebrados (mais sensíveis às perturbações) em algumas áreas de CerMR é um alerta sobre os potenciais efeitos na fauna local. Essas perdas parecem ser maiores nas áreas sob maior distúrbio, por exemplo, pela redução na dispersão ornitocórica em áreas onde a matriz de entorno apresenta baixa cobertura por vegetação nativa.
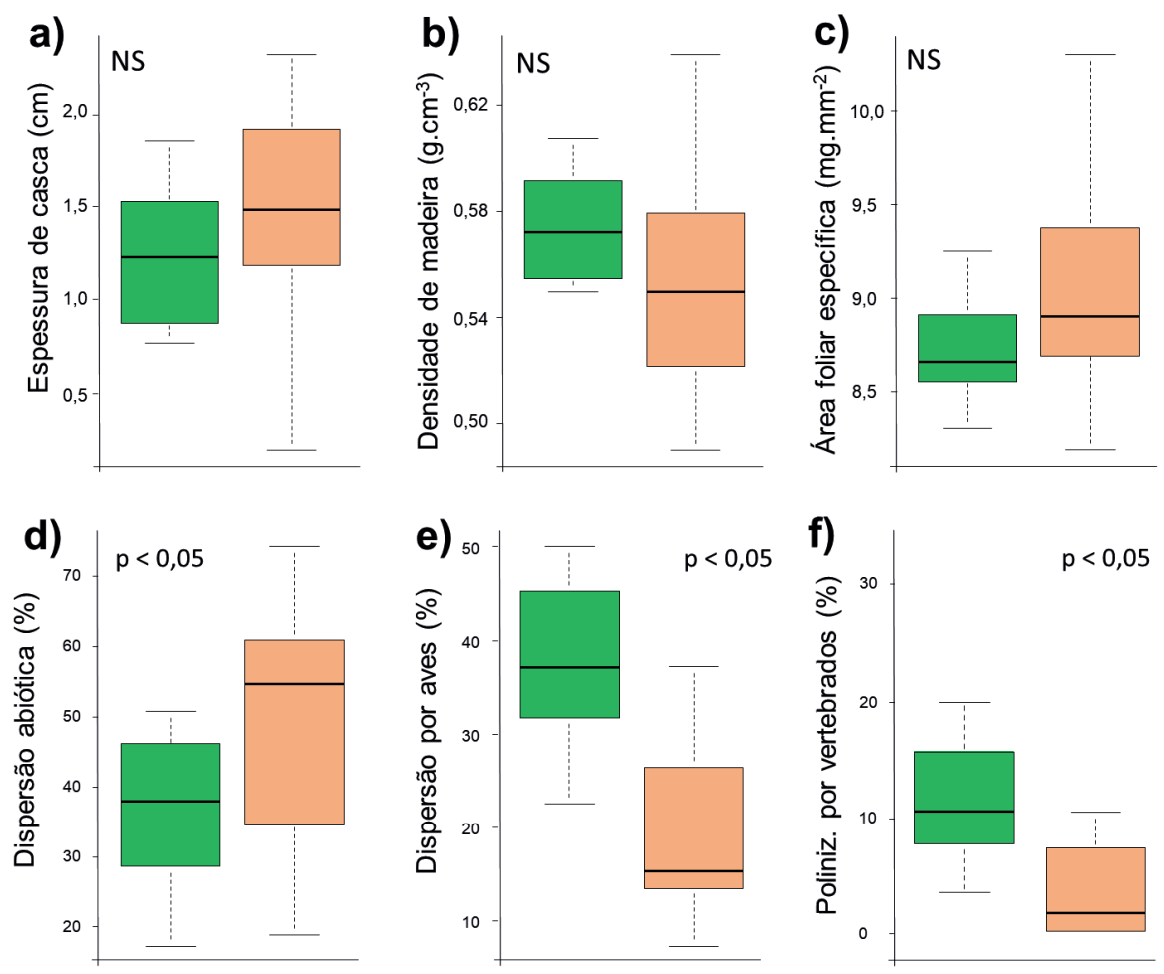

Unidades de conservação

Cerrado às margens de rodovias

Figura 12. A composição funcional relacionada aos traços vegetativos, como espessura de casca (a), densidade de madeira (b) e área foliar específica (c), é similar entre o CerMR (cerrado às margens de rodovias) e as áreas protegidas. Já a composição dos traços reprodutivos é diferente entre essas áreas, sendo maior a dominância de espécies com dispersão abiótica (d), e menor a dispersão por aves (e) e polinização por vertebrados (f) em áreas de CeMR. Esses resultados mostram que serviços ecossistêmicos relacionados às interações com a fauna podem ser perdidos nas áreas de CeMR. 
Considerando-se que a maioria da vegetação nativa do Cerrado está altamente fragmentada, este estudo pode também ajudar na compreensão da resiliência do Cerrado como um todo. Conhecer as espécies dominantes e suas características funcionais nesses ambientes altamente estressantes ajuda na formulação de listas de espécies mais efetivas para recuperação de áreas degradadas, já que os modelos focados em espécies pioneiras e tardias (usados para florestas) são ineficazes para o Cerrado. Além disso, devido à sua vasta extensão, a vegetação às margens de rodovias pode servir como corredores ecológicos, garantindo a dispersão de espécies de cerrado que estão limitadas a pequenos e isolados fragmentos. Por fim, a compreensão da real importância da vegetação às margens de rodovias para a conservação da biodiversidade e de seus serviços ecossistêmicos, permitirão o estabelecimento de políticas públicas que garantam a sua conservação.

\section{Fragmentação de florestas estacionais}

A fragmentação de paisagens naturais contínuas é uma das principais formas pelas quais a ação humana altera a paisagem e a diversidade de espécies. A fragmentação é composta por dois componentes principais: a própria destruição de parte do habitat natural e o isolamento dos remanescentes vegetais. Uma das consequências mais críticas da fragmentação de habitats é um aumento na quantidade de bordas abruptas e artificiais de uma paisagem natural, que aceleram a perda de espécies e simplifica as comunidades arbóreas. Com exceção das vastas regiões do Congo e da Amazônia, a maioria das florestas tropicais atuais é afetada pelo efeito de borda, sofrendo grandes mudanças estruturais.

Diversos estudos têm registrado os efeitos de borda em fragmentos de florestas tropicais e temperadas, mas estudos em florestas estacionais ainda são raros. Os efeitos de borda podem se estender por centenas de metros em direção ao interior da floresta, mas tendem a diminuir à medida que se distancia da borda. Esse efeito também varia com as condições locais da floresta, como diferenças na topografia, matriz de entorno e histórico de uso. Os efeitos alteram muitos serviços ecossistêmicos, como a redução dos estoques de carbono nas porções do fragmento mais próximas à borda, principalmente relacionados à dinâmica mais acelerada, redução na diversidade, maior abundância de espécies pioneiras e morte dos grandes indivíduos.

$\mathrm{O}$ sensoriamento remoto tem se mostrado uma boa ferramenta para a determinação dos padrões de fragmentação florestal e dos impactos do efeito de borda. O monitoramento sistemático dos fragmentos florestais, através de imagens de satélite com séries históricas, ajuda a entender como a matriz de entorno e as condições ambientais alteram os impactos do efeito de borda. Alguns índices de cobertura vegetal obtidos por imagens de satélite têm sido utilizados para avaliar a estrutura florestal em largas escalas temporais e espaciais, dentre eles, o Índice de Vegetação da Diferença Normalizada (NDVI, Normalized Difference Vegetation Index). Esse índice pode ser calculado usando imagens do satélite Landsat, com dados disponíveis para a área de interesse desde 1985, a cada 15 dias e com resolução de $30 \mathrm{~m}^{2}$. Esse índice permite nos estabelecer diferentes tipos de inferências sobre a variação na produtividade de comunidades vegetais ao longo da sucessão.

Em um de nossos estudos, avaliamos como o efeito de borda altera os padrões de NDVI no gradiente de borda em direção ao interior do fragmento e como essa 
variação está relacionada a diferentes parâmetros abióticos como composição da matriz de entorno, tamanho e forma do fragmento e variações climáticas. Os resultados preliminares têm mostrado que as diferenças de NDVI se dão principalmente nos primeiros 60 metros da borda (Figura 13), e que com uma matriz mais antropizada (pastagens, agricultura ou centros urbanos), o efeito de borda pode se estender por mais de 100 metros.

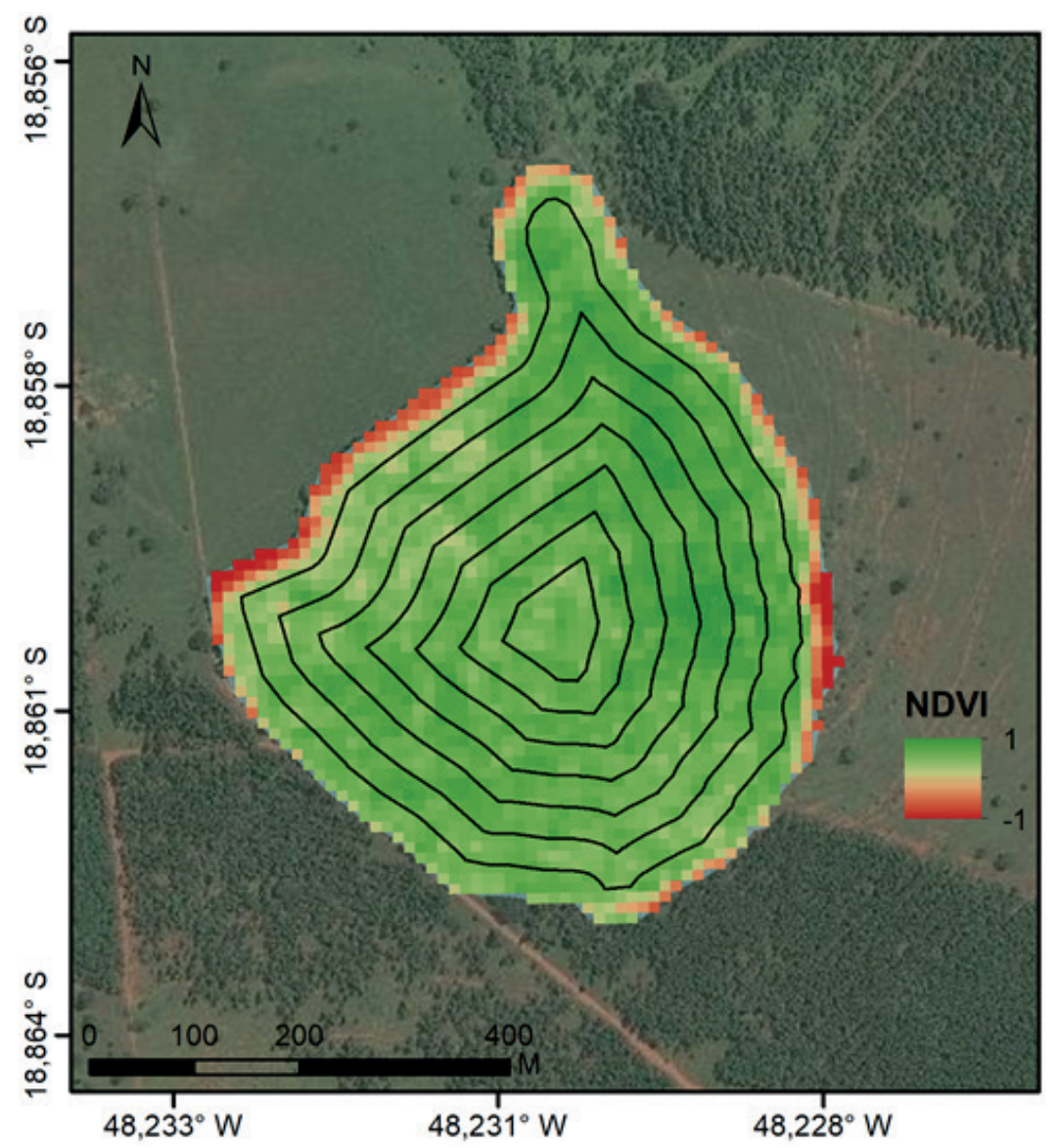

Figura 13. Efeito de borda em um fragmento de floresta estacional semidecidual refletido pelas diferenças no Índice de Vegetação da Diferença Normalizada (NDVI) entre o gradiente de borda e interior do fragmento. Foram criados buffers de 30 metros a partir da borda do fragmento. Tons mais próximos ao verde indicam vegetação mais densa e tons mais próximos ao vermelho indicam mais clareiras e menor cobertura arbórea.

\section{Considerações finais: estudos em macro-escala}

A crescente busca pela padronização de amostragens da vegetação tem permitido a construção de grandes bancos de dados e, consequentemente, estudos em escala global. Entretanto, dados de monitoramento de longo prazo (como os usualmente produzidos pelo PELD) ainda são bastante raros. Atualmente, nossos dados estão compartilhados em bancos de dados globais como o DRY-FLOR - Latin American Seasonally Dry Tropical Forest Floristic Network, disponível em https://www.dryflor.info/) e o TRY - Plant Trait Database (https://www.try-db.org/). Em parcerias estabelecidas com 
intuições nacionais e internacionais, nossos dados de monitoramento têm contribuído com diversos estudos em macro escala. Tais estudos fornecem ferramentas concretas para o planejamento e manejo da vegetação, assim como provem dados empíricos que permitem a criação de leis ambientais que orientem iniciativas de conservação.

Por exemplo, com este tipo de dado pudemos estimar a quantidade de árvores e de espécies existentes nos remanescentes de vegetação em Minas Gerais, bem como quanto dessa biodiversidade está distribuída nas diferentes fitofisionomias (desde savanas abertas às densas florestas estacionais). Nossos resultados indicam a existência de algo em torno de 24 bilhões de árvores em Minas Gerais, e de 3592 a 3743 espécies. Conseguimos estimar que esse total de árvores atual representa pouco mais de $30 \%$ da quantidade original, e que entre 4 a $8 \%$ das espécies originais já foram perdidas. Também conseguimos estabelecer uma lista de espécies dominantes para cada fitofisionomia. Aparentemente, muitas delas tem aumentado sua dominância em pequenos fragmentos com entorno altamente perturbado, o que possivelmente está levando a um empobrecimento na diversidade e crescente homogeneização dessas comunidades.

Vimos ainda que o estoque e sequestro de carbono das florestas neotropicais estão sob forte controle das condições ambientais locais, sendo que as atuais mudanças no regime de precipitação e a crescente perturbação antrópica têm efeitos diretos na perda dos serviços ecossistêmicos. Isto porque a perda local de espécies, e de seus traços funcionais, resultam numa diminuição no estoque e sequestro de carbono dessas florestas, além de torná-las menos resistentes às mudanças climáticas. Estes resultados realçam a importância da conservação biológica como componente efetivo nas estratégias globais de mitigação das mudanças climáticas.

\section{Para saber mais}

Díaz S, Lavorel S, de Bello F, Quétier F, Grigulis K, \& Robson TM (2007) Incorporating plant functional diversity effects in ecosystem service assessments. Proc Natl Acad Sci 104:20684-20689 doi: 10.3410/f.1099094.555296

Durigan G, Ratter JA (2016) The need for a consistent fire policy for Cerrado conservation. J Appl Ecol 53:11-15 doi: 10.1111/1365-2664.12559

Haines-Young R, Potschin M (2010) The links between biodiversity, ecosystem services and human well-being. Ecosystem Ecology: a new synthesis 1:110-139 doi: 10.1017/ cbo9780511750458.007

Lopes SF, Prado-Júnior J, Vale VS, Schiavini I. (2013) Impactos ambientais antrópicos como modificadores da estrutura e funcionalidade de florestas estacionais semideciduais no Triângulo Mineiro, Brasil. Caminhos de Geografia 14:233-242

Lopes SF, Schiavini I, Oliveira AP, Vale VS (2012) An ecological comparison of floristic composition in seasonal semideciduous forest in Southeast Brazil: implications for conservation. International Journal of Forestry Research doi 10.1155/2012/537269

Lopes SF, Vale VS, Schiavini I, Prado J, Oliveira AP, Arantes CS (2014) Canopy stratification in tropical seasonal forests: how the functional traits of community change among the layers. Bioscience Journal 30:1551-1562 doi: 10.1111/gcb.13164. 
Prado-Junior JA, Schiavini I, Vale VS, Arantes CS, Sande MT, Lohbeck M, Poorter L (2016) Conservative species drive biomass productivity in tropical dry forests. J Ecol 104:817-827 doi 10.1111/1365-2745.12543

Prado-Junior JA, Schiavini I, Vale VS, et al (2017) Functional traits shape sizedependent growth and mortality rates of dry forest tree species J Plant Ecol 10:895-906 doi: 10.1093/jpe/rtw103

Poorter L, van der Sande MT, Arets EJMM, Ascarrunz N, Enquist BJ, Finegan B, Licona, JC, Martínez-Ramos M, Mazzei L, Meave JA, Muñoz R, Nytch CJ, Oliveira AA, Pérez-García EA, Prado-Junior JA, Rodríguez-Velázques J, Ruschel AR, SalgadoNegret B, Schiavini I, Swenson NG, Tenorio EA, Thompson J, Toledo M, Uriarte M, van der Hout P, Zimmerman JK, Peña-Claros M (2017) Biodiversity and climate determine the functioning of Neotropical forests. Global Ecol Biogeogr 26:14231434 doi: $10.18174 / 380256$.

Raymundo D, Prado-Junior J, Carvalho FA, Vale VS, Oliveira PE, van der Sande MT (2019) Shifting species and functional diversity due to abrupt changes in water availability in tropical dry forests. J Ecol 107:253-264 doi 101111/1365-274513031

Rodrigues-Souza J, Prado-Júnior JA, Vale VS, Schiavini I, Oliveira AP, Arantes, CS (2015) Secondary forest expansion over a savanna domain at an ecological reserve in the Southeastern Brazil after 15 years of monitoring. Brazilian. J Botany 38: 311-322 doi 101007/s40415-015-0146-X

Terra MCNS, Santos RM, Fontes MAL, Mello JM, Scolforo JRS, Gomide LR, PradoJunior JA, Schiavini I, ter Steege H (2017) Tree dominance and diversity in Minas Gerais, Brazil. Biodivers Conserv 26: 2133-2153 doi: 101007/s10531-017-1349-1

Terra MCNS, Santos RMD, Prado Júnior JA, Mello JM, Scolforo JRS, Fontes MAL, ter Steege H (2018) Water availability drives gradients of tree diversity, structure and functional traits in the Atlantic-Cerrado-Caatinga transition, Brazil. J Plant Ecol11: 803-814 doi 10.1093/jpe/rty017 



\title{
CAPÍTULO 3
}

\section{ECOLOGIA DE PEQUENOS MAMÍFEROS NÃO-VOADORES}

\author{
Rodrigo C. Rossi \\ Claire P.R. Ferrando \\ Marco M. de Oliveira \\ Natalia O. Leiner
}

Os roedores contemplam quase a metade do número de espécies de mamíferos do mundo, e podem ser encontrados em todos os continentes, com exceção da Antártida. Um total de 244 espécies, o que equivale a $10 \%$ do total de espécies conhecidas no mundo todo, ocorrem no Brasil, compondo um grupo com grande variação em tamanho, forma, comportamento e hábito. Mesmo com toda essa variação, que também se reflete em outros aspectos da história de vida desses animais, a grande maioria dos roedores brasileiros (mais de 90\%) apresenta pequeno tamanho e pouca massa corporal (com peso entre $8 \mathrm{~g} \mathrm{a} 5 \mathrm{~kg}$ ), estando incluída no chamado grupo dos pequenos mamíferos nãovoadores. Outra ordem que também compõe esse grupo são os marsupiais, representados por aproximadamente 90 espécies no Brasil. Esses animais são bem menos diversos que os roedores, não só em número de espécies, mas também em formas e hábitos. De fato, em um olhar mais rápido, os marsupiais são morfologicamente muito parecidos entre si, assim como com os roedores. Mas, olhando com mais atenção, notamos que existem particularidades na morfologia destes animais que estão associadas aos seus hábitos de vida.

Os animais que compõem o grupo dos pequenos mamíferos não-voadores são comumente encontrados ao longo de ambientes florestais e fisionomias mais abertas no Brasil. Esse capítulo irá abordar algumas pesquisas relacionadas ao monitoramento de longo prazo das populações de pequenos mamíferos não-voadores em fragmentos de vegetação de cerrado (savana) e de floresta semi-decídua na região do Triângulo Mineiro e Sudeste de Goiás, todas desenvolvidas pela equipe do Laboratório de Ecologia de Mamíferos (LEMA) da Universidade Federal de Uberlândia. Esses estudos visam entender a história natural e a importância ecológica dos pequenos mamíferos nãovoadores, além do impacto da qualidade do habitat e de distúrbios sobre esse grupo.

\section{Diversidade no Triângulo Mineiro}

Dados sobre a diversidade de pequenos roedores e marsupiais na região do Triângulo Mineiro foram compilados da literatura e dos estudos em andamento pelo LEMA. Os poucos estudos sobre a fauna de pequenos mamíferos da região consistem em pesquisas de curta duração (um ano no máximo) com enfoque em captura de espécimes através de armadilhas. Estes trabalhos foram conduzidos em pequenos fragmentos de cerrado ou mata semi-decídua, principalmente no município de Uberlândia. Até o momento, foram registradas pelo menos 31 espécies de pequenos mamíferos nãovoadores, distribuídas em apenas 6 (Uberlândia, Araguari, Ipiaçu, Conceição das 
Alagoas, Uberaba e Indianópolis) dos 26 municípios do Triângulo Mineiro (ver Tabela 1). Levando em conta a escala geográfica amostrada nessa compilação, que enfoca principalmente no município de Uberlândia, sugerimos que o registro de 31 espécies pode ser considerado alto, uma vez que corresponde a $31 \%$ de todos os pequenos mamíferos já registrados no bioma Cerrado (99 espécies). Mais especificamente, os dados da Tabela 1 indicam a presença de 26 espécies de roedores e 5 de marsupiais no Triângulo Mineiro, que correspondem a 34\% do total de roedores e 22\% dos marsupiais já registrados no Cerrado ( 76 e 23 espécies, nesta ordem). O alto número de espécies encontrado deve-se provavelmente às capturas de pequenos mamíferos em diferentes fisionomias do Cerrado (como mata de galeria, mata semi-decídua, pasto, cerrado ralo, cerradão e cerrado sensu stricto) e habitats com graus de conservação distintos. Além disso, o uso de diferentes metodologias em alguns dos estudos analisados na compilação também pode ter contribuído para tais valores. Entre esses métodos, podemos citar o uso de armadilhas de captura, armadilhas de interceptação e queda, pegadas e até mesmo o registro de pequenos mamíferos através de análises da dieta de predadores (como corujas).

O emprego de armadilhas de queda é um importante método complementar para investigar a comunidade de pequenos mamíferos não-voadores. Em todos os fragmentos estudados, esse método foi utilizado apenas na Estação Ecológica do Panga (Uberlândia, MG), durante um intervalo curto de tempo e estava direcionado para a captura de anuros. Mesmo assim, permitiu o único registro de duas espécies de marsupiais, a cuícalanosa Caluromys lanatus e a cuíca-de-cauda-grossa Thylamys karimii. A ausência de outros estudos na região empregando esse método pode ter contribuído para o baixo número de registros de espécies de marsupiais (apenas cinco) no Triângulo Mineiro em comparação com outros estudos no Cerrado. De fato, a baixa abundância de roedores que utilizam galerias subterrâneas (chamados de semi-fossoriais) e de marsupiais essencialmente terrícolas, como é o caso dos gêneros Cryptonanus e Monodelphis, parece ser um reflexo das metodologias empregadas. Sendo assim, o uso desse método nos demais estudos poderia ter aumentado a representatividade desse grupo na região do Triângulo Mineiro.

O Cerrado abriga 21 espécies endêmicas de roedores, e apenas dois de marsupiais. Das 31 espécies registradas na nossa lista (Tabela 1), apenas o roedor Oecomys cleberi (Figura 1G) é endêmico do Cerrado, e pouco se sabe sobre sua biologia e ecologia. Já a cuíca de cauda-grossa (Thylamys karimii), mesmo ocorrendo em fisionomias abertas, é considerada vulnerável na lista de espécies ameaçadas da Rede de Conservação Internacional. As espécies registradas com maior frequência na nossa lista foram os marsupiais Didelphis albiventris e Gracilinanus agilis (Figura 1A e B), ambos sendo registrados em oito estudos diferentes (maioria abrangendo o município de Uberlândia, além dos municípios de Araguari, Ipiaçu e Conceição das Alagoas). Já os roedores mais comumente registrados foram Necromys lasiurus (Figura 1E) e Rhipidomys macrurus (ambos registrados apenas em Uberlândia, em seis e quatro estudos respectivamente ver Figura 1C), Hylaeamys megacephalus (citado em quatro trabalhos realizados em Uberlândia e um em Araguari - ver Figura 1D) e Calomys tener (três em Uberlândia e um em Conceição das Alagoas).

Já as espécies registradas mais raramente nos estudos foram os marsupiais Thylamys karimii, Caluromys lanatus, Lutreolina crassicaudata e os roedores Oecomys 
cleberi (Figura 1G), Euryoryzomys sp., Sooretamys angouya, Rattus norvegicus, Cerradomys maracajuensis e Clyomys laticeps (Figura 1F). Essas espécies foram registradas somente uma vez e em abundâncias baixas (de um a dez indivíduos). Outras menos comuns foram Pseudoryzomys simplex e Oxymycterus delator. Em alguns casos, essa raridade pode refletir lacunas de amostragem em algumas fisionomias, questões metodológicas ou dificuldades na identificação dos indivíduos em nível de espécie. Por exemplo, C. laticeps (Figura 1F) é uma espécie de distribuição local restrita a áreas de campo sujo, porém abundantes nesses locais. Apenas um estudo na compilação de dados apresentados amostrou essa fisionomia, registrando $C$. laticeps. Ao mesmo tempo, $R$. norvegicus é uma espécie exótica, conhecidamente comum em parques urbanos, como é o caso do Parque do Sabiá, em Uberlândia, enquanto $O$. delator só foi encontrado em pastagens que foram raramente amostradas.

Mais da metade das espécies registradas apresenta hábitos terrestres (16 espécies), seguido por espécies arborícolas (oito) ou que usam o solo e o estrato arbóreo (chamadas de escansoriais - três), e por último, espécies semi-fossoriais (duas) e semi-aquáticas (uma). Tal diferença nos registros pode refletir as metodologias de captura empregadas, como a ausência de mais estudos com armadilhas de queda que auxiliam na captura de espécies semi-fossoriais, e a ausência de capturas em fisionomias alagadiças, como veredas, matas de galeria alagadas, e áreas abertas como campos. De fato, o Cerrado é um bioma conhecido por abrigar várias espécies de roedores e marsupiais que têm um longo histórico de associação e evolução em formações vegetais abertas, incluindo gêneros endêmicos dessas formações, como os marsupiais Cryptonanus e Thylamys e os roedores Clyomys, Necromys, Calomys, Pseudoryzomys e Cerradomys. 

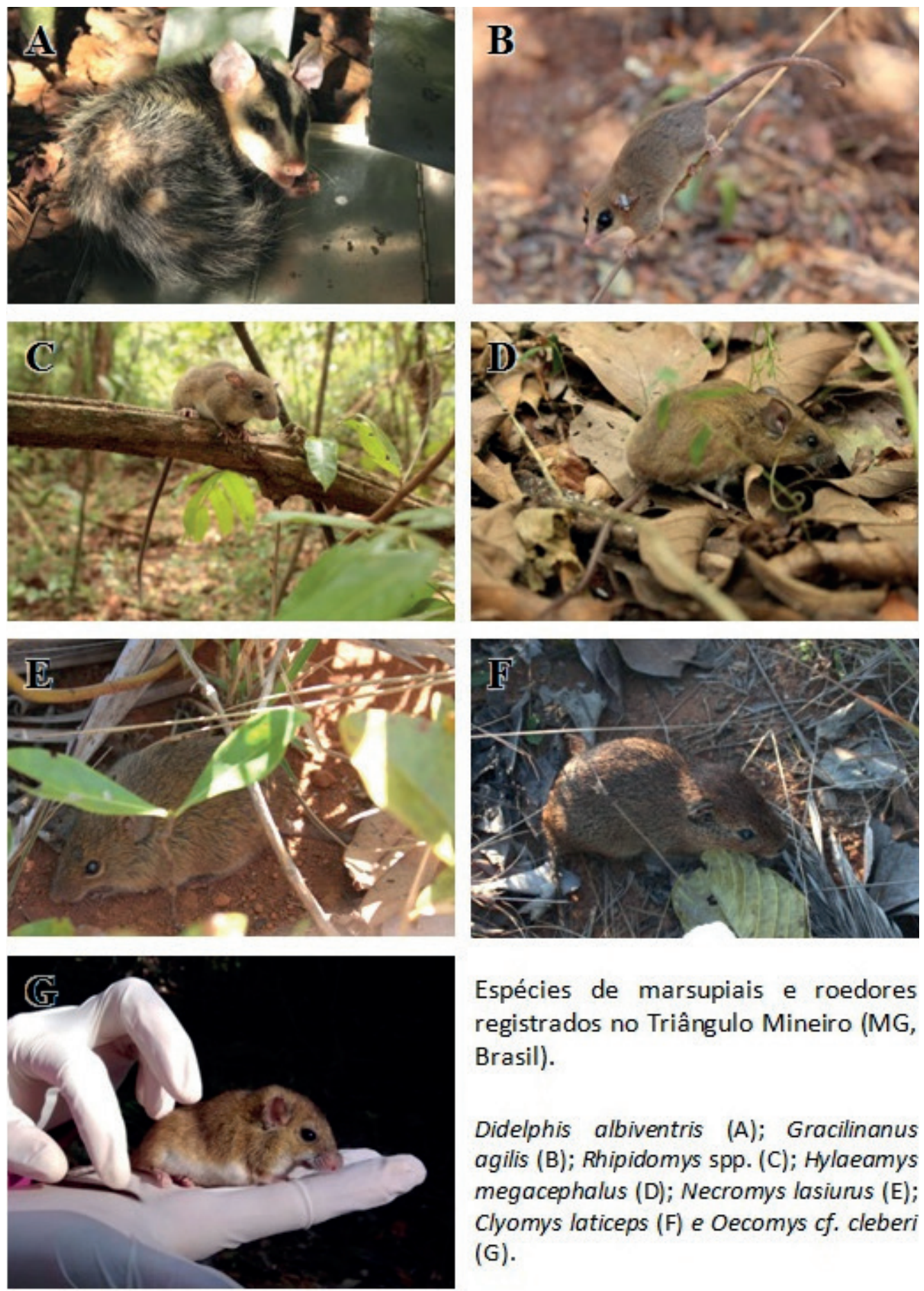

Espécies de marsupiais e roedores registrados no Triângulo Mineiro (MG, Brasil).

Didelphis albiventris (A); Gracilinanus agilis (B); Rhipidomys spp. (C); Hylaeamys megacephalus (D); Necromys lasiurus (E); Clyomys laticeps (F) e Oecomys cf. cleberi (G).

Figura 1: Espécies de marsupiais (A e B) e roedores (C, D, E) mais comumente registrados nos remanescentes do Triângulo Mineiro. Na prancha é possível observar também espécies mais raras, incluindo o rato de espinho Clyomys laticeps $(\mathrm{F})$, encontrado apenas em fisionomias mais abertas, e o roedor Oecomys cleberi (G) que é endêmico do Cerrado. 
A ausência de mais estudos em fisionomias abertas na nossa compilação pode ser responsável pela maior abundância de espécies florestais no Triângulo Mineiro, tais como G. agilis, $R$. macrurus, e H. megacephalus (Figura 1B, C e D, nesta ordem), e a raridade de espécies associadas a formações abertas. Dessa maneira, os resultados sobre a diversidade de pequenos mamíferos na região devem ser considerados preliminares, e novos estudos com diferentes métodos, maior abrangência de fisionomias vegetais e localidades geográficas, assim como maior tempo de duração e esforço de amostragem devem ser encorajados.

\section{Importância ecológica}

Apesar de pequenos em tamanho, tanto os roedores quanto os marsupiais são peças fundamentais para a organização das comunidades e funcionamento dos ecossistemas através de suas atividades físicas e interações bióticas com outras espécies. No âmbito das interações bióticas, os pequenos mamíferos sustentam as cadeias alimentares, uma vez que são presas de serpentes, aves de rapina e mamíferos carnívoros. Dessa forma, a redução das populações de pequenos mamíferos pode impactar negativamente as populações de espécies predadoras. Além disso, a variedade da dieta de pequenos mamíferos, que inclui itens como invertebrados, sementes, frutos e néctar, faz com que esses animais sejam potenciais prestadores de diferentes serviços ecossistêmicos. Esses serviços são prestados por organismos que estão na natureza e que beneficiam direta ou indiretamente os seres humanos, como na produção de alimento, no controle de pragas, na dispersão de sementes e na polinização.

$\mathrm{Na}$ natureza, vertebrados e invertebrados atuam no controle de pragas agrícolas, exercendo um importante serviço ecossistêmico. Inclusive, já foi estimado que o controle de pragas exercido por morcegos, por exemplo, pode gerar ganhos econômicos para os agricultores em plantios de algodão. Pouco se sabe sobre a atuação dos pequenos mamíferos não-voadores nesse sentido, mas o alto consumo de insetos por esses animais torna-os potenciais agentes desse serviço ecossistêmico. De fato, um estudo recente no Cerrado demonstrou que a cuíca-graciosa (Gracilinanus agilis, Figura 1B) consome frequentemente o percevejo-marrom da soja, uma das principais pragas agrícolas da soja e do algodão no Brasil. Esse consumo está restrito à estação seca, o que sugere que o percevejo-marrom pode se deslocar para áreas naturais após a colheita da soja. Esse período coincide com o período de escassez ou baixa qualidade de recursos alimentares para pequenos mamíferos em geral, e o alto consumo de percevejos-marrons pela cuíca graciosa pode contribuir na redução da abundância local deste percevejo, participando do seu controle. Durante os nossos estudos com a dieta da cuíca-graciosa na Estação Ecológica do Panga também observamos o consumo frequente dessa mesma espécie de percevejo, que esteve presente em quase $50 \%$ das amostras de fezes analisadas. Ela consumiu esse inseto com maior frequência do que aquele disponível no ambiente, mostrando uma preferência alimentar por este item, especialmente durante a estação seca (61\% das amostras com percevejo-marrom). Esses resultados sugerem que a cuícagraciosa pode atuar no controle da praga da soja no Cerrado, porém sua efetividade ainda precisa ser testada assim como o valor econômico da sua atuação. 
Tabela 1. Pequenos mamíferos (roedores e marsupiais) registrados em estudos realizados no Triângulo Mineiro (MG, Brasil).

\begin{tabular}{|c|c|c|c|c|}
\hline TAXON & $\begin{array}{l}\text { Hábito } \\
\text { de vida }\end{array}$ & Tipo de Habitat & Registro & Local \\
\hline \multicolumn{5}{|l|}{ RODENTIA } \\
\hline \multicolumn{5}{|l|}{ Caviidae } \\
\hline $\begin{array}{l}\text { Cavia aperea Erxleben, } 1777 \\
\text { (preá) }\end{array}$ & $\mathrm{Te}$ & MS & $\mathrm{AC}$ & UDI \\
\hline Cavia sp. & $\mathrm{Te}$ & $\mathrm{CR}$ & $\mathrm{AF}$ & UDI \\
\hline \multicolumn{5}{|l|}{ Cricetidae } \\
\hline $\begin{array}{l}\text { Calomys expulsus (Lund, 1841) } \\
\text { (rato-do-chão) }\end{array}$ & $\mathrm{Te}$ & $\begin{array}{l}\mathrm{CE}, \mathrm{MG}, \mathrm{MS} \text { e } \\
\mathrm{AA}\end{array}$ & $\begin{array}{l}\mathrm{AC}, \mathrm{AQ} \\
\text { e FZ }\end{array}$ & UDI \\
\hline $\begin{array}{l}\text { Calomys tener (Winge, 1887) } \\
\text { (rato-do-chão) }\end{array}$ & $\mathrm{Te}$ & $\begin{array}{l}\text { CC, CE, CD, } \\
\text { CR, MG e MS }\end{array}$ & $\begin{array}{l}\mathrm{AC}, \mathrm{AQ} \\
\text { e FZ }\end{array}$ & $\begin{array}{l}\text { UDI e } \\
\text { CA }\end{array}$ \\
\hline Calomys spp. & $\mathrm{Te}$ & CE e MS & $\mathrm{AC}$ & UDI \\
\hline $\begin{array}{l}\text { Oligoryzomys nigripes (Olfers, 1818) } \\
\text { (rato-do-mato) }\end{array}$ & $\mathrm{Sc}$ & $\mathrm{CD}, \mathrm{CR}$ e $\mathrm{MS}$ & $\mathrm{AC}$ e $\mathrm{FZ}$ & $\begin{array}{l}\text { UDI e } \\
\text { UB }\end{array}$ \\
\hline $\begin{array}{l}\text { Oligoryzomys fornesi } \\
\text { (Massoia, 1973) } \\
\text { (rato-do-mato) } \\
\end{array}$ & $\mathrm{Sc}$ & MS e AA & $\mathrm{ACe} A \mathrm{Q}$ & UDI \\
\hline Oligoryzomys spp. & $\mathrm{Sc}$ & MS e AA & $\mathrm{AC}$ & UDI \\
\hline $\begin{array}{l}\text { Oecomys bicolor (Tomes, 1860) } \\
\text { (rato-da-árvore) }\end{array}$ & Arb & MG e MS & $\mathrm{AC}$ & $\begin{array}{l}\text { UDI e } \\
\text { IP }\end{array}$ \\
\hline $\begin{array}{l}\text { Oecomys cf. cleberi Locks, } 1981 \text { * } \\
\text { (rato-da-árvore) }\end{array}$ & Arb & MS & $\mathrm{AC}$ & UDI \\
\hline Oecomys spp. & Arb & MS e CE & $\mathrm{AC}$ & UDI \\
\hline $\begin{array}{l}\text { Sooretamys angouya } \\
\text { (G. Fischer, 1814) } \\
\text { (Oryzomys angouya) } \\
\text { (rato-do-mato) }\end{array}$ & $\mathrm{Te}$ & $N I$ & $\mathrm{FZ}$ & UDI \\
\hline Euryoryzomys sp. & $\mathrm{Te}$ & $N I$ & $\mathrm{AC}$ & UDI \\
\hline $\begin{array}{l}\text { Rhipidomys macrurus } \\
\text { (Gervais, 1855) } \\
\text { (rato-da-árvore) } \\
\end{array}$ & Arb & $\begin{array}{l}\mathrm{CC}, \mathrm{CD}, \mathrm{CE} \\
\mathrm{CR}, \mathrm{MS} \text { e } \mathrm{MG}\end{array}$ & $\mathrm{AC}$ & UDI \\
\hline $\begin{array}{l}\text { Rhipidomys mastacalis } \\
\text { (Lund, 1840) } \\
\text { (rato-da-árvore) }\end{array}$ & Arb & $\mathrm{CE}$ & $\mathrm{AC}$ & UDI \\
\hline Rhipidomys spp. & Arb & MS & $\mathrm{AC}$ e $\mathrm{AQ}$ & $\begin{array}{l}\text { UDI e } \\
\text { AR }\end{array}$ \\
\hline $\begin{array}{l}\text { Cerradomys subflavus } \\
\text { (Wagner, 1842) } \\
\text { (rato-do-mato) }\end{array}$ & $\mathrm{Te}$ & $\begin{array}{l}\text { CC, CE, CR, } \\
\text { MG e MS }\end{array}$ & $\mathrm{AC}$ e $\mathrm{FZ}$ & UDI \\
\hline $\begin{array}{l}\text { Cerradomys maracajuensis } \\
\text { (Langguth \& Bonvicino, 2002) } \\
\text { (rato-do-mato) }\end{array}$ & $\mathrm{Te}$ & MG, MS e AA & $\mathrm{AC}$ & UDI \\
\hline
\end{tabular}




\section{Cerradomys scotti}

(Langguth \& Bonvicino, 2002)

$\mathrm{Te}$

CE e MS

$\mathrm{AC}$

UDI

(rato-do-mato)

\begin{tabular}{|c|c|c|c|c|}
\hline Cerradomys spp. & $\mathrm{Te}$ & MS e AA & $\mathrm{AC}$ & UDI \\
\hline $\begin{array}{l}\text { Hylaeamys megacephalus } \\
\text { (G. Fischer, 1814) } \\
\text { (rato-do-mato) }\end{array}$ & $\mathrm{Te}$ & $\mathrm{CE}, \mathrm{CR}$ e $\mathrm{MS}$ & $\mathrm{AC}$ & $\begin{array}{l}\text { UDI e } \\
\text { AR }\end{array}$ \\
\hline Hylaeamys sp. & $\mathrm{Te}$ & MS & $\mathrm{AC}$ & UDI \\
\hline $\begin{array}{l}\text { Oxymycterus delator Thomas, } 1903 \\
\text { (rato-do-brejo) }\end{array}$ & Sf & AA & $\mathrm{AC}$ e $\mathrm{AQ}$ & UDI \\
\hline Oxymycterus spp. & $\mathrm{Sf}$ & AA & $\mathrm{AC}$ & UDI \\
\hline \multicolumn{5}{|l|}{ Echimyidae } \\
\hline $\begin{array}{l}\text { Clyomys laticeps (Thomas, 1909) } \\
\text { (rato-de-espinho) }\end{array}$ & Sf & $\mathrm{CS}$ & $\mathrm{AC}$ & IND \\
\hline \multicolumn{5}{|l|}{ Erethizontidae } \\
\hline $\begin{array}{l}\text { Coendou prehensilis } \\
\text { (Linnaeus, 1758) } \\
\text { (ouriço ou porco espinho) }\end{array}$ & Ar & CE e MS & $\mathrm{V}$ & $\begin{array}{l}\text { UDI e } \\
\text { CA }\end{array}$ \\
\hline \multicolumn{5}{|l|}{ Dasyproctidae } \\
\hline $\begin{array}{l}\text { Dasyprocta azarae } \\
\text { Lichtenstein, } 1823 \\
\text { (cutia) }\end{array}$ & $\mathrm{Te}$ & $\mathrm{CE}, \mathrm{CR}$ e $\mathrm{MS}$ & $\mathrm{AC}$ e $\mathrm{PG}$ & $\begin{array}{l}\text { UDI e } \\
\text { CA }\end{array}$ \\
\hline \multicolumn{5}{|l|}{ Muridae } \\
\hline Mus musculus (Linnaeus, 1758) & $\mathrm{Te}$ & AA & $\mathrm{AC}$ e $\mathrm{FZ}$ & $\begin{array}{l}\text { UDI e } \\
\text { IP }\end{array}$ \\
\hline Rattus rattus Linnaeus, 1758 & $\mathrm{Te}$ & MS e CR & AC e FZ & UDI \\
\hline $\begin{array}{l}\text { Rattus norvegicus } \\
\text { (Berkenhout, 1769) } \\
\text { (rato-do-chão) }\end{array}$ & $\mathrm{Sa}$ & MS & $\mathrm{AC}$ & UDI \\
\hline Akodon montensis Thomas, 1913 & $\mathrm{Te}$ & MS & $\mathrm{AC}$ & AR \\
\hline Akodon sp. & $\mathrm{Te}$ & $N I$ & $\mathrm{AC}$ & UDI \\
\hline $\begin{array}{l}\text { Necromys lasiurus (Lund, 1841) } \\
\text { (rato-do-mato) }\end{array}$ & $\mathrm{Te}$ & $\begin{array}{l}\text { CE, MG, MS e } \\
\text { AA }\end{array}$ & $\begin{array}{l}\mathrm{AC}, \mathrm{AQ} \\
\text { e FZ }\end{array}$ & UDI \\
\hline $\begin{array}{l}\text { Pseudoryzomys simplex } \\
\text { (Winge, 1887) } \\
\text { (rato-do-mato) }\end{array}$ & $\mathrm{Te}$ & $N I$ & $\mathrm{AC}$ e $\mathrm{AQ}$ & UDI \\
\hline Nectomys spp. & $\mathrm{Sa}$ & $\mathrm{AB}$ & $\mathrm{AC}$ & UDI \\
\hline
\end{tabular}

\section{DIDELPHIMORPHIA}

\section{Didelphidae}

Gracilinanus agilis

(Burmeister, 1854)

(cuíca-graciosa)

Didelphis albiventris Lund, 1840 (gambá-de-orelha-branca)

\begin{tabular}{|c|c|c|c|}
\hline Arb & $\begin{array}{l}\mathrm{CC}, \mathrm{CE}, \mathrm{CD}, \\
\mathrm{CR}, \mathrm{MG} \text { e } \mathrm{MS}\end{array}$ & $\mathrm{AC}$ e $\mathrm{AQ}$ & $\begin{array}{l}\text { UDI, } \\
\text { IP, CA } \\
\text { e AR }\end{array}$ \\
\hline $\mathrm{Sc}$ & $\mathrm{MG}, \mathrm{MS}$ e $\mathrm{CE}$ & $\mathrm{AC}$ e $\mathrm{AQ}$ & $\begin{array}{l}\text { UDI, } \\
\text { IP, CA } \\
\text { e AR }\end{array}$ \\
\hline
\end{tabular}


Lutreolina crassicaudata (Desmarest, 1804)

(cuíca-de-cauda-grossa)

Caluromys lanatus (Olfers, 1818)

(cuíca-lanosa)

Thylamys karimii (Desmarest, 1804)

(cuíca-de-cauda-grossa)
$\mathrm{Te}$

$N I$

AC e AQ UDI

Arb

MG

AQ

UDI

Arb

NI

AQ

UDI

Hábito de vida: $\mathrm{Te}=$ terrestre; $\mathrm{Sc}=$ escansorial; $\mathrm{Sf}=$ semi-fossorial; $\mathrm{Arb}=$ arbóreo; $\mathrm{Sa}=$ semi-aquático. Tipo de Habitat: $\mathrm{CC}=$ cerrado ralo; $\mathrm{CD}=$ cerrado denso; $\mathrm{CE}=$ cerrado sensu stricto; $\mathrm{CR}=$ cerradão; $\mathrm{CS}=$ cerrado campo sujo; $\mathrm{MG}=$ mata de galeria ou mata ripária; $\mathrm{MS}=$ mata semidecídua; $\mathrm{AA}=$ área antropizada; $N I=$ não tem informação. Registro: $\mathrm{AC}=$ armadilha de captura com sherman e/ou tomahawk; $\mathrm{AQ}=$ armadilha queda: recipientes enterrados no solo (pitfalls) e interligados (ou não) por cercas-guia; $\mathrm{AF}=$ armadilha fotográfica; $\mathrm{FZ}=$ registro por fezes de predador; $\mathrm{V}=$ avistamento; $\mathrm{PG}=$ pegada. Local registro: $\mathrm{UDI}=$ Uberlândia, $\mathrm{CA}=$ Conceição das Alagoas, $\mathrm{IP}=\mathrm{Ipiaçu}, \mathrm{AR}=$ Araguari, $\mathrm{UB}=$ Uberaba, $\mathrm{IND}=\mathrm{Indianápolis.} \mathrm{*} \mathrm{=}$ espécie endêmica do Cerrado.

Além do controle biológico, os marsupiais também podem prestar outros serviços ecossistêmicos, no caso a polinização e a dispersão de sementes. Ao menos quatro espécies de marsupiais no Brasil já foram observadas visitando flores para consumir néctar, e já foram apontadas como potenciais agentes no processo de produção de frutos das plantas que visitam. Essas flores geralmente apresentam forte odor e se abrem durante a noite, sendo comumente visitadas por morcegos. Dessa forma, os marsupiais são frequentemente considerados polinizadores secundários e de menor importância. Porém, um estudo recente demonstrou que uma planta parasita de raízes de outras plantas tem como principal polinizador o gambá-de-orelha-branca (Didelphis albiventris, Figura 1A). O gambá foi um visitante floral frequente, e extremamente eficiente na remoção do pólen. Aparentemente, através do seu focinho e do polegar opositor na pata traseira esse animal consegue remover as folhas modificadas que recobrem as flores que nascem junto ao chão, e as torna expostas aos polinizadores. Tais resultados abrem caminho para novas linhas de investigação para entender a eficiência dos marsupiais como prestadores do serviço ecossistêmico de polinização.

Já o consumo de frutos por parte dos marsupiais já foi descrito para a maioria das espécies brasileiras, com exceção dos animais mais carnívoros. De fato, a passagem das sementes pelo trato digestivo dos marsupiais pode até mesmo aumentar as chances e/ou acelerar a germinação das sementes, o que mostra a eficiência dessas espécies como dispersores de sementes. Em muitos casos, os marsupiais parecem consumir com maior frequência e em maior abundância frutos de plantas pioneiras, ou seja, plantas que costumam ser mais abundantes nos estágios iniciais de uma regeneração de ambientes. Esse padrão sugere que além de eficientes na dispersão de sementes, os marsupiais podem inclusive auxiliar na regeneração de ambientes após um distúrbio, contribuindo no transporte das sementes que terão maior chance de germinar e de se estabelecer nesse primeiro momento. Os nossos resultados do monitoramento da população da cuíca-graciosa (G. agilis, Figura 1B) na Estação Ecológica do Panga mostram que essa espécie consome frutos, principalmente do gênero Miconia, em maior frequência durante a estação seca. Dessa maneira, esse consumo pode ser uma estratégia para conservar água e aumentar a ingestão de calorias durante a estação seca, dado que os frutos de Miconia contêm aproximadamente 15\% de açúcares e quase $70 \%$ 
de água. Independente da estratégia, observamos que as sementes estavam intactas após a passagem pelo trato digestivo, indicando que a cuíca-graciosa pode atuar como dispersor das sementes dessa espécie.

Com relação aos roedores, não existem estudos no Brasil sugerindo sua atuação como polinizadores, apesar de já ter sido feita uma observação de um roedor visitando a planta parasita de raiz que é primariamente polinizada pelo gambá-de-orelha-branca. Já com relação à dispersão de sementes, a atuação dos roedores é bem documentada, especialmente nas espécies de maior tamanho corporal. Diferente dos marsupiais, a grande maioria dos roedores não consome os frutos, e sim as sementes, sendo considerados principalmente predadores de sementes. Mas o comportamento desses animais é o que os torna relevantes dispersores potenciais. Eles têm o hábito de guardar ou enterrar as sementes para serem consumidas em momentos de escassez de alimento. Tal comportamento de estocagem favorece as plantas, pois muitas sementes escapam da ação de outros predadores, de fungos ou do fogo ao serem enterradas. Além disso, já foi demonstrado que as sementes são dispersas por longas distâncias, escapando da competição por nutrientes e da predação de sementes que é maior embaixo da planta que originou as sementes (chamada de planta mãe). Essa distância de dispersão mais longa é atingida por movimentações múltiplas das sementes realizadas por movimentos de diferentes roedores. Tais movimentações múltiplas também aumentam as chances dos roedores falharem em encontrar as sementes estocadas, permitindo que elas germinem e se estabeleçam. Esse padrão já foi encontrado para roedores de maior tamanho corporal, como cotias e pacas, e também em espécies de tamanho pequeno a médio, como ratos-de-espinho, esquilos e pequenos roedores, indicando a importância dos roedores no processo de dispersão de sementes em diferentes ambientes naturais.

Os pequenos mamíferos não-voadores também podem contribuir para o funcionamento dos ecossistemas através da sua habilidade em modular a disponibilidade de alimento e abrigos nos ecossistemas. Os organismos que têm tal capacidade são chamados de engenheiros do ecossistema, já que sua ação se dá pela construção de estruturas ou alteração do estado físico de materiais abióticos e bióticos e resultam na modificação, manutenção e/ou criação de habitats. Sendo assim, o conceito de engenharia do ecossistema descreve aspectos da relação entre organismos e seu ambiente que não são diretamente de natureza trófica ou competitiva. Grande parte dos organismos vivos têm a capacidade de atuar como engenheiros do ecossistema, porém a magnitude do efeito de cada um para o funcionamento dos ecossistemas e organização das comunidades varia bastante. Além disso, os efeitos desses seres vivos podem durar por um tempo relativamente curto (até um ano) e impactar as espécies localmente, enquanto outros podem persistir por décadas ou mesmo ao longo do tempo geológico e afetar espécies em escala regional ou global. Por fim, seus efeitos sobre a biota podem variar de negativos a positivos.

Entre esses organismos, os roedores possuem um papel importante como engenheiros do ecossistema em diferentes tipos de ambientes. Um exemplo clássico são os castores, que constroem represas, alterando todo o espaço físico e o microhabitat local, influenciando diretamente a abundância de outros organismos. Tanto no Brasil quanto em vários outros países, os roedores que constroem galerias subterrâneas para sobreviver e se manter são exemplos de animais com esse papel no ambiente, já que a construção de galerias altera as condições físicas e químicas do solo e fornece abrigos 
para outras espécies. Durante nosso monitoramento de longo prazo no Parque Estadual da Serra de Caldas Novas (Caldas Novas, GO), analisamos e demonstramos o papel do rato-de-espinho Clyomys laticeps como engenheiro do ecossistema (Figura 2). Esse roedor habita fisionomias mais abertas do Cerrado, e é considerado semi-fossorial, por passar parte do tempo abrigado nas galerias subterrâneas construídas por eles e outra parte do tempo se alimentando e procurando por parceiros na superficíe. Estudos anteriores já demonstraram que as galerias podem ser ocupadas por pelo menos sete espécies de vertebrados, tais como: cobras, sapos, lagartos, outros roedores e até mesmo uma pequena espécie de ave. Estas galerias possuem diversas entradas e saídas com acúmulo de solo revolvido, o qual, durante nosso estudo, mostrou possuir maior concentração de nutrientes do que o solo distante ou dentro das galerias subterrâneas (Figura 2). O enriquecimento do solo, decorrente da atividade do rato-de-espinho, é crucial em um ambiente de solo pobre como o do Cerrado, já que pode afetar o crescimento e estabelecimento das plantas. Além disso, tanto nas entradas das galerias quanto no interior das mesmas, encontramos muitas sementes de palmeiras estocadas, indicando que esse rato-de-espinho também pode atuar como um dispersor eficiente de sementes, porém sua eficiência quanto a esse aspecto ainda precisa ser estudada.
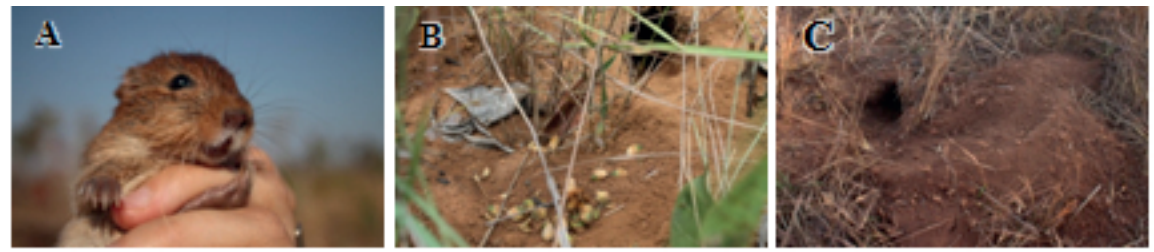

D

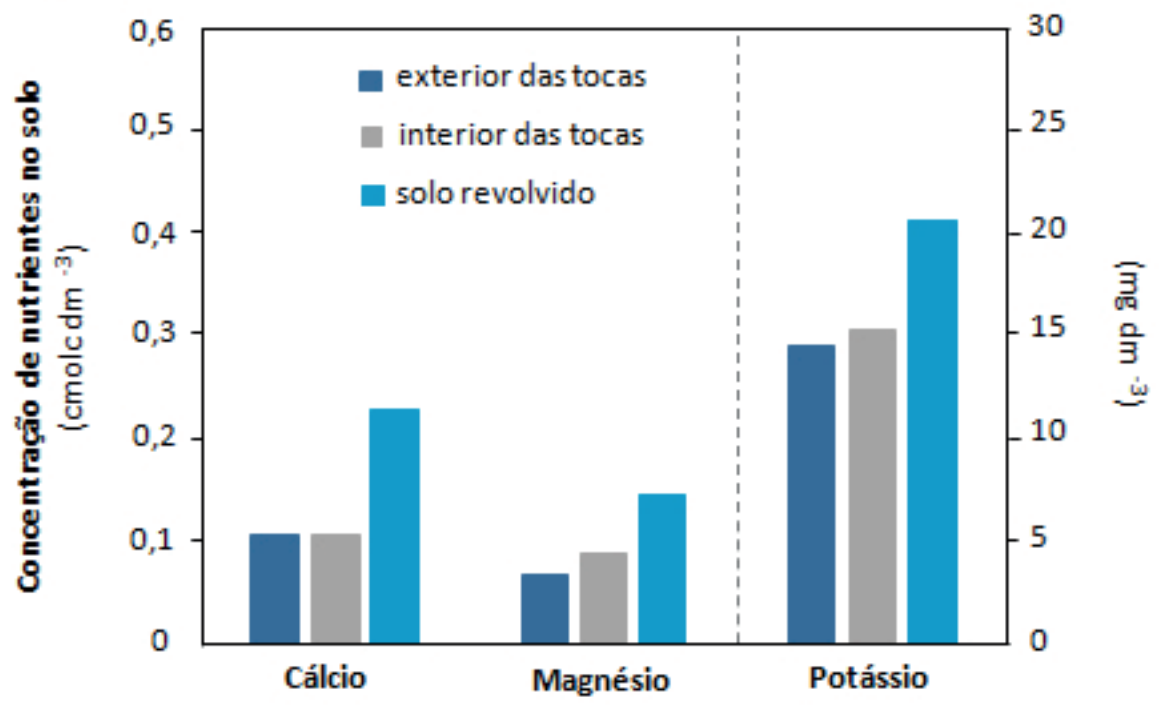

Figura 2. Atuação do rato-de-espinho Clyomys laticeps (A) como prestador de serviços ecossistêmicos no Cerrado. Esse roedor pode atuar como dispersor de sementes de palmeiras, através da deposição de sementes na entrada de suas galerias (B). Também possui atuação como engenheiro do ecossistema, uma vez que suas tocas $(\mathrm{C})$ podem funcionar como abrigo para outras espécies, e o solo revolvido do processo de escavação apresenta maior concentração de nutrientes (D), devido a suas atividades e deposição de matéria orgânica nas galerias. 


\section{Uso do espaço/organização social e sistemas de acasalamento}

A busca e a defesa de diferentes recursos, como alimento, abrigos e parceiros reprodutivos, determinam a distribuição dos indivíduos de uma espécie no tempo e espaço. Assim, o tamanho da área que eles utilizam e a sobreposição ou não entre essas áreas para garantir acesso exclusivo aos recursos que geram os padrões de uso do espaço dos organismos. De maneira geral, esses padrões espaciais refletem as estratégias utilizadas pelos organismos para aumentar suas chances de sobrevivência e de sucesso na reprodução. Entre os mamíferos, o tamanho e a sobreposição das áreas utilizadas dependem, em geral, da massa corporal, idade e estratégia reprodutiva dos indivíduos. Além disso, dependem também da distribuição espacial dos recursos que eles buscam, assim como do número de indivíduos em uma população.

Os machos e as fêmeas de pequenos mamíferos não-voadores apresentam padrões de uso do espaço bem distintos. Isto ocorre porque o principal recurso que determina o sucesso reprodutivo dos machos é o número de cópulas com as fêmeas, de maneira que as suas estratégias de uso do espaço tentam maximizar o acesso e a defesa ao maior número de fêmeas possível. Já no caso das fêmeas, o sucesso na reprodução depende da obtenção e defesa de alimento e abrigo, que são cruciais para produzir, nutrir e proteger os filhotes. Em decorrência dessas diferenças, as fêmeas muitas vezes exibem comportamento territorial, garantindo acesso exclusivo aos recursos que favorecem a sobrevivência e o sucesso da sua prole. Já os machos expandem seus movimentos para encontrar e reproduzir com mais fêmeas, chegando a um sistema de acasalamento chamado de poliginia (quando cada macho consegue se reproduzir com mais de uma fêmea na população). Esse é o sistema mais comum entre os pequenos mamíferos, especialmente porque a grande maioria das espécies é solitária, ou seja, adultos se associam brevemente apenas durante o período reprodutivo. Logicamente existem exceções, com algumas espécies de roedores que apresentam compartilhamento de abrigos fora do período reprodutivo, e até mesmo casos em que há cooperação no cuidado de filhotes e manutenção de ninhos e abrigos. Nesse caso, também pode haver poliginia, em que os grupos são formados por um macho e muitas fêmeas (um harém), ou promiscuidade, em que as áreas utilizadas por ambos os sexos se sobrepõem no espaço e a mobilidade dos machos é reduzida.

Desde 2011 temos monitorado o uso do espaço das duas espécies dominantes da Estação Ecológica do Panga, Rhipidomys mastacalis (rato-da-árvore, Figura 1C) e Gracilinanus agilis (cuíca-graciosa, Figura 1B). Para tal, acompanhamos essas populações através de capturas mensais de indivíduos com armadilhas do tipo Sherman. O registro dos pontos em que cada indivíduo é capturado permite estimar os prováveis tamanhos de área em que os animais se movimentam e as sobreposições entre elas. Os padrões de uso do espaço observados na cuíca-graciosa corresponderam àqueles descritos em animais com sistema de acasalamento poligínico ou promíscuo (Figura 3). Os machos se movimentaram mais do que as fêmeas, especialmente durante a época de acasalamento, período em que a sobreposição nas áreas utilizadas foi maior tanto com outros machos quanto com as fêmeas. As fêmeas, por sua vez, mantiveram movimentos constantes ao longo do ano e a sobreposição entre elas foi bem pequena. Esse resultado sugere que as fêmeas de cuíca-graciosa exibem territorialidade como estratégia de defesa dos seus filhotes, do alimento e dos abrigos. Já os machos exibem 
uma estratégia condizente com o sistema de acasalamento esperado, ou seja, expandem seus movimentos e se sobrepõem espacialmente com indivíduos de outro sexo para conseguir copular com o maior número de fêmeas possível.
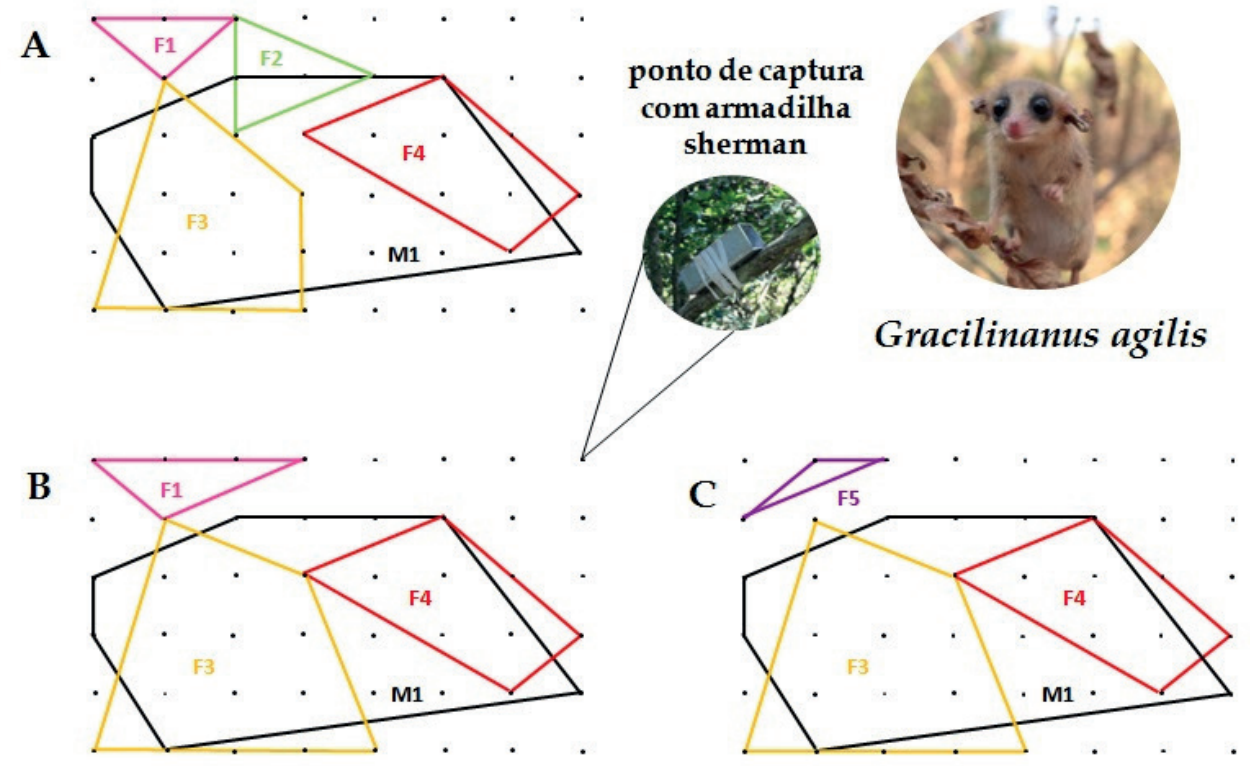

Figura 3. Padrões de sobreposição de uso do espaço entre fêmeas reprodutivas (identificadas pela letra F) e um macho (letra M) de Gracilinanus agilis (cuíca-graciosa) na Estação Ecológica do Panga (Uberlândia, MG). (A) Ausência de sobreposição entre as fêmeas e intensa sobreposição entre o macho e as fêmeas, sugerindo poliginia; (B) aumento das áreas de vida da F3 e F1 após o desaparecimento da F2; (C) ocupação do espaço pela F5 após o desaparecimento da F1.

No caso do rato-da-árvore, observamos que os machos apresentam maior mobilidade do que as fêmeas, independente da variação sazonal no clima (estação seca $\mathrm{x}$ chuvosa) e disponibilidade de alimentos que ocorre no ambiente. Essa constância no uso do espaço parece decorrer de dois fatores: 1) a presença de atividade reprodutiva contínua nessa espécie e 2) a dieta com maior abundância de material vegetal (como folhas). Dessa forma, machos manteriam maior mobilidade o ano todo como estratégia para assegurar as cópulas com fêmeas que se encontram receptivas o tempo inteiro. Ao mesmo tempo, uma disponibilidade quase constante de folhas no ambiente também pode ajudar a explicar a ausência de variação sazonal no uso do espaço dessa espécie.

Também investigamos o uso do espaço do rato-de-espinho (Clyomys laticeps) no Parque Estadual da Serra de Caldas Novas desde 2016 (Figura 4). Nesse caso particular, as armadilhas de captura foram dispostas nas entradas das galerias e o uso do espaço foi avaliado através da técnica do carretel de linha (Figura 4). Nessa metodologia, um carretel especial é acoplado no dorso do animal e após 24 horas, a linha que se desenrola, enquanto o animal se desloca, é mapeada, permitindo o rastreamento da trajetória do animal em um dia. Ao contrário dos machos, as fêmeas foram sempre recapturadas na mesma galeria subterrânea, sugerindo fidelidade ao sítio. Tal fidelidade parece estar relacionada com o cuidado constante com os filhotes, uma vez que a atividade reprodutiva dessa espécie parece ser contínua, ao longo de todo o 
ano. Já os machos apresentaram maior mobilidade do que as fêmeas, e visitaram várias galerias durante o período estudado. Tanto a mobilidade dos machos quanto a das fêmeas não foi afetada pela disponibilidade de um dos recursos alimentares do rato-deespinho C. laticeps, no caso a palmeira Allagoptera campestris. Sendo assim, é muito provável que esse roedor altere sua dieta para outros itens vegetais quando os frutos de palmeira estão ausentes ou pouco abundantes. Mudanças na frequência de consumo de itens alimentares vegetais (como raízes, frutos, sementes, folhas) de acordo com a disponibilidade dos mesmos são bem comuns entre roedores herbívoros, e marsupiais também. Por fim, não observamos nenhum indício claro de compartilhamento das galerias por adultos. Os padrões de uso do espaço do rato-de-espinho encontrados no nosso estudo são condizentes com uma espécie de comportamento solitário e sistema de acasalamento poligínico, isto é, machos se reproduzindo com várias fêmeas (Figura 4).

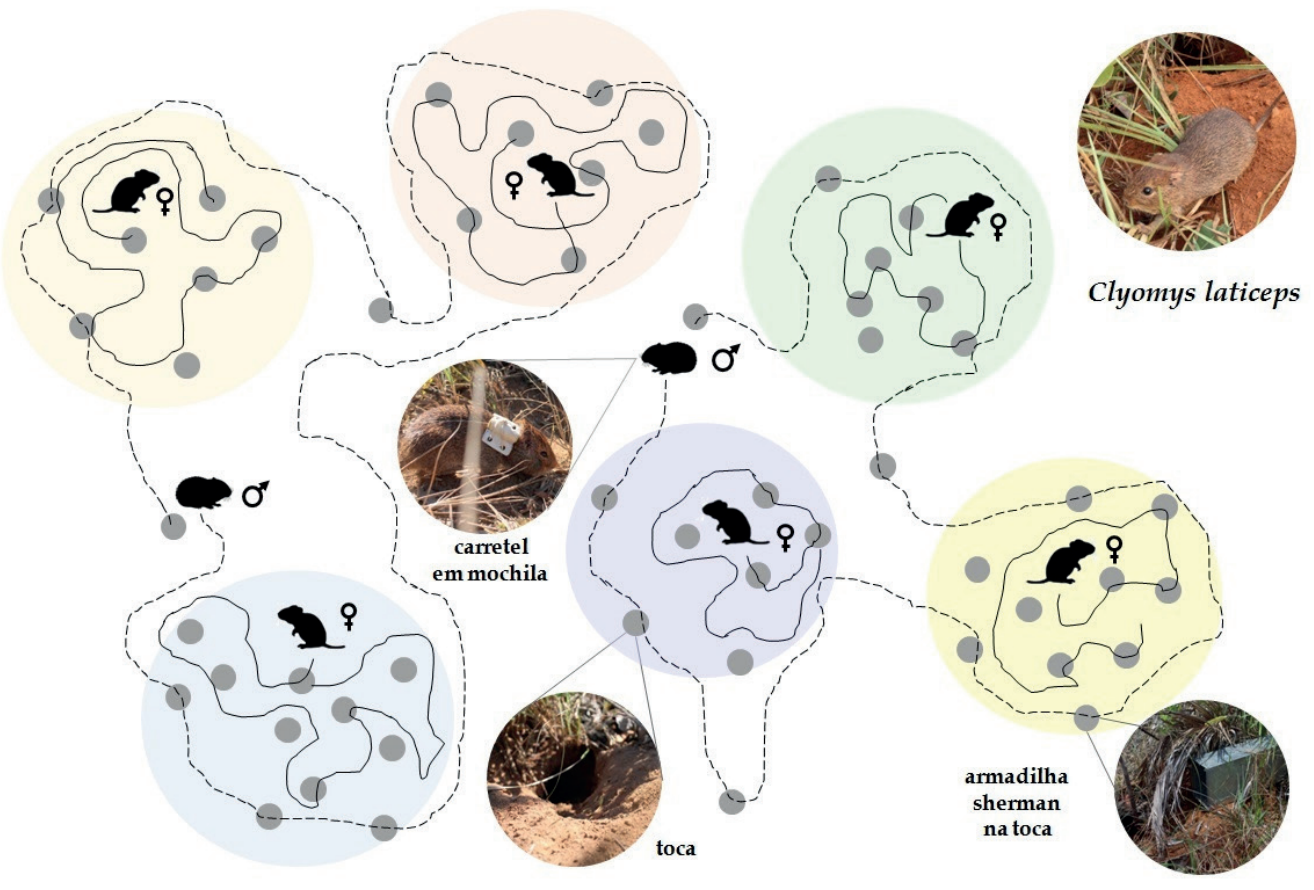

Figura 4. Padrão do uso do espaço observado em Clyomys laticeps (rato-de-espinho) através da técnica do carretel em mochila e captura com armadilhas Sherman no Parque Estadual da Serra de Caldas Novas (Caldas Novas, GO). Os círculos coloridos correspondem às galerias de cada fêmea, e as linhas tracejadas e contínuas, aos movimentos do macho e das fêmeas, respectivamente.

\section{Estratégias Reprodutivas}

As estratégias reprodutivas vão além do número de parceiros em um evento reprodutivo. Elas também são caracterizadas pelo número de reproduções ao longo da vida, assim como, pela duração da época reprodutiva. As espécies podem se reproduzir ao longo de todo o ano (reprodução anual/contínua), apesar de algumas apresentarem maior intensidade na estação seca ou chuvosa, ou somente em estações favoráveis (reprodução sazonal). No caso das duas espécies de roedores estudadas no nosso monitoramento, o rato-da-árvore (Rhipidomys mastacalis, Figura 1C) e o rato- 
de-espinho (Clyomys laticeps, Figura 1F), observamos sinais de atividade reprodutiva ou presença de fêmeas grávidas durante boa parte do ano. Já os marsupiais apresentam uma atividade reprodutiva sazonal, que pode estar restrita a um ou dois períodos durante o ano. A duração do período de atividade reprodutiva pode variar bastante entre espécies, e principalmente de acordo com a latitude, regime de chuvas e disponibilidade de recursos alimentares. Dessa maneira, quando a chuva, e consequentemente a disponibilidade de recursos, é mais abundante e constante (baixas latitudes), o período reprodutivo costuma ser estendido, enquanto em ambientes mais secos e com variação muito grande na abundância de recursos alimentares, o período reprodutivo é mais curto. Isso ocorre porque o sucesso reprodutivo dos marsupiais depende de ajustar o período de cuidado e lactação dos filhotes, que é extremamente dispendioso, ao período de maior abundância de alimento.

Entre os mamíferos, a estratégia reprodutiva mais comum é caracterizada por diversos eventos reprodutivos ao longo de toda vida, variando em duração de acordo com a espécie e o ambiente. Esse tipo de estratégia, chamada de iteroparidade, ocorre em todos os roedores brasileiros e na grande maioria dos marsupiais. Tal estratégia se encontra em um dos extremos de um contínuo associado ao tempo e velocidade da vida do organismo. Já o outro extremo, chamado eixo rápido do contínuo, é representado por uma estratégia reprodutiva denominada semelparidade. Os organismos que exibem tal estratégia participam de apenas um evento reprodutivo, morrendo logo após. A vida nesse caso é muito mais curta, pois o amadurecimento sexual é precoce assim como o período de gestação. Essa estratégia é considerada rara entre mamíferos, mas já foi observada em pelo menos sete espécies diferentes de marsupiais brasileiros e vários outros marsupiais australianos.

Ao longo dos nove anos de monitoramento da população da cuíca-graciosa (Gracilinanus agilis) na Estação Ecológica do Panga observamos que, no período de um ano, os indivíduos nascem, se reproduzem e morrem, não havendo sobreposição de gerações, caracterizando uma estratégia reprodutiva semélpara (Figura 5). A atividade reprodutiva da espécie se inicia em julho, e as primeiras fêmeas lactantes foram encontradas a partir de agosto. Entre setembro e outubro de cada ano, o número de indivíduos da cuíca-graciosa diminui drasticamente em função do desaparecimento dos machos adultos, os quais morrem após o término do período de cópulas. Nas últimas capturas desses machos, estes apresentavam sinais de agressões, provavelmente decorrente de lutas físicas entre machos para conseguir copular com as fêmeas, alta incidência de parasitas intestinais, e sinais de debilitação física, como perda de pelos e, em casos extremos, também de peso. De modo que acreditamos que a acirrada competição entre os machos contribui para tal estado de debilitação, que culmina na mortalidade antecipada desses animais. Por outro lado, as fêmeas adultas só desapareceram da população em meados de fevereiro, quando todos os filhotes já estão desmamados (Figura 5). 


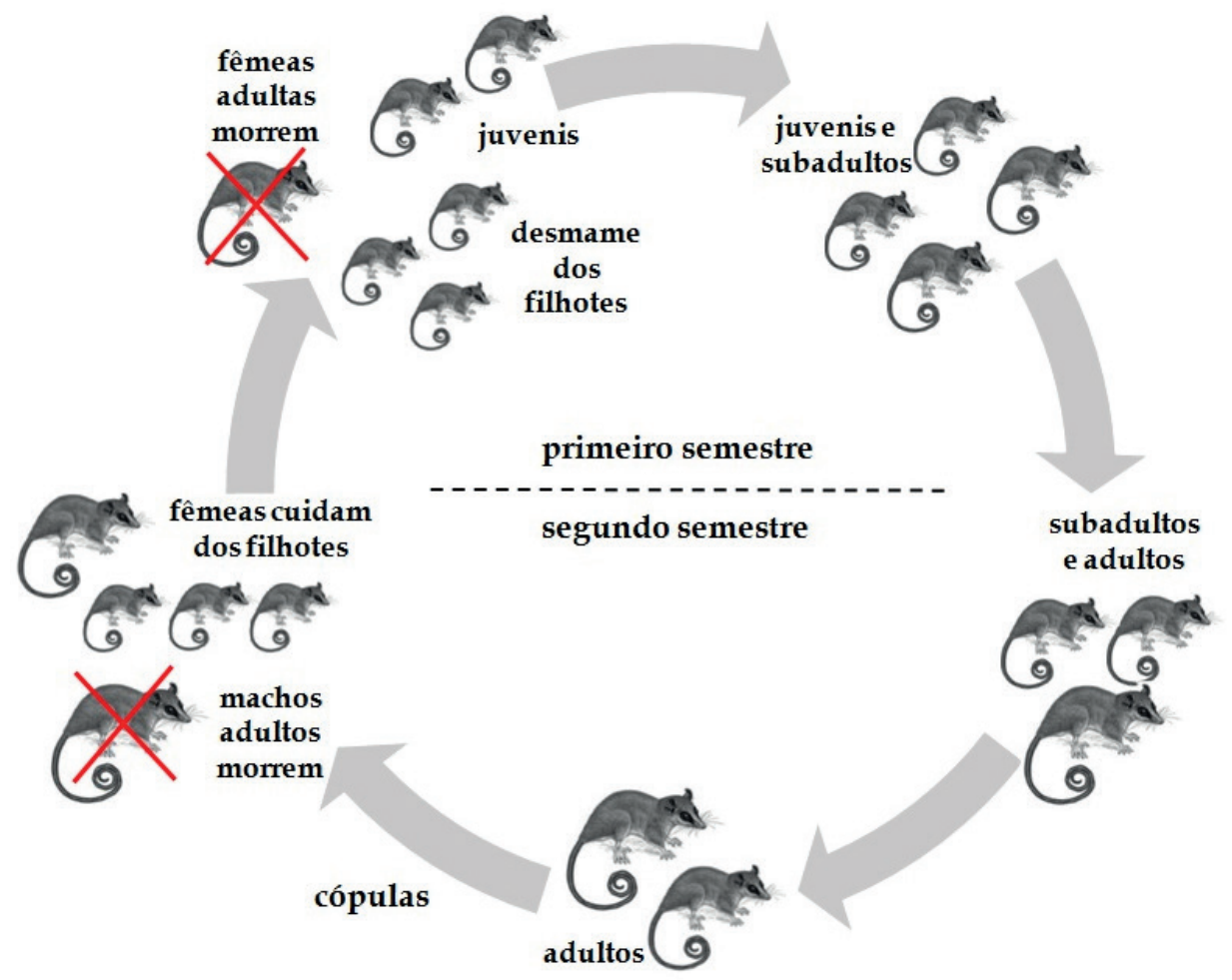

Figura 5. Ciclo de vida de Gracilinanus agilis (cuíca-graciosa) ao longo de um ano, mostrando as evidências de semelparidade.

\section{Conservação de pequenos mamíferos}

Atualmente têm-se observado o desaparecimento ou diminuição no número de indivíduos de alguns roedores e marsupiais em virtude dos distúrbios ambientais e impactos de origem antrópica, como o processo de perda e fragmentação dos habitats. Distúrbios naturais, tais como: incêndios, inundações e períodos de seca moldam o meio ambiente e afetam todos os seres vivos do planeta. Esses eventos naturais sempre estiveram presentes em nosso planeta, variando em frequência e intensidade dependendo da região. Ao mesmo tempo, os efeitos desses distúrbios podem afetar os organismos vivos de formas diferentes, beneficiando algumas espécies e/ou prejudicando espécies em intensidades distintas. $\mathrm{O}$ relevante papel ecológico dos pequenos mamíferos nãovoadores no ambiente, como descrito anteriormente, somado ao seu curto ciclo de vida e facilidade de captura torna esse grupo um modelo ideal para testar os efeitos de distúrbios ambientais sobre as comunidades e populações.

\section{Resposta a distúrbios: o efeito do fogo}

Pesquisas atuais indicam que as ações humanas sobre o ambiente através de desmatamento, queima de combustíveis fósseis, emissão de poluentes e queimadas estão afetando o clima do planeta e o aumento da frequência de eventos climáticos extremos, tais como: períodos de seca severa e inundações. Além disso, as mudanças climáticas e a forma como a espécie humana utiliza o solo para atividades agrícolas e 
de pastoreio estão alterando o regime natural do fogo e aumentando a frequência de incêndios de origem antrópica, sendo esses na maioria das vezes mais intensos que os naturais. Os incêndios, sejam eles naturais ou antrópicos, influenciam a estrutura e funcionamento das comunidades ambientais, através de efeitos diretos e indiretos. O efeito direto causa a morte dos seres vivos em decorrência do contato direto com as chamas, exposição à altas temperaturas ou inalação de fumaça com consequente intoxicação. $\mathrm{O}$ efeito indireto se dá pela redução de recursos alimentares e abrigo para as espécies, influenciando a dinâmica da comunidade animal, através de modificações nas interações entres espécies e redução ou até mesmo extinção local de populações.

Análises dos focos de queimadas no Brasil em 2019 indicaram o Cerrado como o segundo bioma mais afetado, atrás apenas da Amazônia. Os estudos sobre os efeitos do fogo na fauna do Cerrado apresentam resultados idiossincráticos, de maneira que alguns grupos animais são negativamente afetados e podem ter suas populações severamente reduzidas ou até extintas do local, mas também há grupos menos afetados e que se recuperam rapidamente após as queimadas. Essa variação ocorre mesmo entre os pequenos mamíferos, e depende de características da queimada (intensidade, extensão e frequência, por exemplo), além das características de cada espécie, tais como hábitos de vida (terrestre, arbóreo ou fossorial) e capacidade de locomoção. Durante nosso programa de monitoramento na Estação Ecológica do Panga, a reserva foi acometida por dois incêndios: um em outubro de 2014 e outro em setembro de 2017. A ocorrência dessas queimadas e a continuação do nosso monitoramento possibilitou que avaliássemos como a comunidade de pequenos mamíferos foi influenciada. Além disso, conseguimos analisar como o fogo afetou as populações do marsupial Gracilinanus agilis (cuíca-graciosa, Figura 1B) e do roedor Rhipidomys mastacalis (rato-da-árvore, Figura 1C), as espécies mais abundantes em nosso monitoramento.

Desde o início do nosso monitoramento a população da cuíca-graciosa é a mais abundante em nossa área de estudo. Os nossos resultados mostraram que ambos os incêndios tiveram efeitos negativos sobre a população da cuíca-graciosa. Englobando o mesmo esforço de amostragem antes e depois de cada incêndio (31 meses em cada período), pudemos observar que o número de indivíduos capturados desse marsupial caiu de 169 no período antes do fogo para 114 e 100 após o primeiro e segundo incêndio, nesta ordem, indicando uma redução de $33 \%$ e $41 \%$ da população após cada incêndio, respectivamente (ver Tabela 2). Essa espécie apresenta uma variação no número de indivíduos capturados entre as estações climáticas em função da estratégia reprodutiva semélpara e a mortalidade dos machos na estação chuvosa. Antes dos incêndios, o tamanho populacional dessa espécie variava entre um e 23 indivíduos na estação chuvosa e entre oito e 34 indivíduos na estação seca. Após o primeiro incêndio, a abundância da cuíca-graciosa variou entre dois e 14 indivíduos na chuvosa, e entre cinco e 24 indivíduos na estação seca. Já após o segundo incêndio, o número mínimo de indivíduos da espécie na estação chuvosa chegou a zero e o máximo permaneceu em 14, enquanto os valores mínimo e máximo na estação seca se mantiveram iguais. Percebe-se que houve uma redução no tamanho da população desse marsupial entre os períodos antes e depois dos dois incêndios.

A mesma análise foi realizada para o rato-da-árvore ( $R$. mastacalis), que é a segunda espécie mais abundante na área. Apesar de ser a segunda espécie em dominância numérica, os tamanhos populacionais do rato-da-árvore são bem menores do que os da 
cuíca-graciosa, e tais roedores não foram capturados em todos os meses do estudo mesmo antes dos incêndios, diferente do que ocorre com a cuíca-graciosa. Assim como na população do marsupial, os dois incêndios na reserva influenciaram negativamente a abundância desse roedor, que foi reduzida de 58 indivíduos antes dos incêndios para 38 e 23 indivíduos após o primeiro e segundo incêndio, respectivamente. Ainda, os indivíduos dessa espécie só foram recapturados oito meses após o segundo fogo. Porém, 14 meses após o incêndio, o número de indivíduos de $R$. mastacalis voltou a subir, se igualando aos valores encontrados antes dos incêndios, indicando uma recuperação populacional.

A diversidade de espécies na área estudada se manteve a mesma antes e depois dos incêndios, porém a abundância de pequenos mamíferos não-voadores foi reduzida após os incêndios. Além disso, os resultados mostram uma alteração da identidade e abundância das espécies que fazem parte da comunidade antes e depois do fogo (ver Tabela 2). Antes e depois do primeiro incêndio, a comunidade era composta por sete espécies de pequenos mamíferos, mas após a segunda queima o número de espécies encontradas passou a nove. $\mathrm{O}$ aumento no número de espécies após o segundo incêndio reflete a redução no número de indivíduos das duas populações dominantes, cuícagraciosa e rato-da-árvore. Aparentemente, a redução dessas espécies dominantes possibilitou que espécies menos abundantes aumentassem seu número de indivíduos, seja por meio da diminuição da pressão de competição com as espécies dominantes, ou pela chegada de novos indivíduos na área de estudo (imigração). É possível também que mudanças na estrutura da vegetação após o fogo tenham favorecido a chegada e estabelecimento de espécies que preferem ambientes mais abertos.

Tabela 2: Identidade e abundância das espécies de pequenos mamíferos capturados na Estação Ecológica do Panga.

\begin{tabular}{lccc}
\hline Espécies & $\begin{array}{l}\text { Antes dos incêndios } \\
\text { (mar/2012-set/2014) }\end{array}$ & $\begin{array}{c}\text { Após o fogo de 2014 } \\
\text { (out/2014-ago/2017) }\end{array}$ & $\begin{array}{c}\text { Após o fogo de 2017 } \\
\text { (set/2017-mar/2020) }\end{array}$ \\
\hline Didelphis albiventris & 0 & 1 & 3 \\
\hline Gracilinanus agilis & 169 & 114 & 100 \\
\hline Calomys tener & 2 & 6 & 2 \\
\hline Cerradomys scotti & 0 & 4 & 1 \\
\hline Hylaeamys megacephalus & 2 & 4 & 1 \\
\hline Necromys lasiurus & 3 & 10 & 3 \\
\hline Oecomys cf. bicolor & 4 & 0 & 11 \\
\hline Oligoryzomys spp. & 5 & 0 & 23 \\
\hline Rhipidomys mastacalis & 58 & 31 & 146 \\
\hline Total de indivíduos & 243 & 170 & \\
\hline
\end{tabular}

\section{Resposta a impactos antrópicos: efeito das alterações na qualidade do habitat sobre as populações}

O processo de perda de habitat e fragmentação causa modificações na quantidade e qualidade dos ambientes disponíveis para que as espécies possam sobreviver e persistir. A qualidade dos habitats é em geral caracterizada através da estrutura da vegetação, 
presença de corpos de água e disponibilidade de recursos alimentares, uma vez que estes recursos são essenciais para a sobrevivência dos organismos. A avaliação da estrutura da vegetação é feita através de um conjunto de variáveis, tais como: cobertura do dossel, presença de galhos caídos e folhas mortas no solo, densidade da vegetação, tamanho das árvores e outros atributos. Estudos recentes com diferentes grupos de vertebrados têm mostrado que tanto o número quanto a diversidade de espécies são positivamente influenciados pela qualidade do habitat. Dessa maneira, habitats com maior complexidade estrutural (mais preservados) apresentam maior diversidade, enquanto habitats de menor qualidade (menos preservados) abrigam apenas um subconjunto das espécies existentes nos ambientes mais preservados. Esse subconjunto geralmente é dominado por espécies menos sensíveis a alterações e distúrbios nos ambientes, ao passo que as espécies mais sensíveis são as primeiras a desaparecer, caracterizando um processo chamado de homogeneização biótica (Figura 6).

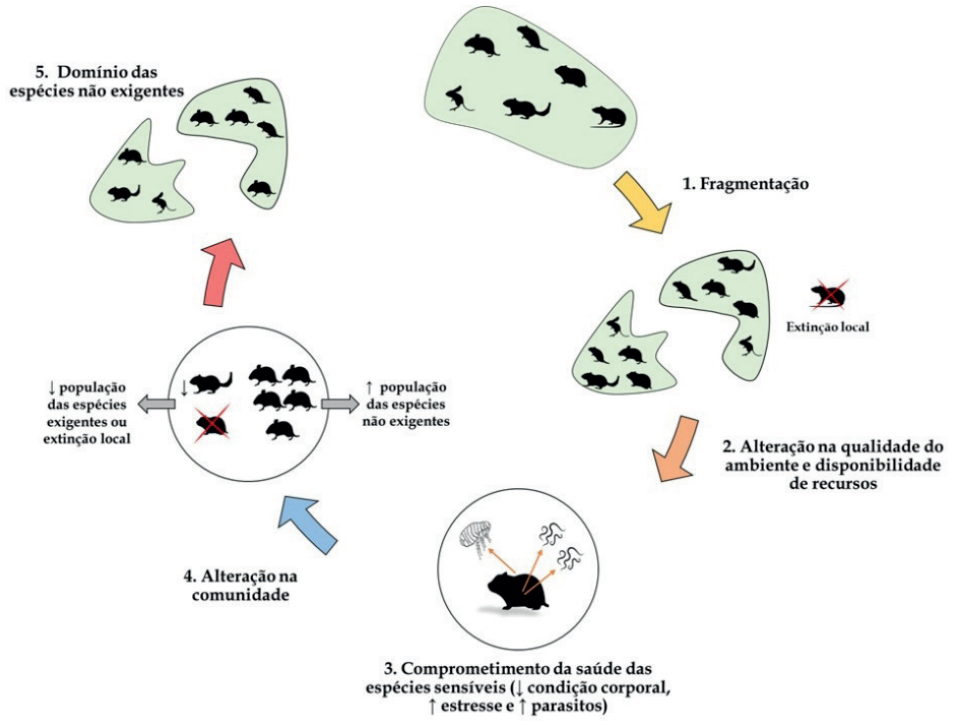

Figura 6. Potenciais efeitos da fragmentação de habitats sobre as populações e comunidades de pequenos mamíferos. A perda e alteração na qualidade de habitat podem comprometer a saúde de espécies mais exigentes, causando diminuição de sua abundância e até mesmo eventos de extinção local. Ao mesmo tempo, essas mudanças no habitat alteram a composição de espécies das comunidades, que passam a ser dominadas por espécies que não são sensíveis aos distúrbios e perda de qualidade de habitat.

Mas a perda de espécies não é um evento que ocorre da noite para o dia. Antes disso, existem alguns sinais que podem ser observados nos organismos, e que podem nos indicar se determinada espécie está com sua persistência ameaçada naquele ambiente (veja Figura 6). O primeiro sinal é uma redução na saúde e no estado nutricional dos indivíduos em decorrência da baixa qualidade do ambiente. Essa redução eventualmente promove o aumento das taxas de mortalidade, reduzindo o número de indivíduos da espécie no ambiente até seu completo desaparecimento naquele habitat. Porém, nem todas as espécies são afetadas negativamente pela perda de qualidade do habitat, dado que existem alguns organismos que preferem ambientes alterados. Uma medida muito usada da saúde dos animais é a avaliação da condição corporal, um método muito semelhante ao Índice de Massa Corporal (IMC), utilizado para calcular o peso ideal para cada pessoa conforme sua altura, e ao Escore de 
Condição Corporal (ECC), aplicado para avaliar a quantidade de gordura e músculo de animais de produção e seu desempenho reprodutivo (utilizado na pecuária com foco no gado leiteiro). Basicamente, a condição corporal nos pequenos mamíferos reflete as reservas energéticas (gordura, massa muscular e estrutura óssea) de cada indivíduo, ou seja, sua capacidade de suportar períodos de escassez de recursos e situações que geram estresse crônico (como infecções por parasitos e outros microrganismos). Dessa forma, a condição corporal pode funcionar como um indicador de sensibilidade dos indivíduos à qualidade do ambiente.

No Triângulo Mineiro restam apenas pequenos fragmentos de mata espalhados pela região. Esses fragmentos são bem distintos em tamanho, estrutura da vegetação e qualidade do habitat disponível para os pequenos mamíferos não-voadores. Nesse contexto, desde 2018 estamos categorizando cinco fragmentos de acordo com a qualidade do habitat, utilizando medidas de complexidade da vegetação, tamanho do fragmento e abundância de material vegetal (serapilheira) depositada no solo, que indica oferta de recursos alimentares e rotas de fuga e abrigo para esses animais. Com base nesses dados, estamos tentando compreender como a qualidade do habitat pode afetar a saúde das populações naturais, através de uma métrica de condição corporal que permite comparações entre populações de diferentes áreas estudadas. Essa métrica envolve a obtenção de uma medida de comprimento do corpo (Figura 7) e outra de massa corporal (peso). Por fim, pretendemos comparar as comunidades de pequenos mamíferos não-voadores entre as áreas estudadas.

Os fragmentos que estamos avaliando são: Fazenda Água Fria (200 ha), localizada nas imediações do município de Araguari (MG), Estação de Pesquisa e Desenvolvimento Ambiental Galheiro (2.847 ha), situada no município de Perdizes (MG), Estação Ecológica do Panga (409,5 ha), Fazenda Experimental do Glória (30 ha) e Fazenda São José (20 ha), todas as três últimas localizadas em Uberlândia (Figura 8).

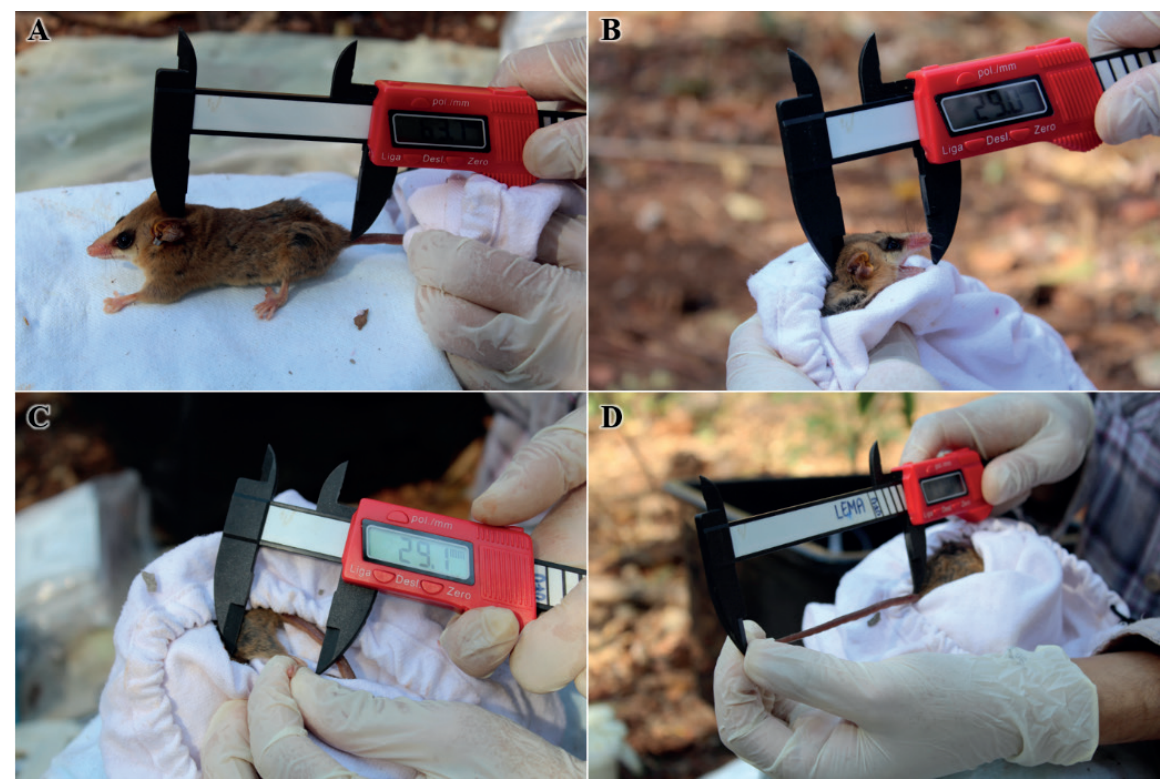

Figura 7. Obtendo medidas morfológicas de Gracilinanus agilis (cuíca-graciosa) capturada na Fazenda São José. Comprimento do corpo (A), da cabeça (B), da tíbia (C) e da cauda (D). 

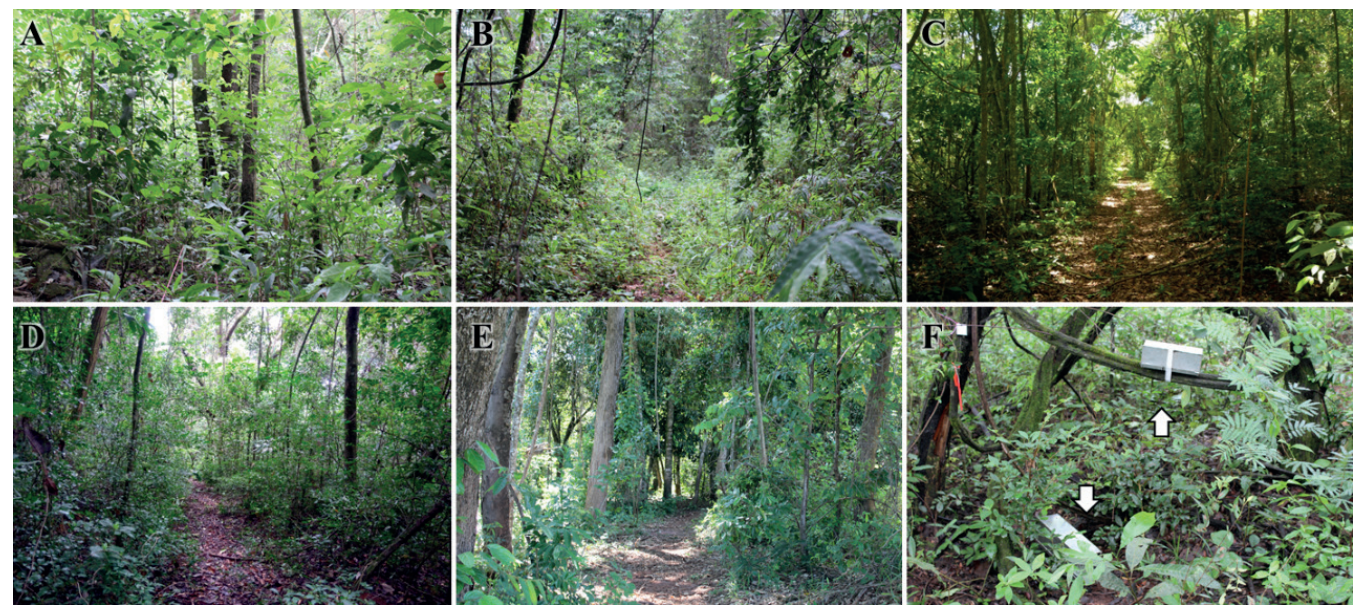

Figura 8. Locais de captura dos pequenos mamíferos não-voadores. Trilha de acesso às matas da Estação Ecológica do Panga (A), Estação de Pesquisa e Desenvolvimento Ambiental Galheiro (B), Fazenda Água Fria (C), Fazenda Experimental do Glória (D) e Fazenda São José (E). Armadilhas Sherman (F) dispostas no solo e em um cipó (indicadas por setas).

As duas últimas áreas estão situadas na zona leste da cidade, constituindo os fragmentos cujo entorno possui maior impacto da ação humana. Conforme nossas análises, foi possível estabelecer um gradiente de qualidade ambiental, variando das áreas cuja vegetação é mais aberta e com menos serapilheira (Fazenda Experimental do Glória e Fazenda São José) a áreas com vegetação mais fechada e com maior disponibilidade de serapilheira (Estação de Pesquisa e Desenvolvimento Ambiental Galheiro e Estação Ecológica do Panga), englobando uma área com características intermediárias da qualidade ambiental (Fazenda Água Fria). Tais dados condizem com o estado de conservação e tamanho dos fragmentos de mata e/ou reservas naturais.

O roedor Rhipidomys spp. (Figura 1C) foi a espécie mais abundante em todos os fragmentos, com exceção da Estação de Pesquisa de Galheiro onde esse roedor não foi registrado. Outra diferença marcante entre as comunidades foi a ausência de Hylaeamys megacephalus (rato-do-mato, Figura 1D) na Fazenda São José, sendo que esse roedor foi a segunda espécie mais abundante na Fazenda Experimental do Glória e também na Estação de Pesquisa e Desenvolvimento Ambiental Galheiro. O marsupial Didelphis albiventris (gambá-de-orelha-branca, Figura 1A) apresentou a maior abundância na Fazenda do Glória, com mais do que o dobro do número de indivíduos encontrados nos outros fragmentos. Já a cuíca-graciosa (Gracilinanus agilis, Figura 1B) foi a espécie mais abundante na Estação de Pesquisa e Desenvolvimento Ambiental Galheiro, e a segunda em dominância na Fazenda Água Fria e Fazenda São José. Porém, foi rara na Fazenda do Glória, talvez em decorrência da grande abundância de Rhipidomys spp. nessa área. Tanto a Fazenda Água Fria, quanto a Estação de Pesquisa e Desenvolvimento Ambiental Galheiro e a Estação Ecológica do Panga apresentaram duas espécies de roedores exclusivas de cada área que ainda estão em processo de identificação por especialistas.

A Fazenda Água Fria apresentou maior número de espécies (sete) e maior diversidade do que a Fazenda São José (quatro espécies). Já a Fazenda Experimental do Glória apresentou cinco espécies e valores intermediários de diversidade. Tais valores não foram diferentes dos das outras duas áreas. A Estação Ecológica do Panga e a Estação de Pesquisa e Desenvolvimento Ambiental Galheiro foram amostradas 
menos vezes, dificultando a comparação com os outros fragmentos. Mas ao fazer uma padronização do esforço de capturas em cada fragmento, podemos observar que ambas as áreas apresentam comunidades que não são compostas por espécies dominantes (diferente das Fazendas São José e Experimental do Glória, que apresentaram alta dominância de determinadas espécies). Além disso, a Estação Ecológica do Panga apresentou inicialmente valores superiores em número de espécies (sete) e diversidade de espécies em comparação com a Fazenda São José, se assemelhando à Fazenda Água Fria. Apesar de esses resultados serem preliminares, em função da necessidade de maior esforço de amostragem nos dois fragmentos mais conservados, os mesmos sugerem um processo de perda de espécies na Fazenda São José, e de maior diversidade de espécies em ambientes mais complexos.

Como a pesquisa ainda está em andamento e a composição de espécies foi diferente entre os fragmentos, só foi possível comparar a condição corporal das populações de Rhipidomys spp. entre a Fazenda Água Fria, Fazenda São José e Fazenda Experimental do Glória e das populações de cuíca-graciosa entre os dois primeiros fragmentos. Diferente do esperado, os indivíduos de Rhipidomys spp. não apresentaram maior condição corporal na Fazenda Água Fria, que foi categorizada como intermediária em termos de qualidade de habitat. Pelo contrário, essa espécie apresentou maior condição corporal na Fazenda Experimental do Glória seguido da Fazenda São José, áreas ranqueadas como de baixa qualidade ambiental. Esses dados indicam que essa espécie pode preferir ambientes alterados e ser favorecida por distúrbios. De fato, Rhipidomys spp. foi pouco abundante ou até mesmo ausente nos fragmentos mais conservados. A maior condição corporal de Rhipidomys spp. na Fazenda do Glória está de acordo com a dominância dessa espécie na comunidade desse fragmento, o que indica que há algum fator que parece favorecer o crescimento da população e a saúde dos indivíduos. É possível que a presença de diferentes cultivos, que estão em constante rotatividade, na área adjacente do fragmento contribua para garantir oferta suficiente e constante de alimento para essa espécie.

Já para a cuíca-graciosa, G. agilis, não encontramos diferenças na condição corporal dos indivíduos entre as populações da Fazenda Água Fria e Fazenda São José. Esses dados também indicam que esse marsupial não é sensível às alterações de estrutura da vegetação, ou que as diferenças entre os fragmentos analisados não são expressivas o suficiente para alterar o estado nutricional dos indivíduos. Logicamente, a ausência das áreas mais bem categorizadas em termos de qualidade de habitat na nossa análise pode ter dificultado a observação dos padrões. Além disso, outros parâmetros de saúde animal que não a condição corporal, podem ser afetados por mudanças na qualidade dos habitats. Dessa forma, estudos avaliando a condição fisiológica de roedores e marsupiais, mais especificamente parâmetros como estresse, ectoparasitismo, parasitismo intestinal e sanguíneo dos indivíduos, estão sendo conduzidos nesses fragmentos para investigar mais a fundo a saúde das populações naturais.

\section{Considerações finais}

Embora os roedores e marsupiais (principalmente gambás) sejam, muitas vezes, tratados como pragas e/ou transmissores de doenças aos seres humanos, este capítulo descreve o relevante papel ecológico dos pequenos mamíferos não-voadores nos ambientes naturais, buscando desmistificar tais (pré) concepções. Em resumo, os 
pequenos mamíferos atuam como dispersores de sementes, engenheiros de ecossistema, base de cadeias tróficas e, até mesmo, no controle de pragas, além de exibirem comportamentos e estratégias de reprodução variadas e curiosas. Com o aumento na frequência e intensidade de distúrbios antrópicos, tais como incêndios, fragmentação de áreas naturais e a iminente mudança no clima, torna-se essencial o entendimento de como esses eventos podem afetar o ambiente e os pequenos mamíferos não-voadores, seja por ação direta ou indireta.

Os nossos resultados mostraram que os incêndios ocorridos durante $o$ monitoramento reduziram as populações das espécies de pequenos mamíferos dominantes, alterando assim a composição de espécies da comunidade. No futuro, pretendemos avaliar se essa redução no tamanho populacional ocorre através de um aumento da mortalidade (efeito direto) ou diminuição dos nascimentos (efeito indireto) após o fogo. Também pretendemos avaliar qual o tempo de recuperação das populações das espécies dominantes, e o efeito a longo prazo dos incêndios sobre a composição de espécies e diversidade da comunidade na área estudada. Essas investigações só serão possíveis através de estudos de longo prazo, dado que o contínuo monitoramento consegue detectar as mudanças na comunidade e nas populações das diferentes espécies, permitindo entender e até prever quais as causas e consequências dessas mudanças.

Com relação aos efeitos da fragmentação decorrentes de alterações na qualidade dos habitats, nossos resultados ainda são incipientes em virtude do pouco tempo de pesquisa. Mesmo assim, os resultados indicam que há perda de espécies sensíveis aos distúrbios nos ambientes de menor qualidade, e maior diversidade de espécies em ambientes de maior qualidade. O aumento do esforço de captura em todos os fragmentos poderá tornar esse padrão mais claro, além de estudos futuros que incluam áreas antropizadas, como pastagens, plantações de soja e de cana de açúcar. Por fim, em um estudo de longa duração, poderemos investigar se a redução na abundância de algumas espécies é seguida pelo seu desparecimento do ambiente, e se essa redução é precedida por mudanças na saúde dos indivíduos. Entre as medidas de saúde que estamos avaliando ao longo do tempo nos diferentes fragmentos estão a condição corporal, estresse crônico e frequência e abundância de parasitas intestinais e sanguíneos. A compreensão no padrão geral de resposta de cada espécie frente aos distúrbios pode auxiliar no gerenciamento das unidades de conservação, através de mudanças no plano de manejo e na tomada de decisões por parte de autoridades.

\section{Para saber mais}

Amorim FW, Ballarin CS, Mariano G. Lacerda-Barbosa PA, Costa JG, Hachuy-Filho L, Zabin DA, Queiroz HGD, Servilha JH, Morellato LPC (2020) Good heavens what animal can pollinate it? A fungus-like holoparasitic plant potentially pollinated by opossums. Ecology 101:e03001. 10.1002/ecy.3001

Camargo NF de, Camargo AJA de, Mendonça AF, Vieira EM (2017). Potencial serviço ecossistêmico prestado pelo marsupial Gracilinanus agilis (Didelphimorphia:Didelphidae) com predação do percevejo marrom (Euchistus heros (Hemiptera:Pentatomidae). Boletim de Pesquisa e Desenvolvimento. Embrapa Cerrados, Brasília 
Carmignotto AP, de Vivo M, Langguth A (2012) Mammals of the Cerrado and Caatinga. Distribution patterns of the tropical open biomes of central South America. In: Patterson BD, Costa, LC (eds) Bones, clones, and biomes: The history and geography of Recent Neotropical mammals. Chicago University Press, Chicago, pp 307- 350

Ferrando CPR, Lamberto JM, Leiner NO (2019) Space use patterns of the burrowing echimyid rodent, Clyomys laticeps. Ethology 125:133-141.

Lamberto JM, Leiner NO (2019) Broad-headed spiny rats (Clyomys laticeps) as ecosystem engineers in the Brazilian savannah. J Zool doi:10.1111/jzo.12684

Lopes GP, Leiner NO (2015) Semelparity in a population of Gracilinanus agilis (Didelphimorphia: Didelphidae) inhabiting the Brazilian cerrado. Mamm Biol 80:1-16

Prevedello JA, Mendonça AF, Vieira MV (2008) Uso do espaço por pequenos mamíferos: uma análise dos estudos realizados no Brasil. Oecologia Brasiliensis 12: 310-325 



\title{
CAPÍTULO 4
}

\section{ECOLOGIA DE CANÍDEOS SILVESTRES EM AGROECOSSISTEMAS}

\author{
Kátia G. Facure \\ Frederico G. Lemos \\ Fernanda C. Azevedo \\ Bianca M. Kotviski \\ Mozart C. Freitas-Junior \\ Izabella L. Rigobello \\ Talita A. Silva \\ Susana Faria Nalla \\ César Gómez-Hernández \\ Karine Rezende-Oliveira
}

Os canídeos compõem um grupo bem sucedido de mamíferos carnívoros, tanto no tempo passado como no presente. Apresentam uma distribuição ampla, são abundantes, bem adaptados e atualmente estão representados por muitas espécies. Além disso, desempenham um papel importante nas cadeias alimentares, controlando populações de presas e ajudando a manter a estabilidade dos ecossistemas. De acordo com o Grupo de Especialistas de Canídeos da União Internacional para a Conservação da Natureza (IUCN), cinco espécies estão atualmente ameaçadas de extinção e outras cinco, quase ameaçadas. A perda de habitat representa a principal ameaça à conservação dos canídeos silvestres. Enquanto algumas espécies são raras e estão em declínio, outras são abundantes e podem estar envolvidas em questões importantes de manejo, como a transmissão de doenças e a predação de animais domésticos. Conhecer como as espécies de canídeos vivem em habitats transformados tem uma grande relevância para a conservação de suas populações em ambientes impactados. Nesse capítulo, apresentamos aspectos da ecologia e evolução dos canídeos silvestres e descrevemos dois estudos realizados nos últimos 10 anos sobre três espécies comumente encontradas em áreas naturais e antropizadas do Bioma Cerrado, a raposado-campo (Lycalopex vetulus), o cachorro-do-mato (Cerdocyon thous) e o lobo-guará (Chrysocyon brachyurus). Os objetivos específicos desses estudos foram comparar a ecologia alimentar das três espécies em uma área de fazendas de gado localizada em um ecótono entre Cerrado e Mata Atlântica no sudeste de Goiás e apresentar a diversidade de parasitos intestinais que circulam nesses canídeos em áreas impactadas de Cerrado no Pontal do Triângulo Mineiro.

\section{História Natural}

Os Canídeos pertencem à ordem Carnivora, um grupo monofilético que compreende 16 famílias existentes. A maioria dos membros desse grupo possuem adaptações para perseguir, matare se alimentar de outros animais. Uma das características principais que definem os mamíferos carnívoros é a presença do aparelho carniceiro, composto pelo quarto pré-molar superior e o primeiro molar inferior (Figura 1). Esses dentes, conhecidos como carnassiais, têm uma morfologia parecida com uma lâmina, 
que cria um movimento do tipo tesoura quando a mandíbula é fechada, e são utilizados para cortar a carne das presas, garantindo um consumo mais eficiente.

Os canídeos são uma das três famílias modernas de carnívoros, notáveis por incluir predadores de topo, ao lado da família dos gatos (Felidae) e da família das hienas (Hyaenidae). As três famílias apresentam estratégias diferentes para abater presas com tamanho corporal maior do que o deles. Os felídeos são predadores de emboscada que realizam ataques surpresa, aproximando-se de suas presas furtivamente e subjugando a vítima no menor tempo possível. Por outro lado, os canídeos modernos apresentam uma tática diferente, adequada ao estilo de vida de seus ancestrais nas planícies abertas. Nesse cenário, o ataque surpresa raramente é alcançado e os canídeos caçam utilizando o trabalho em equipe. Com grande resistência física, sua estratégia de caça se baseia na perseguição por longas distâncias e presas grandes são abatidas à medida que são mordidas enquanto correm. O corpo flexível, os membros alongados e o andar cursorial digitígrado (apoio sobre os dedos) são adaptações para perseguir presas em ambientes abertos. Evolutivamente, os hienídeos são mais proximamente relacionados aos felídeos, mas seu comportamento e morfologia se assemelham aos dos canídeos. Eles também são altamente sociais e matam suas presas durante perseguições de longa distância. Essas semelhanças são resultado da evolução convergente em ambientes igualmente abertos.

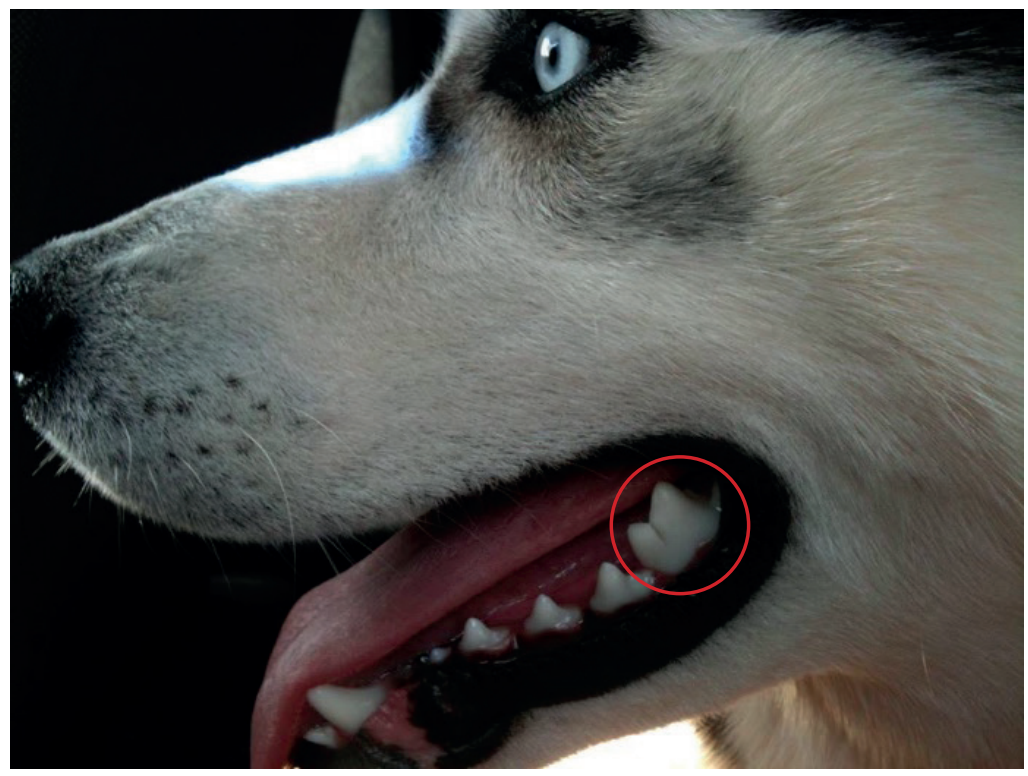

Figura 1. Primeiro molar inferior de um cachorro-doméstico (Canis lupus familiaris), parte do aparelho carniceiro dos carnívoros. Foto: Kátia G. Facure.

A origem e a primeira diversificação dos canídeos ocorreu no continente norte-americano, durante o Eoceno, levando ao reconhecimento de três subfamílias: Hesperocyoninae (de $\sim 39$ a $15 \mathrm{Ma}$ ), Borophaginae (de 36 a $2 \mathrm{Ma}$ ) e Caninae (de $\sim 34 \mathrm{Ma}$ até o presente). Única sobrevivente, a subfamília Caninae se dispersou para a Eurásia e África no final do Mioceno (5 Ma) e para a América do Sul no final do Plioceno e início do Pleistoceno, a partir da formação do istmo do Panamá, há cerca de $3 \mathrm{Ma}$. Nestes continentes, encontraram novas condições ambientais e tipos de 
presas que, aliados ao isolamento geográfico, possibilitaram processos de especiação e resultaram em faunas parcialmente endêmicas. Apesar da origem norte-americana e da recente invasão do continente, a América do Sul apresenta a maior diversidade de canídeos viventes, com seis gêneros e 11 espécies reconhecidas. Essa diversidade tem sido atribuída à estratégia alimentar oportunista e generalista da maioria das espécies, que consomem vertebrados, frutos e invertebrados de acordo com a disponibilidade no ambiente, e às suas adaptações para uma variedade de hábitats.

Atualmente são reconhecidas 36 espécies de canídeos, que variam em tamanho corporal desde as menores raposas pesando menos de $1 \mathrm{~kg}$, até o lobo-cinzento (Canis lupus), que pode pesar até $80 \mathrm{~kg}$. O dimorfismo sexual, quando presente, é mínimo, com machos um pouco maiores que as fêmeas. A variação interespecífica em tamanho corporal pode estar relacionada à disponibilidade de alimentos, uma vez que as espécies menores geralmente vivem em ambientes áridos e com menor abundância de presas, nos quais apenas uma pequena massa corporal pode ser mantida durante todo o ano. Apesar da grande variação em tamanho, as formas corporais são semelhantes entre as espécies, que, em sua maioria, apresentam focinho afilado, cauda espessa e orelhas eretas.

A família Canidae ocorre em todos os continentes, com exceção da Antártida, desde o Ártico até as florestas tropicais. A ampla distribuição dos canídeos está associada à sua alta mobilidade e capacidade de ocupar quase todos os habitats terrestres, incluindo ambientes extremos como a tundra do Ártico e desertos, além de florestas tropicais e temperadas, savanas, campos de gramíneas, regiões montanhosas, terras cultivadas e áreas urbanas. Alguns até exploram parcialmente ambientes aquáticos, como o cachorro-do-mato-de-orelhas-curtas (Atelocynus microtis), e arbóreos, como o cão-guaxinim e a raposa-cinzenta (Urocyon cinereoargenteus). Apenas duas espécies vivem permanentemente em florestas densas, o cão-guaxinim (Nyctereutes procyonoides), originário das florestas da Sibéria, leste da Ásia e Japão, e o cachorrodo-mato-vinagre (Speothos venaticus), das florestas da América do Sul.

A reprodução é sazonal e ocorre anualmente, a partir do primeiro ou segundo ano de vida. A gestação leva de 49 a 72 dias e o tamanho da ninhada varia de 1 a 16 filhotes, que nascem com os olhos e ouvidos fechados e necessitam do cuidado dos pais por um longo período. $\mathrm{O}$ casal reprodutivo permanece unido após o nascimento dos filhotes e dividem os cuidados com a cria. Filhos adultos podem permanecer no grupo e ajudar a criar os irmãos mais novos. Os canídeos são os únicos mamíferos capazes de regurgitar alimentos para seus filhotes. Esse comportamento é importante no fornecimento de alimentos para filhotes antes, durante e após o desmame e, às vezes, para a mãe durante as primeiras semanas após o parto. Apesar da grande diversidade de comportamentos, com variação entre e dentre espécies, a monogamia representa um aspecto comum dos canídeos. A monogamia com cuidado paterno é adotada por apenas 3 a $9 \%$ das espécies de mamíferos e $16 \%$ das espécies de Carnivora, mas é encontrada em todas as espécies de canídeos estudadas até hoje. Em nenhuma outra família de mamíferos a manutenção do par reprodutivo é tão onipresente.

\section{Filogenia dos canídeos atuais}

As relações evolutivas entre as espécies de canídeos atuais foram estudadas no passado usando abordagens morfológicas, mas essas filogenias não têm sido apoiadas por estudos moleculares, indicando a existência de paralelismo (aquisição de caracteres 
semelhantes sem descendência comum) em muitas linhagens. Mesmo métodos de análise filogenética baseados em dados moleculares também podem apresentar tendenciosidades. Em algumas espécies, a divergência genética foi suprimida pelo fluxo gênico entre diferentes populações com a formação de grandes zonas de hibridação. Existem inúmeros relatos de canídeos silvestres ou domésticos que hibridam com espécies raras ou em risco de extinção, ameaçando sua integridade genética. No Brasil, a destruição da Mata Atlântica e sua substituição por pastagens e plantações, tem colocado em contato duas espécies de canídeos do gênero Lycalopex, a raposa-docampo (L. vetulus), endêmica do Cerrado, e o graxaim-do-campo (L. gymnocercus), natural dos Pampas. Ambas espécies são típicas de ambientes abertos e a presença da floresta representava a principal barreira que impedia o encontro entre elas. Uma consequência desse contato é a hibridização, evidenciada pela presença de genes das duas espécies em populações intermediárias no estado de São Paulo.

A maioria das análises filogenéticas moleculares encontrou quatro grupos distintos (Figura 2) na família Canidae: (1) Canina (canídeos parecidos com lobos), (2) Vulpini (canídeos parecidos com raposas), (3) Cerdocyonina (canídeos sul-americanos) e (4) Urocyon (canídeos parecidos com a raposa cinzenta). Apesar do tamanho menor em relação aos canídeos parecidos com lobos (Canina), os canídeos sulamericanos são mais aparentados com esses, do que com as raposas (Vulpini). Das dez espécies, oito são referidas como raposas e reconhecidas como um grupo monofilético compreendendo seis espécies do gênero Lycalopex e os gêneros monoespecíficos Cerdocyon e Atelocynus. O lobo-guará e o cachorro-do-mato-vinagre compartilham um ancestral comum mais recente entre si e um mais antigo com os outros canídeos sul-americanos.

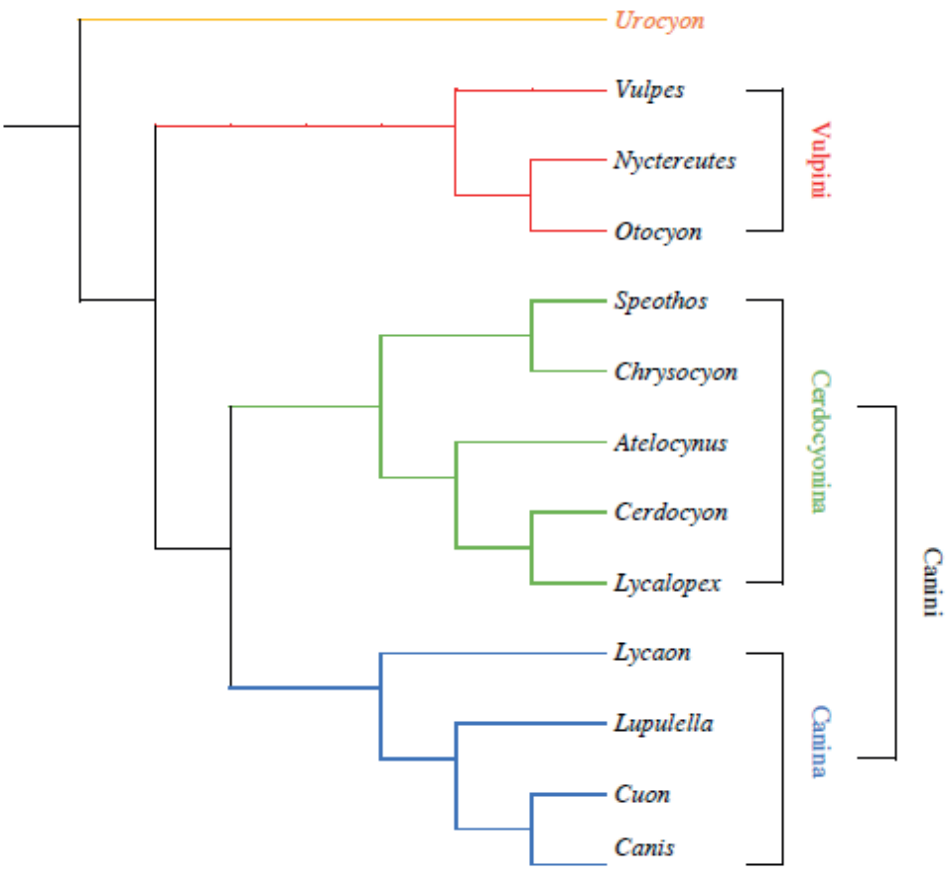

Figura 2. Filogenia dos gêneros de canídeos atuais combinando caracteres morfológicos, comportamentais, moleculares e espécies fósseis (Zrzavý et al. 2018). As cores destacam quatro agrupamentos monofiléticos reconhecidos atualmente. 


\section{Sobreposição de nicho trófico e partilha de recursos entre canídeos do Cerrado}

O nicho trófico representa o status funcional de uma espécie com base em sua posição na cadeia alimentar. Quando existe sobreposição nas dietas de diferentes espécies, a competição pode resultar na exclusão de uma delas da comunidade. No entanto, os recursos alimentares também podem ser partilhados espacial ou temporalmente entre espécies vivendo juntas em uma determinada região, reduzindo assim a competição e favorecendo a coexistência. Diferenças na utilização dos recursos entre espécies com distribuições geográficas parcialmente sobrepostas podem estar relacionadas a diferenças morfológicas ou em tamanho do corpo.

Das seis espécies de canídeos silvestres encontradas no Brasil, quatro ocorrem no Cerrado, o cachorro-do-mato-vinagre (Speothos venaticus), o lobo-guará (Chrysocyon brachyurus), o cachorro-do-mato (Cerdocyon thous) e a raposa-do-campo (Lycalopex vetulus). Com exceção do cachorro-do-mato-vinagre, que ocorre em ambiente florestal, as demais podem ocorrer juntas em ambientes antropizados, como áreas de cultivo e pastagens, e são concorrentes em potencial devido a suas preferências alimentares. Nesse contexto, um entendimento aprofundado da partição de recursos entre esses canídeos em agroecossistemas poderia auxiliar na concepção e implementação de estratégias de manejo e conservação. Para determinar como essas espécies partilham os recursos alimentares, utilizamos um conjunto de amostras fecais coletadas ao longo de sete anos em um ecótono (área de transição ambiental) desprotegido e alterado entre a savana do Cerrado e as florestas da Mata Atlântica, abordando as seguintes questões: (1) Como o tipo e a proporção de itens alimentares variam entre as espécies permitindo sua coexistência? (2) As diferenças de tamanho corporal entre os três canídeos estão relacionadas à largura do nicho alimentar e à sobreposição de nicho trófico?

$\mathrm{O}$ estudo foi realizado em fazendas de gado no município de Cumari, em Goiás. A cobertura vegetal da região era originalmente composta pelas espécies características da savana e da floresta estacional semidecidual, atualmente alteradas pelas atividades agrícolas. Quase 72\% da vegetação da área foi substituída por pastagens exóticas, para criação extensiva de gado, e pequenos e médios remanescentes da vegetação original representam aproximadamente $26 \%$ da região.

As espécies estudadas estão representadas na Figura 3. A raposa-do-campo é a menor e a mais delgada delas, com um peso médio de 3,4 kg. É uma espécie endêmica do Cerrado, mas tem se expandido a partir dos limites de sua distribuição, conforme a vegetação natural vem sendo substituída por pastagens e cultivos. Alimenta-se principalmente de insetos, complementando a dieta com pequenos vertebrados e frutos. Adaptações para uma dieta insetívora incluem dentes carnassiais pequenos, molares largos para esmagar o exoesqueleto das presas e bula auditiva excepcionalmente grande. Monogâmicos, cada casal de raposa-do-campo pode compartilhar áreas de vida de 3,8 a 4,6 $\mathrm{km}^{2}$. Produzem ninhadas de 2-5 filhotes uma vez por ano durante os meses de julho e agosto. Tocas de tatu-peba (Euphractus sexcinctus) são usadas como ninho. O casal é responsável pelo cuidado com os filhotes.

O cachorro-do-mato apresenta um porte pequeno a médio $(5-8 \mathrm{~kg})$ e é relativamente comum ao longo de toda a sua distribuição, que inclui desde regiões montanhosas e litorâneas do norte da Colômbia e Venezuela até a Argentina, passando por grande parte do Brasil. Ocupa diversos tipos de habitats, incluindo cerrado, 
caatinga, matas de galeria e áreas de cultivo. São onívoros oportunistas e sua dieta varia entre as estações do ano. Caçam individualmente, mas são vistos quase sempre em pares. O hábito frugívoro possibilita que dispersem sementes de várias espécies de plantas nativas e cultivadas. A área de vida varia entre 2,2 e 5,3 $\mathrm{km}^{2}$. Reproduzem-se uma vez por ano, os filhotes nascem no final do inverno e o casal divide o cuidado com os filhotes.

O lobo-guará é o maior canídeo da América do Sul, pesando em média $26 \mathrm{~kg}$. Inconfundível devido à pelagem alaranjada, orelhas grandes e membros alongados, que representam adaptações para caminhar em locais com capim alto. Habita campos e áreas de vegetação arbustiva na região central da América do Sul. No Brasil, ocorre nos biomas Cerrado e Pampa. Onívoros, consomem principalmente frutos e vertebrados pequenos a médios, e podem passar até 8 horas consecutivas forrageando. A frutado-lobo (Solanum lycocarpum) cresce em grande parte da sua área de distribuição e representa um recurso alimentar importante. Ao contrário das espécies menores, os lobos-guarás ocorrem em baixas densidades, são solitários e possuem áreas de vida extensas, entre 20 e $115 \mathrm{~km}^{2}$. A reprodução ocorre entre os meses de abril e junho e os nascimentos (1-5 filhotes/ninhada) entre junho e setembro.

Os três canídeos possuem hábito crepuscular-noturno e por isso não são frequentemente vistos. Porém, durante a busca por alimentos podem visitar pomares e instalações rurais, ficando expostos ao encontro com animais domésticos e o homem. Devido à crença de serem predadores de galinhas, indivíduos das três espécies são caçados ou envenenados pelos agricultores e pecuaristas. No entanto, não existe evidência de que animais de criação sejam parte importante da dieta de nenhuma delas. Outras ameaças incluem atropelamentos, confronto com cachorros domésticos e doenças adquiridas desses, como a sarna sarcóptica e a cinomose.

Os dados foram coletados de 2009 a 2015 usando três métodos complementares. Mais de $60 \%$ das amostras fecais foram coletadas diretamente dos animais durante procedimentos de captura para instalação de rádio-colares. As demais amostras foram obtidas de indivíduos monitorados durante observações do seu comportamento ou oportunisticamente, em estradas e trilhas no local do estudo. Foram coletadas 155 amostras fecais: 65 de raposas-do-campo, 60 de cachorros-do-mato e 30 de lobosguará. As amostras coletadas oportunisticamente foram identificadas por características morfológicas, como forma, tamanho, odor, conteúdo, experiência dos autores com as espécies estudadas e associação com pegadas (Figura 4). Os itens presentes em cada amostra (pelos, dentes, ossos, escamas, sementes e exoesqueletos de insetos) foram separados em seis categorias alimentares: frutos, insetos, anuros, escamados, aves e mamíferos e identificados no menor nível taxonômico possível. 

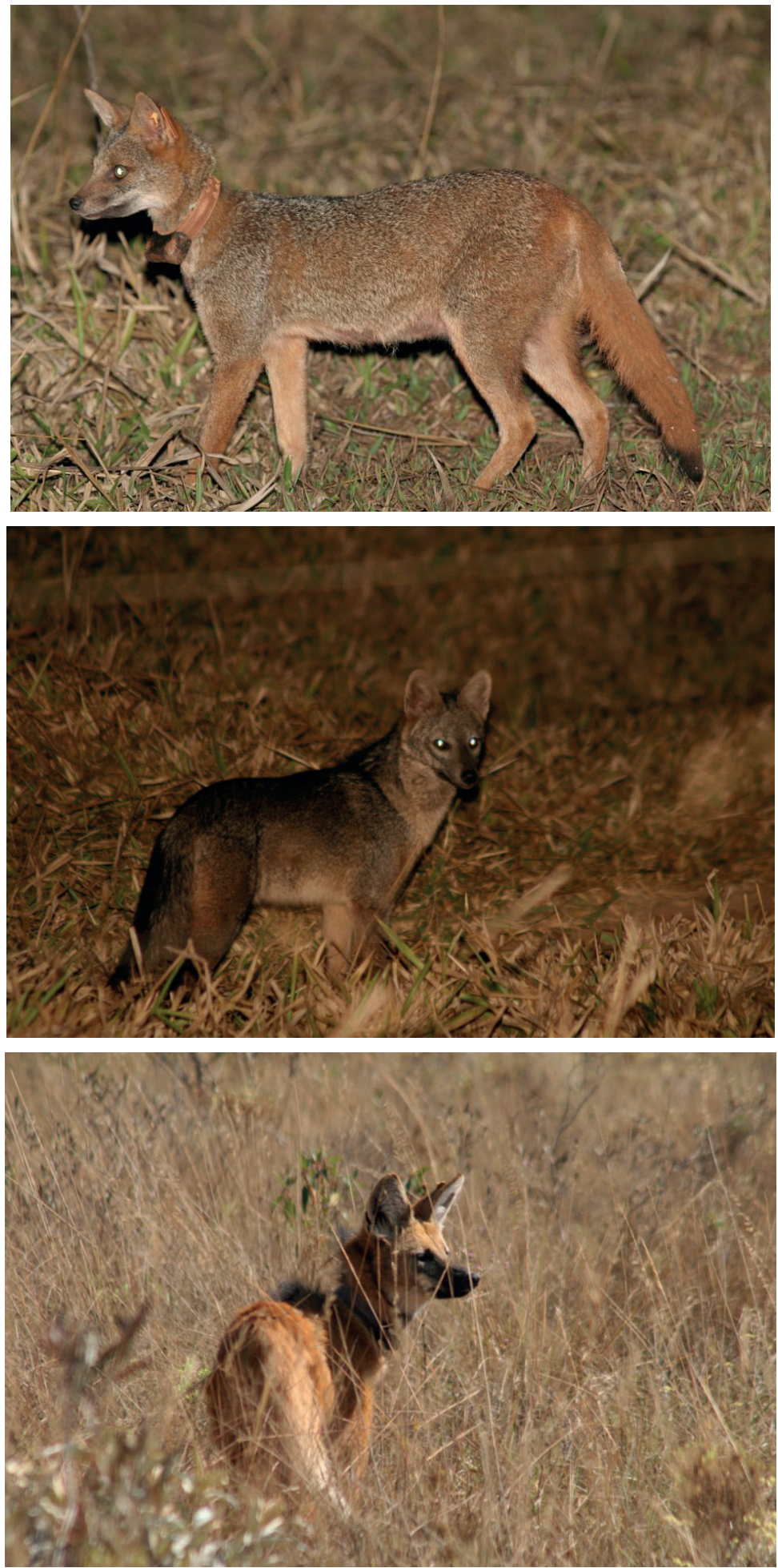

Figura 3. Raposa-do-campo (acima), cachorro-do-mato (meio) e lobo-guará (abaixo). Fotos: Frederico G. Lemos. 

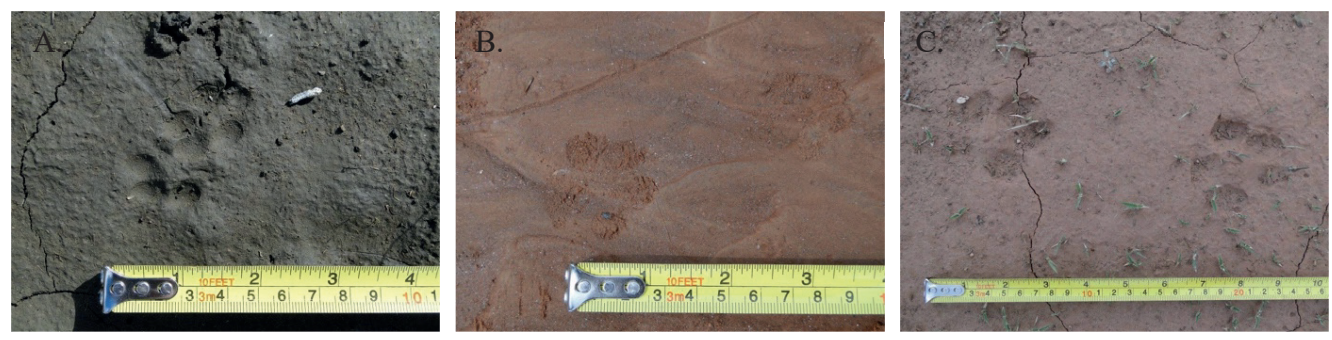

Figura 4. Pegadas de canídeos silvestres evidenciando as diferenças em tamanho. A. Raposa-do-campo; B. Cachorro-do-mato e C. Lobo-guará. Fotos: Kátia G. Facure.

Identificamos um total de 35 tipos de itens alimentares nas dietas das três espécies de canídeos, das quais 13 eram de origem vegetal, incluindo frutos de espécies cultivadas, como a goiaba (Psidium guajava), e de espécies nativas, como coquinho (Syagrus sp.) e figo (Ficus sp.), e 22 de origem animal, incluindo insetos de diversos grupos, anuros, escamados (serpentes e lagartos), aves e roedores silvestres (Cricetidae). A frequência relativa dos itens de origem animal variou de $63 \%$ para o lobo-guará e $76 \%$ para o cachorro-do-mato até $86 \%$ para a raposa-do-campo, embora vertebrados tenham sido frequentes apenas na dieta dos lobos-guarás. Insetos dos grupos Scarabaeidae (besouros escaravelhos) e Orthoptera (gafanhotos, esperanças e grilos) foram importantes para as duas espécies menores e, além desses, a raposa-docampo também consumiu frequentemente Isoptera (cupins) (Figura 5). Por outro lado, a frequência de insetos foi baixa na dieta do lobo-guará, que se alimentou principalmente de vertebrados e frutos. A fruto-do-lobo (Solanum lycocarpum) (Figura 6) foi o recurso alimentar mais importante para essa espécie, representando $22 \%$ do total de itens. A importância das principais categorias de presas diferiu entre as três espécies de canídeos (Figura 7). A raposa-do-campo apresentou maior consumo de insetos e menor consumo de frutos e vertebrados. Entre os vertebrados, as aves Passeriformes (pássaros) foram frequentes apenas na dieta do lobo-guará.
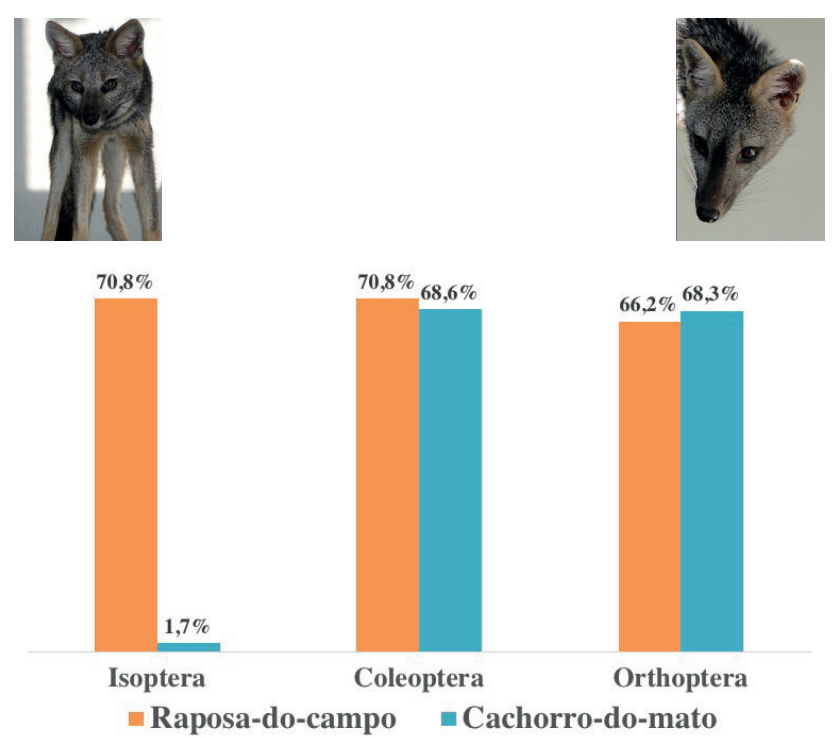

Figura 5. Porcentagem de amostras contendo os grupos de insetos consumidos pelas duas espécies de canídeos menores. Fotos: Kátia G. Facure. 


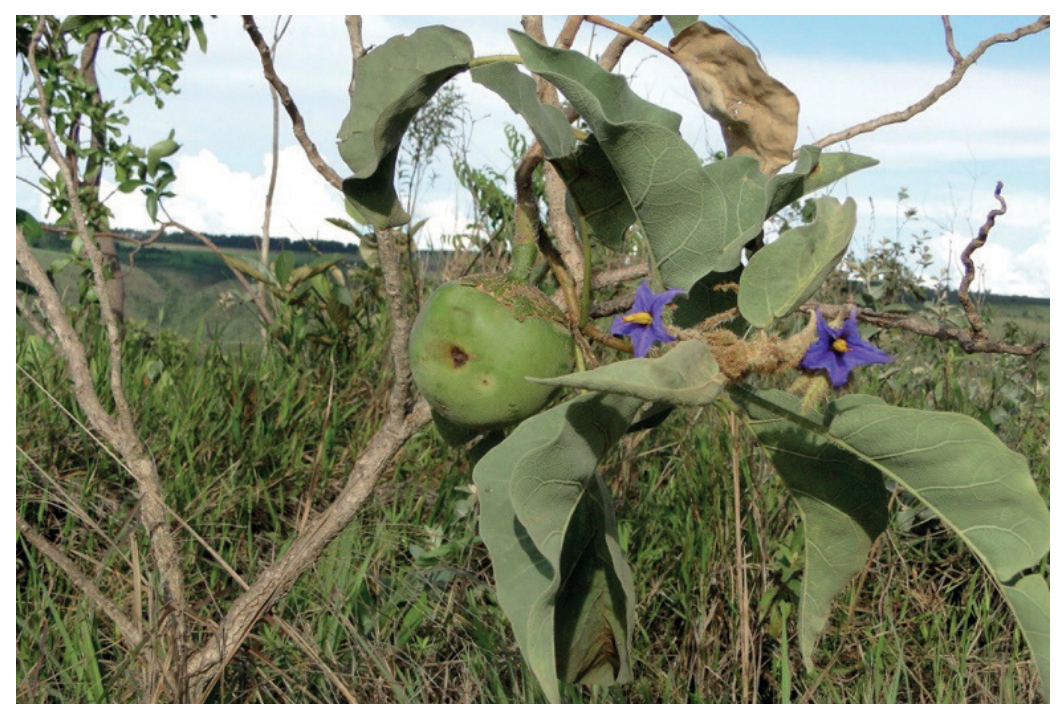

Figura 6. Fruta-do-lobo (Solanum lycocarpum), item frequente na dieta do lobo-guará. Espécie arbustiva comum no bioma Cerrado. Foto: Kátia G. Facure.
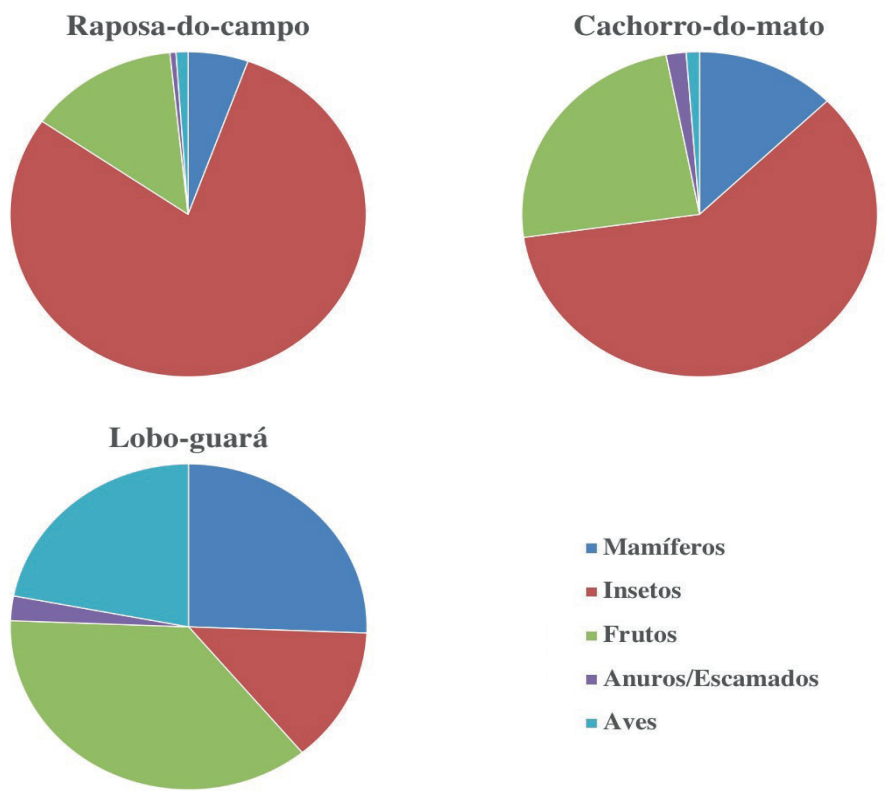

$$
\begin{aligned}
& \text { — Mamíferos } \\
& \text { - Insetos } \\
& \text { — Frutos } \\
& \text { - Anuros/Escamados } \\
& \text { " Aves }
\end{aligned}
$$

Figura 7. Importância das categorias alimentares na dieta de três espécies de canídeos silvestres em um agroecossistema no Bioma Cerrado.

A sobreposição de nicho foi muito alta entre a raposa-do-campo e o cachorrodo-mato, totalizando $66,1 \%$ para os itens alimentares e $80,8 \%$ para as categorias de alimentos; foi médio entre o cachorro-do-mato e o lobo-guará (36,5\%, para os itens e $52,8 \%$, para as categorias ), e baixa entre a raposa-do-campo e o lobo-guará para itens alimentares $(25,1 \%)$ e médio para categorias $(34,1 \%)$. Apesar da sobreposição na dieta, as três espécies ficaram bem separadas em uma análise de ordenação com base na frequência dos itens alimentares na dieta, com a raposa-do-campo mais associada aos 
cupins, os lobos-guarás, aos frutos e às aves e os cachorros-do-mato, aos ortópteros, escaravelhos, pequenos mamíferos e frutos (Figura 8).

Nossas análises indicaram que, em agroecossistemas no Bioma Cerrado, as raposas-do-campo e os cachorros-do-mato, canídeos com tamanho corporal semelhante, apresentam um nicho trófico mais restrito, consumindo principalmente insetos. As duas espécies apresentam ainda uma alta sobreposição alimentar. Por outro lado, os insetos foram menos frequentes na dieta da espécie de maior porte, o loboguará, que consumiu uma maior variedade de vertebrados e uma maior proporção de frutos, principalmente a fruta-do-lobo. Além disso, o lobo-guará foi a única espécie que frequentemente consumiu aves (frequência relativa $>20 \%$ ) e, portanto, apresentou um nicho trófico mais amplo. Cabe destacar que as aves consumidas foram identificadas como pertencentes ao grupo dos pássaros e não encontramos nenhuma evidência da predação de galinhas nem pelo lobo-guará nem pelas demais espécies.
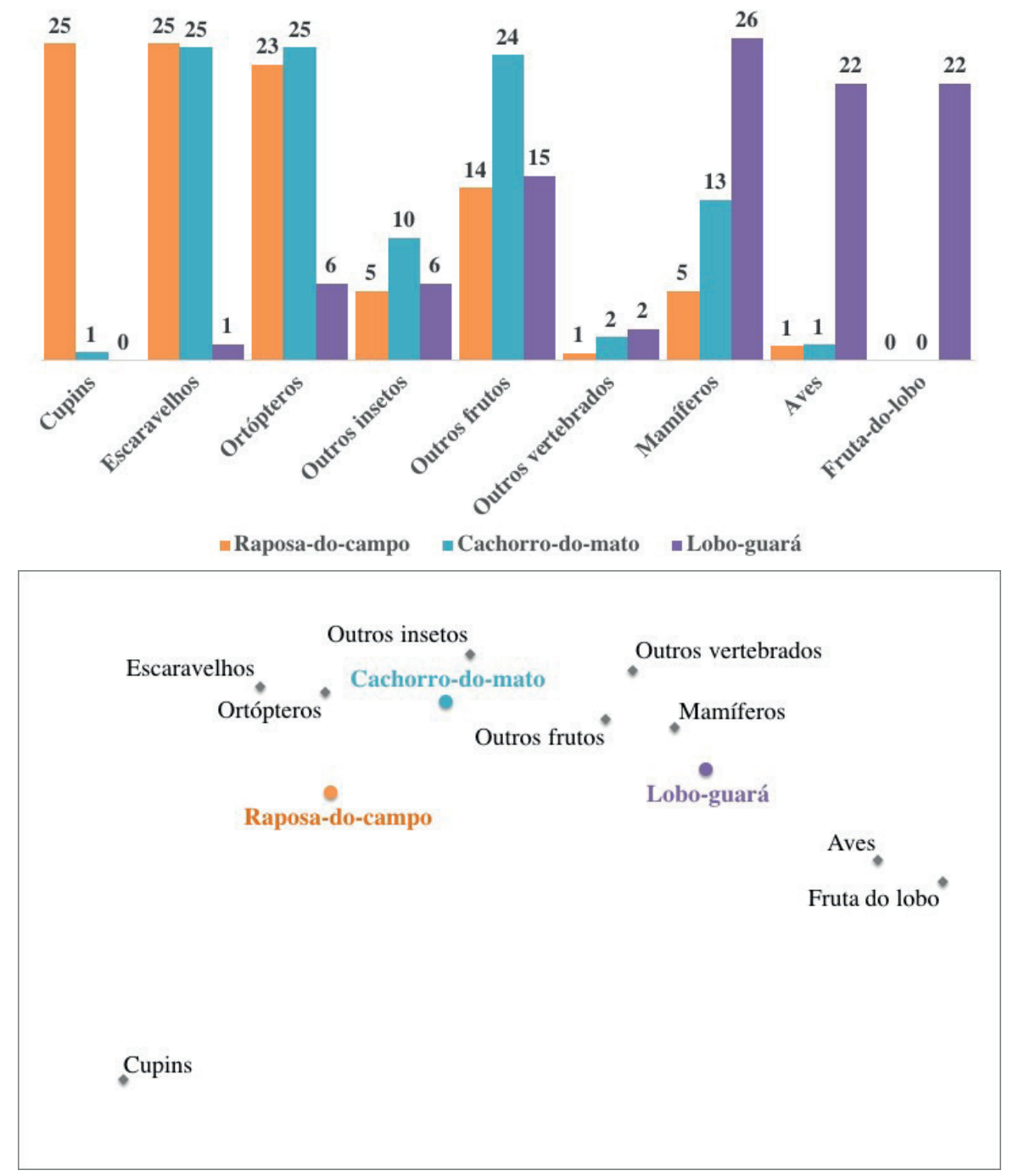

Figura 8. Ordenação das três espécies de canídeos silvestres de acordo com a utilização dos itens alimentares em uma área de agroecossistemas no bioma Cerrado. 
A preferência por cupins pelas raposas-do-campo permite que partilhem recursos alimentares e coexistam com os outros canídeos silvestres no Cerrado, como o cachorro-do-mato e o lobo-guará, que, além de não consumirem frequentemente cupins, se alimentam em maior quantidade de frutos e pequenos vertebrados. O elevado consumo de cupins pela raposa-do-campo é uma característica conhecida da espécie ao longo de sua distribuição e esses insetos são considerados sua principal fonte de proteína, caracterizando uma dieta primariamente insetívora. Por outro lado, o alto consumo de insetos pelos cachorros-do-mato pode estar relacionado a dois fatores: (1) a menor abundância de frutos em nossa área de estudo, pois estudos anteriores em outras regiões mostraram uma maior frequência de frutos em sua dieta e (2) o comportamento oportunista dos cachorros-do-mato e a disponibilidade de Orthoptera e Coleoptera em pastagens para a criação de gado. A maior amplitude de nicho alimentar do lobo-guará pode estar relacionada ao fato de terem áreas-de-vida maiores e percorrerem longas distâncias por várias horas consecutivas durante o forrageamento (busca por alimento).

\section{Parasitos intestinais de canídeos silvestres em áreas impactadas do Bioma Cerrado}

A degradação dos ambientes naturais, associada à perseguição por conflitos com pecuaristas e à alta mortalidade por atropelamentos representam as principais ameaças à conservação dos canídeos silvestres. Além dessas causas antrópicas, interações ecológicas do tipo consumidor-recurso (por exemplo, predação e parasitismo) podem influenciar negativamente a densidade de suas populações. Ambientes alterados favorecem o contato da fauna nativa com animais domésticos, levando ao aparecimento de doenças que não circulavam no meio silvestre. Dentre as doenças que podem impactar de forma direta os canídeos silvestres estão as endoparasitoses, que são morbidades causadas por parasitos intestinais e que podem estar relacionadas à fatores intrínsecos, como susceptibilidade do hospedeiro, e extrínsecos, como sazonalidade climática e características do habitat. Indivíduos jovens podem ser mais suscetíveis à contaminação, devido ao sistema imunológico ainda em desenvolvimento, e o acometimento de parasitoses nessa fase pode se tornar um obstáculo para que alcancem a idade reprodutiva, comprometendo o crescimento populacional.

Um trabalho in loco foi realizado para conhecer a diversidade de parasitos intestinais que circulam nos canídeos silvestres, na região do Pontal do Triângulo Mineiro, a partir da análise parasitológica de fezes. As amostras fecais foram coletadas em trilhas e estradas de terra (Figura 9) inseridas em áreas rurais do município de Ituiutaba, MG. A vegetação original é representada pelas fitofisionomias típicas de cerrado sensu stricto, impactadas com o crescente avanço da monocultura de cana-deaçúcar e da criação de animais de produção. As modificações antrópicas nestes locais favorecem a presença de canídeos silvestres, que saem de seus habitats para procurar alimento em áreas peridomiciliares. 


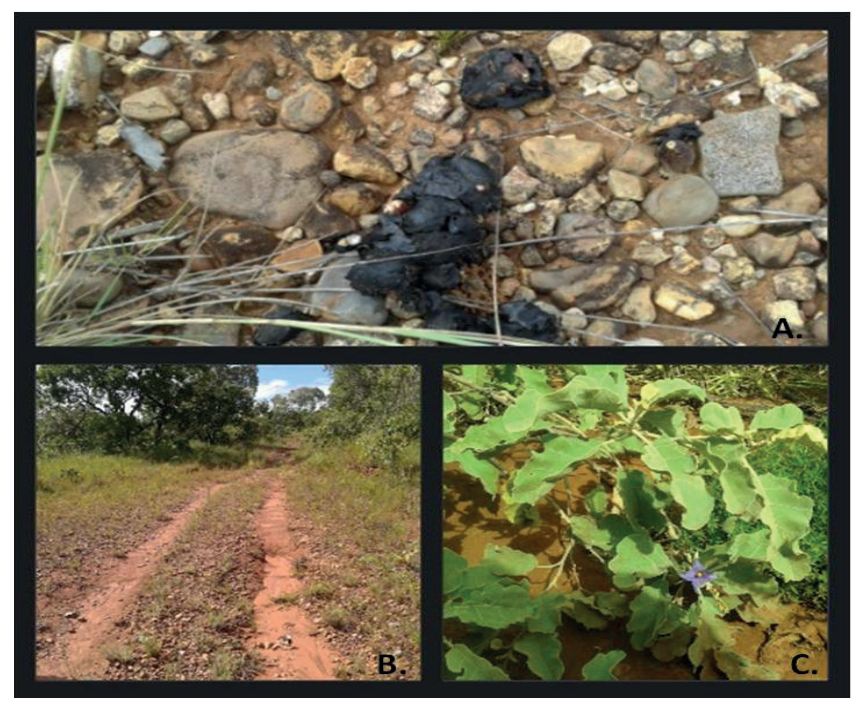

Figura 9. Área antropizada na Serra das Três Cruzes e na Serra do Corpo Seco, Ituiutaba, Minas Gerais. A. Amostra de fezes de canídeo coletada na Serra das Três Cruzes. B. Trilha percorrida durante a coleta do material biológico na Serra do Corpo Seco. C. Presença da espécie arbustiva Solanum lycocarpum, conhecida como fruta-do-lobo, na Serra das Três Cruzes. Fotos: Talita A. Silva.

A identificação da espécie que depositou as fezes foi realizada na área da coleta, através do encontro de pegadas, ou no laboratório, considerando características morfológicas (tamanho e forma), conteúdo das amostras e presença de pelos ingeridos durante a auto-limpeza. Foram coletadas 44 amostras de fezes, sendo 33 de cachorrodo-mato e 11 de lobo-guará, em áreas de fazendas de gado, entre janeiro e dezembro de 2013. Para conhecer a influência da sazonalidade climática sobre a prevalência de endoparasitas, 17 amostras adicionais de lobo-guará foram coletadas em plantações de cana-de-açúcar, durante a primavera de 2018 e no outono de 2019.

$\mathrm{Na}$ coleta de 2013, foram identificadas formas parasitárias pertencentes a nove táxons (Figura 10). A presença de protozoários Coccidia nas amostras de fezes do loboguará e do cachorro-do-mato pode estar relacionada ao processo de ingestão de oocistos esporulados no solo, contaminado por fezes de animais infectados, ou pela ingestão de carne de ruminantes ou roedores previamente infectados. É possível que animais de produção como o gado, presentes na área, também estejam infectados por coccídeos, mantendo o ciclo de infecção para os animais silvestres. Outro fator importante está relacionado ao hábito alimentar oportunista e generalista dos dois canídeos, que, por meio da ingestão de insetos e pequenos roedores, podem se contaminar, conforme evidenciado pelo encontro de ovos e larvas de helmintos em suas fezes. Ressalta-se que muitos parasitos são heteroxênicos, ou seja, possuem ao menos dois hospedeiros participando de seu ciclo de vida. Deste modo, artrópodes e roedores se tornam peças importantes para a continuidade do ciclo e participação da cadeia de transmissão do agente etiológico.

A sazonalidade climática da região do Bioma Cerrado, com uma época seca bem definida nos meses de outono e inverno pode influenciar tanto a dieta dos canídeos silvestres quanto a prevalência de endoparasitas. A análise das 17 amostras fecais de loboguará coletadas na área de monocultura de cana-de-açúcar em diferentes épocas do ano possibilitou a observação de formas evolutivas de diferentes grupos de parasitos (Figura 11). 
Os parasitas intestinais Spirometra sp., Trichuridae, Spirocerca sp. e Hymenolepis sp. foram encontrados apenas nas amostras dos meses mais quentes e úmidos, que correspondem à primavera e verão. É possível que uma temperatura e umidade adequadas favoreçam a reprodução e sobrevivência das formas parasitárias no ambiente. Sendo assim, as infecções se tornam mais abrangentes na primavera e verão, pois existe uma maior variabilidade e quantidade de parasitas. No outono e inverno, quando o clima está seco, pode haver uma queda nas taxas de parasitismo em virtude da maior mortalidade das formas parasitárias por dissecação.

Lobo-Guará (Chrysocyon brachyurus)

Cachorro-do-mato (Cerdocyon thous)

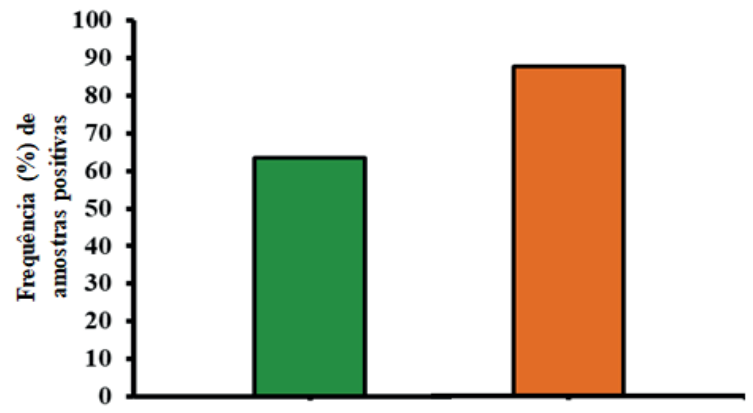

\begin{tabular}{lllcl} 
Parasito & N & $\%$ & N & $\%$ \\
\hline Coccidia & 1 & 9,09 & 10 & 30,30 \\
Spirometra sp & 2 & 18,18 & 7 & 21,21 \\
Hymenolepis sp & 1 & 9,09 & 8 & 24,24 \\
Strongyloides sp & 1 & 9,09 & 0 & 0 \\
Anoplocephalidae & 0 & 0 & 2 & 6,06 \\
Physaloptera sp & 0 & 0 & 1 & 3,03 \\
Larvas do filo Nematoda & 1 & 9,09 & 0 & 0 \\
Toxocara sp & 1 & 9,09 & 0 & 0 \\
Taeniidae & 0 & 0 & 1 & 3,03 \\
\hline
\end{tabular}

Figura 10. Frequência de parasitos intestinais encontrados na análise parasitológica de amostras fecais de canídeos silvestres em áreas de pastagens e criação de gado no Pontal do Triângulo Mineiro.
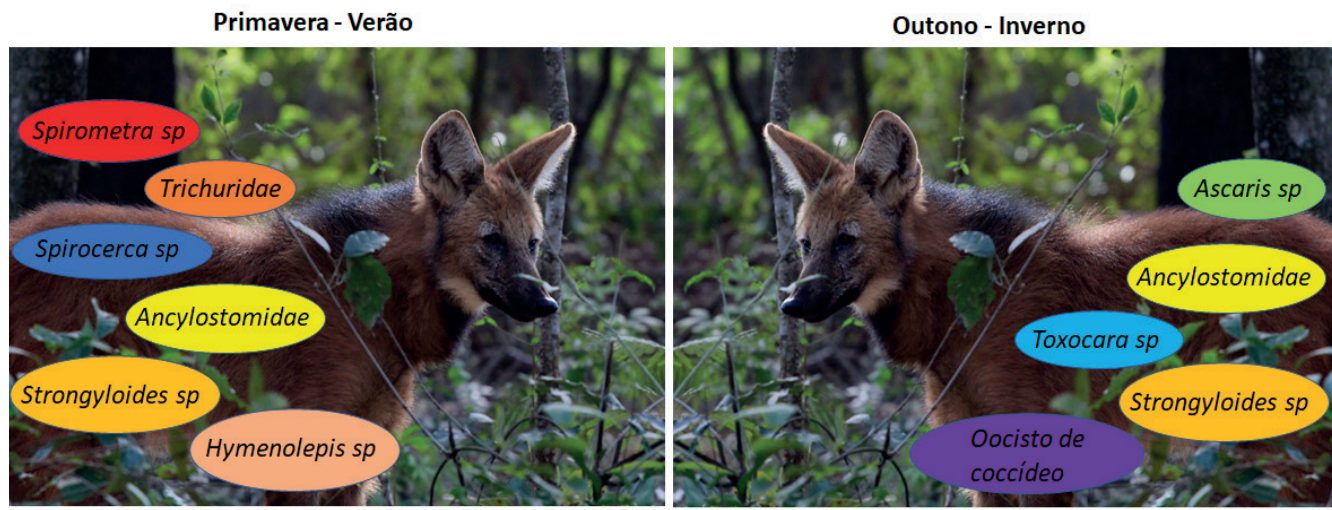

Figura 11. Grupos de parasitos intestinais encontrados na análise parasitológica de amostras fecais de lobo-guará coletadas em diferentes épocas do ano em áreas de monocultura da cana-de-açucar no Pontal do Triângulo. Fotos: Kátia G. Facure. 
A Figura 12 ilustra algumas formas evolutivas de parasitos intestinais encontradas nas fezes dos canídeos silvestres estudados. A presença de diferentes parasitos intestinais nestas amostras de fezes estárelacionado à dinâmica do ciclo de transmissão de parasitoses entre humanos, animais domésticos e animais silvestres resultando na contaminação do ambiente e contribuindo com o fluxo das doenças no meio silvestre e rural.

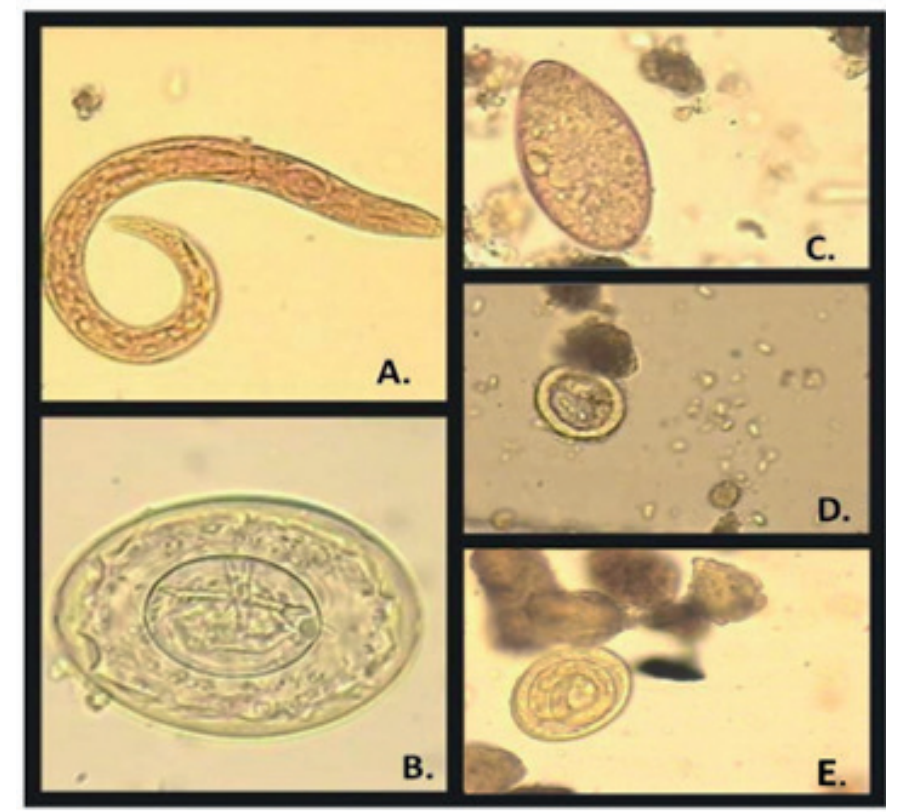

Figura 12. Formas parasitárias encontradas na análise parasitológica de amostras fecais de cachorro-domato e de lobo-guará coletadas em áreas antropizadas no Pontal do Triângulo Mineiro. A. Larva do Filo Nematoda. B. Ovo do gênero Hymenolepis. C. Ovo do gênero Spirometra. D. Oocisto de Coccideo. E. Ovo larvado de Strongiloydes. Aumento 400x. Fotos: Talita A. Silva.

\section{Implicações para a conservação de canídeos no Cerrado}

Embora a importância dos canídeos na manutenção da estrutura da comunidade seja bem conhecida, seja através de efeitos nas populações de presas ou na dispersão de sementes, o tamanho e o número de suas populações têm sido acentuadamente reduzidos nas últimas décadas. Perda e fragmentação de habitat, atropelamentos e danos causados por interações diretas e indiretas com cães domésticos são os principais efeitos antrópicos que ameaçam os canídeos silvestres no Brasil. De fato, tanto a raposa-do-campo como o lobo-guará são considerados "Vulneráveis" de acordo com a Lista Nacional Oficial de Espécies da Fauna Ameaçada de Extinção (ICMBio 2014), enquanto o status do cachorro-do-mato é considerado "Menos Preocupante". No entanto, ainda existem grandes lacunas no conhecimento sobre a ecologia dessas espécies, dificultando a avaliação de seu risco de extinção.

Nossos resultados sobre ecologia alimentar indicam que, apesar das três espécies conseguirem ocupar ambientes modificados pelo homem, seus ajustes forçados a essas condições podem levar à redução da diversidade da dieta e, consequentemente, aumento da sobreposição no uso dos recursos, potencialmente levando à exclusão competitiva. Nesse contexto, sugerimos que, para a perpetuidade de canídeos silvestres 
em agroecossistemas no Cerrado, é importante manter uma oferta diversificada de alimentos, como frutos cultivados e silvestres, e evitar o uso indiscriminado de pesticidas, uma vez que cupins e pequenos roedores são presas importantes para as espécies estudadas.

Os dados sobre parasitoses intestinais são de grande importância epidemiológica e de saúde pública, considerando a frequente aproximação do meio rural com o meio urbano e as áreas de pastagens e monoculturas de cana-de-açúcar, que adentram o habitat natural dos canídeos silvestres. A identificação desses parasitos e o conhecimento da ação que o meio externo tem sobre eles como, por exemplo, a influência do clima, cobertura vegetal e hábito alimentar do hospedeiro, podem auxiliar no estabelecimento de medidas de controle, evitando a proliferação de doenças entre animais domésticos e silvestres.

\section{Para saber mais}

Castelló JR (2018) Canids of the World: Wolves, Wild Dogs, Foxes, Jackals, Coyotes, and Their Relatives. Princeton University Press, Princeton (NJ)

ICMBio 2014. Listas das Espécies da Fauna Brasileira Ameaçadas de Extinção (Portarias MMA 444/2014 e 445/2014). Instituto Chico Mendes de Conservação da Biodiversidade, Brasil. doi: 10.5585/rdb.v14i6.444

Kotviski BM, Facure KG, Azevedo FC, Freitas Jr MC, Lemos FG (2019). Trophic niche overlap and resource partitioning among wild canids in an anthropized neotropical ecotone. Mastozool Neotrop 26:368-376 doi: 10.31687/saremMN.19.26.2.0.29

Lemos FG (2016) Ecologia e conservação da raposa-do-campo (Lycalopex vetulus) e interações com canídeos simpátricos em áreas antropizadas do Brasil Central. $168 \mathrm{f}$. Tese (Doutorado em Ecologia e Conservação de Recursos Naturais) - Universidade Federal de Uberlândia, Uberlândia. Disponível em: http://dx.doi.org/1014393/ufu. te. 2019.1207

Sillero-Zubiri C, Hoffmann M., Macdonald DW (2004). Canids: Foxes, Wolves, Jackals and Dogs: Status Survey and Conservation Action Plan. IUCN/SSC Canid Specialist Group, IUCN, Gland, Switzerland and Cambridge, UK.

Wang X, Tedford RH, Antón M (2008) Dogs: Their Fossil Relatives and Evolutionary History. Columbia University Press, New York (NY) ISBN: 9780231135283

Zrzavý J, Duda P, Robovský J, Okřinová I, Pavelková Řičánková V (2018) Phylogeny of the Caninae (Carnivora): Combining morphology, behaviour, genes and fossils. Zool Scr. 47:373-389 doi: 10.1111/zsc. 12293 



\title{
CAPÍTULO 5
}

\section{OS MAMÍFEROS DE MÉDIO E GRANDE PORTE DO PARQUE ESTADUAL DO PAU FURADO}

\author{
Natália M.Tôrres \\ Letícia Benavalli \\ Luma A. Lopes \\ Vitor A. Egêa
}

Os mamíferos pertencem a uma Classe denominada Mammalia, definida dentro do reino animal por uma série de características, algumas exclusivas (como as glândulas mamárias) e outras compartilhadas com outros grupos de animais. Entre esses animais, existe uma variação enorme de tamanho do corpo, hábitos de vida e preferências de hábitat, sendo que mamíferos de médio e grande porte são aqueles cuja massa corporal de um indivíduo adulto é maior que um quilograma. A maioria destes mamíferos tem hábito noturno, o que torna muito difícil sua observação na natureza, sendo os vestígios por eles deixados, muitas vezes, os meios mais eficazes para notar sua presença. Constantemente observamos suas pegadas, fezes ou tocas ao longo de estradas e trilhas, sendo que os cheiros deixados também testemunham sua passagem pelos locais onde vivem. Estes sinais são importantes indicadores da presença dessas espécies nos ambientes e podem ser usados para a condução de estudos científicos.

Em geral, os mamíferos são considerados seres carismáticos, despertando grande interesse nas pessoas, devido à sua diversidade, beleza, utilidade, ou problemas que podem causar. Por ocuparem tanta variedade de ambientes e nichos, as espécies desse grupo são de reconhecida importância em uma série de processos nos ecossistemas em que ocorrem. Os carnívoros, por exemplo, desempenham importante função ecológica nos diversos habitats em que vivem, diretamente através do controle de populações das espécies de presas, e indiretamente na manutenção da diversidade e abundância de espécies vegetais. Predadores como a onça-pintada, a onça-parda e o lobo-guará são solitários, territoriais e necessitam de extensas áreas de vida e uma alta abundância de presas naturais para se manterem, reproduzirem e dispersarem. Já as espécies frugívoras ou herbívoras, tais como veados, alguns roedores, queixadas, catetos e antas, são importantes para a manutenção da diversidade de plantas, pois atuam na dispersão de sementes e predação de plântulas.

O Cerrado é reconhecido pela sua biodiversidade e, para os mamíferos de médio e grande porte, são descritas cerca de 50 espécies, sendo 18 listadas como ameaçadas de extinção e quatro endêmicas, ou seja, que ocorrem apenas neste bioma. Especificamente no Triângulo Mineiro, esses animais vivem nas diferentes paisagens naturais que formam essa região, alguns preferem os ambientes de matas, como a jaguatirica, enquanto outros preferem áreas mais abertas, como a raposa-do-campo. Como as paisagens naturais vêm sendo amplamente modificadas, principalmente para a produção de soja e cana-de-açúcar, é mais comum que se encontrem animais onívoros próximo às lavouras. Isso ocorre pois suas dietas são mais flexíveis, o que acaba favorecendo a sobrevivência nesses locais. Por outro lado, os carnívoros enfrentam a diminuição do tamanho de suas populações, podendo ser extintos localmente. 
A perda de hábitats naturais é um dos maiores problemas que os mamíferos de médio e grande porte enfrentam. Quando isso ocorre, eles encontram dificuldades em conseguir alimento para si e seus filhotes, além de não terem um local seguro para se proteger e se reproduzir. Ao se deslocarem em busca de novos locais para sua sobrevivência, eles acabam se deparando com rodovias e estradas, onde muitas vezes são atropelados e mortos, podendo causar graves acidentes aos motoristas durante a colisão. Espécies como o lobo-guará, cachorro-do-mato, tatu-peba, tatu-galinha, tamanduábandeira, jaritatacas e gambás são frequentemente avistadas mortas nessas vias.

$\mathrm{O}$ conhecimento sobre a distribuição da fauna em uma determinada área é fundamental para se conduzir um programa de preservação de espécies ou de conservação da natureza. Entretanto, estudos abordando a distribuição geográfica de mamíferos no Cerrado são fragmentários e pouco conclusivos devido às dificuldades de execução de levantamentos faunísticos sistemáticos. Em função disto, estamos conduzindo um inventário detalhado dos mamíferos de médio e grande porte do Parque Estadual do Pau Furado (PEPF). Essa unidade de conservação possui 2.187 hectares e está localizada entre os municípios de Araguari e Uberlândia, no Triângulo Mineiro, uma das regiões de Minas Gerais que mais tem sofrido com o desmatamento. O PEPF protege diversas fisionomias vegetais, como florestas de galeria, estacional decidual e semidecidual, cerradão e cerrado stricto sensu.

\section{Metodologias aplicadas}

Utilizamos armadilhas fotográficas (Figura 1), cuja principal vantagem é a de permitir a determinação acurada da presença de espécies (inclusive as crípticas, de difícil visualização), assim como a possibilidade de avaliação da idade e sexo dos indivíduos fotografados. Esta metodologia, quando adotada em estudos de longo prazo, permite ainda avaliar a estrutura e a abundância relativa e absoluta das populações. Em especial para o monitoramento de mamíferos de médio e grande porte, este método tem sido utilizado com sucesso.

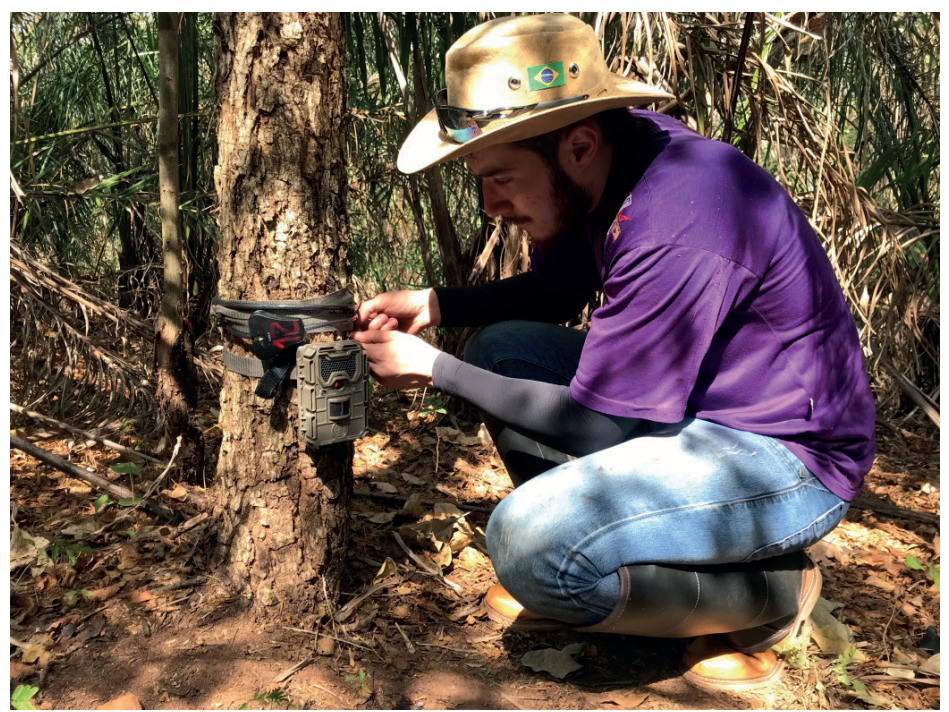

Figura 1. Instalação de uma das armadilhas fotográficas no Parque Estadual do Pau Furado, em julho de 2019. 
A máquina fotográfica fica acoplada a um sistema capaz de detectar calor corporal irradiado e movimentos. Quando um animal passa em frente à armadilha, ocorre o disparo da máquina e o registro do indivíduo (no formato de foto e vídeo). O datador registra o dia e a hora de cada registro, sendo que neste estudo as armadilhas foram programadas para funcionar 24 horas por dia, com um período de trava entre registros consecutivos de cinco minutos. Isso evita que sequências de registros de um mesmo grupo, por exemplo, saturem os cartões de memória e gastem desnecessariamente as pilhas. Após uma avaliação prévia de aspectos da geografia, formação vegetal e acessos dentro do Parque Estadual do Pau Furado, foram estipulados locais para a instalação das armadilhas fotográficas. Em julho de 2019, foi realizada a instalação de 13 armadilhas (Figura 2), dispostas a uma distância mínima de $1500 \mathrm{~m}$, em diferentes tipos de formações vegetais. A seleção dos pontos foi feita seguindo sinais da presença dos animais, tais como rastros, fezes, trilhas e intersecções de trilhas, sempre utilizando árvores para fixação das mesmas, a uma altura de cerca de $40 \mathrm{~cm}$ do solo. A fim de aumentar as chances de registro das espécies, utilizamos banana e bacon como isca. As armadilhas ficaram instaladas por quatro meses, sendo revisadas a cada 21 dias aproximadamente.

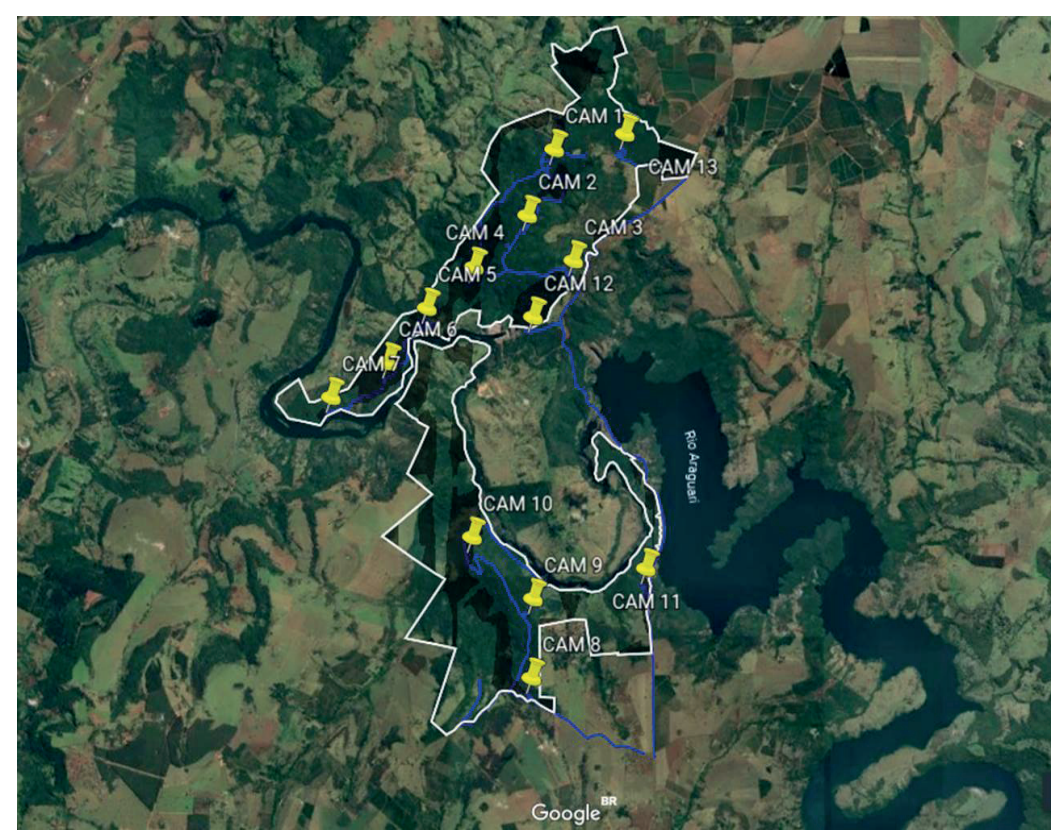

Figura 2. Imagem de satélite (Google Earth) com a localização das 13 armadilhas fotográficas (marcadores amarelos) instaladas ao longo do Parque Estadual do Pau Furado (limites em branco) e principais percursos percorridos pela equipe (em azul).

Também foram realizadas entrevistas com moradores do entorno do Parque a fim de complementar as informações obtidas por meio das armadilhas fotográficas (Figura 3). A entrevista com moradores locais é um método fácil e com resultados bastante satisfatórios, considerando o grupo de estudo em questão (mamíferos de médio e grande porte). Entrevistar moradores de uma região sobre a ocorrência da fauna nativa requer pelo menos três considerações básicas com relação ao perfil do entrevistado: a) considerar apenas informações depessoas que residem no local há um tempo mínimo suficiente para a familiarização com as espécies da região (um ano, por exemplo); 
b) certificar de que as atividades do entrevistado permitam a convivência mínima necessária com a fauna e seu ambiente (ou com pessoas diretamente ligadas a ela) ao ponto de gerar as informações de interesse; c) certificar de que o entrevistado não possui residência temporária ou que visite outros biomas freqüentemente, levando à confusão de localidades de ocorrência das espécies relatadas. Essas entrevistas foram feitas de forma semi-estruturada, oferecendo ao entrevistado a chance de descrever livremente as espécies de mamíferos de que tem conhecimento.

Como resultado dessas entrevistas e do inventário com armadilhas fotográficas, registramos 21 espécies no PEPF, sendo as mais abundantes o gambá, o quati e o tatugalinha (Tabela 1). Com relação ao nível de ameaça, $76,2 \%$ das espécies enquadram-se na categoria "Menos Preocupante", 19,0\% na categoria "Vulnerável" enquanto 4,8\% não têm dados suficientes para serem avaliadas.

Tabela 1. Lista de espécies de mamíferos de médio e grande porte registradas no Parque Estadual do Pau Furado. As categorias de ameaça incluem: dados insuficientes para avaliação (DD), Menos Preocupante (LC), Vulnerável (VU) e Quase Ameaçada (NT).

\begin{tabular}{|c|c|c|c|c|c|}
\hline Ordem & Família & Espécie & $\begin{array}{l}\text { Nome } \\
\text { popular }\end{array}$ & $\begin{array}{l}\text { Abundância } \\
\text { Relativa }\end{array}$ & $\begin{array}{l}\text { Categoria } \\
\text { de Ameaça } \\
\text { no Brasil* }\end{array}$ \\
\hline \multirow{4}{*}{ Artiodactyla } & \multirow{2}{*}{ Cervidae } & $\begin{array}{l}\text { Mazama } \\
\text { americana }\end{array}$ & $\begin{array}{l}\text { Veado- } \\
\text { mateiro }\end{array}$ & 1,38 & DD \\
\hline & & $\begin{array}{l}\text { Mazama } \\
\text { gouazoubira }\end{array}$ & $\begin{array}{l}\text { Veado- } \\
\text { catingueiro }\end{array}$ & 14,49 & $\mathrm{LC}$ \\
\hline & Tayassuidae & Pecari tajacu & $\begin{array}{l}\text { Cateto / } \\
\text { caititu }\end{array}$ & 22,8 & $\mathrm{LC}$ \\
\hline & Suidae & Sus scrofa & Javali & 1,38 & $\mathrm{LC}^{\#}$ \\
\hline \multirow{8}{*}{ Carnivora } & \multirow{2}{*}{ Canidae } & $\begin{array}{l}\text { Cerdocyon } \\
\text { thous }\end{array}$ & $\begin{array}{l}\text { Cachorro- } \\
\text { do-mato }\end{array}$ & 2,76 & $\mathrm{LC}$ \\
\hline & & $\begin{array}{l}\text { Chrysocyon } \\
\text { brachyurus }\end{array}$ & Lobo-guará & 3,45 & VU \\
\hline & \multirow{3}{*}{ Felidae } & $\begin{array}{l}\text { Leopardus } \\
\text { pardalis }\end{array}$ & Jaguatirica & 4,14 & $\mathrm{LC}$ \\
\hline & & Puma concolor & Onça-parda & 2,76 & VU \\
\hline & & $\begin{array}{l}\text { Puma } \\
\text { yagouaroundi }\end{array}$ & $\begin{array}{l}\text { Gato- } \\
\text { mourisco }\end{array}$ & 0,69 & VU \\
\hline & Mustelidae & Eira barbara & $\begin{array}{l}\text { Irara / Papa- } \\
\text { mel }\end{array}$ & 13,8 & $\mathrm{LC}$ \\
\hline & \multirow[b]{2}{*}{ Procyonidae } & Nasua nasua & Quati & 88,68 & $\mathrm{LC}$ \\
\hline & & $\begin{array}{l}\text { Procyon } \\
\text { cancrivorus }\end{array}$ & Mão-pelada & 7,59 & $\mathrm{LC}$ \\
\hline \multirow{2}{*}{ Cingulata } & \multirow{2}{*}{ Dasypodidae } & $\begin{array}{l}\text { Dasypus } \\
\text { novemcinctus }\end{array}$ & Tatu-galinha & 58,62 & $\mathrm{LC}$ \\
\hline & & $\begin{array}{l}\text { Euphractus } \\
\text { sexcinctus }\end{array}$ & Tatu-peba & 8,28 & $\mathrm{LC}$ \\
\hline Didelphimorphia & Didelphidae & $\begin{array}{l}\text { Didelphis } \\
\text { albiventris }\end{array}$ & Gambá & 166,2 & $\mathrm{LC}$ \\
\hline
\end{tabular}




\begin{tabular}{|c|c|c|c|c|c|}
\hline \multirow{2}{*}{ Pilosa } & \multirow{2}{*}{ Myrmecophagidae } & $\begin{array}{l}\text { Myrmecophaga } \\
\text { tridactyla }\end{array}$ & $\begin{array}{l}\text { Tamanduá- } \\
\text { bandeira }\end{array}$ & 30,35 & VU \\
\hline & & $\begin{array}{l}\text { Tamandua } \\
\text { tetradactyla }\end{array}$ & $\begin{array}{l}\text { Tamanduá- } \\
\text { mirim }\end{array}$ & 5,52 & LC \\
\hline Primates & Cebidae & $\begin{array}{l}\text { Sapajus } \\
\text { libidinosus }\end{array}$ & $\begin{array}{l}\text { Macaco- } \\
\text { prego }\end{array}$ & 2,07 & NT \\
\hline \multirow{3}{*}{ Rodentia } & Cuniculidae & Cuniculus paca & Paca & 2,76 & LC \\
\hline & Erethizontidae & $\begin{array}{l}\text { Coendou } \\
\text { prehensilis }\end{array}$ & $\begin{array}{l}\text { Ouriço- } \\
\text { cacheiro }\end{array}$ & 1,38 & LC \\
\hline & Hydrochoerus & $\begin{array}{l}\text { Hydrochoerus } \\
\text { hydrochaeris }\end{array}$ & Capivara & 0,69 & LC \\
\hline
\end{tabular}

*Categoria de Ameaça no Brasil, segundo o Livro Vermelho de Espécies Ameaçadas (2018).

\# Espécie exótica, considerada como menos preocupante pela IUCN (União Internacional para a Conservação da Natureza).

Registros fotográficos de mamíferos do Parque Estadual do Pau Furado

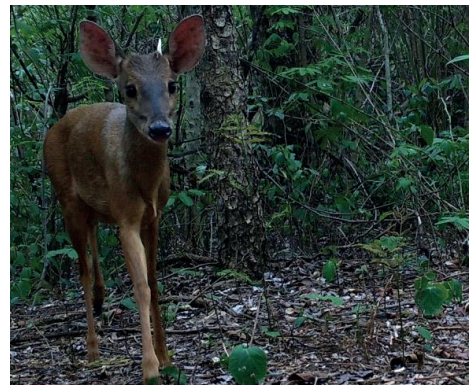

Veado-catingueiro (Mazama gouazoubira)

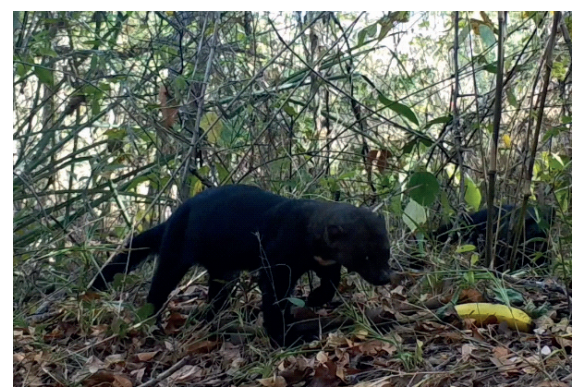

Irara (Eira barbara)

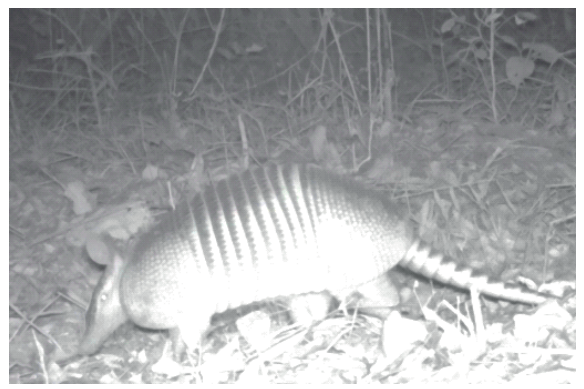

Tatu-galinha (Dasypus novemcinctus)

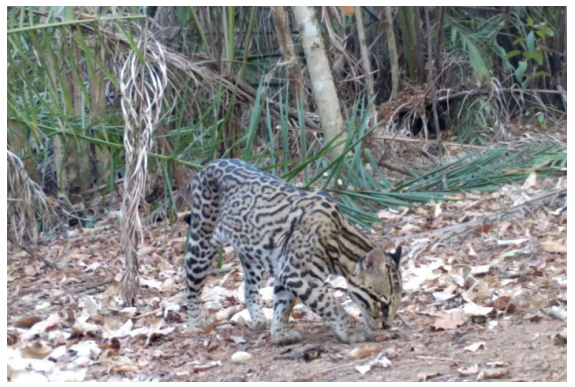

Jaguatirica (Leopardus pardalis)

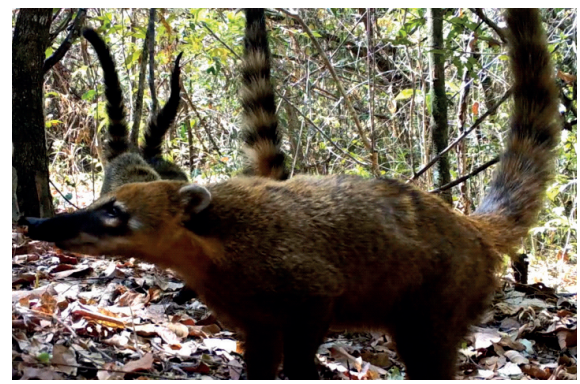

Quati (Nasua nasua)

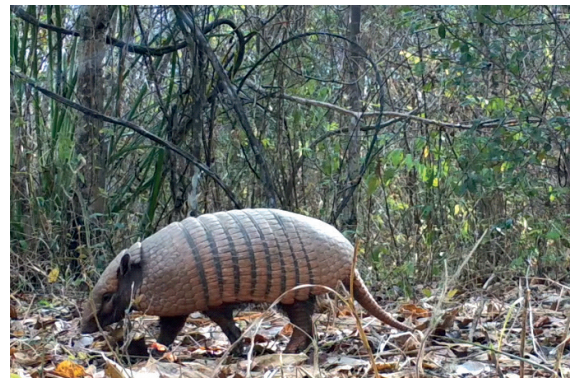

Tatu-peba (Euphractus sexcinctus) 


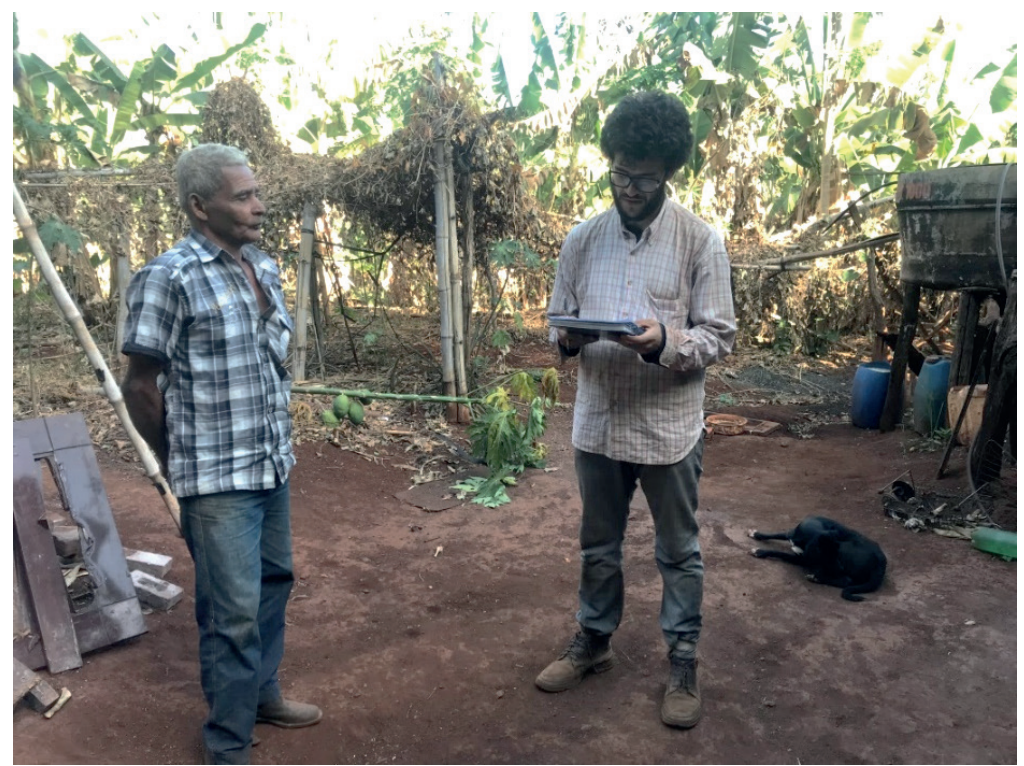

Figura 3. Entrevista realizada com um dos moradores do entorno do Parque Estadual do Pau Furado, a respeito dos mamíferos que ele conhece da região.

\section{Espécies ameaçadas}

De acordo com o Livro Vermelho de Espécies Ameaçadas, dentre os mamíferos de médio e grande porte registrados no Parque Estadual do Pau Furado, quatro são considerados como vulneráveis à extinção. Abaixo, seguem algumas informações relevantes sobre essas espécies.

A onça-parda, também conhecida como suçuarana (Puma concolor), é um felino de grande porte que se alimenta de uma grande variedade de presas, incluindo aves, répteis, pequenos mamíferos e espécies maiores, como capivaras, tamanduás e veados. Tal flexibilidade alimentar é atribuída à habilidade de viver em diferentes ambientes, possibilitando a capacidade de se adaptar aos mais diversos habitats. Apesar de ser amplamente distribuída em todos os biomas do Brasil (Figura 4), em alguns locais as populações de onças-pardas são reduzidas ou, até mesmo, extintas localmente, como no litoral sul maranhense ou na porção leste do estado da Bahia. As principais ameaças responsáveis pelo declínio populacional dessa espécie são a perda e fragmentação de habitat, atropelamentos e o conflito com humanos devido à retaliação pelo prejuízo que causam a criações domésticas.

O gato-mourisco ou jaguarundi (Puma yagouaroundi) alimenta-se de artrópodes, cobras, anfíbios e roedores, podendo eventualmente predar mamíferos maiores, como os gambás. Os indivíduos dessa espécie podem percorrer grandes distâncias em um dia, o que permite que suas áreas de vida variem entre cerca de seis e $18 \mathrm{~km}^{2}$. Habitam ambientes mais abertos, como cerrado, mas também podem ser encontrados em florestas. Apesar da ampla distribuição em todo território brasileiro (Figura 4), ocorrem em baixas densidades populacionais, sendo que a perda e fragmentação de habitats, devido à expansão agropecuária, são as principais ameaças ao gato-mourisco.

Outra espécie ameaçada registrada no PEPF é o lobo-guará (Chrysocyon brachyurus), que é o maior canídeo sul-americano (Figura 5). Esses animais ocorrem em 
habitats abertos, e também podem ser registrados em áreas alteradas como as pastagens. A área de vida dos indivíduos dessa espécie varia de 20 a $115 \mathrm{~km}^{2}$, dependendo da disponibilidade de recursos e da qualidade do habitat em que vivem. No Brasil, a distribuição original do lobo-guará correspondia às amplas áreas de campos e cerrados desde a foz do rio Parnaíba no nordeste brasileiro até o extremo sul do estado do Rio Grande do Sul. Dentre as principais ameaças às populações de lobo-guará, encontramse: a perda de habitat, os conflitos com humanos e os atropelamentos.

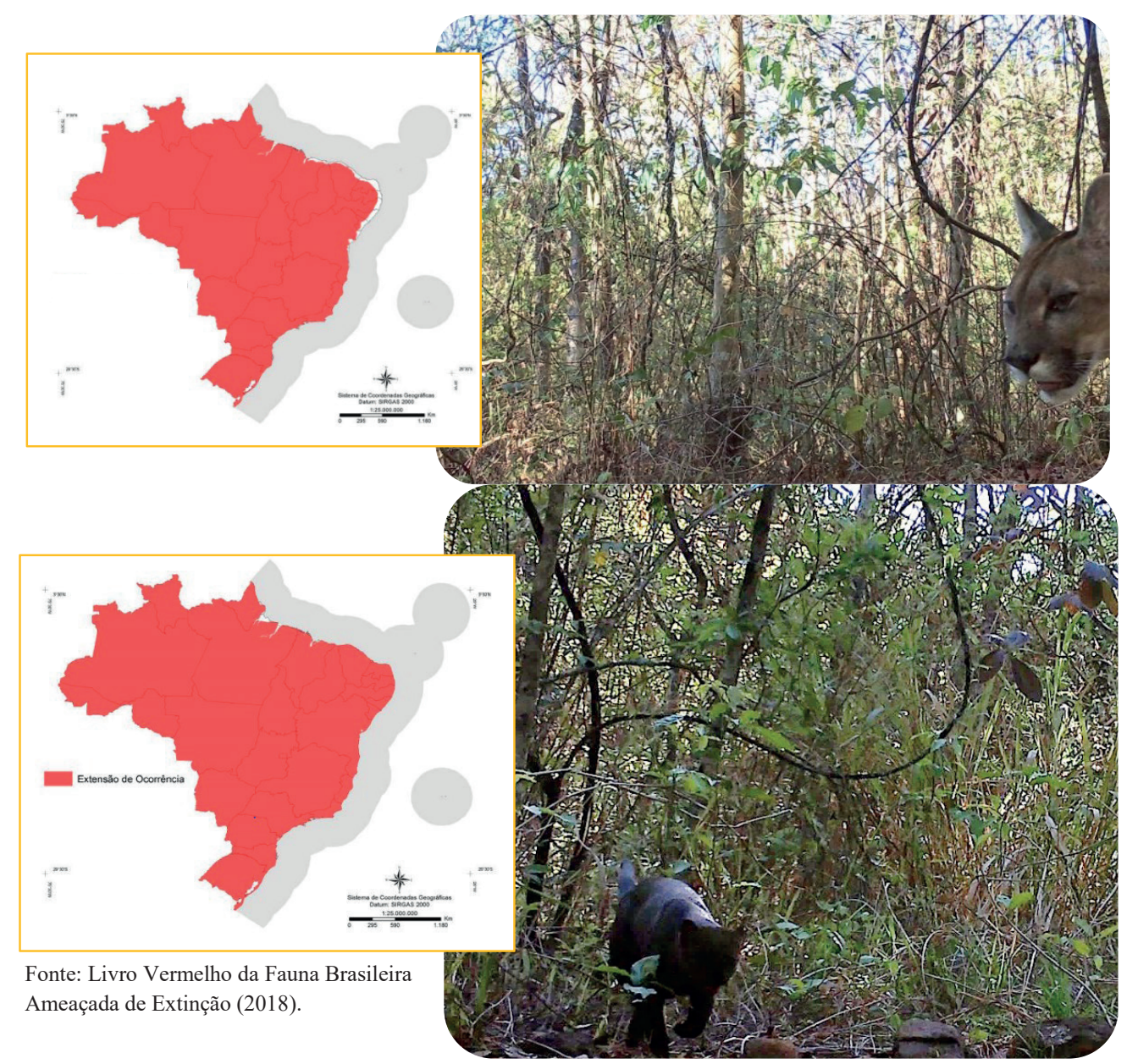

Figura 4. Onça parda (Puma concolor, acima) e jaguarundi (Puma yagouaroundi, abaixo) registrados no Parque Estadual do Pau Furado. Ao lado esquerdo e em vermelho, a extensão de ocorrência dessas espécies no Brasil.

A quarta e última espécie registrada no PEPF e considerada como vulnerável é o tamanduá-bandeira (Myrmecophaga tridactyla), que é o maior representante dos tamanduás, podendo atingir até $2,2 \mathrm{~m}$ de comprimento e cerca de $45 \mathrm{~kg}$. Historicamente, a distribuição geográfica dessa espécie se dava desde o sul da América Central até o sul da América do Sul. No Brasil, ocorre em todos os biomas (Figura 5), mas a distribuição atual está reduzida se for comparada com a original, tendo sido extinto de Santa Catarina, por exemplo. As principais ameaças às populações do tamanduábandeira são a alteração e redução do habitat e os atropelamentos. 

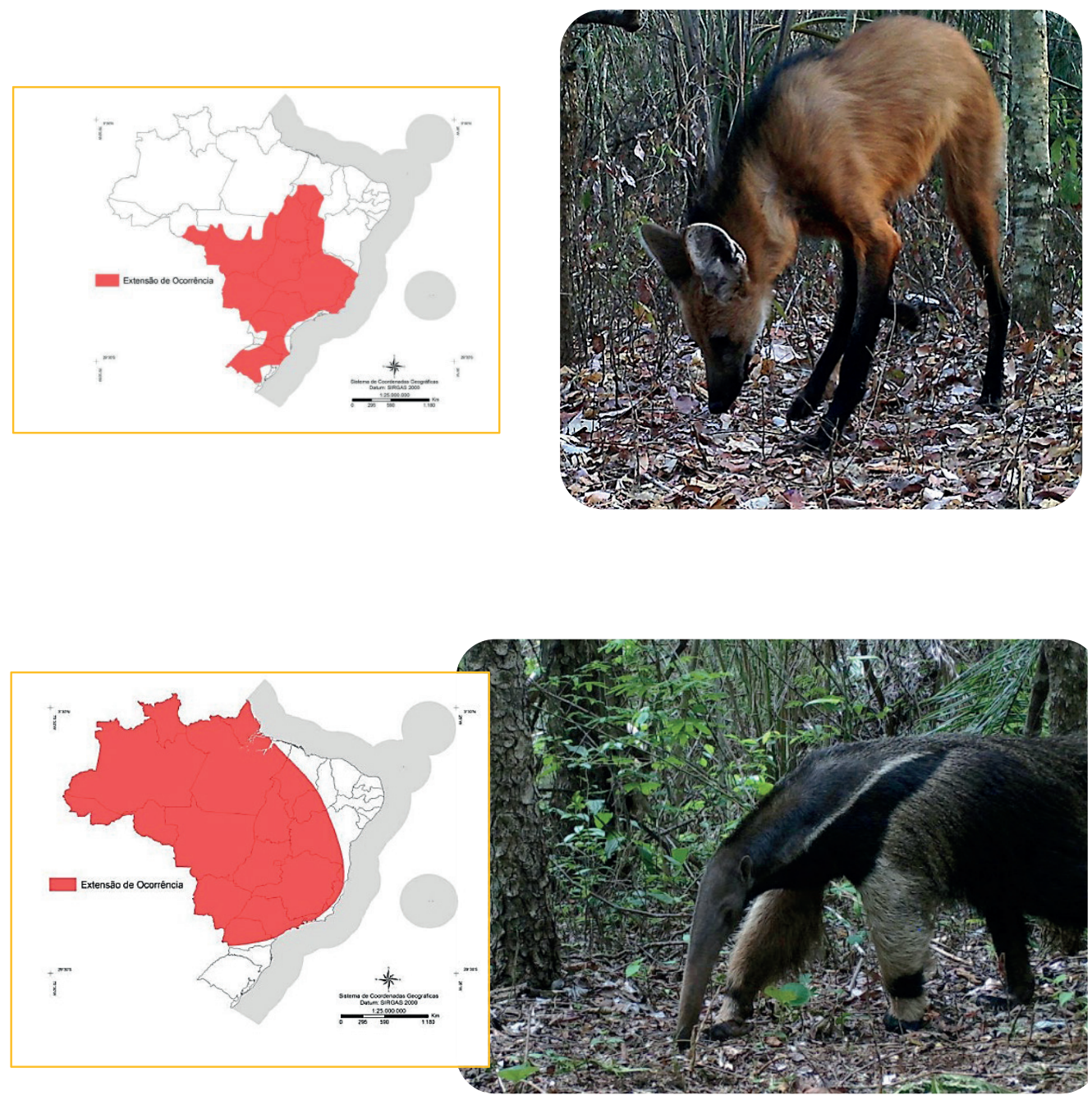

Figura 5. Lobo-guará (Chrysocyon brachyurus, acima) e tamanduá-bandeira (Myrmecophaga tridactyla, abaixo) registrados no Parque Estadual do Pau Furado. Ao lado esquerdo e em vermelho, a extensão de ocorrência dessas espécies no Brasil.

$\mathrm{O}$ contexto do PEPF e seu entorno apresenta ameaças às espécies ocorrentes nessa região, mas a situação é ainda mais grave para as espécies ameaçadas, visto que já sofrem processos de redução populacional na natureza. Poluição, queimadas criminosas, contaminação por agrotóxicos e atividades antrópicas na zona de amortecimento do Parque dificultam a locomoção das espécies de grandes mamíferos, principalmente os carnívoros, que requerem grandes áreas para viver. Além disso, a expansão urbana no entorno do parque e o fácil acesso de caçadores, pescadores e motociclistas pode aumentar as chances de conflito entre animais silvestres e humanos. Outros problemas são relacionados com o crescente aumento populacional de espécies vegetais exóticas, o que pode desencadear uma sequência de danos em cascata, ao reduzir as chances de sobrevivência de plantas nativas, dos herbívoros que se alimentam dessas e, finalmente, dos carnívoros que se alimentam de suas presas herbívoras. 


\section{Espécies exóticas e domésticas}

Entre as espécies exóticas registradas no PEPF está o javali, Sus scrofa, um animal de grandes dimensões, que pode atingir até $250 \mathrm{~kg}$ e 1,80 m de comprimento (Figura 6). Essa espécie é nativa da Europa, Ásia, Ilhas Sonda e Norte da África. Chegou ao Brasil em meados de 1980, devido à invasão de javalis que atravessaram o estado do Rio Grande do Sul, vindos da Argentina e Uruguai. Com a criação e a consequente fuga ou soltura intencional por parte dos criadores brasileiros, formou-se uma população que cada vez mais avança no território brasileiro. O crescimento contínuo e descontrolado desses animais pode ser atribuído à falta de predadores naturais, ao cruzamento com o porco doméstico, gerando proles mais numerosas e, finalmente, à oferta de recursos alimentares abundantes. Tais fatores conferem ao javali, o reconhecimento de ser uma das espécies com maior potencial invasor e de danos ao meio ambiente, pois esses animais competem com espécies nativas, dificultam a regeneração de espécies vegetais e contribuem para o assoreamento de nascentes de rios, além de serem portadores de doenças.

A ocorrência de javalis dentro do PEPF é extremamente alarmante no que diz respeito à competição por recursos alimentares com os porcos selvagens nativos, como o cateto. A longo prazo, essa competição pode gerar um declínio populacional das espécies nativas pela diminuição da disponibilidade de alimentos. O comportamento do javali de remexer o solo em busca de alimento também causa prejuízos à vegetação do Parque ao afetar o banco de sementes e crescimento de plântulas.

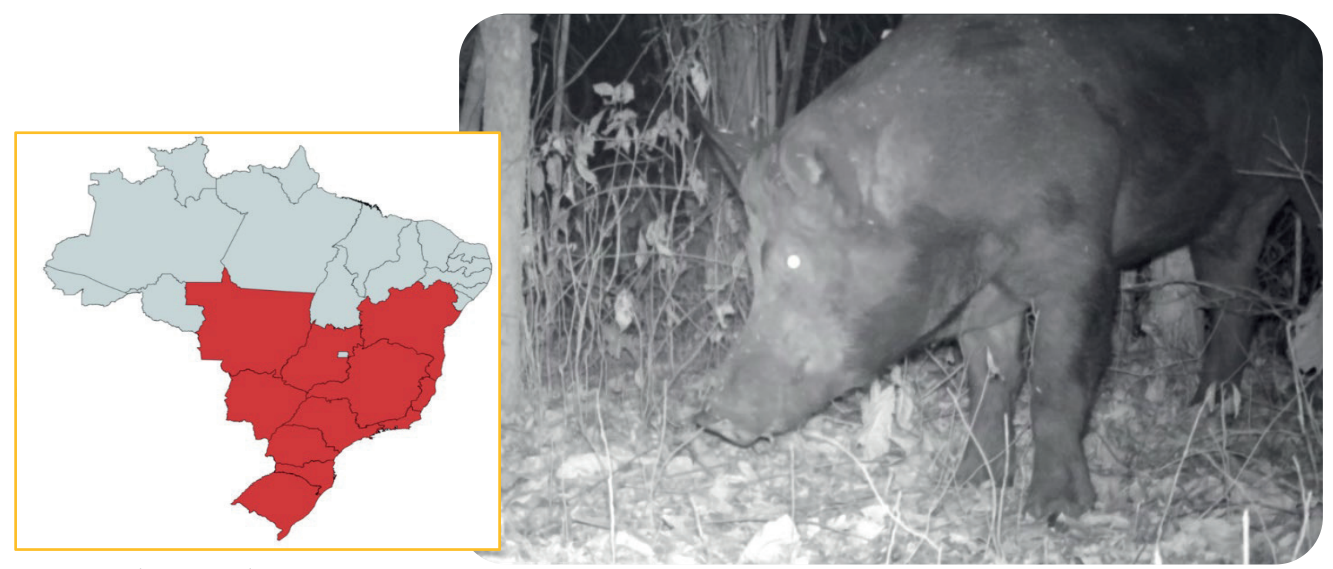

Fonte: Pedrosa et. al 2015

Figura 6. Indivíduo de javali (Sus scrofa) registrado no Parque Estadual do Pau Furado. Ao lado esquerdo e em vermelho, a atual distribuição geográfica dessa espécie no Brasil.

A presença de cães domésticos (Canus lupus familiaris) e gado bovino (Bos taurus) dentro de Unidades de Conservação é um problema em todo o país. No PEPF registramos a ocorrência de gado bovino em áreas de vegetação fechada, indicando que esses animais podem causar prejuízos para a regeneração da flora, seja por pisoteamento ou pelo hábito alimentar herbívoro. Quanto aos cães domésticos, estes podem funcionar como vetores de doenças aos lobos-guará, tamanduás-bandeira e outros animais silvestres. O risco epidemiológico pela transmissão de patógenos sugere que pode ocorrer um impacto significativo considerando que as doenças podem reduzir o sucesso 
reprodutivo de espécies já previamente descritas como ameaçadas. Adicionalmente, a presença de cães pode causar competição territorial, de forma que o território de animais silvestres nativos diminui com o avanço dos domésticos; ou ainda, competição alimentar, pois os cães podem diminuir a disponibilidade de presas para os predadores silvestres. Dessa forma, há uma necessidade de monitoramento contínuo em longo prazo que auxilie a compreender melhor os impactos ecológicos dessas espécies que ameaçam a biodiversidade do PEPF. Juntamente, deve-se adotar medidas de manejo, tanto preventivas quanto reparadoras, que contenham os impactos negativos causados dentro do Parque. Reforçamos, ainda, a importância da implementação de ações de comunicação social e de educação ambiental para com a comunidade local, uma vez que os moradores podem ser agentes auxiliadores da manutenção da diversidade do Parque Estadual do Pau Furado.

\section{Para saber mais}

Brooks TM, Mittermeier RA, Mittermeier CG, et al (2002) Habitat loss and extinction in the hotspots of biodiversity. Conserv Biol 16: 909-923 doi: 10.1046/j.15231739.2002.00530.x

Bruna EM, Guimarães JF, Lopes CT, Duarte P, Gomes ACL, Belentani SCS, Pacheco R, Facure KG, Lemos FG, Vasconcelos HL (2010) Mammalia, Estação Ecológica do Panga, a Cerrado protected area in Minas Gerais state, Brazil. Check List 6:668-675 doi: org/10.15560/6.4.668

dos Santos-Filho M, Nazareth Ferreira da Silva M(2002) Uso de habitats por mamíferos em área de Cerrado do Brasil Central: um estudo com armadilhas fotográficas. Rev Bras Zoociências 4:57-73

Egêa VA, Benavalli L, Lopes LA, Tôrres NM (2019) Levantamento de Mamíferos de médio e grande porte no Parque Estadual do Pau Furado. II Simpósio de Brasília, Brasília

Juarez KM, Marinho-Filho J(2002) Diet, habitat use, and homeranges of sympatric canids in central Brazil. J Mammal 83: 925-933 doi: 10.1644/1545-1542(2002)083<0925:dh uahr $>2.0 .00 ; 2$

Lessa I, Guimarães TCS, Bergallo HG, Cunha A, Vieira EM (2016). Domestic dogs in protected areas: a threat to Brazilian mammals? Natureza \& Conservação 14: 46-56 doi: 10.1016/j.ncon.2016.05.001

Livro Vermelho da Fauna Brasileira Ameaçada de Extinção (2018), 1 ed, ICMBio/ MMA, Brasília

Marinho-Filho J (2007) Mastofauna do Cerrado e Pantanal - diversidade e conservação. In: Yoshida K A, Alve M (eds) Cerrado e Pantanal áreas e ações prioritárias para conservação da biodiversidade. Ministério do Meio Ambiente, Brasília, pp 300-321

Pedrosa F, Salerno R, Padilha FVB, Galetti M (2015) Current distribution of invasive feral pigs in Brazil: economic impacts and ecological uncertainty. Natureza \& Conservação 13: 84-87 doi: 10.1016/j.ncon.2015.04.005 
Plano de Manejo do Parque Estadual do Pau Furado (2011), 1ed, Instituto Estadual de Florestas, Uberlândia

Trolle M, Noss AJ, Lima EDS, Dalponte JC (2007) Camera-trap studies of maned wolf density in the Cerrado and the Pantanal of Brazil. Biodiver Conserv 16: 1197-1204 doi: 10.1007/978-1-4020-6320-6_24 



\title{
CAPÍTULO 6
}

\section{DIVERSIDADE E BIOMONITORAMENTO DE AVES}

\author{
Camilla Q. Baesse \\ Paulo V. A. Ribeiro \\ Vanessa F. Gonçalves \\ Vitor C. M. Tolentino \\ Celine de Melo
}

Atualmente no Brasil são reconhecidas, de acordo com o Comitê Brasileiro de Registros Ornitológicos, pelo menos 1.919 espécies de aves - das quais 238 são endêmicas - o que representa mais da metade das espécies da América do Sul, que possui 3.413 espécies. Pelo menos 171 espécies de aves que ocorrem no Brasil estão ameaçadas de extinção (classificadas como "criticamente em perigo", "em perigo" ou "vulnerável") e outras 126 classificadas como quase-ameaçadas de extinção, aquelas espécies que ainda não se enquadram nas categorias anteriores, mas que mostram indícios de que estarão ameaçadas em pouco tempo.

No Cerrado ocorrem cerca de 864 espécies aves e, destas, 32 são consideradas endêmicas do bioma. Já nas regiões do Triângulo Mineiro/Alto Paranaíba em Minas Gerais e do Sudeste de Goiás são registradas pelo menos 525 espécies de aves, sendo que 22 são consideradas endêmicas do Cerrado. Hoje, pelo menos, 54 espécies de aves que ocorrem no Triângulo Mineiro/Alto Paranaíba e Sudeste de Goiás estão ameaçadas ou quase-ameaçadas de extinção em nível global, 19 estão ameaçadas de extinção no Brasil e 36 espécies estão ameaçadas de extinção em Minas Gerais.

Na região do Cerrado estão definidas pelo menos 20 Áreas Prioritárias para Conservação da Biodiversidade. Segundo especialistas os principais impactos e ameaças à conservação da biodiversidade na Mesorregião do Triângulo Mineiro/Alto Paranaíba e Sudeste de Goiás, em especial à conservação das espécies de aves, são a expansão das áreas destinadas a agricultura e pecuária, o turismo desordenado, queimadas não naturais, extração de minério e o isolamento dos fragmentos de vegetação natural causados pelo desmatamento.

\section{Principais ameaças à conservação das espécies de aves: poluição atmosférica e poluição sonora}

As aves respondem tanto às alterações locais, como poluição atmosférica e sonora, quanto às drásticas mudanças em nível global. A maioria dos estudos que abordam os efeitos das alterações ambientais sobre as comunidades de aves consideram quantas e quais espécies eventualmente são perdidas. No entanto, o que acontece com aquelas espécies que permanecem nos ambientes? Os fatores de estresse nos ambientes, como por exemplo a poluição, podem gerar outros efeitos que não seja somente a extinção das espécies, mas também alterações no núcleo das células sanguíneas e/ ou no perfil leucocitário e no padrão de vocalização das aves remanescentes. Nesse contexto, os organismos que permanecem em locais com estresse ambiental podem indicar a qualidade do ambiente e, portanto, serem utilizados como biomonitores. 
Biomonitores são aqueles organismos com maior sensibilidade às mudanças ambientais e que, por meio do seu comportamento de resposta a esta mudança, possibilitam o monitoraramento de diferentes áreas ou situações. Um biomonitor ideal para avaliação deve ter uma resposta a substâncias tóxicas que é análoga, porém mais rápida, que a observada em humanos, além de acesso relativamente simples para a obtenção de amostras para estudos. É nesse cenário que as aves se encaixam, aumentando a probabilidade de identificar espécies biomonitoras.

As aves estão expostas a diferentes tipos de poluição, como a poluição do ar e a poluição sonora, que são fatores responsáveis pelo declínio populacional deste grupo em todo o mundo. Elas têm um elevado metabolismo e o seu sistema respiratório está exposto direta ou indiretamente a um intenso e contínuo fluxo de ar. Além disso, para o voo elas acumulam grandes volumes de ar. Essas características permitem que as aves tenham mais contato com os gases e as partículas presentes no ar do que outros grupos, e assim podem servir como indicadores úteis para a detecção precoce do efeito da poluição do ar na saúde pública devido à sua coabitação com seres humanos.

Diversas pesquisas mostram que a poluição sonora é um dos fatores negativos com maior influência sobre a diversidade e abundância de aves e pode causar alterações em seu canto. Diversas espécies de aves podem deixar ambientes com altos níveis de ruído antrópico como resultado de sua sensibilidade ou intolerância ao ruído. Por alterarem os padrões de distribuição, abundância, diversidade e vocalização em função das condições do meio em que se encontram, as aves podem ser consideradas eficientes objetos de estudo dentro da Bioacústica e serem utilizadas como indicadoras de ruído ambiental.

Neste capítulo serão abordados estudos desenvolvidos pela equipe do Laboratório de Ornitologia e Bioacústica da Universidade Federal de Uberlândia em áreas florestais do Triângulo Mineiro. Esses estudos envolvem o uso de diferentes técnicas de biomonitoramento com aves, tais como anomalias nucleares eritrocitárias, perfil leucocitário, parasitos sanguíneos e bioacústica. Grande parte dos estudos envolveram coletas de dados por vários anos que só foram possíveis dentro do apoio financeiro de um projeto de longa duração, como o Programa de Pesquisas Ecológicas de Longa Duração (PELD).

\section{Anomalias nucleares eritrocitárias}

Uma das ferramentas de biomonitoramento ambiental é a análise de anomalias nucleares eritrocitárias, que são alterações no núcleo das células sanguíneas causados por substâncias tóxicas. As anomalias normalmente se formam quando um indivíduo é exposto a um xenobiótico (composto químico estranho a um sistema biológico), gerando um efeito genotóxico que interfere na estrutura ou função do aparelho mitótico, produzindo uma falha na incorporação de cromossomos ou fragmentos cromossômicos no núcleo principal. Dentre as anomalias, que podem ocorrer no núcleo das células sanguíneas de aves, podemos citar os micronúcleos, eritroplastídeos, célula binucleada, constricção assimétrica, núcleo entalhado e núcleo deslocado (Figura 1).

A análise das anomalias nucleares eritrocitárias apresenta custo relativamente baixo, rapidez nos resultados e eficácia tanto em estudos de laboratório quanto em estudos de campo, uma vez que é possível observar a presença ou ausência dessas alterações por meio de uma pequena amostra de sangue sem ser necessário sacrificar os indivíduos. 
Nossos estudos com anomalias eritrocitárias nucleares começaram com os testes de micronúcleos em aves em 2013 quando pouco se conhecia sobre o assunto. Em nossas publicações, analisamos o sangue de aves que foram capturadas em quatro fragmentos florestais. Destes fragmentos, dois foram considerados próximos a centros urbanos por estarem a menos de $5 \mathrm{~km}$ de área urbana e rodovias e dois foram considerados distantes de centros urbanos, pois se encontram a mais de $20 \mathrm{~km}$ do perímetro urbano. Demos continuidade aos estudos no tema, sempre buscando mais explicações sobre a influência da poluição atmosférica no surgimento de micronúcleos em aves. Para isto, também capturamos aves em fragmentos florestais localizados dentro de dois parques urbanos (áreas inseridas em centros urbanos), para podermos analisar as aves que estão em contato direto com gases poluentes, o que resultou em seis áreas de estudo. Analisamos o sangue de 1.308 aves (87 espécies) e encontramos um total de 1.403 micronúcleos. A quantidade de micronúcleos nas aves variou entre as áreas de estudo (Figura 2A), estando relacionada ao nível de urbanização. Para comprovar que a poluição aérea é o principal fator de influência no desenvolvimento do micronúcleo, foi feita a avaliação do tráfego de veículos próximo às áreas de estudo. Encontramos que quanto maior o tráfego de veículos próximo às áreas, maior a quantidade de micronúcleos nas aves (Figura 2B). A fim de conseguirmos mais explicações, testamos a diferença na quantidade de micronúcleos nas aves entre as estações seca e chuvosa, considerando que, na estação seca, os índices de poluição aérea são maiores.

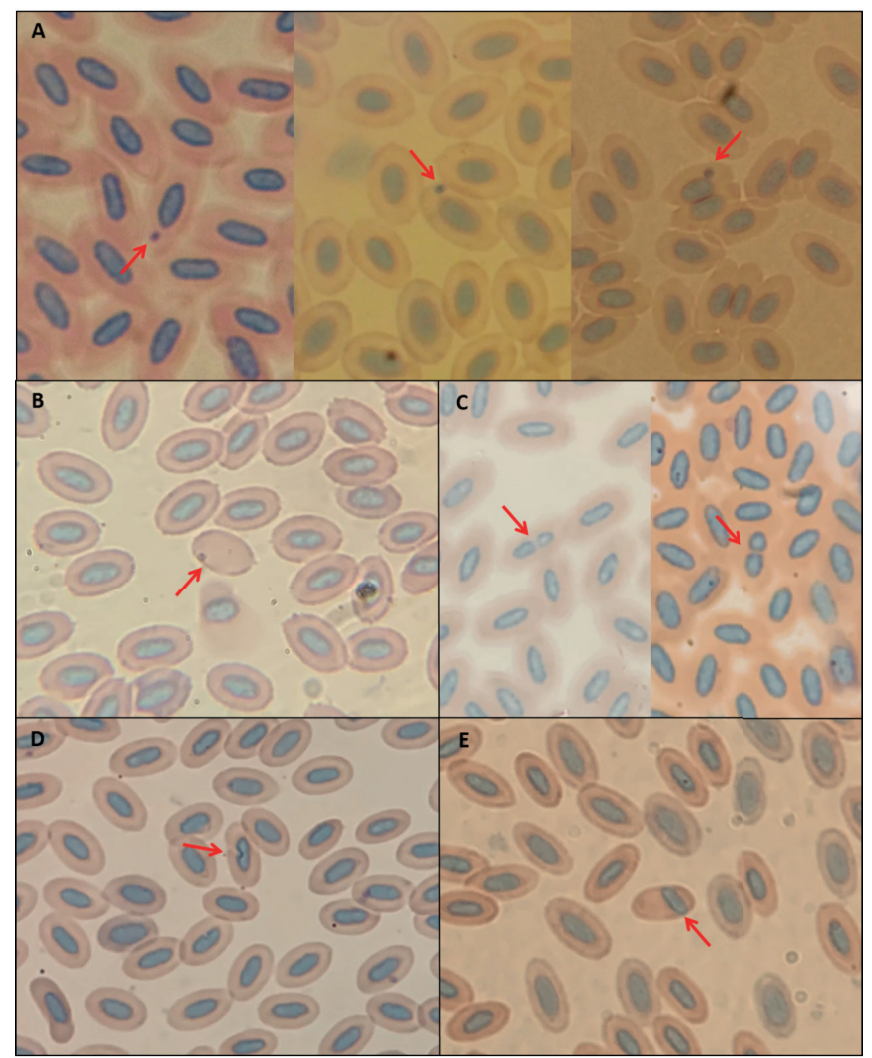

Figura 1. Imagens de microscopia óptica evidenciando pelas setas vermelhas: A) micronúcleos, B) eritroplastídeo, (C) células binucleadas, (D) núcleo entalhado e (E) núcleo deslocado. Fotos: Camilla Baesse e Vanessa Gonçalves. 
A partir disso, encontramos que na estação seca as aves analisadas apresentaram mais micronúcleos do que na chuvosa (Figura 2C). Foram analisadas dez espécies de aves que foram capturadas em todas as áreas de estudo: soldadinho (A. galeata), pulapula (B. culicivorus), cambacica (Coereba flaveola), pipira-da-taoca (E. penicillata), enferrugado (Lathrotriccus euleri), cabeçudo (Leptopogon amaurocephalus), canáriodo-mato (M. flaveola), tempera-viola (Saltator maximus), bico-chato-de-orelha-preta (Tolmomyias sulphurescens) e sabiá-branco (Turdus leucomelas) (Figura 3). Todas as dez espécies analisadas apresentaram diferença na quantidade de micronúcleos entre os tipos de áreas, com maiores valores em áreas inseridas nas cidades (média $=1,81$ ) e menores valores em áreas distantes de cidades (média $=0,08$ ) (Figura 2D). Em todos nossos estudos as aves apresentaram mais micronúcleos em fragmentos florestais próximos a centros urbanos, sugerindo que a poluição antrópica gerou o aumento de micronúcleo nas aves e demonstrando a importância das aves como biomonitoras da qualidade ambiental aliado ao teste de micronúcleo.

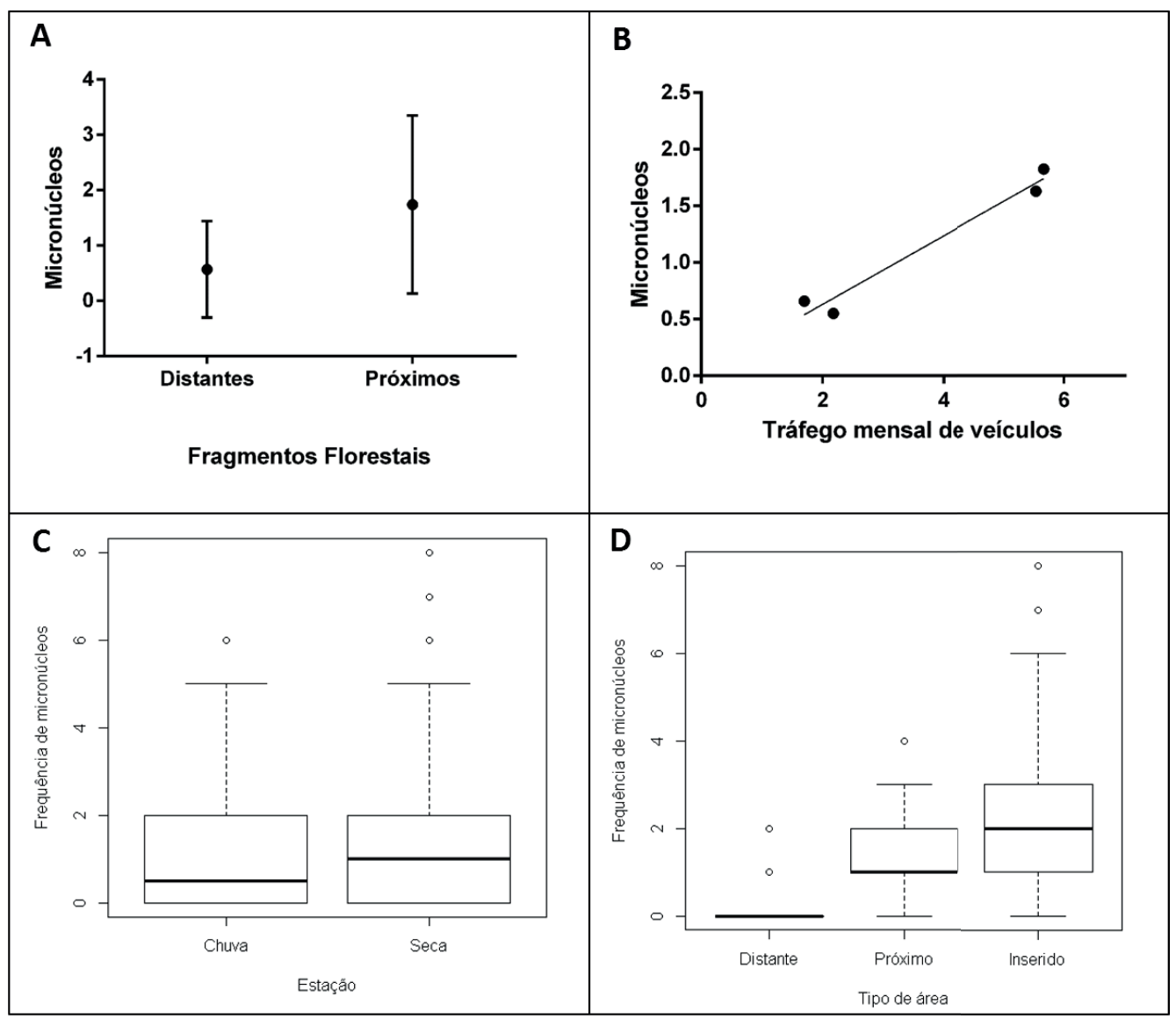

Figura 2. Frequência de micronúcleos em aves: A) entre fragmentos florestais distantes e próximos de cidades, B) relação entre o tráfego de veículos e micronúcleos, C) variação de micronúcleos entre as estações e D) variação de micronúcleos entre os tipos de áreas. 


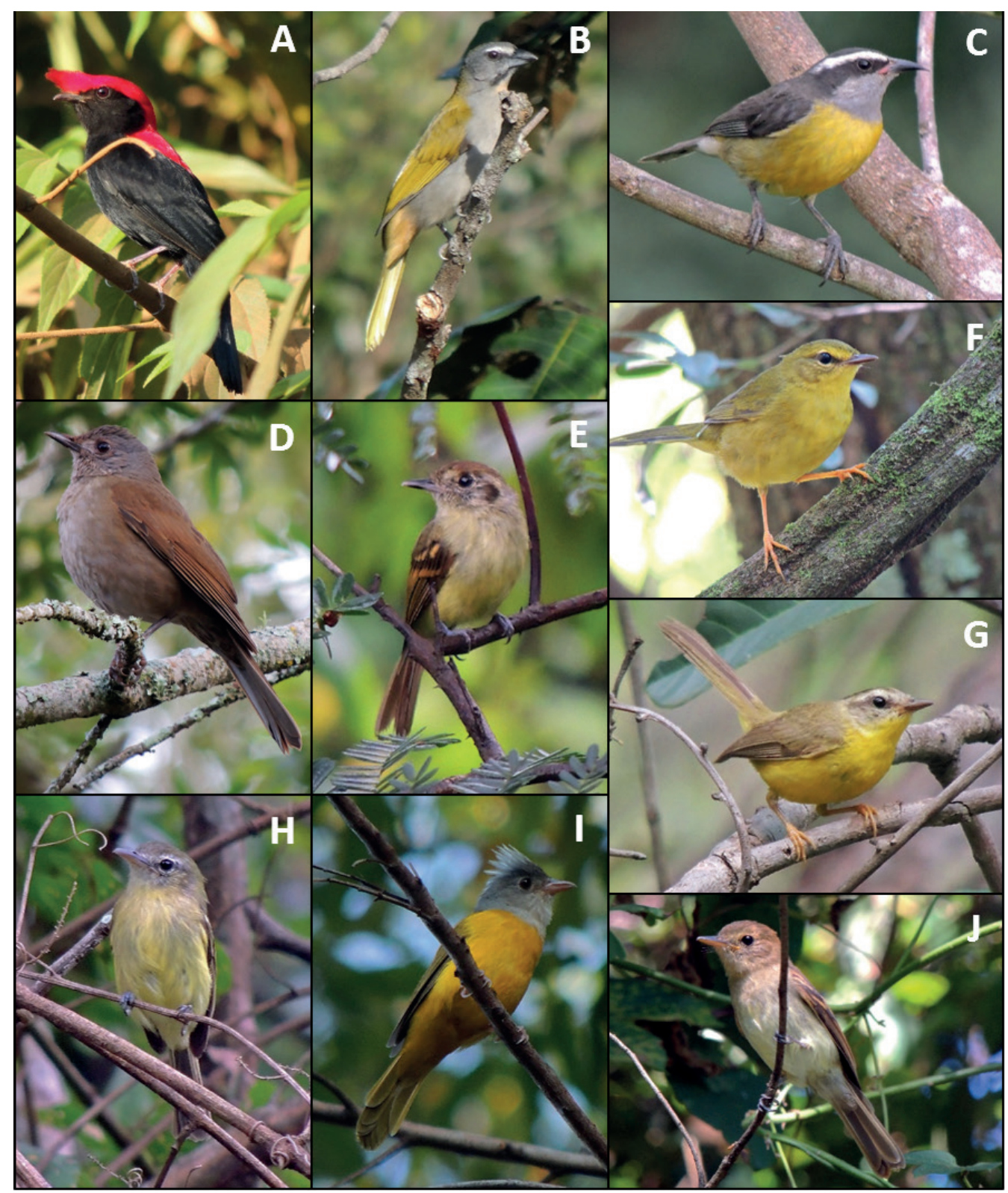

Figura 3. Espécies de aves presentes em todos os fragmentos florestais estudados. A) Antilophia galeata (soldadinho), B) Saltator maximus, (tempera-viola) C) Coereba flaveola (cambacica), D) Turdus leucomelas (sabiá-barranco), E) Leptopogon amaurocephalus (cabeçudo), F) Myiothlypis flaveola (canário-do-mato, G) Basileuterus culicivorus (pula-pula), H) Tolmomyias sulphurescens(bicho-chato-deorelha-preta). I) Eucometis penicillata (pipira-da-taoca) e J) Lathrotriccus euleris (enferrujado). Fotos: Vitor C.M. Tolentino.

Além disso, durante esses estudos, foi observada a presença de eritroplastídeos (eritrócitos sem núcleo) nas células sanguíneas, sendo que a espécie que apresentou essa anomalia foi $A$. galeata. Em cinco áreas situadas a diferentes distâncias do centro urbano, observamos a presença de 44 eritroplastídeos em 28 indivíduos, correspondendo a $35,8 \%$ do total de indivíduos capturados. O número de indivíduos 
com eritroplastídeos variou entre os fragmentos: nenhum dos indivíduos capturados no fragmento mais distante do ambiente urbano apresentou eritroplastídeos; por outro lado, na área inserida em ambiente urbano oumais próxima do centro urbano, detectamos a maior quantidade de eritroplastídeos $(\mathrm{n}=10)$.

Outras anomalias nucleares eritrocitárias: célula binucleada, constricção assimétrica, núcleo entalhado e núcleo deslocado foram registradas em seis espécies (A. galeata, B. culicivorus, E. penicillata, L. amaurocephalus, M. flaveola e T. leucomelas) capturadas nos mesmos seis fragmentos florestais.

\section{Perfil leucocitário}

Outra técnica de biomonitoramento que apresentou resultados satisfatórios em aves foi a análise de parâmetros hematológicos, como o perfil leucocitário, ferramenta comumente utilizada na mensuração do estresse em animais vertebrados. Este perfil é determinado por meio da contagem total e diferencial de leucócitos, também conhecidos como glóbulos brancos, os quais são um dos principais componentes do sistema imunológico dos vertebrados, constituído por diferentes tipos celulares que oferecem proteção contra agentes patogênicos e estressores.

As aves apresentam cinco principais tipos de leucócitos: os linfócitos, heterófilos, monócitos, eosinófilos e basófilos. Os tipos leucocitários mais abundantes são os linfócitos e heterófilos (Figura 4), pois juntos compõem aproximadamente $80 \%$ dos leucócitos das aves. Os linfócitos desempenham funções importantes para a imunidade adquirida ou adaptativa, como a produção de anticorpos e respostas específicas a patógenos. Os heterófilos atuam na primeira linha de defesa imune, a imunidade inata, e são as principais células fagocíticas envolvidas em respostas inflamatórias. As quantidades e proporções destas células podem sofrer alterações, de acordo com as concentrações dos hormônios de estresse, os corticosteróides. Quando presentes em altos níveis, estes hormônios elevam o número de heterófilos e diminuem os de linfócitos, resultando em aumentos nos valores da razão entre estes, também chamada de razão H/L, o que caracteriza o perfil leucocitário de estresse.

Estudos mostram que o perfil leucocitário é uma ferramenta eficaz na mensuração do estresse em aves, pois alterações na quantidade e proporção destas células têm sido registradas em aves em diferentes situações estressantes, tais como: poluição, baixa disponibilidade de recursos alimentares, períodos de reprodução, migração e parasitismo. 


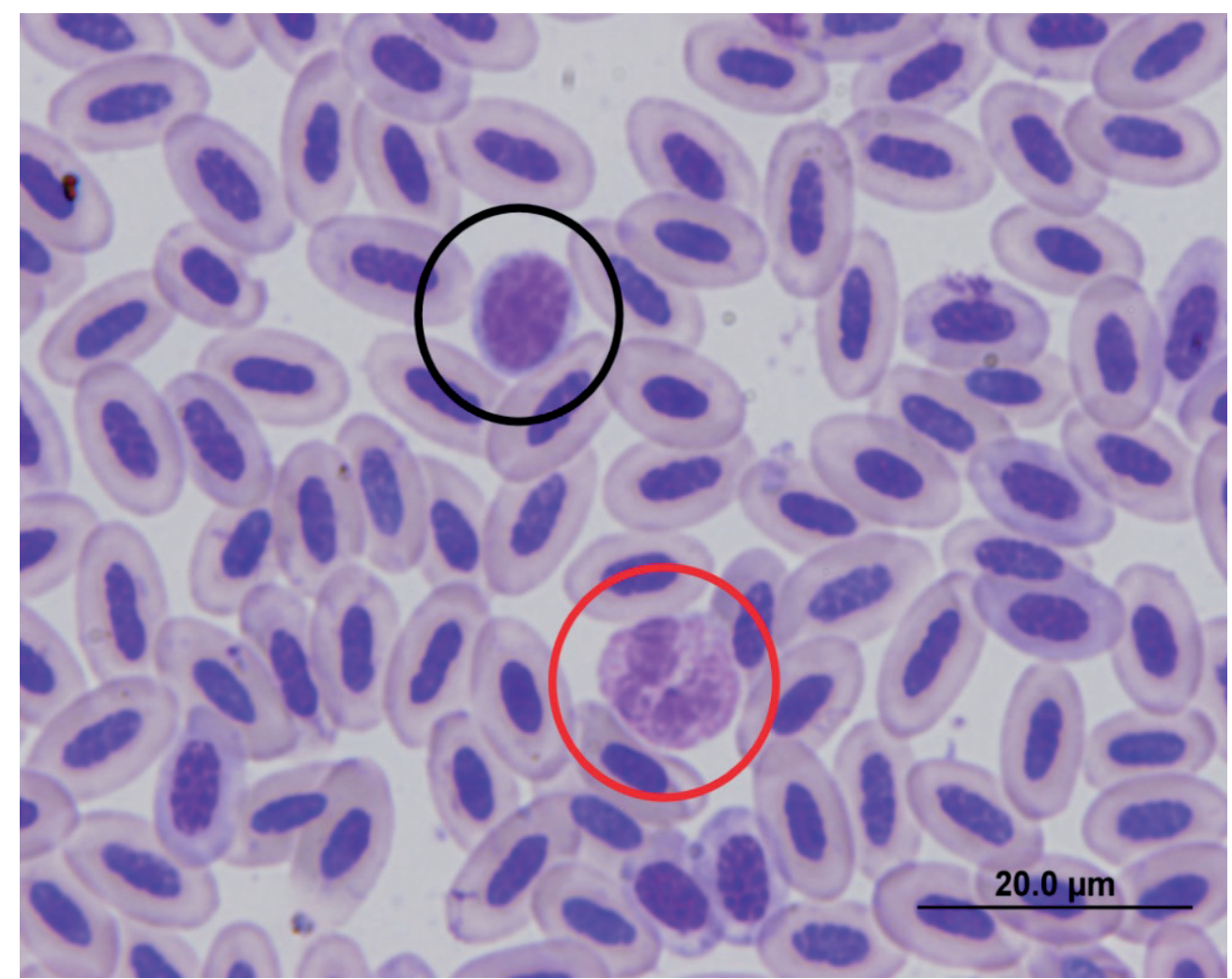

Figura 4. Principais leucócitos aviários: linfócito (dentro do círculo preto) e heterófilo (dentro do círculo vermelho) encontrados no sangue de um indivíduo de A. galeata. Foto: Paulo V. A. Ribeiro.

Em nosso estudo, analisamos o perfil leucocitário de uma população de soldadinho (Antilophia galeata) procedentes de uma área florestal do Triângulo Mineiro. Esta espécie foi escolhida por ser abundante na região do estudo, territorialista, dependente de ambientes florestais e endêmica do Cerrado, características que a tornam uma potencial espécie para o biomonitoramento ambiental. Ao todo foram examinadas amostras sanguíneas de 89 indivíduos. Verificamos que o perfil leucocitário diferiu entre os sexos e período de reprodução de A. galeata. O número de linfócitos foi menor nos indivíduos que estavam em período reprodutivo e também foi menor nas fêmeas (Figura 5), o que pode indicar que as atividades exercidas por estas são mais estressantes, pois as fêmeas de $A$. galeata são as principais encarregadas pela construção do ninho, incubação e cuidado com ninhegos.

Acreditamos que, ao associar o perfil leucocitário com outra ferramenta bioindicadora, como micronúcleos, seria possível ter uma visão mais abrangente do perfil de estresse fisiológico das aves do que examinar apenas um único indicador. Desta forma, verificamos que a quantidade de micronúcleos se correlacionou com a quantidade total de leucócitos e com a razão H/L dos indivíduos de $A$. galeata, ou seja, indivíduos com mais micronúcleos apresentaram indícios leucocitários de estresse. Considerando que os micronúcleos são biomarcadores de dados genotóxicos, estas relações podem indicar que os indivíduos são sensíveis e reagem a distúrbios ambientais. Assim, o perfil leucocitário pode ser considerado uma ferramenta útil para responder questões ecológicas aplicadas na conservação de espécies de aves em ambientes degradados. 

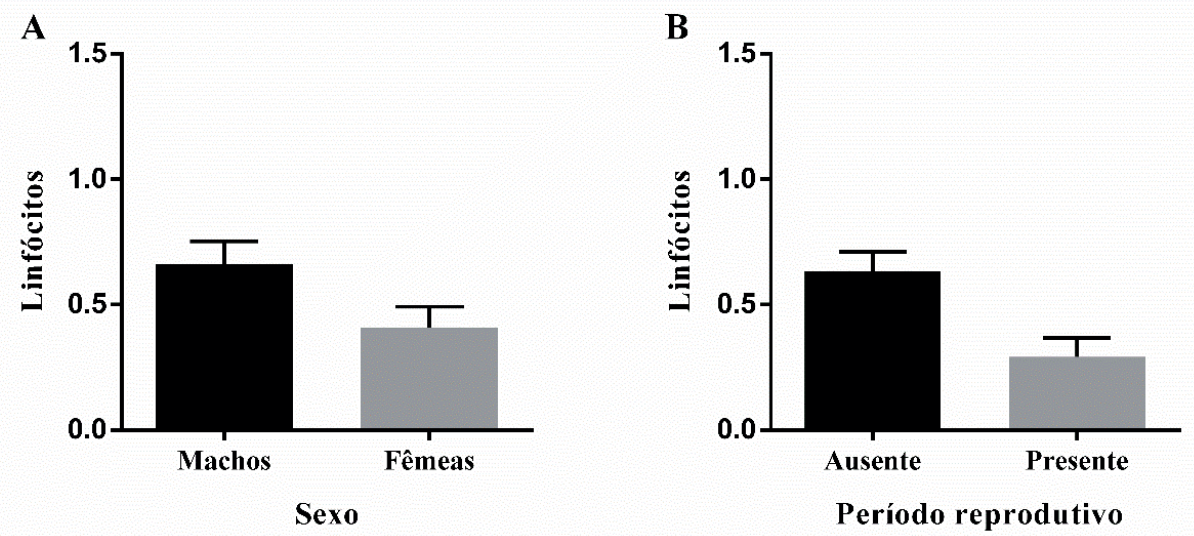

Figura 5. Número de linfócitos de Antilophia galeata em relação ao sexo (A) e presença ou ausência do período reprodutivo (B). As caixas representam as médias, enquanto as barras representam os erros padrões.

\section{Parasitos sanguíneos}

A análise de parasitos sanguíneos é outra técnica que apresentou resultados satisfatórios em estudos de biomonitoramento nas aves. As aves podem ser acometidas por uma diversa fauna parasitária, incluindo protozoários, helmintos e artrópodes. $\mathrm{O}$ parasitismo é considerado um fator estressor, pois os parasitos podem comprometer a saúde dos hospedeiros. Os efeitos do parasitismo podem ser potencializados por influências humanas, como o desmatamento, a fragmentação do habitat e a introdução de espécies exóticas.

Um grupo de parasito bem estudado em aves são os protozoários hemosporídeos causadores da malária (Haemoproteus e Plasmodium), que são transmitidos por mosquitos hematófagos (Diptera). Estes parasitos podem diminuir o sucesso reprodutivo e a sobrevivência dos hospedeiros, principalmente quando introduzidos em populações não adaptadas, podendo gerar alta patogenicidade, mortalidade e por fim extinções. Os hemosporídeos apresentam ampla distribuição geográfica e podem ocorrer em quase todas as espécies de aves do planeta. No Brasil, vários autores têm publicado registros inéditos de hemosporídeos em diferentes espécies de aves nos últimos anos. Tal fato demonstra a potencialidade de estudos ecológicos sobre parasitos aviários em ambientes com elevada diversidade de espécies, como o Brasil.

Em nosso estudo, foram examinadas amostras sanguíneas de 549 indivíduos de 56 espécies de aves provenientes de quatro fragmentos florestais. No total, 109 $(19,85 \%)$ indivíduos estavam infectados, sendo 13 (2,36\%) por Haemoproteus e 103 (18,76\%) por Plasmodium (Figura 6). Das 56 espécies analisadas, 34 (60,7\%) demonstraram positividade para hemosporídeos, como A. galeata, B. culicivorus, E. penicillata, L. euleri, L. amaurocephalus, M. flaveola, S. maximus, T. sulphurescens, $T$. leucomelas, que também apresentaram sensibilidade nos estudos citados anteriormente. Além disso, nove espécies (Arremon flavirostris, Casiornis rufus, Clibanornis rectirostris, Corythopis delalandi, E. penicillata, M. leucophrys Synallaxis scutata, T. sulphurescens e Taraba major) foram registradas pela primeira vez como hospedeiras de hemosporídeos. 


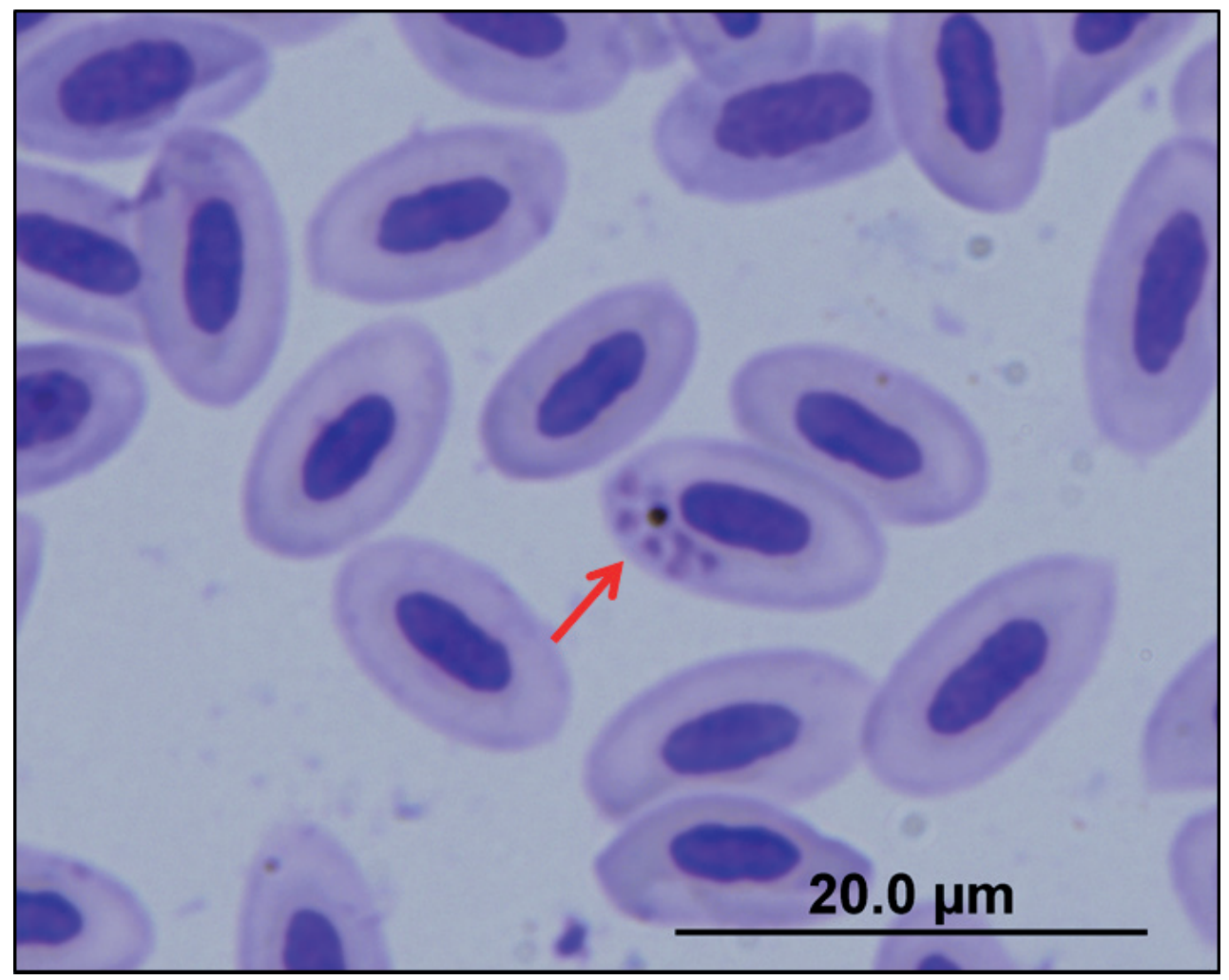

Figura 6. Exemplar de parasito sanguíneo do gênero Plasmodium no eritrócito (apontado pela seta) de um indivíduo de Antilophia galeata. Foto: Paulo V. A. Ribeiro.

A menor prevalência de hemosporídeos $(3,6 \%)$ foi registrada na área de estudo com menor tamanho e mais próxima do ambiente urbano. É um fragmento florestal circundado por pastagens e áreas agrícolas, e considerado como uma área em baixo grau de preservação ambiental. Nas demais áreas foram registradas as seguintes prevalências: 26\% (Glória), 20\% (Galheiros) e 13\% (Água Fria). Quando comparadas com São José, estas três áreas podem estar menos perturbadas. Galheiros e Água Fria são fragmentos florestais grandes, distantes de ambientes urbanos e com baixo grau de antropização. Glória, embora seja um fragmento florestal pequeno e próximo ao ambiente urbano, está em direção a um estágio de maturidade vegetacional avançado devido à complexidade estrutural e de fisionomia semelhante a formações primárias.

É provável que as características das áreas tenham influenciado as prevalências de hemosporídeos, uma vez que o aumento da pressão antrópica pode levar a uma diminuição na probabilidade de infecção por estes parasitos, devido à presença de fatores que reduzem a abundância dos mosquitos vetores, como inseticidas, pesticidas e poluição. Desta forma, acredita-se que a degradação ambiental pode comprometer os ciclos de transmissão dos hemosporídeos, e com isso, as relações parasito-hospedeiro poderiam ser eventualmente perdidas. Assim, os resultados encontrados podem demonstrar o potencial dos hemosporídeos aviários em indicar a qualidade ambiental de fragmentos florestais. 


\section{Bioacústica}

A Bioacústica é o estudo de todo tipo de comunicação de animais através de sinais sonoros, com ampla aplicação na conservação da biodiversidade e monitoramento ecológico das comunidades. $\mathrm{O}$ estudo dos sinais sonoros pode ser relacionado à diversidade e demais questões ecológicas, permitindo a coleta de informações sobre a ecologia de populações, comunidades e paisagens e indicando processos ecológicos. Os sinais sonoros emitidos pelas aves possuem função principal de reconhecimento da espécie e estão relacionados com a atração da fêmea, defesa do território e competição. Portanto, cada espécie possui seu próprio sistema de comunicação dependendo de suas relações, organização social, ambiente onde vive e processos evolutivos.

Os sons presentes em cada ambiente podem ser caracterizados através da paisagem acústica, que nos permite conhecer a diversidade das comunidades animais (biofonia) e de demais sons naturais não animais (geofonia) ou antrópicos (antrofonia). Para representar as características da paisagem acústica e buscar entender a influência das atividades humanas e da urbanização sobre os animais, surgiram vários indicadores acústicos, criados para qualificar e quantificar os sons de um determinado ambiente. Exemplos de indicadores acústicos são: (a) o Índice Bioacústico, que calcula a diversidade de sons naturais de um ambiente excluindo os sons de origem antrópica, e (b) o Índice Normalizado de Diferença da Paisagem Acústica, que calcula o nível de distúrbio antrópico na paisagem acústica a partir da razão entre os sinais sonoros antrópicos e os sinais sonoros de origem natural. Ambos estes indicadores podem ser ferramentas rápidas e práticas para a avaliação da biodiversidade sob uma abordagem de paisagem acústica.

Nas últimas décadas, a expansão das cidades e processos de urbanização têm elevado os níveis de ruído de origem antrópica e intensificado o processo de fragmentação de áreas de vegetação nativa. Altos níveis de ruído, isolamento e diminuição do tamanho de fragmentos vegetais são processos relacionados à diminuição da riqueza, diversidade e abundância de aves. Além destas alterações em padrões de distribuição das aves, os altos níveis de ruído das cidades e rodovias são os principais fatores que levam as aves que vivem próximas a estas fontes de barulho a alterarem seus padrões de vocalização, podendo cantar menos vezes durante o dia ou tendo que cantar mais alto para conseguirem se comunicar.

Nossos estudos relacionados à Bioacústica foram realizados em 27 fragmentos florestais, divididos em quatro grupos formando um gradiente de antropização de acordo a proximidade às cidades e rodovias (rurais, semi-rurais, semi-urbanos e urbanos). Foram feitas 76,5 horas de gravações e 320 horas de observação através de busca ativa em transecções nas áreas de estudo. Além disso, os níveis de ruído ambiental de cada área foram medidos com aparelho específico.

O nível de ruído ambiental médio nos fragmentos urbanos foi de 45,43 decibéis (dB), nos semi-urbanos de 43,21 dB, nos semi-rurais de 36,91 dB e nos rurais de 35,44 dB. Os dados mostram que, quanto mais próximos os fragmentos de vegetação estão de cidades e rodovias, maiores são os níveis de ruído.

Considerando os dados de todas as áreas de estudo em conjunto, os sons mais comuns foram os sons de aves $(54,43 \%)$ e insetos $(16,92 \%)$, seguidos pelos sons de tráfego de veículos (12,58\%) (Figura 7). Os fragmentos em áreas rurais, distantes de 
cidades e rodovias, apresentaram paisagem acústica composta por $86,19 \%$ de sons provenientes de animais e apenas $7,43 \%$ de sons antrópicos. Já os fragmentos urbanos apresentaram $47,30 \%$ de sons de animais e $48,90 \%$ dos sons de origem antrópica. Foi observado que existe um padrão onde a quantidade dos sons animais diminui e a quantidade de sons antrópicos aumenta à medida que a distância para cidades e rodovias diminui. A riqueza de aves vocalizando nas áreas estudadas variou entre os grupos, sendo maior nos fragmentos rurais $(75,25)$, seguido pelos semi-urbanos $(65,33)$, semi-rurais $(63,50)$ e urbanos $(49,25)$. Houve relação negativa entre os níveis de ruído ambiental e a riqueza total de espécies gravadas nas áreas de estudo, sendo que, quanto maior o nível de ruído ambiental, menor a riqueza de espécies de aves.

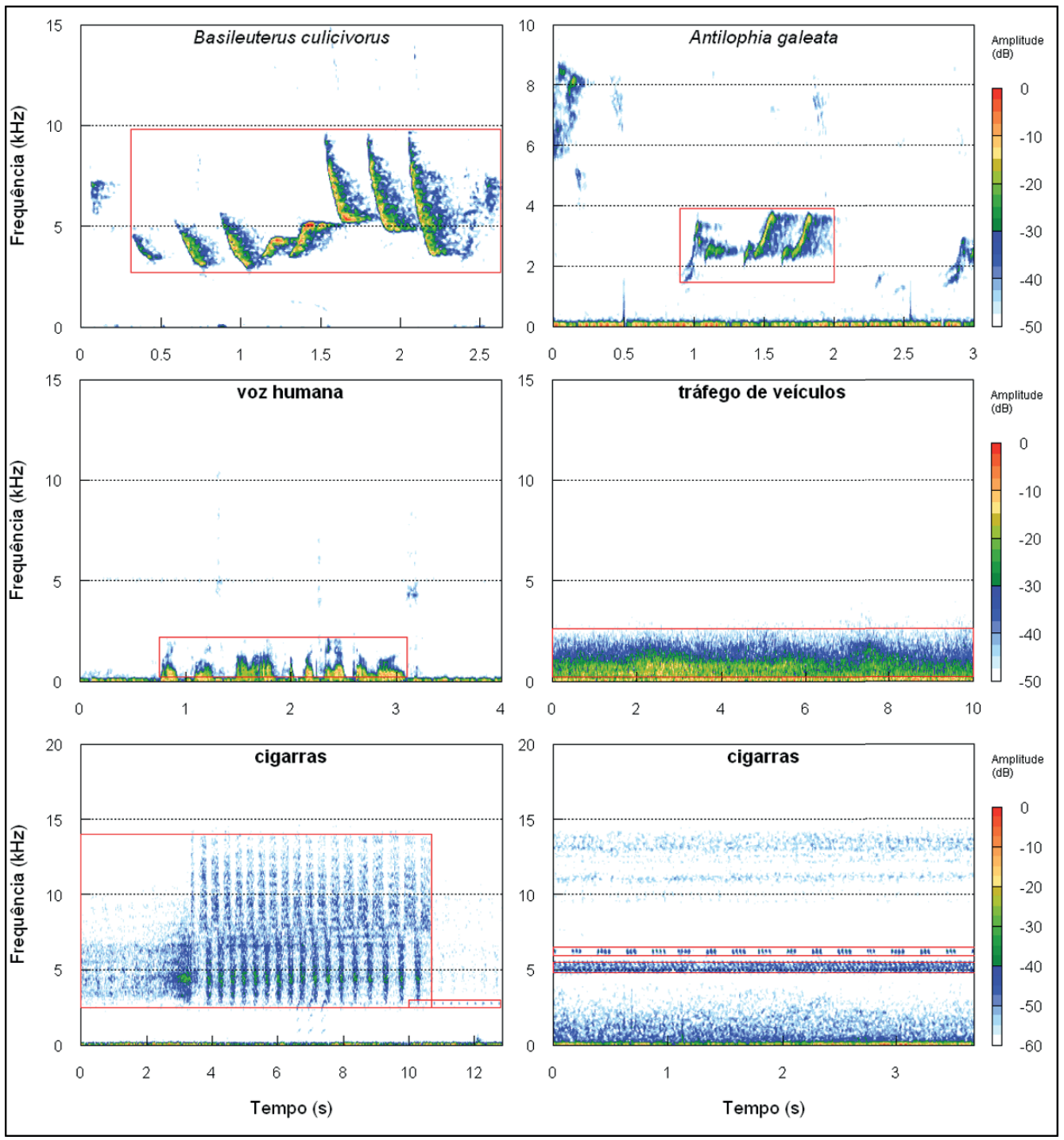

Figura 7. Sonogramas (representação gráfica dos sons) dos sons de aves, humanos, cigarras e do tráfego de veículos. Os retângulos em vermelho representam o intervalo de tempo em que o som foi registrado. 
A riqueza de aves registradas durante o estudo foi de 334 espécies. O fragmento florestal urbano "Bosque John Kennedy" em Araguari, MG, apresentou a menor riqueza, com 93 espécies de aves e o fragmento rural "RPPN Galheiros", com 192 espécies, foi a que apresentou maior riqueza de aves durante o período do estudo. Houve diferença na riqueza de espécies de aves entre os quatro grupos de fragmentos, sendo a média nos rurais de 161,8, nos semi-rurais 148,1, nos semi-urbanos 131 e nos urbanos de 99 espécies. Nota-se, que a riqueza de espécies de aves forma um gradiente: quanto maiores as distâncias para cidades e rodovias maiores são os valores de riqueza de aves. Com relação ao tamanho das áreas, as áreas urbanas foram as que apresentaram menor tamanho médio (14,9 ha), seguido pelas áreas semi-rurais (33,5 ha), semi-urbanas (40,1 ha) e as áreas rurais foram as que apresentaram maior tamanho médio ( $78,3 \mathrm{ha})$. Em nosso trabalho, o tamanho das áreas e os níveis de ruído ambiental foram os fatores que melhor explicam as variações na riqueza de espécies de aves, sendo que a riqueza de aves está negativamente relacionada aos níveis de ruído ambiental e positivamente relacionada ao tamanho das áreas (Figura 8).

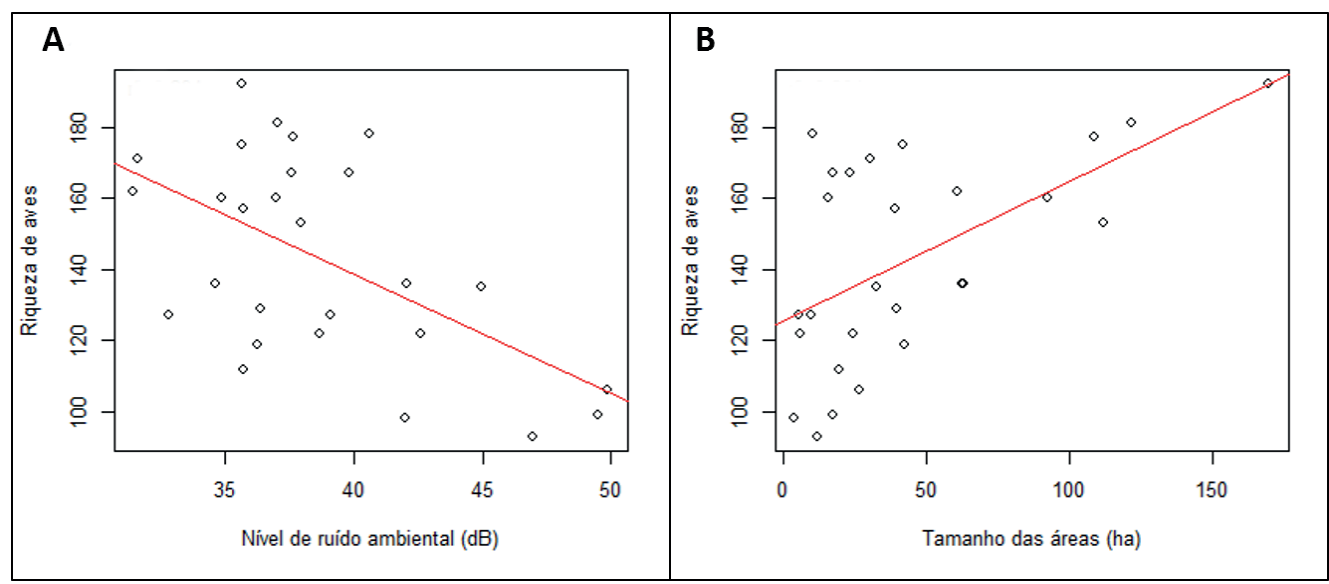

Figura 8. Relação ente a riqueza de espécies de aves e A) nível de ruído ambiental e B) tamanho dos fragmentos florestais.

O índice Normalizado da Diferença da Paisagem Acústica, apresentou menores valores em áreas com elevados níveis de ruído, como as áreas urbanas, demonstrando o potencial de uso deste índice na avaliação de impactos ambientais relacionados à urbanização e às atividades antrópicas sobre áreas florestais e sua fauna dependente. A maioria dos índices acústicos calculados mostrou relação positiva com a riqueza de espécies de aves vocalizando nos fragmentos estudados, podendo assim ser utilizados para a verificação da riqueza e diversidade de aves em ambientes florestais no Cerrado.

Foram analisados parâmetros acústicos (características físicas do canto) de 44 espécies de aves. As espécies risadinha (Camptostoma obsoletum), balança-rabo-demáscara (Polioptila dumicola) e maria-cavaleira-de-rabo-enferrujado (Myiarchus tyrannulus) (Figura 9) foram as que apresentaram variação no maior número de parâmetros entre os grupos de fragmentos. Apenas o risadinha apresentou todos os parâmetros acústicos relacionados aos níveis de ruído ambiental das áreas de estudo. Maiores níveis de ruído ambiental resultam em maior frequência mínima do canto em 
$84,1 \%$ das espécies estudadas, maior frequência máxima e maior frequência dominante em $72,7 \%$, maior amplitude dos cantos em 70,5\% e menor duração do canto em $40,9 \%$. A frequência mínima é o parâmetro de canto que melhor responde ao aumento dos níveis de ruído do ambiente, pois apresenta a mesma faixa de frequência do ruído e por isso deve ser alterado para que os sons sejam transmitidos com eficiência.

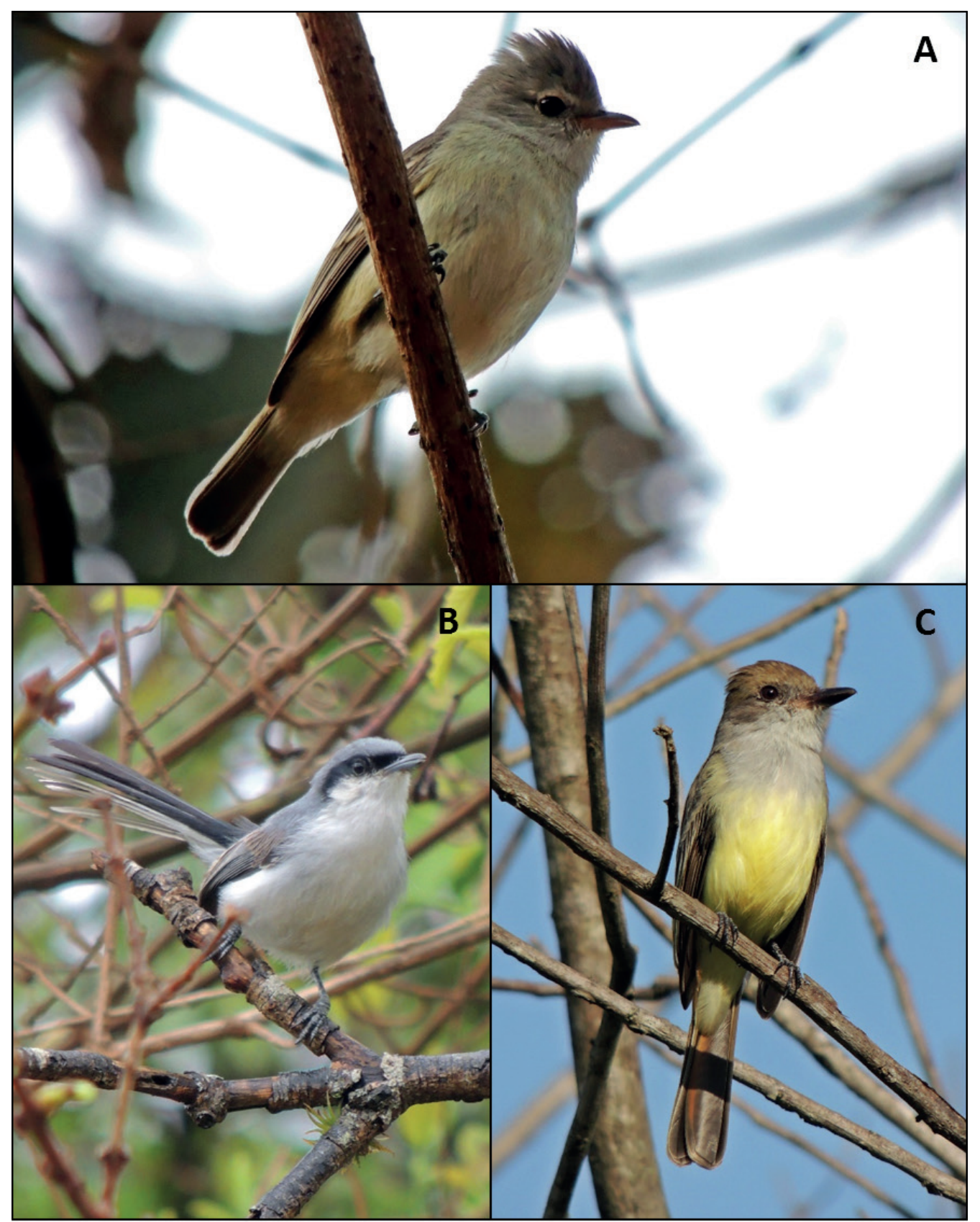

Figura 9. Espécies de aves que mais alteraram a sua vocalização em áreas com altos níveis de ruído. A) Camptostoma obsoletum (risadinha), B) Polioptila dumicola (balança-rabo-de-máscara) e C) Myiarchus tyrannulus (maria-cavaleira-de-rabo-enferrujado). Fotos: Vitor C. M.Tolentino. 


\section{Considerações finais}

Nossa pesquisa sobre a utilização das aves em áreas florestais do Cerrado como objeto de estudo em biomonitoramento completa sete anos em 2020. Nossas metodologias têm se mostrado eficientes em registrar e compreender a ecologia da avifauna da região do Triângulo Mineiro e as influências dos impactos antrópicos sobre as mesmas. As análises do sangue das aves proporcionaram a obtenção de diferentes ferramentas úteis para pesquisa, tais como as anomalias nucleares eritrocitárias, perfil leucocitário e presença de diferentes parasitos sanguíneos. Dentro da bioacústica, outra metodologia empregada em nossas pesquisas, a análise dos sons emitidos pelas aves e a sua relação com os demais sons naturais e sons de origem antrópica, a avaliação da riqueza de espécies, o uso de índices acústicos para estimativas de riqueza e impactos ambientais relacionados ao ruído e a avaliação dos parâmetros de canto das aves também são ferramentas que se mostraram úteis.

Os principais destaques da nossa pesquisa foram que as áreas florestais mais próximas de cidades e rodovias possuem maiores níveis de ruído ambiental; as aves que habitam áreas florestais próximas ou inseridas em ambientes urbanos apresentaram maior quantidade de micronúcleos e eritroplastídeos, além de apresentarem alterações nos padrões de vocalização quando comparadas com aves de áreas florestais distantes do ambiente urbano; e que a riqueza de espécies de aves é maior em áreas florestais mais distantes de ambientes urbanos. Estes resultados evidenciam os impactos das alterações de origem antrópica sobre as aves de áreas florestais do Cerrado do Triângulo Mineiro.

Uma espécie de importância nos nossos estudos foi o soldadinho (Antilophia galeata), que se mostrou sensível ao uso das ferramentas de análise sanguínea para o biomonitoramento. Os indivíduos dessa espécie apresentaram anomalias nucleares eritrocitárias, parasitos sanguíneos e indícios de estresse pelo perfil leucocitário, principalmente nos ambientes mais próximos de cidades e rodovias. É uma espécie abundante na região e fiel aos territórios que habita, sendo capaz de permanecer nos diferentes ambientes submetidos às pressões antrópicas, contribuindo para o estudo de biomonitoramento no Cerrado brasileiro.

Programas contínuos de incentivo e financiamento à pesquisa, como o Programa de Pesquisas Ecológicas de Longa Duração (PELD) são essenciais para a produção de estudos que visam conhecer, compreender e monitorar de forma abrangente e continuada a avifauna de um determinado ecossistema. Assim, com o apoio do PELD, foi possível o desenvolvimento de anos de pesquisas sobre a avifauna do Cerrado do Triângulo Mineiro, e a obtenção dos dados apresentados neste capítulo. No entanto, nossa pesquisa sobre a utilização das aves do Cerrado como biomonitores da qualidade ambiental continua em andamento. Esperamos encontrar novas informações, mas que sejam complementares aos resultados atuais, proporcionando maior entendimento para a conservação da avifauna e dos ambientes da região.

\section{Para saber mais}

Baesse CQ, Tolentino VCM, Morelli S, Melo C (2019) Effect of urbanization on the micronucleus frequency in birds from forest fragments. Ecotox Environ Safe 171: 631637 doi: 10.1016/j.ecoenv.2019.01.026 
Baesse CQ, Tolentino VCM, Silva AM, Silva AA, Ferreira GA, Paniago, LPM, Nepomuceno JC, Melo C (2015) Micronucleus as biomarker of genotoxicity in birds from Brazilian Cerrado. Ecotox Environ Safe 115: 223-228 doi: 10.1016/j. ecoenv.2015.02.024

Tolentino VCM, Baesse CQ, Melo C (2018) Dominant frequency of songs in tropical bird species is higher in sites with high noise pollution. Environ Pollut 235:983-992 doi: 10.1016/j.envpol.2018.01.045 



\section{CAPÍTULO 7}

\section{DIVERSIDADE, DISTRIBUIÇÃO E CONSERVAÇÃO DOS ANFÍBIOS ANUROS}

Thiago R. de Carvalho Ariovaldo A. Giaretta

Os anfíbios viventes (Lissamphibia) são representados por três grandes grupos: o das salamandras, o das cobras-cegas ou cecílias, e o dos anuros, que inclui os sapos, rãs e pererecas (Figura 1). Os anfíbios estão amplamente distribuídos nos variados ecossistemas terrestres e aquáticos do planeta, com ocorrência desde a região equatorial até altas latitudes. As regiões polares, ilhas oceânicas, e ambientes marinhos são exceções à distribuição do grupo. A distribuição cosmopolita dos anfíbios se deve principalmente à ampla distribuição dos anuros, enquanto salamandras e cecílias estão comparativamente mais restritas geograficamente: as salamandras estão concentradas no hemisfério norte (Eurásia e África setentrional), com a ocorrência nas Américas, tendo a Amazônia como limite sul de distribuição. As cecílias, por outro lado, estão restritas às regiões tropicais do planeta (distribuição pantropical), exceto a Oceania.

A diversidade atual dos anfíbios é composta por mais de 8.000 espécies, sendo que quase $90 \%$ dessa diversidade é representada pelos anuros. Os anuros podem ser facilmente diferenciados dos outros dois grupos de anfíbios, na maior parte dos casos, com base em sua locomoção aos saltos, presença de girinos (larvas altamente modificadas que passam por metamorfose na transição com a fase adulta) e comunicação acústica.

A riqueza de espécies de anuros está concentrada nas regiões tropicais do planeta, com referência especial à região neotropical, que contém toda a América do Sul e Central, as ilhas do Caribe, e porção do extremo sul da América do Norte. Os níveis mais elevados de diversidade e endemismo de espécies neotropicais estão associados aos habitats tropicais da América do Sul, tais como as florestas amazônica e atlântica, e os Andes.

Na região neotropical, a anurofauna é diversa no número de espécies, no uso de habitat, nos modos reprodutivos, na diversidade acústica, entre outras. Existem também diferentes padrões de distribuição do grupo nessa região. A troca na composição de espécies pode ocorrer em associação com características da paisagem, devido à heterogeneidade dentro dos ecossistemas, ao longo de sua extensão e suas interfaces com outras formações majoritariamente abertas (Pantanal e Caatinga) e florestais (Amazônia e Mata Atlântica). A anurofauna do Cerrado é rica em espécies e essa riqueza também tem relação com a heterogeneidade de habitats que incluem complexos de montanha e seus gradientes altitudinais. 

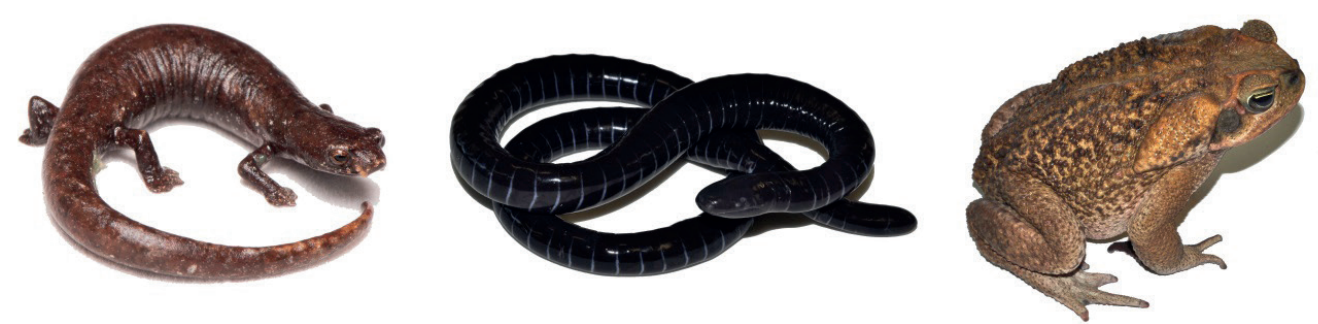

Figura 1. Representantes dos três grupos de Lissamphibia. Da esquerda para a direita: a salamandra Bolitoglossa paraensis (Urodela), a cecília Siphonops paulensis (Gymnophiona), e o sapo Rhinella dypticha (Anura). Créditos da foto de B. paraensis: Pedro L. V. Peloso.

\section{Breve histórico dos primeiros estudos sobre anuros no Cerrado}

Naturalistas visitaram o Cerrado ainda no século XIX, quando houve coletas históricas importantes para diversos grupos de animais, plantas e fósseis. As regiões do Triângulo Mineiro e sul goiano apareceram na história como região de coleta de anfíbios apenas no século XXI. As coletas pioneiras e/ou descrições por naturalistas brasileiros no Cerrado de Minas Gerais e Goiás se destacaram a partir da década de 1920 com as descrições de quatro espécies de anuros em 1925 pelo naturalista Adolpho Lutz (Ameerega flavopicta, Bokermannohyla pseudopseudis, Pseudis bolbodactyla, Rhinella rubescens), e quatro espécies novas em 1937 pelo naturalista Alípio MirandaRibeiro (Barycholos ternetzi, Proceratophrys goyana, Pseudopaludicola ternetzi, e Scinax fuscomarginatus). Nas décadas de 1950 a 1990, cerca de vinte e cinco novas espécies foram descritas para o Cerrado de Minas Gerais e Goiás, principalmente nas séries de contribuições científicas de Adão Cardoso, Bertha Lutz, Ivan Sazima, Ulisses Caramaschi, e Werner Bokermann. A partir dos anos 2000, o número de descrições teve um grande salto, totalizando mais de quarenta novas espécies descritas para a região até a última data de consulta para esse capítulo (maio/2020). Dentre elas, nove espécies foram descobertas no Triângulo Mineiro-sul/sudeste goiano (Figura 2).

Os dois herpetólogos dedicados à pesquisa com anuros e atuantes na região do Triângulo Mineiro-sul/sudeste goiano são Rogério Bastos (Universidade Federal de Goiás) e um dos autores desse capítulo (Ariovaldo Giaretta, Universidade Federal de Uberlândia). Muitos dos profissionais formados por eles ao longo dos últimos 20 anos ainda são atuantes na região e também têm contribuído para o aumento do número de espécies descobertas e descritas cientificamente.

\section{Riqueza, distribuição e endemismo}

O Cerrado é reconhecido pelo alto endemismo de alguns grupos específicos, notavelmente as plantas, peixes e lagartos. Em número menor, mas relevante, o Cerrado também possui endemismo de anfíbios. Existem mais de 200 espécies registradas para o Cerrado, sendo pelo menos 150 associadas principalmente ao bioma e 60 espécies típicas do bioma (Valdujo et al. 2012). Dentre esses exemplos, é possível observar espécies ou grupos de espécies com distribuição restrita a uma região particular do Cerrado, outras com distribuição ampla ao longo do bioma, ou até mesmo com ocorrência em biomas vizinhos. Existem ainda várias espécies com ocorrência restrita apenas à região onde foram descobertas e descritas, chamadas de microendêmicas. 
Há também dezenas de espécies amplamente distribuídas no Cerrado e biomas vizinhos. Como bons exemplos as mais bem distribuídas e mais comumente encontradas são: Dendropsophus minutus, Boana albopunctata, Scinax fuscovarius, Leptodactylus fuscus, L. macrosternum, Physalaemus cuvieri, Pseudopaludicola mystacalis, Rhinella dypticha, Trachycephalus typhonius. Há ainda um terceiro grupo formado por espécies típicas do Cerrado, mas com ocorrência registrada em biomas vizinhos (Tabela 1). Alguns grupos de anuros com diversificação concentrada nos biomas florestais adjacentes ao Cerrado têm representatividade de uma ou algumas espécies no Cerrado. Exemplos de grupos com a riqueza de espécies distribuídas principalmente na Amazônia são os anuros dos gêneros Allobates e Ameerega (Dendrobatoidea), e Oreobates e Pristimantis (Craugastoridae). Uma espécie de cada um desses gêneros é endêmica do Cerrado, exceto Ameerega com duas espécies endêmicas desse bioma. Há também exemplos de grupos com riqueza e distribuição concentradas na Mata Atlântica, como os gêneros Aplastodiscus, Ololygon e Vitreorana (Hylidae), Crossodactylodes (Hylodidae), e Ischnocnema (Brachycephalidae). Cada um desses gêneros tem uma espécie endêmica do Cerrado, com a exceção de Ololygon, com cinco espécies florestais registradas no Cerrado de Minas Gerais e Goiás.

Espécies de diferentes grupos de anuros podem ter distribuições relacionadas a formações geomorfológicas. No Cerrado o caso mais emblemático é o das espécies que ocorrem em associação direta aos ambientes de savanas e campos rupestres. Vale a ressalva que esses ambientes podem estar inseridos no Cerrado (p. ex., Serra da Canastra e Chapada dos Veadeiros), mas também podem ter interface com a Mata Atlântica (complexos do Espinhaço e da Mantiqueira) ou completamente inseridos neste bioma, assim como na Caatinga (Chapada Diamantina).
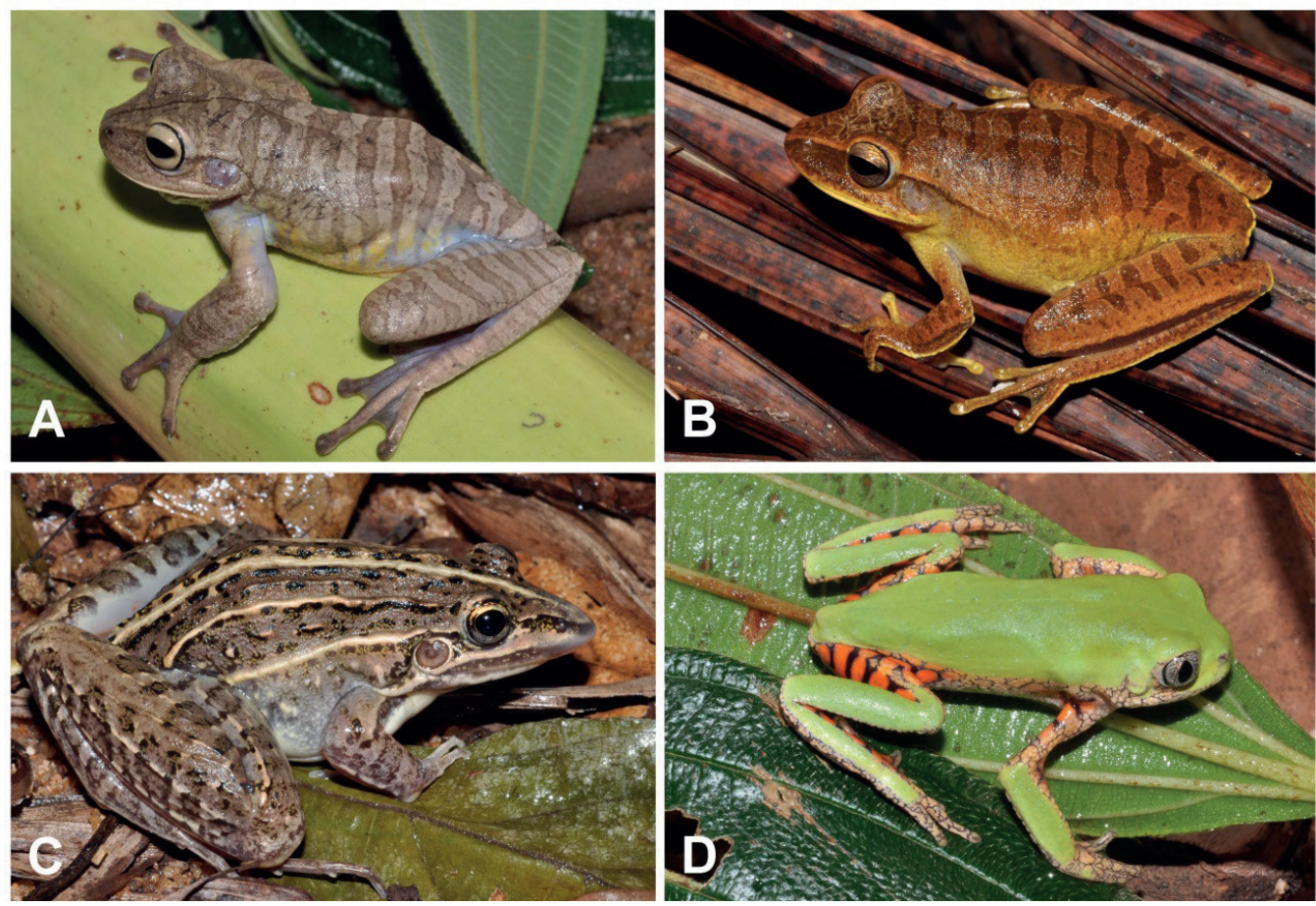

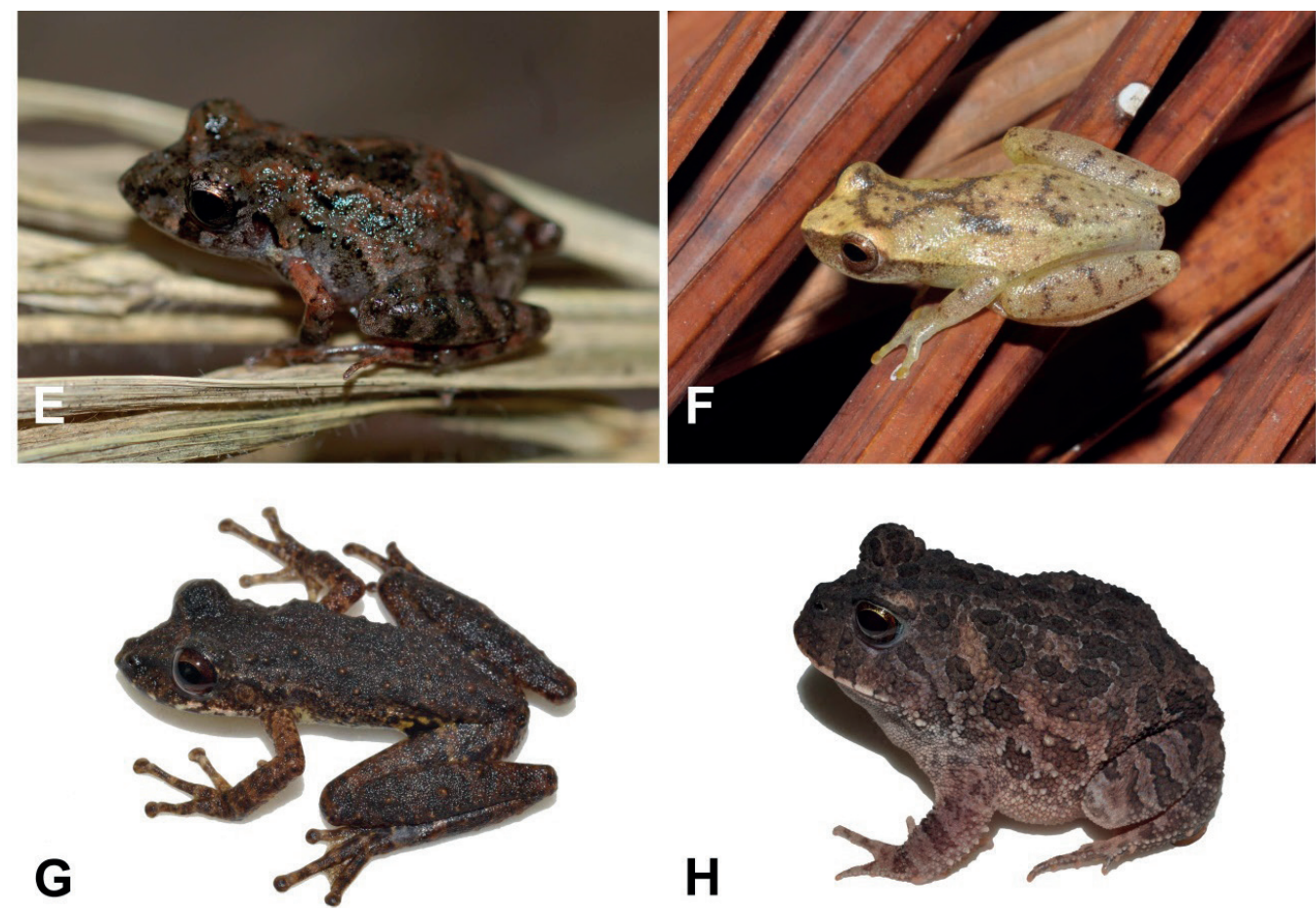

Figura 2. Oito das nove espécies de anuros descritas no Cerrado do Triângulo Mineiro e sul/sudeste goiano: (A) Bokermannohyla napolii, (B) Boana paranaiba, (C) Leptodactylus sertanejo, (D) Pithecopus araguari, (E) Ischnocnema penaxavantinho, (F) Dendropsophus cruzi, (G) Ololygon centralis, , e (H) Proceratophrys vielliardi.

A atribuição de espécies endêmicas dos campos rupestres ao padrão de endemismo no Cerrado, portanto, é controversa e deve ser examinada caso a caso. Dentre os anuros que ocorrem nos campos rupestres inseridos no Cerrado, há espécies distribuídas em diferentes complexos serranos (p. ex., Leptodactylus cunicularius nos complexos do Espinhaço, Mantiqueira e Canastra), assim como espécies endêmicas de uma região específica de campos rupestres no Cerrado (p. ex., Scinax cabralensis na Serra do Cabral e Leptodactylus tapiti na Chapada dos Veadeiros). Outras características da paisagem parecem determinar a ocorrência e microendemismo de espécies no Cerrado. Há casos de microendemismo associados a ecossistemas peculiares em áreas nucleares de Cerrado ou na interface do bioma com a Mata Atlântica. Dois exemplos interessantes são o de Ischnocnema karst, que tem ocorrência restrita a florestas deciduais associadas a afloramentos carbonáticos na interface Cerrado-Mata Atlântica da região de Arcos (MG), e o de Oreabates antrum, conhecida apenas das matas secas do extremo nordeste do estado de Goiás.

Este capítulo se dedica às diferentes diversidades listadas acima e relacionadas aos anuros do Cerrado, com enfoque especial em espécies ou grupos de espécies com distribuição no Triângulo Mineiro-Alto Paranaíba e sul goiano (sensu IBGE 1990), a partir daqui região referida como TMSG. Nesse recorte, apenas as três microrregiões goianas da mesorregião do sul goiano mais próximas ao Triângulo Mineiro (Catalão, Pires do Rio e Meia Ponte) foram incluídas.

A riqueza atual de espécies de anuros conhecidas para o Cerrado da região TMSG é composta por quase 80 espécies, sendo que nove espécies foram descobertas 
e descritas nessa região do Cerrado. Em ordem cronológica de descrição, apresentamos comentários sobre cada uma dessas espécies. No final da década de 1990, duas espécies foram descritas da Floresta Nacional de Silvânia: Ololygon centralis e Dendropsophus cruzi. A primeira espécie tem distribuição associada às matas de galeria de Goiás e Distrito Federal, a maior parte dela no TMSG, enquanto $D$. cruzi é amplamente distribuída no Cerrado do sudeste, centro-oeste e norte do Brasil, e na Bolívia. Em 2007, três espécies foram descritas do Triângulo Mineiro. Duas espécies do município de Uberlândia: Ischnocnema penaxavantinho da Reserva Ecológica do Panga e Leptodactylus sertanejo da reserva particular de Cerrado do Clube de Caça e Pesca Itororó de Uberlândia. A terceira espécie, Pithecopus araguari, foi descrita da Estação de Pesquisa e Desenvolvimento Ambiental Galheiro (EPDA-Galheiro), localizada no município de Perdizes. A primeira espécie (I. penaxavantinho) tem distribuição restrita ao TMSG e região mineira adjacente no noroeste do estado (Paracatu e Presidente Olegário). A segunda (L. sertanejo) está amplamente distribuída no Cerrado, enquanto a terceira (P. araguari) é conhecida apenas da localidade onde foi descoberta e descrita. Outras duas espécies foram descritas mais recentemente de localidades citadas acima: Bokermannohyla napolii (2012) da EPDA-Galheiro em Perdizes e Pseudopaludicola facureae (2013) da área urbana do município de Uberlândia. A primeira espécie só é conhecida da localidade de descrição, enquanto $P$. facureae é endêmica do Triângulo Mineiro. Outras duas espécies foram descritas do TMSG: Boana paranaiba (2010) de área rural do município de Araguari e Proceratophrys vielliardi (2013) do Parque Estadual da Serra de Caldas Novas. Ambas as espécies são conhecidas para o Cerrado de Minas Gerais e Goiás. Três das nove espécies descritas para o TMSG são endêmicas dessa região ou têm distribuição em grande parte associada a ela (como é o caso de $B$. napolii, O. centralis, P. facureae).

É importante ressaltar que vários estudos têm apontado para a existência de várias espécies que ainda não carregam um nome formal devido a dois fatores principais. Primeiramente, há espécies que carregam um histórico taxonômico-nomenclatural complexo e nem sempre é possível solucionar completamente esses casos complexos. Algumas vezes simplesmente pela falta de informações de localidade atreladas aos espécimes utilizados como base para a descrição da espécie. Outras vezes, os espécimes de referência em museus e coleções de zoologia podem estar descaracterizados pelo tempo e qualidade da preservação do material, além de descrições breves e inespecíficas que dificultam a identificação da espécie. Mais recentemente, com o uso intensificado de evidências outras além da morfologia para a identificação de espécies têm revelado que a riqueza de espécies ainda é muito subestimada. Em alguns casos isso se deve ao padrão recorrente de similaridade morfológica entre espécies diferentes, sejam elas próximas entre si ou com graus de parentesco mais distantes do que esperados com base em suas morfologias conservadas.

No caso dos anuros, as ferramentas que têm se mostrado mais eficazes, principalmente se combinadas, são a acústica e as sequências de DNA mitocondrial. Através dos sons que as espécies produzem é possível identificar várias espécies, mesmo que informações morfológicas não estejam disponíveis. Essa ferramenta é poderosa, principalmente nos casos em que algumas informações geográficas e ecológicas estejam disponíveis, como a localidade de coleta e o tipo de habitat que a espécie usa. O "DNA barcoding" (código de barras do DNA) é uma ferramenta que se popularizou nas últimas duas décadas. Esse "barcoding" consiste no uso de sequências 
de DNA mitocondrial para identificar espécies através do seu "código de barras", que é a informação genética que a espécie carrega em determinados genes.

$\mathrm{O}$ uso de grupos de dados distintos e independentes tem sido o protocolo mais utilizado para a resolução para muitos desses casos taxonômicos complexos. Essa abordagem é denominada taxonomia integrativa. No Cerrado, existem espécies de alguns gêneros que só podem ser diferenciadas entre si pelas suas vocalizações peculiares, notavelmente entre as várias de Pseudopaludicola que ocorrem no bioma, incluindo o Triângulo Mineiro-sul/sudeste goiano (Tabela 1). Embora a associação de dados morfológicos, acústicos e moleculares seja a mais comum em estudos integrativos, outras evidências podem ser cruciais para a resolução taxonômica de grupos específicos de anuros ou como aporte para o entendimento da sistemática e evolução desses grupos. Dados citogenéticos e da morfologia larval têm se mostrado valiosos para o entendimento da taxonomia e evolução de alguns grupos. Com o aumento rápido no número de descrições de espécies novas no bioma, é consensual que a riqueza de espécies de anuros do Cerrado ainda seja subestimada. Além disso, é importante considerar que há espécies com distribuição potencial no TMSG, atualmente conhecidas em regiões adjacentes em Minas Gerais e/ou Goiás, sendo alguns exemplos Pseudopaludicola atragula, Scinax tigrinus e Trachycephalus nigromaculatus.

\section{Considerações taxonômicas}

Algumas espécies foram recorrentemente citadas como ocorrendo no TMSG, porém os exemplos a seguir requerem uma avaliação caso a caso por diferentes razões. Um exemplo é o par de espécies Dendropsophus elianeae e D. rubicundulus que têm diferenciação morfológica sutil e vocalizações muito similares. A grande maioria dos registros de ocorrência no TMSG representa $D$. elianeae com base em morfologia, mesmo que muitas dessas populações da região têm sido referidas como D. rubicundulus. Contudo, registros no limite leste do TMSG (p. ex., região de São Gotardo) confirmam a ocorrência de D. rubicundulus na região. Ainda assim, vale a ressalva de que a simpatria (co-ocorrência) das duas espécies ainda não foi confirmada para o TMSG. Outro exemplo envolve o gênero Pseudis. A espécie P. bolbodactyla é comumente registrada na região, embora haja o registro de uma segunda espécie para o TMSG (P. platensis). Mais uma vez, a diferenciação morfológica e acústica é quase inexistente entre essas espécies e a citogenética e padrões geográficos (bacias hidrográficas) têm sido utilizados na identificação de populações.

Tabela 1. Espécies de anuros registradas no Cerrado do Triângulo Mineiro-sul/sudeste goiano. Padrões de distribuição: $\mathrm{AD}=$ amplamente distribuída, com ocorrência em pelo menos dois biomas; $\mathrm{E}=$ endêmica do Cerrado; $\mathrm{M}=$ microendêmica de uma região do Cerrado; $\mathrm{TC}=$ típica do Cerrado, distribuída principalmente no Cerrado, mas com ocorrência em biomas vizinhos ou ecótonos; $\mathrm{TO}$ = típica de outro bioma, mas ocorre no Cerrado. * Registros de espécies formalizados pela primeira vez para a região com base em espécimes na coleção de anfíbios da Universidade Federal de Uberlândia (AAG-UFU).

\begin{tabular}{lll}
\hline Espécie & Distribuição & Referência principal \\
\hline Adenomera cf. hylaedactyla & AD & Carvalho et al. (2019) Copeia 107:708-723 \\
\hline Adenomera saci & EN & Carvalho e Giaretta (2013) Zootaxa 3701:207-237 \\
\hline
\end{tabular}




\begin{tabular}{|c|c|c|}
\hline Allobates goianus & EN & Ramalho et al. (2020) Cuad Herpetol 34:93-97 \\
\hline Ameerega flavopicta & $\mathrm{TC}$ & Martins e Giaretta (2012) Check List 8:502-504 \\
\hline Aplastodiscus lutzorum & $\mathrm{E}$ & Berneck et al. (2007) Zookeys 642:115-130 \\
\hline Barycholos ternetzi & $\mathrm{E}$ & Valdujo et al. (2012) S Am J Herpetol 7:63-78 \\
\hline Boana albopunctata & $\mathrm{AD}$ & Valdujo et al. (2012) S Am J Herpetol 7:63-78 \\
\hline Boana faber & TO & Valdujo et al. (2012) S Am J Herpetol 7:63-78 \\
\hline Boana goiana & $\mathrm{E}$ & Ramalho et al. (2019) Neotrop Biodivers 5:10-21 \\
\hline Boana lundii & $\mathrm{E}$ & Valdujo et al. (2012) S Am J Herpetol 7:63-78 \\
\hline Boana paranaiba & $\mathrm{E}$ & Carvalho et al. (2010) Zootaxa 2521:37-52 \\
\hline Boana raniceps & $\mathrm{AD}$ & Valdujo et al. (2012) S Am J Herpetol 7:63-78 \\
\hline Boana stenocephala* & $\mathrm{TO}$ & Coleção AAG-UFU \\
\hline Bokermannohyla ibitiguara & $\mathrm{E}$ & Fiorillo et al. (2019) Herpetol Notes 12:565-575 \\
\hline Bokermannohyla napolii & $\mathrm{E}$ & Carvalho et al. (2012) Zootaxa 3321:37-55 \\
\hline Bokermannohyla sapiranga & $\mathrm{E}$ & Carvalho et al. (2013) Zootaxa 3746:383-392 \\
\hline Bokermannohyla sazimai & $\mathrm{E}$ & Carvalho e Giaretta (2013) Phyllomedusa 12:33-45 \\
\hline Chiasmocleis albopunctata & $\mathrm{TC}$ & Silva et al. (2009) Check List 5:314-316 \\
\hline Dendropsophus cruzi & $\mathrm{E}$ & Valdujo et al. (2012) S Am J Herpetol 7:63-78 \\
\hline Dendropsophus elianeae & $\mathrm{E}$ & Valdujo et al. (2012) S Am J Herpetol 7:63-78 \\
\hline Dendropsophus jimi & $\mathrm{E}$ & Valdujo et al. (2012) S Am J Herpetol 7:63-78 \\
\hline Dendropsophus melanargyreus & $\mathrm{TC}$ & Valdujo et al. (2012) S Am J Herpetol 7:63-78 \\
\hline Dendropsophus minutus & $\mathrm{AD}$ & Valdujo et al. (2012) S Am J Herpetol 7:63-78 \\
\hline Dendropsophus nanus & $\mathrm{AD}$ & Valdujo et al. (2012) S Am J Herpetol 7:63-78 \\
\hline Dendropsophus rubicundulus* & $\mathrm{E}$ & Coleção AAG-UFU \\
\hline Dermatonotus muelleri & $\mathrm{AD}$ & Oliveira et al. (2018) J Biogeogr 45:1-12 \\
\hline Elachistocleis cesarii & $\mathrm{AD}$ & Valdujo et al. (2012) S Am J Herpetol 7:63-78 \\
\hline Ischnocnema penaxavantinho & $\mathrm{E}$ & Assis et al. (2018) Herpetol Notes 11:561-563 \\
\hline Leptodactylus cunicularius & $\mathrm{E}$ & Giaretta et al. (2008) Iheringia 98:181-188 \\
\hline Leptodactylus furnarius & $\mathrm{AD}$ & Santos et al. (2010) Check List 6:253-254 \\
\hline Leptodactylus fuscus & $\mathrm{AD}$ & Valdujo et al. (2012) S Am J Herpetol 7:63-78 \\
\hline Leptodactylus labyrinthicus & $\mathrm{AD}$ & Valdujo et al. (2012) S Am J Herpetol 7:63-78 \\
\hline Leptodactylus aff. latrans & $\mathrm{TC}$ & Magalhães et al. (2020) Herpetol Monogr (in press) \\
\hline Leptodactylus macrosternum & $\mathrm{AD}$ & Magalhães et al. (2020) Herpetol Monogr (in press) \\
\hline Leptodactylus cf. mystaceus & $\mathrm{TC}$ & Silva et al. (2020) Zootaxa 4779:151-189 \\
\hline Leptodactylus mystacinus & $\mathrm{AD}$ & Schneider et al. (2019) PeerJ 7:e7869 \\
\hline Leptodactylus cf. natalensis* & TO & Coleção AAG-UFU \\
\hline Leptodactylus podicipinus & $\mathrm{AD}$ & Heyer (1994) Sm C Zool 546:1-124 \\
\hline Leptodactylus syphax & $\mathrm{AD}$ & Heyer et al. (2010) CAAR 868:1-9 \\
\hline Leptodactylus sertanejo & $\mathrm{E}$ & Pansonato et al. (2017) Herpetol Notes 10:579-583 \\
\hline Odontophrynus cultripes & $\mathrm{E}$ & Valdujo et al. (2012) S Am J Herpetol 7:63-78 \\
\hline Ololygon berthae & $\mathrm{TO}$ & Nascimento et al. (2016) Herpetol Notes 9:81-85 \\
\hline Ololygon canastrensis & $\mathrm{E}$ & Moura e Cazelli (2011) Check List 7:606-607 \\
\hline Ololygon centralis & $\mathrm{E}$ & Moura et al. (2010) Check List 6:173-175 \\
\hline Ololygon luizotavioi* & $\mathrm{TO}$ & Coleção AAG-UFU \\
\hline
\end{tabular}




\begin{tabular}{|c|c|c|}
\hline Phyllomedusa burmeisteri* & TO & Coleção AAG-UFU \\
\hline Physalaemus centralis & E & Valdujo et al. (2012) S Am J Herpetol 7:63-78 \\
\hline Physalaemus cuvieri & $\mathrm{AD}$ & Valdujo et al. (2012) S Am J Herpetol 7:63-78 \\
\hline Physalaemus marmoratus & $\mathrm{E}$ & Valdujo et al. (2012) S Am J Herpetol 7:63-78 \\
\hline Physalaemus nattereri & $\mathrm{E}$ & Valdujo et al. (2012) S Am J Herpetol 7:63-78 \\
\hline Pithecopus araguari & $\mathrm{E}$ & Giaretta et al. (2007) Zootaxa 1614:31-41 \\
\hline Pithecopus ayeye & $\mathrm{TC}$ & Magalhães et al. (2017) Ecol Evol 7:8812-8828 \\
\hline Pithecopus hypochondrialis & $\mathrm{AD}$ & Bruschi et al. (2013) BMC Genetics 14:e70 \\
\hline Pithecopus oreades & $\mathrm{E}$ & Ramalho et al. (2019) Neotrop Biodivers 5:10-21 \\
\hline Proceratophrys goyana & $\mathrm{E}$ & Ramalho et al. (2019) Neotrop Biodivers 5:10-21 \\
\hline Proceratophrys moratoi & $\mathrm{E}$ & Martinse Giaretta (2012)SAmJ Herpetol 7:203-212 \\
\hline Proceratophrys salvatori & $\mathrm{E}$ & $\begin{array}{l}\text { Morais et al. (2012) Neotrop Biodiver Conserv } \\
\text { 166:98-102 }\end{array}$ \\
\hline Proceratophrys vielliardi & $\mathrm{E}$ & Brandão et al. (2012) Herpetol Notes 5:223-225 \\
\hline Pseudopaludicola facureae & $\mathrm{E}$ & Andrade et al. (2020) Eur J Taxon (in press) \\
\hline Pseudopaludicola giarettai & $\mathrm{E}$ & Carvalho et al. (2015) Pap Avulsos Zool 55:245-254 \\
\hline Pseudopaludicola murundu & $\mathrm{TC}$ & Fiorillo et al. (2019) Herpetol Notes 12:565-575 \\
\hline Pseudopaludicola mystacalis & $\mathrm{AD}$ & Pansonato et al. (2014) Adv Zool 2014:e563165 \\
\hline Pseudopaludicola saltica & $\mathrm{E}$ & Andrade et al. (2016) Salamandra 52:107-124 \\
\hline Pseudopaludicola ternetzi & $\mathrm{E}$ & Andrade et al. (2017) Zootaxa 4319:391-400 \\
\hline Rhinella cf. crucifer* & TO & Coleção AAG-UFU \\
\hline Rhinella diptycha & $\mathrm{AD}$ & Valdujo et al. (2012) S Am J Herpetol 7:63-78 \\
\hline Rhinella mirandaribeiroi & $\mathrm{AD}$ & Narvaes e Rodrigues (2009) Arq Zool 40:1-73 \\
\hline Rhinella ocellata & $\mathrm{E}$ & Ramalho et al. (2019) Neotrop Biodivers 5:10-21 \\
\hline Rhinella rubescens & $\mathrm{E}$ & Valdujo et al. (2012) S Am J Herpetol 7:63-78 \\
\hline Scinax constrictus & $\mathrm{E}$ & Neves et al. (2014) Herpetol Notes 7:745-746 \\
\hline Scinax fuscomarginatus & $\mathrm{AD}$ & Valdujo et al. (2012) S Am J Herpetol 7:63-78 \\
\hline Scinax fuscovarius & $\mathrm{AD}$ & Valdujo et al. (2012) S Am J Herpetol 7:63-78 \\
\hline Scinax squalirostris & $\mathrm{AD}$ & Neves et al. (2019) Herpetozoa 32:113-123 \\
\hline Scinax similis & $\mathrm{TO}$ & Valdujo et al. (2012) S Am J Herpetol 7:63-78 \\
\hline Trachycephalus typhonius & $\mathrm{AD}$ & Valdujo et al. (2012) S Am J Herpetol 7:63-78 \\
\hline Vitreorana cf. eurygnatha & $\mathrm{TO}$ & Bang et al. (2020) Phyllomedusa 19:35-47 \\
\hline Vitreorana franciscana & $\mathrm{E}$ & Bang et al. (2020) Phyllomedusa 19:35-47 \\
\hline
\end{tabular}

Um terceiro exemplo envolve o par de espécies Dendropsophus melanargyreus e $D$. soaresi. Ambas as espécies têm sido citadas para o TMSG, o que reflete a impossibilidade de diferenciação morfológica e acústica entre elas. Por proximidade geográfica e composição de espécies em nível regional (diversidade-beta) compartilhada entre o TMSG e as regiões de onde elas foram descritas (Chapada dos Guimarães, MT, e Picos, PI), adotamos apenas um dos nomes para as populações do TMSG ( $D$. melanargyreus). Como no exemplo anterior, os registros de ocorrência de Scinax similis e $S$. $x$-signatus se baseiam em uma diferenciação incerta entre essas espécies. O nome S. similis foi adotado por ser o mais comumente usado para o TMSG. 
Diferente dos outros exemplos, as citações de ocorrência de Pseudopaludicola falcipes para o Cerrado se deve à identificação errada das espécies do gênero na região. A espécie Leptodactylus chaquensis é comumente citada para o TMSG, mas nos referimos a ela como sendo L. macrosternum. Esse rearranjo nomenclatural se deve à recente revisão desse grupo, que resultou na sinonimização dessas espécies, e apenas o nome L. macrosternum continuará válido. Outra espécie de Leptodactylus tem sido referida com diferentes nomes: L. petersii, L. aff. leptodactyloides, Leptodactylus sp. (gr. melanonotus), mas a identidade específica das populações do TMSG ainda não foi completamente resolvida. Pelo fato de não compartilhar a mesma morfologia das duas espécies amazônicas citadas acima, e ser mais similar morfológica e acusticamente à espécie atlântica L. natalensis, atribuímos provisoriamente as populações do TMSG ao nome L. cf. natalensis. Após a descrição de Pithecopus araguari, um estudo da sistemática desse grupo de anuros sugeriu que a espécie pudesse ser coespecífica a outra espécie do Cerrado (P. oreades). Como a sinonimização nunca foi formalizada, o nome $P$. araguari foi adotado para as populações da região da localidade tipo no Triângulo Mineiro.

\section{Uso do habitat e diversidade de modos reprodutivos}

Outras características ligadas aos padrões de distribuição dos anuros do Cerrado são os tipos de habitat. Esse grupo de vertebrados apresenta uma alta diversidade de modos reprodutivos (aproximadamente 40), fazendo que características das paisagens possam ser determinantes para a ocorrência de espécies. Uma característica interessante é o desdobramento de vários subtipos de um mesmo modo reprodutivo, que estão ligados à quantidade de ovos, ao modo de postura deles no ambiente, dentre outras características. Assim, espécies que usam o mesmo tipo de habitat para reprodução, como uma lagoa, podem ter modos reprodutivos distintos. O Cerrado é bem conhecido por suas águas: as cachoeiras, os riachos encachoeirados, e os corpos de água em geral que correm sobre diferentes tipos de fundo (pedregoso, rochoso, arenoso). Algumas espécies de anuros têm predileção por esses tipos de habitats. Os corpos de água de pequeno porte associados a florestas (matas de galerias) também apresentam um habitat particular para vários grupos de espécies. Um terceiro grupo é composto por aquelas que usam áreas temporariamente alagadas no período chuvoso, tanto em campos úmidos de áreas baixas quanto em complexos montanhosos.

Quando pensamos em diversidade de modos reprodutivos é difícil imaginar espécies que não dependem de água para a reprodução, já que as larvas dos anuros, os girinos, dependem de água como regra geral. A diversidade de modos reprodutivos inclui diferentes níveis de terrestrialidade em vários grupos de anuros. Exemplos extremos são aqueles que não possuem girinos no seu desenvolvimento após a eclosão dos ovos e aqueles com girinos semiterrestres. No Cerrado, diferentes estratégias reprodutivas com graus variados de terrestrialidade são observadas em diferentes grupos de anuros. As pererecas-folha (Phyllomedusidae) tem um modo reprodutivo muito peculiar. Há espécies dessa família de anuros que depositam seus ovos na superfície das folhas e as enrolam como um charuto. Cápsulas gelatinosas são depositadas sobre folha juntamente com a desova. As cápsulas são viscosas e permitem que as extremidades da folha se colem quando o casal dobra a folha longitudinalmente após a postura e fertilização dos 
ovos (Figura 3). Quando as larvas já estão bem formadas, elas escorregam da folha como um funil e terminam o desenvolvimento na água. Outro exemplo de algum nível de terrestrialidade pode ser observado nas espécies de rã-de-dardo (Dendrobatidae), cujo modo reprodutivo consiste no transporte dos girinos pelo macho em busca de corpos de água onde possam completar seu desenvolvimento até a metamorfose (Figura 3). Ainda há algumas espécies do grupo de rãs terrestres (Terrarana) que evoluíram um modo reprodutivo completamente independente de corpos de água, no qual os embriões se desenvolvem dentro dos ovos e, quando eclodem, são miniaturas dos adultos (Figura 3).

As espécies da família Leptodactylidae, comumente encontradas no Cerrado, são bem conhecidas por produzirem ninhos de espuma (a grande maioria das espécies) e diferentes grupos na família possuem modos reprodutivos com diferentes graus de terrestrialidade. Os ninhos de espuma são produzidos pelos machos, que batem o fluído cloacal liberado pela fêmea amplexada (abraçada pelo macho), concomitantemente à fertilização dos ovos liberados (veja Figura 4A para um exemplo de amplexo em anuros). Os ninhos são produzidos na superfície da água, na borda de corpos de água em contato com o solo, em depressões que acumulam água sobre a rocha, ou podem ser subterrâneas. Os ninhos subterrâneos podem ter contato com água através da abertura da câmara ou estarem completamente isolados da água, dependendo de enxurradas para carrear as larvas aos corpos de água. Os ovos eclodem e os embriões se desenvolvem até estágios diferentes dependendo da espécie ou grupo de espécies, ou ainda como reflexo de predação, que podem forçar o abandono do ninho para a água precocemente. Espécies do grupo de Leptodactylus fuscus constroem ninhos subterrâneos isolados da água, mas os girinos precisam alcançar a água em um estágio avançado de desenvolvimento para completarem o seu desenvolvimento e metamorfose. As espécies tendem a usar depressões que serão inundadas pela água durante o período chuvoso, assim, os girinos são lavados da câmara subterrânea para poças temporárias, ondem terminam seu desenvolvimento. Em outro gênero de Leptodactylidae, Adenomera, o modo reprodutivo mais comum tem um passo a mais em direção à terrestrialidade. As espécies constroem ninhos de espuma em câmaras subterrâneas como as espécies do grupo de L. fuscus, mas os girinos completam o seu desenvolvimento no ninho de espuma, de onde saem já metamorfoseados como miniaturas dos adultos.

\section{Diversidade acústica}

Quando se fala em diversidade acústica, diferentes coisas podem vir à mente. Ao escutar o canto de um sabiá-laranjeira, sua vocalização pode ser chamada de diversa ou complexa. Quando comparados às aves, os sons produzidos dos anuros podem ser vistos como simples e estereotipados se as espécies forem examinadas individualmente. Por outro lado, as espécies de aves, sobretudo as aves canoras, tendem a incorporar vários sons distintos em sequências muito variadas, chamadas de frases. Além disso, a variação individual e intraespecífica é muito maior em aves do que em anuros. Em anuros, a produção de sons tem especial relevância na reprodução da grande maioria das espécies. Os machos das espécies geralmente vocalizam para atração de fêmeas de sua espécie (Figura 4B). Espécies territoriais também vocalizam para o estabelecimento e manutenção de territórios. Existem outros tipos de vocalização conhecidas para anuros, mas as "vocalizações reprodutivas" são as mais comuns dentre as espécies 
de anuros. Cabe a ressalva que algumas espécies não usam sons como parte do seu comportamento reprodutivo. Se olharmos para a variação entre espécies, os anuros passam a se tornar mais interessantes em termos de diversidade acústica, uma vez que as espécies produzem sons diferentes entre si consistentemente, de modo que podemos separar dezenas de espécies de anuros vocalizando numa dada área e ao mesmo tempo.
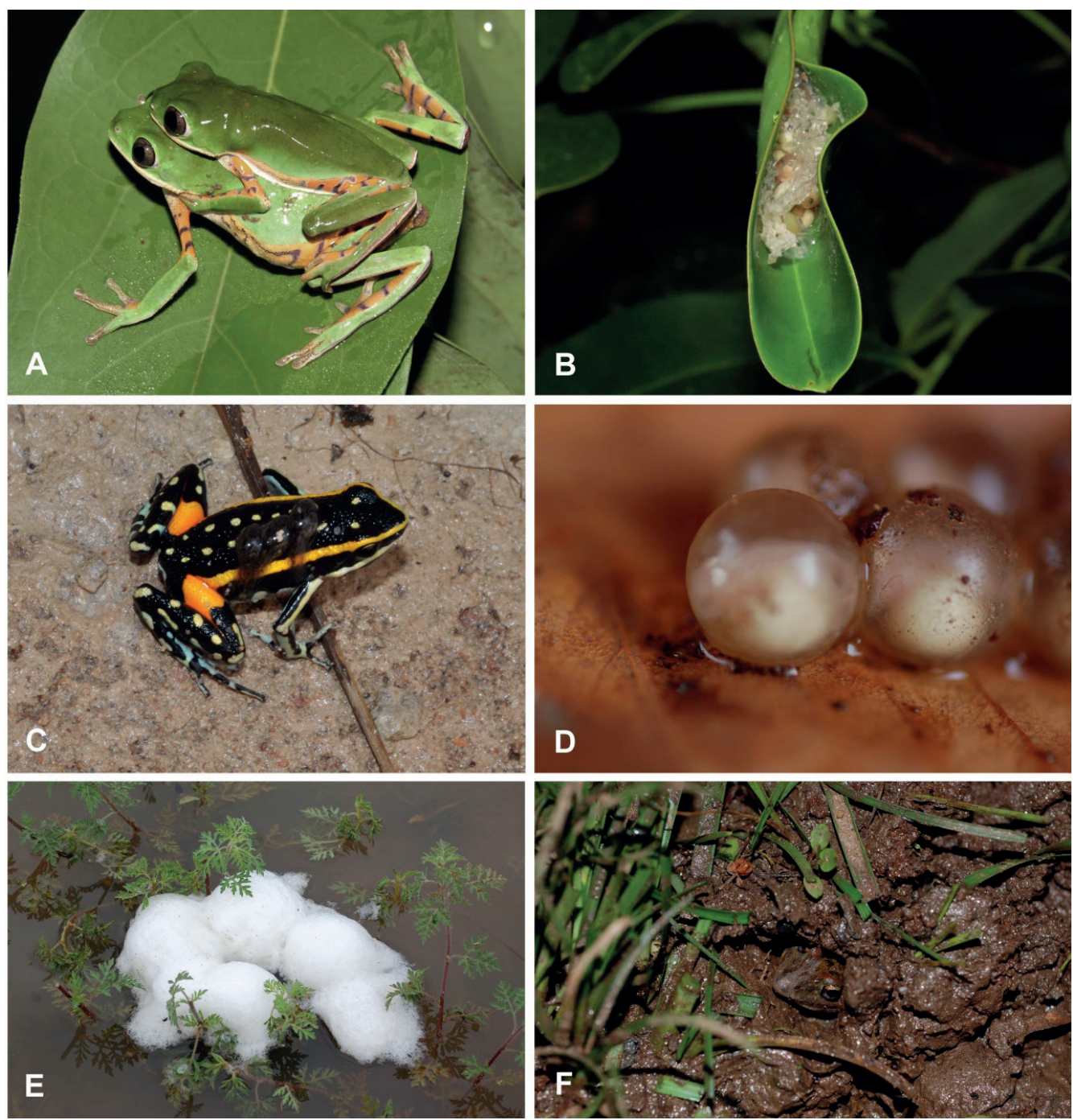

Figura 3. Modos reprodutivos com diferentes graus de terrestrialidade. (A-B) Casal de Pithecopus hypochondrialis e desova da espécie em folha fechada pelo casal; foto: Leandro A. da Silva. (C) Macho de Ameerega flavopicata carregando girinos a corpo de água. (D) Desova terrestre de Barycholos ternetzi encontrada no folhiço de um capão de mata no Cerrado. (E) Ninhos de espuma (desova comunal) de Physalaemus marmoratus em uma poça temporária. (F) Macho de Leptodactylus fuscus dentro da câmara subterrânea construída por ele, e onde ele constrói o ninho de espuma juntamente com a fêmea (desova subterrânea). 
Os padrões de diversidade acústica podem ser analisados através de diferentes perspectivas. Uma delas é a maneira que as espécies organizam os sons que produzem. Elas podem emitir sons isoladamente e estes podem ser emitidos de maneira regular ou não. Outras espécies emitem sons em sequências definidas. Além disso, existem outras diferenças na estrutura das vocalizações que são sensíveis ao ouvido humano. Muitas espécies emitem sons comumente denominados pulsados, que são percebidos por nós como um som com unidades repetidas rapidamente. Esses sons podem nos lembrar o raspar de uma cuia, o trinado de insetos, estalidos, ou sons diversos produzidos por mamíferos (balidos, gemidos, etc.). Essas características podem ser caracterizadas formalmente em análises acústicas. Outra característica sensível a nós é a modulação na frequência. Muitas espécies produzem sons assobiados que ora modulam a frequência do início ao fim (percepção de grave e agudo) ora não. As espécies ainda podem combinar diferentes tipos de sons em suas emissões. Todas essas características, quando reunidas, geram padrões gerais dos sons produzidos pelos anuros e nos auxiliam na identificação de muitas espécies antes mesmo de visualizá-las.

No Cerrado, alguns padrões acústicos são únicos e merecem atenção. Há uma espécie de pererecas do gênero Bokermannohyla (B. sapiranga) que ocorre em riachos encachoeirados e grotas, incluindo o sul/sudeste goiano. Ela é emblemática pelo seu canto, que pode lembrar o piado de corujas. A semelhança é tamanha que ornitólogos se confundem quando escutam os sons desse anuro. Espécies de diferentes gêneros produzem sons que remetem a assobios curtos ou longos. A espécie tradicionalmente relacionada à sua vocalização é a rã-assobiadora (Leptodactylus fuscus). Além dela, outras espécies na região produzem assobios: Pseudopaludicola giarettai, a única espécie de seu gênero que produz esse tipo de som; e Adenomera saci. Esta última foi nomeada com base em seus assobios, que foram associados na descrição original aos assobios do saci-pererê, icônico personagem do nosso folclore.
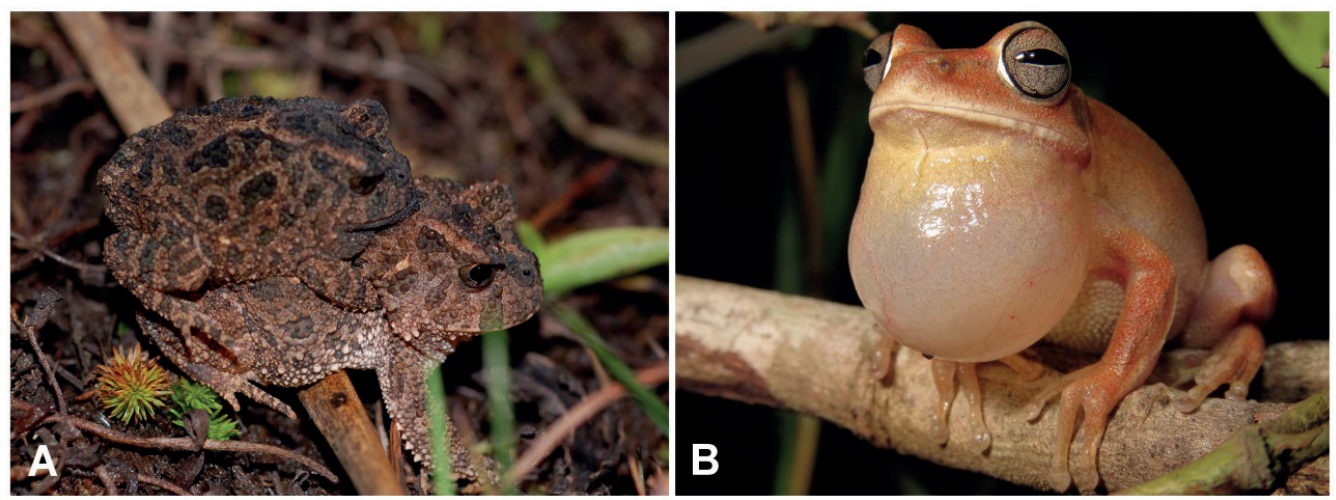

Figura 4. (A) Casal de Proceratophrys moratoi em amplexo. O macho é notavelmente menor que a fêmea da espécie. (B) Macho de Boana caiapo vocalizando; foto: Leandro A. da Silva.

Outros casos emblemáticos são as espécies de pererecas do gênero Boana. A perereca-carneiro ou perereca-cabrinha (Boana albopunctata) produz sons que lembram o balido de uma cabra. A perereca-risada (B. raniceps) vocaliza como se estivesse gargalhando. O sapo-ferreiro ou sapo-martelo (B. faber) emite estampidos repetidamente que nos faz lembrar o som de um martelo contra alguma superfície. 
A rã-cachorro (Physalaemus cuvieri) vocaliza como se estivesse latindo, enquanto a rã-choradeira (P. marmoratus) como um gemido longo e lamurioso. O sapo-apito (Elachistocleis cesarii) produz um som longo e agudo que nos remete a um apito de um juiz de futebol. A rã-gotinha (Leptodactylus podicipinus) produz um piado tão curto e modulado que nos remete ao som do cair de gotas de água. O nome raspa-cuia é associado a diferentes espécies (Pseudis bolbodactyla e Scinax fuscovarius) com sons que nos lembram o raspar de cuia com uma colher. Os sons peculiares de algumas dessas espécies de anuros podem ser ouvidos através deste link: https://www.youtube. com/playlist?list=PLm6IqoWIC80_7EttM-qW1RIhFOtAdFQ28.

\section{Panorama atual sobre as ameaças e conservação}

Em comparação com os biomas florestais no país (Amazônia e Mata Atlântica), a riqueza total de anfíbios no Cerrado não é equiparável à dos outros dois biomas. Mesmo assim, a riqueza conhecida de espécies distribuídas no Cerrado (endêmicas ou não) é relevante. Além da riqueza total e padrão de endemismo de anfíbios no bioma, há um fator preponderante para a análise de ameaças potenciais e risco de extinção das espécies no Cerrado: a proporção da área total que originalmente correspondia ao bioma que já foi perdida, principalmente pela expansão das áreas urbanas e atividades agropecuárias. Em um cenário com áreas naturais pequenas e fragmentadas, as ameaças à conservação das espécies aumentam drasticamente. O Cerrado é o bioma que atualmente mais sofre com a expansão agropecuária e as unidades de conservação existentes não são necessariamente suficientes em área e continuidade dos ecossistemas para garantir o sucesso e estabilidade das populações.

Há ao menos uma espécie de anuro (Allobates goianus; Figura 5) com ocorrência no TMSG classificada como "em perigo" na lista vermelha de espécies brasileiras. A principal ameaça a essa espécie é a perda de habitat. As poucas populações conhecidas de A. goianus estão isoladas em fragmentos florestais no estado de Goiás. Além dessa espécie, existem dezenas de outras potencialmente ameaçadas pela perda de habitat no Cerrado, espécies essas atualmente incluídas na categoria "dados insuficientes". Assim como A. goianus, muitas espécies de anuros do Cerrado são conhecidas de apenas uma ou poucas localidades, e informações sobre o tamanho e a viabilidade das populações, além da susceptibilidade a outras ameaças, como patógenos, são necessárias para a avaliação do real perigo de extinção dessas espécies. Somado a isso, vale ressaltar que ainda não temos conhecimento suficiente sobre a diversidade de anuros no bioma. Infelizmente, o cenário é desanimador quando olhamos para a destruição dos vários ecossistemas do Cerrado em uma velocidade não equiparável às descobertas científicas e publicação delas pelos cientistas. Além de investimento em educação e ciência, políticas públicas que promovam programas de conservação de espécies e regiões e a fiscalização ambiental eficiente são contrapartidas necessárias para uma mudança efetiva desse cenário. 


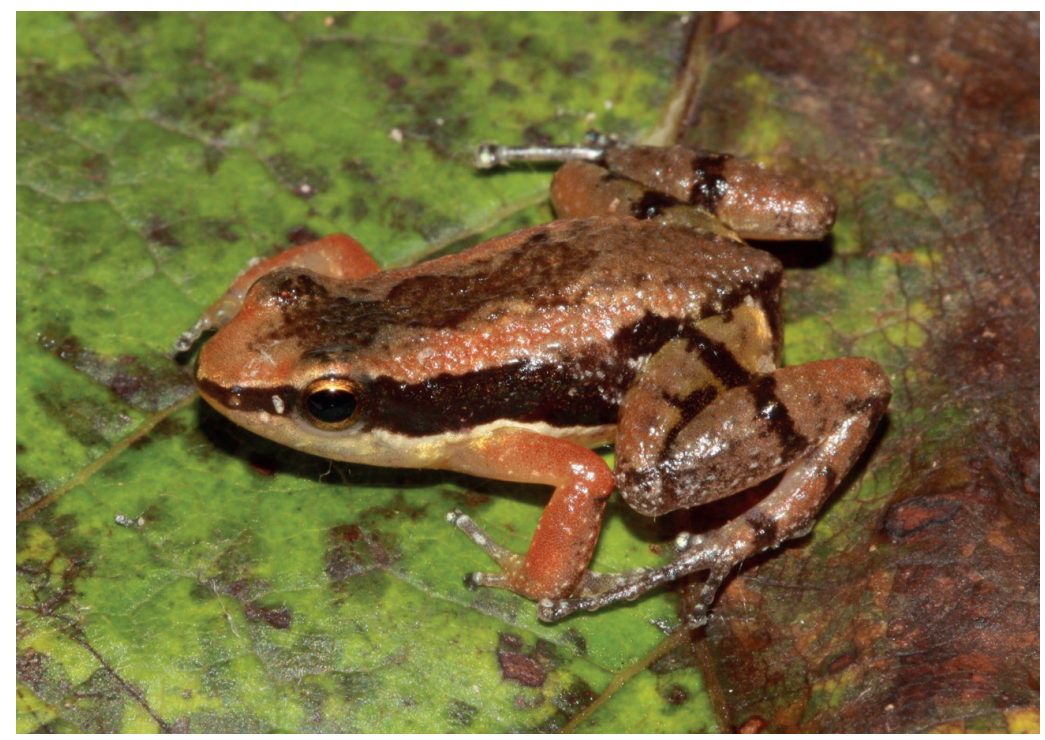

Figura 5. Indivíduo de Allobates goianus, espécie endêmica do Cerrado goiano, atualmente classificada na categoria "em perigo" na lista vermelha de espécies brasileiras devido à perda de habitat.

\section{Para saber mais}

Giaretta AA, Menin M, Facure KG, Kokubum MNC, Oliveira-Filho JC (2008) Species richness, relative abundance, and habitat of reproduction of terrestrial frogs in the Triângulo Mineiro region, Cerrado biome, southeastern Brazil. Iheringia, Série Zoologia 98:181-188

Haddad CFB, Prado CPA (2005) Reproductive modes in frogs and their unexpected diversity in the Atlantic Forest of Brazil. BioScience 55:207-217 doi: 10.1641/0006-3568(2005)055[0207:RMIFAT]2.0.CO;2

Instituto Brasileiro de Geografia e Estatística (1990) Divisão regional do Brasil em mesorregiões e microrregiões geográficas. Ministério da Economia, Fazenda e Planejamento, Brasília.

Instituto Chico Mendes de Conservação da Biodiversidade (2018) Livro Vermelho da Fauna Brasileira Ameaçada de Extinção. ICMBio/MMA, Brasília

Magalhães FM, Lyra ML, Carvalho TR, Baldo D, Brusquetti F, Burella P, Colli GR, Gehara MC, Giaretta AA, Haddad CFB, Langone JA, López JA, Napoli MF, Santana DJ, de Sá RO, Garda AA (2020) Taxonomic review of South American butter frogs: phylogeny, biogeographic patterns, and species delimitation in the Leptodactylus latrans species group (Anura: Leptodactylidae). Herpetol Monogr (no prelo)

Morais AR, Siqueira MN, Lemes P, Maciel NM, De Marco Jr P, Brito D (2013) Unraveling the conservation status of Data Deficient species. Biol Conserv 166:98-102 doi: 10.1016/j.biocon.2013.06.010

Neves MO, Yves A, Pereira EA, Alves L, Vasques JB, Coelho JFT, Silva PS (2019) Herpetofauna in a highly endangered area: the Triângulo Mineiro region, in Minas Gerais State, Brazil. Herpetozoa 32:113-123 doi: 10.3897/herpetozoa.32.e35641 
Ramalho WP, Jorge RF, Guimarães TVC, Pires RAP, Peña AP, Guerra V (2019) Structure and regional representativeness of the herpetofauna from Parque Estadual da Serra de Caldas Novas, Cerrado, Central Brazil. Neotrop Biodivers 5:10-21 doi: 10.1080/23766808.2019.1583305

Silvano DL, Valdujo PH, Colli GR (2016) Priorities for conservation of the evolutionary history of amphibians in the Cerrado. In: Pellens R, Grandcolas P (eds) Biodiversity conservation and phylogenetic systematics, topics in biodiversity and conservation 14, Springer, Berlim, pp 287-304 doi: 10.1007/978-3-319-22461-9_14

Valdujo PH, Silvano DL, Colli GR, Martins M (2012) Anuran species composition and distribution patterns in Brazilian Cerrado, a neotropical hotspot. South American J Herpetol 7:63-78 doi: 10.2994/057.007.0209 



\title{
CAPÍTULO 8
}

\section{OS MACROINVERTEBRADOS AQUÁTICOS}

\author{
Giuliano B. Jacobucci \\ Renata M. G. Souto \\ Marina C. Cunha \\ Ana Cláudia G. Barboza \\ Ariádine C. Almeida
}

As comunidades aquáticas de águas continentais são representadas por diferentes organismos, incluindo desde bactérias e microalgas até invertebrados e peixes. Os invertebrados aquáticos representam um dos grupos com maior biodiversidade nos diferentes ecossistemas aquáticos. Embora não haja estimativas precisas, certamente o número de espécies de invertebrados dulcícolas é da ordem de centenas de milhares de espécies. Essa diversidade não está uniformemente distribuída nos ecossistemas aquáticos. Ambientes rasos de regiões litorâneas lacustres e cursos d'água de pequenas dimensões são altamente heterogêneos em termos de habitats e usualmente abrigam elevada diversidade de organismos. Por outro lado, ambientes profundos ou eutrofizados tendem a apresentar baixa diversidade.

Os invertebrados aquáticos usualmente são classificados de acordo com seu tamanho, sendo os macroinvertebrados representados por organismos que apresentam dimensões superiores a $0,5 \mathrm{~mm}$ e geralmente são visíveis a olho nu. A maioria dos macroinvertebrados aquáticos apresenta hábito bentônico, ou seja, vive associada a diferentes tipos de substratos, como folhiço, troncos, raízes e galhos de plantas terrestres, seixos e plantas aquáticas que ocorrem no fundo de ambientes lênticos, como lagos e represas, que apresentam reduzida movimentação da água; e também em ambientes lóticos, como rios e riachos, com maior movimentação de água.

Os macroinvertebrados aquáticos são representados principalmente por insetos, anelídeos e moluscos, mas incluem outros grupos taxonômicos como crustáceos, poríferos e platelmintos (Figura 1). Os insetos aquáticos correspondem ao grupo com maior diversidade registrada dentre os macroinvertebrados, tanto do ponto de vista taxonômico, quanto de suas adaptações morfológicas e fisiológicas e de características ecológicas como sua organização trófica. O gráfico da figura 2 possibilita visualizar a variação da riqueza de insetos aquáticos entre algumas regiões do mundo, mas certamente subestimam o número de espécies no Brasil para a maioria dos grupos, visto que muitas regiões do país ainda foram pouco inventariadas, particularmente a região amazônica, e há relativamente poucos entomólogos especialistas, considerandose a extensão territorial continental e a diversidade de ambientes aquáticos do país. Para citar apenas um exemplo, especialistas estimam que haja mais de 300 novas espécies de Trichoptera a serem descritas, depositadas em museus no Brasil e, principalmente, no exterior. 

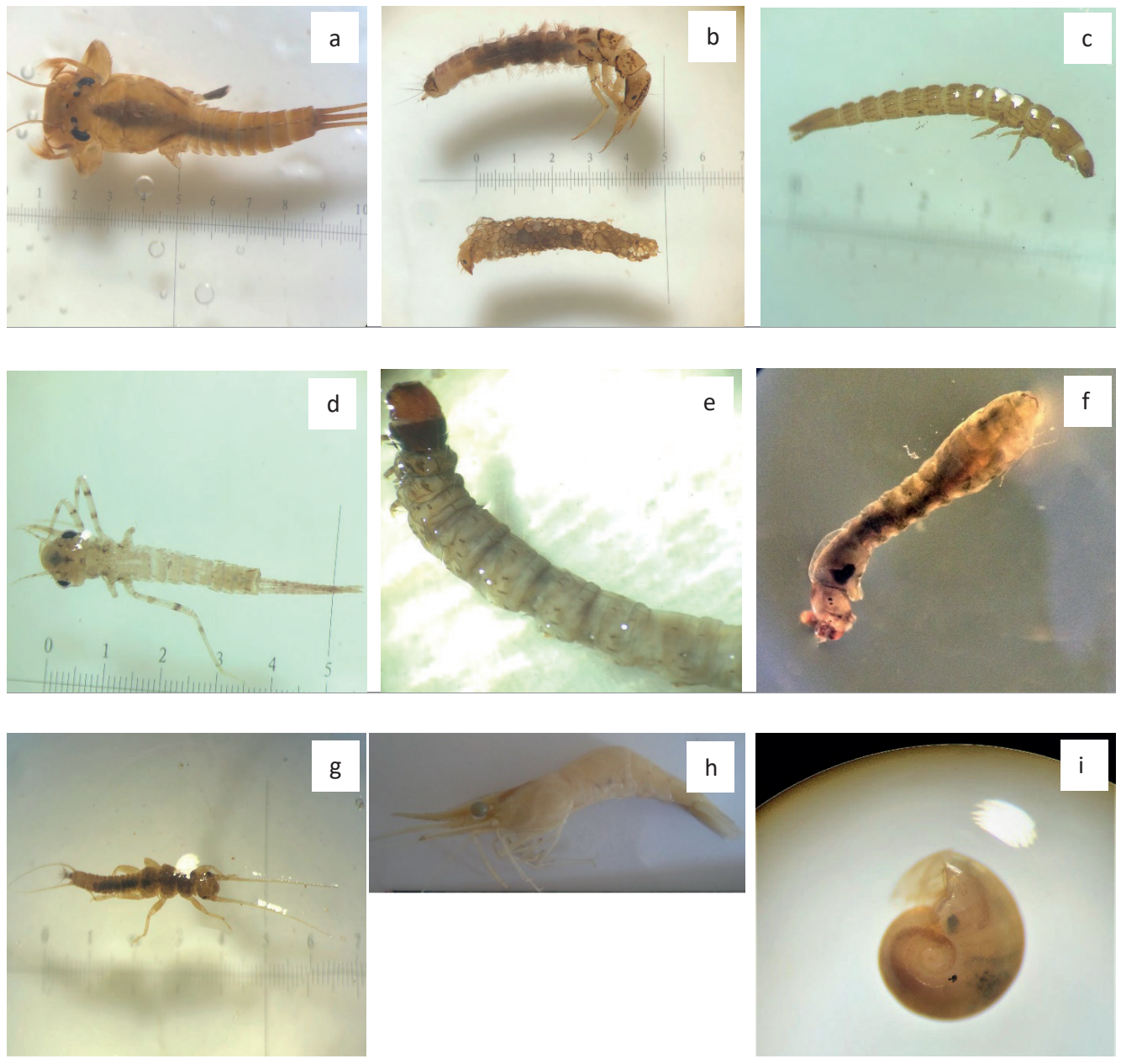

Figura 1. Alguns grupos de macroinvertebrados bentônicos, incluindo as ordens de insetos (a) Ephemeroptera, (b) Trichoptera, (c) Coleoptera, (d) Odonata, (e) Lepidoptera, (f) Diptera, (g) Plecoptera, crustáceo decápode (h) e molusco gastrópode (i).

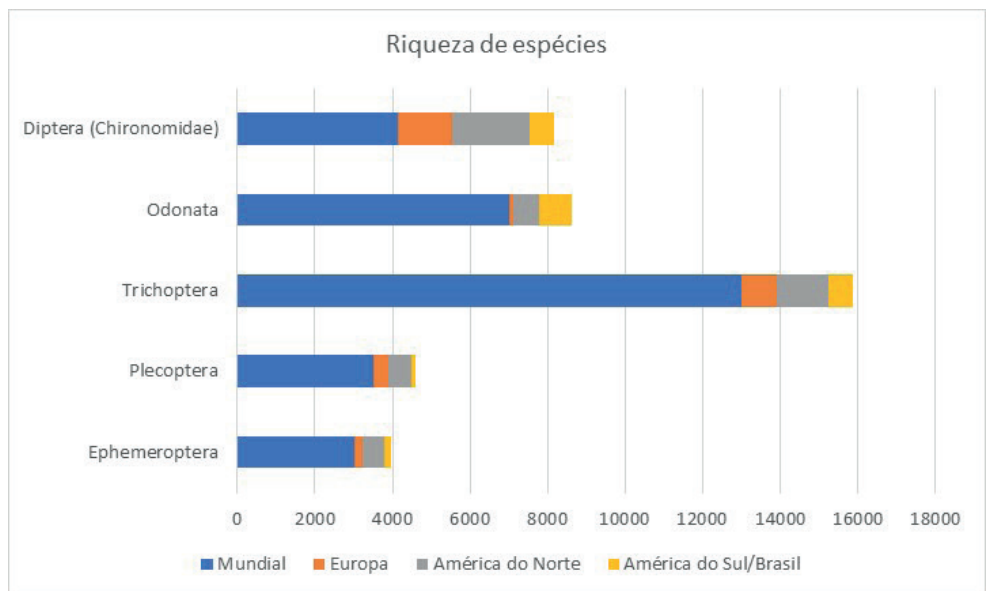

Figura 2. Riqueza de espécies de alguns grupos de insetos aquáticos. A riqueza de Diptera Chironomidae refere-se à região Neotropical. 
Os insetos aquáticos, em sua maioria, apresentam somente a parte juvenil (larvas e ninfas) de seu ciclo de vida na água, sendo os adultos terrestres. É o caso, por exemplo, de representantes das ordens Ephemeroptera, Plecoptera, Trichoptera, Odonata, Diptera, Megaloptera e Lepidoptera. Já os representantes das ordens Coleoptera e Hemiptera apresentam todo seu ciclo de vida no ambiente aquático.

\section{Padrões de distribuição em diferentes escalas espaciais}

A distribuição dos macroinvertebrados aquáticos varia em diferentes escalas espaciais e depende, em última análise, de fatores ambientais e interações bióticas que caracterizam os diferentes ambientes aquáticos em que esses organismos ocorrem. Dentre os fatores ambientais podemos citar o $\mathrm{pH}$, a temperatura, a velocidade da corrente, a concentração de oxigênio dissolvido na água, a disponibilidade de alimento e o tipo de substrato, dentre outros. Interações bióticas como predação, competição e parasitismo também influenciam a distribuição dos macroinvertebrados.

Por conta da variação dos fatores ambientais e das interações, a distribuição das comunidades de macroinvertebrados tende a ser heterogênea. Em lagos e rios de grande porte, a região litorânea apresenta maior diversidade taxonômica e trófica de macroinvertebrados, pois apresenta maior heterogeneidade de micro habitats, recursos alimentares e níveis de oxigênio mais elevados. Na região profunda, o nível de oxigenação e a variedade de recursos alimentares tende a ser menor, o que reduz a diversidade de macroinvertebrados, embora os organismos presentes nesse ambiente possam ser muito abundantes. Em ambientes lóticos de menor porte, a velocidade de corrente é um fator estruturador importante, pois influencia o tipo de substrato presente e, consequentemente, a disponibilidade de alimento e abrigo, além de favorecer, em maior ou menor intensidade, o arrasto dos organismos.

\section{Organização trófico-funcional}

Nos ambientes aquáticos, luz, nutrientes e temperatura determinam mudanças no equilíbrio entre os processos de autotrofia e heterotrofia (Figura 3). Ambientes com maior incidência luminosa terão maior produtividade primária resultante dos processos fotossintéticos de algas e plantas aquáticas, ou seja, matéria orgânica de origem autóctone, gerada dentro do próprio ecossistema. Já os ambientes aquáticos mais sombreados pela vegetação ripária, dependerão da entrada de matéria orgânica de origem alóctone (terrestre). Nesse último caso, a matéria orgânica do ambiente terrestre é lixiviada ou carreada para a água a partir do ambiente terrestre circundante. 


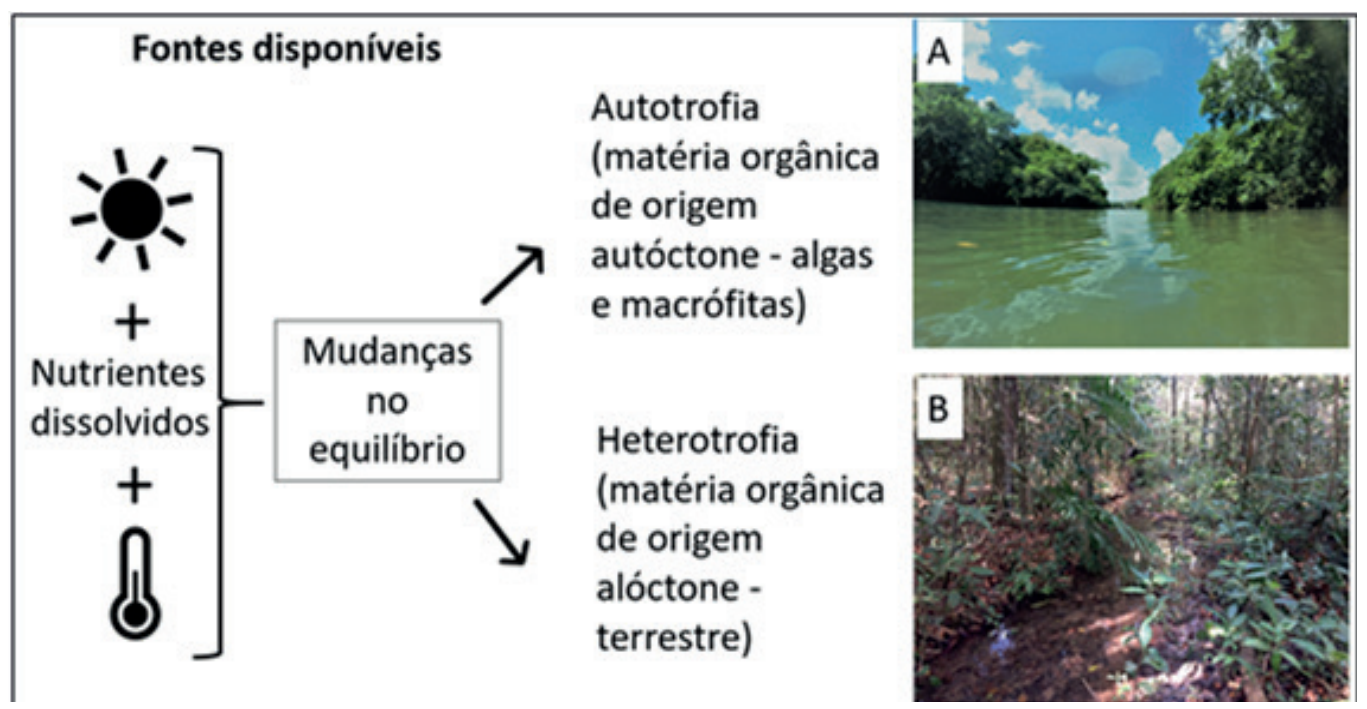

Figura 3. Fontes disponíveis de energia. A) Ambiente aquático com maior incidência de energia luminosa. B) Ambiente aquático sombreado pela vegetação ripária.

Variações no equilíbrio de matéria orgânica autóctone e alóctone influenciam a estrutura das comunidades de macroinvertebrados aquáticos, determinando quais grupos de adaptações para a aquisição de alimentos são favorecidos. O conceito de grupo funcional de alimentação (GFA), utilizando o papel ecológico dos macroinvertebrados aquáticos de riachos, surgiu na América do Norte há mais de 40 anos. Desde então, o método de classificação de GFA, embora com algumas adaptações, tem sido adotado para diversos outros tipos de ambientes dulcícolas, incluindo aqueles de climas tropicais. Os GFA consideram os componentes fenotípicos (adaptações morfológicas e comportamentais) dos macroinvertebrados que influenciam os processos de degradação da matéria orgânica, em vez do alimento ingerido propriamente dito. Para isso, tem sido dada ênfase na compartimentalização das categorias desses recursos, caracterizando-os por tipo e tamanho, além de destacar a microbiota que vive associada a eles, podendo esse particionamento refletir a fonte do alimento. Cinco são os grupos funcionais básicos relacionados a essas diferentes formas de se utilizar os recursos alimentares disponíveis: (i) fragmentadores (herbívoros e detritívoros), (ii) coletores (filtradores e catadores); (iii) raspadores, (iv) sugadores-herbívoros e (v) predadores.

Os fragmentadores podem morder e/ou mastigar tanto macrófitas (plantas e macroalgas) quanto detritos foliares ou matéria orgânica particulada grossa (MOPG), que apresenta dimensões superiores a $1 \mathrm{~mm}$. As macrófitas podem ser encontradas enraizadas no sedimento com as folhas emersas (acima da lâmina da água), submersas ou flutuando, além daquelas que vivem submersas livres ou flutuantes (não enraizadas). Já o detrito foliar (liteira ou serapilheira), composto por fragmentos de caules, folhas (Figura 4), frutos e sementes, encontra-se acumulado no leito do ambiente aquático.

Geralmente, os fragmentadores dão preferência a fragmentos intensamente colonizados por microorganismos (fungos, bactérias e protozoários) em função do maior valor nutricional agregado. A matéria orgânica fragmentada é transformada em partes menores, podendo ser disponibilizada aos coletores, além de que, durante a degradação das plantas ou da excreção pelos macroinvertebrados, os compostos orgânicos podem 
ser liberados na água, retornando o nutriente rapidamente ao ecossistema aquático. No que se refere à caracterização ambiental dos riachos, por haver uma associação entre fragmentadores e a vegetação ripária, sua abundância pode indicar, por exemplo, a qualidade da cobertura da vegetação ripária e a disponibilidade desse detrito no ambiente.

Os coletores são organismos com partes do aparelho bucal adaptados para coletar pequenas partículas. Podem ser tanto coletores-filtradores como coletorescatadores. Ambos dependem, geralmente, de matéria orgânica particulada fina (MOPF) de origem alóctone, com menos de $1 \mathrm{~mm}$. Coletores-filtradores possuem adaptações para se alimentarem das partículas diretamente na coluna de água e coletores-catadores daquelas depositadas em áreas com reduzida movimentação da água no leito do ambiente aquático. Coletores são muitas vezes abundantes em riachos com velocidade da água lenta, onde partículas finas são abundantes. A proporção de coletores não só pode indicar a presença de detritos finos estocada no sedimento e a importância desse recurso alimentar, como também revelar uma carga de MOPF maior do que o normal nos riachos.

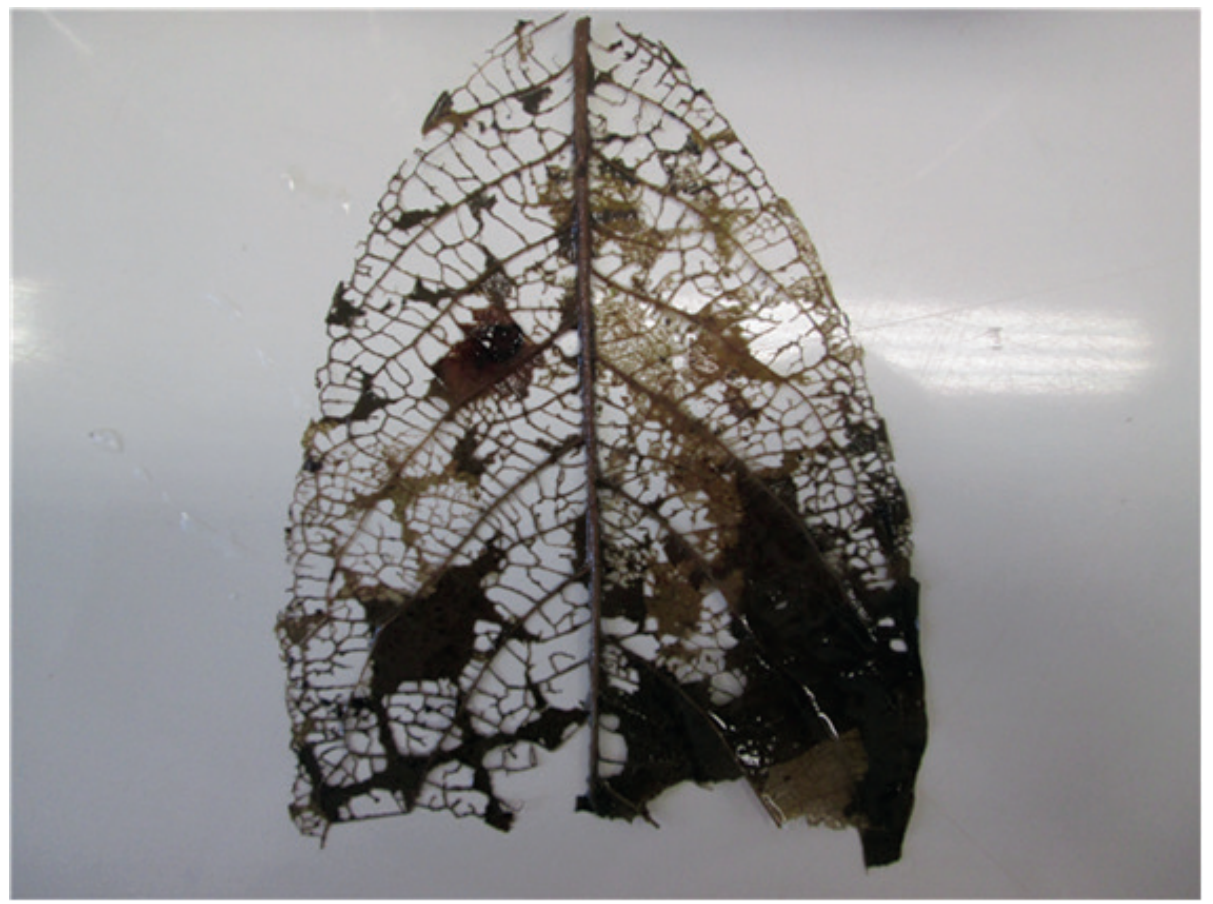

Figura 4. Fragmento de folha presente na serapilheira de um riacho com evidências da ação de macroinvertebrados fragmentadores. Foto: Thalles Gomes Peixoto.

Os raspadores removem o perífiton, que é representado por uma fina camada de biofilme constituída por uma complexa comunidade de microorganismos (algas filamentosas, fungos e protozoários), detritos orgânicos e inorgânicos aderidos a substratos inorgânicos ou orgânicos (vivos ou mortos). A proporção de perifíton está diretamente relacionada à insolação dos ambientes aquáticos o que, por sua vez, influencia a proporção de raspadores no ambiente. Alguns trabalhos apontam o importante papel dos raspadores tanto por consumir a biomassa de produtores como por seus efeitos na produção e composição das algas. 
Os sugadores-herbívoros alimentam-se perfurando e sugando o citoplasma de células de macrófitas. A função ecológica desse grupo ainda é pouca conhecida, mas é possível que influenciem de forma significativa a dinâmica das comunidades de macroalgas e plantas aquáticas.

Os predadores possuem várias estratégias de captura que incluem desde modificações do aparelho bucal até o comportamento. São carnívoros engolidores ou perfuradores. Os engolidores alimentam-se tanto de animais (invertebrados aquáticos e pequenos vertebrados) inteiros como de partes deles, sendo as larvas de insetos, as presas mais comuns. Já os perfuradores, perfuram os tecidos e sugam os fluidos das presas. A figura 5 apresenta de forma sintética as relações entre os grupos funcionais de alimentação, exemplificados com táxons que ocorrem na região do Triângulo Mineiro, e os recursos alimentares utilizados.

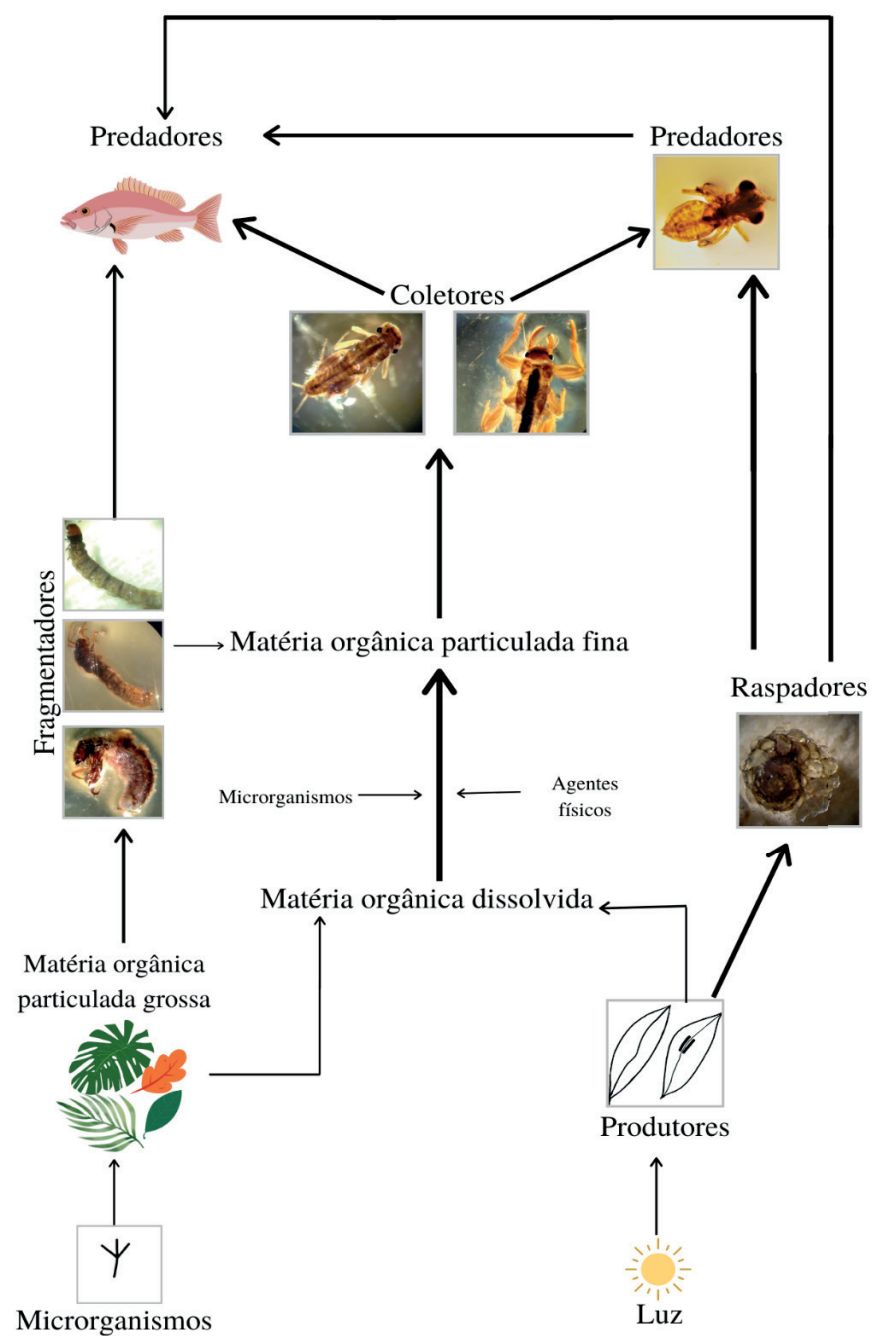

Figura 5. Esquema simplificado dos grupos funcionais de alimentação e de suas relações com os recursos alimentares disponíveis. Representantes de Lepidoptera Pyralidae, Trichoptera Odontoceridae e Calamoceratidae são indicados como fragmentadores, Ephemeroptera Leptophlebidae e Euthyplociidae como coletores, Trichoptera Helicopsychidae como raspador e Odonata Libellulidae como predador. Adaptado de Cummins (1973). 


\section{Macroinvertebrados aquáticos como bioindicadores}

A avaliação da qualidade de ambientes aquáticos tem sido realizada desde o final do século XIX, mas baseava-se principalmente em características físicas e químicas da água como forma de caracterizar a poluição de um corpo hídrico ou sua adequação a um determinado uso. Essa abordagem ainda é frequentemente utilizada, mas uma de suas principais limitações é que as características físicas e químicas avaliadas referemse apenas às condições em que a amostra foi coletada, ou seja, podemos fazer uma analogia com uma "foto" do ambiente no momento de coleta dos dados. Por outro lado, ao utilizar comunidades biológicas para avaliar a qualidade de um ambiente aquático, tem-se uma avaliação de condições pretéritas e atuais, ou seja, pode-se dizer que dados biológicos apresentam um "filme" do passado recente do ambiente avaliado.

Dentre os organismos presentes em ecossistemas aquáticos de águas continentais, os macroinvertebrados aquáticos têm sido os mais frequentemente utilizados como bioindicadores de qualidade ambiental, pois apresentam uma série de características que favorecem sua utilização. São organismos abundantes e sensíveis a perturbações que ocorrem em praticamente todos os ambientes aquáticos continentais; apresentam elevada riqueza taxonômica, possibilitando um amplo espectro de respostas a perturbações; são relativamente sedentários, o que permite avaliar localmente os efeitos de perturbações; apresentam ciclo de vida relativamente longo, o que permite avaliar temporalmente o efeito de perturbações regulares ou intermitentes; há conhecimento taxonômico relativamente bem estabelecido para a maioria das regiões do mundo; e os métodos de análise são bem estabelecidos e de custo relativamente baixo.

Os diferentes níveis de tolerância dos macroinvertebrados bentônicos às condições dos ecossistemas aquáticos possibilitam categorizar sua qualidade ambiental em função de características da estrutura da comunidade de organismos presente. Particularmente, para ambientes aquáticos lóticos, ou seja, rios e riachos, a presença e/ ou a proporção de diferentes grupos de organismos é um bom indicativo de sua situação quanto à poluição orgânica e qualidade de habitat.

Atualmente existem diferentes metodologias para avaliar a qualidade ambiental de ecossistemas aquáticos, incluindo diferentes tipos de índices bióticos que levam em conta a tolerância diferencial dos grupos taxonômicos a alterações no ambiente (Tabela 1). Escores distintos são atribuídos a cada táxon em função de seu nível de tolerância em relação à poluição orgânica, por exemplo. Esses escores, associados à abundância ou proporção dos grupos encontrados no ambiente aquático, permitem calcular um valor único que representa a qualidade ambiental. Os níveis taxonômicos mais usualmente utilizados são ordem, família e gênero, dependendo dos objetivos e do detalhamento da avaliação desejada.

Outra abordagem utilizada na avaliação da qualidade ambiental de sistemas aquáticos é a utilização de medidas múltiplas (métricas) da estrutura e função das comunidades de macroinvertebrados aquáticos. Essas métricas podem ser agrupadas em categorias, incluindo: riqueza de táxons (mais comumente em nível de família ou gênero); enumerações (abundância de indivíduos coletados, proporção de táxons selecionados como as ordens de insetos Ephemeroptera, Plecoptera e Trichoptera EPT ou de oligoquetos); índices de diversidade das comunidades (índice de Shannon, por exemplo); índices de similaridade de comunidades (índice de Pinkham-Pearson, 
por exemplo) ou razões de grupos trófico-funcionais (razão entre fragmentadores e coletores, por exemplo).

Tabela 1. Um índice biótico regional (BMWP Triângulo). Os escores exemplificados representam a tolerância de algumas famílias de macroinvertebrados aquáticos a alterações ambientais. Quanto maiores os valores, mais sensíveis são os organismos.

\begin{tabular}{|c|c|}
\hline Taxa & Escore \\
\hline $\begin{array}{l}\text { Gerridae, Heliopsichidae, Hydrobiosidae, Limnephilidae, Mesoveliidae, } \\
\text { Polymirtacyidae, Psychodidae, Psephenidae, Sericostomatidae, Tabanidae }\end{array}$ & 10 \\
\hline $\begin{array}{l}\text { Ceratopogonidae, Elmidae, Hydroptilidae, Leptophlebiidae, Libellulidae, } \\
\text { Nematoda, Tipulidae, Veliidae }\end{array}$ & 7 \\
\hline Ephydridae, Hydrobiidae, Physidae, Planorbidae & 3 \\
\hline
\end{tabular}

\section{Métodos de estudo}

Existem diversos métodos de estudo de macroinvertebrados aquáticos, incluindo diferentes técnicas de coleta e processamento das amostras. A escolha dos métodos a serem utilizados está diretamente relacionada aos objetivos específicos do trabalho, aos recursos financeiros e ao tempo disponível, além das características do corpo hídrico a ser amostrado. Por exemplo, avaliações de biomonitoramento em larga escala espacial usualmente demandam grandes equipes trabalhando de forma a otimizar o tempo de coleta e o processamento de amostras. De forma geral, esses estudos envolvem pequeno número de amostras por local e identificação em grandes grupos taxonômicos (ordens e famílias). Por outro lado, investigações acerca da estrutura das comunidades de macroinvertebrados aquáticos, usualmente necessitam de amostragens mais elaboradas e identificação em níveis taxonômicos menores (gênero).

A coleta de macroinvertebrados aquáticos pode ser realizada utilizando-se diferentes tipos de amostradores. Em ambientes lóticos de pequenas dimensões, como riachos, que apresentam profundidades reduzidas, é usual a utilização de redes do tipo Surber ou em D. Em ambientes com maiores profundidades, incluindo rios e ambientes lênticos como lagos e represas é usual a utilização de dragas (Figura 6). Outra técnica de coleta usual é a utilização de substratos artificiais de diferentes formas, tamanhos e materiais (Figura 7). No caso de redes e dragas as amostras são obtidas no momento da coleta, enquanto no caso dos substratos artificiais, as amostras são obtidas após um período de colonização pelos organismos, definido em função dos objetivos do estudo.

Todas as técnicas de coleta apresentam vantagens e desvantagens, amplamente discutidas na literatura, que devem ser consideradas previamente ao início das amostragens. Uma vez coletadas, as amostras normalmente são fixadas em formaldeído a $4 \%$ ou álcool $80 \%$ e devidamente etiquetadas. No laboratório as amostras podem ser submetidas a um processo de lavagem em água corrente sob peneiras com diferentes malhas (é usual utilizar peneiras de 2 ou $4 \mathrm{~mm}$ ) para separação do material mais grosseiro (ex: folhas, galhos e seixos) do material particulado de menores dimensões, processo que facilita a triagem e separação dos macroinvertebrados aquáticos. 

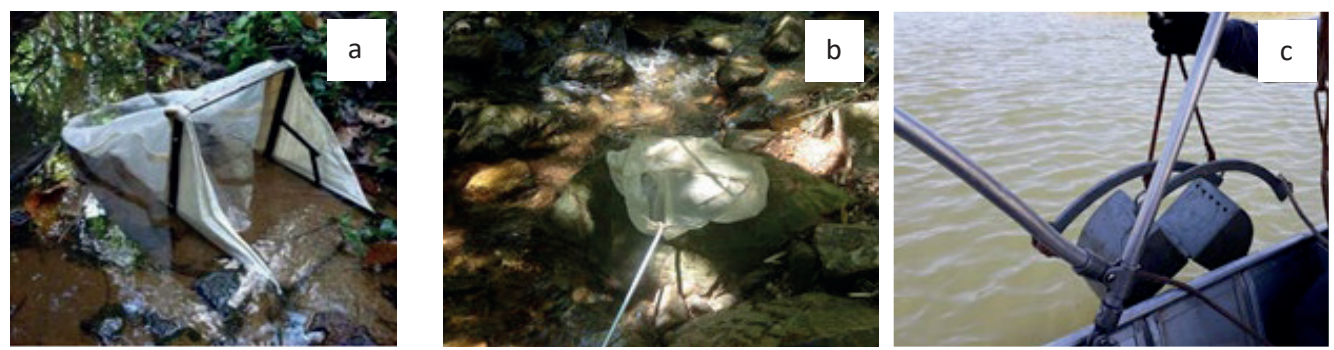

Figura 6. Equipamentos de coleta: (a) Surber; (b) rede D; (c) Draga de Van Veen. Foto: Regina Célia Gonçalves.
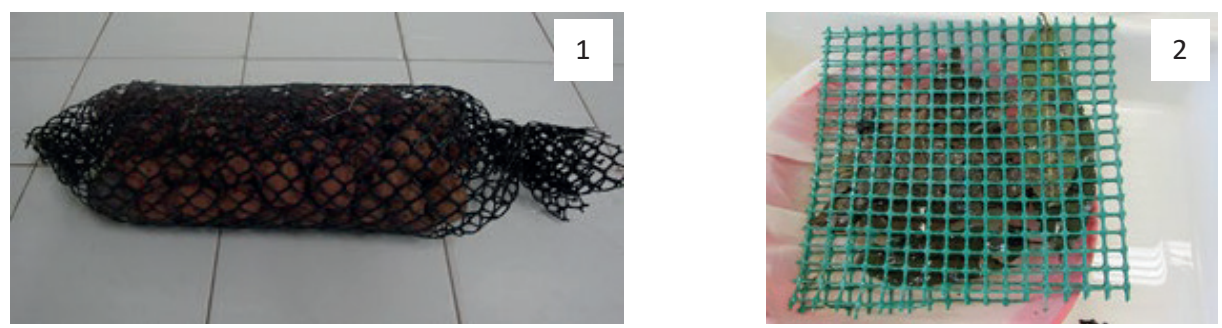

Figura 7. Substratos artificiais: (1) tela com argila expandida; (2) tela e folhas -leaf packs. Foto: Thalles Gomes Peixoto.

O material de menores dimensões, que inclui sedimento, pequenos seixos e os organismos é triado sob estereomicroscópio. Os macroinvertebrados são então identificados até o nível taxonômico adequado à proposta do estudo, sob estereomicroscópio ou microscópio óptico. As diferenças morfológicas das principais ordens de insetos aquáticos possibilitam sua identificação de forma relativamente simples. A chave dicotômica abaixo (Figura 8) permite de forma prática a identificação das principais ordens de insetos aquáticos presentes em diferentes tipos de ambientes.

A identificação em nível de família e de gênero demanda chaves específicas. Geralmente não é possível a identificação em espécie, pois a maioria dos indivíduos são juvenis e não há caracteres evidentes que permitam identificar nesse nível. Após a identificação os organismos são contados e armazenados em frascos rotulados contendo álcool $70 \%$.

\section{Diversidade de macroinvertebrados aquáticos no Triângulo Mineiro e Sudeste de Goiás}

Estudos ecológicos de comunidades de macroinvertebrados aquáticos são relativamente recentes no Brasil, iniciando de forma mais consistente a partir da década de 1980. Na região do Triângulo Mineiro e Sudeste de Goiás, há registros de estudos a partir do final dos anos 90 e início dos anos 2000, geralmente envolvendo grupos taxonômicos específicos ou áreas bem restritas. É o caso de trabalho realizado em riachos na região do Parque Estadual da Serra de Caldas Novas (GO) envolvendo representantes da ordem Trichoptera, que registrou 11 das 16 famílias presentes no Brasil e 24 gêneros. Estudos mais amplos, objetivando avaliar a qualidade ambiental de cursos d'água e represas das bacias dos rios Paranaíba e Grande, na região do Triângulo Mineiro, só passaram a ser realizados no início dos anos 2000. 
Nos últimos 15 anos, trabalhos realizados no Laboratório de Ecologia de Ecossistemas Aquáticos (LEEA) do Instituto de Biologia da Universidade Federal de Uberlândia e alguns estudos pontuais de outras instituições ampliaram significativamente o conhecimento sobre a diversidade das comunidades de macroinvertebrados aquáticos da região. Para algumas ordens representativas foi registrada elevada riqueza de famílias e gêneros em relação ao total de táxons do país. Cerca de $50 \%$ de todos os gêneros de Ephemeroptera, Plecoptera e Trichoptera presentes no país foram registrados para a região (Tabela 2).

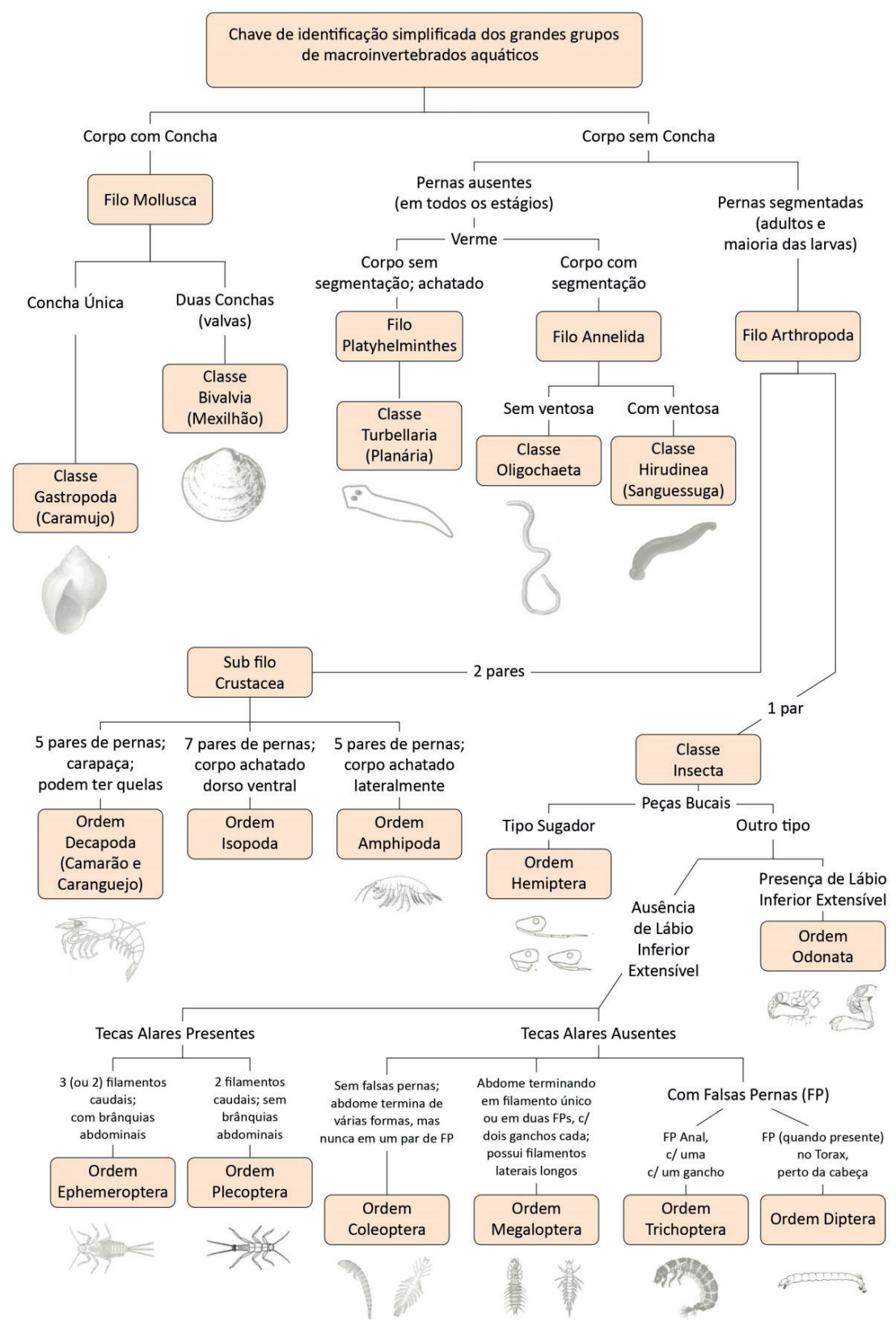

Figura 8. Chave dicotômica ilustrada para separação dos principais táxons de macroinvertebrados aquáticos. 
Tabela 2. Riqueza de famílias e gêneros de ordens de insetos aquáticos no Brasil e na região do Triângulo Mineiro/sudeste de Goiás

\begin{tabular}{lcccc}
\hline & \multicolumn{2}{c}{ Brasil } & \multicolumn{2}{c}{ Triângulo Mineiro/sudeste Goiás } \\
\hline & Famílias & Gêneros & Famílias & Gêneros \\
\hline Ephemeroptera & 10 & 77 & 8 & 39 \\
\hline Plecoptera & 2 & 10 & 2 & 5 \\
\hline Trichoptera & 16 & 70 & 14 & 34 \\
\hline Odonata & 15 & 147 & 10 & 43 \\
\hline
\end{tabular}

Infelizmente, principalmente nas áreas urbanas e periurbanas dos municípios da região, essa diversidade encontra-se ameaçada pelo elevado nível de impacto ambiental causado pela poluição e degradação da vegetação marginal de rios e riachos. No entanto, a presença de ambientes aquáticos íntegros em fragmentos preservados de vegetação nativa de unidades de conservação (UCs) governamentais e particulares tem mantido regionalmente a diversidade da fauna de macroinvertebrados aquáticos.

Estudos sistemáticos vinculados ao Programa Ecológico de Longa Duração (PELD) indicaram que os cursos d'água presentes nessas UCs apresentam comunidades de macroinvertebrados aquáticos com diversidade temporalmente pouco variável, indicando manutenção das características ambientais desses locais. Além disso, essas áreas tendem a apresentar comunidades bentônicas com composição relativamente diferenciada. Em estudo conduzido em cinco UCs, foram identificadas 49 famílias de macroinvertebrados, das quais 19 famílias $(38,7 \%$ do total) ocorreram exclusivamente em um dos locais.

Apesar da ampliação do conhecimento acerca da diversidade das comunidades de macroinvertebrados aquáticos da região, ela ainda é certamente subestimada, visto que apenas parte dos estudos realizados fornece dados de identificação em nível de gênero. Nesse sentido são necessários novos estudos que permitam compreender de forma mais detalhada os padrões de diversidade dessas comunidades aquáticas.

\section{Crustáceos decápodes: Diversidade, papel trófico e biologia populacional}

Entre os invertebrados mais conhecidos popularmente, o filo Crustacea tem seu destaque uma vez que inclui representantes apreciados na gastronomia, como as lagostas, os camarões e os caranguejos. Estes invertebrados são encontrados nos mais variados ambientes, desde o terrestre até o aquático, incluindo o marinho, estuarino e dulcícola, e em diversas profundidades, representando um dos maiores táxons do reino animal. Além de sua relevância econômica reconhecida por meio da culinária, resultado do cultivo e da pesca de algumas espécies, os crustáceos constituem-se importantes componentes das cadeias tróficas, sendo ecologicamente essenciais para o tamanho, complexidade e funcionamento dos ecossistemas a que pertencem.

Das ordens que compõe este filo, a Decapoda é a mais numerosa, com aproximadamente 15 mil espécies descritas, distribuídas em 2.725 gêneros. Quase $80 \%$ deste total ocorre em seu ambiente ancestral, o marinho, enquanto menos de $20 \%$ conquistaram com sucesso os ambientes estuarino e dulcícola, e menos de $2 \%$ o ambiente terrestre. Esta baixa porcentagem de espécies não marinhas indica que a 
transição dos oceanos para os ambientes estuarino, dulcícola e terrestre exigiu de tais espécies a superação de diversos desafios no curso de tal transição.

Considerando-se especificamente o ambiente dulcícola, as concentrações reduzidas de íons inorgânicos, como o sódio e o cálcio, estão entre as mudanças mais drásticas nas condições ambientais a que estas espécies foram submetidas. Assim, a conquista deste ambiente pelos crustáceos decápodos ancestrais exigiu adaptações morfológicas e fisiológicas mínimas necessárias para a proteção iônica e osmótica ao longo de sua evolução, sendo alcançadas com sucesso por aproximadamente $32 \%$ das espécies. Além disso, tal conquista foi acompanhada por mudanças significativas nas condições nutricionais e em fatores bióticos, como a predação por exemplo, resultando também em adaptações nos padrões reprodutivos, comportamentais e de desenvolvimento destes crustáceos.

As adaptações nos padrões acima citados estão relacionadas às necessidades específicas dos decápodos ao longo de seu ciclo de vida e às distintas condições ecológicas dos ambientes que ocupam. Assim, as transições evolutivas do ambiente marinho para o dulcícola somente podem ser compreendidas se questões adaptativas forem consideradas no contexto da história de vida desses animais no que diz respeito às mudanças na osmorregulação, morfologia, locomoção, crescimento e alimentação dos estágios de desenvolvimento iniciais. Em relação a este último, a redução ou até mesmo a eliminação de fases larvais pode ocorrer. Neste contexto, ancestrais de crustáceos decápodos hololimnéticos (que ocorrem exclusivamente em ambiente dulcícola durante todo seu desenvolvimento), como alguns caranguejos, eliminaram totalmente a fase larval, apresentando desenvolvimento direto e cuidado parental. Espécies colonizadoras recentes, por sua vez, apresentam padrões intermediários com desenvolvimento larval lecitotrófico completo, parcial ou abreviado, no qual a larva se alimenta de reservas nutritivas presentes no vitelo, como em alguns camarões.

Diante deste cenário podemos compreender o motivo pelo qual os crustáceos decápodos dulcícolas são tão relevantes enquanto modelos evolutivos, mas, ainda assim, infelizmente negligenciados. Até meados dos anos 90, por exemplo, não havia registros de tais animais em Minas Gerais, estado onde localiza-se parte do segundo maior bioma brasileiro, o Cerrado, o qual se destaca por abrigar em seu território as nascentes dos principais rios das bacias Amazônica, do Prata e São Francisco. Por se tratar de um bioma que vem sendo amplamente devastado pela expansão da agropecuária, faz-se necessário o conhecimento de informações que vão além da taxonomia e de inventários faunísticos, mas que proporcionem a compreensão do ciclo de vida das espécies.

Neste sentido, a equipe do Laboratório de Ecologia de Ecossistemas Aquáticos do Instituto de Biologia da Universidade Federal de Uberlândia vem desenvolvendo, desde 2012, estudos com as espécies de crustáceos decápodos de ambiente dulcícola registradas na região do Triângulo Mineiro, os camarões Macrobrachium amazonicum (Heller, 1862) e M. brasiliense (Heller, 1862) e o caranguejo Dilocarcinus pagei Stimpson, 1861. Estes estudos incluem algumas áreas essenciais das ciências básica e aplicada, como taxonomia e inventários faunísticos, padrões sazonais de abundância e suas relações com alguns fatores abióticos, seleção de substratos e microhabitats, dieta, estrutura populacional,periodicidadeeintensidadereprodutiva,recrutamentojuvenil,razãosexual, morfologia, maturidade sexual, longevidade e crescimento e variabilidade genética.

A espécie Macrobrachium amazonicum (Figura 9) apresenta expressiva variabilidade intraespecífica. Provavelmente em função de sua ampla distribuição 
geográfica, alcançada graças a fatores naturais (eventos geológicos nas bacias do Paleolítico e elevação da Serra de Maracaju, no Pleistoceno) e antrópicos (alagamentos das cataratas do Guaíra, escape acidental no rio Pardo), a espécie adaptou-se a diferentes ambientes, ocorrendo em diferentes níveis de salinidade e de fluxo de água, estando presente tanto em ambientes lênticos como lóticos. Tais fatos podem ter colaborado para explicar a grande plasticidade fenotípica apresentada pela espécie.

Além dessa característica plástica, a espécie apresenta importância econômica, já que é usada como fonte de renda e de alimento pela população ribeirinha da região amazônica e tem sido indicada como um importante recurso alimentar para algumas espécies de peixes nos rios e reservatórios onde ocorre. Considerando várias categorias alimentares para a biomassa total dos peixes capturados em um estudo desenvolvido na bacia do Paraná, a participação de M. amazonicum na dieta de tucunarés (Cichla piquite, Cichla kelberi), traíras (Hoplias intermedius), corvinas (Plagioscion squamosissinus) e acarás (Astronotus crassipinnis) foi de 50\%. Desta forma, a espécie configurouse como um importante recurso alimentar nas teias tróficas de peixes na bacia do Paraná, logo, compreender sua organização populacional pode auxiliar nos esforços de conservação das comunidades nos reservatórios, pois variações significativas na estrutura populacional e na disponibilidade desses animais podem afetar diretamente a dinâmica alimentar de espécies de peixes importantes da respectiva bacia.

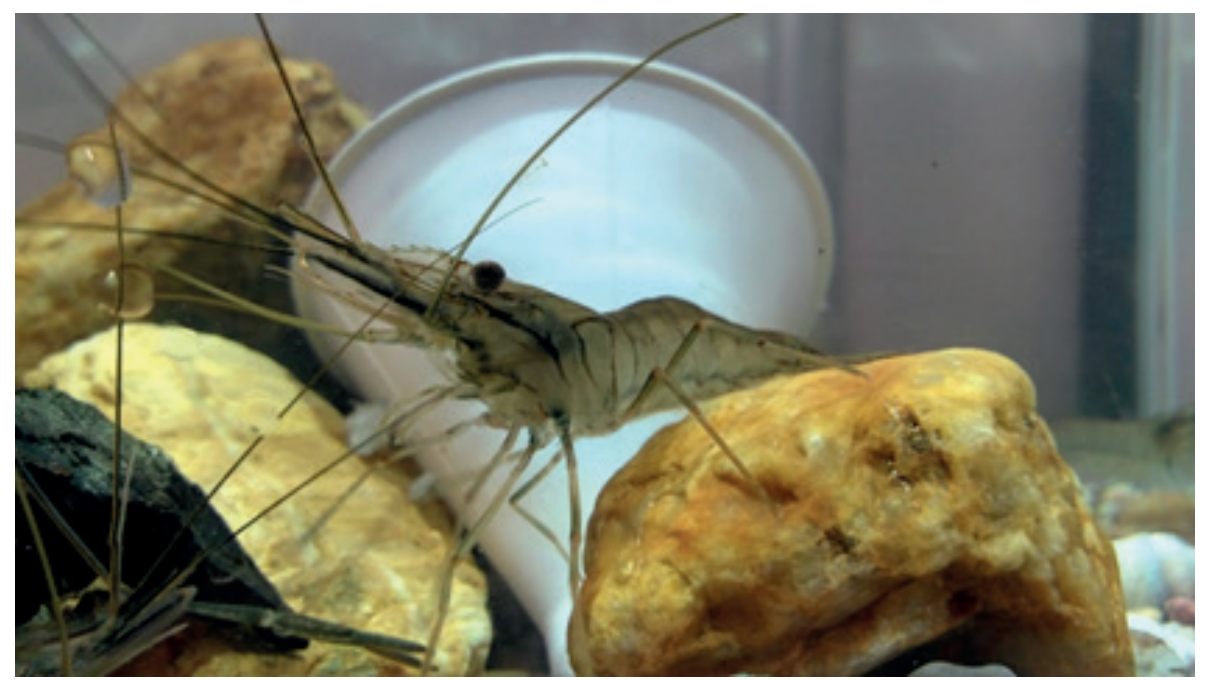

Figura 9. Espécime de Macrobrachium amazonicum proveniente do rio Grande.

O LEEA vem estudando populações dessa espécie presente nas bacias dos rios Araguari e Grande, que também compõe a bacia do rio Paraná. Nas populações estudadas do rio Araguari notou-se que a razão sexual é desviada a favor das fêmeas e que há um padrão de reprodução contínuo, com picos reprodutivos percebidos nos meses de maior pluviosidade e temperaturas mais elevadas (Figura 10). Neste rio, as fêmeas foram, em média, $21,2 \%$ maiores que os machos. 


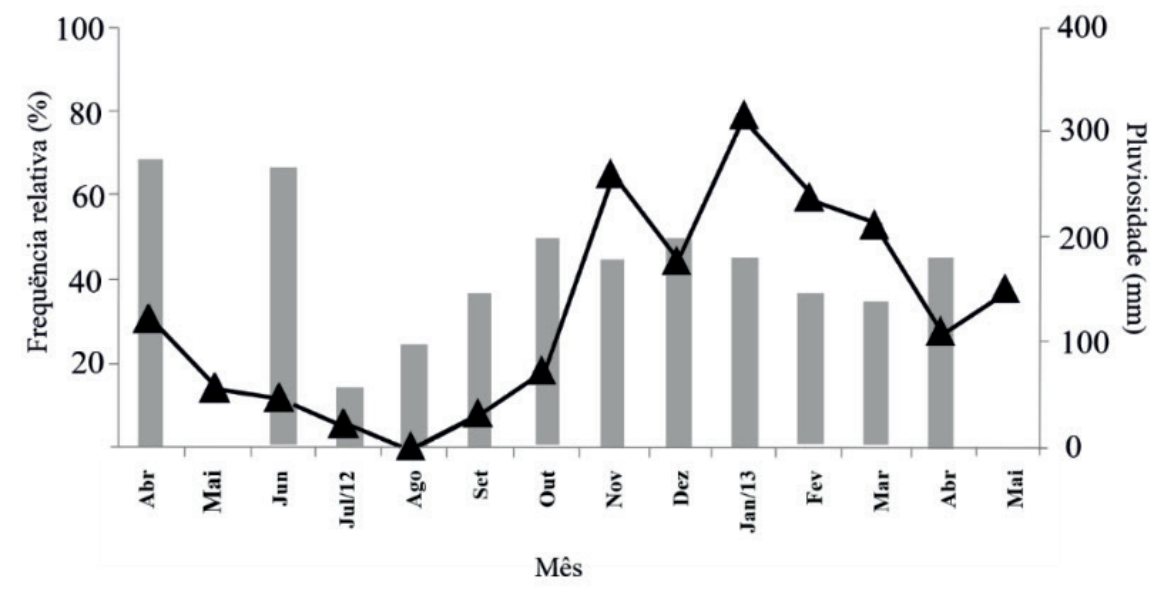

Figura 10. Frequência relativa de fêmeas ovígeras de $M$. amazonicum (barras cinzas) conforme a pluviosidade (mm) amostrada de abril/2012 a maio/2013

No estudo de outra população do reservatório de Nova Ponte, no rio Araguari, foram descritas as curvas médias de crescimento para machos e fêmeas. Houve diferença significativa entre o coeficiente de crescimento conforme o sexo, com machos crescendo, proporcionalmente, mais rápido que as fêmeas, mas atingindo tamanhos inferiores a elas. A longevidade foi estimada em 0,97 anos para machos de M. amazonicum e 1,12 anos para fêmeas de M. amazonicum (Figura 11).

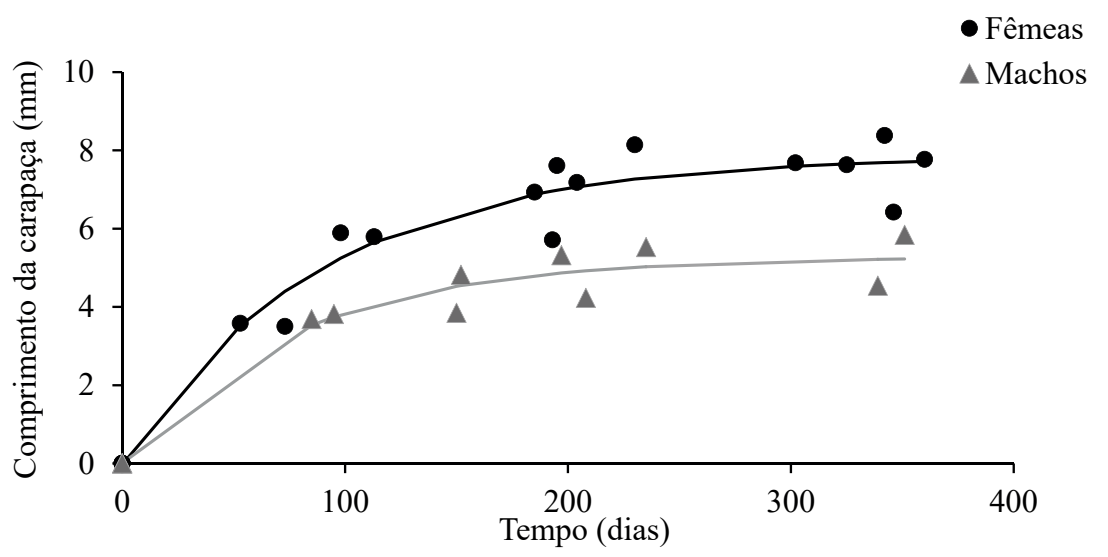

Figura 11. Curvas de crescimento para machos (cinza) e para fêmeas (preto) de Macrobrachium amazonicum no reservatório de Nova Ponte, rio Araguari (MG).

Por outro lado, em uma população do rio Grande não foram observadas diferenças na razão sexual, nem no tamanho médio dos indivíduos machos e fêmeas. Além disso, o tamanho médio dos camarões do rio Grande foi maior que os do rio Araguari, machos foram em média 21,43\% maiores e as fêmeas 2,27\% (Figura 12). Já no rio Araguari, a razão sexual foi desviada a favor das fêmeas e estas apresentaram-se, em média, $21,24 \%$ maiores que os machos.

Ainda que as populações presentes nos rios Araguari e Grande não apresentem as características de tamanho encontradas nas populações da Amazônia, que conferem 
à espécie vocação para uso econômico, principalmente na gastronomia, acreditamos que é possível desenvolver o mercado de M. amazonicum no Triângulo Mineiro, focado na produção de ração para criação de animais aquáticos e de iscas para atividade de pesca esportiva.

Assim como relatado para M. amazonicum, o camarão M. brasiliense (Figura 13) tem importante papel trófico no ambiente em que ocorre, com dieta que inclui detrito vegetal e outros invertebrados aquáticos e servindo como presa de peixes e outros vertebrados. No que diz respeito ao seu valor comercial, é utilizado na aquariofilia como organismo ornamental, devido à sua coloração e robustez. Apesar de sua ampla distribuição geográfica, estudos sobre a espécie ainda são escassos, e aqueles realizados por nós até o momento fornecem informações inéditas de uma população de $M$. brasiliense em um riacho nos arredores do município de Uberlândia.

De maneira geral, a densidade populacional da espécie é relativamente baixa em comparação a $M$. amazonicum, com captura média de 21 indivíduos ao mês por dois coletores durante $90 \mathrm{~min}$ de amostragem no riacho Água Limpa. A população investigada é caracterizada por um maior número de indivíduos jovens em comparação aos adultos. Um dimorfismo sexual em relação ao comprimento da carapaça (CC, medido em mm) é notável em M. brasiliense, com machos apresentando maiores tamanhos que as fêmeas (Macho: 9,6 $\pm 4,2 \mathrm{~mm}$ CC; Fêmeas: 7,0 $\pm 3,3 \mathrm{~mm} \mathrm{CC}$ ). Consequentemente, tal padrão também é perceptível no tamanho da maturidade sexual morfológica da espécie, estimada em 8,64 e 8,03 mm CC para machos e fêmeas, respectivamente. Por outro lado, a razão sexual é desviada a favor das fêmeas, diferindo da proporção esperada de 1:1.

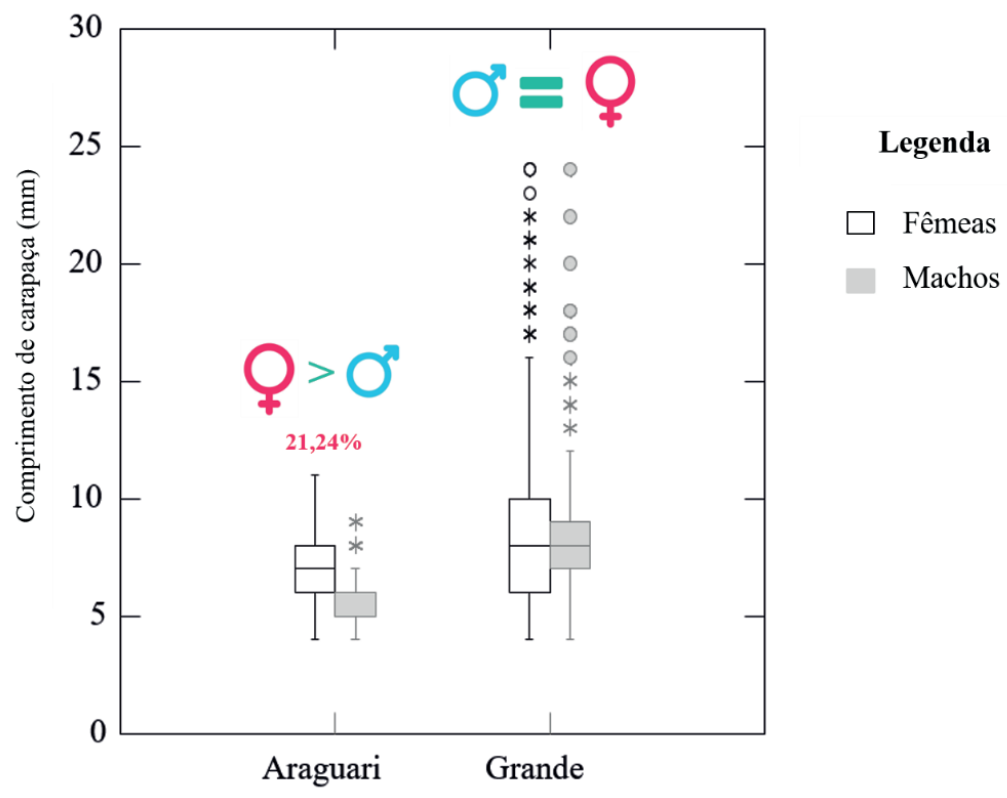

Figura 12. Comparação entre a frequência de M. amazonicum por classe de comprimento de Carapaça (CC) nos rios Araguari e Grande. 


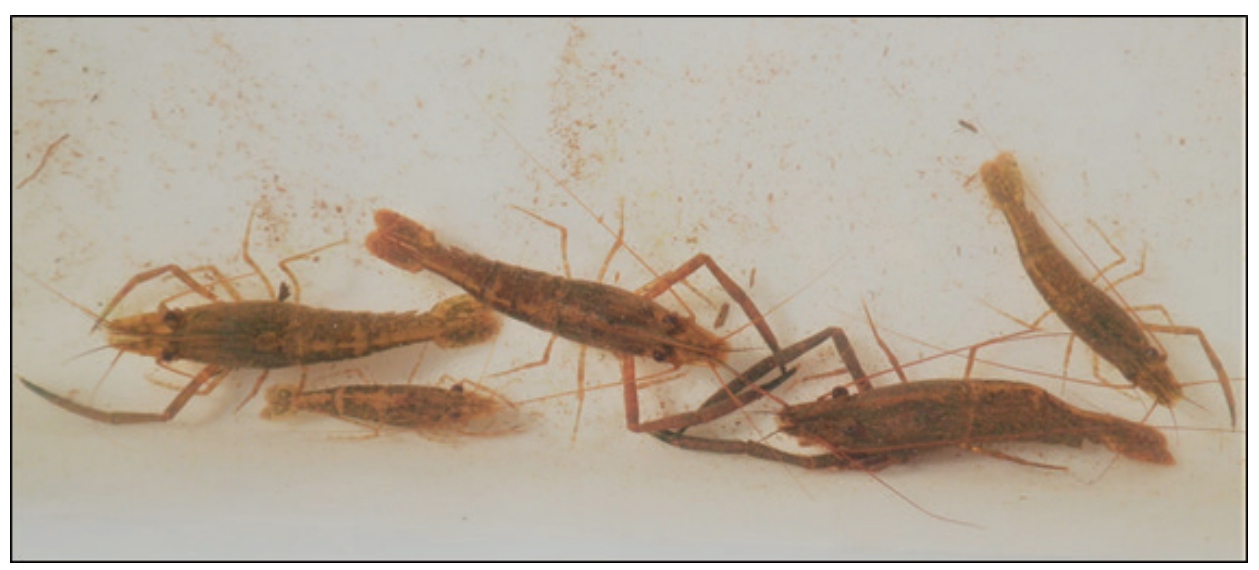

Figura 13. Exemplares de Macrobrachium brasiliense coletados no riacho Água Limpa, na região de Uberlândia, MG.

O crescimento e a longevidade calculados para M. brasiliense evidenciam um ciclo de vida com duração de aproximadamente 3,25 anos para a espécie e, especificamente, 2,83 anos para machos e 2,78 anos para fêmeas. Ao longo de tal ciclo de vida, variações morfológicas são perceptíveis principalmente entre estágios de desenvolvimento iniciais e finais. Assim como ocorre em outros artrópodos, como os insetos por exemplo, o crescimento neste crustáceo decápodo ocorre por meio de trocas consecutivas do exoesqueleto, favorecendo assim mensurações precisas de distintas estruturas corpóreas.

Algumas destas estruturas evidenciam claramente variações morfológicas relacionadas à aquisição da maturidade sexual de $M$. brasiliense por meio do desenvolvimento dos apêndices torácicos (pereiópodos) em machos e da pleura abdominal em fêmeas, estruturas diretamente relacionadas à reprodução no que diz respeito à disputa e proteção de fêmeas pelo macho e a maior expansão da região do abdômen para incubação dos ovos pela fêmea. Porém, curiosamente os relatos sobre a presença de fêmeas ovígeras na população são raros. Estudos indicam um número reduzido de ovos, mas com elevado volume (vitelo) em relação a outras espécies do gênero.

Um dos últimos estudos realizados em parceria com o Laboratório de Biologia de Camarões Marinhos e de Água Doce da Faculdade de Ciências da Universidade Estadual Paulista "Júlio de Mesquita Filho", Campus de Bauru, trouxe contribuições relevantes para a compreensão da biologia de $M$. brasiliense, evidenciando pela primeira vez a presença de diferentes morfotipos de machos na população. Estes foram identificados de acordo com o tamanho, coloração e ornamentação dos pereiópodos, a saber: Mirim, com quelípodos menos desenvolvidos $(23,31 \pm 3,08 \mathrm{~mm})$ e com poucos espinhos ou em formação, e $A c ̧ u$, com quelípodos maiores $(41,39 \pm 8,14 \mathrm{~mm})$ e muitos espinhos completamente desenvolvidos ao longo dos mesmos (Figura 14).

A partir dos resultados obtidos nos estudos desenvolvidos pela equipe até o momento, podemos apresentar um panorama geral da população de $M$. brasiliense. A densidade populacional restrita, o tamanho elevado dos machos e a presença de morfotipos, além do número reduzido de ovos incubados pelas fêmeas observado por outros pesquisadores, são indicativos evolutivos da transição do ambiente marinho para o dulcícola, com destaque para as estratégias reprodutivas da espécie. 


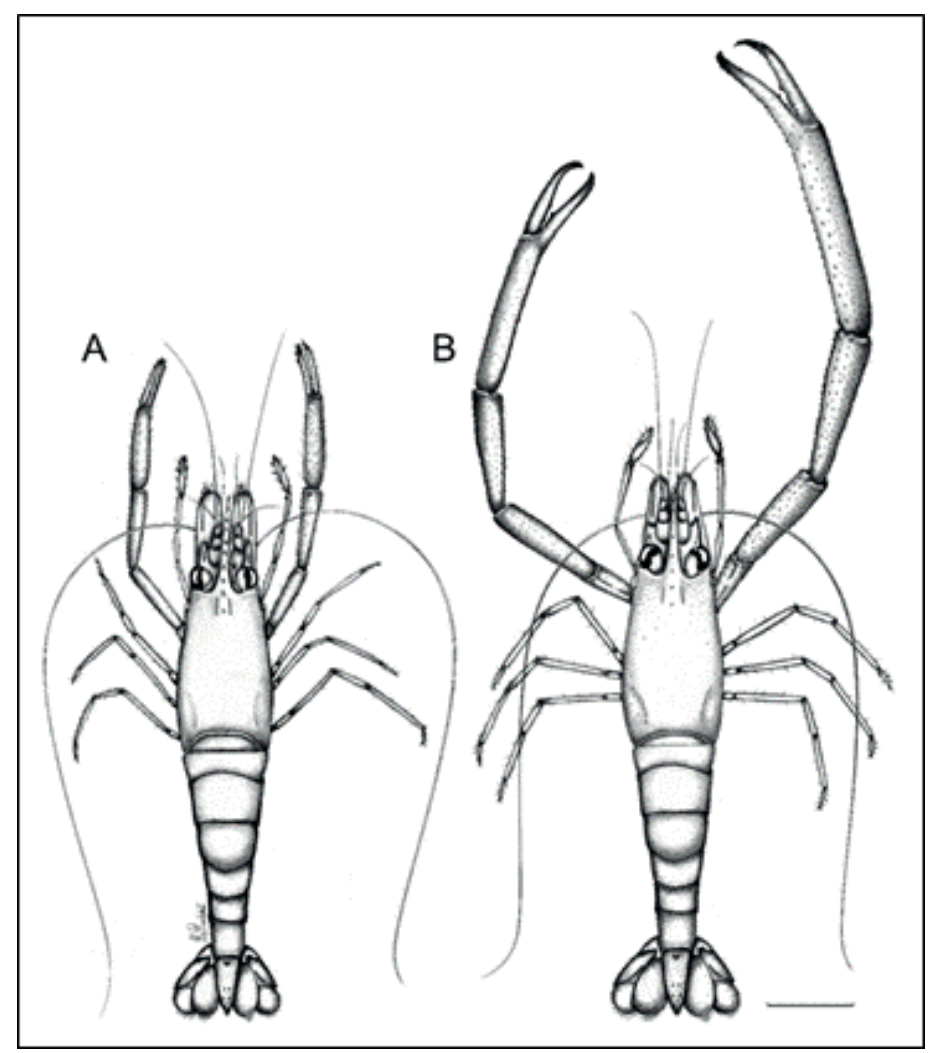

Figura 14. Macrobrachium brasiliense (Heller, 1862). Vista dorsal dos dois morfotipos descritos baseados nas análises morfométricas e morfológicas. À esquerda, o morfotipo Mirim (A) e a direita o morfotipo Açu (B). Ilustração por João Alberto Farinelli Pantaleão. Barra de escala: $10 \mathrm{~mm}$.

É possível que M. brasiliense apresente um sistema de acasalamento complexo denominado "guarda temporária da fêmea", no qual o macho protege a fêmea de potenciais predadores e de outros machos durante seu período reprodutivo, guardando-a até o momento da cópula. No que diz respeito ao desenvolvimento larval, este parece ser abreviado, evidenciando uma tendência para a lecitotrofia, na qual a larva se alimenta de reservas nutritivas presentes no vitelo, garantindo que os estágios iniciais do desenvolvimento larval ocorram dentro do ovo. Porém, a fim de fundamentarmos estas e outras hipóteses, além de ampliar o conhecimento da biologia de M. brasiliense, contribuindo também para sua conservação e para a conservação do ecossistema em que se encontra, temos como propósito a continuidade de investigações sobre a espécie, principalmente na área da ecologia comportamental.

Em relação aos representantes da família Trichodactylidae, poucos são os estudos feitos. Esta apresenta um padrão de distribuição segregada, com ocorrência de algumas espécies no sul do México e de outras nas bacias hidrográficas da América do Sul com drenagem para o oceano Atlântico, entre as quais está o caranguejo dulcícola Dilocarcinus pagei Stimpson, 1861 (Figura 15). Apesar da ampla distribuição da espécie em vários estados do Brasil, o primeiro registro em Minas Gerais foi obtido em 2010 no Lago de Furnas, possivelmente devido à dispersão de D. pagei após sua introdução na bacia do alto rio Paraná, onde tem se adaptado bem, com sua população 
aumentando em tamanho. Características morfológicas, fisiológicas e comportamentais apresentadas pela espécie são decorrentes das adaptações evolutivas ao ambiente dulcícola. Essas características compreendem baixa fecundidade, desenvolvimento direto com todas fases larvais ocorrendo dentro do ovo e eclosão de um indivíduo jovem morfologicamente semelhante ao indivíduo adulto, cuidado parental, baixa taxa de dispersão por ausência de fases larvais pelágicas e especificidades nos habitats em que $D$. pagei ocorre, resultando em uma alta taxa de endemismo.

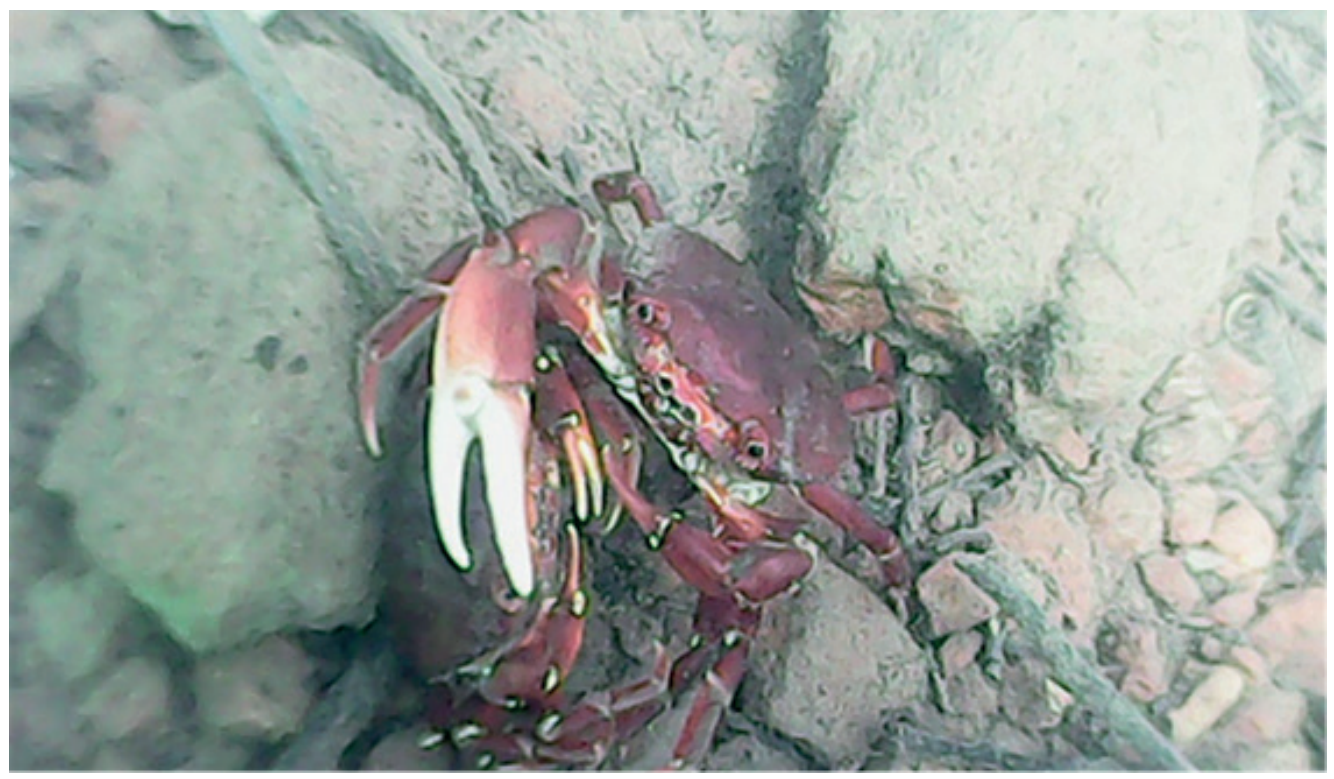

Figura 15. Dilocarcinus pagei no leito da represa Amador Aguiar II, rio Araguari, Uberlândia (MG). Foto: Wberjunio Rodrigues Gonzaga.

Nossos estudos registram a ocorrência de D. pagei na represa Amador Aguiar II, no rio Araguari, no município de Uberlândia e na represa de Igarapava, no rio Grande. É importante ressaltar que a estabilidade do ambiente dulcícola no qual $D$. pagei pode ser encontrado tem sido constantemente ameaçada pelo desmatamento, alteração dos padrões de drenagem e poluição, ameaças estas que aumentaram consideravelmente com a globalização e a urbanização. Neste contexto, esperamos elucidar questões relacionadas à vulnerabilidade populacional de D. pagei em função de seu endemismo, levando em consideração tanto ações antrópicas quanto fenômenos naturais e o reflexo de tal vulnerabilidade nas funções específicas exercidas pela espécie em seu habitat.

\section{Avaliação da qualidade ambiental de cursos d'água da região utilizando ma- croinvertebrados aquáticos como bioindicadores}

Os ecossistemas aquáticos são impactados por inúmeras atividades humanas resultantes de atividades agrícolas, que podem causar erosão do solo e escoamento de grandes quantidades de sedimentos finos, nutrientes (por exemplo, nitrogênio, fósforo), metais pesados e pesticidas. A urbanização também é responsável por inúmeros impactos, incluindo poluição por derivados de petróleo, esgoto doméstico e resíduos sólidos (Figura 16). 


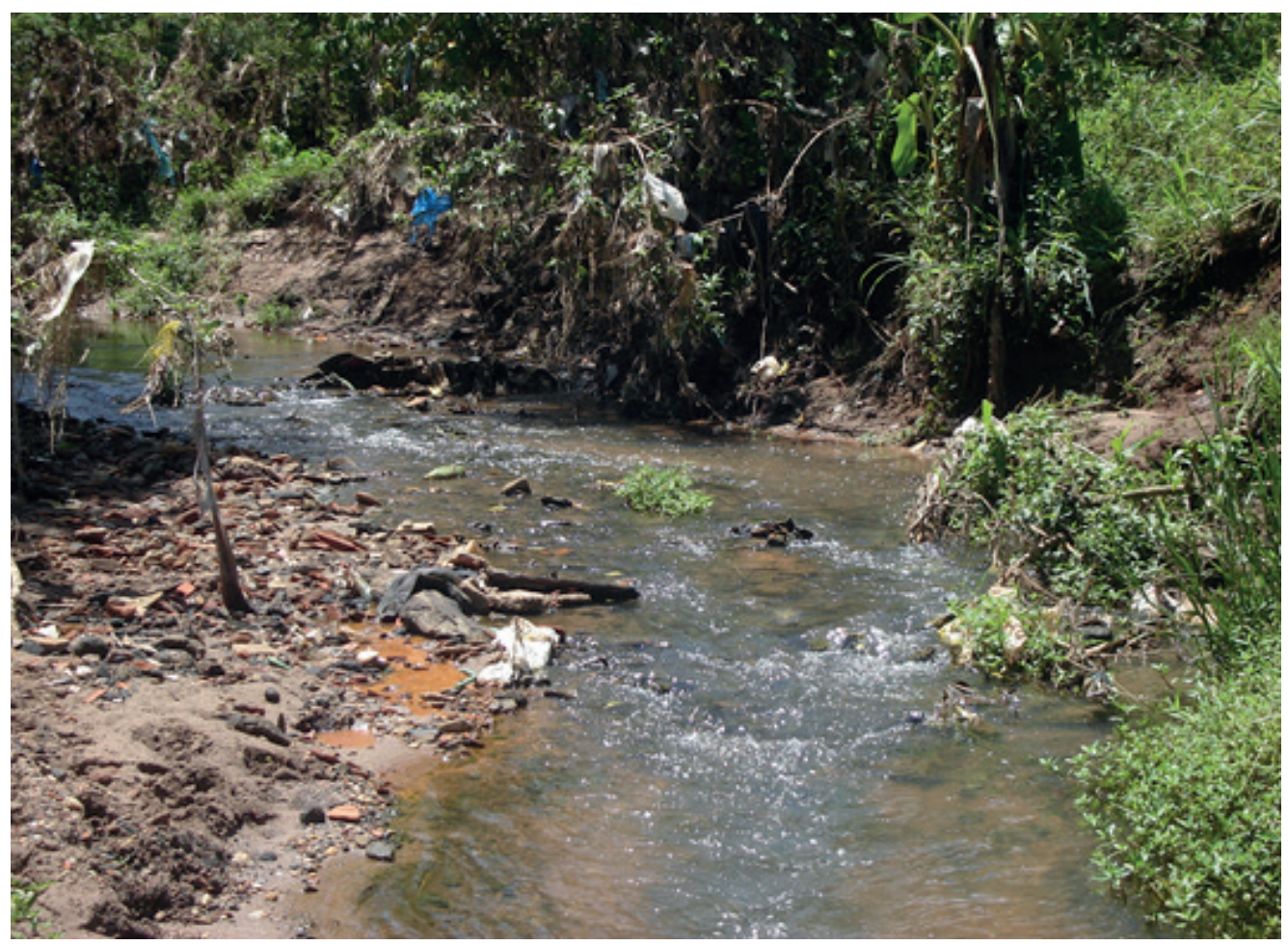

Figura 16. Riacho em área urbana de Uberlândia com evidências de processos erosivos nas margens, assoreamento, presença de lixo e degradação da vegetação ripária.

De forma geral, essas alterações favorecem o aumento de grupos de macroinvertebrados aquáticos tolerantes, como oligoquetas, alguns moluscos e gêneros da família Chironomidae (Insecta: Diptera) e diminuição de grupos sensíveis, como insetos aquáticos das ordens Ephemeroptera, Plecoptera e Trichoptera (EPT), levando a um processo de homogeneização das comunidades e redução de diversidade.

A produção de índices bióticos que levam em conta a variabilidade de resposta dos macroinvertebrados possibilita a avaliação da qualidade ambiental de corpos d'água, particularmente de rios e riachos, de forma relativamente simples. Um desses índices é o BMWP (Biological Monitoring Working Party), originalmente proposto para avaliar a qualidade de ambientes aquáticos no Reino Unido, mas que tem sido utilizado, pela sua simplicidade e adaptabilidade em diferentes regiões do mundo, inclusive em áreas de Cerrado do Brasil.

No BMWP, são atribuídas pontuações entre 1 e 10 para os diferentes táxons de macroinvertebrados aquáticos, em função de sua sensibilidade à poluição. $\mathrm{O}$ cálculo do BMWP é feito através da soma dos valores de pontuação para os táxons que ocorrem no trecho do curso d'água que se quer avaliar e quanto maior a pontuação, melhor a condição ecológica do sistema aquático em questão.

Em estudos realizados no LEEA, avaliamos as condições ecológicas de diversos cursos d'água do Triângulo Mineiro, particularmente na microbacia do rio Uberabinha, incluindo afluentes e trechos da calha principal desse rio. Os resultados obtidos para o BMWP de 12 afluentes do rio Uberabinha indicam que os riachos localizados na área rural apresentam, de forma geral, melhores condições ambientais que os riachos 
urbanos do município de Uberlândia (Figura 17). Outras métricas avaliadas, incluindo riqueza de táxons e proporção de EPT, também apresentaram valores mais elevados nos riachos da área rural em relação à área urbana.

Os resultados já eram esperados, uma vez que a concentração de poluentes tende a ser maior na área urbana em relação à área rural. Além disso, a partir de 2009, a parte superior da bacia do rio Uberabinha, fora da área urbana do município, tem sido objeto de um programa de restauração de matas ciliares (Programa Buriti), estabelecido pelo Departamento de Água e Esgoto de Uberlândia, o que garante maior integridade de habitat dos cursos d'água dessa área. Por sua vez, a avaliação de trechos do rio Uberabinha indicou que as comunidades de macroinvertebrados permaneceram bastante alteradas, mesmo após cerca de $5 \mathrm{~km}$ dos limites urbanos do município. Análises de parâmetros físicos, químicos e microbiológicos realizados de forma complementar à avaliação dos macroinvertebrados indicaram alterações consideráveis na qualidade da água desses trechos.
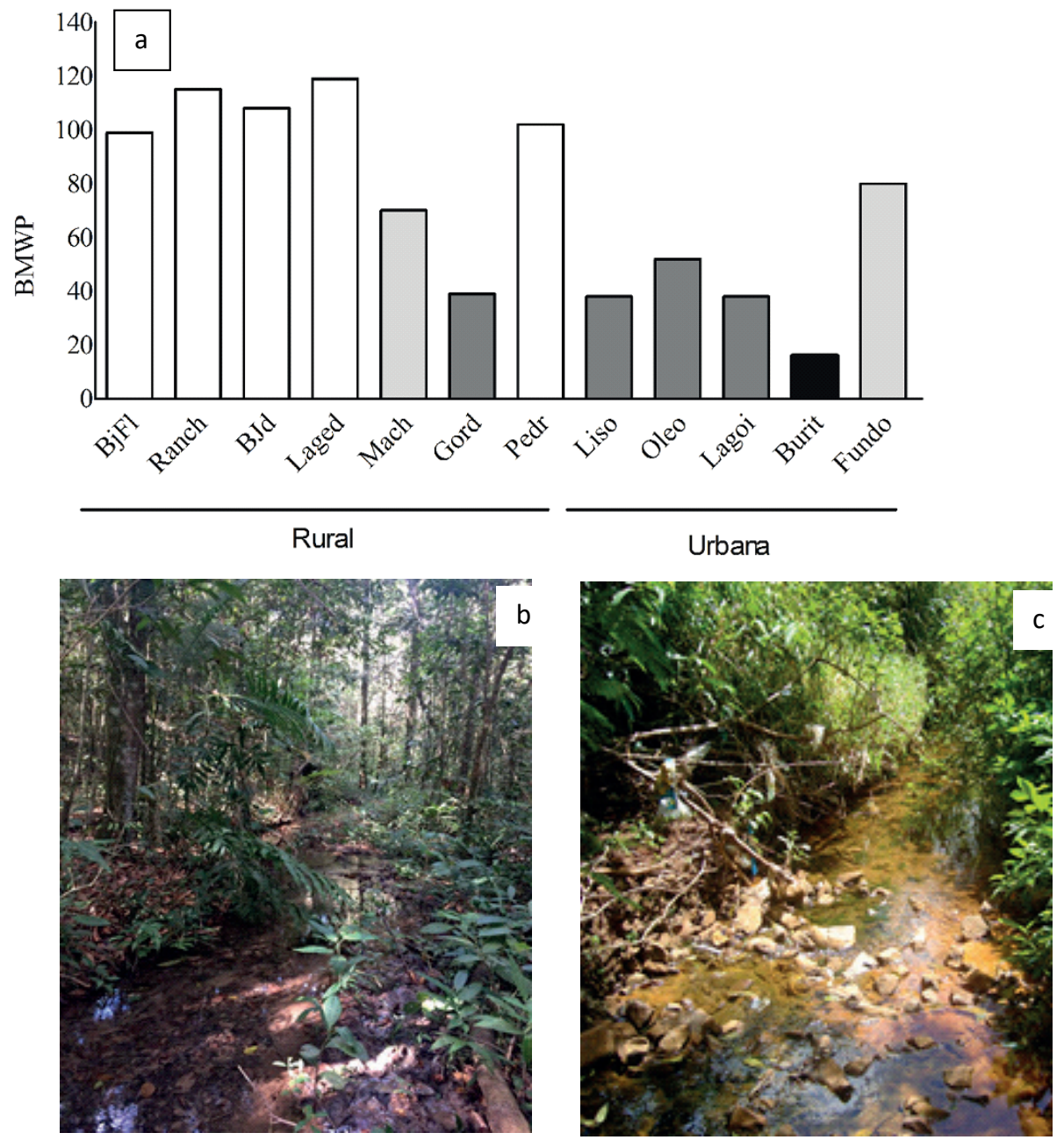

Figura 17. (a) Valores do índice BMWP e qualidade ambiental de riachos na região de Uberlândia. Cores diferentes representam qualidade de água diferente: Branco - excelente; Cinza claro - bom; Cinza escuro satisfatório; preto - ruim; (b) trecho de um riacho íntegro; (c) trecho de um riacho impactado. 


\section{Bioacumulação de metais pesados em macroinvertebrados aquáticos}

A bioacumulação é um processo pelo qual ocorre a concentração de substâncias nos tecidos de seres vivos, que pode acontecer passivamente, por absorção dos compostos na coluna d'água, ou ativamente, pela ingestão de alimentos que contenham tais substâncias. A partir da bioacumulação pode ocorrer a biomagnificação, que consiste no aumento da concentração de compostos em níveis tróficos superiores, em decorrência das relações tróficas que ocorrem nas cadeias alimentares.

Dentre os vários tipos de contaminantes dos ecossistemas aquáticos brasileiros, os metais pesados estão amplamente distribuídos em diferentes tipos de ambientes aquáticos. São provenientes de diferentes fontes, mas em áreas rurais, principalmente de alguns tipos de fertilizantes (cuja composição contém principalmente chumbo, níquel, cromo, cádmio e zinco), que podem atingir os sistemas hídricos adjacentes em virtude do escoamento superficial no solo. Essa contaminação é ainda maior na ausência de vegetação ripária, a qual pode minimizar o carreamento de produtos tóxicos para os ambientes aquáticos.

Diversos estudos conduzidos em sistemas aquáticos contaminados por metais pesados reportaram correlação entre a concentração de metais em matrizes abióticas (água, sedimentos) e a fauna residente (peixes e macroinvertebrados). Os efeitos tóxicos dos metais para a comunidade de macroinvertebrados aquáticos estão relacionados ao aumento da taxa de mortalidade das espécies sensíveis, além da alteraração de processos vitais, como o crescimento e a reprodução.

Os insetos aquáticos representam cerca de $90 \%$ da fauna de invertebrados aquáticos e podem constituir um importante elo para a transferência de metais do sedimento para os organismos de níveis tróficos superiores, como peixes e outros vertebrados. Alguns estudos apontam que o processo de bioacumulação em macroinvertebrados aquáticos pode ocorrer de forma diferenciada em função do grupo trófico a que esses organismos pertencem.

Nesse sentido o LEEA-UFU desenvolveu uma pesquisa comparativa da bioacumulação de metais considerando os principais grupos tróficos funcionais que ocorrem na entomofauna aquática tropical (filtradores, coletores, fragmentadores e predadores). Metais pesados (cobre, manganês, cádmio, zinco) foram avaliados no sedimento e em insetos aquáticos em três córregos situados na região do Triângulo Mineiro. Todos os quatro metais analisados no sedimento foram detectados neste compartimento, embora em concentrações relativamente baixas. Na fauna foi detectada a bioacumulacão de cobre, manganês e zinco, não sendo detectada a presença de cádmio em nenhuma das amostras de insetos.

Foi evidenciada concentração diferencial de metais entre os grupos tróficos funcionais para os elementos cobre e manganês. Os fragmentadores apresentaram concentrações de cobre significativamente menores que filtradores e predadores. Com relação ao manganês, os insetos predadores acumularam concentrações significativamente menores que os demais grupos tróficos (Figura 18). 

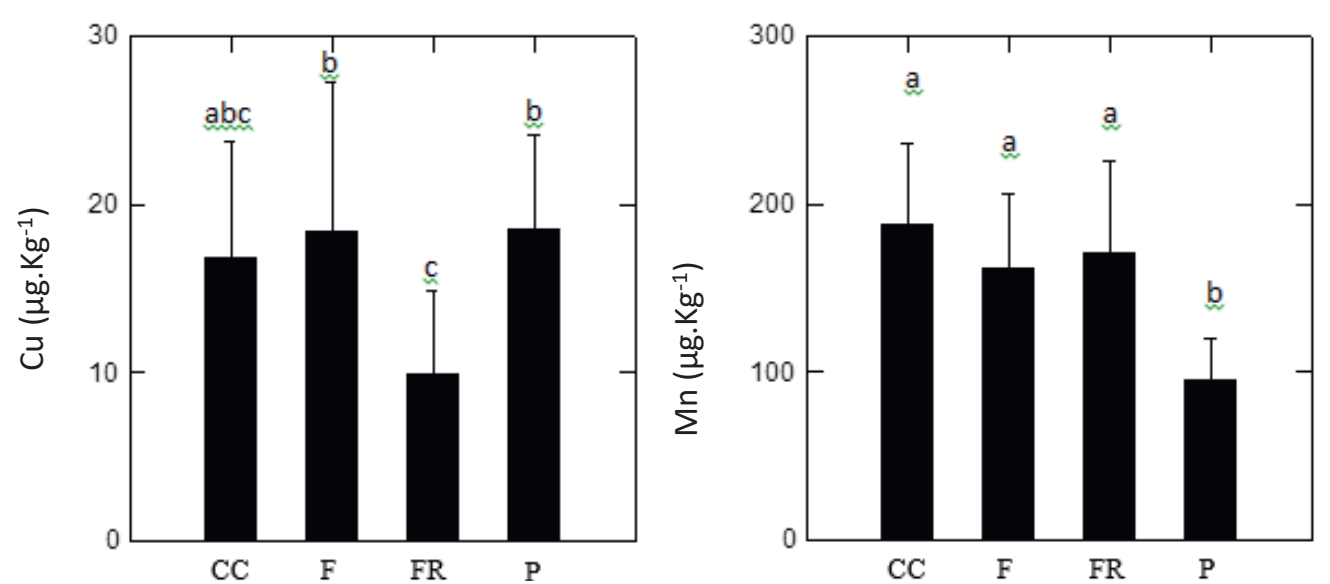

Figura 18. Média e desvio padrão da concentração de metais $\left(\mu \mathrm{g} \cdot \mathrm{Kg}^{-1}\right)$ em grupos tróficos funcionais de macroinvertebrados bentônicos. CC- coletor catador; F - coletor filtrador; FR- fragmentador e P- predador. A - Cobre; B - Manganês. *Médias seguidas da mesma letra não diferem significativamente.

De forma distinta ao de outros estudos existentes, que encontraram concentrações de metais significativamente maiores nos coletores, no nosso estudo este padrão não foi encontrado, tendo sido evidenciada variabilidade na bioacumulação dos diferentes metais testados. É possível que o nível distintivo de bioacumulação possa não ser o de guildas alimentares, mas estar relacionando ao grupo taxonômico, havendo variação considerável em função de características metabólicas e do tamanho do corpo dos insetos aquáticos.

\section{O papel da vegetação ripária na conservação de comunidades de macroinverte- brados bentônicos de riachos}

As matas ripárias constituem elementos essenciais para o estabelecimento da comunidade de macroinvertebrados bentônicos. Representam um importante elo de transição aquático-terrestre possibilitando inúmeras contribuições ecológicas para a integridade do hábitat e, por consequência, das comunidades aquáticas. Podem receber diversas denominações: vegetação ripária, mata ciliar, mata de galeria, florestas ribeirinhas, dentre outras. São inúmeros e de naturezas diversas os serviços ecológicos das matas ripárias para a comunidade de macroinvertebrados bentônicos de ambientes lóticos. Talvez um dos principais e mais evidentes seja o de prover nutrientes e energia para os organismos aquáticos, sobretudo em riachos de baixa ordem (de cabeceira), os quais são geralmente cobertos com vegetação, recebendo pouca luz, acarretando forte dependência da vegetação ripária como principal provedora de material orgânico. Esse material externo ao ambiente aquático, denominado material alóctone, inclui folhas, frutos, sementes e material lenhoso. Além de serem fonte de alimento, todos esses materiais são importantes locais de abrigo para a fauna aquática. Bancos de folhas (Figura 19), por exemplo, que se constituem a partir da entrada de serapilheira no ecossistema aquático, abrigam uma rica e abundante comunidade e macroinvertebrados aquáticos. Outros importantes papéis desempenhados pelas matas ripárias são a manutenção da qualidade da água, promoção da estabilidade das margens dos rios, equilíbrio térmico, 
formação de corredores ecológicos, sombreamento, controle da erosão e ainda podem atuar como "tampão" contra os impactos de pastagens e agricultura em áreas adjacentes aos cursos de água.

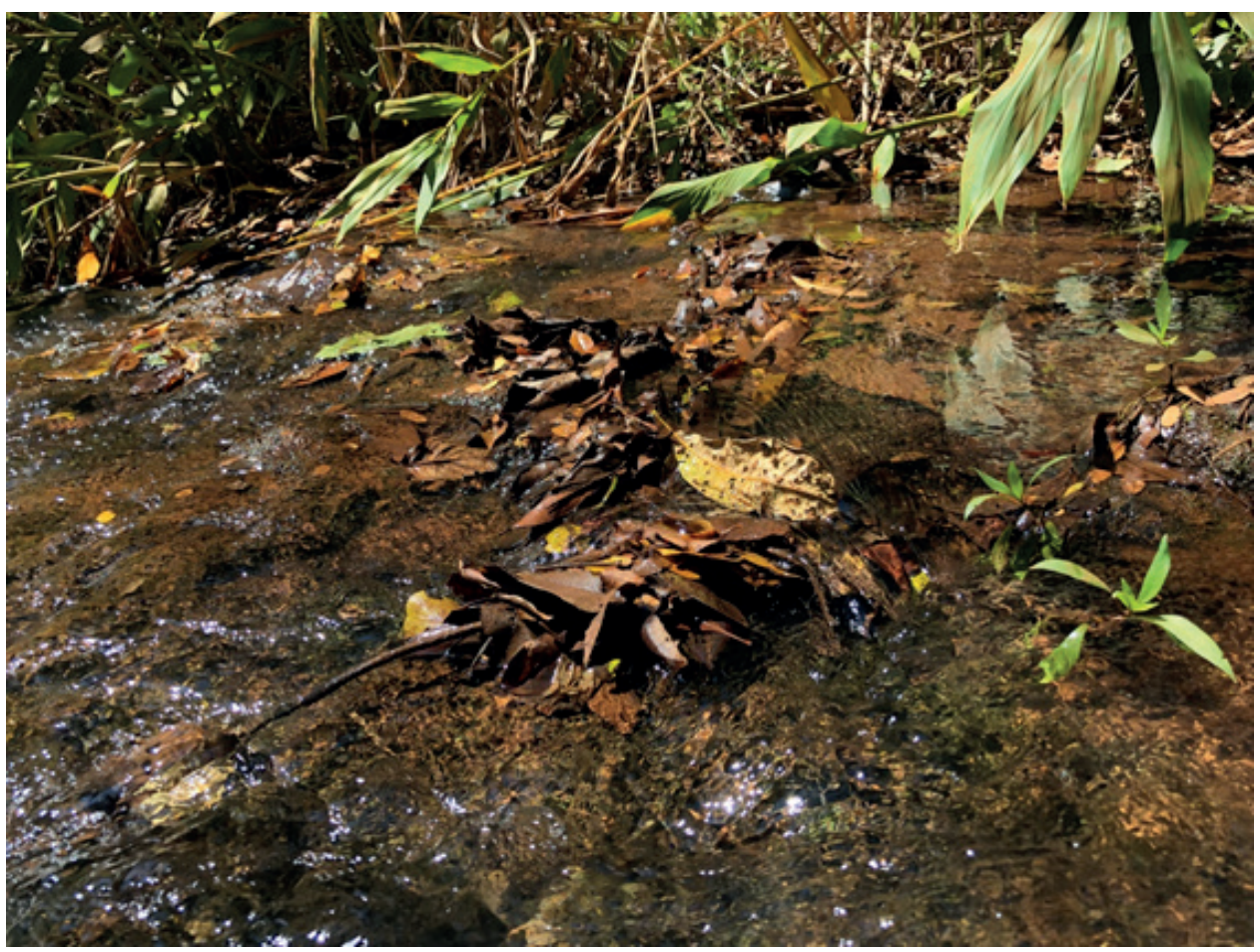

Figura 19. Banco de folhas em um riacho da Bacia do Rio Uberabinha (MG).

Estudos avaliando o efeito de lavouras e pastagem no entorno de ecossistemas aquáticos nas comunidades de macroinvertebrados bentônicos indicam que a riqueza e a diversidade são significativamente menores em riachos impactados por essas atividades agropecuárias. Há um empobrecimento das comunidades bentônicas, com predominância de táxons tolerantes (ex: oligoquetas e quironomídeos). Nesses estudos, a escassez ou a ausência de vegetação ripária é o fator que melhor explica o empobrecimento das comunidades de macroinvertebrados bentônicos. De fato, vários estudos conduzidos em riachos de áreas temperadas indicam que a presença de vegetação ripária parece amortecer os efeitos do uso do solo em comunidades aquáticas. No Brasil, assim como em vários países em desenvolvimento da região Neotropical, com uma crescente expansão das atividades agropecuárias, acreditamos que é uma questão ecológica muito importante a ser avaliada.

Nesse sentido, avaliamos se as matas ripárias exercem um efeito tampão sobre as comunidades de macroinvertebrados aquáticos de riachos, comparando sua estrutura em riachos com mata ripária localizados em áreas naturais (unidades de conservação públicas e privadas, consideradas áreas de referência) aos riachos em áreas de agricultura e pastagem. Foram selecionados riachos com atividades agropecuárias com no mínimo $30 \mathrm{~m}$ de vegetação ripária em ambas as margens (Figura 20). 

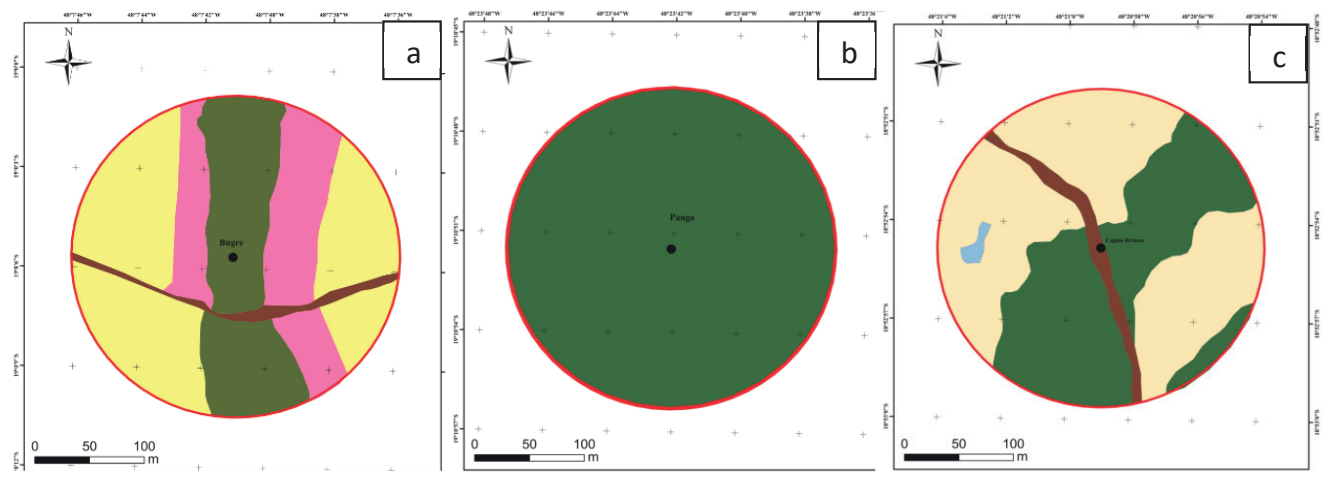

Figura 20. Mapas de uso e ocupação do solo. a) área de agricultura, b) área natural e c) área de pastagem. Legenda - amarelo: agricultura, magenta: vereda, verde: floresta, azul: corpo hídrico e bege: pastagem.

Foi registrada uma comunidade de macroinvertebrados bentônicos bastante diversa e abundante nas três categorias de riachos. Foram amostrados 29.038 indivíduos distribuídos em 66 táxons: 11.647 indivíduos (55 táxons) em riachos naturais, 7.827 indivíduos (50 táxons) em áreas de pastagem e 9.564 (54 táxons) em áreas agrícolas. Os resultados não indicaram diferenças na estrutura das comunidades, avaliada através de diferentes métricas (Índice de Simpson, Índice de Diversidade de Shannon-Winner, $\%$ Chironomidae, Equidade, Riqueza, \% EPT e \% de grupos tróficos funcionais (Figura 21) entre as categorias de uso do solo.

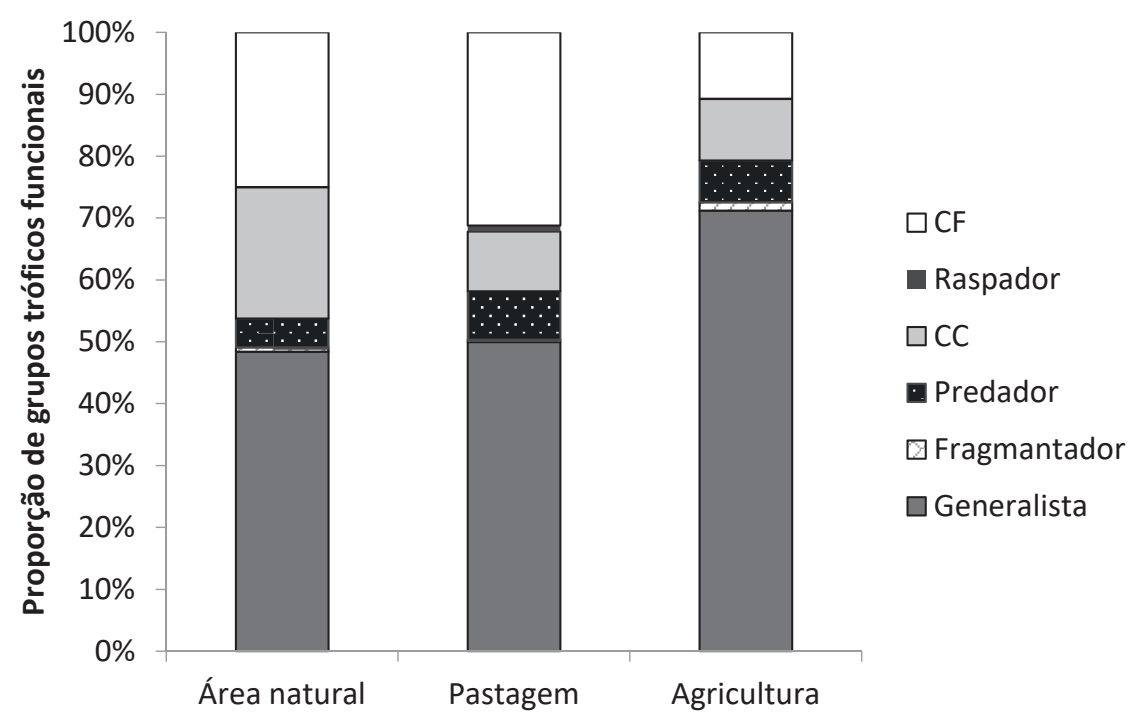

Figura 21. Proporção de grupos tróficos funcionais nos riachos estudados (CF: coletor-filtrador. CC: coletor-catador).

Os dados sugerem que as atividades de pastagem e agricultura não geram um impacto negativo significativo nas comunidades de macroinvertebrados quando os cursos de água têm a vegetação ripária preservada. Essas descobertas são importantes em contextos ambientais no Brasil e em outros países onde as atividades pecuárias e agrícolas são amplamente exploradas e, infelizmente, não existe uma cultura forte 
para a preservação ambiental. Sendo assim, sistemas de gestão ambiental devem concentrar esforços para a manutenção e/ou recuperação das matas ripárias a fim de que estas atendam os limites mínimos estabelecidos pela legislação ambiental vigente, entendendo que, dessa forma, os serviços ecológicos das mesmas continuarão sendo ofertados, contribuindo assim para um desenvolvimento sustentável das atividades agrícolas e pecuárias.

\section{Espécies exóticas invasoras de macroinvertebrados aquáticos na região}

Espécies exóticas invasoras são aquelas provenientes de outros ambientes e que, uma vez introduzidas, passam a se reproduzir e proliferar exageradamente. Esse processo é usualmente facilitado pela ausência de predadores e parasitas especializados. Segundo a IUCN, as espécies exóticas invasoras representam uma das maiores causas de perda de biodiversidade no planeta.

Ambientes aquáticos são particularmente susceptíveis à introdução de espécies invasoras, em função da conectividade intrínseca que apresentam. Nas últimas décadas foi evidenciado um aumento de populações de espécies invasoras em ambientes aquáticos continentais, possivelmente em função do aumento da circulação de embarcações e de alterações ambientais que facilitam o estabelecimento desses organismos. No entanto, esse aumento também pode resultar de intensificação dos esforços de pesquisa e dos programas de monitoramento de órgãos ambientais. A introdução de espécies exóticas em ecossistemas aquáticos continentais pode afetar tanto a biodiversidade, por causarem a extinção de espécies, quanto as atividades econômicas, com danos à atividade pesqueira, riscos sanitários, gastos com manutenção de turbinas em hidroelétricas, dentre outros.

No Brasil, o estabelecimento de reservatórios artificiais, principalmente para a produção de energia hidrelétrica, tem sido um fator facilitador do processo de introdução de espécies invasoras, pois são ecossistemas aquáticos que apresentam comunidades biológicas simplificadas em relação aos ambientes anteriores ao barramento, sendo mais susceptíveis ao estabelecimento de organismos invasores.

Algumas espécies invasoras de invertebrados límnicos apresentam ampla distribuição e populações estabelecidas em diferentes bacias hidrográficas do centrosul do país, sendo favorecidas pela elevada quantidade de reservatórios nessa região. É o caso dos moluscos bivalves Corbicula fluminea (Müller, 1774) e Limnoperna fortunei (Dunker, 1856), do gastrópode Melanoides tuberculatus (Müller, 1774) (Silva \& Barros, 2008) e do crustáceo decápodo Dilocarcinus pagei (Stimpson, 1861).

Corbicula fluminea é uma espécie originária do sudeste asiático e que foi registrada pela primeira vez no Brasil ao final da década 1970, no estado Rio Grande do Sul. Esse bivalve pode dominar comunidades de invertebrados bentônicos, aumentar a taxa de mineralização de nutrientes, reduzir a turbidez da água e promover a extinção de espécies nativas de bivalves. Ocorrem tanto em ambientes lóticos, quanto lênticos, podendo atingir densidades muito elevadas $\left(>10.000 \mathrm{ind} / \mathrm{m}^{2}\right)$.

Limnoperna fortunei, conhecida popularmente como mexilhão dourado, é a outra espécie invasora de bivalve a entrar na América do Sul, vinda da Ásia, via bacia do Rio da Prata. Um dos principais impactos ecológicos desta espécie é a competição com espécies nativas por espaço e alimento. Essa espécie também pode gerar danos econômicos de grande montante em sistemas de distribuição de água e irrigação, devido 
ao seu alto poder de incrustação (Figura 22), além de reduzir o diâmetro e a velocidade da água em tubulações de usinas hidrelétricas e produzir acumulação de conchas vazias e oclusão de canos.

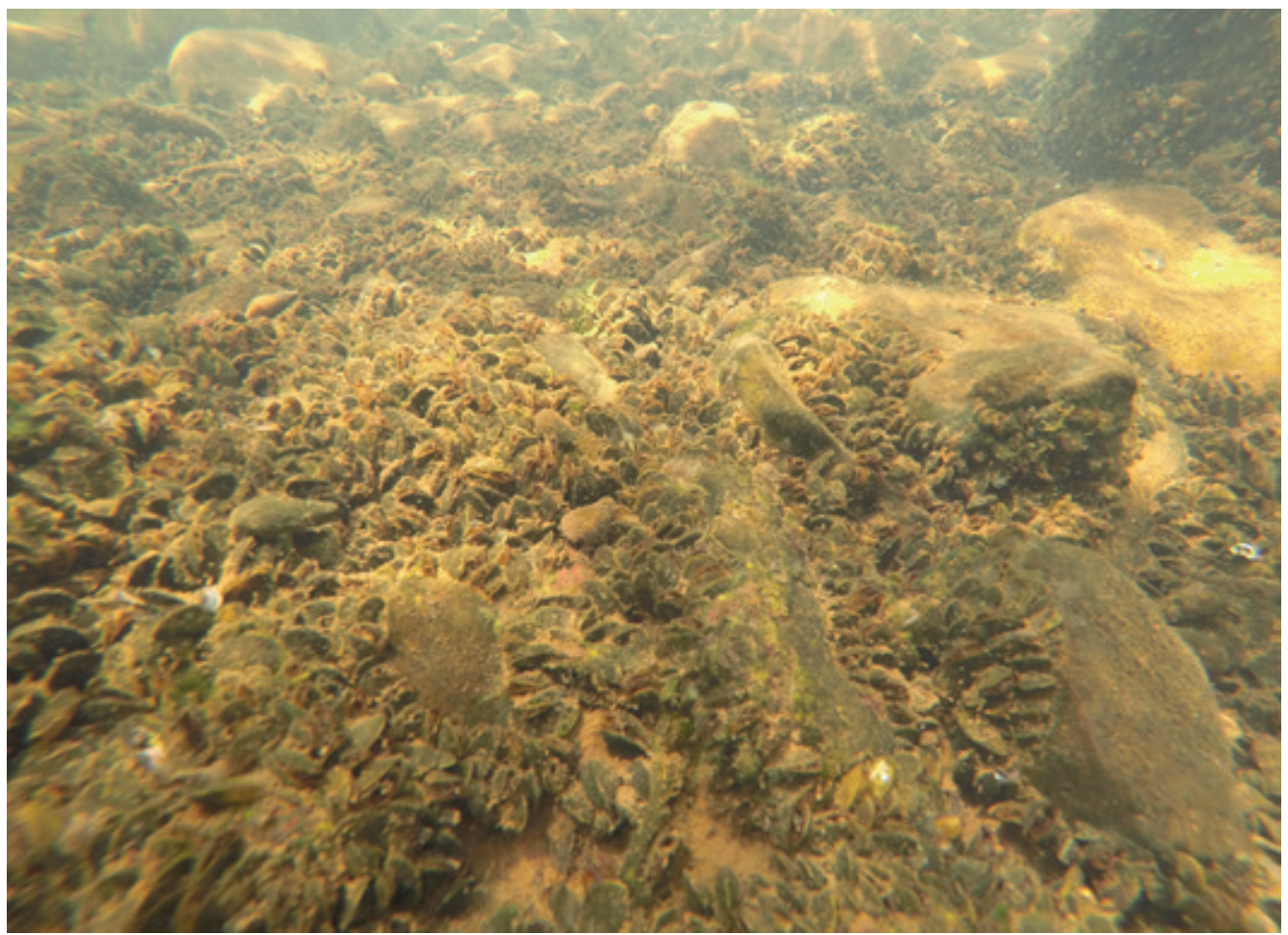

Figura 22. Leito rochoso de trecho do rio Grande com elevada densidade de indivíduos de mexilhão dourado.

Melanoides tuberculatus (Müller, 1774) é um gastrópode raspador e depositívoro originário do leste e norte da África, sudeste da Ásia, China e ilhas do Indo-Pacífico, sendo registrado pela primeira vez no Brasil na cidade de Santos (SP) em 1967. Em função de sua elevada abundância, sua presença é potencialmente capaz de desestabilizar as comunidades bentônicas nativas, principalmente as populações de caramujos nativos.

Dilocarcinus pagei é um decápodo onívoro nativo do Brasil nas regiões da bacia do rio Amazonas, rio Paraguai e baixo rio Paraná. Atualmente, há registros da espécie na bacia do alto Paraná, nos estados de São Paulo e Paraná. Não há registros do impacto da dispersão dessa espécie, mas acredita-se que ela possa gerar uma possível competição com espécies nativas nos locais onde é introduzida. Como é uma espécie utilizada como isca viva para a pesca desportiva, a ampliação de sua área de dispersão no Brasil apresenta um elevado risco potencial.

As quatro espécies já foram registradas na região do Triângulo Mineiro e sudeste de Goiás, particularmente nos grandes afluentes do rio Paraná, os rios Paranaíba e Grande. Na bacia do rio Araguari, tributário do rio Paranaíba, a equipe do LEEA tem feito registros ao longo dos últimos anos, particularmente nos reservatórios de suas hidrelétricas. Estudos específicos dessas espécies foram iniciados neste ano, visando ampliar o conhecimento ecológico sobre esses organismos e avaliar seu potencial de impacto nas comunidades aquáticas da região. 


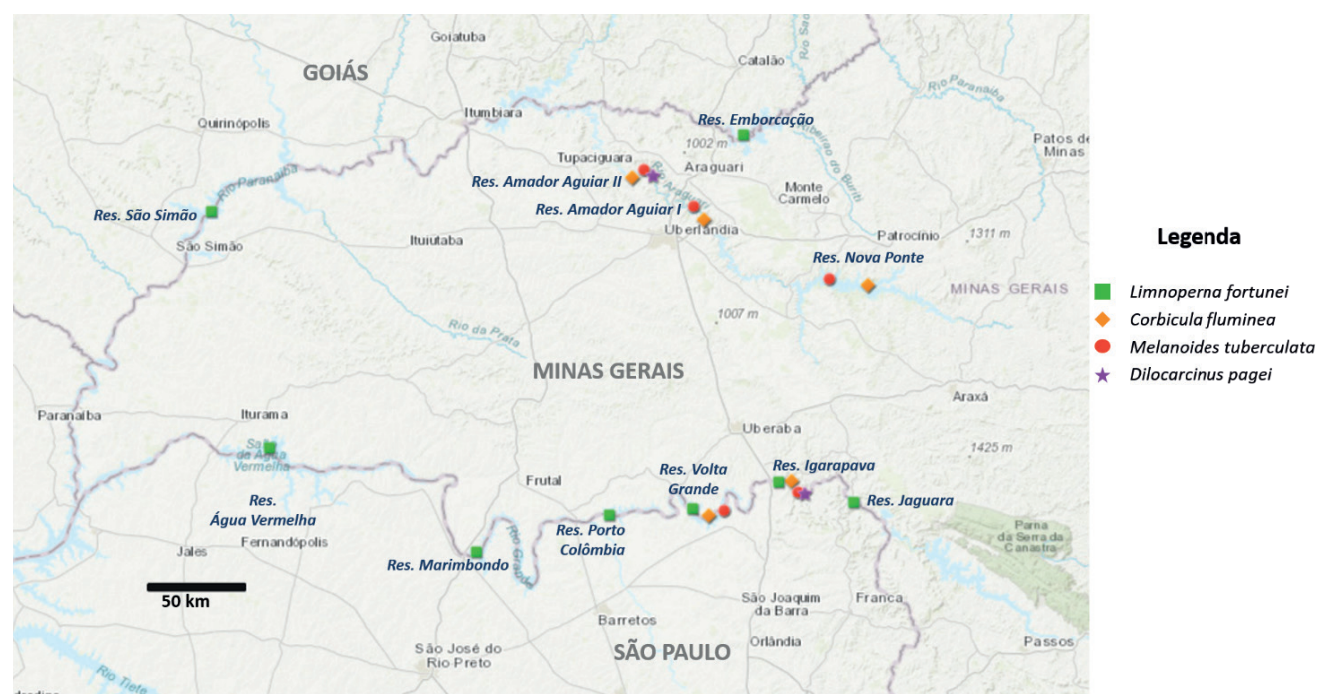

Figura 23. Registros de macroinvertebrados aquáticos invasores na região do Triângulo Mineiro. Os dados foram obtidos a partir da literatura e de coletas do LEEA - UFU.

\section{Considerações finais}

Os estudos sintetizados acima representam uma parcela das pesquisas desenvolvidas no Laboratório de Ecologia de Ecossistemas Aquáticos do Instituto de Biologia da Universidade Federal de Uberlândia e vem contribuindo para a produção de conhecimento básico e aplicado em ecologia e conservação de ecossistemas aquáticos através de publicações e formação de recursos humanos em nível de graduação e pósgraduação.

Além da contribuição geral para a ampliação do conhecimento em ecologia de ecossistemas aquáticos, particularmente das comunidades de macroinvertebrados aquáticos, as pesquisas relacionadas ao PELD têm possibilitado avaliar e monitorar as condições ambientais dos ecossistemas aquáticos do Triângulo Mineiro e Sudeste de Goiás. Essa região tem apresentado uma das mais altas taxas de desenvolvimento do país nas últimas décadas, com elevação considerável da densidade populacional e expansão das atividades econômicas, com consequente intensificação dos impactos nos ecossistemas aquáticos.

O estudo das comunidades de macroinvertebrados aquáticos que temos desenvolvido tem se mostrado uma ferramenta útil na compreensão das relações ecológicas que envolvem esses organismos, assim como das consequências dos diversos impactos ambientais nessas comunidades biológicas.

Pesquisas que visam conhecer aspectos da ecologia trófica e reprodutiva de crustáceos decápodos, processos de bioacumulação e efeitos de poluentes em diferentes táxons e dinâmica populacional de espécies invasoras são alguns dos estudos que estamos iniciando no LEEA e que devem trazer contribuições significativas para o conhecimento da ecologia e conservação de ecossistemas aquáticos. 


\section{Para saber mais}

Cummins KW (1973) Trophic relations of aquatic insects. Annu Rev Entomol 18:183206 doi: 10.1146/annurev.en.18.010173.001151

Cummins KW, Merritt RW, Andrade PCN (2005) The use of invertebrate functional groups to characterize ecosystem attributes in selected streams and rivers in south Brazil. Stud Neotrop Fauna E 40:69-89 doi: 10.1080/01650520400025720

Guimarães-Souto RM, Corbi JJ, Jacobucci GB (2019) Aquatic insects as bioindicators of heavy metals in sediments in Cerrado streams. Limnetica 38:575-586 doi: 10.23818/ limn.38.33

Mugnai R, Nessimian JL, Baptista DF (2010) Manual de identificação de macroinvertebrados aquáticos do Estado do Rio de Janeiro: para atividades técnicas, de ensino e treinamento em programas de avaliação da qualidade ecológica dos ecossistemas lóticos. Technical Books, Rio de Janeiro

Nascimento AL, Martins FA, Jacobucci GB (2018) Assessment of ecological water quality along a rural to urban land use gradient using benthic macroinvertebrate-based indices. Biosci J 34:194-209 doi: 10.14393/BJ-v34n1a2018-37842

Nogueira CS, Costa TM, Almeida AC (2018) Habitat choice behavior in Macrobrachium brasiliense (Heller, 1862) (Decapoda, Palaemonidae) under laboratory conditions. Oecologia Australis 22:55-62 doi: 10.4257/oeco.2018.2201.05

Nogueira CS, Pantaleão JAF, Almeida AC, Costa RC (2020) Male morphotypes of the freshwater prawn Macrobrachium brasiliense (Decapoda: Caridea: Palaemonidae). Invertebr Biol 139: e12279 doi: 10.1111/ivb.12279

Nogueira CS, Oliveira MS, Jacobucci GB, Almeida AC (2019) Relative growth of freshwater prawn Macrobrachium brasiliense (Decapoda, Palaemonidae) and its implications for reproduction. Iheringia, Sér. Zool. 109:e2019005 doi: 10.1590/1678$4766 \mathrm{e} 2019005$

Silva RC, Cunha MC, Mossolin EC, Jacobucci GB (2019) Population structure of Macrobrachium amazonicum (Heller, 1862) (Decapoda: Palaemonidae) in Miranda Hydroelectric Plant Reservoir, Araguari river, Minas Gerais, Brazil. Acta Limnol Bras 31:e14 doi: 10.1590/s2179-975x4318

Silva RC, Mossolin E, Jacobucci GB (2017) Reproductive biology of Macrobrachium amazonicum (Heller, 1862) (Decapoda: Palaemonidae) in a reservoir situated in Minas Gerais State, southeastern Brazil. Lat Am J Aquat Res 45:776-786 doi: 10.3856/vol45issue4-fulltext-13

Sousa EF, Guimarães-Souto RM, Jacobucci GB (2014) Distribuição e variação sazonal de Ephemeroptera, Plecoptera e Trichoptera (Arthropoda: Insecta) em ambientes aquáticos de áreas de Cerrado em Minas Gerais, Brasil. Biosc J 30:879-890 doi: $10.1590 / \mathrm{S} 0073-47212010000400004$ 


\section{CAPÍTULO 9}

\section{AS FORMIGAS: ECOLOGIA E HISTÓRIA NATURAL}

Jonas B. Maravalhas Heraldo L. Vasconcelos

'Ou o Brasil acaba com as saúvas, ou as saúvas acabam com o Brasil'. Desde que a célebre frase foi dita pelo naturalista francês Auguste Saint-Hillaire em sua visita ao país no início do século XIX, não acabaram nem as saúvas nem o Brasil! Embora as saúvas sejam pragas vorazes, elas também desempenham importantes funções no ambiente. E não só as saúvas, mas as formigas como um todo, são seres fascinantes, tanto pelo seu bem sucedido sistema de vida social quanto pela sua importância ecológica e diversidade. Neste capítulo iremos apresentar aspectos da história natural das formigas, sua evolução na região Neotropical e, em especial no Cerrado, bem como sua importância para o funcionamento dos ecossistemas e para a conservação da região.

\section{História natural}

As formigas são insetos da ordem Hymenoptera, que também inclui as vespas e abelhas. As operárias (castas não reprodutoras) de formigas não possuem asas, diferente dos demais Hymenoptera sociais. Os Hymenoptera possuem um sistema de determinação sexual, o sistema haplodiploide (Figura 1), que os tornou especialmente propensos à vida em sociedade (sim, as formigas são insetos sociais!). Neste sistema, as fêmeas são diploides, isto é, possuem um par de cada tipo de cromossomo, enquanto os machos, haploides, possuem apenas um cromossomo de cada tipo. Para compreender melhor este sistema, vamos exemplificá-lo usando o ciclo de vida das saúvas (Figura 2).

Muitos já presenciaram uma revoada de formigas, fenômeno que em geral ocorre quando as primeiras chuvas encerram o período de seca. Na revoada, as içás (machos e fêmeas de formigas com asas) saem do ninho para se reproduzir. O macho morre após o acasalamento, enquanto a fêmea armazena os espermatozoides na espermateca, uma estrutura próxima aos ovários que permite controlar a fecundação dos óvulos. Depois de fecundada, a fêmea (ou rainha) constrói um pequeno ninho no interior do solo, dentro do qual permanecerá por toda a vida, e o fecha para então dar início à produção de formigas operárias e ao cultivo do fungo simbiótico.

Sim, as saúvas são agricultoras! Embora as saúvas cortem folhas de plantas, estas não servem de alimento para as formigas. As folhas são levadas para dentro do ninho e utilizadas como substrato para o cultivo de um fungo que serve de alimento para estas formigas. Ao sair do ninho materno uma fêmea reprodutora (futura rainha) carrega na boca um pedaço do fungo de seu antigo ninho e o utiliza para cultivar seu próprio jardim de fungos. Na fundação de um novo ninho a rainha não pode se arriscar do lado de fora do ninho coletando folhas. Nesse período ela não se alimenta do fungo em crescimento, sobrevivendo à custa da metabolização dos músculos das asas e de suas 
reservas de gordura. Além disso, ela deposita ovos não fecundados (haploides) para servir de alimento para ela mesma! Estes ovos também alimentam as primeiras larvas que são oriundas de ovos fecundados (diploides). Estas se tornam operárias e então começam a auxiliar a rainha nos cuidados da colônia além de serem as responsáveis pela coleta de folhas que servirão de substrato para o jardim de fungo.

Quando a colônia estiver grande o suficiente, as operárias começam a selecionar larvas para um tratamento especial. Essas larvas darão origem a novas fêmeas aladas, ou seja, futuras rainhas em outros ninhos. Ao mesmo tempo, a rainha volta a colocar ovos não fecundados que, por sua vez, darão origem a machos alados. Com a chegada das chuvas, fêmeas e machos alados saem do ninho para acasalar com machos e fêmeas de outras colônias (revoada). Após a cópula as fêmeas fundam novas colônias, completando o ciclo de vida das saúvas. Vimos assim que as operárias de uma colônia carregam os genes tanto da mãe (rainha) como do pai (macho), enquanto os machos carregam somente os genes da mãe. Devido ao sistema haplodiploide, portanto, o grau de parentesco entre operárias irmãs de uma mesma colônia é de $75 \%$, entre a rainha e suas filhas de apenas $50 \%$, enquanto que entre a rainha e seus filhos machos o grau de parentesco é de $100 \%$. Essa é uma das explicações para o surgimento da eussocialidade (socialidade verdadeira) nos Hymenoptera, visto que a cooperação e o altruísmo entre irmãs se tornam evolutivamente favoráveis. A eussocialidade evoluiu independentemente entre oito e 11 vezes nesta ordem de insetos, destacando-se alguns grupos de grande sucesso ecológico, como as formigas e as abelhas e vespas sociais.

Um organismo é definido como eussocial quando três estágios evolutivos são atingidos: a criação cooperativa da ninhada, a presença de castas reprodutivas e a sobreposição de múltiplas gerações em um mesmo ninho. A criação cooperativa da ninhada é o estágio inicial da socialidade. Geralmente ocorre quando fêmeas irmãs compartilham um mesmo ninho e se ajudam na proteção e alimentação da prole. Em seguida, uma determinada fêmea começa a exercer dominância sobre as outras, até que gradativamente só uma fêmea reproduza, enquanto as outras somente buscam alimento e cuidam da prole. Por fim, a fêmea reprodutiva (rainha) se torna mais longeva e, assim, várias gerações da prole coexistem no ninho, de modo que as operárias mais velhas cuidam de uma ou mais gerações de operárias mais jovens. 


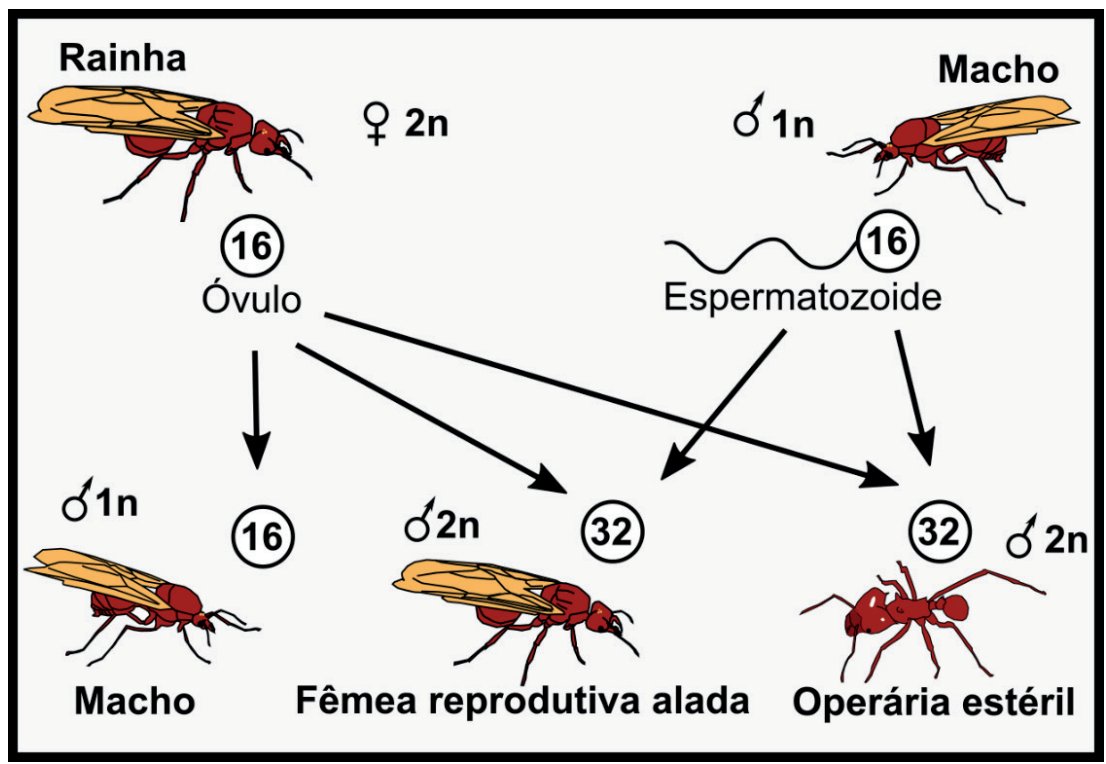

Figura 1. Sistema haplodiploide de determinação sexual das formigas e demais Hymenoptera.

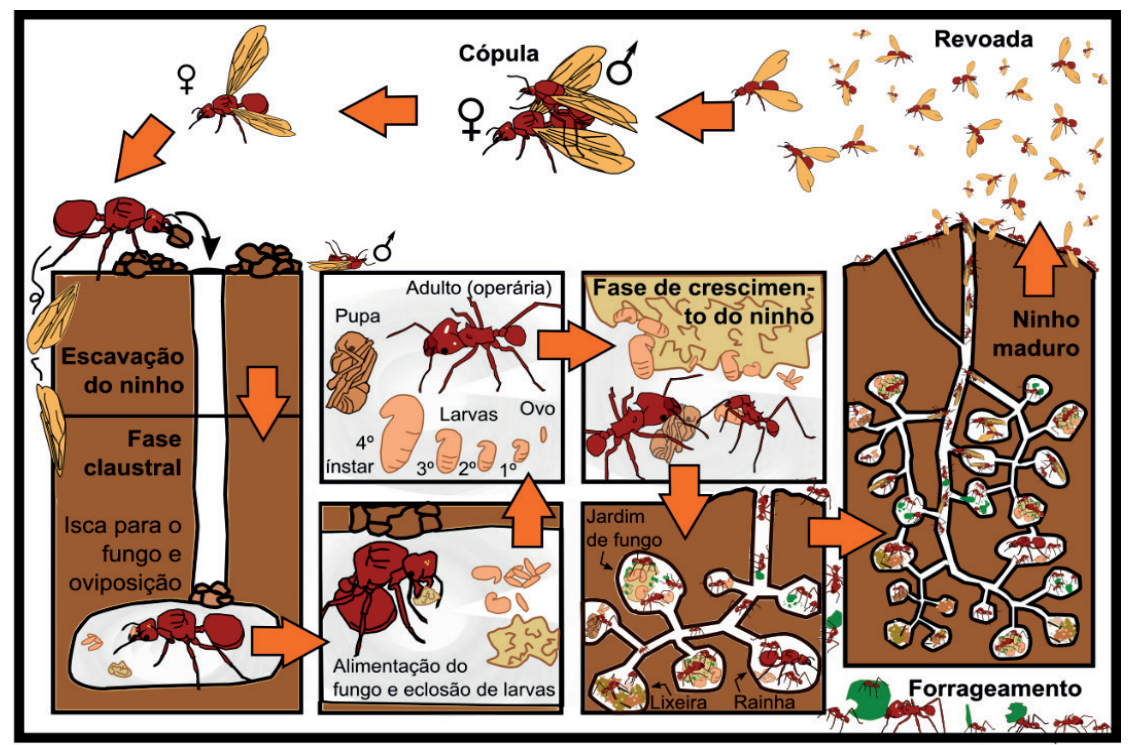

Figura 2. Representação esquemática do ciclo de vida das formigas usando as saúvas (gênero Atta) como exemplo.

As formigas, diferentemente das abelhas e vespas, são organismos exclusivamente eussociais, sendo essa característica um dos principais motivos de seu grande sucesso ecológico. As formigas estão presentes em todos os continentes (exceto a Antártida) sendo animais dominantes na maioria dos ecossistemas terrestres. As formigas podem nidificar e buscar alimento em diferentes habitats, como a copa das árvores, a superfície do solo e o subsolo. Elas estão envolvidas em múltiplas interações ecológicas: algumas espécies são importantes herbívoros, como as saúvas por exemplo, enquanto outras são predadoras vorazes de artrópodes. Por isso, as formigas podem realizar associações 
mutualísticas com plantas (através de nectários extraflorais) e com insetos sugadores (produtores de excretas açucarados), oferecendo, respectivamente, proteção contra herbívoros ou contra predadores e parasitóides em troca desses alimentos ricos em carboidratos. Por fim, as formigas competem intensamente entre si, tanto por alimentos como por sítios de nidificação, sendo úteis para compreender como as comunidades naturais se estruturam.

As formigas formam um grupo monofilético dentro de Hymenoptera e possuem uma taxonomia relativamente bem resolvida para um grupo de inseto tão diverso. São bastante ubíquas e fáceis de coletar e identificar. De um modo geral, as comunidades de formigas são bastante sensíveis a variações ambientais naturais, como por exemplo, diferenças na estrutura do habitat ou no microclima, bem como a variações devido à atividade humana, como o fogo, a mineração, e o uso da terra. As formigas, portanto, tem grande potencial de bioindicação, isto é, podem ser utilizadas para informar sobre a resposta de outros organismos às variações naturais e aos impactos antrópicos. Embora o clima tenha forte influência sobre os padrões globais de diversidade de formigas, a história evolutiva das diferentes províncias biogeográficas revela idiossincrasias na resposta das comunidades de formiga às variações ambientais naturais e aos impactos antrópicos nas diferentes regiões do nosso planeta. Desse modo, o estudo dos padrões de diversidade de formiga tem importância não só teórica, de modo a compreender a evolução destes insetos, como também uma importância aplicada, utilizando esse conhecimento para auxiliar no desenvolvimento de estratégias de conservação.

\section{Padrões históricos e macroecológicos de diversidade de formigas no Cerrado}

Existem pelo menos 15 mil espécies de formigas descritas no mundo, um número impressionante se considerarmos que estes insetos pertencem a somente uma família (Formicidae). O Brasil abriga em torno de $10 \%$ dessa diversidade, ou seja, por volta de 1.500 espécies de formigas já foram registradas no país. Já para o Cerrado, ainda são necessários estudos para catalogar todas as formigas que ocorrem na região. No entanto, um inventário das formigas em 29 localidades distribuídas por toda a extensão do Cerrado revelou um total de 455 espécies pertencentes a 72 gêneros (Figura 3) ocorrendo em áreas de vegetação savânica (cerrado sensu stricto). Apenas três espécies estavam presentes em todas as localidades, sendo essas Camponotus senex, Pheidole fracticeps e Pheidole triconstricta. Por outro lado, 137 espécies (30\% do total) foram encontradas em um único local, ressaltando a grande proporção de espécies raras. Ao menos 10 das espécies registradas neste estudo são consideradas endêmicas do Cerrado, senda elas: Mycetagroicus cerradensis, Sericomyrmex maravalhas, Ectatomma planidens, Dinoponera australis, Cephalotes adolphi, C. betoi, C. eduarduli, C. liepini, C. specularis e Leptomyrmex relictus. Outras nove espécies, Mycetomoellerius dichrous, Mycetomoellerius urichii, Mycetophylax letcus, Sericomyrmex scrobifer, Cyatta abscondita, Ectatomma opaciventre, Cephalotes persimilis e Gracilidris pombero, provavelmente também são endêmicas do Cerrado.

Estima-se que as formigas tenham originado entre 139 e 158 milhões de anos atrás, no período Cretáceo. No entanto, a evolução dos principais grupos de formigas (as subfamílias) se deu há aproximadamente 40 milhões de anos. Neste período as formigas se tornaram mais comuns no registro fóssil, indicando seu sucesso ecológico. 
Como os demais grupos hiperdiversos de insetos, acredita-se que a diversificação das formigas tenha se dado de forma concomitante à evolução das plantas com flores (Angiospermas). Dessa maneira, as florestas tropicais foram muito relevantes para a diversificação das formigas, sendo provável que esse importante grupo de inseto tenha se originado na região Neotropical. Estudos recentes no Cerrado nos dão algumas pistas sobre a origem e diversificação das formigas.

Um exemplo é a descoberta da espécie Leptomyrmex relictus na região central do Cerrado. Todas as demais espécies deste gênero são encontradas na Australásia e, portanto, acreditava-se que haviam se originado nesta região. Entretanto, com a análise filogenética descobriu-se que L. relictus é, na realidade, a espécie-irmã, isto é, a mais antiga das demais espécies do gênero. Isto é indício de que a origem destas formigas se deu na região Neotropical, por volta de 46 milhões anos atrás, e que elas posteriormente se dispersaram para a Australásia. Duas hipóteses explicam esse evento único de dispersão ocorrido no período Paleogeno: 1. Balsas naturais formadas por fragmentos de vegetação que levaram colônias ou rainhas fundadoras pela corrente Sul Equatorial, atravessando o Oceano Pacífico; 2. Dispersão por terra, atravessando a Antártida em um período geológico em que as massas de terra da atual América do Sul, Antártida e Oceania estavam unidas. Após a dispersão, as espécies presentes na atual Australásia se diversificaram, enquanto as espécies supostamente presentes na Antártida se extinguiram com o resfriamento do continente. O mesmo ocorreu para todas as espécies sul-americanas, exceto L. relictus, que sobreviveu como um testemunho da antiga conexão entre os continentes austrais.

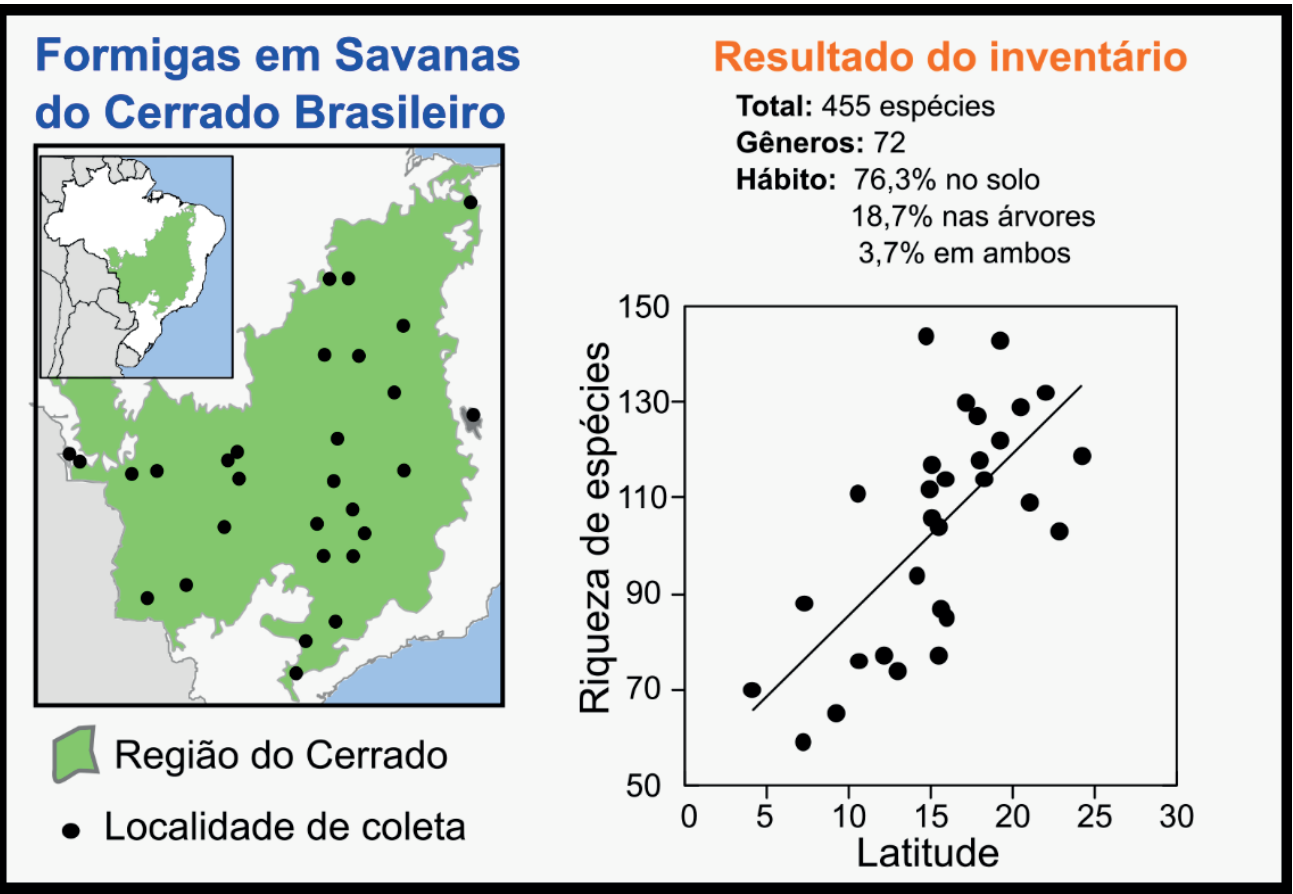

Figura 3. Inventário padronizado das comunidades de formigas em savanas do Cerrado. Mapa mostrando a distribuição dos locais, gráfico mostrando a relação entre a riqueza de espécies de formigas e a posição geográfica (latitude) da localidade amostrada. 
Outro exemplo vem do estudo que realizou um inventário em 29 localidades do Cerrado e que mostrou haver um gradiente latitudinal invertido de diversidade de formigas nesta região (Figura 3). Em geral, a diversidade de plantas e animais é maior em latitudes menores (próximo à linha do Equador) e diminui com o aumento da latitude (em direção aos polos). Entretanto, para as formigas do Cerrado há uma maior riqueza de espécies em latitudes menores, i.e., na região sul do Cerrado, em comparação com a região norte, mais pobre em espécies (Figura 3). Este padrão pode ser explicado tanto pela história evolutiva das formigas da região, como por fatores climáticos contemporâneos. Conforme dito anteriormente, as formigas provavelmente se originaram em florestas tropicais úmidas e quentes. Portanto, a fauna de formigas do Cerrado possui grande afinidade com esse tipo de clima, o que indica que mais espécies estão adaptadas ao clima mais úmido que caracteriza a região sul do Cerrado. Por outro lado, o clima contemporâneo pode atuar como um filtro para o estabelecimento e a permanência de determinadas espécies. Este provavelmente é o caso na região norte e nordeste do Cerrado, cuja fauna é composta de um subconjunto das espécies encontradas no restante do bioma. O clima menos favorável (mais seco) provavelmente resultou em diversos eventos de extinção local, resultando num empobrecimento da fauna de formigas nesta região. Como comparação podemos novamente olhar para as formigas da Austrália. Diferentemente do Cerrado, a diversidade de formigas australianas não parece ser determinada pelos padrões de precipitação na região, visto que a evolução das formigas nessa região se deu num contexto de extrema aridez e, portanto, as espécies ali presentes são em geral adaptadas a esse clima.

\section{Padrões de diversidade nas escalas da paisagem e local}

Vimos anteriormente que tanto fatores evolutivos como diferenças na quantidade de chuva determinam os padrões de diversidade de formigas na região do Cerrado. O clima, no entanto, explica somente parte da variação na diversidade de formigas, especialmente quando medimos esta diversidade em uma escala espacial menor. As coletas padronizadas no Cerrado nos permitiram estimar quantas espécies de formigas ocorrem no bioma como um todo (maior escala espacial), bem como em cada local de coleta (escala intermediária). Além disso, foi possível estimar quantas espécies ocorrem numa escala espacial menor ainda, ou seja, em uma parcela amostral de poucos metros quadrados. Nesse caso, vimos que características do solo (e não do clima) é que melhor ajudaram a explicar a variação geográfica na diversidade de formigas na menor escala espacial, ou seja, solos mais favoráveis propiciam uma maior densidade de espécies de formigas no Cerrado (Figura 4).

Nas coletas padronizadas realizadas no Cerrado a amostragem sempre se deu em áreas de cerrado sensu stricto, que é o tipo de vegetação dominante neste bioma. E quanto às outras fisionomias vegetais, como campos, cerradões e matas, também comuns na região? A amostragem em 12 áreas do Triângulo Mineiro mostrou que a composição de espécies de formigas variou bastante entre as fisionomias vegetais analisadas (vereda, cerrado ralo, cerrado sensu stricto e cerradão; Figura 5). A riqueza de espécies, por outro lado, foi similar entre todas as fisionomias, exceto a vereda que apresentou menor número de espécies, possivelmente porque é um ambiente com 
baixa complexidade estrutural e sujeito a inundações periódicas (Figura 5). Na região de estudos como um todo foi encontrado um total de 150 espécies, sendo que a maior parte $(51 \%)$ desta diversidade regional foi atribuída às diferenças na composição de espécies de formigas entre as diferentes fisionomias vegetais (Figura 5). Estes resultados mostram a importância da heterogeneidade ambiental (isto é, a variabilidade na estrutura da vegetação) na manutenção da diversidade de formigas no Cerrado.

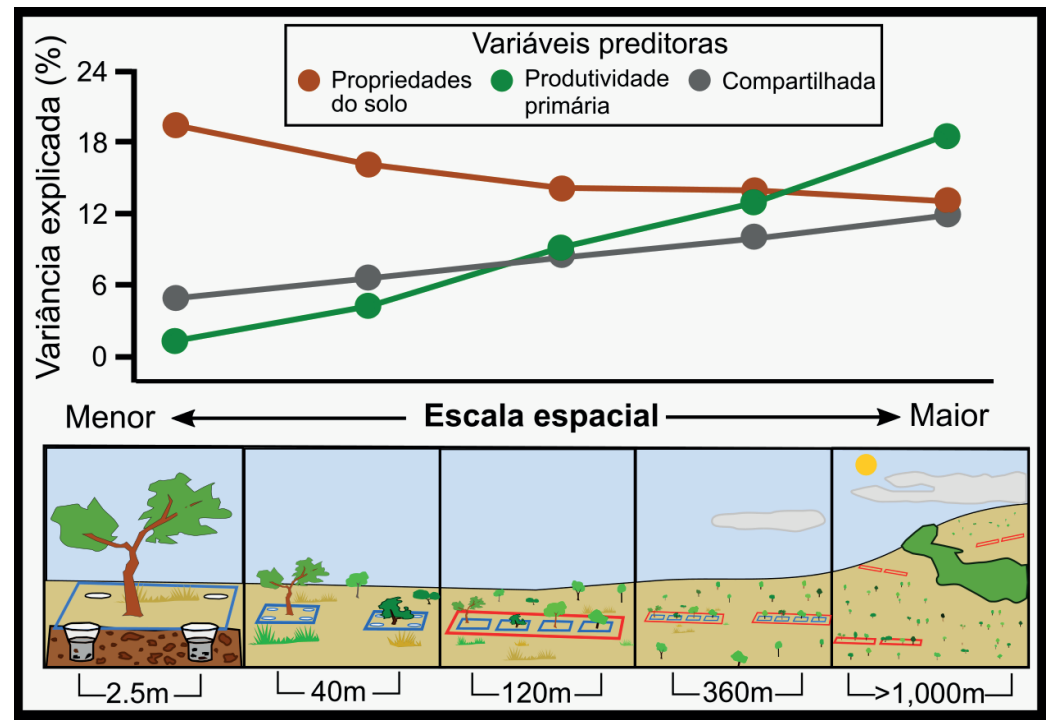

Figura 4. Fatores que determinam a diversidade de formigas em diferentes escalas espaciais. No gráfico está indicada a percentagem de variação da variável resposta (diversidade de formigas) que é explicada exclusivamente pela variável preditora (solo ou produtividade primária) ou que é explicada pela ação conjunta de ambas as preditoras (compartilhada).

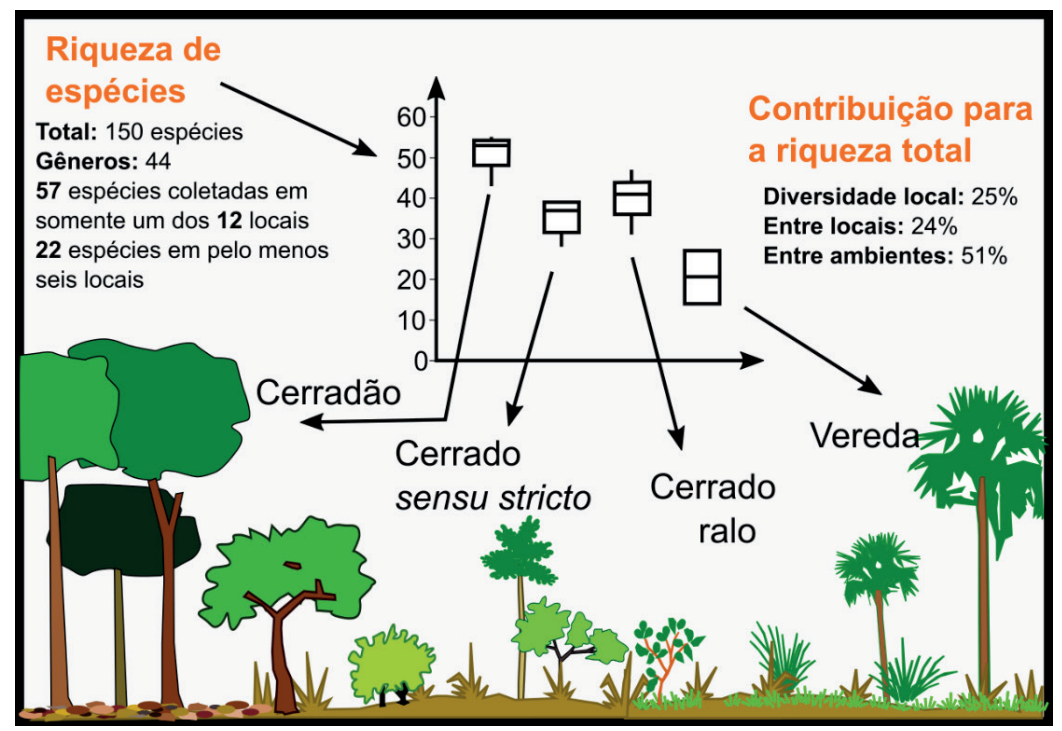

Figura 5. Variação natural na estrutura da vegetação do Cerrado e seu efeito na diversidade de formigas da região do Triângulo Mineiro. Embora cada tipo de vegetação sozinho suporte um número relativamente baixo de espécies, a região como um todo é bastante diversa devido às diferenças na composição de espécies entre os tipos de vegetação (ambientes). 
Vimos, dessa forma, que os padrões de diversidade de formigas do Cerrado dependem de fatores que ocorrem em grandes escalas espaciais (como a variação do clima ao longo do bioma Cerrado) e de fatores ambientais locais (como as características do solo ou o tipo de vegetação). Porém, existem ainda dois fatores que são cruciais para determinar quais espécies vão ocorrer em um determinado local por um determinado período de tempo. Um desses fatores é o acaso, isto é, a sucessão aleatória de eventos que em grande parte explica (ou melhor, não explica, pois é um efeito neutro) os padrões que observamos na natureza. Este complexo tema não é o foco deste capítulo, então partiremos para o segundo fator: as interações entre as espécies. Este é o último filtro de estruturação de qualquercomunidade de organismos, visto que, em um determinado local, muitas espécies têm o potencial de colonização, porém nem todas de fato ocorrem lá.

Para avaliar os fatores que determinam a coexistência de espécies de formigas arbóreas (que fazem ninho e/ou buscam alimento nas árvores), foi comparada a ocorrência natural de pares de espécies observadas nas árvores da Reserva Ecológica do Panga com ocorrências geradas ao acaso. Este método permite prever se duas espécies têm uma relação mutualística (associação positiva), se competem entre si (negativa), se a associação não difere do aleatório (neutra) ou se a associação é explicada por uma preferência de habitat (Figura 6). Embora a maior parte dos pares de espécies encontrados ocorra de maneira aleatória, alguns apresentaram associações estatisticamente significativas (isto é, diferente do acaso): a maioria das associações era negativa, porém algumas poucas foram positivas ou foram explicadas por diferenças no habitat de ocorrência das espécies e não pela competição (Figura 6). Estes resultados são evidência de que a competição é o principal fator determinante da coexistência das espécies de formigas em uma dada árvore. A competição entre espécies ocorre por algum recurso limitado, como, por exemplo, os locais de nidificação ou fontes de alimento. De fato, formigas arbóreas apresentam, como estratégia para melhor competir por alimento, uma rápida descoberta de recursos seguida pelo recrutamento de outras operárias para a defesa desse recurso contra possíveis competidores. 


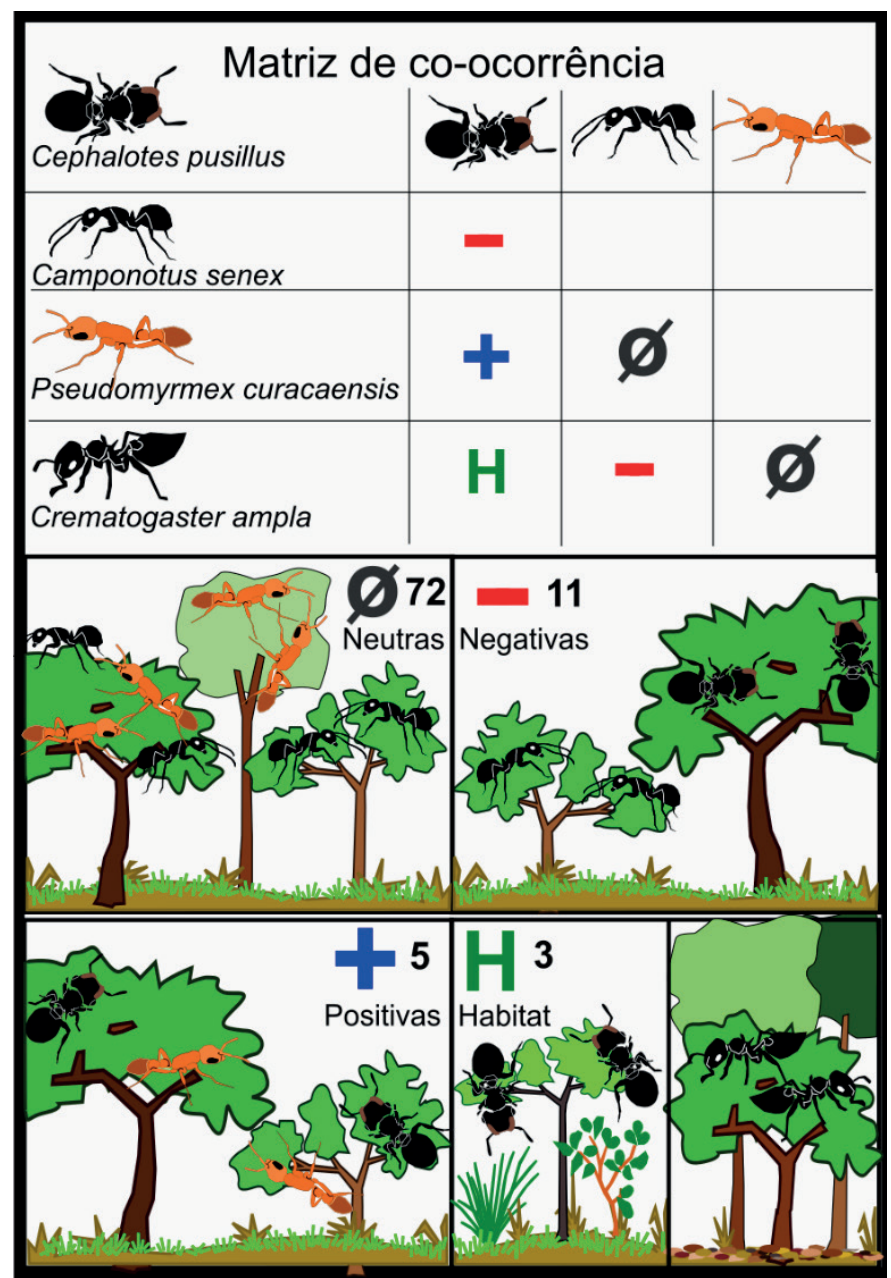

Figura 6. Representação esquemática de estudo sobre fatores que afetam a coexistência de espécies de formigas arbóreas na Reserva Ecológica do Panga. A matriz de coocorrência indica o tipo de associação entre pares de espécies, e os números nas figuras abaixo indicam quantas vezes aquele tipo de associação foi registrada.

\section{Mudanças temporais e o efeito de perturbações na comunidade de formigas}

Os estudos citados anteriormente nos ajudam a compreender quais fatores ecológicos determinam os padrões de diversidade de formigas entre diferentes escalas espaciais: desde escalas grandes, como a região do Cerrado como um todo, escalas intermediárias, como a paisagem, composta por diferentes coberturas da terra - naturais ou antrópicas - até a menor escala espacial, isto é, os locais onde os pesquisadores podem observar como os organismos interagem entre si e com o ambiente a sua volta. Existe outra escala, que não a espacial, que também influencia a diversidade de plantas, animais e outros organismos. Esta é a escala temporal, e analisando-a podemos compreender como a diversidade muda com o tempo e quais fatores possivelmente influenciam estas mudanças.

Para isto foi feita uma série de coletas em savanas da Reserva Ecológica do Panga e do Parque Estadual da Serra de Caldas Novas (Pescan) com o intuito de 
avaliar possíveis mudanças temporais na composição de gêneros de formigas arbóreas e compreender os fatores que determinam estas mudanças (Figura 7). No Pescan foram observadas mudanças na composição de espécies ao longo do tempo, porém estas mudanças não foram direcionais. Isto significa que a comunidade não estava, por exemplo, avançando em um processo sucessional (que seria uma mudança direcional), mas sim variando naturalmente e de maneira sutil ainda que, durante o período de estudos tenha havido um evento de fogo na reserva. Em contraste, na Reserva Ecológica do Panga, mudanças abruptas na comunidade de formigas arbóreas foram observadas em função de dois incêndios de grande severidade que atingiram essa reserva. Estes resultados ressaltam a importância de estudos ecológicos de longo prazo para melhor compreender os fatores que afetam a dinâmica das comunidades e, assim, subsidiar a tomada de decisão em questões conservacionistas.

Vimos que em algumas situações o fogo pode causar grandes mudanças na comunidade de formigas. $\mathrm{O}$ fogo, no entanto, é um importante agente de perturbação no Cerrado, ocorrendo naturalmente por meio de descargas elétricas no início e fim da estação seca. O fogo é parte da evolução do Cerrado e, portanto, é essencial para manter a estrutura e a heterogeneidade ambiental e assim proteger sua biodiversidade. De fato, completa supressão de queimadas em vegetações savânicas pode levar a uma mudança permanente no tipo de vegetação presente, de modo que a savana se transforma em uma formação florestal, como um cerradão ou mata seca. Da mesma forma, a supressão do fogo pode aumentar as chances de ocorrências de incêndios de alta severidade como os que ocorreram na Reserva Ecológica do Panga. Veremos, a seguir, como alguns estudos com comunidade de formigas do Cerrado podem nos auxiliar no desenvolvimento de estratégias de manejo de queimadas na região, de modo que o fogo não seja um vilão, mas sim um aliado na conservação ambiental.

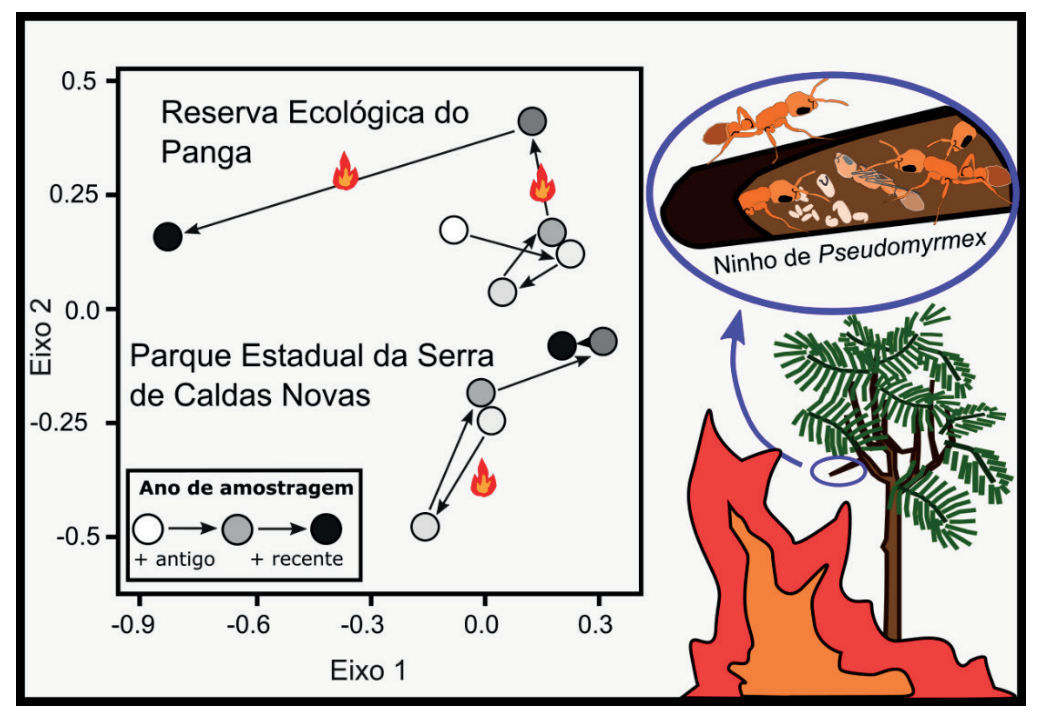

Figura 7. Mudanças temporais na composição de gêneros de formigas na Reserva Ecológica do Panga, antes e após dois incêndios severos e no Parque Estadual da Serra de Caldas Novas, antes e após um incêndio de baixa severidade. O gráfico indica a variação na composição de gêneros entre diferentes anos amostrais nos dois locais estudados, sendo que, quanto mais próximos os pontos, mais semelhante é a composição da comunidade. 
Um primeiro estudo mediu os impactos diretos e de curto prazo de uma queimada na comunidade de formigas e detectou uma redução na atividade de formigas nas árvores e um aumento da atividade no solo como consequência do fogo. Este efeito, no entanto, foi transitório, não sendo mais observado no ano seguinte ao fogo (Figura 8). Por outro lado, ao se medir os impactos indiretos e de longo prazo de uma série de queimadas controladas (ou seja, regimes de fogo) na comunidade de formigas, foi observada pouca variação na riqueza de espécies, tanto no solo como na vegetação, entre os diferentes regimes de fogo aplicados (Figura 8). Entretanto os diferentes regimes de fogo (que diferiam com a relação à frequência de queimadas ou ao período de aplicação do fogo), causaram diferenças marcantes na estrutura da vegetação e consequentemente na fauna de formigas. Houve grande variação na composição de espécies entre os regimes de fogo, o que ajuda a explicar a ocorrência de um grande número de espécies (162) na paisagem que compõe este estudo experimental (Figura 8).

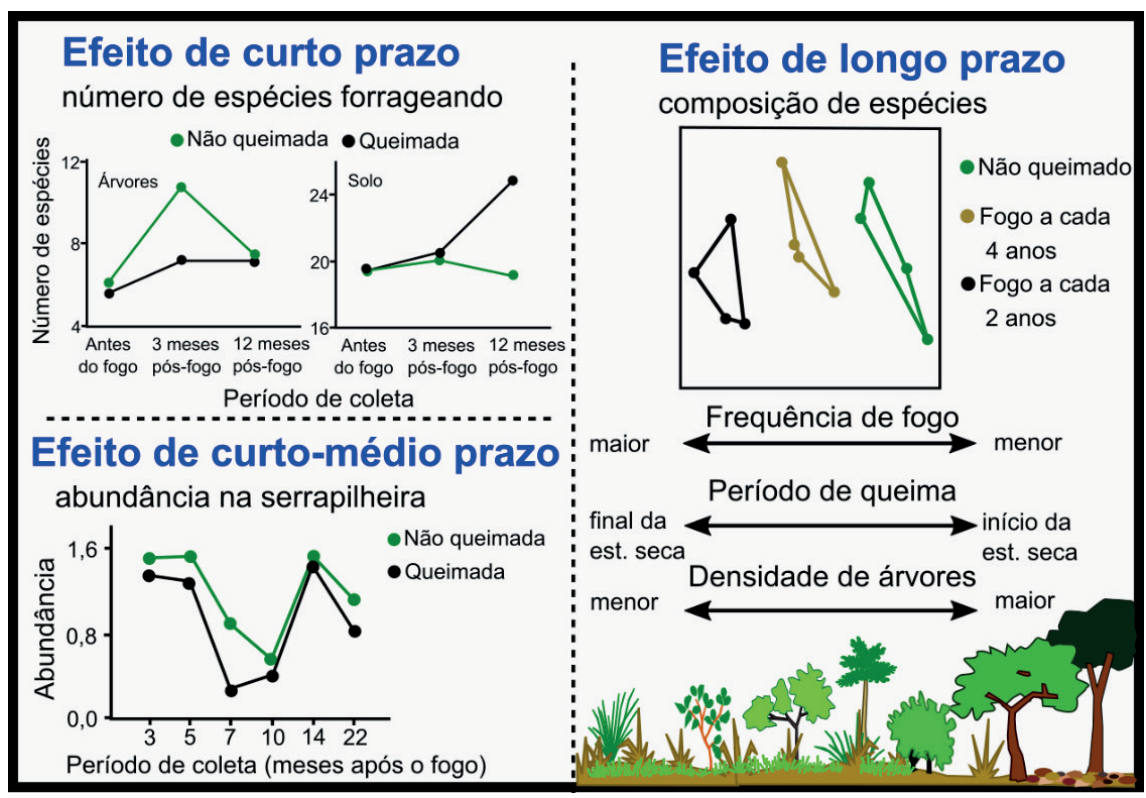

Figura 8. Efeitos de curto, médio e longo prazo na comunidade de formigas do Cerrado. Os gráficos indicam os efeitos de um único evento de fogo (curto e médio prazo) ou de repetidos eventos de fogo (longo prazo) sobre a riqueza de espécies, a abundância ou a composição de espécies formigas.

Estes resultados mostram a resiliência da fauna de formigas do Cerrado ao fogo. Os efeitos de um único evento de fogo rapidamente desaparecem na comunidade, enquanto que eventos frequentes de fogo podem causar diferenças duradoras, mas que ajudam a manter a diversidade de formigas aumentando a heterogeneidade nas escalas locais e da paisagem (Figura 8). No entanto, alguns estudos apontam que a falta de um manejo adequado de fogo pode ser prejudicial para a fauna de formigas. Por exemplo, enquanto as árvores da savana possuem adaptações a incêndios frequentes, as árvores das florestas não, e apenas um evento de fogo pode ser bastante danoso para este tipo de vegetação. Da mesma forma, muitas espécies de formigas vivem na serrapilheira, isto é, na camada de folhas e galhos caídos que cobre o solo de áreas com maior cobertura vegetal (cerradões e florestas). Ao se analisar os efeitos diretos e indiretos do fogo 
em uma savana densa com presença de serrapilheira (Figura 8), observou-se que a queimada afeta negativamente a fauna de formigas e demais artrópodes da serrapilheira, como aracnídeos, outros insetos e colêmbolos. Para a maioria dos grupos este efeito negativo foi devido à mortalidade direta do fogo com a queima da serrapilheira, enquanto que para outros, como as formigas, o efeito pode estar relacionado à redução da disponibilidade de serrapilheira em si, e não com os efeitos diretos do fogo. Embora os efeitos negativos do fogo tenham desaparecido após dois anos, isto indica que aumentos na frequência de queimadas - uma realidade na região do Triângulo Mineiro e Sudeste de Goiás - podem impedir a recuperação da fauna entre os eventos de fogo.

Outro exemplo dos drásticos efeitos de queimadas descontroladas na fauna vem de um estudo de longo prazo comparando a comunidade de formigas arbóreas da Reserva Ecológica do Panga (área queimada) com o Parque Estadual da Serra de Caldas Novas (área controle, não queimada). Este estudo é semelhante ao citado anteriormente (Figura 7), porém dessa vez foi analisado o efeito do fogo na riqueza e composição de espécies de formigas. Este estudo foi realizado numa área de savana, onde as árvores possuem adaptações para sobreviver ao fogo. Muitas espécies de formigas arbóreas, no entanto, fazem ninhos em extremidades finas dos galhos e estão, portanto, sujeitas a mortalidade direta do fogo caso as chamas atinjam estes galhos. No Panga os pesquisadores acompanharam a fauna de formigas em 240 árvores de seis espécies típicas do Cerrado, como, por exemplo, o pequizeiro (Caryocar brasiliense) o barbatimão (Stryphnodendron polyphyllum) e o pau-terra (Qualea grandiflora). Este acompanhamento durou nove anos e, no final, 169 árvores ainda estavam vivas. Neste período dois grandes incêndios descontrolados atingiram a reserva, em 2014 e 2017. Havia muito acúmulo de combustível seco, além de baixa umidade e ventos, propiciando queimadas de grande intensidade e chamas muito altas. Observou-se um forte efeito negativo na fauna de formigas que nidificam nas árvores, como Cephalotes e Pseudomyrmex, enquanto que espécies que nidificam tanto nas árvores como no solo, como as do gênero Camponotus, mostraram uma recuperação mais rápida. Além disso, houve uma grande diferença na composição de espécies ao comparar os anos pré-fogo com os anos pós-fogo. Por outro lado, as áreas amostradas em Caldas Novas não foram atingidas por queimadas de alta intensidade, mostrando pouco declínio na riqueza e menor variação na composição de espécies entre os anos amostrados.

Os efeitos negativos destas queimadas na comunidade de formigas arbóreas da Reserva Ecológica do Panga tiveram consequências que vão além da própria comunidade de formigas. Muitas árvores do Cerrado possuem estruturas, chamadas de nectários extra-florais, em suas folhas, caules e/ou inflorescências. Estas estruturas oferecem néctar, que em geral são consumidos por formigas. Devido a seu comportamento social, as formigas recrutam muitas operárias para defender este precioso recurso, afugentando outros insetos das plantas. As formigas e as plantas, portanto, exercem uma associação mutualística, isto é, interagem de modo que ambas saem ganhando. As formigas recebem recursos em forma de néctar e as plantas são defendidas contra herbívoros.

Foi realizada uma série de experimentos para medir a efetividade desta associação entre formigas e pequizeiros (Caryocar brasiliense), uma árvore que possui nectários extra-florais em folhas e inflorescências novas (Figura 9). Foram marcadas folhas em início de expansão, sendo que em metade destas as formigas foram excluídas com o 
uso de uma resina, enquanto que na outra metade as formigas tinham livre acesso às folhas. Após três meses as folhas eram retiradas das árvores, fotografadas e então a área total da folha e a área danificada por herbívoros (em sua maioria lagartas) era medida. No primeiro ano do experimento, antes da ocorrência do fogo, a presença de formigas diminuiu significativamente a herbivoria nas folhas de pequi, que foi, portanto, maior nas folhas em que as formigas foram excluídas (Figura 9). O mesmo ocorreu logo após a ocorrência do fogo, quando houve um grande aumento na herbivoria nas folhas não protegidas por formigas. Esse aumento pode ser explicado por um surto de lagartas na área como resposta à rebrota massiva de folhas logo após a queimada. Nos dois anos seguintes ao fogo, no entanto, o efeito protetivo das formigas não foi detectado, indicando um enfraquecimento da relação mutualística entre formigas e pequizeiros (Figura 9). Este resultado provavelmente se deve à perda de espécies de formigas especializadas em nidificar nas plantas como consequência da queimada de alta intensidade na área. Logo após a queimada a ausência de formigas arbóreas foi compensada por um aumento na abundância de formigas do solo, o que não ocorreu nos dois anos seguintes.

\section{Mudanças no uso da terra e os efeitos nas comunidades de formiga}

Uma das principais ameaças à conservação da biodiversidade do Cerrado é a conversão de áreas naturais em áreas de pastejo e agricultura. Estudos desenvolvidos por nosso grupo de pesquisas ressaltam a importância da manutenção de áreas naturais adjacentes às áreas de cultivo, de modo a preservar a biodiversidade e as funções ecológicas que ela gera nos agroecossistemas. Em um desses estudos a comunidade de formigas foi amostrada em áreas de cultivo e nas reservas legais (vegetação nativa) de seis fazendas próximas à Uberlândia. As coletas resultaram num total de 200 espécies de formigas nas áreas nativas, enquanto nas áreas de cultivo foram registradas 101 espécies (Figura 11). Este padrão de menor riqueza em áreas de cultivo foi observado em todas as fazendas, e foi independente do tipo de cultivo (soja, milho ou sorgo), do tipo de vegetação nativa (savana ou floresta) ou do tamanho da reserva legal (39-149 ha) (Figura 11). Estes resultados ressaltam a importância da manutenção de vegetação nativa nos agroecossistemas, visto que as reservas legais podem assegurar a manutenção de 41 a $76 \%$ da diversidade de formigas nestes sistemas. Foram encontradas diversas espécies com forte associação com as áreas nativas, como, por exemplo, Camponotus lespesii, Ectatomma edentatum e Pachycondyla harpax, enquanto que nas áreas de cultivo somente as espécies Dorymyrmex brunneus e Pheidole megacephala (uma espécie exótica invasora) foram típicas das áreas cultivadas (Figura 10). 


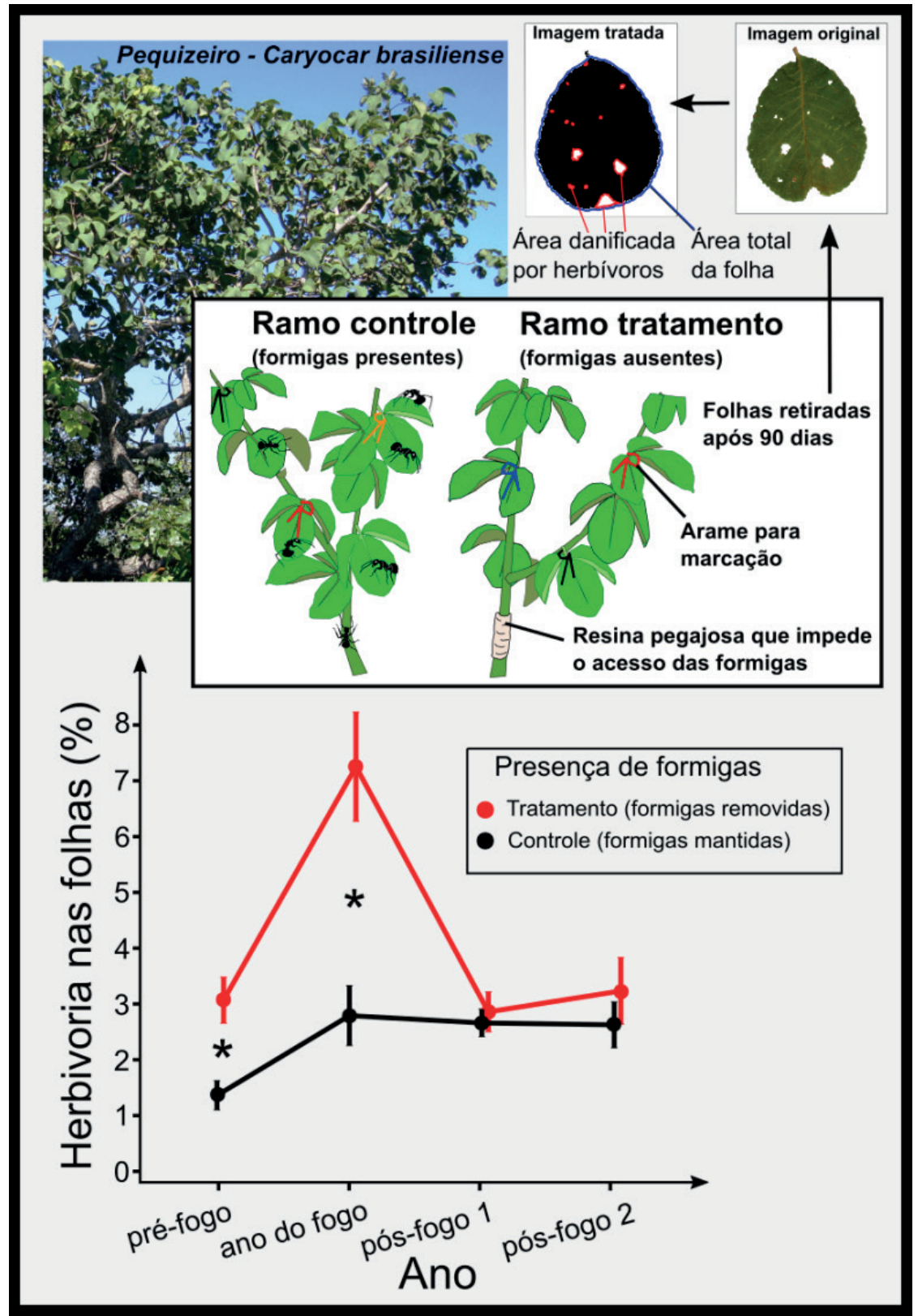

Figura 9. Experimento de exclusão de formigas em pequizeiros (Caryocar brasiliense). As folhas em expansão eram marcadas e designadas como tratamento (formigas excluídas) ou controle (formigas mantidas); as folhas eram coletadas após 90 dias e escaneadas. As imagens permitem medir a área total da folha e a área danificada por herbívoros. No gráfico é mostrada a porcentagem de herbivoria em ramos com e sem formigas ao longo dos anos. Os asteriscos indicam diferenças significativas entre os tratamentos. 


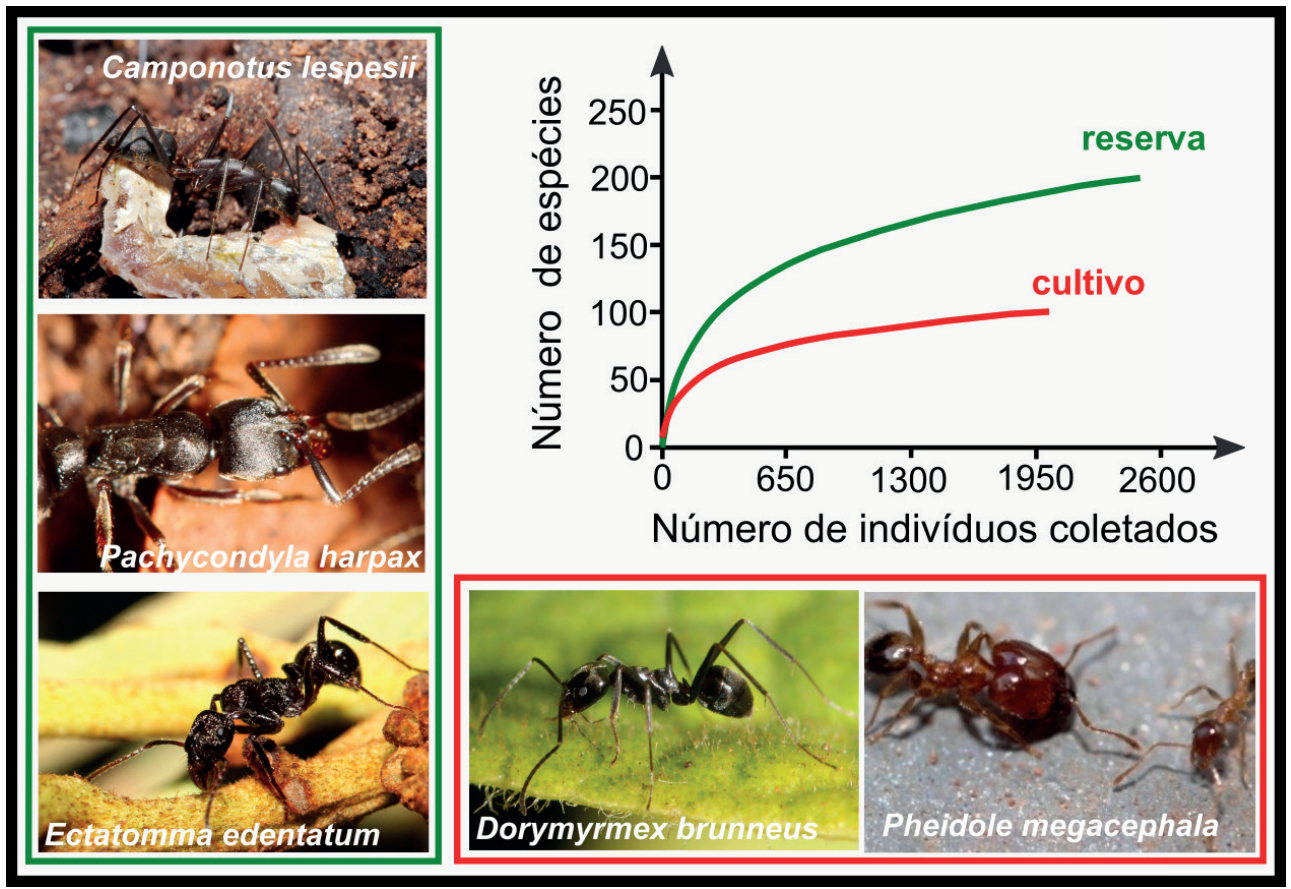

Figura 10. Número cumulativo de espécies de formigas encontradas em monoculturas ou nas reservas legais adjacentes em função do esforço amostral (número de indivíduos coletados). Os dados mostram maior diversidade de espécies de formigas nas reservas legais. As fotos mostram espécies de formiga típicas das áreas naturais (moldura verde) ou de cultivos (moldura vermelha).

Em um segundo estudo, foi comparada a fauna de formigas entre áreas naturais (cerrado sensu stricto) e áreas convertidas (pasto e plantio de soja). A coleta foi feita tanto abaixo das árvores como a $30 \mathrm{~m}$ de distância de qualquer árvore (nas áreas convertidas), de modo a avaliar a importância da presença de árvores isoladas para a manutenção de espécies de formigas nas áreas agrícolas (Figura 11). Foi detectada uma menor diversidade de espécies em áreas convertidas comparadas às áreas de cerrado. Essa diferença, no entanto, foi muito maior para o plantio de soja do que para o pasto, indicando que a atividade pastoril representa um impacto menos severo para a comunidade de formigas (Figura 11). O impacto negativo na fauna de formigas foi, no entanto, amenizado pela presença de árvores isoladas nas áreas antropizadas. De fato, nas pastagens, o número de espécies de formigas encontrado abaixo das árvores foi muito semelhante ao encontrado nas áreas de cerrado, enquanto que longe das árvores havia mais espécies no cerrado que nas pastagens. Um padrão semelhante foi encontrado nos plantios de soja, embora mesmo abaixo das árvores a riqueza de espécies de formigas foi bem menor nos plantios do que nos pastos ou no cerrado. 


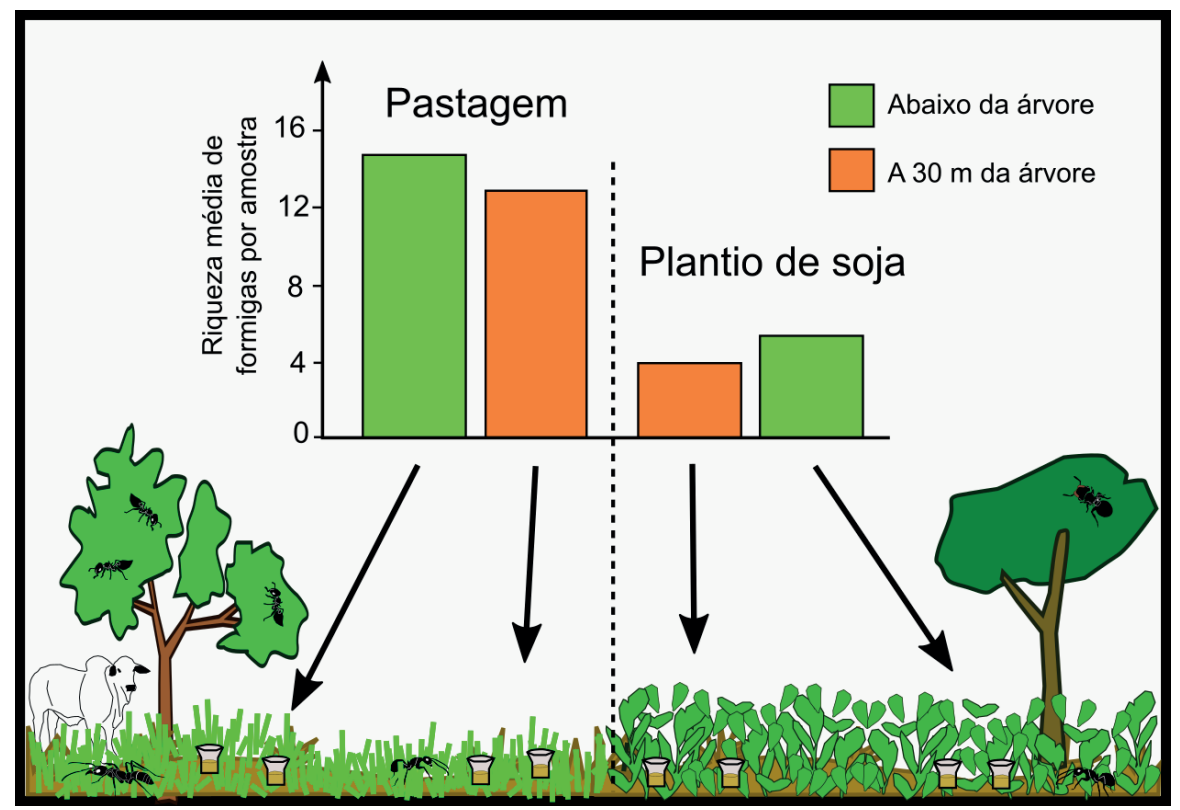

Figura 11. Efeito da presença de árvores isoladas na manutenção da diversidade de formigas em pastagens e plantios de soja. Para cada uso da terra, o gráfico indica o número médio de espécies de formigas encontradas abaixo de árvores isoladas ou a $30 \mathrm{~m}$ de distância de qualquer árvore.

Em concordância com os resultados apresentados anteriormente, um estudo recente analisou os atributos das comunidades de formigas em diferentes usos da terra, encontrando uma menor riqueza de espécies nos plantios de soja. As áreas com vegetação savânica (cerrado) foram as mais ricas em espécies, enquanto as florestas, pastos e plantações de eucalipto tiveram níveis similares de riqueza. Os pesquisadores analisaram, ainda, como os atributos funcionais (características morfológicas que podem refletir os papéis ecológicos desempenhados pelas diferentes espécies) das comunidades de formiga variavam entre os usos da terra. Espécies de ambientes mais fechados são maiores e possuem olhos relativamente menores e posicionados mais dorsalmente, comparado com espécies de ambientes mais abertos.

\section{Serviços ecológicos}

As formigas desempenham diversos serviços de grande relevância para o funcionamento dos ecossistemas, tanto os naturais como os manejados pelo homem. Dentre esses serviços podemos citar as associações mutualísticas com plantas nativas (como vimos anteriormente nas árvores de pequizeiro), a dispersão de sementes e o controle de insetos herbívoros por meio da predação. Este serviço de predação pode ser de grande relevância em cultivos agrícolas, já que as formigas podem ser eficientes no controle de pragas. Evidência disto foi obtida em um estudo que comparou as taxas de predação por formigas sobre larvas de besouro (Tenebrio molitor) entre áreas de cerrado e áreas cultivadas, tanto sobre a superfície do solo como abaixo dela (subsolo). $\mathrm{Na}$ superfície do solo as taxas de predação de larvas pelas formigas não diferiu entre as áreas cultivadas e nativas, porém, no subsolo as taxas de predação foram menores na área de cultivo. Essa diferença foi atribuída à menor abundância de formigas nas áreas 
cultivadas e em especial de formigas de correição, as quais tem hábito nomádico e são predadoras vorazes de outros artrópodes.

Várias espécies de formigas são granívoras, isto é, se alimentam de sementes. No processo de coleta, transporte e consumo destas sementes, muitas se perdem ou são descartadas em lixeiras dentro dos ninhos das formigas. Nestes casos as sementes podem germinar, de modo que as formigas são consideradas importantes agentes de dispersão de sementes no Cerrado. Um estudo em fazendas próximas a Uberlândia quantificou a taxa de remoção de sementes de espécies vegetais pioneiras, isto é, plantas capazes de colonizar áreas degradadas e dar início ao processo sucessional de regeneração do habitat. Ao impedir o acesso de diferentes organismos às sementes, os pesquisadores puderam comparar o quanto destas sementes era removido por formigas, por pequenos roedores ou por aves. Este experimento revelou que as formigas foram os mais eficientes removedores de sementes e que as taxas de remoção eram maiores nas áreas naturais comparadas às áreas de cultivo. Isso sugere que as formigas desempenham um importante serviço no processo de regeneração de ambientes degradados por meio da dispersão de plantas pioneiras.

Os estudos citados anteriormente enfatizam a importância da manutenção in situ de espécies nativas de formigas, visto que elas desempenham funções essenciais no funcionamento dos ecossistemas. Entretanto, com o crescimento desenfreado da população humana e o consequente inchaço dos centros urbanos, se torna essencial também conhecer e conservar a biodiversidade presente nas cidades. Novamente as formigas podem nos auxiliar para atingir este objetivo. Um inventário das formigas de praças e parques do município de Uberlândia (Figura 12) mostrou que nas praças públicas localizadas em regiões comerciais o número de espécies foi bastante baixo, provavelmente devido à grande abundância de espécies exóticas, principalmente a espécie invasora Pheidole megacephala. Nas praças situadas em zonas residenciais o número de espécies foi maior do que nas zonas comerciais, enquanto nos parques o número de espécies foi ainda maior do que nas praças (Figura 12). Esta maior diversidade nos parques parece ser explicada pela proximidade dos parques às áreas naturais do entorno da cidade, assim como pela presença de vegetação nativa dentro dos limites do parque, garantindo assim a manutenção de espécies de formigas nativas. 


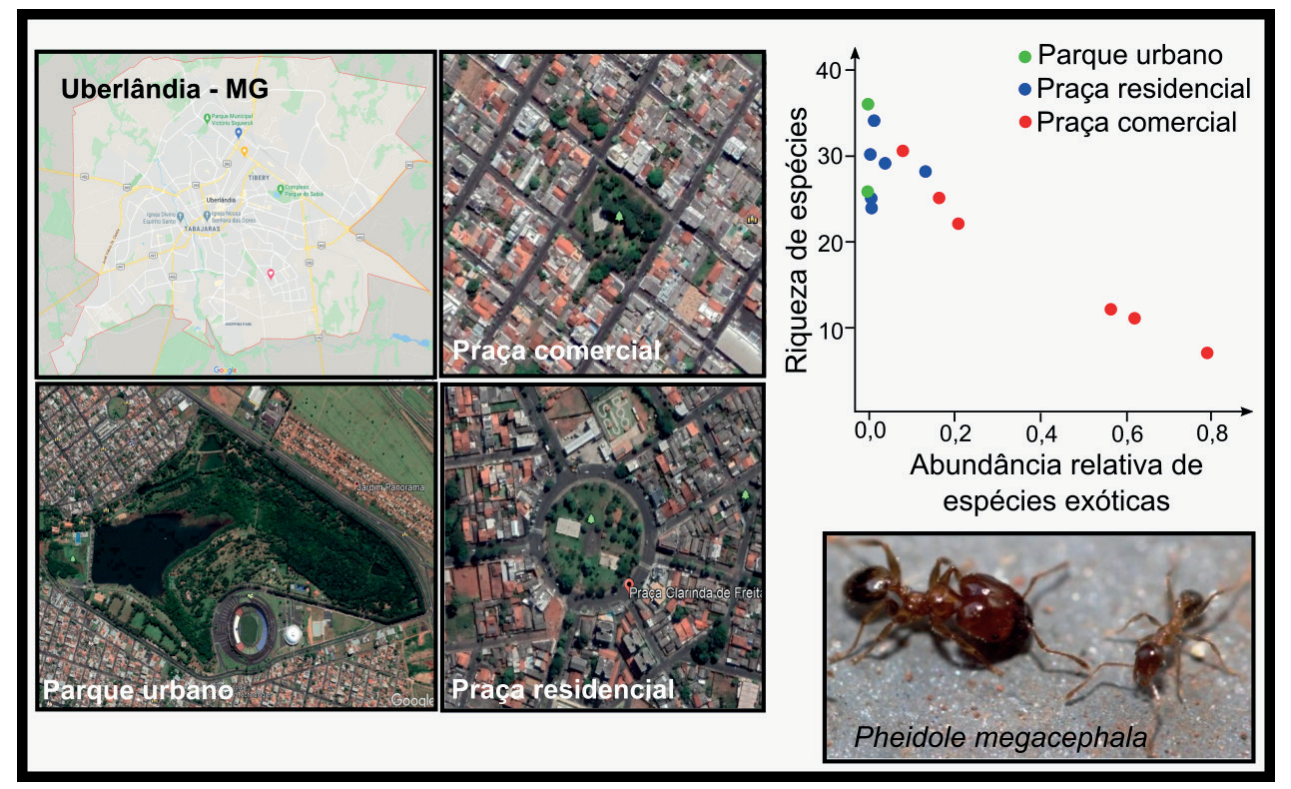

Figura 12. Diversidade de formigas em áreas verdes urbanas: praças em áreas comerciais, praças em áreas residenciais e parques urbanos. O gráfico indica a variação na riqueza de espécies entre os diferentes tipos de áreas verdes em relação à abundância de espécies exóticas, em especial Pheidole megacephala (foto).

Este estudo ressalta a importância do controle de espécies exóticas invasoras para a manutenção da diversidade de formigas tanto em ambientes naturais como nos manejados. Muitas espécies de formigas são invasoras bem sucedidas em diferentes ambientes e em praticamente todos os continentes (com exceção da Antártida). Muitas das principais espécies invasoras do mundo são nativas justamente da região do Cerrado, como é caso de Brachymyrmex patagonicus, Solenopsis invicta, Solenopsis geminata e Wasmannia auropunctata. No entanto, muitas espécies de outros lugares foram introduzidas e se estabeleceram com sucesso na nossa região; estas se tornaram, portanto, espécies invasoras, muitas vezes associadas a ambientes não naturais, como as áreas urbanas ou agro-silvipastoris. Dentre as principais espécies invasoras presentes na região do Triângulo Mineiro e Sudeste de Goiás podemos citar: Cardiocondyla emeryi, Pheidole megacephala, Tapinoma melanocephalum, Paratrechina longicornis e Monomorium pharaonis. Estas espécies em geral formam grandes populações e não possuem predadores ou parasitoides naturais nas áreas invadidas, garantindo assim uma vantagem sobre as espécies nativas. As espécies invasoras podem, portanto, causar a extinção local de espécies nativas e assim minar os esforços conservacionistas.

\section{Implicações para a conservação}

O acompanhamento de longo prazo das formigas arbóreas na Reserva Ecológica do Panga e do Parque Estadual da Serra de Caldas Novas demonstra que incêndios de alta severidade podem ter consequências drásticas para estes insetos que são especializados em fazer ninhos nas árvores. A depauperação dessa fauna pode ter consequências indiretas, como o enfraquecimento de interações ecológicas. Como exemplo, vimos a redução na proteção contra herbívoros por formigas que forrageiam 
em pequizeiros. Dessa forma, enfatiza-se a necessidade de um manejo adequado do fogo em áreas preservadas do Cerrado. Este manejo pode ser realizado por meio de queimadas controladas. A aplicação do fogo no início da estação seca, enquanto a umidade do ambiente ainda é alta, permite o consumo de biomassa vegetal morta, evitando assim incêndios no auge e final da estação seca, que são muito mais severos para as plantas e animais. Além disso, o fogo no início da estação é menos intenso e, por isso, se espalha de forma heterogênea, deixando manchas de vegetação não queimadas. O manejo ativo do fogo, portanto, pode ser útil em pelo menos quatro aspectos: 1) minimizar o avanço de espécies invasoras; 2) consumir biomassa vegetal combustível, reduzindo a frequência de incêndios descontrolados e criando aceiros negros que protegem tipos de vegetação sensíveis ao fogo; 3 ) excluir espécies vegetais sensíveis ao fogo de áreas mais abertas e, assim, manter a estrutura da vegetação; e 4) manter uma maior heterogeneidade ambiental - tanto na microescala como na escala da paisagem - e, portanto, uma maior biodiversidade.

Visto o grande número de ameaças à conservação da natureza e quão complexas são as medidas para mitigá-las, é de extrema importância que políticas futuras de conservação busquem o investimento em pesquisas e na ampliação da rede de áreas protegidas. Os estudos com as formigas doCerradocitados aolongodeste capítuloindicam que as medidas de conservação devem levar em conta as diferentes escalas espaciais:

1) $\mathrm{Na}$ escala local, as unidades de conservação devem abranger ambientes heterogêneos, de modo a proteger uma maior parcela da diversidade, sendo o manejo do fogo uma estratégia apropriada para isso. Ele permite, ao mesmo tempo, a manutenção dessa heterogeneidade no local, além de proteger plantas e animais sensíveis às queimadas de alta frequência e intensidade. As áreas protegidas devem ter uma área grande e, se possível, serem circundadas por uma zona tampão com atividades humanas de menor impacto ambiental. Isto visa proteger populações viáveis de plantas, animais e outros organismos ao longo do tempo, garantindo assim a manutenção de serviços ecológicos essenciais tanto em ecossistemas naturais como em agroecossistemas.

2) No nível das paisagens que abrangem a região do Triângulo Mineiro e Sudeste de Goiás deve-se priorizar a criação e expansão das áreas protegidas, novamente abrangendo uma variedade de tipos vegetacionais, altitudes, e tipos de solos, além de uma grande abrangência geográfica, visto a raridade de muitas espécies. Maximizar estes fatores pode ser uma estratégia efetiva para proteger a biodiversidade regional, já que mudanças climáticas vindouras podem causar a migração de espécies para locais mais favoráveis e que precisam estar protegidos. Outra importante estratégia é estimular atividades econômicas de menor impacto, como o pastejo, a silvicultura ou a agricultura familiar, visto que a proteção da biodiversidade é fundamental para o desenvolvimento sustentável da região do Triângulo Mineiro e Sudeste de Goiás.

3) No nível regional, abrangendo todo o bioma Cerrado, também se faz necessária a expansão da rede de áreas protegidas. Isto deve ser realizado em toda a extensão do bioma, visto as diferenças marcantes na composição de espécies entre as diferentes regiões do Cerrado. Nesse sentido deve se levar em conta 
que a parte sul do Cerrado possui uma maior riqueza de espécies. Entretanto, devido ao histórico de ocupação humana, os remanescentes de vegetação nativa nesta região são pequenos e estão muito fragmentados. Já o norte do Cerrado as áreas de vegetação nativa são maiores além de serem financeiramente mais acessíveis. Ademais, esta é uma região cuja diversidade foi pouco explorada, além de possuir grande relevância biogeográfica por ser o ponto de encontro entre o Cerrado, a Amazônia e a Caatinga.

\section{Para saber mais}

Boudinot BE, Probst RS, Brandão CRF, Feitosa RM, Ward, PS. (2016) Out of the Neotropics: newly discovered relictual species sheds light on the biogeographical history of spider ants (Leptomyrmex, Dolichoderinae, Formicidae). Syst Entomol41: 658-667 671 doi: 10.1111/syen.12181Camarota F, Powell S, Melo AS, Priest G, Marquis RJ, Vasconcelos HL (2016) Co-occurrence patterns in a diverse arboreal ant community are explained more by competition than habitat requirements. Ecol Evol 6:8907-8918 doi: 10.1002/ece3.2606

Frizzo TLM, Campos RI, Vasconcelos HL (2012) Contrasting effects of fire on arboreal and ground-dwelling ant communities of a Neotropical savanna. Biotropica. 44: 254261 doi: $10.1111 /$ j.1744-7429.2011.00797.x

Frizzo TLM, Vasconcelos HL (2013) The potential role of scattered trees for ant conservation in an agriculturally dominated Neotropical landscape. Biotropica 45: 644651.

Maravalhas J., Vasconcelos H.L. (2014) Revisiting the pyrodiversity-biodiversity hypothesis: long-term fire regimes and the structure of ant communities in a Neotropical savanna hotspot. J Appl Ecol 51:1661-1668 doi: 10.1111/1365-2664.12338

Maravalhas, J. B., Vasconcelos, H. L. (2020) Ant diversity in Neotropical savannas: Hierarchical processes acting at multiple spatial scales. J Anim Ecol, 89(2), 412-422 doi: 10.1111/1365-2656.13111

Moreau CS, Bell CD, Vila R, Archibald SB, Pierce NE (2006) Phylogeny of the ants: diversification in the age of angiosperms. Science 312:101-104 doi: 10.1126/ science. 1124891

Pacheco R, Camacho G, Frizzo TLM, Vasconcelos HL (2017) Effects of land-use changes on ecosystem services: decrease in ant predation in human-dominated landscapes in central Brazil. Entomol Exp Appl 162:302-308.

Pacheco R, Vasconcelos HL (2007) Invertebrate conservation in urban areas: Ants in the Brazilian Cerrado. Landscape Urban Plann 81:193-199 doi: 10.1016/j. landurbplan.2006.11.004

Pacheco R, Vasconcelos HL (2012) Habitat diversity enhances ant diversity in a naturally heterogeneous Brazilian landscape. Biodivers Conserv 21:797-809 doi: 10.1007/s10531-011-0221-y 
Pacheco R, Vasconcelos HL, Groc S, Camacho G, Frizzo TLM (2013) The importance of remnants of natural vegetation for maintaining ant diversity in Brazilian agricultural landscapes. Biodivers Conserv 22: 983-997 doi:10.1007/s10531-013-0463-y

Rocha-Ortega M, Bartimachi A, Neves J, Bruna EM, Vasconcelos HL (2017) Seed removal patterns of pioneer trees in an agricultural landscape. Plant Ecol 218: 737-748 doi:10.1007/s11258-017-0725-y

Vasconcelos HL, Pacheco R, Silva RC, Vasconcelos PB, Lopes CT, Costa AN, Bruna EM (2009) Dynamics of the leaf-litter arthropod fauna following fire in a Neotropical Woodland Savanna. Plos One 4:e7762 doi: 10.1371/journal.pone.0007762

Vasconcelos HL, Maravalhas JB, Feitosa RM, Pacheco R, Neves KC, Andersen AN (2018) Neotropical savanna ants show a reversed latitudinal gradient of species richness, with climatic drivers reflecting the forest origin of the fauna. J Biogeogr 45:248-258 J Biogeogr 45:248-258. doi: 10.1111/jbi.13113 



\title{
CAPÍTULO 10
}

\section{ABELHAS DAS ORQUÍDEAS (EUGLOSSINI): IMPORTÂNCIA DOS REMANESCENTES FLORESTAIS PARA A CONSERVAÇÃO DA DIVERSIDADE}

\author{
Solange C. Augusto \\ Thiago H. A. Tosta \\ Leo C. Rocha Filho
}

As abelhas da tribo Euglossini (Hymenoptera, Apidae), conhecidas popularmente como abelhas-das-orquídeas, ocorrem predominantemente na região Neotropical, em uma faixa de distribuição que se estende desde o sul dos Estados Unidos até o norte da Argentina. A maior diversidade de espécies dessa tribo está nas florestas tropicais úmidas e florestas subtropicais da América Central e da América do Sul. São aproximadamente 249 espécies distribuídas em cinco gêneros, três deles contendo espécies de vida livre, Euglossa Latreille (140 espécies), Eufriesea Cockerell (70) e Eulaema Lepeletier (29); e dois, Exaerete Hoffmannsegg (9) e Aglae Lepeletier \& Serville (1), contendo apenas espécies cleptoparasitas de outras abelhas Euglossini, dos gêneros Eufriesea e Eulaema.

O nome comum abelhas-das-orquídeas se deve ao fato de que os machos dessas abelhas visitam flores de orquídeas, bem como de outras espécies vegetais, para a coleta de compostos aromáticos voláteis. Esses compostos serão posteriormente armazenados nas tíbias altamente modificadas do terceiro par de pernas. Na década de 1960, por meio da técnica da cromatografia a gás, foi feito o isolamento e identificação de mais de 60 compostos presentes em espécies da família Orchidaceae que são visitadas por machos de Euglossini. O isolamento destes compostos permitiu a realização de muitos estudos sobre ecologia e genética dessas abelhas, assim como levantamentos faunísticos realizados com o uso de iscas-odoríferas para atração dos machos.

Acredita-se que o comportamento de coleta de fragrâncias florais pelos machos esteja associado à seleção sexual. Uma vez nas flores, os machos secretam lipídeos provenientes de suas glândulas labiais sobre o substrato vegetal para que os compostos aromáticos voláteis possam ser dissolvidos e, desse modo, transferidos para suas tíbias posteriores. Alguns estudos demonstraram que as substâncias voláteis armazenadas pelos machos são ativamente liberadas durante a exibição de comportamentos de corte em pequenos territórios, como hastes e galhos de árvores, onde as cópulas podem ocorrer.

Além de serem importantes agentes da polinização de orquídeas, uma vez que cerca de $10 \%$ das espécies de Orchidaceae são exclusivamente polinizadas por machos de Euglossini, vale ressaltar que as abelhas dessa tribo desempenham um papel chave na biologia reprodutiva de uma infinidade de plantas da região Neotropical. Os registros de visita às plantas, assim como análises polínicas do conteúdo residual do alimento larval presente em ninhos, ou mesmo dos grãos de pólen aderidos aos corpos de adultos, revelaram uma alta diversidade de espécies de plantas visitadas e um comportamento generalista quanto à coleta de recursos florais (Figura 1). 
Além da importância na polinização de muitas espécies de plantas tropicais, as abelhas Euglossini são importantes para os estudos voltados para o entendimento da evolução do comportamento social nas abelhas corbiculadas, ou seja, abelhas cujas fêmeas apresentam uma estrutura na perna posterior, na qual o pólen é depositado e acomodado para ser transportado ao ninho. Esse grupo inclui também os táxons Apini, Meliponini e Bombini, sendo Euglossini o único táxon de abelhas corbiculadas que apresenta espécies solitárias ou com diferentes níveis de organização social. Isso as diferencia dos outros táxons, cujas espécies de vida livre são todas eussociais (Bombini), ou altamente eussociais (Apini e Meliponini), com grandes colônias e diferenças morfológicas e fisiológicas entre as castas de rainha e operária.

As espécies de Euglossini de vida livre fundam seus ninhos solitariamente e, geralmente, em cavidades preexistentes, incluindo substratos artificiais, os quais podem ser usados como ninhos-armadilha (Figura 2). Entretanto, ninhos no solo (Figura 3) e aéreos, presos a galhos ou folhas, também podem ser encontrados. Após a seleção do local, a fêmea trabalha sozinha na construção do ninho, construindo células de cria e botando seus ovos nessas células. Por exemplo, uma fêmea fundadora de Euglossa cordata pode ovipositar até 10 células, já uma fêmea de Eulaema nigrita, até 23 células. Após finalizar suas atividades de aprovisionamento e oviposição de células no ninho, a fêmea fundadora pode abandoná-lo ou permanecer nele até a emergência de sua prole. Os indivíduos, após a emergência, sejam machos ou fêmeas, deixam o ninho materno. Os machos vão forragear por compostos aromáticos para a formação do buquê e por néctar para alimentação, enquanto as fêmeas produzidas fundarão novos ninhos. Contudo, em algumas espécies, ninhos comunais ou eussociais podem ser observados. Nesses casos, as fêmeas produzidas podem permanecer no ninho materno, reutilizando-o, na presença ou ausência da fêmea fundadora (Figura 4). Em ninhos comunais, essas fêmeas constroem suas células de forma independente na ausência da fêmea mãe ou fundadora. Esse tipo de organização social foi bem descrito para $E l$. nigrita.

Ninhos eussociais são assim definidos por apresentarem fêmeas de diferentes gerações, cuidado cooperativo com a prole e divisão reprodutiva de trabalho. Assim, as fêmeas que nascem em um ninho podem permanecer nele na presença da mãe e uma divisão reprodutiva de trabalho entre elas pode ser estabelecida, na qual a mãe ou a fêmea mais velha assume a função de dominante e as filhas, de subordinadas. Todas as fêmeas são fecundadas, desenvolvem ovários e ovipositam frequentemente. As fêmeas subordinadas constroem e aprovisionam suas células, enquanto a dominante mantém essa função realizando oofagia nas células ovipositadas pelas subordinadas e, geralmente, exibindo interações agonísticas em relação a elas. Ninhos eussociais foram bem descritos para algumas espécies de Euglossa, como Eg. cordata e Eg. fimbriata.

As espécies de Euglossini de vida livre podem ter seus ninhos atacados por diferentes inimigos naturais, como parasitoides e cleptoparasitas. Os parasitoides depositam seus ovos dentro ou sobre o corpo do hospedeiro, ali se desenvolvendo até levá-lo à morte. Como exemplos de parasitoides verificados em ninhos de espécies de Euglossa encontradas na região do Triângulo Mineiro temos: (i) Physocephala bipunctata (Diptera, Conopidae), que emergiu de uma fêmea adulta de Euglossa melanotricha (Figura 5AeB); (ii) Polistomorpha fasciata (Hymenoptera, Leucospidae), que emergiu de ninhos de Euglossa townsendi (Figura 5C e D); e (iii) Anthrax oedipus 
(Diptera, Bombyliidae), que emergiu de células de cria de ninhos de Eg. townsendi. Diferentemente dos parasitoides, as espécies cleptoparasitas, ao invadirem os ninhos das abelhas, acabam inviabilizando a prole de seus hospedeiros, uma vez que seus imaturos se desenvolvem utilizando o alimento larval depositado nas células de cria do hospedeiro. Como exemplos de cleptoparasitas registrados na região do Triângulo Mineiro, temos as abelhas Coelioxys (Cyrtocoelioxys) costaricensis e Hoplostelis nigritula (Hymenoptera, Megachilidae) em ninhos de Eg. townsendi. Além desses inimigos naturais, existem muitas espécies, de diferentes famílias, registradas em ninhos de Euglossini coletados em diferentes ecossistemas da região Neotropical, incluindo outras abelhas-das-orquídeas, como Aglae caerulea e Exaerete spp. (Tabela 1).

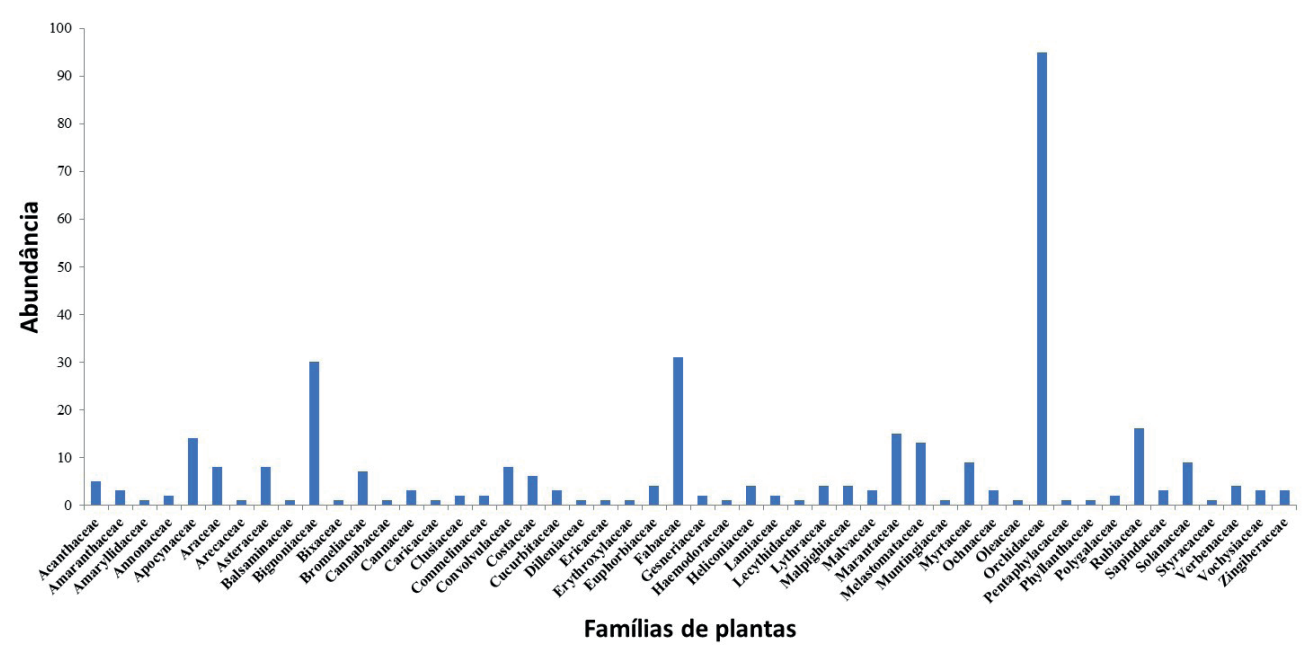

Figura 1. Número de espécies (abundância) de cada família de plantas visitadas por abelhas Euglossini. Dados compilados pelos autores, a partir de 44 artigos publicados entre 2001 e 2019. 


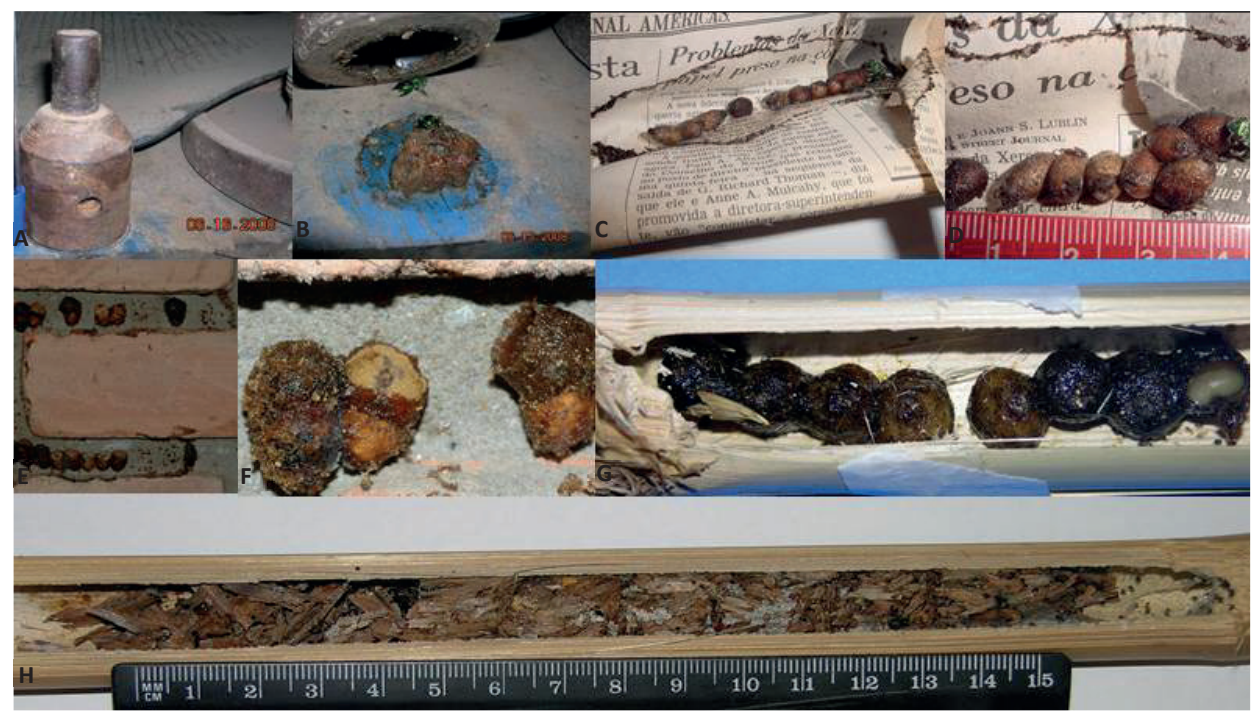

Figura 2. Ninhos de abelhas Euglossini. A e B - Ninho de Euglossa sp. construído em acoplamento de uma mandriladora, usada na construção da Usina Hidrelétrica de São Salvador - Tocantins. C e D - Ninho de Euglossa townsendi construído em folhas de jornal. E - Ninhos de Eg. townsendi construídos em uma parede de tijolo à vista (esse ninho estava recoberto por uma placa de ferro). F - Detalhe de algumas células desse ninho de E. townsendi construído na parede. G - Ninho de Eg. townsendi construído em um gomo de bambu, utilizado como ninho-armadilha. H - Ninho de Eufriesea violacea construído em um colmo de bambu usado como ninho-armadilha. Note-se que os ninhos de Euglossa spp. têm suas células de cria construídas com resina, enquanto os ninhos de espécies de Eufriesea são construídos com pequenos fragmentos de cascas de árvores, os quais são aderidos uns ao outros com resina. Fonte: À exceção das imagens A e B, de autoria de Adelio Soares Pinto, todas as demais foram produzidas pelos autores.

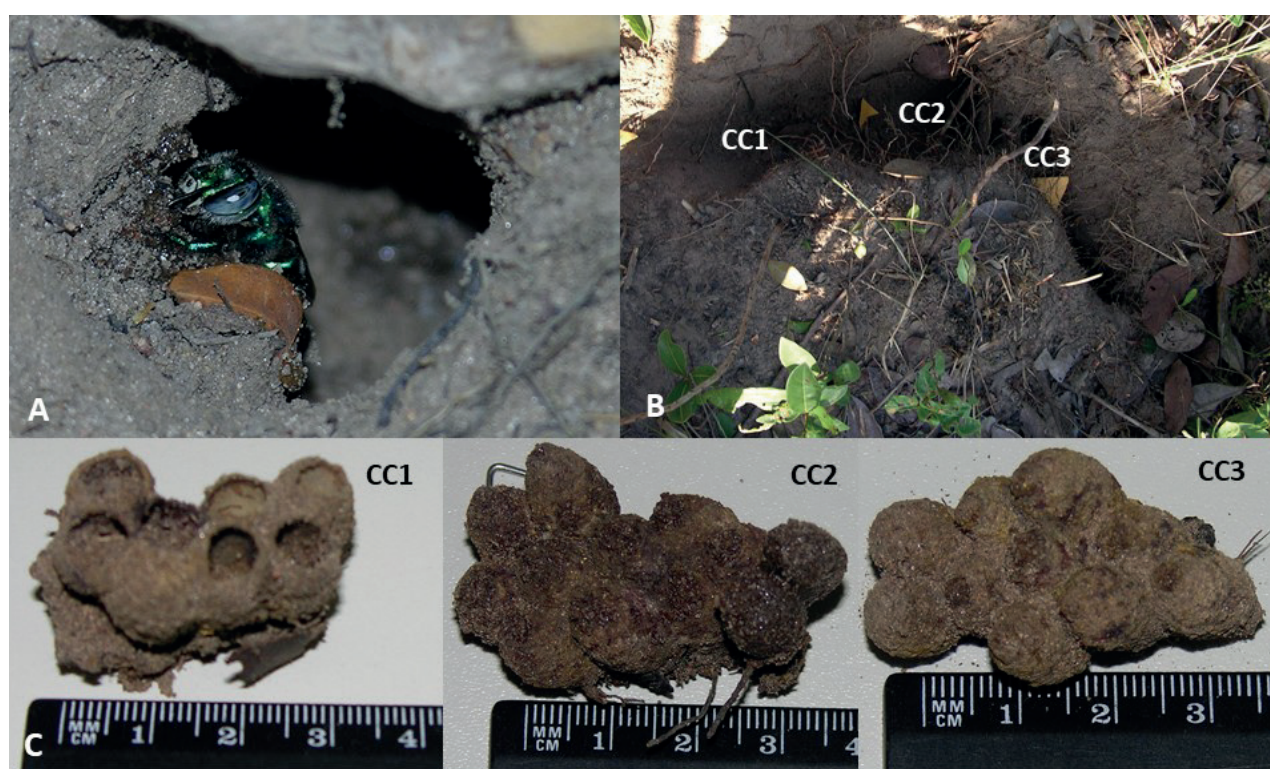

Figura 3. Ninho de Euglossa melanotricha coletado em uma cavidade no solo. A - Fêmea fundadora construindo a entrada do ninho. B - Ninho escavado após a primeira reativação e localização dos três conjuntos de células (CC). C - Conjuntos de células encontrados no ninho. CC1- Células abertas e uma em que não houve emergência. CC2 e CC3 - conjuntos com células de cria operculadas. Fonte: Augusto, dados não publicados. 


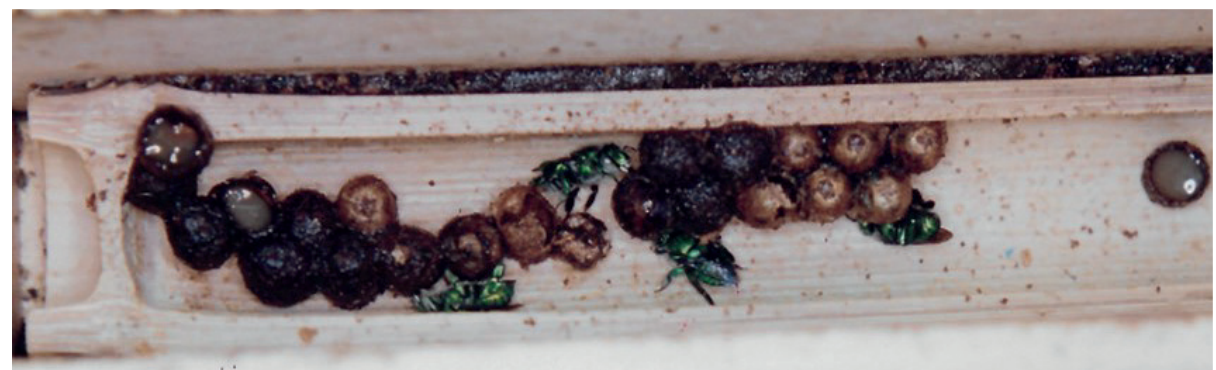

A

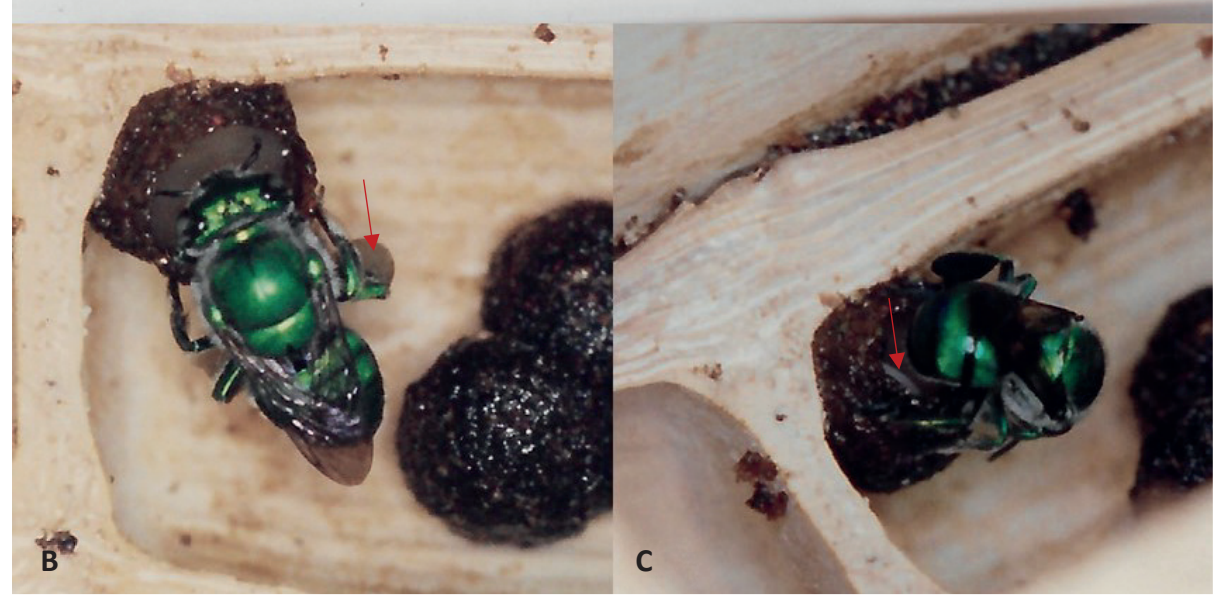

Figura 4. Ninho compartilhado de Euglossa townsendi. A - As quatro fêmeas que compartilham o ninho. B - Uma das fêmeas com alimento larval (apontado pela seta) na corbícula, inspecionando a célula de cria que será aprovisionada. C - Fêmea realizando oviposição na célula de cria (note-se o ovo depositado sobre o alimento larval). Fonte: Augusto, dados não publicados.

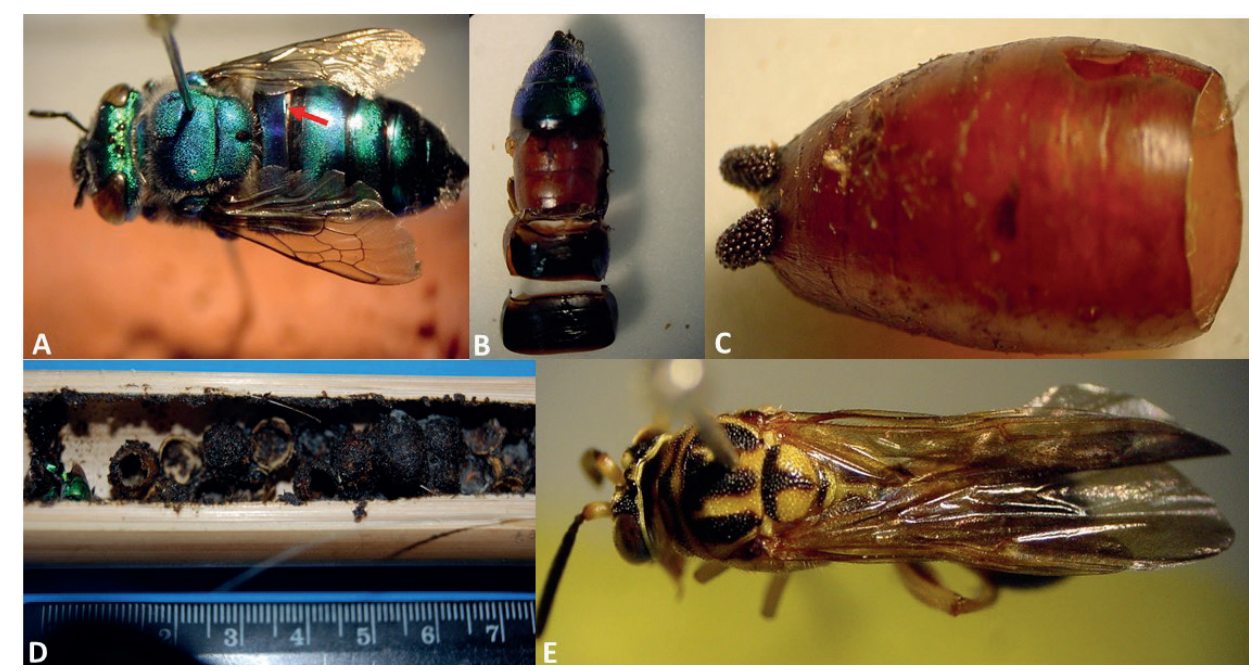

Figura 5 Inimigos naturais de Euglossa spp. A - Fêmea de Euglossa melanotricha parasitada por Physocephala bipunctata. Note-se o abdômen distendido e a seta indicando o local por onde o parasita emergiu. B - Abdômen após a remoção dos tergitos, para visualização do casulo. C- Casulo de Physocephala bipunctata. D- Ninho de Euglossa townsendi parasitado por Polistomorpha fasciata. EFêmea de Polistomorpha fasciata que emergiu do ninho de Eg. townsendi. Fonte: Augusto et al, dados não publicados. 
Tabela 1- Inimigos naturais de imaturos ou de adultos de Euglossini que ocorrem em diferentes regiões brasileiras.

\begin{tabular}{|c|c|c|c|c|c|}
\hline Ordens & Famílias & $\begin{array}{l}\text { Inimigos } \\
\text { naturais }\end{array}$ & tipo & $\begin{array}{l}\text { Hospedeiros } \\
\text { confirmados }\end{array}$ & Referências \\
\hline \multirow[t]{4}{*}{ Coleoptera } & Meloidae & $\begin{array}{l}\text { Meloetyphlus } \\
\text { fuscatus }\end{array}$ & Cleptoparasita & $\begin{array}{l}\text { Eulaema cingulata, } \\
\text { Eulaema meriana, } \\
\text { Eulaema nigrita e } \\
\text { Eulaema terminata }\end{array}$ & $\begin{array}{l}\text { Bennett 1965; Dodson } \\
\text { 1966; Cameron } \\
\text { \& Ramírez 2001; } \\
\text { Garófalo et al. } 2011\end{array}$ \\
\hline & & Meloetyphlus sp. & $?$ & Eufriesea violacea & $\begin{array}{l}\text { Peruquetti \& Campos } \\
1997\end{array}$ \\
\hline & & $\begin{array}{l}\text { Tetraonyx } \\
\text { zonatus }\end{array}$ & $?$ & Eufriesea smaragdina & Kamke et al. 2008 \\
\hline & Ripiphoridae & $\begin{array}{l}\text { Pelectomoides } \\
\text { succinta }\end{array}$ & $?$ & Eulaema nigrita & Ducke 1903 \\
\hline \multirow[t]{4}{*}{ Diptera } & Bombyliidae & Anthrax oedipus & Parasitoide & $\begin{array}{l}\text { Euglossa annectans, } \\
\text { Euglossa pleosticta, } \\
\text { Euglossa townsendi e } \\
\text { Euglossa truncata }\end{array}$ & $\begin{array}{l}\text { Garófalo et al. 1993, } \\
\text { 1998; Augusto \& } \\
\text { Garófalo } 2004\end{array}$ \\
\hline & Conopidae & $\begin{array}{l}\text { Physocephala } \\
\text { bipunctata* }^{*}\end{array}$ & Parasitoide & Euglossa anodorhynchi & Melo et al. 2008 \\
\hline & & $\begin{array}{l}\text { Physocephala } \\
\text { sp.* }\end{array}$ & Parasitoide & Euglossa intersecta & Melo et al. 2008 \\
\hline & Phoridae & $\begin{array}{l}\text { Melaloncha } \\
\text { ronnai }\end{array}$ & Parasitoide & $\begin{array}{l}\text { Euglossa townsendi } \\
\text { Euglossa cordata }\end{array}$ & Ament et al. 2014 \\
\hline \multirow[t]{12}{*}{ Hymenoptera } & Apidae & Aglae caerulea & Cleptoparasita & Eulaema nigrita & Myers 1935 \\
\hline & & Exaerete dentata & Cleptoparasita & $\begin{array}{l}\text { Eufriesea auriceps, } \\
\text { Eufriesea smaragdina, } \\
\text { Eufriesea surinamensis }\end{array}$ & $\begin{array}{l}\text { Zucchi et al. } 1969 \text {, } \\
\text { Bennett 1972, Kamke } \\
\text { et al. } 2008\end{array}$ \\
\hline & & Exaerete frontali & $s$ Cleptoparasita & Eulaema meriana & $\begin{array}{l}\text { Ackerman \& } \\
\text { Montalvo } 1985\end{array}$ \\
\hline & & $\begin{array}{l}\text { Exaerete } \\
\text { smaragdina }\end{array}$ & Cleptoparasita & Eulaema nigrita & $\begin{array}{l}\text { Garófalo \& Rozen } \\
2001\end{array}$ \\
\hline & Eulophidae & Melittobia spp. & Parasitoide & $\begin{array}{l}\text { Eufriesea smaragdina, } \\
\text { Eufriesea violacea, } \\
\text { Euglossa annectans }\end{array}$ & $\begin{array}{l}\text { Peruquetti \& Campos } \\
\text { 1997; Garófalo et al. } \\
\text { 1998; Kamke et al. } \\
\text { 2008 }\end{array}$ \\
\hline & Eurytomidae & $\begin{array}{l}\text { Aximopsis } \\
\text { masneri }\end{array}$ & Parasitoide & $\begin{array}{l}\text { Euglossa cordata, } \\
\text { Euglossa townsendi }\end{array}$ & $\begin{array}{l}\text { Freiria et al. 2017, } \\
\text { Werneck \& Campos } \\
2020\end{array}$ \\
\hline & Leucospidae & $\begin{array}{l}\text { Polistomorpha } \\
\text { fasciata }\end{array}$ & Parasitoide & $\begin{array}{l}\text { Euglossa cordata, } \\
\text { Euglossa townsendi }\end{array}$ & $\begin{array}{l}\text { Freiria et al. 2017; } \\
\text { Augusto, dados não } \\
\text { publicados }\end{array}$ \\
\hline & Megachilidae & $\begin{array}{l}\text { Coelioxys } \\
\text { costaricensis }\end{array}$ & Cleptoparasita & Euglossa townsendi & $\begin{array}{l}\text { Augusto \& Garófalo } \\
2004\end{array}$ \\
\hline & & Coelioxys spp. & Cleptoparasita & $\begin{array}{l}\text { Euglossa annectans, } \\
\text { Euglossa pleosticta, } \\
\text { Euglossa townsendi, } \\
\text { Euglossa truncata }\end{array}$ & $\begin{array}{l}\text { Garófalo et al. 1993, } \\
1998\end{array}$ \\
\hline & & $\begin{array}{l}\text { Hoplostelis } \\
\text { nigritula }\end{array}$ & Cleptoparasita & $\begin{array}{l}\text { Euglossa cordata, } \\
\text { Euglossa townsendi }\end{array}$ & $\begin{array}{l}\text { Augusto \& Garófalo } \\
\text { 1998; Augusto \& } \\
\text { Garófalo 2004; Rocha- } \\
\text { Filho et al. } 2019\end{array}$ \\
\hline & & $\begin{array}{l}\text { Rhynostelis } \\
\text { multiplicata }\end{array}$ & Cleptoparasita & Eufriesea laniventris & $\begin{array}{l}\text { Parizotto \& Urban } \\
2012\end{array}$ \\
\hline & Mutillidae & $\begin{array}{l}\text { Hoplomutilla } \\
\text { spinosa }\end{array}$ & Parasitoide & Eulaema nigrita & $\begin{array}{l}\text { Quintero \& Cambra } \\
2001\end{array}$ \\
\hline
\end{tabular}




\begin{tabular}{|c|c|c|c|c|}
\hline & $\begin{array}{l}\text { Hoplomutilla } \\
\text { triumphans }\end{array}$ & Parasitoide & Eufriesea sp. & Lenko 1964 \\
\hline & $\begin{array}{l}\text { Pappognatha } \\
\text { patruelis }\end{array}$ & Parasitoide & Euglossa sp. & Luz et al. 2016 \\
\hline Sapygidae & $\begin{array}{l}\text { Huarpea } \\
\text { wagnerella }\end{array}$ & Parasitoide & Eufriesea violacea & $\begin{array}{l}\text { Rocha-Filho et al. } \\
2016\end{array}$ \\
\hline
\end{tabular}

\section{Diversidade de abelhas euglossini no Cerrado}

O Cerrado brasileiro é um dos ambientes mais ricos em espécies de plantas e animais do mundo. É o segundo maior bioma do território brasileiro e é classificado como um hotspot, área com grande endemismo e menos de $30 \%$ de vegetação natural restante. Para se ter uma ideia, entre os anos de 2001 e 2019, aproximadamente 283 mil $\mathrm{km}^{2}$ foram desmatados no Cerrado, sendo que as formações florestais foram uma das mais afetadas pelo avanço das fronteiras agrícolas e o crescimento urbano. Entre os anos de 2002 e 2011, o Cerrado registrou uma taxa de desmatamento 2,5 vezes maior que a da Floresta Amazônica, o que pode levar à extinção de aproximadamente 480 espécies vegetais endêmicas do bioma até o ano de 2050. Nem mesmo áreas destinadas à conservação da biodiversidade presentes no bioma Cerrado estão de fato exercendo o seu papel, uma vez que apresentam taxas de desmatamento similares a locais que não são classificados como áreas de proteção. As abelhas estão sujeitas aos impactos da devastação que avança sobre o Cerrado. As principais consequências desse processo para esse grupo de inseto são a diminuição da quantidade e qualidade de fontes de recursos florais, bem como de sítios propícios para nidificação, fatores que podem leválas à extinção.

De um modo geral, a diversidade de abelhas é maior em ambientes semiáridos. Entretanto, as abelhas-das-orquídeas apresentam um comportamento oposto. Há o registro de poucas espécies em ambientes savânicos, sendo que a maior diversidade é encontrada em ambientes florestais úmidos. O Cerrado, com todas as suas peculiaridades ambientais, abrange um mosaico de fitofisionomias florestais e savânicas, as quais são capazes de sustentar uma diversidade de seres vivos com diferentes exigências microclimáticas. Nesse mosaico de fitofisionomias temos as florestas úmidas, como as florestas estacionais semideciduais e as matas de galeria e ciliares, as quais acompanham os corpos d'água. Esses ambientes contribuem de forma significativa para a manutenção de uma maior riqueza de abelhas Euglossini no bioma, uma vez que são mais favoráveis à ocorrência de várias espécies. Levantamentos da fauna de abelhas em remanescentes desse tipo de vegetação inseridos no Cerrado evidenciam que a riqueza de espécies de Euglossini é semelhante à de outros remanescentes de florestas úmidas de Mata Atlântica localizadas no sudeste do Brasil. Somente na região do Triângulo Mineiro foram registradas cerca de 20 espécies de abelhas Euglossini de todos os cincos gêneros (Tabela 2), sendo a maioria das espécies amostradas mais frequentemente, ou exclusivamente, em áreas florestais úmidas do Cerrado.

Dentre as espécies amostradas no Cerrado mineiro, chama a atenção o registro recente de Aglae caerulea. Essa espécie, conhecida como cleptoparasita de El. nigrita, era tida como endêmica da bacia Amazônica até 2006, quando foi registrada no bioma Cerrado da região Centro-Oeste brasileira. A partir de outros registros de ocorrência, 
foram desenvolvidos modelos matemáticos que previam sua ocorrência em Minas Gerais. Esta previsão foi confirmada por estudos de monitoramento conduzidos no âmbito do Programa de Pesquisas Ecológicas de Longa Duração (PELD), desenvolvidos no Triângulo Mineiro e no Sudeste de Goiás. Considerando todos os registros feitos fora da Bacia Amazônica, provavelmente, trata-se de outra espécie que depende das áreas florestais úmidas do Cerrado para sua dispersão.

\section{Diversidade e estudos populacionais}

No âmbito do projeto PELD-TMSG, a fauna de Euglossini foi amostrada em oito remanescentes florestais localizados na região do Triângulo Mineiro. Estes remanescentes possuíam diferentes tamanhos (Figura 6) e graus de perturbação. A riqueza, composição de espécies (Tabela 2) e proporção de indivíduos dos diferentes gêneros variaram entre os remanescentes (Figura 6). Alguns dos remanescentes apresentaram baixa similaridade quanto à composição (Figura 7). Isso demostra que a fauna de Euglossini pode variar em um raio relativamente pequeno de distribuição $(<100$ $\mathrm{km}$ ), o que é extremamente importante quando consideramos a diversidade regional.

A análise usando dados de composição e abundância das espécies para seis dos oitos remanescentes estudados evidenciou a formação de dois grupos (Figura 8A): (i) um formado exclusivamente pelo remanescente da Fazenda Mata da Água fria (FMAF), como resultado da presença das espécies Euglossa amazonica, Euglossa truncata e A. caerulea (Figura $8 \mathrm{~B}$ ); e (II) todos os outros remanescentes, devido à presença das outras espécies amostradas (Figura 8B). O remanescente MAFF é bem preservado e possui a dominância de plantas com uma área basal maior, sendo caracterizado como em um estágio sucessional mais avançado. Além disso, sua flora possui características de Mata Atlântica de interior, com várias espécies vegetais típicas da Mata Atlântica de encosta. Esses fatores podem ter colaborado para a ocorrência exclusiva ou com maior frequência das espécies de Euglossini amostradas nesse remanescente.

Como já mencionado, a riqueza de espécies foi comparável ao registrado em remanescentes de Mata Atlântica lato sensu de mesma latitude. Além disso, é importante destacar que os remanescentes estudados estão próximos a um dos centros de endemismos determinados especificamente para a Mata Atlântica, o centro conhecido como "Componente Sudeste de Minas Gerais, Centro e Costa de São Paulo, Centro e Costa do Paraná". Em um contexto biogeográfico mais específico, oito das 16 espécies amostradas no Triângulo Mineiro, Eg. fimbriata, Euglossa imperialis, Euglossa leucotricha, Euglossa pleosticta, Eg. truncata, Eulaema cingulata, Eulaema helvola e Exaerete frontalis, são consideradas como pertencentes a esse componente. Além disso, a fauna de Euglossini do Triângulo Mineiro possui espécies supostamente endêmicas de outros biomas, como A. caerulea, Eg. amazonica, Euglossa decorata, Euglossa despecta e Euglossa viridis. Tais fatos corroboram a hipótese de utilização de florestas úmidas inseridas no Cerrado como corredores ecológicos de dispersão e que, portanto, esses ambientes são fundamentais para a manutenção da diversidade de Euglossini no Cerrado.

Por outro lado, apesar de a riqueza de espécies nos remanescentes florestais do Triângulo Mineiro ser comparável à de outros remanescentes de Mata Atlântica da região sudeste, a diferença no número de indivíduos coletados pode ser até 20 vezes 
menor. Esse fato pode ser um reflexo do declínio das populações dessas abelhas, que dependem dos remanescentes florestais para sua manutenção no Cerrado. Desde o início de sua exploração e colonização, o histórico do Cerrado tem registro de destruição e fragmentação de habitats, devido, principalmente, às práticas agropastoris, o que pode ter impactado as populações de Euglossini.

Tentativas de estimar os tamanhos populacionais foram feitas para algumas espécies de Euglossini associadas aos ambientes florestais, utilizando-se um método de captura e recaptura com marcação permanente não letal, que envolveu a remoção do pré-tarso e parte do tarso das pernas de machos atraídos e capturados por iscasaromáticas. Pode-se verificar que o número de recapturas foi relativamente baixo para a maioria das espécies, variando de menos de $1 \%$ até cerca de $20 \%$, resultado que está de acordo com estudos sobre captura e recaptura feitos para machos de abelhas-dasorquídeas, mesmo aqueles que utilizam outros métodos de marcação. Este resultado poderia levar à conclusão de que as populações de Euglossini são numerosas nos remanescentes florestais do Triângulo Mineiro. Entretanto, características inerentes às espécies dessa tribo devem ser levadas em consideração, como sua grande capacidade de dispersão. Por outro lado, o uso de métodos de captura e recaptura associados a um método de marcação não letal permitiu verificar variações significativas no tamanho populacional de Eg. imperialis na Reserva Ecológica do Panga, em Uberlândia, ou em alguns dos remanescentes estudados, quando se agrupou todas as espécies do gênero Euglossa coletadas (Figura 9). 
Tabela 2-Espécies de Euglossini registradas na região do Triângulo Mineiro. FSJFazenda São José; FEG - Fazenda Experimental do Glória; REP- Reserva Ecologia do Panga; FI- Fazenda Irara; FMAF - Fazenda da Mata da Água Fria; FSC - Fazenda Sucupira-Cassu; FC- Fazenda Cruzeiro; FM - Fazenda Marimbondo.

\begin{tabular}{|c|c|c|c|c|c|c|c|c|}
\hline \multirow[t]{2}{*}{ Espécies } & \multicolumn{8}{|c|}{ Áreas $^{1}$} \\
\hline & FSJ & FEG & REP & FI & FMAF & FSC & $\mathrm{FC}$ & FM \\
\hline Aglae caerulea Lepeletier \& Serville & & & & & $\mathrm{X}$ & & & \\
\hline Eufriesea auriceps (Friese) & & & $\mathrm{X}$ & & & & $\mathrm{X}$ & \\
\hline Eufriesea surinamensis (Linnaeus) & & & $\mathrm{X}$ & & & & & \\
\hline Euglossa (Euglossa) amazonica Dressler & $\mathrm{X}$ & $\mathrm{X}$ & & & $\mathrm{X}$ & & & $\mathrm{X}$ \\
\hline Euglossa (Euglossa) cordata Linnaeus & $\mathrm{X}$ & $\mathrm{X}$ & & $\mathrm{X}$ & $\mathrm{X}$ & & & $\mathrm{X}$ \\
\hline Euglossa (Euglossa) despecta Moure & & & & & & & & $\mathrm{X}$ \\
\hline Euglossa (Euglossa) fimbriata Moure & $\mathrm{X}$ & $\mathrm{X}$ & & $\mathrm{X}$ & & & & $\mathrm{X}$ \\
\hline Euglossa (Euglossa) melanotricha Moure & $\mathrm{X}$ & $\mathrm{X}$ & $\mathrm{X}$ & $\mathrm{X}$ & & & & $\mathrm{X}$ \\
\hline Euglossa (Euglossa) pleosticta Dressler & $\mathrm{X}$ & $\mathrm{X}$ & $\mathrm{X}$ & $\mathrm{X}$ & $\mathrm{X}$ & $\mathrm{X}$ & $\mathrm{X}$ & $\mathrm{X}$ \\
\hline Euglossa (Euglossa) securigera Dressler & $\mathrm{X}$ & $\mathrm{X}$ & & $\mathrm{X}$ & & & & $\mathrm{X}$ \\
\hline Euglossa (Euglossa) truncata Rebêlo \& Moure & $\mathrm{X}$ & $\mathrm{X}$ & $\mathrm{X}$ & $\mathrm{X}$ & $\mathrm{X}$ & & & $\mathrm{X}$ \\
\hline Euglossa (Euglossa) townsendi Cockerell & & & $\mathrm{X}$ & & & & & \\
\hline Euglossa (Euglossella) decorata Smith & & & $\mathrm{X}$ & & & & & \\
\hline Euglossa (Euglossella) viridis Perty & $\mathrm{X}$ & & $X$ & & $\mathrm{X}$ & $\mathrm{X}$ & & \\
\hline Euglossa (Glossura) imperialis Cockerell & $\mathrm{X}$ & $\mathrm{X}$ & $\mathrm{X}$ & $\mathrm{X}$ & $\mathrm{X}$ & $\mathrm{X}$ & $\mathrm{X}$ & $\mathrm{X}$ \\
\hline Eulaema (Apeulaema) cingulata Fabricius & $\mathrm{X}$ & $\mathrm{X}$ & $\mathrm{X}$ & & $\mathrm{X}$ & & & $\mathrm{X}$ \\
\hline Eulaema (Apeulaema) nigrita Lepeletier & $\mathrm{X}$ & $\mathrm{X}$ & $\mathrm{X}$ & $\mathrm{X}$ & $\mathrm{X}$ & $\mathrm{X}$ & $\mathrm{X}$ & $\mathrm{X}$ \\
\hline Eulaema (Eulaema) helvola Moure & $\mathrm{X}$ & & & & & & & \\
\hline Exaerete dentata Linnaeus & $\mathrm{X}$ & & & & & & & \\
\hline Exaerete smaragdina Guérin & & & $\mathrm{X}$ & $\mathrm{X}$ & & $\mathrm{X}$ & & $\mathrm{X}$ \\
\hline Riqueza de espécies & 13 & 10 & 12 & 9 & 9 & 5 & 4 & 12 \\
\hline
\end{tabular}




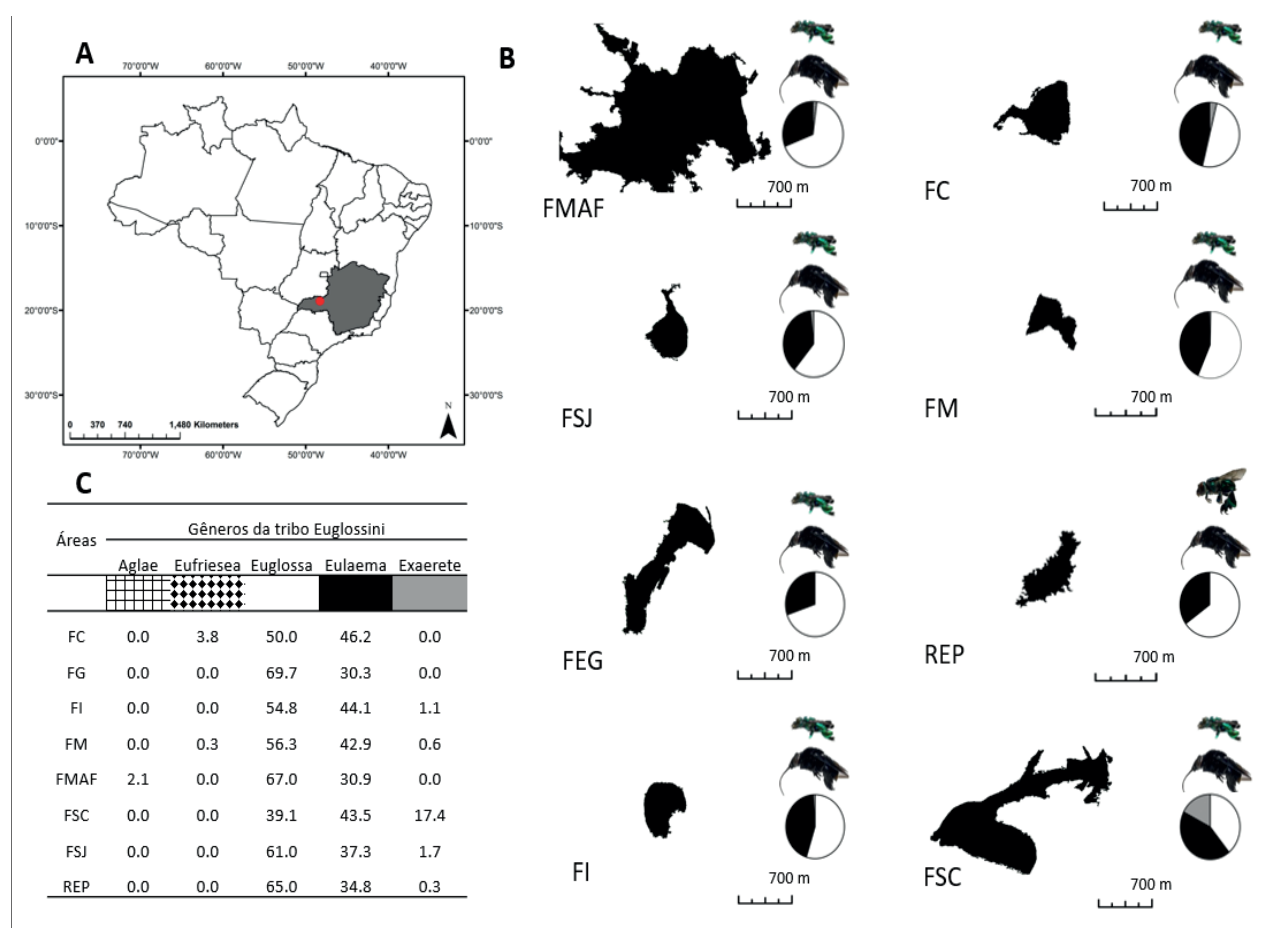

Figura 6. Remanescentes estudados na região do Triângulo Mineiro. A - Localização dos remanescentes. B - Remanescentes estudados e abundância relativa dos gêneros mais amostrados em cada um deles: FMAF - Fazenda Mata da Água Fria; FC - Fazenda Cruzeiro; FSJ - Fazenda São José; FM - Fazenda Marimbondo; FEG - Fazenda Experimental do Glória; REP - Reserva Ecológica do Panga; FI - Fazenda Irara; FSC -Fazenda Sucupira-Cassu. C- Proporção de indivíduos amostrados por gêneros.

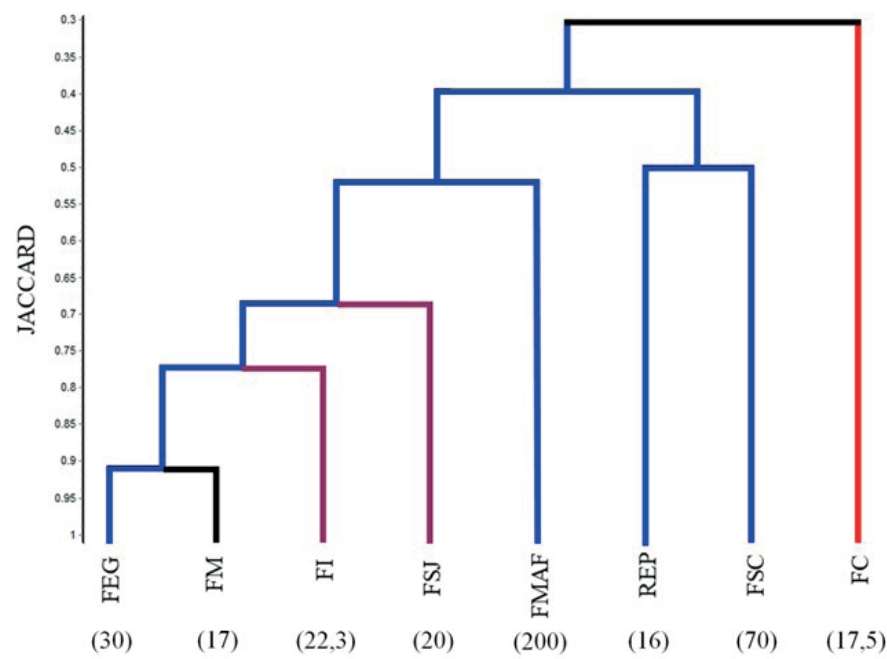

Figura 7. Similaridade dos remanescentes amostrados quanto a composição de espécies. As cores das linhas estão relacionadas ao grau de impacto sofridos por estes remanescentes: Linha azul = impacto brando; Linha roxa = impacto intermediário; Linha vermelha $=$ impacto forte; Linha preta $=$ sem dados. Os números entre parênteses representam o tamanho (em hectares) de cada remanescente. FEG - Fazenda Experimental do Glória; FM - Fazenda Marimbondo; FI- Fazenda Irara; FSJ- Fazenda São José; FMAF - Fazenda da Mata da Água Fria; REP- Reserva Ecologia do Panga; FSC - Fazenda Sucupira-Cassu; FCFazenda Cruzeiro. 

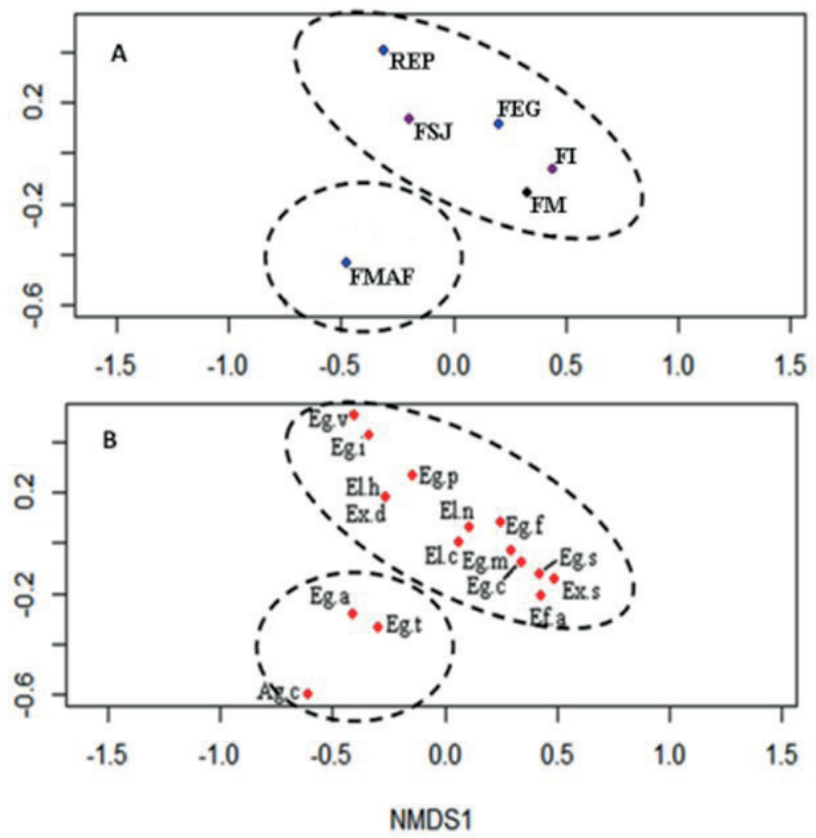

Figura 8. Ordenação dos remanescentes baseada na composição e abundância de espécies. Agrupamentos dos remanescentes (A) e as espécies que determinaram esses agrupamentos (B). FMAF - Fazenda Mata da Água Fria; FI - Fazenda Irara; REP -Reserva Ecológica do Panga; FEG - Fazenda Experimental do Glória; FM - Fazenda Marimbondo; FSJ - Fazenda São José; Ag. c - Aglae caerulea; Ef. a - Eufriesea auriceps; Eg. a - Euglossa amazonica; Eg. c - Euglossa cordata; Eg. f - Euglossa fimbriata; Eg. i - Euglossa imperialis; Eg. m - Euglossa melanotricha; Eg. p - Euglossa pleosticta; Eg. s - Euglossa securigera; Eg. $\mathrm{t}$ - Euglossa truncata; Eg. v - Euglossa viridis; El. c - Eulaema cingulata; El. h - Eulaema helvola; El. $\mathrm{n}$-Eulaema nigrita; Ex. d - Exaerete dentata; Ex. s - Exaerete smaragdina.

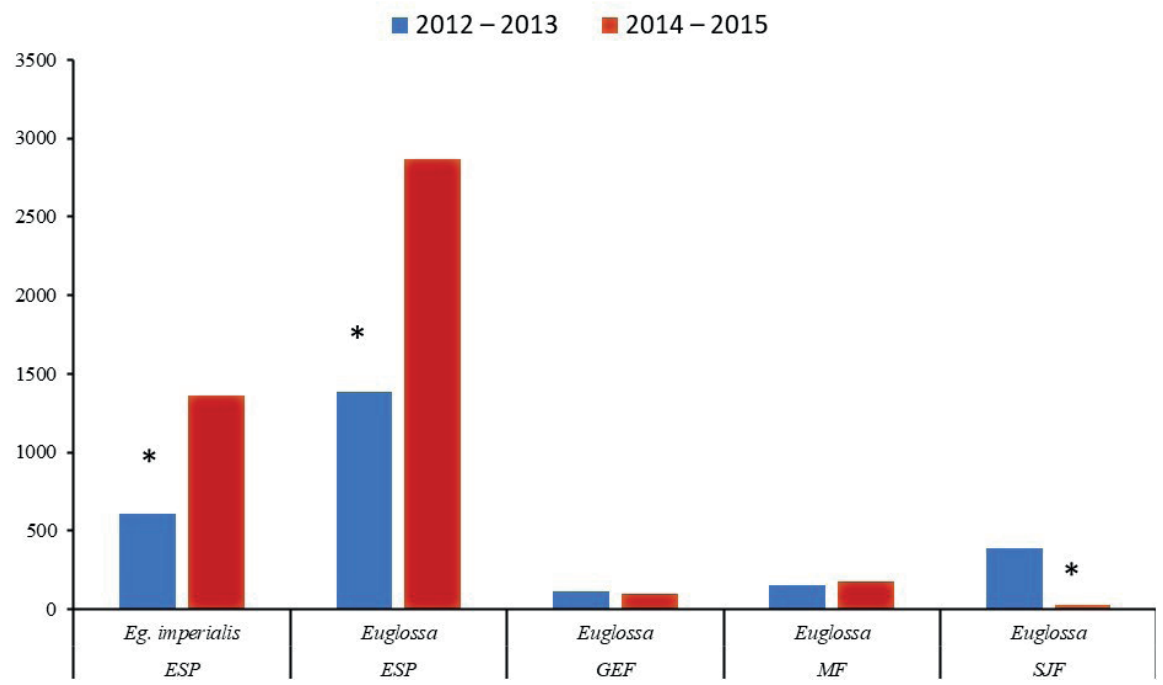

Figura 9. Estimativas populacionais de Euglossini, realizadas em remanescentes florestais do Triângulo Mineiro em dois períodos, 2012-2013 e 2014-2015. * casos em que foram observadas variações significativas $(\mathrm{p}<0,05)$. REP - Estação Ecológica do Panga; FEG - Fazenda Experimental do Glória; FM - Fazenda Marimbondo; FSJ - Fazenda São José. 


\section{Considerações finais}

Os estudos sobre a fauna de Euglossini em remanescentes florestais do Cerrado Mineiro, realizados no âmbito do projeto PELD, evidenciam a importância das florestas úmidas para a manutenção da diversidade do grupo no bioma Cerrado. Destaca-se a riqueza de espécies amostradas, comparável à de remanescentes de Mata Atlântica na mesma latitude. Por outro lado, os dados de abundância das espécies e as estimativas populacionais feitas nos remanescentes monitorados, parecem indicar a ocorrência de pequenos tamanhos populacionais, o que pode significar uma ameaça à sobrevivência das espécies dependentes de áreas úmidas. O uso do método de captura e recaptura associado a uma marcação não letal mostrou-se útil para a realização de estimativas populacionais, podendo ser mais amplamente utilizado em estudos que envolvam um monitoramento de longa duração.

\section{Para saber mais}

Augusto SC, Garófalo CA (2011) Task allocation and interactions among females in Euglossa carolina nests (Hymenoptera, Apidae, Euglossini). Apidologie 42: 162-173 doi: 10.1051/apido/2010040

Ascher JS, Pickering J (2020) Discover Life bee species guide and world checklist (Hymenoptera: Apoidea: Anthophila). Disponível em https://www.discoverlife.org/ mp/20q?\%20guide=Apoidea_species.htm. Acessado em 21 Março 2020.

Dodson CH, Dressler HG, Hills RM, Adams RM, Williams NH (1969) Biologically active compounds in orchid fragrances. Science 164: 1243-1249 doi: 10.1126/ science.164.3885.1243

Dressler RL (1982) Biology of the orchid bees (Euglossini). Annu Rev Ecol Syst 13:373-394.

Freiria GA, Rocha-Filho LC, Del Lama MA, Garófalo CA (2017) Surrounded by foes: Parasitism in Euglossa spp. (Apidae, Euglossini) caused by six species of natural enemies. J Apic Res 56: 255-261 doi: 10.1080/00218839.2017.1302911

Michener CD (2007) The Bees of the World. 2nd edition. The John Hopkins University Press, Baltimore, USA.

Roubik DW, Hanson PE (2004) Orchid bees of tropical America: Biology and field guide. Instituto Nacional de Biodiversidad (INBio), Heredia, Costa Rica.

Santos ML, Garófalo CA (1994) Nesting biology and nest re-use of Eulaema nigrita (Hymenoptera, Apidae, Euglossini), Ins Soc 41:99-110 doi: 10.1007/BF01240577

Silva DP, Aguiar AJC, Melo GAR, Anjos-Silva EJ, Marco Jr P (2013) Amazon species within the Cerrado savanna new records and potential distribution for Aglae caerulea (Apidae: Euglossini). Apidologie 4:673-683 doi: 10.1007/s13592-013-0216-7

Silveira GC, Freitas RF, Tosta THA, Rabelo LS, Gaglianone MC, Augusto SC (2015) The orchid bee fauna in the Brazilian savanna: do forest formations contribute to higher species diversity? Apidologie 46:197-208 doi: 10.1007/s13592-014-0314-1 
Tosta THA, Silveira GC, Schiavini I, Sofia SH, Augusto SC (2017) Using shortterm surveys and mark-recapture to estimate diversity and population size of orchid bees in forest formations of the Brazilian savanna. J Nat Hist 51:391-403 doi: $10.1080 / 00222933.2016 .1274441$ 


\title{
CAPÍTULO 11
}

\section{ECOLOGIA E DIVERSIDADE DE BESOUROS ESCARABEÍNEOS}

\author{
Raquel L. Carvalho \\ Lino A. Zuanon
}

Heraldo L. Vasconcelos

Os besouros escarabeíneos são insetos pertencentes à ordem Coleoptera. Eles são conhecidos popularmente como "besouros rola-bosta" devido ao comportamento que várias espécies possuem de rodar bolotas de fezes e as enterrar no solo. Esses besouros ocupam principalmente as regiões tropicais, sendo conhecidas cerca de $7 \mathrm{mil}$ espécies em todo o mundo, das quais 700 ocorrem no Brasil. A maioria das espécies é coprófaga, utilizando principalmente fezes de mamíferos como recurso alimentar e de nidificação. Entretanto, alguns besouros também podem se alimentar de carcaças (necrófagos), ou fungos (micetófagos), frutos em decomposição (carpófagos), ou restos vegetais (saprófagos). Por fim, há espécies que são predadoras de diplópodes, piolhosde-cobra ou formigas (Figura 1).

Esses besouros também exibem uma grande variação de tamanho (tamanho do corpo, medido entre o clípeo e o pigídio, varia de 2 a $60 \mathrm{~mm}$ ), cores e formatos (Figura 2), sendo que o dimorfismo sexual está presente em muitas espécies do grupo. Nestas, os machos possuem grandes cornos ("chifres") na cabeça, que são úteis tanto na construção de túneis quanto nas disputas por fêmeas.

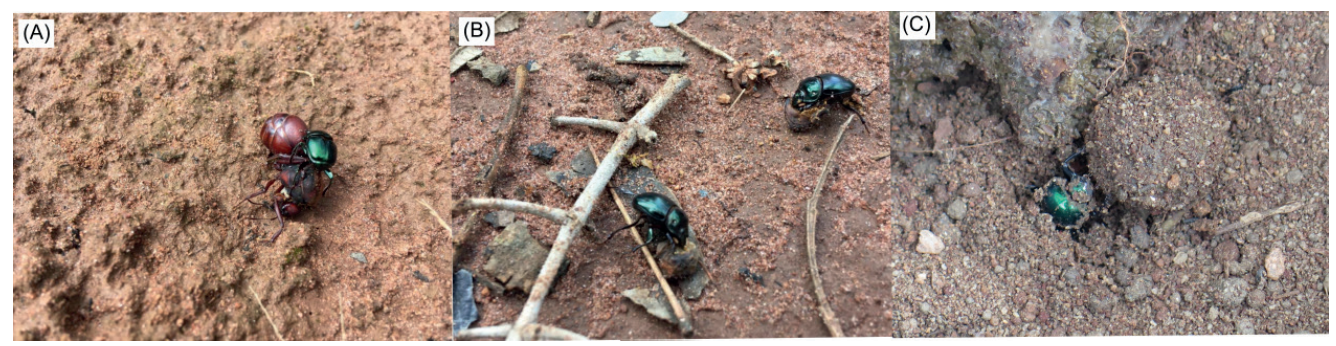

Figura 1. (A) Canthon virens predando uma rainha de Atta laevigata, (B) Besouros da espécie Malagoniella aenicollis alimentando-se de um fruto em decomposição de Byrsonima intermedia e (C) Canthon smaragdulus confeccionando uma bolota de fezes para enterrar no solo. 


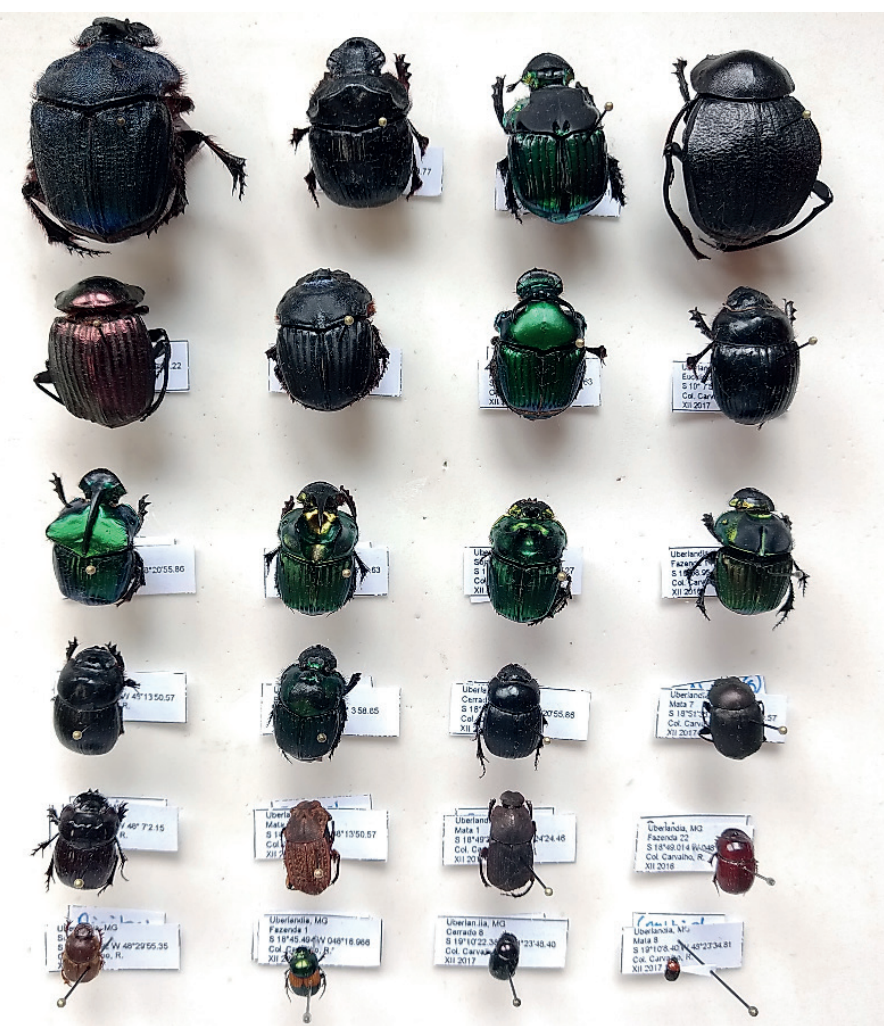

Figura 2. Variação de cor e tamanho em besouros escarabeíneos coletados na região do Triângulo Mineiro. Material depositado na Coleção Zoológica da Universidade Federal de Uberlândia.

\section{Estratégias de utilização dos recursos alimentares}

Os besouros escarabeíneos podem ser divididos em três grupos de acordo com a forma como consomem ou manipulam os recursos. Os "residentes" se alimentam e nidificam no interior das fezes; os "escavadores" constroem túneis imediatamente abaixo ou próximo do recurso, para que este seja enterrado; enquanto os "roladores" formam bolotas que são enterradas a certa distância do depósito de fezes (Figura 3). Os roladores usam as luzes emitidas pelas estrelas da Via Láctea para se orientar e assim conseguem carregar a bolota de fezes em linha reta e não em círculos. Acredita-se que estas diferenças na forma de consumo e manipulação das fezes ajudam a explicar a grande diversidade de espécies de besouros escarabeíneos, uma vez que hábitos diferentes ajudam a diminuir a competição entre as espécies, aumentando a chance de coexistência.

\section{Ciclo de vida}

Os besouros rola-bosta são holometábolos, ou seja, apresentam metamorfose completa, passando por quatro estágios de desenvolvimento. Na primeira etapa, os ovos são depositados pela fêmea adulta dentro das fezes. Dos ovos eclodem as larvas, que se desenvolvem no interior das fezes e passam para o estágio de pupa, que é a fase intermediária entre larva e adulto, e onde ocorrem as maiores modificações em 
termos fisiológicos. Em seguida, as pupas se transformam em indivíduos adultos, que escavam um túnel até a superfície do solo para sair à procura de alimento e/ou parceiro reprodutivo (Figura 4). Os adultos se acasalam quando encontram um depósito de fezes, sendo que os machos emitem substâncias químicas, os chamados feromônios, para atrair as fêmeas. Após a cópula o ciclo recomeça outra vez.
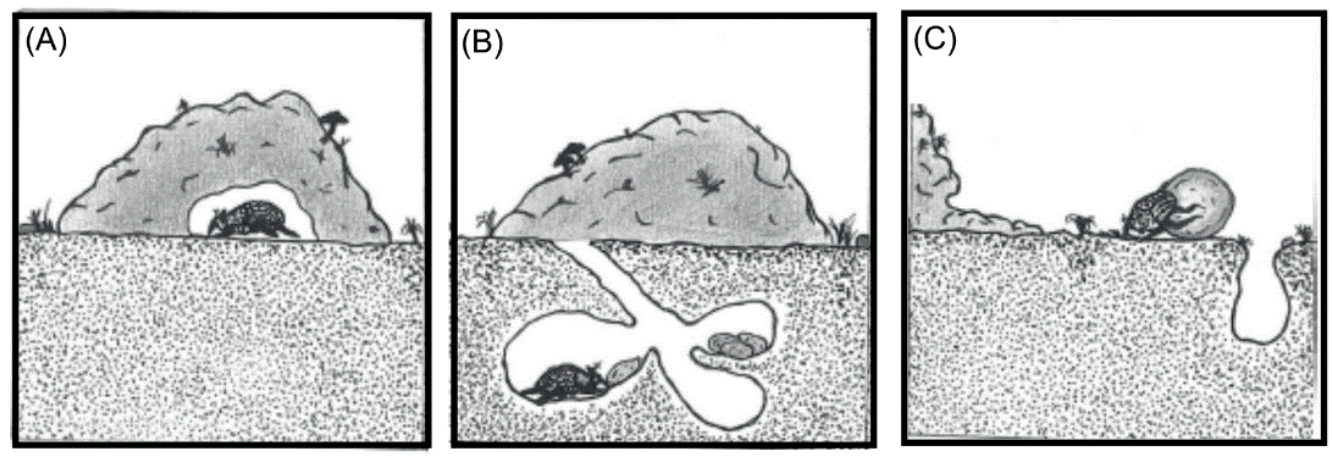

Figura 3. Estratégias de consumo e manipulação das fezes por diferentes espécies de besouros escarabeíneos: (A) Residente; (B) Escavador e (C) Rolador. Adaptado de Halffter \& Edmonds 1982

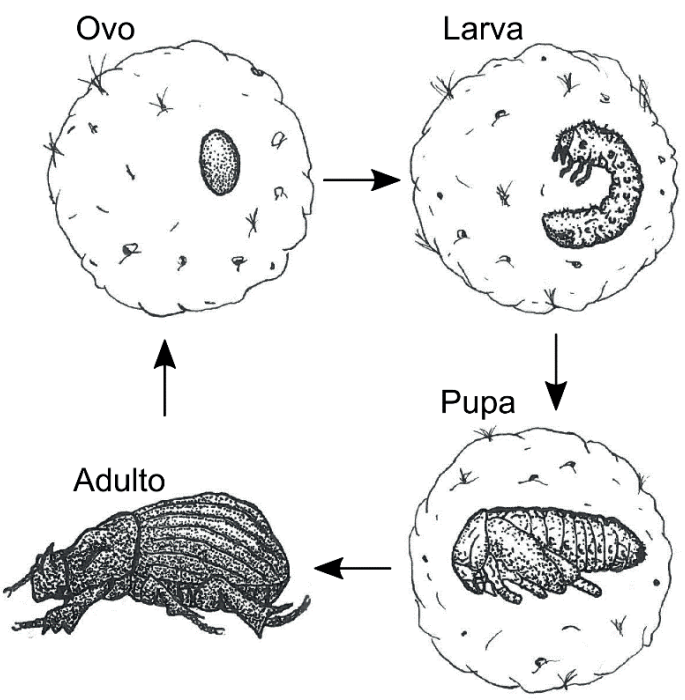

Figura 4. Ciclo de vida do besouro escarabeíneo mostrando os quatro estágios de desenvolvimento: ovo, larva, pupa e adulto.

\section{Origem e radiação}

Os besouros rola-bosta evoluíram de ancestrais que se alimentavam de detritos vegetais. À medida que a decomposição da matéria vegetal ocorre, ela é degradada em partículas menores e em nutrientes. Dessa maneira, a mudança para uma alimentação de fezes é compreensível devido à semelhança dos dois substratos, visto que ambos são formados por celulose e microrganismos.

A rápida radiação dos besouros ocorreu no período Terciário, durante a diversificação de mamíferos herbívoros, há aproximadamente 65 milhões de anos. $\mathrm{O}$ 
aumento desses mamíferos proporcionou um aumento também no volume de fezes disponível no ambiente, possibilitando aos besouros rola-bosta conquistarem ambientes que antes seriam inabitáveis para eles.

\section{Amostragem dos besouros}

Os besouros escarabeíneos apresentam alto grau de especificidade com os ambientes, possivelmente por variações em características do solo, estrutura da vegetação, temperatura e umidade. Por isso são frequentemente utilizados como indicadores ecológicos. A amostragem da fauna de besouros escarabeíneos é comumente feita utilizando armadilhas de queda (Figura 5), as quais podem ser feitas de modo que mantenham os besouros vivos ou não após a queda destes, de acordo com o objetivo do estudo. Armadilhas para coleta de besouros vivos ficam instaladas $24 \mathrm{~h}$, e geralmente são mais fundas, e com serrapilheira no interior. As armadilhas em que os besouros morrem ficam instaladas por $48 \mathrm{~h}$, sendo mais rasas e tem no interior uma solução composta por água, sal e detergente. É importante salientar que a maioria das espécies é atraída por fezes humanas, e por isso esse recurso vem sendo cada vez mais utilizado nos protocolos de coleta envolvendo esse grupo. Entretanto, existem espécies que utilizam apenas recursos específicos, e por isso outras metodologias podem ser empregadas para complementar à amostragem, como armadilhas de interceptação de voo e armadilhas luminosas. Os besouros coletados são levados para o laboratório, onde são montados com alfinetes entomológicos e depositados em coleções zoológicas para serem identificados até o menor nível taxonômico possível (Figura 6).
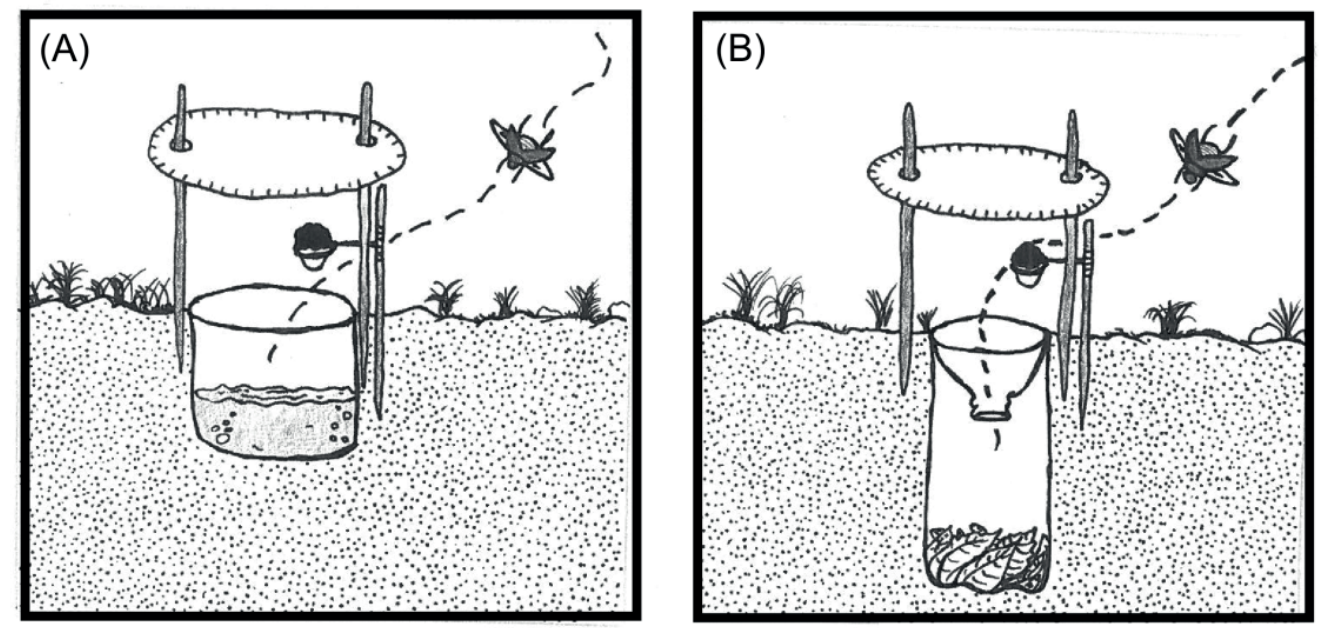

Figura 5. Armadilhas de queda utilizadas para amostrar besouros escarabeíneos a) mortos e b) vivos. 


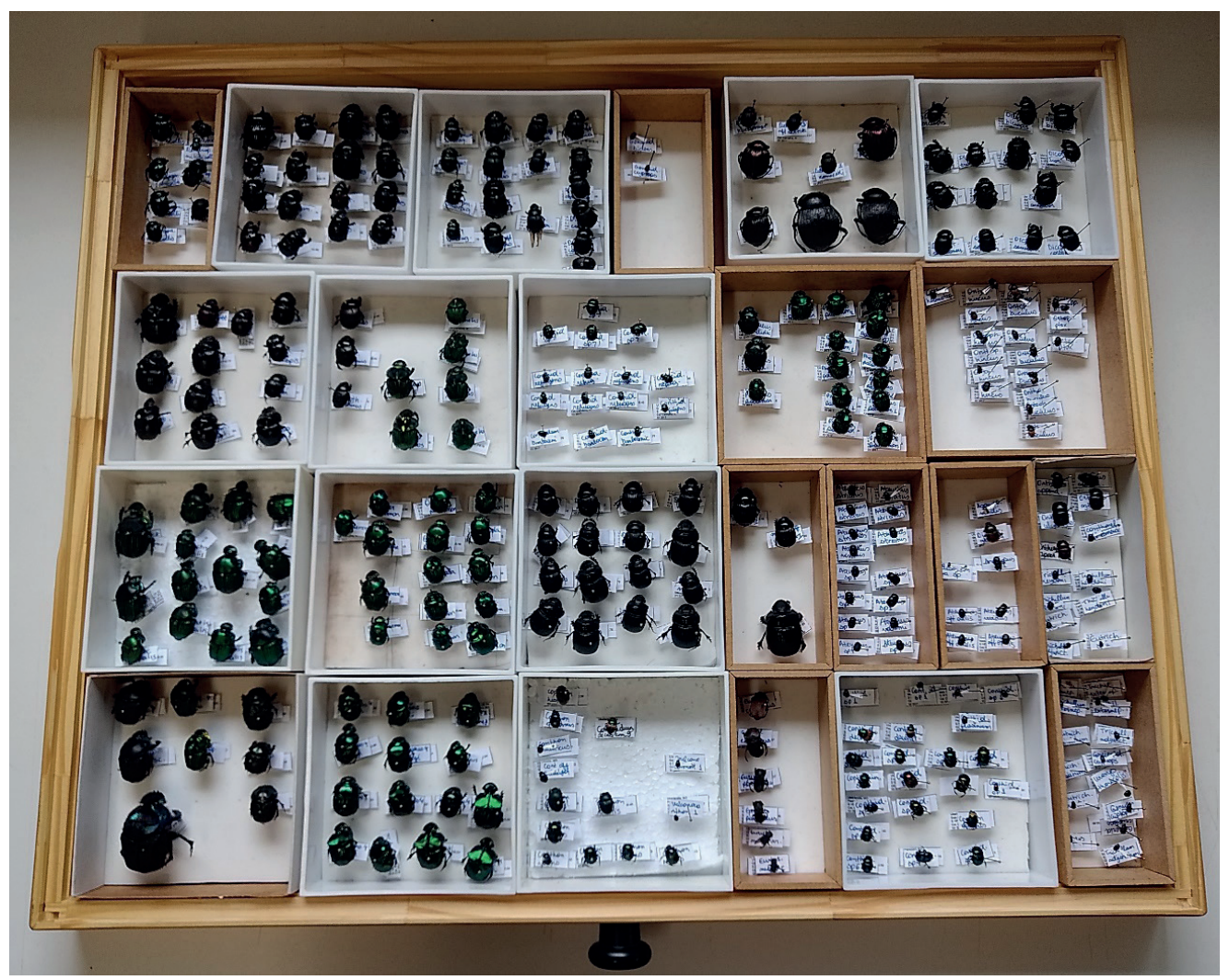

Figura 6. Gaveta entomológica com espécimes de besouros da região do Triângulo Mineiro.

\section{Importância ecológica}

Os besouros escarabeíneos possuem várias funções ecológicas e são extremamente importantes para o ambiente, devido ao seu comportamento alimentar e hábitos de nidificação. Os besouros participam da remoção de matéria orgânica da superfície do solo ao construírem túneis e galerias para enterrarem as fezes (ou outros recursos). Neste processo eles também alteram as propriedades físicas e químicas do solo, já que afetam a ciclagem de nutrientes e aumentam a passagem de ar e água no solo em que cavam seus túneis. Os besouros também contribuem para a dispersão secundária de sementes, já que estas podem ser encontradas em muitas das fezes de animais enterradas por eles. Essas sementes são beneficiadas, pois ao serem enterradas com fezes pelos besouros elas sofrem uma menor taxa de predação, menor competição, além de estarem menos sujeitas à dessecação, favorecendo assim sua germinação. Além disso, os besouros podem exercer um controle indireto sobre a população de moscas e parasitas gastrointestinais que afetam a pecuária. Através da remoção das fezes de bovinos pelos besouros rola-bosta, elimina-se o desenvolvimento de organismos prejudiciais ao gado gerando um aumento na saúde dos animais, o que é de grande importância econômica. 


\section{Diversidade em ambientes naturais e manejados}

Nossos levantamentos na região do Triângulo Mineiro mostram que os besouros escarabeíneos são muito abundantes e diversos nas savanas (cerrado sensu stricto) e matas desta região. Para capturar estes besouros utilizamos armadilhas de queda, que continham como isca fezes humanas misturadas a fezes de porco (proporção 1:4) (Figura 5-A). As armadilhas ficaram no campo por $48 \mathrm{~h}$ e, neste período, uma única armadilha foi capaz de capturar até 238 besouros. Distribuímos estas armadilhas em oito áreas de cerrado sensu stricto e oito de mata semidecídua. No total, registramos 75 espécies de besouros, sendo 57 na mata e 50 na savana. O número de espécies que coletamos pode ser considerado alto se comparado com outros estudos realizados no bioma. Por exemplo, pesquisadores encontram 29 espécies em florestas e $32 \mathrm{em}$ vegetação de cerrado no sul de Minas Gerais (Almeida e Louzada, 2009).

Embora 32 das espécies que coletamos tenham ocorrido tanto na mata quanto na savana, houve diferenças marcantes nas características da fauna de cada um deste habitats. Nas áreas de savana encontramos uma dominância de besouros roladores, com atividade diurna e hábito coprófago, enquanto nas florestas foram mais abundantes os besouros escavadores e os residentes de atividade noturna e hábito alimentar generalista. Os besouros roladores, com atividade diurna, são comuns na vegetação mais aberta de cerrado porque necessitam do calor externo para otimizarem sua atividade locomotora. Além disso, a maioria das espécies é coprófaga, provavelmente devido à grande diversidade de espécies de mamíferos que são encontrados nessa fitofisionoma (aproximadamente 194 espécies). Já nas florestas, como os besouros roladores são pouco frequentes à noite, os besouros escavadores e residentes, que são competitivamente inferiores se comparado aos roladores, tornam-se mais abundantes. Além disso, os besouros da floresta são generalistas quanto ao hábito alimentar, pois utilizam vários recursos presente nessa fitofisionomia, como fezes, carcaças, frutas em decomposição e fungos.

Outra diferença marcante entre besouros de savana e de mata é a coloração. Os besouros de savana apresentam principalmente uma coloração esverdeada, enquanto os da mata uma coloração escura. Um estudo demonstrou que besouros com atividade diurna são coloridos, e apresentam uma coloração metálica. Já os besouros com atividade noturna possuem uma coloração mais escura e geralmente são pretos. (Figura 7). Algumas das espécies amostradas, como Agamopus viridis, Canthidium barbacenicum, Ontherus ulcopygus e Coprophaneus horus, são apenas encontradas no bioma Cerrado (Figura 8). Nós capturamos nas áreas de savana uma espécie nova do gênero Coprophaneus, que possivelmente é endêmica da região do Triângulo Mineiro. 


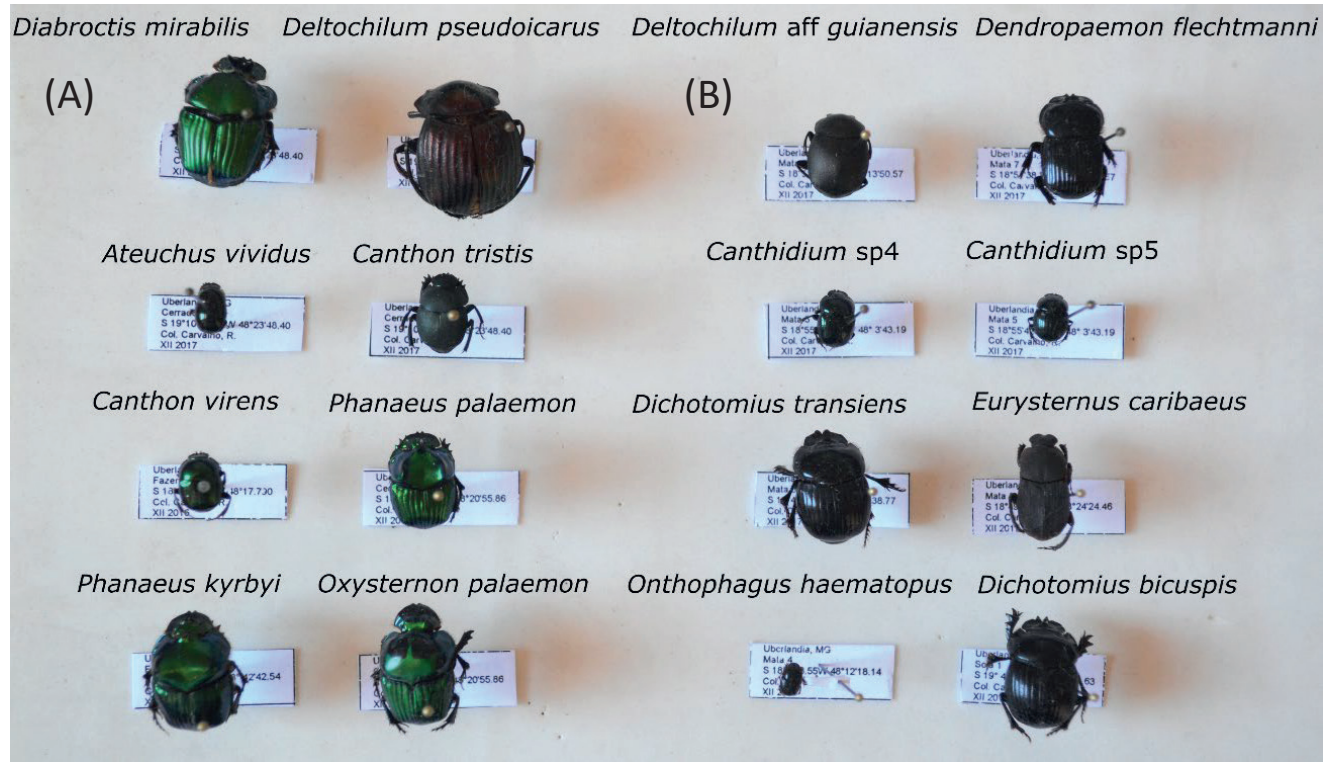

Figura 7. Besouros coletados com maior frequência em áreas de savana (A) e em áreas de mata (B) na região do Triângulo Mineiro.

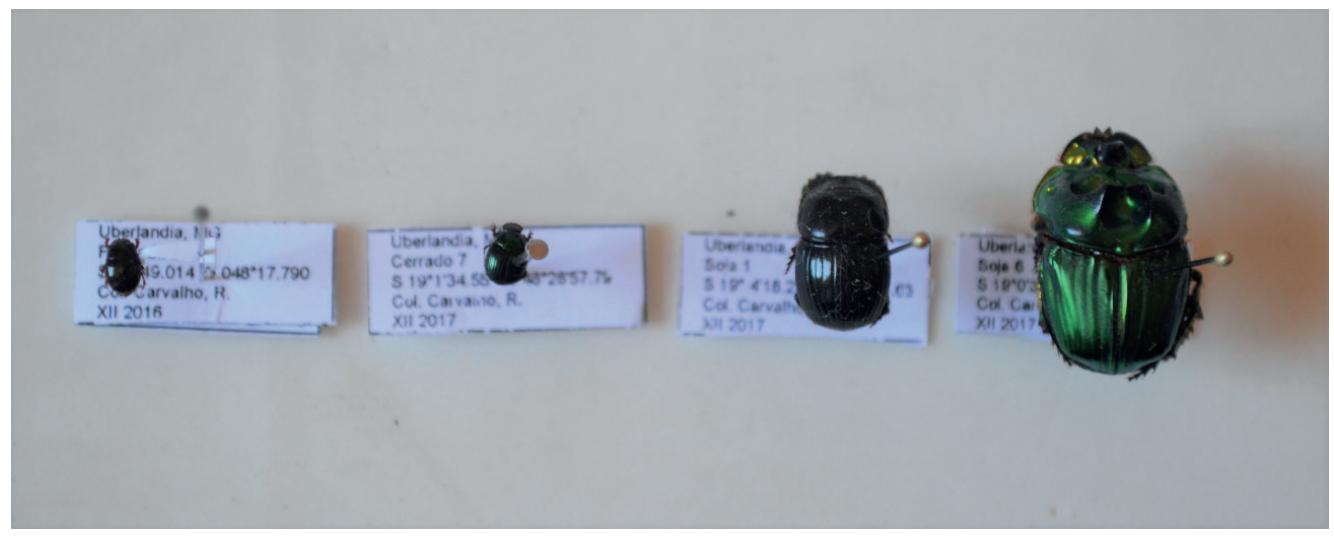

Figura 8. Espécies de besouros (Agamopus viridis, Canthidium barbacenicum, Ontherus ulcopygus e Coprophaneus horus) endêmicas do Cerrado.

Também amostramos Dichotomius aff interstitialis (Luederwaldt, 1931) no cerrado sensu stricto, uma espécie rara cujo último e único registro foi feito no Vale do Anhangabaú, na cidade de São Paulo, em 1926. Por fim, como nossa coleta é a primeira na região, foi possível atualizar o registro de ocorrência de várias espécies. Por exemplo, antes de nossas amostragens não existia ocorrência das espécies do gênero Vulcanocanthon para a savana. Esse tipo de informação é fundamental para entendermos os impactos antrópicos sobre as comunidades de besouros.

Além das coletas em matas e savanas, realizamos coletas em plantações de eucalipto, pastagens e em plantações de soja com o intuito de determinar como a conversão das áreas de vegetação nativa afeta a comunidade de besouros escarabeíneos. Surpreendentemente encontramos que o número de espécies de besouros diferiu pouco 
entre áreas nativas e não nativas. Entretanto, a floresta semidecidua foi o único ambiente que apresentou várias espécies exclusivas, ressaltando a importância de conservar os remanescentes deste tipo de vegetação ainda existentes em nossa região de estudo.

Nós esperávamos que a conversão de áreas naturais em plantações de eucalipto afetasse principalmente a comunidade de besouros de ambientes savânicos, uma vez que as plantações de eucalipto amostradas tinham cerca de seis anos e uma similaridade estrutural maior com ambientes florestais do que com os savânicos. Porém, nossos resultados demonstraram que as plantações de eucalipto foram capazes de conservar mais espécies da savana do que da floresta semidecídua. Em uma metanálise foi demonstrado que a resposta dos besouros frente à modificação do ambiente depende do contexto da paisagem. Como na paisagem amostrada a vegetação de cerrado é predominante, enquanto as áreas de floresta são poucas e esparsas, é possível que isso tenha influenciado o conjunto de espécies de besouros encontrados em plantações de eucalipto (Figura 9). A conversão de áreas de vegetação nativa em áreas de pastagem ou monocultura de soja levou à substituição de besouros escavadores e roladores grandes por besouros residentes pequenos. Essa mudança pode afetar algumas das funções ecológicas realizadas pelos besouros, já que nem todas as funções podem ser compensadas. Por exemplo, besouros pequenos, quando abundantes, são capazes de remover uma grande quantidade de fezes. Entretanto, eles não conseguem compensar todas as funções realizadas por outras espécies, já que escavam menos solo e dispersam menos sementes (principalmente as grandes) se comparadas às espécies maiores. Além disso, os besouros residentes, devido ao comportamento de nidificarem no interior das fezes, contribuem muito menos para a escavação do solo e dispersão de sementes do que os besouros roladores e escavadores.

Embora as funções ecológicas realizadas pelos besouros não tenham sido quantificadas, vários estudos tem considerado que mudanças nas métricas da comunidade (riqueza de espécies, abundância e biomassa total) podem ser usadas para inferir possíveis consequências funcionais sobre o ecossistema. Por exemplo, em um estudo realizado em florestas tropicais, foi demonstrado que a transformação de florestas primárias em áreas de agrofloresta, agricultura e pastagem afetava negativamente três atributos da comunidade (riqueza, abundância e biomassa), assim como as três funções ecológicas mensuradas (remoção de fezes, escavação do solo e dispersão secundária de sementes).
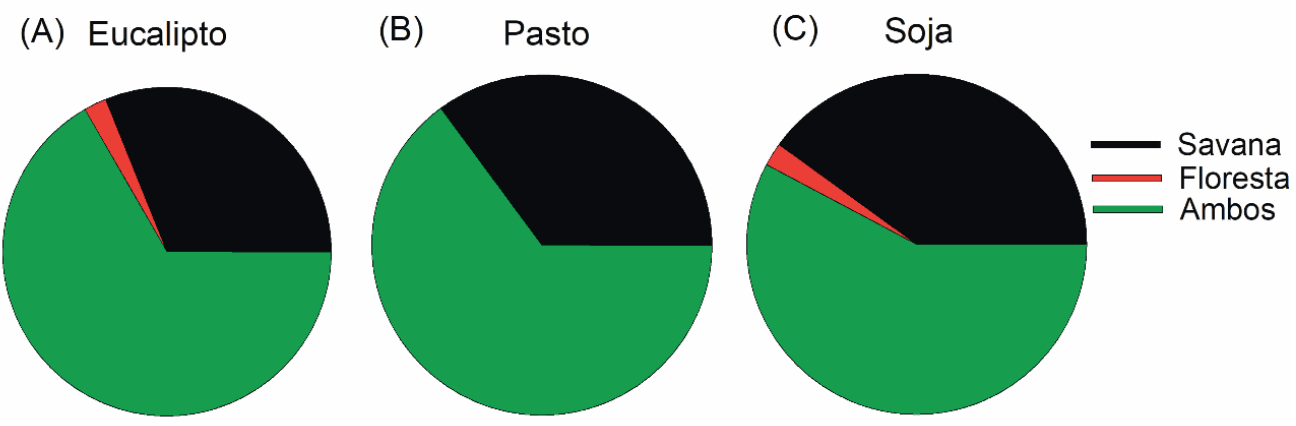

Figura 9. Quantidade de espécies compartilhadas entre áreas naturais e áreas de (A) Eucalipto, (B) Pasto, (C) Soja. 


\section{Efeito do manejo e da estrutura da vegetação em pastagens}

O Cerrado possui um dos maiores rebanhos bovinos do país. A atividade pecuária neste bioma sofreu modificações e teve uma rápida expansão durante as últimas décadas. Uma destas modificações envolveu a substituição de gramíneas nativas por gramíneas exóticas através de incentivos fiscais aos produtores rurais, com o objetivo de aumentar a capacidade de suporte das áreas de pastagem. De acordo com estudos conduzidos no sul de Minas Gerais por Almeida et al. (2011) esta substituição teve impactos significativos sobre a biodiversidade de besouros escarabeíneos assim como sobre as funções ecológicas desempenhada por eles. Em particular, verificou-se que as pastagens com gramíneas exóticas apresentavam menor riqueza, abundância e biomassa de besouros do que as pastagens nativas. Baseado em estudos realizados em outras regiões, os autores sugerem que pastagens com menor diversidade de besouros têm menor taxa de remoção de fezes e menos nutrientes (potássio e nitrogênio) no solo, o que pode diminuir a produtividade primária desses ambientes. A utilização do arado antes de plantar gramíneas exóticas, pode levar à destruição das galerias e ninhos construídos pelos besouros.

A substituição de gramíneas nativas por exóticas nas pastagens ocasionou também uma modificação nos sistemas de criação, transformando-os de extensivo em intensivo ou muito intensivo. No sistema extensivo, a taxa de lotação de bovinos é baixa (de 1,6 a 2,7 cabeças por hectare), e eles ocupam a área de criação durante todo o ano. Já no sistema intensivo e muito intensivo, as áreas de pastagem são separadas em piquetes, de forma que possam passar por um período de ocupação e descanso pelo gado (Figura 8). A diferença entre esses sistemas é que no intensivo a taxa de lotação é moderada (4,0 a 7,5 cabeças/ha), enquanto que no sistema muito intensivo é alta $(7,7$ a 12,9 cabeças/ha). Embora essa separação tenha sido realizada pela Embrapa, nós verificamos que a densidade de bovinos na região do triângulo Mineiro varia mais do que essa apresentada.

A intensificação do uso da terra no sistema pastoril envolve mudanças no manejo e no uso de insumos, como por exemplo, a adubação, a correção do solo e a utilização do arado nas pastagens, assim como o aumento no uso de produtos médicos veterinários, especialmente aqueles a base de Ivermectina, para o controle dos parasitas, produtos altamente tóxicos se consumidos pela fauna de organismos não alvo. Independente do sistema de produção, árvores com alguma importância econômica geralmente são mantidas nas pastagens, já que estas reduzem a temperatura do solo, resultando no bem estar dos bovinos.

Verificamos quais variáveis associadas ao manejo e ao ambiente melhor explicam a comunidade de besouros e seus grupos funcionais. Para isso, os besouros foram amostrados com armadilhas iscadas com fezes bovinas em 24 pastagens com gramíneas exóticas, incluindo-se aqui pastagens de diferentes idades, cobertura de gramíneas, densidade de árvores, densidade de gado e frequência no uso de parasiticidas.

Nós encontramos que a frequência do uso de parasiticidas teve um efeito negativo em seis dos oito atributos da comunidade mensurados (riqueza total, abundância total, biomassa total e a abundância de roladores pequenos, residentes pequenos e escavadores grandes), enquanto que a densidade de gado influenciou a composição de espécies. Em relação às variáveis relacionadas à estrutura da vegetação, somente a 
cobertura de gramíneas afetou a abundância dos roladores pequenos. O efeito negativo do uso de Ivermectina na comunidade de besouros indica o efeito prejudicial do uso de parasiticidas sobre os invertebrados que alimentam e/ou nidificam nas fezes (Figura 10).
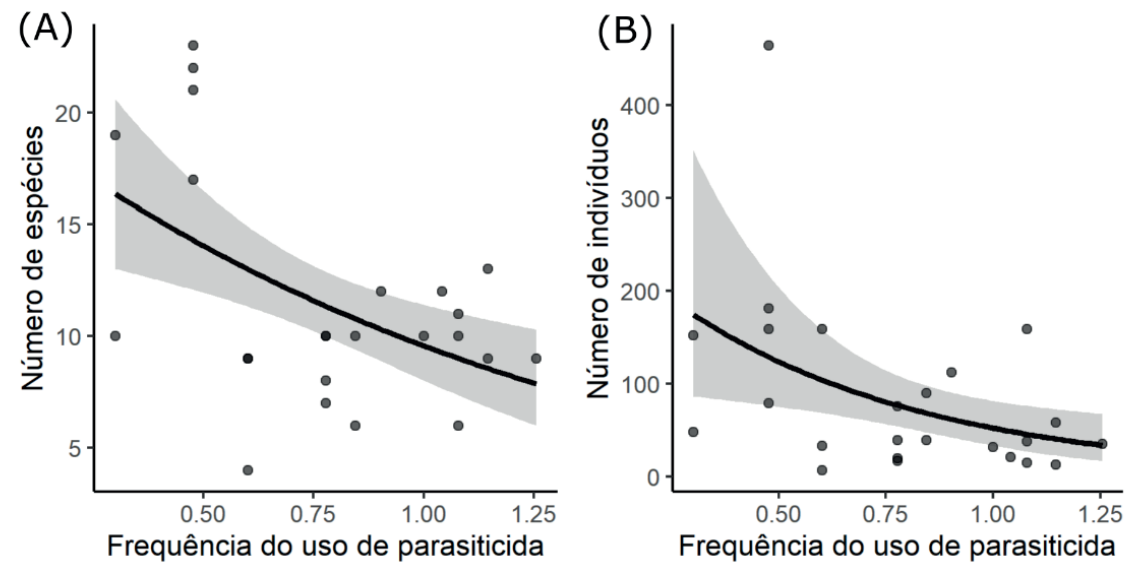

Figura 10. Relação negativa entre a frequência de uso de parasiticida e a riqueza (A) e abundância de besouros escarabeíneos (B).

O uso muito frequente de parasiticida nos bovinos aponta a necessidade de uma fiscalização mais rígida de órgãos do governo, além da criação de políticas públicas que conscientizem os proprietários dos riscos associados à utilização exagerada desses produtos veterinários. Ainda, são necessárias ações que incentivem os produtores a substituírem os produtos à base de Ivermectina por produtos que causem menos impactos. Uma alternativa seria a utilização de produtos à base de Azadirachta indica (Nim), uma planta que contém substâncias com potencial inseticida. O Nim tem pouco impacto na fauna de insetos não alvo e não possui efeitos sobre a saúde humana.

\section{Espécies exóticas}

As invasões biológicas são consideradas um dos principais fatores que levam a perda da biodiversidade em escala mundial. Entretanto, o efeito que as invasões têm nas comunidades nativas é pouco entendido no Brasil. Nas últimas décadas, vários países têm introduzido espécies de besouros coprófagos nas pastagens com o objetivo de aumentar a taxa de remoção de fezes e auxiliar no controle de helmintos gastrointestinais e de mosca-dos-chifres que se reproduzem na massa fecal.

Em 1989, a Empresa Brasileira de Pesquisa Agropecuária (Embrapa), introduziu no Brasil a espécie Digitonthophagus gazella (Fabricius, 1787) que é amplamente distribuída em regiões tropicais da África e na península da Árábia, Índia e Sri Lanka. Essa espécie é bem adaptada a ambientes abertos e ao uso de fezes bovinas e de grandes herbívoros. Embora seu tamanho seja pequeno $(15 \mathrm{~mm})$, um casal é capaz de enterrar cerca de $7 \mathrm{~kg}$ de fezes por ano, cerca de 10 vezes mais que algumas espécies brasileiras.

A atual distribuição do $D$. gazela tem preocupado diversos pesquisadores devido aos possíveis efeitos negativos na fauna de besouros nativos, já que não houve estudos 
prévios à introdução dessa espécie. Espécies exóticas que se estabelecem bem no novo ambiente podem mudar a distribuição e até levar ao desaparecimento das espécies nativas através da competição por recursos limitados.

Nós realizamos duas amostragens, durante a estação chuvosa de 2016 e de 2017, em 32 pastagens da região rural de Uberlândia utilizando armadilhas de queda iscadas com fezes bovinas ou humanas. Nós registramos 52 espécies nativas e 14 mil indivíduos, dentre esses, encontramos apenas 12 indivíduos de $D$. gazela que foram capturados em sete fazendas da amostragem. A ausência dessa espécie na maioria das pastagens amostradas pode ser devido ao pouco tempo de dispersão e estabelecimento da espécie na região do Triângulo Mineiro, ou porque a fauna nativa apresenta alguma resistência à invasão. Por isso, estudos de longo prazo como os realizados pelo PELD TMSG são importantes para monitorar o status de invasão dessa espécie e outros potenciais invasores na região e seus possíveis efeitos na biodiversidade desse sistema.

\section{Considerações finais}

Nossa amostragem de besouros escarabeíneos na região do Triângulo Mineiro mostra haver uma alta diversidade de besouros tanto em áreas florestais quanto em áreas de savana. Encontramos também um alto número de espécies de besouros em áreas modificadas pelo homem ; entretanto, algumas espécies são exclusivas dos ambientes naturais. Nossos resultados indicam ainda um efeito prejudicial do aumento na frequência de uso de parasiticidas sobre a comunidade de besouros em pastagens. Apesar de termos encontrado um elevado número de espécies, é importante ressaltar a necessidade de realizar outras coletas, já que provavelmente muitas espécies ainda não foram amostradas. Além disso, seria interessante a realização de trabalhos futuros que avaliem o efeito do fogo de diferentes intensidades e frequências sobre os besouros, ou verifiquem como a comunidade de besouros responde às mudanças no uso da terra em longo prazo. Um melhor entendimento sobre como os besouros reagem aos principais distúrbios da região é fundamental para avaliar a resiliência da comunidade frente às modificações ambientais. As informações obtidas por nós e divulgadas através desse capítulo de livro podem funcionar como base para o entendimento do papel dos besouros nos ambientes naturais e agrícolas, ajudando no processo de tomada de decisão em pequenas e grandes escalas.

\section{Para saber mais}

Almeida S, Louzada JN (2009) Estrutura da comunidade de Scarabaeinae (Scarabaeidae: Coleoptera) em fitofisionomias do Cerrado e sua importância para a conservação. Neotrop Entomol 38:32-43 doi: 10.1590/S1519-566X2009000100003

Almeida S, Louzada J, Sperber C, Barlow J (2011) Subtle land-use change and tropical biodiversity: dung beetle communities in Cerrado grasslands and exotic pastures. Biotropica 43:704-710 doi: 10.1111/j.1744-7429.2011.00751.x

Braga RF, Korasaki V, Andresen E, Louzada J (2013) Dung beetle community and functions along a habitat-disturbance gradient in the Amazon: a rapid assessment of ecological functions associated to biodiversity. PLoS One 8(2) doi: 0.1371/journal. pone.0057786 
Carvalho RL, Andresen E, Barônio GJ, Oliveira VH, Louzada J, Braga RF (2020) Is dung removal a good proxy for other dung beetle functions when monitoring for conservation? A case study from the Brazilian Amazon. Ecol Indic 109:105841 doi: 10.1016/j.ecolind.2019.105841

Carvalho RL, Andersen AN, Anjos DV, Pacheco R, Chagas L, Vasconcelos HL (2020) Understanding what bioindicators are actually indicating: Linking disturbance responses to ecological traits of dung beetles and ants. Ecol Indic 108:105764.7 doi. org/10.1016/j.ecolind.2019.105764

Hernández MIM (2002) The night and day of dung beetles (Coleoptera, Scarabaeidae) in the Serra do Japi, Brazil: elytra colour related to daily activity. Rev Bras Entomol 46:597600 doi 10.1590/S0085-56262002000400015

Nichols E, Larsen T, Spector S, Davis AL, Escobar F, Favila M, ... \& Network, TSR (2007) Global dung beetle response to tropical forest modification and fragmentation: a quantitative literature review and meta-analysis. Biological conservation, 137(1), 1-19.

Slade EM, Mann DJ, Villanueva JF, Lewis OT (2007) Experimental evidence for the effects of dung beetle functional group richness and composition on ecosystem function in a tropical forest. J Anim Ecol 76:1094-1104 doi: 10.1111/j.1365-2656.2007.01296.x 


\title{
CAPÍTULO 12
}

\section{BIOLOGIA E DIVERSIDADE DE GALHAS NOS CERRADOS}

\author{
Vitor C Martini \\ Pedro HP Gonçalves \\ Denis C Oliveira
}

Galhas são estruturas formados pela interação entre um organismo indutor (galhador) e os tecidos da planta hospedeira. Esta interação estimula o aumento da divisão celular dos tecidos vegetais parasitados (hiperplasia) e o crescimento do tamanho das células (hipertrofia) destes tecidos, culminando no desenvolvimento da galha ou tumor. Estes estímulos podem ser desencadeados por compostos salivares do organismo galhador, danos mecânicos, interação química, oviposição e/ou ação de hormônios presente nos tecidos da planta hospedeira, que são controlados pelo parasita galhador. As galhas podem ocorrer em raízes, caules, flores, frutos, sementes e, especialmente, em folhas, criando um ambiente que fornece alimento ao organismo galhador e proteção contra seus inimigos naturais e intempéries do ambiente.

De forma geral, galhas são resultado de interações parasíticas e causam prejuízo às plantas hospedeiras. Entretanto, podemos encontrar relações positivas. Alguns autores consideram que estruturas como nódulos fixadores de nitrogênio, que fixam e disponibilizam nitrogênio para as plantas em uma relação mutualística, também podem ser consideradas galhas. Outro exemplo é o caso das vespas do figo, que induzem galha nas flores, porém, os adultos da vespa oferecem um importante serviço, a polinização. Em geral, dentre os organismos galhadores, podemos citar vírus, bactérias, protozoários, nematoides, plantas, ácaros e principalmente insetos. Aqui, consideramos galhas como estruturas simétricas e conservativas induzidas principalmente por insetos. Assim, nesse capítulo apresentaremos os principais grupos de insetos galhadores, alvo de estudo do nosso grupo de pesquisa. Além disso, trataremos da diversidade de galhas e formas associadas ao grupo taxonômico destes insetos no bioma Cerrado, especialmente na região do Triângulo Mineiro e Alto Paranaíba. Mostraremos a relação do ciclo de vida destes insetos com os padrões fenológicos das plantas hospedeira e exemplos da relação entre insetos galhadores e seus inimigos naturais.

\section{Diversidade de insetos galhadores e morfotipos de galhas}

Acredita-se que existam cerca de 133 mil espécies de insetos galhadores associados a diferentes espécies de plantas e distribuídas em praticamente todos os biomas do planeta. Essa diversidade de insetos galhadores ocorre principalmente dentro das ordens Diptera, Hymenoptera e Hemiptera, com predominância nas famílias Cecidomyiidae e Cynipidae e na superfamília Psylloidea, respectivamente. Na região Neotropical, onde está situado o Brasil, a maioria dos insetos galhadores conhecidos pertencem à família Cecidomyiidae, contudo, espécies pertencentes à 
família Cynipidae, Psyllidae, Eriophydae e Apionidae e à superfamília Gelechioidea também são encontrados com frequência. A relação entre insetos galhadores e plantas hospedeiras é altamente especializada, e muitas vezes espécie-específica, sendo o resultado desta interação, a galha, uma estrutura única e com morfologia peculiar.

O fenótipo das galhas de insetos depende, a princípio, da espécie do galhador e de como cada espécie de galhador é capaz de manipular os tecidos da planta hospedeira para formar estruturas morfológicas únicas. Esta capacidade de manipulação depende do hábito alimentar de cada espécie, interagindo de diferentes maneiras com outros organismos ao redor da galha. Aqui cabe deixar claro a diferença entre tumor e galha. Tumores são estruturas pouco complexas, semelhantes a uma massa de células desorganizadas que, em geral, são induzidas por vírus, bactérias e nematóides. As galhas de insetos são estruturas complexas, com morfologia e forma determinada, simétrica e conservativa. Inclusive, alguns autores consideram galhas apenas como aquelas estruturas induzidas por inseto.

Muitas galhas, induzidas em diferentes espécies de hospedeiras, são coletadas e catalogadas em inventários sem a devida identificação dos galhadores. Isso acontece devido a grande diversidade de insetos galhadores nos neotrópicos e a falta de profissionais especializados no estudo e descrição destas espécies. Assim, uma vez que o fenótipo da galha depende da espécie do inseto indutor, em interação geralmente espécie-específica, é comum usar o fenótipo das galhas como uma maneira de determinar a diversidade de insetos galhadores de uma área. Estes fenótipos são comumente chamados de morfotipos. Em síntese, cada morfotipo de galha em uma mesma espécie de planta hospedeira é considerado uma espécie diferente de inseto galhador.

De fato, o uso de morfotipos como um substituto para determinação da diversidade de galhas em um determinado local é amplamente aceito. Entretanto, inconsistências poderiam ocorrer devido à falta de normatização e padrão para determinar a vasta diversidade morfológica das galhas. Em um trabalho publicado por nosso grupo foi feita uma análise de nove inventários que abordam a diversidade de insetos galhadores na região Neotropical, inclusive no Cerrado. A partir destes inventários foram contadas 806 galhas em 443 espécies de plantas hospedeiras de 74 famílias. Com os resultados obtidos foi proposto um protocolo de coleta para inventários de galhas com as seguintes informações de cada sistema coletado: identificação da planta hospedeira, identificação do galhador no menor nível taxonômico possível, posição da galha no hospedeiro, morfotipo da galha, coloração, presença de indumento, características fenológicas e de desenvolvimento e associação com outros níveis tróficos. Este protocolo de coleta e padrão de morfotipos é usado nas coletas de galhas durante as atividades do nosso grupo (Tabela 1).

Em geral existe uma relação positiva entre a diversidade de plantas e a diversidade de insetos. Sítios com maior diversidade de plantas representam uma maior diversidade de recursos, e acumulam uma maior diversidade de nichos, suportando mais insetos. Entretanto, essa relação não é comum entre os insetos galhadores. Em vez disso, a presença de espécies denominadas "plantas super-hospedeiras" é um dos fatores mais importantes. Estas super-hospedeiras são espécies que hospedam vários morfotipos de galhas, até dentro de um mesmo indivíduo e período. No Cerrado, tanto em ambientes florestais como de savana, existem super-hospedeiras. Espécies como 
Copaifera langsdorffii e Protium heptaphyllum são árvores bem frequentes no bioma e abrigam ao menos 10 morfotipos de galhas cada. Além delas, plantas das famílias Asteraceae, Burseraceae, Fabaceae e Melastomataceae também possuem espécies super-hospedeiras de galhas.

\section{Principais morfotipos de galhas da região do Triângulo Mineiro}

Apesar das hipóteses sobre a diversificação dos insetos galhadores, pouco ainda se sabe sobre os fatores que determinam a forma das galhas. As galhas podem variar desde câmaras abertas até completamente fechadas, de galhas gigantes com centenas de galhadores até galhas lenticulares nas folhas, formando estruturas quase invisíveis. Na região do Cerrado são encontrados os morfotipos de galhas globulares, cônicas, clavadas, lenticulares, cilíndricas, bivalves, fusiformes, rosetas, enroladas, amorfas, galhas de chifres e em formato de feijão (Figura 1, Tabela 1). Toda essa diversidade de formas parece, até o momento, estar exclusivamente ligada à espécie do inseto galhador. Apesar de não ter sido encontrado um padrão, a abundância de morfotipos está distribuída de forma desigual, o que indica a presença de direcionadores. O morfotipo mais comum são as galhas globulares, seguidas de galhas lenticulares e fusiformes. Os morfotipos mais raros são os em formato de feijão e clavadas. Devido à grande lacuna na identificação da espécie do inseto os levantamentos são feitos principalmente usando esses morfotipos como separadores de espécies, assim como exemplificado acima. Isso dificulta uma estimativa precisa sobre a abundância de cada grupo, podendo haver uma subestimação ou superestimação dos números. Apesar disso, nas coletas feitas na região de estudos do PELD TMSG foram encontrados 67 morfotipos de galhas em hospedeiros arbóreos. Este número representa $9 \%$ dos morfotipos de galhas atualmente conhecidos para o Brasil. Dos insetos galhadores encontrados, 38 formam galhas globulares $(57 \%), 12$ lenticulares $(18 \%), 6$ cônicas $(10 \%)$, e as demais galhas amorfas, cilíndricas ou fusiformes. Dos três morfotipos fusiformes encontrados, todos foram em caule, uma tendência apresentada por esses morfotipos. O outro morfotipo comum de encontrar em caule é o globular, e aqui tivemos cinco galhas globulares (13\% das globulares) em caule. Dos 67 morfotipos coletados, 16 são Diptera, todos da família Cecidomyiidae; cinco Hemiptera, sendo quatro Psyllidae e um Eriococcidae; e um Lepidoptera da família Agonoxenidae. O órgão mais atacado foi a folha (com 53 morfotipos encontrados), seguido do caule (com sete morfotipos) e a gema foliar (com quatro) (Tabela 1).

Um raro exemplo descrito a partir de amostras coletadas no Triângulo Mineiro é o do psilídio galhador, Pseudophacopteron longicaudatum (Hemiptera), que é capaz de induzir galhas em duas espécies de hospedeiras do mesmo gênero (Aspidosperma macrocarpon e $A$. tomentosum) e que são simpátricas (isto é, ocorrem na mesma região). O fenótipo das galhas induzidas nestas espécies de Aspidosperma é muito similar, sendo globular intralaminar nas duas hospedeiras. Há, no entanto, diferenças no tamanho, sendo as galhas induzidas em $A$. tomentosum maiores do que aquelas induzidas em $A$. macrocarpon. Posteriormente, o mesmo padrão de diferença em tamanho foi observado por uma espécie de afídeo, Tetraneura yezoensis, capaz de formar galhas em Ulmus davidiana e Ulmus iaciniata no Japão, e pode indicar que este é um efeito comum na especiação por troca de hospedeiros na comunidade de insetos galhadores. 

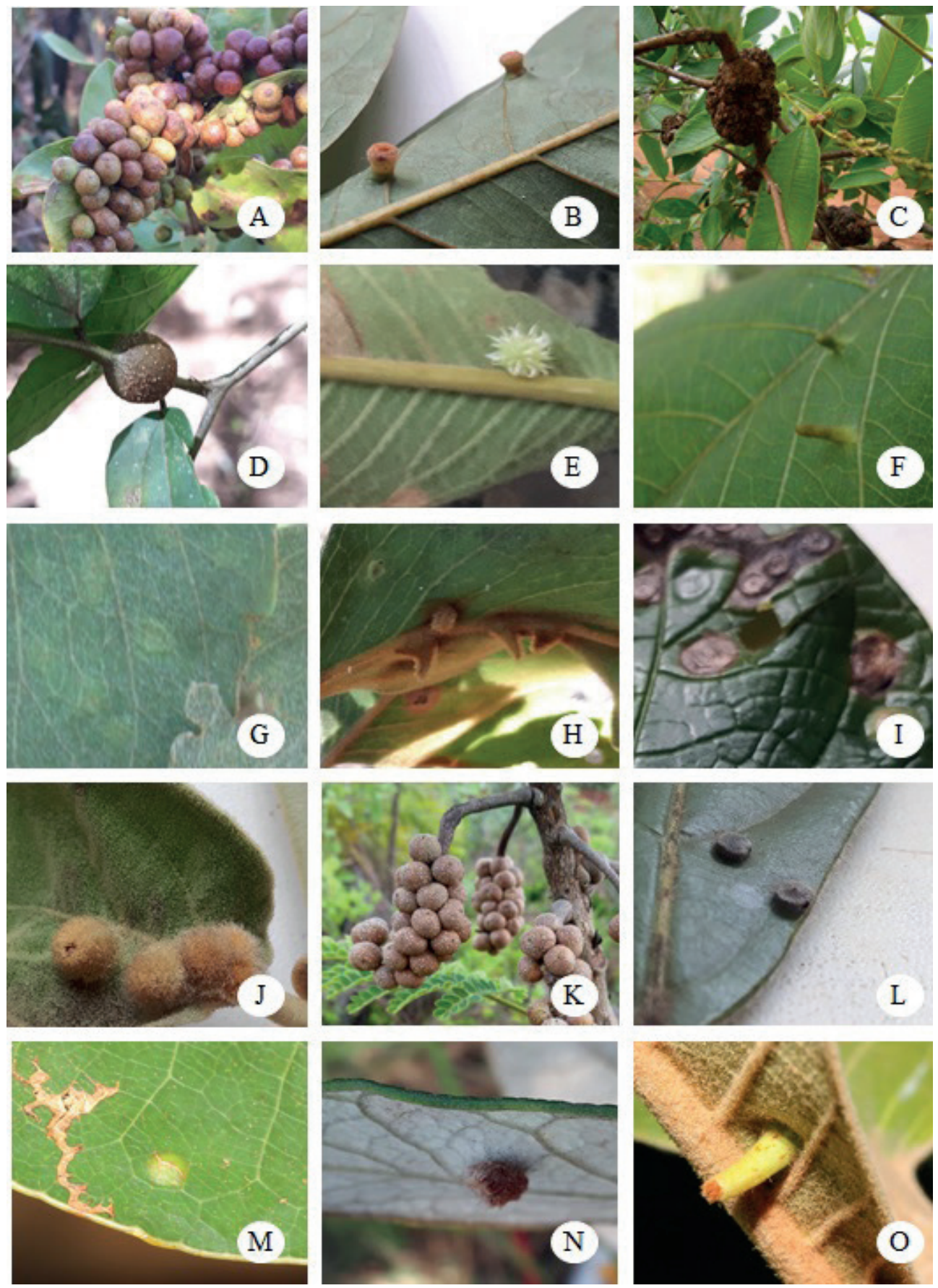

Figura 1. Morfotipos de galhas do Cerrado na região do Triangulo Mineiro e Sudeste de Goiás. $+=$ Galhas de folha; - = Galha de caule; * = Galha de Gema; \# = Galha de Flor; $\sim=$ Galha de Fruto; A) Psidium laruotteanum (Globular +); B) Matayba guianensis (Cilíndrica +); C) Qualea grandiflora (Amorfa -); D) Celtis iguanaea (Globular -); E) Qualea multiflora (Globular +); F) Pseudobombax longiflorum (Globular +); G) Roupala montana (Lenticular + ); H) Roupala montana (Conica +); I) Rudgea viburnoides (Lenticular +); J) Solanum lycocarpum (Globular +); K) Stryphnodendron adstringens (Globular \#); L) Terminalia glabrescens (Lenticular +); M) Vatairea macrocarpa (Globular +); N) Byrsonima afinis (Globular +); O) Pouteria ramiflora $($ Conica +$)$. 
Tabela 1. Espécies de plantas hospedeiras e os morfotipos de galhas amostrados na área de abrangência do PELD Triangulo Mineiro e Sudeste de Goiás.

\begin{tabular}{|c|c|c|c|c|c|}
\hline Planta hospedeira & $\begin{array}{l}\text { Ordem do } \\
\text { inseto }\end{array}$ & $\begin{array}{l}\text { Família do } \\
\text { inseto }\end{array}$ & Espécie do inseto & $\begin{array}{l}\begin{array}{l}\text { Órgão } \\
\text { atacado }\end{array} \\
\end{array}$ & Morfotipo \\
\hline Andira vermifuga & & & & Folha & Globular \\
\hline Andira vermifuga & & & & Folha & Amorfa \\
\hline Andira vermifuga & Díptera & Cecidomyiidae & & Folha & Lenticular \\
\hline $\begin{array}{l}\text { Aspidosperma } \\
\text { macrocarpon }\end{array}$ & Hemíptera & Psyllidae & & Folha & Globular \\
\hline $\begin{array}{l}\text { Aspidosperma } \\
\text { subincanum }\end{array}$ & & & & Folha & Cilíndrica \\
\hline $\begin{array}{l}\text { Aspidosperma } \\
\text { tomentosum }\end{array}$ & Hemíptera & Psyllidae & & Folha & Globular \\
\hline Astronium fraxinifolium & Hemíptera & Psyllidae & & Folha & Amorfa \\
\hline Bauhinia sp. & & & & Folha & Amorfa \\
\hline Byrsonima afinis & & & & Folha & Globular \\
\hline Caryocar brasiliense & & & & Folha & Lenticular \\
\hline Caryocar brasiliense & Díptera & Cecidomyiidae & & Folha & Globular \\
\hline Connarus suberosus & Díptera & Cecidomyiidae & & Folha & Globular \\
\hline Connarus suberosus & Díptera & Cecidomyiidae & & Gema & Amorfa \\
\hline Copaifera langsdorffii & & & & Folha & Cônica \\
\hline Dalbergia miscolobium & Díptera & Cecidomyiidae & & Folha & Globular \\
\hline Dimorphandra mollis & & & & Folha & Globular \\
\hline Duguetia furfuracea & & & & Folha & Globular \\
\hline $\begin{array}{l}\text { Eremanthus } \\
\text { glomerulatus }\end{array}$ & & & & Folha & Cônica \\
\hline $\begin{array}{l}\text { Eremanthus } \\
\text { glomerulatus }\end{array}$ & & & & Caule & Globular \\
\hline Eriotheca pubescens & Díptera & Cecidomyiidae & & Folha & Globular \\
\hline $\begin{array}{l}\text { Erythroxylum } \\
\text { suberosum }\end{array}$ & Díptera & Cecidomyiidae & $\begin{array}{l}\text { Myrciariamyia } \\
\text { admirabilis }\end{array}$ & Folha & Globular \\
\hline Erythroxylum tortuosum & & & & Folha & Globular \\
\hline Guapira noxia & & & & Gema & Globular \\
\hline Guapira graciliftora & & & & Folha & Lenticular \\
\hline Guazuma ulmifolia & & & & Folha & Globular \\
\hline Hymenaea courbaril & & & & Folha & Cônica \\
\hline Inga laurina & & & & Folha & Globular \\
\hline Inga laurina & & & & Caule & Fusiforme \\
\hline Inga laurina & & & & Flor & Globular \\
\hline Kielmeyera coriacea & & & & Folha & Globular \\
\hline Kielmeyera grandiflora & & & & Folha & Globular \\
\hline $\begin{array}{l}\text { Leptolobium } \\
\text { dasycarpum }\end{array}$ & Díptera & Cecidomyiidae & & Folha & Lenticular \\
\hline
\end{tabular}


Luehea grandiflora

Macairea radula

Matayba guianensis

Matayba guianensis

Miconia albicans

Miconia chamissois

Myrcia variabilis

Myrsine umbellata

Naucleopsis sp.

Neea theifera

Ouratea spectabilis

Piptocarpha

rotundifolia

Pouteria ramiflora

Protium heptaphyllum

Protium heptaphyllum

Protium heptaphyllum

Protium heptaphyllum

Pseudobombax

longiflorum

Psidium laruotteanum

Psidium myrsinites

Qualea grandiflora

Qualea grandiflora

Qualea multiflora

Qualea multiflora

Qualea parviflora

Roupala montana

Roupala montana

Rudgea viburnoides

Siparuna guianensis

Solanum lycocarpum

Stryphnodendron adstringens

Styrax ferrugineus

Terminalia glabrescens

Vatairea macrocarpa

Celtis iguanaea
Feixe

Vascular

Fusiforme

Lepidoptera

Agonoxenidae

Palaeomystella

Díptera Cecidomyiidae

oligophaga

Gema

Globular

Hemíptera

Eriococcidae

Lopesia Mataybae

Folha

Globular

Bystracoccus mataybae

Folha

Cilíndrica

Caule Globular

Fruto Globular

Gema Globular

Folha Globular

Diptera Cecidomyiidae

Folha

Globular

Folha Lenticular

Díptera Cecidomyiidae

Folha

Lenticular

Díptera Cecidomyiidae

Caule

Folha Cônica

Folha Globular

Folha Cônica

Folha Cilíndrica

Caule Globular

Folha Cônica

Hemíptera

Psyllidae

Neotrioza sp.

Folha

Globular

Folha Globular

Folha Globular

Caule Globular

Díptera Cecidomyiidae

Folha Globular

Folha Globular

Díptera Cecidomyiidae

Díptera Cecidomyiidae

Folha

Globular

Folha Lenticular

Folha Cônica

Folha Lenticular

Folha Lenticular

Folha Globular

Flor Globular

Díptera Cecidomyiidae

Folha Lenticular

Folha Lenticular

Folha Lenticular

Caule Globular 


\section{Relação com a fenologia da planta hospedeira}

Insetos galhadores tendem a sincronizar seu ciclo de vida com as fases fenológicas da planta hospedeira, em busca de melhores condições morfológicas e fisiológicas para a indução das galhas e sobrevivência de sua prole. Os picos de brotação foliar no início da estação chuvosa disponibilizam sítios ativos para indução de galhas destes insetos. Este ajuste fenológico entre a espécie hospedeira e o ciclo de vida do inseto galhador determinam, de certa forma, a quantidade de ciclos anuais de indução de galhas e do organismo galhador. O PELD Triângulo Mineiro e Sudeste de Goiás está inserido dento do Cerrado, um dos biomas mais importantes da região Neotropical. Este bioma contém a maior diversidade de galhas do Brasil, e apresenta uma sazonalidade hídrica marcante, com invernos secos e verões chuvosos o que implica em uma vegetação arbórea de semidecídua a decídua. Como exemplo, nosso grupo de pesquisa mostrou o efeito da sazonalidade no ajuste fenológico entre hospedeiro e insetos galhadores. A hospedeira Matayba guianensis (Sapindacae), um típico arbusto encontrado em áreas de cerrado sensu stricto, apresenta galhas induzidas por Bystracoccus mataybae (Eriococcidae). Nesse sistema galhador-planta hospedeira, as ninfas de segundo instar induzem galhas em folhas jovens, durante o período de brotação foliar. As galhas se desenvolvem durante a maturação da folha da hospedeira e a fêmea adulta engravida por partenogênese. No final da estação seca, antes da queda das folhas, a fêmea adulta do inseto galhador libera as ninfas de primeiro instar, que caminham em direção ao caule. No caule, as ninfas de primeiro instar induzem galhas rudimentares e mudam para o segundo instar quando um novo ciclo de brotação foliar se inicia, começando assim um novo ciclo de indução de galhas (Figura 2). Este exemplo deixa claro o ajuste do ciclo do galhador com a fenologia da planta hospedeira. Desta forma, qualquer alteração climática que leve a mudanças fenológicas na hospedeira pode alterar o ciclo de vida ou até extinguir o inseto galhador. 


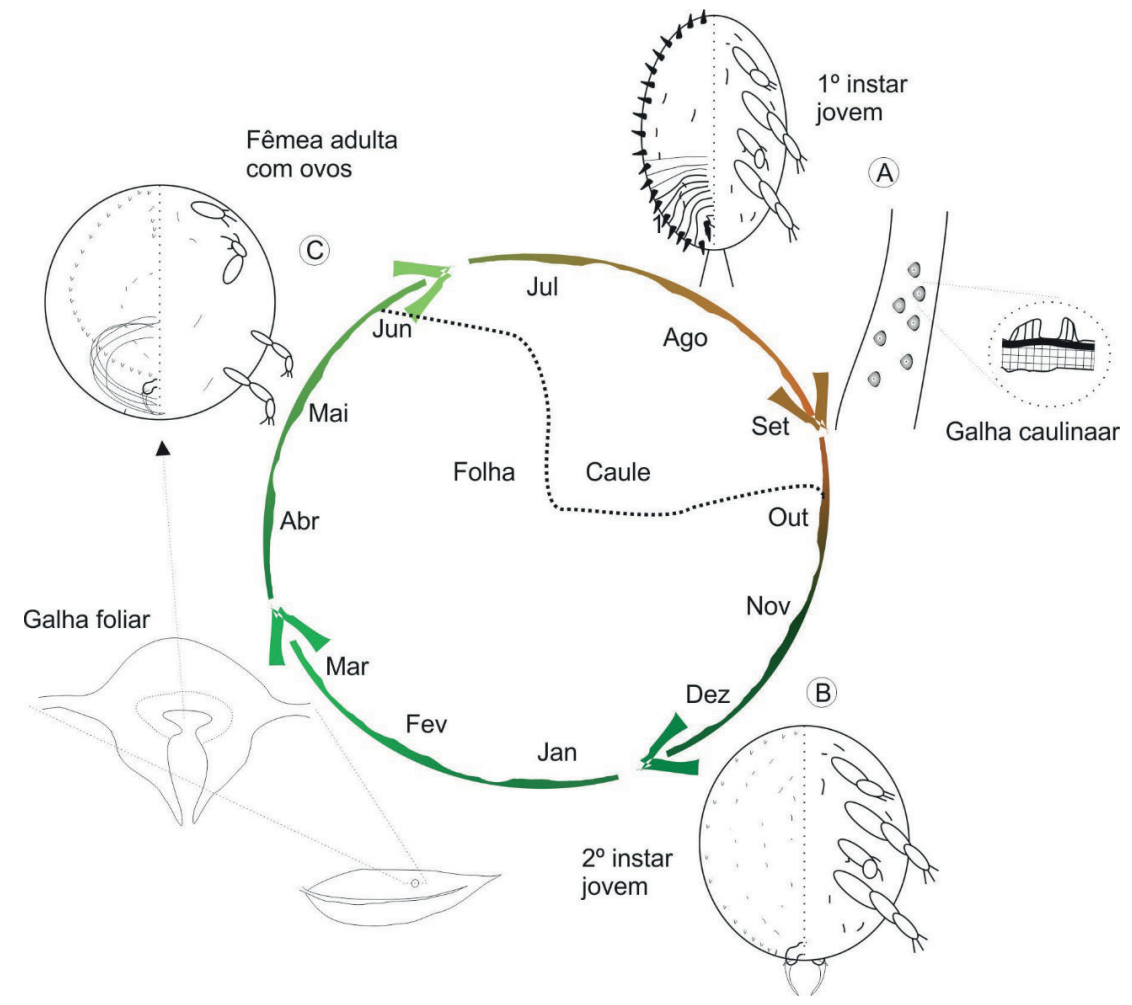

Figura 2. Ciclo de vida do inseto hemíptero galhador Bystracoccus mataybae (Eriococcidae) na planta hospedeira Matayba guianensis (Sapindaceae). A) Galhas caulinares são feitas por ninfas de primeiro instar na estação seca. B) Ninfa de segundo instar eclodem no começo da estação das chuvas e caminham até as folhas. C) A fêmea adulta engravida por partenogênese e explode, liberando as novas ninfas de primeiro instar no começo da seca.

\section{Relação do galhador com inimigos naturais}

Durante o desenvolvimento dentro da galha, o inseto galhador é séssil, e fica vulnerável ao predador que conseguir detectar e ultrapassar todas as barreiras impostas pela galha. Vespas parasitoides são predadores que se aproveitam das larvas dos insetos galhadores e que são comuns na vegetação do Cerrado. Os parasitoides inserem seu aparelho ovipositor na galha e colocam seus ovos dentro da câmara larval ou dentro do próprio galhador. As larvas destes parasitoides se alimentam do inseto galhador causando sua morte e, em seguida, se tornam uma pupa dentro da galha. Um bom exemplo é a galha induzida por Palaeomystela oligophaga (Lepidoptera) em Macairea radula (Melastomatacae), uma planta arbustiva do Cerrado (Figura 3). Neste sistema, o inseto galhador, $P$. oligophaga, é atacado por diferentes espécies de inimigos naturais que se alimentam tanto do tecido da galha quanto do inseto galhador. E, apesar da morte do inseto galhador após o ataque, as galhas muitas vezes se mantem vivas e ficam senescentes após a saída do parasitoide. Esse parasitoide que ataca o galhador, em alguns casos, pode até continuar alterando a composição dos tecidos da galha, assumindo a manutenção da estrutura da galha. Outros inimigos naturais, como os cecidófagos, são frequentemente encontrados em galhas induzidas por insetos. Os cecidófagos são insetos que consomem os tecidos da galha e assim podem matar o 
galhador por inanição. No caso das galhas induzidas pelo P. oligophaga em M. radula os cecidófagos são a maior causa da mortalidade do inseto galhador.

Após a saída do galhador ou de seus inimigos naturais, aquelas galhas que porventura ficam fixadas à planta hospedeira podem servir de refúgio e local de caça para outros organismos, como aranhas, besouros e formigas. Essa característica de engenheiro de ecossistema foi até o momento pouco explorada e se configura como um caminho para o estudo de galhas e seu impacto na comunidade de artrópodes ao redor. Por exemplo, há indícios de que plantas com galhas senescentes que abrigam aranhas apresentam menor quantidade de herbívoros que as plantas vizinhas sem essas galhas.

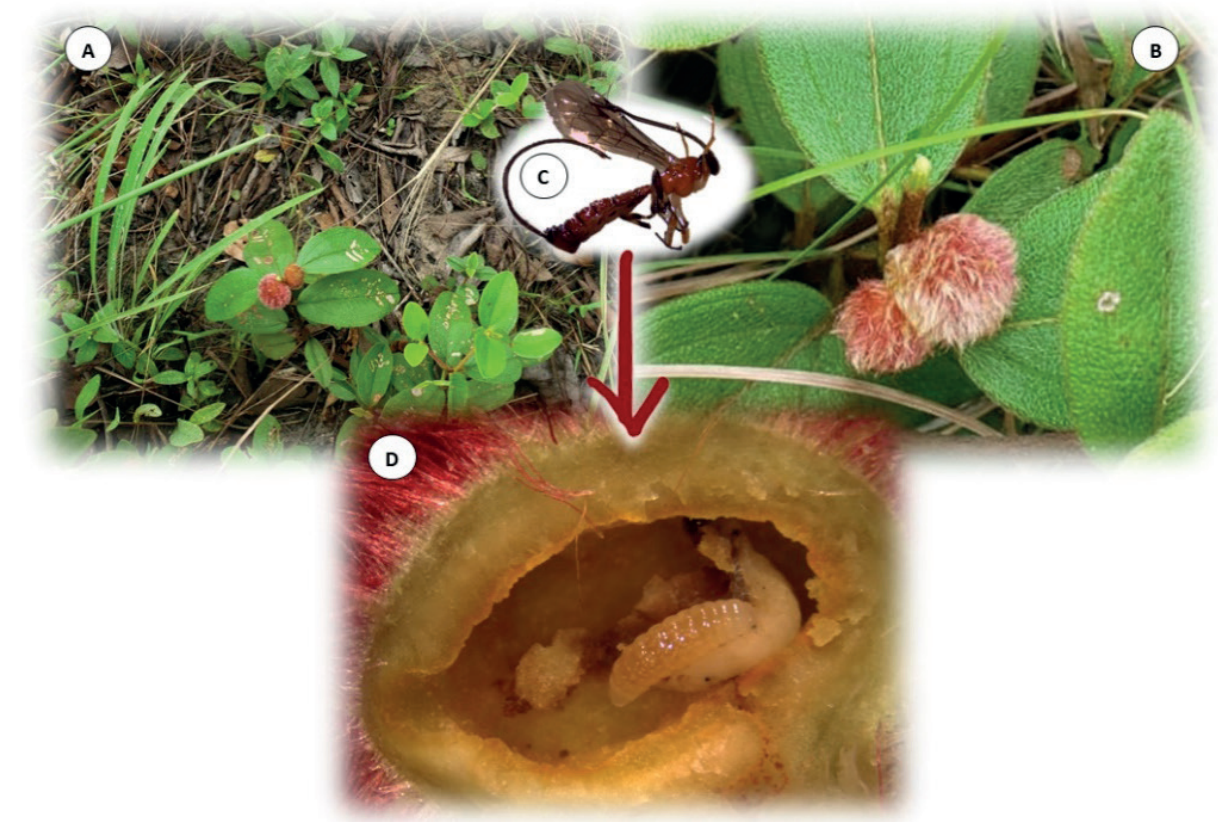

Figura 3. (A) Macairea radula (Melastomataceae) com galhas globóides (B) induzidas por Pallaeomystella oligophaga (Lepidoptera) em gemas reprodutivas. C). Parasitoide adulto fêmea do gênero Calliephialtes sp., inimigo natural do inseto galhador. D). Parasitoide Calliephialtes sp. em estágio larval se alimentando do inseto galhador.

\section{Considerações finais}

Os insetos galhadores são um dos herbívoros mais especializados, capazes de alterar as células e tecidos de um organismo hospedeiro em benefício próprio, como um verdadeiro engenheiro de ecossistemas. No Cerrado, estes insetos são capazes de induzir diferentes galhas, com morfologia extremamente peculiar e específica. Assim, por apresentar morfologia específica e conservativa, galhas podem ser usadas como um substituto (ou proxy) para se estimar de forma rápida e precisa a diversidade de insetos galhadores em uma determinada área. Ainda, o estudo da diversidade de galhas, assim como do ciclo de vida dos seus galhadores e hospedeiros, podem ser considerados bons termômetros para avaliação do impacto antrópico e das mudanças climáticas no Cerrado. Isto porque qualquer impacto na distribuição, morfologia, fisiologia e fenologia das plantas hospedeiras podem afetar negativamente a formação das galhas e a diversidade dos insetos galhadores e seus inimigos naturais. 


\section{Para saber mais}

Isaias RMS, Carneiro RGS, Oliveira DC, Santos JC (2013) Illustrated and annotated checklist of braziliam gall morphotypes. Neotrop Entomol 42: 230-239 doi: 10.1007/ s13744

Fernandes GW, Santos JC (2014) Neotropical Insect Galls. New York: Springer.

Oliveira DC, Isaias RMS, Fernandes GW, Ferreira BG, Carneiro RGS, Fuzaro L (2016) Manipulation of host plant cells and tissues by gall-inducing insects and adaptive strategies used by different feeding guilds. J Insect Physiol 84: 103-113 doi: 10.1016/j. jinsphys.2015.11.012

Pfeffer L, Rezende UC, Barônio GJ, Oliveira DC (2018) Building two houses on a single host plant: galling insect synchronizes its life cycle with plant phenology. Oecologia Australis 22: 438-448.

Malenovský I, Burckhardt D, Queiroz DL, Isaias RMS, Oliveira DC (2015) Descriptions of two new Pseudophacopteron species (Hemiptera: Psylloidea: Phacopteronidae) inducing galls on Aspidosperma (Apocynaceae) in Brazil. Acta entomologica Musei Nationalis Pragae 55: 523-538.

Rezende U, Cardoso JC, Kuster VC, Gonçalves LA, Oliveira DC (2018). How the activity of natural enemies changes the structure and metabolismo of the nutritive tissue in galls? Evidence from the Palaeomystella oligophaga (Lepidoptera) - Macairea radula (Melastomataceae). Protoplasma 256: 669-677 doi: 10.1007/s00709-018-1321-2

Harris MO, Pitzschke A (2019) Plants make galls to accomodate foreigners: some are friends, most are foes. New Phytol 225: 1852-1872 doi: 10.1111/nph.16340 


\section{PARTE 2}

\section{ADAPTAÇÕES E PROCESSOS ECOLÓGICOS}

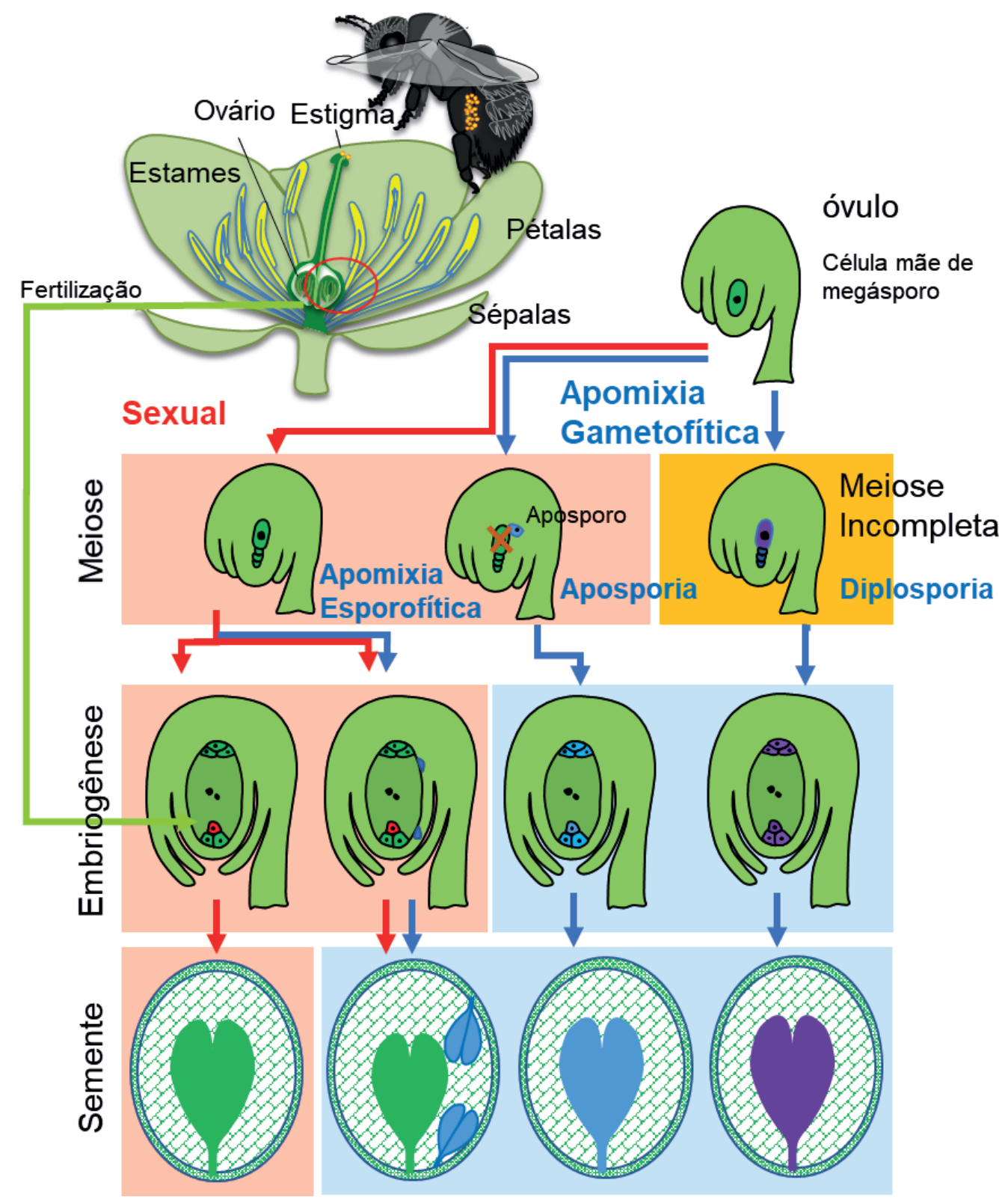





\title{
CAPÍTULO 13
}

\section{ECOLOGIA E COMPORTAMENTO DE ARANHAS}

\author{
Marcelo O. Gonzaga \\ Adilson Quero \\ Rafael R. Moura \\ Aline L. Nascimento \\ Felipe A. Meira \\ Renan B. Pitilin \\ Gabriel M. Xavier
}

Até o momento, existem 48.913 espécies de aranhas descritas, distribuídas em 4.188 gêneros e 128 famílias. Este número, no entanto, certamente representa apenas uma pequena parte da totalidade das espécies existentes. Só entre 2010 e 2018 foram descritas 7.524 novas espécies de aranhas e a taxa de descrições continua crescendo. As aranhas estão distribuídas em todos os ambientes terrestres e em todos os continentes (exceto a Antártida), apresentando uma maior diversidade em regiões tropicais. Embora a comparação não seja simples, devido às diferenças no esforço amostral já realizado e nos métodos utilizados, os dados referentes aos poucos grupos e locais intensivamente estudados sugerem que biomas brasileiros, como a Mata Atlântica, estão entre os de maior riqueza de espécies no mundo. Infelizmente, no entanto, vastas extensões do nosso território são subamostradas e a intensificação dos estudos em áreas de Cerrado no Brasil central, por exemplo, ainda tem muito a contribuir para a expansão do conhecimento sobre o grupo.

Para que se possa ter uma ideia do estado atual do conhecimento sobre a riqueza e esforço de coleta já realizado nos biomas brasileiros, pesquisadores da Universidade Federal de Minas Gerais e Instituto Butantan analisaram dados publicados entre 1757 e 2009 em 725 artigos sobre taxonomia e inventários de aranhas realizados em território nacional. Os resultados de todo esse trabalho permitiram a geração de mapas detalhados que atestam a escassez de informações na quase totalidade do país. A maior parte do país não foi amostrada (não há um registro sequer) e mesmo nas regiões Sul e Sudeste, certamente as mais amostradas, houve um esforço de coleta muito pequeno. O Cerrado está entre os biomas com pior amostragem e, consequentemente, aparenta ter uma riqueza limitada, muito longe do que efetivamente estamos encontrando conforme as pesquisas se intensificam nesse bioma (Figura 1). 

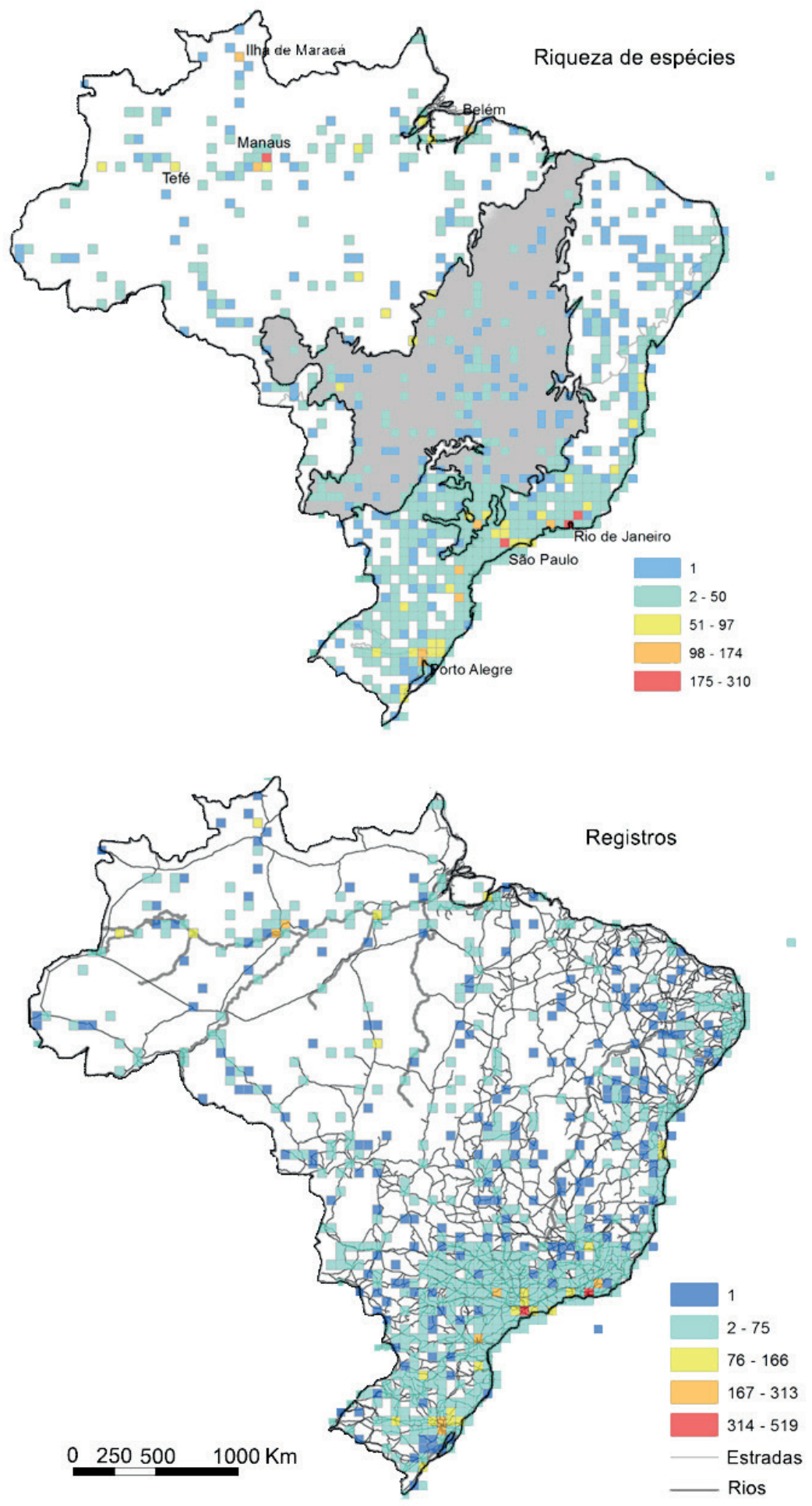

Figura 1. Mapas de riqueza e número de registros de aranhas com células de grid de $0.5^{\circ}$. As cores indicam o número de registros e espécies em cada uma dessas células. A área em cinza no primeiro mapa indica o bioma Cerrado. Modificado de Oliveira et al. (2017). 
Embora estudos como esses, envolvendo análises de diversidade e biogeografia, sejam essenciais para conservação e para que possamos entender melhor os padrões de distribuição espacial de um determinado grupo taxonômico, estudos sobre ecologia comportamental mostram-se igualmente importantes. Essa linha de pesquisa pode revelar aspectos da biologia das espécies que as tornam mais ou menos susceptíveis a impactos ambientais, a flutuações populacionais, dispersão e muito sobre suas interações com outros organismos. Estudos sobre forrageamento, por exemplo, foram essenciais para estimar o impacto que as aranhas podem ter no consumo anual de insetos no mundo. O impressionante número estimado (entre 395-805 milhões de toneladas de presas por ano) atesta a grande importância ecológica do grupo e motiva novos estudos, especialmente em áreas onde ainda existem as maiores lacunas de conhecimento.

Neste capítulo serão abordados alguns estudos que vêm sendo desenvolvidos pela equipe do Laboratório de Aracnologia da Universidade Federal de Uberlândia em áreas com remanescentes de Cerrado no Triângulo Mineiro e, principalmente, na área de silvicultura da Fazenda Nova Monte Carmelo, de propriedade da Empresa LD Celulose, situada em Estrela do Sul, MG. Esses estudos envolvem estratégias utilizadas pelas aranhas como forma de minimizar riscos de predação e parasitismo, forrageamento e seleção de presas, socialidade, interações com vespas parasitoides, seleção sexual e cuidado parental. Alguns desses estudos envolvem o acompanhamento de populações por vários anos, com a realização de sequências de experimentos que só foram possíveis dentro de um projeto de longa duração, como o PELD. Para cada uma das linhas de pesquisa listadas abaixo será apresentada uma introdução ao tema e um breve panorama geral dos principais resultados que obtivemos durante o período do projeto.

\section{Cuidado paternal}

O cuidado parental é essencial para a sobrevivência da prole de muitas espécies de animais. Esse cuidado, que é definido como qualquer comportamento realizado pelos pais que aumente a sobrevivência de seus filhotes, pode envolver a proteção contra predadores e parasitas, contra condições ambientais adversas e o fornecimento de alimentos durante um período que varia desde poucos momentos após a eclosão ou nascimento até boa parte da vida. É claro que expor-se ao ataque de predadores que estão interessados em consumir seus filhotes ou gastar tempo e energia no fornecimento de recursos para a prole implica em um custo para os pais. O custo, nesse caso, pode ser traduzido como um comprometimento de reproduções futuras, o que reduz o número de filhotes total produzido pelos indivíduos ao longo de suas vidas. Trata-se, portanto, de uma estratégia arriscada.

Se há custos, no entanto, deve haver também benefícios que os superem em determinadas condições, caso contrário esses comportamentos não seriam mantidos ao longo de sucessivas gerações. Isso significa que o possível comprometimento de uma futura reprodução pode ser compensado pelo maior número de filhotes que sobrevive como reflexo direto do cuidado. Como isso frequentemente ocorre, essa estratégia tornou-se muito comum na natureza, podendo apresentar algumas variações importantes. O cuidado, por exemplo, pode ser bi ou uniparental e, neste último 
caso, tanto os machos quanto as fêmeas podem ser exclusivamente responsáveis pela proteção ou alimentação dos filhotes. Além disso, em algumas espécies, a desistência ou redução dos cuidados parentais por parte de um dos pais pode induzir o aumento das atividades de cuidado pelo outro. Essas variações nas características do cuidado parental são moduladas por fatores como a intensidade da pressão de predação sobre a prole, a capacidade de cada sexo em fornecer proteção efetiva e comida à prole, $\mathrm{o}$ tamanho da ninhada e também pelas possíveis vantagens na adoção de uma estratégia alternativa, como procurar outros parceiro(a)s para acasalamento, propiciando eventos reprodutivos adicionais.

Como os machos geralmente apresentam potencial para fertilizar várias fêmeas durante uma determinada estação reprodutiva, tradicionalmente consideravase que a estratégia mais vantajosa em termos de número de filhotes produzidos seria abandonar as fêmeas logo após a cópula e procurar novas parceiras. Com isso, os machos assegurariam a paternidade de um grande número de filhotes. Em alguns casos, no entanto, a permanência dos machos junto às fêmeas durante o período de desenvolvimento dos embriões e durante o período em que sua prole estará mais vulnerável aos agentes de mortalidade pode ser essencial. Além disso, não são raros os casos em que oportunidades de novas cópulas são muito limitadas devido a fatores como competição com outros machos e baixa disponibilidade (ou grande dispersão) das fêmeas receptivas no ambiente. Essas duas condições, baixa espectativa de conseguir novas parceiras e importância do cuidado dos pais para a sobrevivência dos filhotes, constituem, então, fatores muito importantes para que os pais permaneçam junto à prole oferecendo comida e/ou proteção.

Em aranhas, o cuidado uniparental maternal é comum. As fêmeas constróem envoltórios de seda para proteger seus ovos de condições adversas de umidade e temperatura, podem protegê-los ativamente contra predadores e parasitoides, fornecer alimento para os filhotes durante um período que pode estender-se por vários estágios de desenvolvimento e, em casos extremos, podem oferecer seus próprios corpos como recursos a serem consumidos pela prole (o que é chamado de matrifagia). Já os machos, na grande maioria dos casos, não chegam a presenciar o nascimento dos filhotes, morrendo ou partindo em busca de novas parceiras logo após a cópula. Isso pode acontecer por vários motivos usualmente complementares: 1) pode haver baixa certeza de paternidade. Como as fêmeas podem copular com mais de um macho, se um determinado macho utilizar a estratégia de copular com apenas uma fêmea e cuidar dos filhotes que emergirem da ooteca depositada por ela, poderia estar dedicando um grande investimento na prole de outro macho e não em sua própria; 2) Os machos frequentemente são menores que as fêmeas. Essa diferença de tamanho pode determinar uma baixa eficiência relativa dos machos na defesa da prole e baixa capacidade de prover recursos aos filhotes; e 3) Machos frequentemente vivem menos que as fêmeas. A baixa longevidade reduz o tempo disponível para o investimento em cuidado. Além disso, pode haver um risco de predação muito grande no deslocamento entre teias de fêmeas durante o período reprodutivo. Isso tornaria a estratégia alternativa, de tentar copular com várias parceiras, uma opção que poderia facilmente resultar em uma morte precoce.

$\mathrm{Na}$ aranha Manogea porracea algumas dessas condições, que possivelmente constituem restrições ao estabelecimento do cuidado paterno em outras espécies de aranhas, estão ausentes. Observamos, por exemplo, que os machos constroem suas teias 
utilizando as teias das fêmeas como suporte e que continuam capturando presas durante todo o período reprodutivo. As fêmeas só aceitam copular com machos que construíram essa teia, o que pode conferir ao macho dominante uma posição de relativa confiança de que será o pai dos filhotes. Além disso, o número de fêmeas em teias contendo sacos de ovos torna-se gradualmente pequeno ao longo do período reprodutivo, mas o número de machos permanece relativamente estável. Essa diminuição faz com que oportunidades adicionais de cópulas com outras fêmeas sejam cada vez mais raras com o passar do tempo. Assim, muitos machos permanecem na teia de fêmeas que copularam com eles mesmo quando ficam sozinhos com as ootecas. Nessa condição passam a defender as ootecas e filhotes recém eclodidos contra o ataque de aranhas cleptoparasitas e araneofágicas e realizam atividades de reparo na estrutura da teia. Essas ações podem contribuir muito para a sobrevivência dos filhotes.

Em um dos trabalhos que realizamos para determinar a importância do cuidado paternal para os filhotes, mantivemos em campo teias com machos e fêmeas, teias apenas com fêmeas, teias apenas com machos e teias em que as ootecas permaneceram sem nenhuma proteção parental. Os resultados mostraram um número de filhotes relativamente alto e similar nos três grupos cujas ootecas permaneceram sob cuidado. Já o grupo sem cuidado teve um número de filhotes bem menor. Esses resultados motivaram a realização de um experimento, desta vez em laboratório, para testar a eficácia dos machos em reduzir o ataque às ootecas por duas espécies de aranhas que frequentemente invadem suas teias: Faiditus caudatus e Argyrodes elevatus, ambas da família Theridiidae. Nesse experimento estabelecemos cinco grupos: 1) ooteca e macho presente, sem predador; 2) ooteca e $A$. elevatus; 3 ) ooteca, A. elevatus e macho de $M$. porracea; 4) ooteca e $F$. caudatus; 5) ooteca, $F$. caudatus e macho de $M$. porracea. Observamos que os machos foram muito bem sucedidos em evitar a ação predatória das duas espécies de aranhas invasoras sobre a prole (Quadro 1).

Após esses resultados iniciais o sistema passou a ser sistematicamente e continuamente estudado, buscando entender outros aspectos comportamentais importantes da espécie, como a ocorrência em várias populações de pareamento entre machos e fêmeas dependente do tamanho dos indivíduos ("size assortative mating") e a influência do tamanho corporal dos machos em sua propensão a cuidar dos filhotes (veja refererências sobre esses estudos no final do capítulo).

\section{Influência da escolha de parceiras e competição intrassexual no estabelecimento de pareamentos assortativos em Manogea porracea (Araneidae)}

Na maioria das aranhas da família Araneidae, as fêmeas constroem suas teias e permanecem lá, à espera de parceiros, durante toda a estação reprodutiva. Durante esse período elas podem produzir feromônios, que são depositados na teia e dispersos pelo ar, indicando que estão disponíveis para o cortejo e cópula. Os machos, por sua vez, começam a buscar ativamente por parceiras logo que se tornam adultos, visitando algumas teias até escolherem fêmeas receptivas para cortejarem, copularem e a protegerem contra outros pretendentes. Na aranha Manogea porracea, os machos maturam sexualmente antes das fêmeas e já selecionam pretendentes subadultas, que ainda não são capazes de copular. Esse fenômeno é chamado de protandria e assegura que o macho consiga copular com uma parceira virgem tão logo ela complete 
sua maturação. Como as fêmeas ficam na teia esperando seus possíveis parceiros, a formação dos casais é fortemente afetada pelas escolhas feitas por esses últimos. Ao selecionarem suas parceiras, os machos constroem suas teias em uma posição que lhes permita rápido acesso às fêmeas e na qual possam monopolizar as possibilidades de cópula. Esse comportamento é raro no grupo, tendo sido anteriormente descrito apenas para algumas espécies do clado Cyrtophorinae. A permanência do macho na teia da fêmea por um longo período para assegurar a paternidade e a existência de cuidado paternal, como descrito no tópico anterior, permitem aos machos uma alta exigência durante a escolha de parceiras. Deve também estimular uma competição intensa pelas parceiras mais atraentes (as maiores e, consequentemente, mais férteis). Portanto, a escolha de parceiras pelos machos e a intensa competição intrassexual podem afetar a formação de casais nessa espécie.

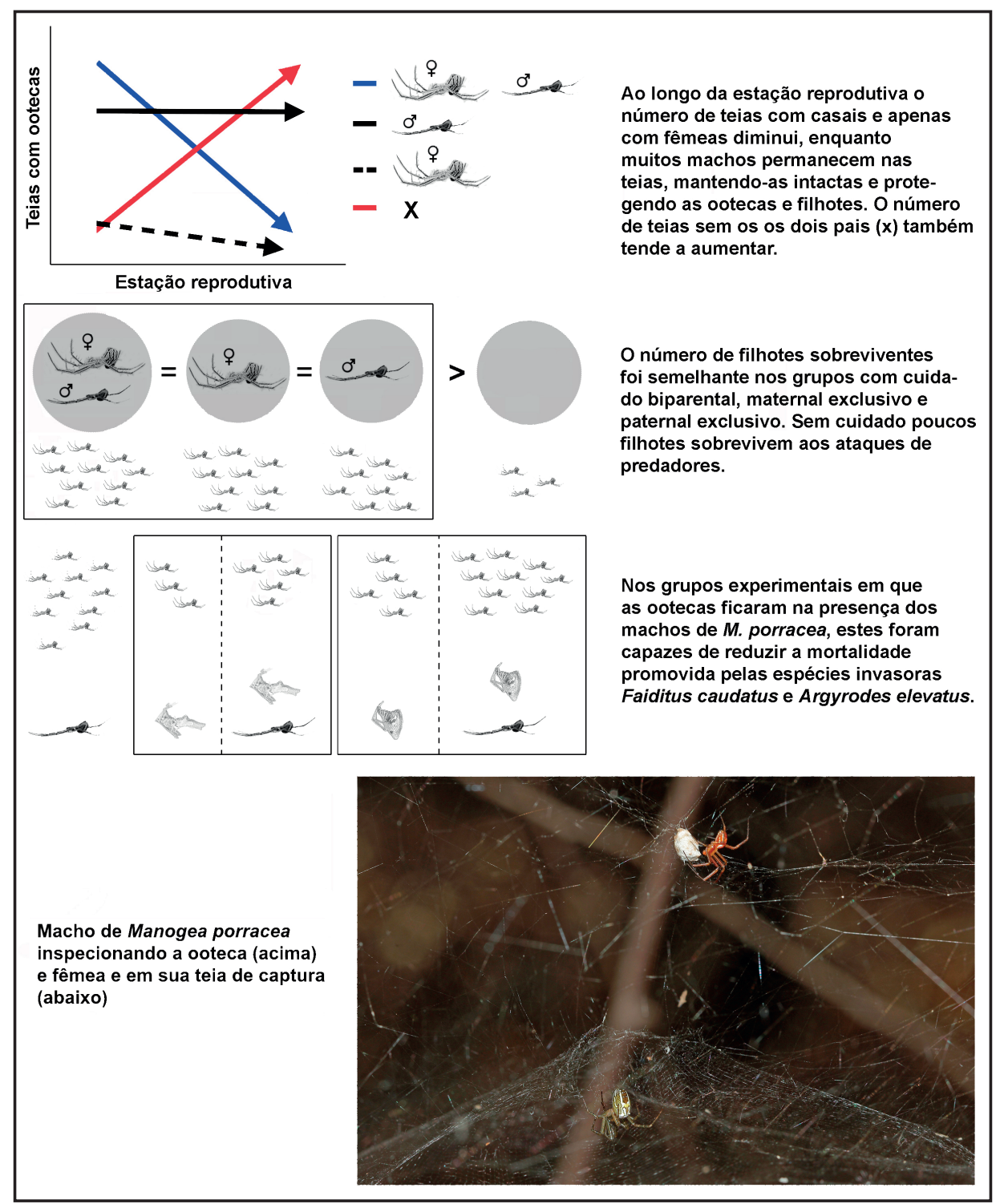

Quadro 1. Cuidado paternal em Manogea porracea 
Na primeira estação reprodutiva em que estudamos a espécie na Fazenda Nova Monte Carmelo observamos o que é chamado de pareamento assortativo. Trata-se de um padrão de formação de casais que acontece com base na similaridade ou dissimilaridade fenotípica do par. Ou seja, os indivíduos formam pares durante a estação reprodutiva considerando o quanto o parceiro/parceira é parecido ou diferente deles próprios. Esse fenômeno foi observado também em outros estudos que realizamos, com a formiga Tranopelta gilva (Hexapoda: Myrmicinae) e com o hemíptero Edessa contermina (Hemiptera: Pentatomidae), em outra área incluída no PELD, o Parque Estadual da Serra de Caldas Novas. No caso em questão, todavia, observamos que o padrão assortativo não se repetiu em uma estação subsequente (Quadro 2). Isso pode ter acontecido porque as medidas dos tamanhos das aranhas pareadas foi feita em um momento mais tardio da estação reprodutiva, no qual fêmeas sem parceiros são mais raras. Assim, a competição intrassexual pode ter se tornado mais intensa e assim limitado a possibilidade dos machos selecionarem as parceiras preferidas. Essa variação entre estações nos levou a considerar que é muito importante avaliar a consistência dos padrões de pareamento no tempo e que muitos estudos descrevendo padrões de pareamento assortativo (ou sua ausência) devem ser analisados com cautela por estarem limitados a registros pontuais.

A maioria dos autores ainda estima as relações de atributos fenotípicos dos casais apenas em um determinado período da estação reprodutiva ou juntam medidas de estações diferentes ou até de populações diferentes. Uma metanálise que fizemos recentemente evidenciou que essas práticas produzem resultados que são mal interpretados, já que os pareamentos podem variar tanto espacial quanto temporalmente. Com vimos, essa variação pode ser explicada por mudanças na intensidade de competição intrassexual, mas essa hipótese ainda carece de mais evidências empíricas. O tempo de vida curto e a facilidade de encontrar e manipular aranhas e outros artrópodes os tornam bons modelos para testar o poder preditivo da hipótese de intensidade de competição por parceiras sobre as variações espaciais e temporais dos pareamentos reprodutivos. Esperamos poder desenvolver novos estudos nessa linha em breve.

\section{Manipulação comportamental de hospedeiros por vespas parasitoides}

Parasitoides são insetos que depositam seus ovos no interior ou na superfície do corpo de seus hospedeiros e cujas larvas, invariavelmente, levam esses hospedeiros à morte. Essa, inclusive, é a diferença básica entre os parasitas e os parasitoides. Enquanto os primeiros consomem nutrientes do corpo de seus hospedeiros, podendo apenas ocasionalmente atingir níveis de infestação que tenham consequências fatais, nos últimos a morte do hospedeiro é certa. O mais interessante, no entanto, é que a morte não é a pior coisa que pode acontecer às vítimas desses insetos, como será apresentado a seguir. 


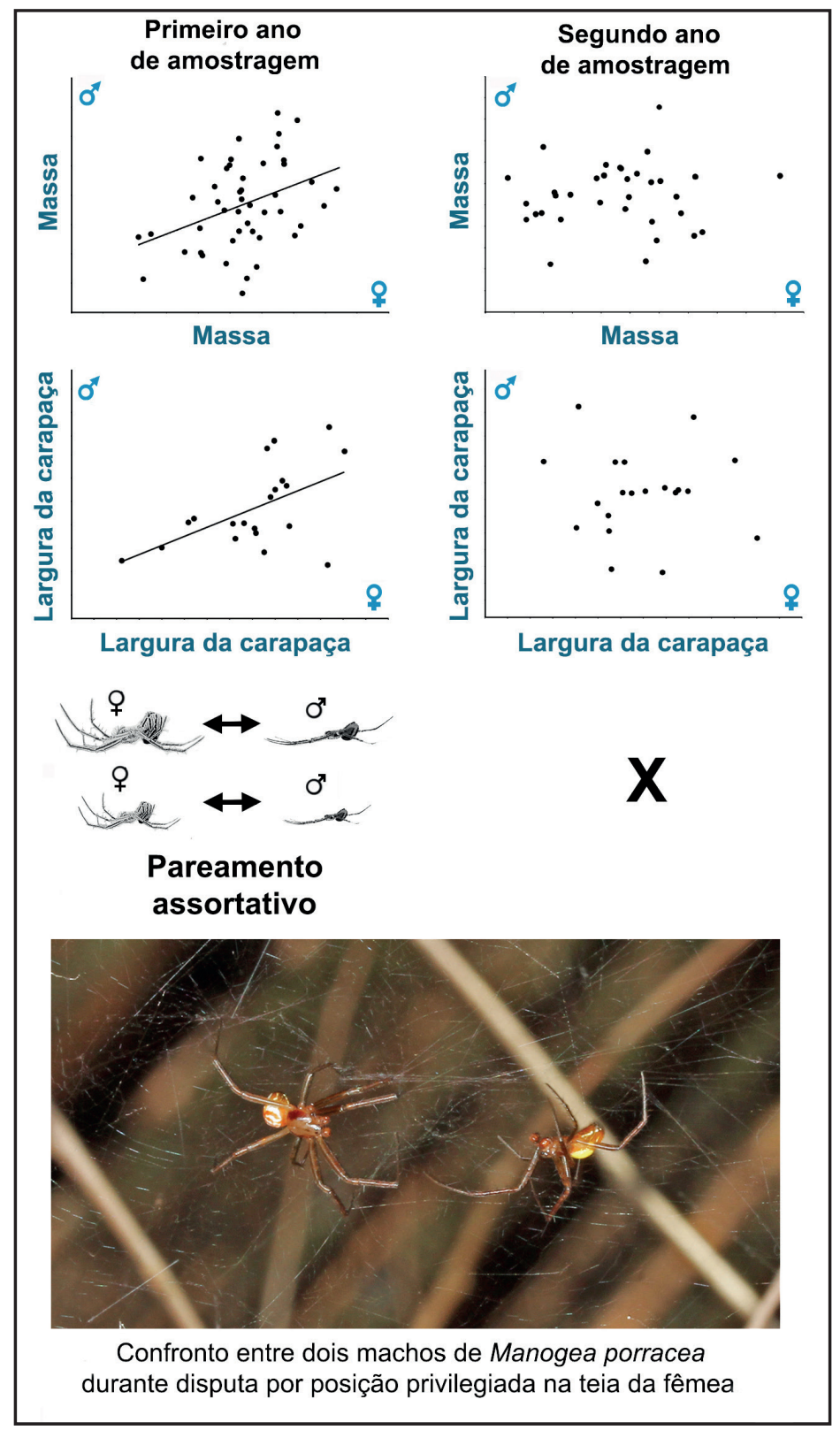

Quadro 2. Seleção sexuall em Manogea porracea

Alguns parasitoides são capazes de induzir alterações comportamentais em hospedeiros. Os mecanismos que levam a essas alterações ainda não estão bem definidos na maioria dos casos, mas sabe-se que os novos comportamentos dos hospedeiros sempre beneficiam os parasitoides. Esses benefícios geralmente estão associados a uma diminuição do risco de morte por inimigos naturais durante a fase de pupa. Vários exemplos são conhecidos, como vespas que tornam larvas de mariposas da família Geometridae extremamente agressivas contra joaninhas (principais predadoras de suas pupas) ou fazem com que as lagartas construam barreiras de seda que impedem que hiperparasitoides (parasitoides que atacam outros parasitoides) consigam se aproximar. 
Nas interações entre vespas parasitoides e aranhas, o que acontece é que a vespa adulta seleciona um hospedeiro de tamanho apropriado e o ataca, introduzindo seu ovipositor modificado na boca da aranha e secretando uma substância paralisante (provavelmente em um ponto próximo ao sistema nervoso). A aranha permanece imóvel por até uma hora após o ataque. Nesse tempo, a vespa inspeciona o corpo de sua vítima, procurando por ovos que tenham eventualmente sido depositados por outra vespa em um ataque anterior. Se encontra, o ovo é removido. Após a inspeção, a vespa deposita um ovo, que permanece aderido ao abdome da aranha. Esse ovo dá origem a uma larva e esta passa cerca de duas semanas furando o corpo da aranha para beber sua hemolinfa. Passa por duas mudas e então, atingindo o terceiro estádio de desenvolvimento, a larva secreta uma substância no corpo da aranha que altera o comportamento de construção de teia. O próximo passo será matar aranha, consumir a quase totalidade de seus tecidos e empupar, construindo um casulo que ficará preso a essa teia.

A modificação comportamental dos hospedeiros, nesse caso, resulta na construção de teias com características estruturais muito distintas daquelas normalmente tecidas por indivíduos não parasitados. As teias modificadas geralmente apresentam mais pontos de fixação à vegetação, uma estrutura espacial mais complexa (muitas vezes com a conversão de uma teia orbicular bidimensional em uma estrutura tridimensional (composta por uma malha aparentemente desordenada), podem apresentar componentes conhecidos como fios de barreira (que possivelmente dificultam a aproximação de predadores e/ou hiperparasitoides), contam com fios mais grossos e não apresentam espirais ou fios pegajosos. Esta última característica é especialmente importante porque reduz a probabilidade de ruptura das teias pela ação de insetos interceptados durante a luta para se livrarem dos fios adesivos.

A espécie Leucauge volupis (Tetragnathidae), que ocorre nos eucaliptais e remanescentes de Cerrado da Fazenda Nova Monte Carmelo e também na Reserva Ecológica do Panga, na região do Triângulo Mineiro, é atacada por uma espécie de vespa do gênero Hymenoepimecis (Ichneumonidae). A teia modificada, cuja construção é induzida pela larva do parasitoide, apresenta uma série de características que estão presentes nas teias de muda construídas por indivíduos imaturos dessa espécie, como fios de barreira acima e abaixo da posição ocupada pela aranha. As teias de muda são estruturas mais estáveis e resistentes, contando com barreiras físicas de seda que possivelmente protegem as aranhas de seus predadores durante o período de imobilidade necessário à ecdise (Quadro 3). A similaridade entre essas teias e as teias modificadas sugere que o mecanismo de manipulação deve envolver alguma substância similar (ou igual) àquela que desencadeia o processo de ecdise. Assim, é possível que o parasitoide secrete o hormônio promotor da ecdise, chamado ecdisona, ou algum precursor dessa substância.

A investigação de novos casos dessas interações, incluindo a descrição das teias modificadas e comparação com teias de muda, é muito importante para que possamos determinar se existe um único mecanismo envolvido e suas variações. Dados recentes com outras espécies das famílias Araneidae sugerem que realmente há um aumento na concentração de ecdisona no corpo do hospedeiro logo antes do início da construção das teias. Esperamos obter mais informações sobre outros sistemas similares nas mesmas áreas de estudo. Até o momento ao menos um outro caso, envolvendo uma nova espécie de Hymenoepimecis e a aranha Manogea porracea, já foi identificado. 


\section{Cooperação e disputas por presas em Parawixia bistriata (Araneidae)}

A formação de agregações e estruturas sociais mais complexas pode ser encontrada em espécies animais de diversos grupos taxonômicos, como insetos, aracnídeos, peixes, aves e mamíferos. Isso possivelmente ocorre devido ao desenvolvimento de comportamentos cooperativos que asseguram a redução no risco de predação, aumentam a capacidade de defender recursos, aumentam a eficiência de forrageamento e possibilitam a existência de cuidado parental indiscriminado entre membros do grupo. No entanto, a permanência em grupo também pode apresentar custos para os indivíduos, como a maior transmissão de parasitas e a ocorrência de interações agressivas durante o forrageamento (geralmente mais intensas quando os indivíduos apresentam tamanhos corporais semelhantes e quando a disponibilidade de recursos no ambiente é pequena ou restrita a manchas).

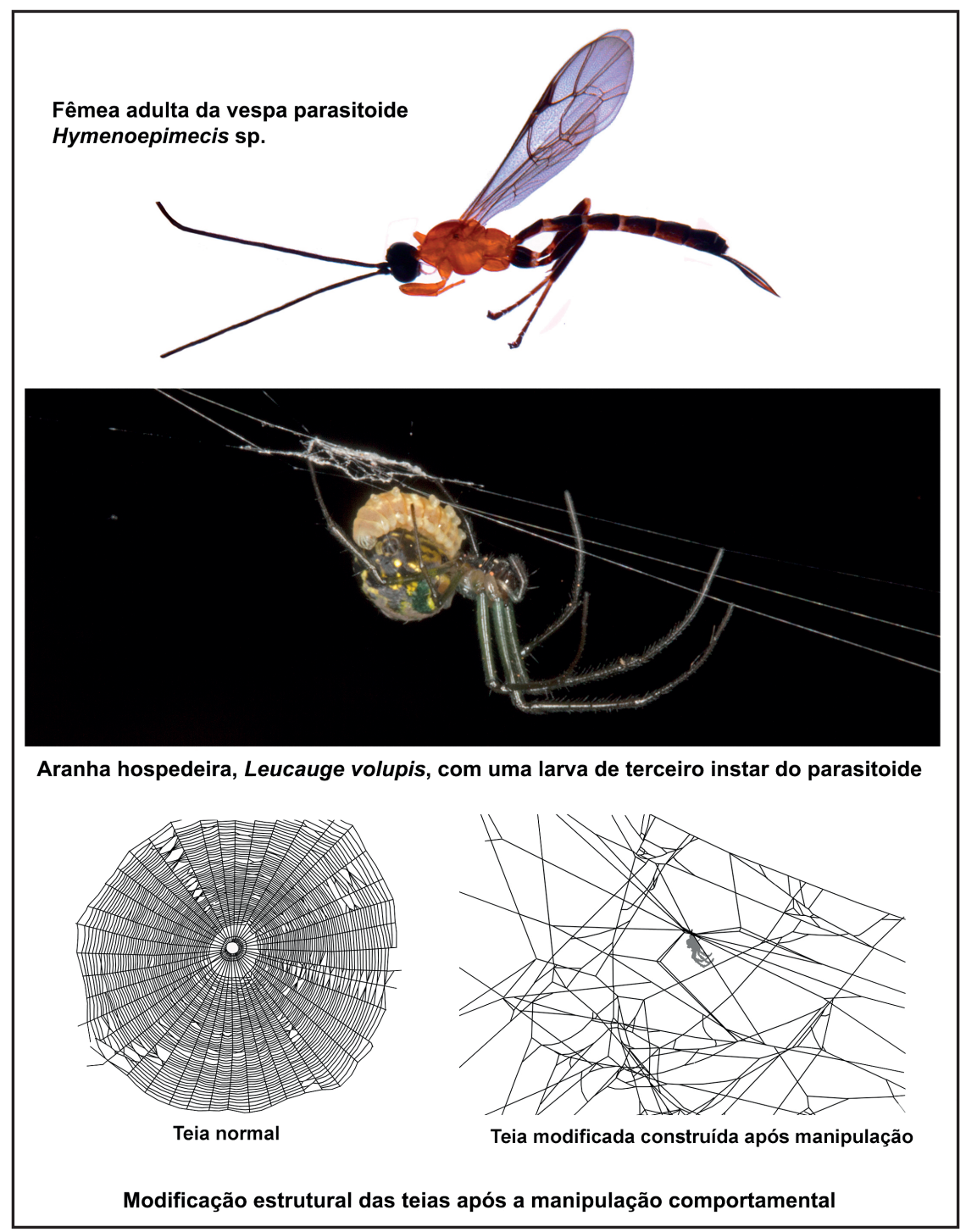

Quadro 3. Manipulação comportamental de Leugauge volupis 
Em aranhas, o comportamento social pode ocorrer de diversas formas. Algumas espécies mantêm agregações por um tempo limitado, apenas sob condições favoráveis de disponibilidade de alimento. Outras chegam a formar colônias estáveis por várias gerações. Apesar disso, a maioria das espécies não tolera a proximidade de co-específicos, com exceção dos primeiros instars de desenvolvimento, quando os imaturos geralmente são tolerantes à presença da mãe e de seus irmãos, e durante o período de acasalamento.

As estruturas sociais em aranhas são usualmente classificadas de acordo com a duração, permanente ou temporária, e a presença ou ausência de territorialidade entre os indivíduos. Nas famílias Theridiidae e Eresidae, por exemplo, as teias irregulares não permitem a manutenção de territórios pelos indivíduos. Essa característica possivelmente constituiu um elemento facilitador ao estabelecimento de interações mais complexas entre os indivíduos nas teias coletivas, como a captura cooperativa de presas com tamanho corporal muito superior ao tamanho máximo que um indivíduo consegue imobilizar e o cuidado parental cooperativo. Em aranhas construtoras de teias orbiculares, no entanto, cada indivíduo continua sempre mantendo seu território, embora interações com vizinhos que tenham teias conectadas possam ser frequentes. Os benefícios da formação dos agregados nessas espécies territoriais geralmente estão relacionados principalmente ao forrageio e à proteção.

Em espécies coloniais de aranhas construtoras de teias orbiculares, um dos principais benefícios ligados ao aumento da eficiência de forrageio deriva do efeito ricochete. Nesse caso, as presas têm sua energia cinética amortecida após se chocarem com as teias do agregado que ficam em posições periféricas e acabam sendo interceptadas por teias adjacentes. Isso acontece principalmente com presas médias e grandes, que dificilmente ficam retidas na primeira teia com que se chocam. A formação de colônias também possibilita a exploração de habitats que não estão disponíveis para indivíduos solitários. Além disso, os indivíduos podem utilizar fios de suporte produzidos por outras aranhas do grupo, economizando energia com a produção de seda. Outro benefício potencial é a redução do risco de predação, como foi descrito em Metepeira incrassata (Araneidae), em que indivíduos agregados são capazes de perceber a presença de um possível predador de forma mais eficiente. A partir dos movimentos evasivos de outros indivíduos do grupo, sinais vibracionais são transmitidos, permitindo uma reação mais rápida contra uma possível ameaça.

Além do incremento na interceptação de presas devido ao efeito ricochete, a interconexão de teias orbiculares pode propiciar a cooperação e aumento da eficiência no processo de captura de presas grandes, assim como ocorre em colônias de espécies não territoriais. O tipo de presa interceptada, além de seu tamanho, pode também afetar o comportamento das aranhas. Por exemplo, alguns insetos, como himenópteros, são muito ágeis e escapam das teias com maior frequência. Outros, como ortópteros, movimentam-se relativamente pouco e, embora possam representar risco de injúria durante o processo de imobilização, ficam retidos por mais tempo após a interceptação. Os diferentes padrões vibratórios causados por esses insetos quando interceptados nas teias também são capazes de afetar o número de aranhas atraídas para a captura e alimentação coletiva. Mariposas, com frequente vibração de asas após a interceptação, podem atrair um número maior de aranhas em comparação a gafanhotos ou grilos, que tendem a mover suas pernas com força, mas em baixa frequência. Assim, a propagação 
da vibração resultante da movimentação de diferentes tipos (e tamanhos) de presas deve ser distinta, fazendo com que o número de aranhas que percebem a interceptação do inseto seja diferente e que essas aranhas possam perceber características da presa antes da aproximação.

Indivíduos vivendo em grupo podem também entrar em conflitos, principalmente em casos de espécies territoriais. As disputas, nesse caso, podem ocorrer pela falta de espaço para a construção das teias, motivando interações agressivas entre as aranhas; ou durante a renovação e reparação de teias, como ocorre em Cyrtophora moluccensis (Araneidae), em que indivíduos podem mover-se e passar para teias de aranhas vizinhas enquanto estão examinando e reparando as extremidades de suas teias. As interações agonísticas podem ocorrer por vibrações nas teias, para sinalizar os limites dos territórios das aranhas ou, em caso de invasão da teia, podem ocorrer perseguições ou brigas, com contato físico. O resultado dos conflitos pode ser afetado tanto pela diferença de tamanho entre os indivíduos envolvidos quanto pela diferença entre ser o residente ou o invasor da teia. Outra forma de disputa territorial entre indivíduos agregados, menos explorada na literatura, é a ocorrência de conflitos durante a captura de presas. Esses conflitos podem possibilitar que aranhas invasoras, de maior tamanho, roubem presas diretamente de teias adjacentes, ganhando disputas com as residentes vizinhas.

Interações agonísticas após a captura de uma presa também podem ocorrer mesmo em espécies não territoriais quando, por exemplo, os indivíduos envolvidos tentam puxar os insetos, ou partes deles, para seus refúgios ou quando intrusos que não participaram da captura tentam se alimentar de presas capturada por outras aranhas. Em Anelosimus eximius (Theridiidae), por exemplo, fêmeas de maior peso podem expulsar aranhas menores de presas grandes capturadas cooperativamente, o que pode afetar a distribuição de recursos e a variação intracolonial no tamanho corporal dos indivíduos. Presas de grande porte (em relação ao tamanho das aranhas) podem representar uma porção significativa da biomassa interceptada pelas teias de espécies sociais em regiões tropicais e, assim, interações entre os indivíduos (cooperativas e agonísticas) podem ser de grande relevância para determinar a distribuição de alimento entre os membros dos grupos.

Agrande variação na organização social de aranhas pode ter diferentes implicações para as frequências de cooperação e conflito. Espécies sociais não territoriais são as que mais cooperam entre si, enquanto agregações de aranhas territoriais apresentam cooperação bastante limitada, principalmente durante a captura de presas. A própria arquitetura das teias individuais de espécies territoriais pode representar um obstáculo para a captura coletiva de presas. Nesses casos, cada indivíduo caça em sua própria teia e as vibrações das presas interceptadas geralmente não são transferidas de forma eficiente entre as teias do agregado. No entanto, a aranha colonial Parawixia bistriata é uma exceção. Apesar de construírem teias orbiculares individuais nas agregações, os indivíduos exibem comportamentos cooperativos durante a captura de presas de grande porte. Isso pode ocorrer devido à formação de "redes de captura" compostas por várias teias individuais conectadas entre si e sustentadas por fios de suporte construídos pelo grupo de aranhas. Entretanto, isso também pode aumentar a ocorrência de conflitos por presas entre os indivíduos da mesma colônia, possibilitando que o roubo de presas aconteça de maneira mais frequente. 
As colônias de $P$. bistriata são, normalmente, compostas por indivíduos aparentados, advindos da mesma ooteca, e que apresentam sincronia de mudas durante seu desenvolvimento. As teias dessa espécie são tecidas geralmente ao anoitecer e consumidas ao amanhecer. Essa construção diária das teias pode mudar a posição e o tamanho das teias dos indivíduos dentro da agregação (o que pode ter influência nas interações entre eles). Essas condições tornam P. bistriata um modelo experimental ideal para avaliar a cooperação e competição durante a captura de presas, de acordo com o tamanho e padrão vibracional dos insetos, e as possíveis implicações de comportamentos cooperativos e interações agonísticas na variabilidade de tamanho entre indivíduos de uma mesma colônia. Nos estudos que desenvolvemos com essa espécie no Triângulo Mineiro e no Parque Estadual da Serra de Caldas Novas, em Goiás, buscamos estimar a frequência de cooperação e de conflitos durante a captura de presas em dois diferentes estágios de desenvolvimento da espécie e testar experimentalmente o efeito de dois diferentes tipos de presa, Lepidoptera e Orthoptera, sobre o comportamento de captura de presas.

Observamos que aranhas mais jovens, nos primeiros instars, mantém uma frequência de comportamentos cooperativos maior que as aranhas mais velhas. Essa diminuição gradual da frequência de cooperação pode ocorrer como consequência de uma diminuição da tolerância, culminando na adoção de hábitos solitários ao atingirem a maturação. Além disso, as vantagens em realizar capturas com a participação de seus irmãos e irmãs devem ser maiores para indivíduos mais jovens. As aranhas mais velhas (e consequentemente maiores) podem capturar todo o espectro de tamanhos de presas disponível eficientemente de forma solitária. Já as aranhas pequenas seriam incapazes de capturar presas grandes sem que houvesse a participação de vários indivíduos (Quadro 4).

Outro resultado importante que obtivemos está relacionado à relevância de considerarmos o comportamento das presas e seus tamanhos como fatores determinantes das interações interindividuais nas colônias. Através de experimentos lançando gafanhotos e mariposas nas teias, observamos que as mariposas atraem mais indivíduos de teias adjacentes, possivelmente porque as vibrações provocadas por suas tentativas de evasão propagam-se por longas distâncias. Mariposas maiores atraem ainda mais indivíduos. Já os gafanhotos, embora promovam vibrações esporádicas com chutes, o fazem em uma frequência relativamente baixa e é provável que a vibração não seja percebida mesmo pelas aranhas que estão em teias vizinhas. 


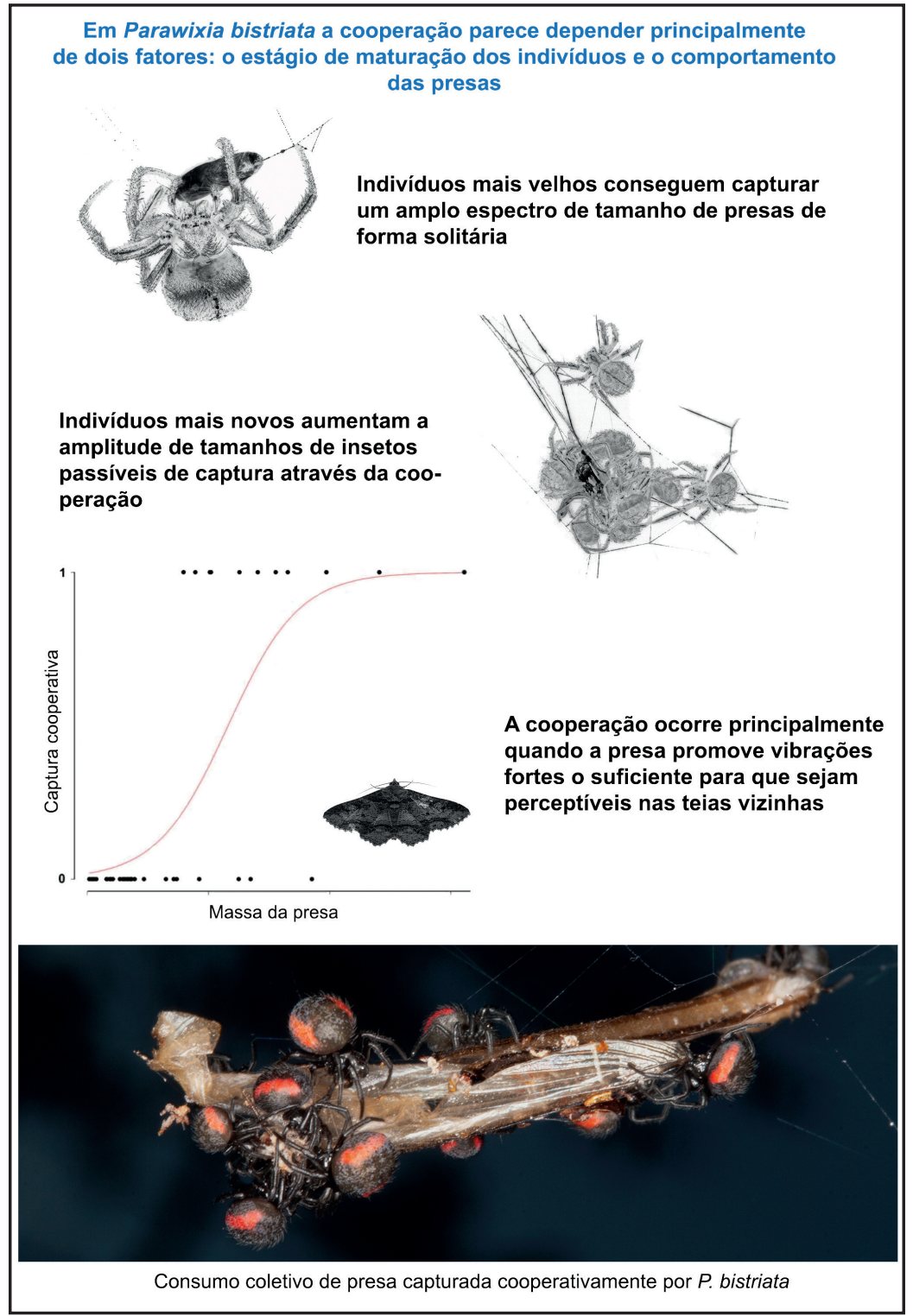

Quadro 4. Cooperação em Parawixia bistriata

\section{Cripticidade e disfarces em espécies do gênero Cyclosa e em Wixia abdominalis}

Vários animais utilizam estratégias para evitar predação que envolvem aparentar serem itens distintos daqueles que seus predadores estão procurando (disfarce) e/ou minimizar o contraste cromático entre seus corpos e o fundo, escolhendo microhabitats com cores específicas e, assim, reduzindo a probabilidade de serem detectados (cripsia). Algumas espécies crípticas são capazes ainda de maximizar a eficiência de sua defesa adotando posturas corporais que dificultam ainda mais sua a detecção por predadores visualmente orientados. Da mesma forma, essas posturas particulares e a seleção de determinados microhabitats podem ser importantes para que o disfarce se torne eficiente. 
Muitas espécies de aranhas pertencentes às famílias Araneidae, Tetragnathidae e Uloboridae incorporam estruturas densas e/ou conspícuas de seda em suas teias, denominadas estabilimentos ou decorações. Embora estas estruturas tenham sido inicialmente descritas como promotoras de estabilidade das teias, as funções que permanecem com maior sustentação na literatura são as de atração de presas (principalmente no caso daquelas compostas unicamente por seda) e de redução na conspicuidade das aranhas a seus predadores. Aranhas do gênero Cyclosa (Araneidae), por exemplo, constroem seus estabilimentos com seda, detritos, restos de presas e ootecas, permanecendo em meio a essas estruturas, o que promove uma aparente ruptura do sinal visual de seu contorno corporal. A similaridade cromática entre a aranha e seu estabilimento nos sugere que se trata de uma estratégia de disfarce, tornando o corpo da aranha parte da figura composta pelos detritos. No caso de Cyclosa, a construção de estruturas lineares que lembram gravetos ou estruturas complexas que podem simular aranhas grandes (Figura 2), o posicionamento das aranhas em posição contígua a essas estruturas e a similaridade cromática existente entre o corpo das construtoras e suas estruturas de seda e detritos, podem reduzir a probabilidade de que predadores visualmente orientados as identifiquem como presas em potencial. De fato, já foi previamente reportado que modelos de massa de modelar com formato de estabilimentos de Cyclosa são menos atacados por vespas que modelos em forma de aranha, sugerindo que a redução da intensidade de predação deve ocorrer devido à quebra de contorno do corpo da aranha.

Uma particularidade do gênero Cyclosa na construção de estabilimentos é a grande variação na sua composição e formatos. Embora muitas espécies apresentem predomínio de estruturas lineares compostas por seda e detritos, alguns indivíduos podem construir formatos muito distintos desse padrão, como estruturas descontínuas formadas por grumos de tamanho similar ao da aranha construtora ou mesmo estruturas em formato de aranha, indicando que a distorção do tamanho aparente também pode constituir uma estratégia utilizada nesse gênero. Além disso, as posições ocupadas pela aranha na coluna de detritos são muito variáveis e essa variação pode ser importante para a manutenção da imprevisibilidade de sua localização, mesmo para inimigos naturais que estejam ativamente procurando por estabilimentos como sinais indicativos da presença de suas presas/hospedeiras. Esse pode ser o caso, por exemplo, de parasitoides do gênero Polysphincta (Hymenoptera, Ichneumonidae), recentemente descritos atacando espécies de Cyclosa em áreas de Mata Atlântica.

Enquanto Cyclosa spp. aparentam ser gravetos construindo estruturas de seda e detritos, outra espécie da família Araneidae, Wixia abdominali, reduz sua exposição à predadores e parasitoides através de uma estratégia de disfarce que envolve apenas a forma peculiar de seu abdome, que é muito parecido com um galho quebrado ou espinho. Essas aranhas têm hábitos de forrageio noturnos, passando todo o dia completamente imóveis e com as pernas retraídas sobre galhos finos com coloração muito semelhante à de seus corpos. Esse posicionamento as torna praticamente imperceptíveis, ao menos aos olhos humanos, durante o dia. Já durante a noite, alguns indivíduos posicionam-se no centro de suas teias orbiculares, enquanto outros constroem teias com setores livres e permanecem sobre os galhos segurando um fio que se estende até a posição central da teia.

Nós investigamos a similaridade cromática entre aranhas do gênero Cyclosa e seus estabilimentos e entre Wixia e os galhos sobre os quais repousam durante o 
dia. Nesses casos, a eficiência da estratégia de defesa no ambiente natural depende do modelo visual de seus principais predadores/parasitoides. Isso quer dizer que não podemos afirmar que os padrões de reflexão são similares sem considerar como o observador (predador/parasitoide) enxerga. Modelos fisiológicos de visão têm sido usados para determinar como algumas espécies são capazes de distinguir as cores. Tais modelos incorporam, basicamente, a sensibilidade das células fotorreceptoras de cada observador, a iluminação do ambiente, e a reflectância do plano de fundo (vegetação nativa) e de cada um dos objetos observados (aranhas, estabilimentos, galhos, etc.). Por meio do cálculo de contrastes cromáticos e acromáticos, determinam como possíveis predadores ou presas (geralmente himenópteros e aves) distinguem as cores dos seus alvos em potencial.

Os resultados para Wixia abdominalis mostraram que tanto aves como vespas são incapazes de distinguir os padrões cromáticos e acromáticos das aranhas dos padrões dos substratos utilizados por elas para repouso. Isso significa que o sinal visual da aranha pode ser facilmente confundido com uma estrutura do próprio galho, dificultando sua localização por predadores que estejam buscando o sinal visual de uma aranha para realizarem a captura (Quadro 5). Já no caso das várias espécies do gênero Cyclosa que estamos estudando, de maneira geral, o ajuste entre aranhas e seus estabilimentos parece ser grande o suficiente para impossibilitar a distinção das aranhas por aves, mas não por himenópteros. É possível que aves constituam os principais predadores dessas aranhas e a estratégia de defesa tenha evoluído em resposta a esses predadores. Apesar da capacidade de himenópteros em distinguir o padrão cromático das aranhas, é possível também que a presença dos estabilimentos promova uma confusão durante as decisões que devem ser tomadas pelo predador/parasitoide durante um ataque rápido. Essa pequena vantagem conferida pela estrutura já poderia ser suficiente para aumentar as chances de sobrevivência e reprodução dos indivíduos que a construíssem, possibilitando que a estratégia de defesa se perpetuasse.

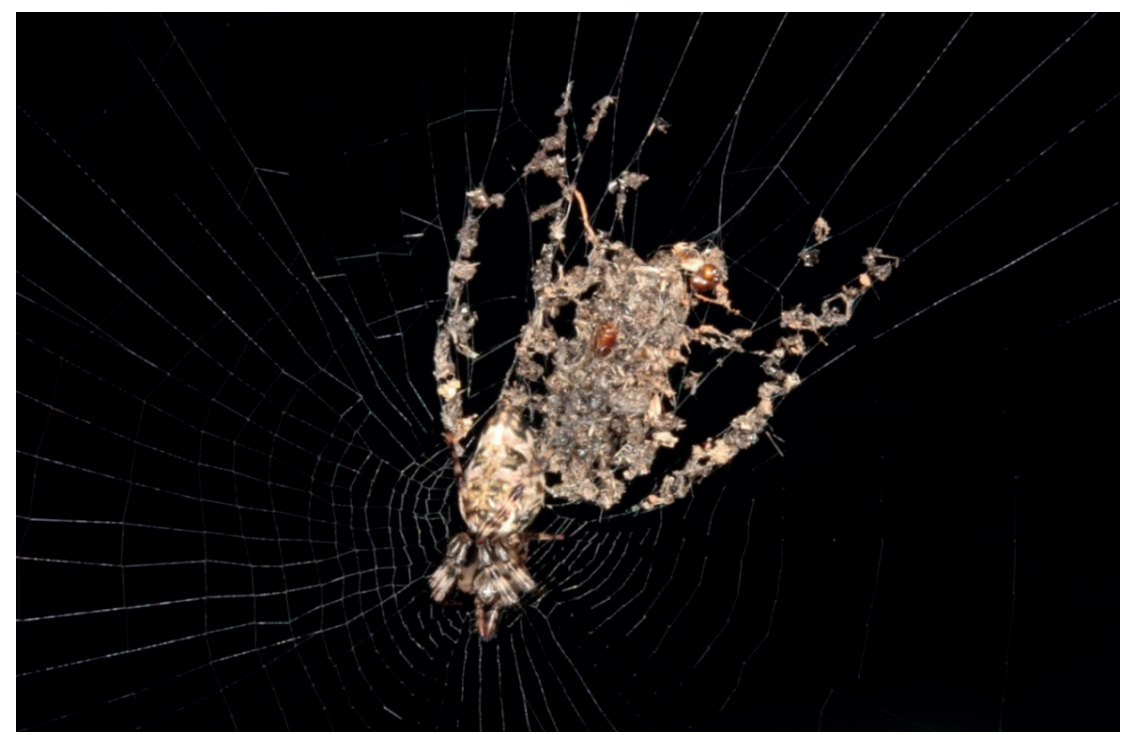

Figura 2. A aranha Cyclosa sp. em posição contígua a seu estabilimento (estrutura composta por seda e detritos adicionada ao centro da teia) de forma complexa. Neste caso a forma da estrutura de detritos pode ser interpretada como sendo uma aranha maior. 


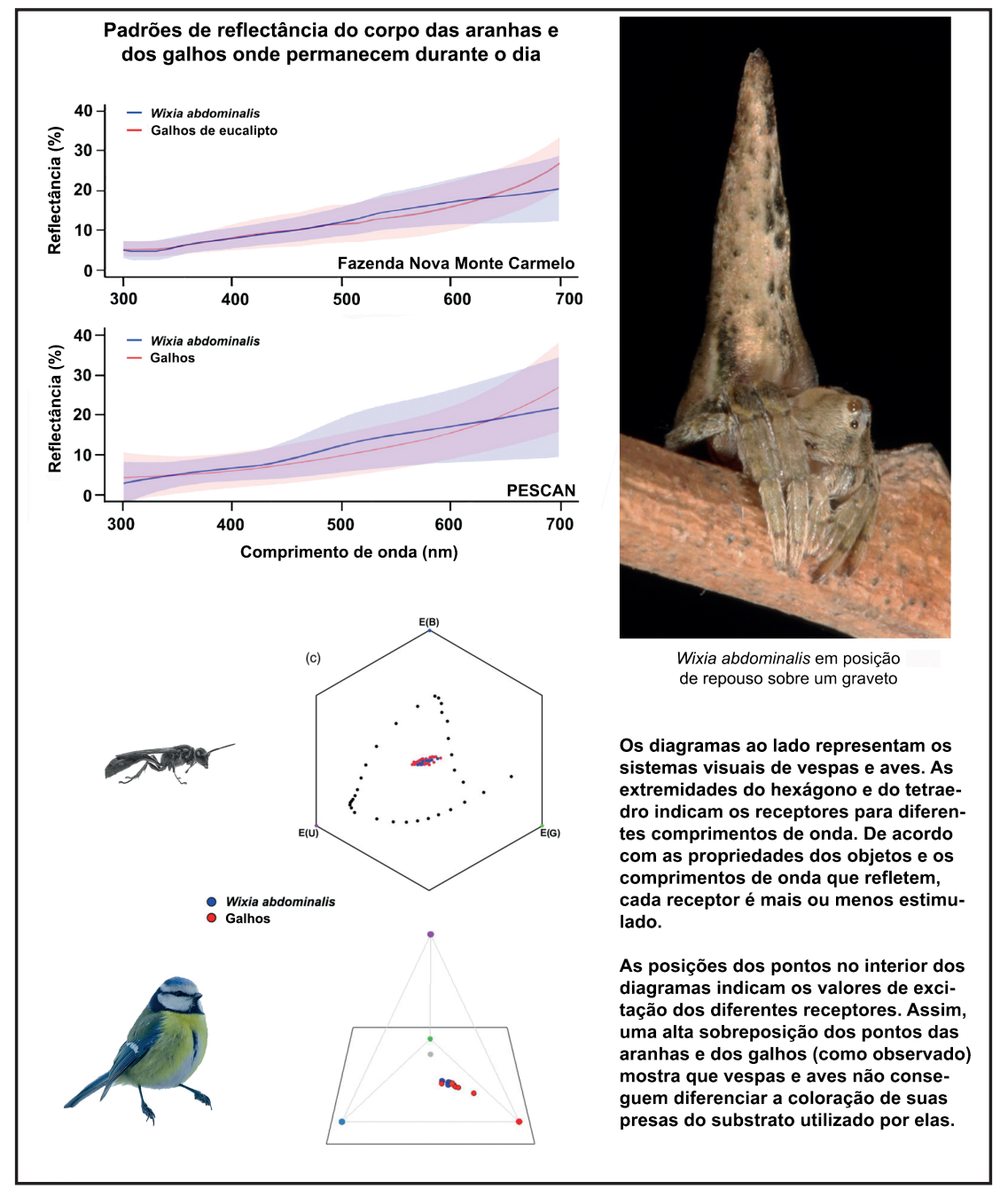

Quadro 5. Cripticidade e disfarce em Wixia abdominalis

\section{Forrageamento em Tidarren haemorrhoidale e Nihonhimea tesselata}

Predadores podem ser classificados, com base na variedade de presas incluídas em suas dietas, em estenófagos ou eurífagos. O termo estenófago refere-se às espécies que capturam e consomem uma amplitude relativamente pequena de espécies de presas. Nestes casos, os predadores geralmente utilizam comportamentos específicos e, por isso, apresentam maior frequência de sucesso em tentativas de captura. As aranhas boleadeiras (Mastophora spp., Araneidae), por exemplo, consomem quase exclusivamente mariposas. Essas aranhas tecem um único fio de seda com um aglomerado de teia com substâncias voláteis em sua extremidade. Ao prender esse fio em uma de suas pernas e girar no ar, essas substâncias são dispersas e, por possuírem componentes químicos similares aos feromônios sexuais de algumas espécies de mariposas, atraem machos dessas espécies de presas que estão buscando por parceiras. Já o termo eurífago refere-se a uma estratégia alimentar que envolve a capacidade de predar uma ampla gama de presas. Espécies eurífagas investem em mecanismos 
de captura menos específicos e, por isso, geralmente menos eficientes para cada tipo particular de presa. Tais termos, "estenófago" e "eurífago", no entanto, representam apenas os extremos de um contínuo de variação do nicho trófico dos predadores.

Diversos fatores influenciam a amplitude de dieta de um predador, como a capacidade de subjugar diferentes tipos de presas, competição interespecífica e os riscos de injúrias para o predador durante a captura. Além disso, a preferência de um predador por determinados itens pode também estar fortemente condicionada às suas demandas nutricionais e características fisiológicas. Cada espécie de presa apresenta quantidades variáveis de proteínas, carboidratos e lipídios, além de variarem na composição específica de micronutrientes. Predadores, portanto, podem investir em determinados mecanismos para capturar presas com quantidades maiores dos nutrientes específicos que carecem, ou até mesmo extrair das presas apenas os nutrientes que necessitem, incorporando-os em sua biomassa. Alguns são capazes de viver com uma dieta mais limitada, outros precisam incluir itens com composição variável para assegurarem um status nutricional favorável à sobrevivência e reprodução.

Outro ponto importante é que a oportunidade que um predador tem de capturar sua presa geralmente é influenciada diretamente pela disponibilidade de tal presa no ambiente. Assim, a densidade de cada espécie de presa no ambiente é um componente importante na determinação da dieta de predadores generalistas (eurífagos). Além disso, principalmente para predadores estenófagos, a densidade e abundância das populações de presas no ambiente afetam diretamente suas próprias dinâmicas populacionais. $\mathrm{Ou}$ seja, não só os predadores controlam as populações de suas presas, mas a abundância de presas também pode influenciar diretamente as populações de seus predadores.

Embora aranhas, como grupo taxonômico, sejam tradicionalmente consideradas como predadores eurífagos, existem vários casos descritos de espécies que apresentam dietas muito limitadas. Além disso, mesmo entre aquelas que consomem vários tipos de presas, há uma restrição relativa ao grupo de presas que podem ser eficientemente interceptados, subjugados e consumidos. Mesmo pequenas variações nas características das teias (como a presença e distribuição de gotículas adesivas nos fios, densidade de fios em partes específicas da teia, etc) podem determinar maior ou menor sucesso na obtenção de determinados itens alimentares.

Tidarren haemorrhoidale e Nihonhimea tesselata são duas espécies que ocorrem na mesma área de plantação de eucaliptos na Fazenda Nova Monte Carmelo. Embora pertençam a mesma família (Theridiidae) apresentam teias com características distintas. Enquanto a primeira constrói densos emaranhados de fios irregularmente dispostos utilizando galhos finos das árvores e o tronco como suporte, a segunda constrói uma teia com lençol de interceptação e vários fios de sustentação que funcionam como uma barreira para interceptar insetos em voo. Nosso objetivo, no caso, era investigar a amplitude e sobreposição de dieta dessas espécies. Analisando as caraterísticas de teias e comportamento de forrageamento de ambas, tínhamos como hipótese que $T$. haemorrhoidale apresentaria uma dieta restrita a poucos tipos de presas, que poderiam ser capturados por ataques diretos quando tocassem fios que estivessem em contato com o substrato por onde estivessem se deslocando. Já $N$. tesselata supostamente capturaria uma grande variedade de insetos voadores.

Nossas suposições, nesse caso, estavam parcialmente corretas. Coletamos quase 500 presas capturadas pelas duas espécies e, embora ambas tenham capturado 
nove ordens de insetos, houve uma grande dominância de formigas na dieta de $T$. haemorrhoidale ( $69,5 \%$ dos itens capturados), enquanto $N$. tesselata apresentou maior equilíbrio em uma dieta composta principalmente por insetos das ordens Psocoptera, Hemiptera e Hymenoptera. Observamos baixa sobreposição na dieta das duas espécies, o que pode reduzir a competição em um ambiente relativamente pobre em alimento e permitir a manutenção de populações maiores. Essa baixa sobreposição, além de possivelmente ser consequência das diferenças na arquitetura das teias, pode também ser explicada por particularidades de cada espécie quanto à seleção de microhabitats para fixação de seus fios de captura (Quadro 6).

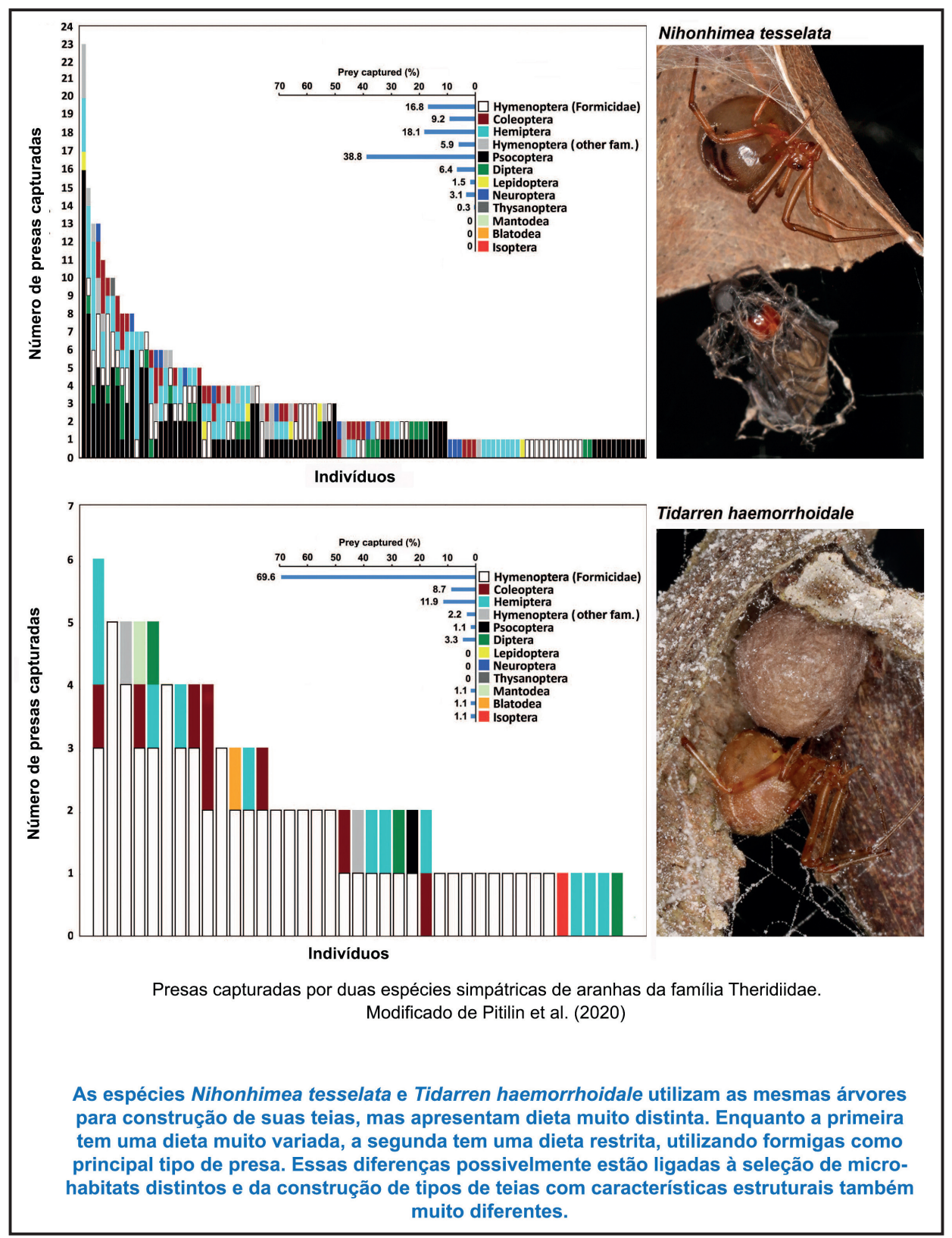

Quadro 6. Dieta de Nihonhimea tesselata e Tidarren haemorrhoidale 


\section{Considerações finais}

Os trabalhos apresentados nesse capítulo ilustram apenas parte das linhas de pesquisa sobre ecologia comportamental de aranhas que estamos desenvolvendo no Triângulo Mineiro e que recebem incentivos do programa Peld. Diversos outros projetos envolvendo principalmente seleção sexual, forrageamento em espécies cleptoparasitas e araneofágicas e diferentes aspectos da manipulação comportamental de hospedeiros por parasitoides estão em andamento, e esperamos que possam gerar informações interessantes em breve. Programas, como o Peld, que possibilitam que linhas de pesquisa sejam desenvolvidas de forma contínua são essenciais para a consolidação de grupos de trabalho e para que sistemas complexos e de grande interesse científico possam ser explorados com o cuidado e detalhamento que merecem.

\section{Para saber mais}

Eberhard WG, Gonzaga, MO (2019) Evidence that Polysphincta-group wasps (Hymenoptera: Ichneumonidae) use ecdysteroids to manipulate the -web-construction behaviour of their spider hosts. Biol J Linn Soc 127: 429-471 doi: 10.1093/biolinnean/ blz044

Gonzaga MO, Moura RR, Pêgo PT, Bang DL, Meira FA (2015) Changes to web architecture of Leucauge volupis (Araneae: Tetragnathidae) induced by the parasitoid Hymenoepimecis jordanensis (Hymenoptera: Ichneumonidae). Behaviour 152: 181193 doi: 10.1163/1568539X-00003238

Moura RR, Gonzaga MO (2017) Temporal variation in size-assortative mating and male mate choice in a spider with amphisexual care. Science of Nature 104:28 doi: 10.1007/s00114-017-1448-6

Moura RR, Gonzaga MO (2018) Sex ratio and density may affect temporal variation in size-assortative mating in a Neotropical ant species. Zool Anz 276:50-56.

Moura RR, Gonzaga MO (2019) Spatial variation in sex ratio and density explains subtle changes in the strength of size-assortative mating in Edessa contermina (Hemiptera: Pentatomidae). Acta Oecol 95: 86-92 doi: 10.1016/j.actao.2018.12.003

Moura RR, Vasconcellos-Neto J, Gonzaga MO (2017) Extended male care in Manogea porracea (Araneae: Araneidae): the exceptional case of a spider with amphisexual care. Animal Behaviour 123:1-9 doi: 10.1016/j.anbehav.2016.09.018

Moura RR, Vasconcellos-Neto J, Gonzaga MO (2019) Female sexual maturity as a determining factor of size-assortative pairing in the protandrous spider Manogea porracea (Araneae, Araneidae). Zool Anz 284:1-6 doi: 10.1016/j.jcz.2019.11.003

Moura RR, Pinto NS, Vasconcellos-Neto J, Gonzaga MO (2019) Does body size influence male care? Investigating an alternative reproductive tactic in Manogea porracea (Araneae: Araneidae), a spider with amphisexual care. Journal of Insect Behavior 32:1-5 doi: 10.1007/s10905-019-09725-w

Oliveira U, Brescovit AD, Santos AJ (2017) Sampling effort and species richness assessment: a case study on Brazilian spiders. Biodiver Conserv 26:1481-1493 doi: $10.1111 /$ jbi.12803 
Pitilin RB, Moura RR, Gonzaga MO (2020) Population and individual trophic niche of two sympatric cobweb spiders, Nihonhimea tesselata and Tidarren haemorroidale (Araneae, Theridiidae). J of Arachnology 48:59-66 doi: 10.1636/0161-8202-48.1.59

Xavier GM, Brito VLG, Gonzaga MO (2018) Colour matching in an orb-web spider: a twig-masquerading species as seen by potential predators. Journal of Zoology 306: 48-57 doi: 10.1111/jzo. 12568 



\title{
CAPÍTULO 14
}

\section{ECOFISIOLOGIA DE PLANTAS DO CERRADO: SOBREVIVÊNCIA EM UM AMBIENTE COM ALTA SAZONALIDADE HÍDRICA, POUCA DISPONIBILIDADE DE NUTRIENTES E SOB A AÇÃO DO FOGO}

\author{
Ana Silvia F. P. Moreira \\ Ana Paula de Faria \\ Jessica F. de Lima
}

O Cerrado é o segundo maior bioma do Brasil, ocupando aproximadamente $25 \%$ do território nacional, principalmente em sua região central. É formado por um mosaico de diferentes fitofisionomias, que envolvem desde campos abertos até áreas florestais, em um gradiente altamente heterogêneo com uma alta diversidade de plantas, estimada em aproximadamente 12.400 espécies. Destas espécies, acredita-se que cerca de $30 \%$ sejam encontradas somente no Cerrado, o que denominamos como alto grau de endemismo. A alta diversidade de espécies vegetais e o grande número de espécies exclusivas deste bioma são produto de uma história evolutiva que hoje reflete um conjunto de estratégias morfo-fisiológicas. Estas estratégias permitem às plantas lidar de forma eficiente com características do ambiente que poderiam prejudicar seu crescimento, como a marcante sazonalidade hídrica, a ação do fogo e as condições limitantes de solo, tudo em um equilíbrio perfeito. Nosso grupo de pesquisa busca avaliar e entender estas estratégias, especialmente em plantas que utilizam a PEP-carboxilase como principal enzima fixadora de $\mathrm{CO}_{2}$. Desta forma, plantas com metabolismo CAM $\mathrm{e}_{4}$ são nosso principal objeto de estudo e serão foco ao longo deste capítulo.

\section{Lidando com a sazonalidade hídrica}

Apesar da alta taxa pluviométrica na maior parte do Cerrado (média de precipitação de 800 a $2.000 \mathrm{~mm}$ por ano), distribuição sazonal com concentrações de chuva em alguns meses do ano impõe um período de estiagem que se estende de maio a setembro. Durante estes aproximadamente cinco meses, a baixa umidade relativa do ar e as poucas chuvas determinam um alta demanda evaporativa. Além disso, os solos em sua maioria encontram-se com pouca disponibilidade de água (Figura 1), um conjunto que faz da estação seca um período altamente estressante para as espécies vegetais do Cerrado. Por outro lado, durante o período de chuvas, o solo encontra-se saturado (potencial hídrico do solo próximo a 0,0 MPa), durante a seca as camadas superficiais perdem sua água e o potencial hídrico chega a níveis tão baixos como -9,0 MPa. Consideramos, então, a seca como um dos principais fatores limitantes à sobrevivência das plantas no Cerrado, de forma que o desenvolvimento de várias características é necessário para sua sobrevivência. 

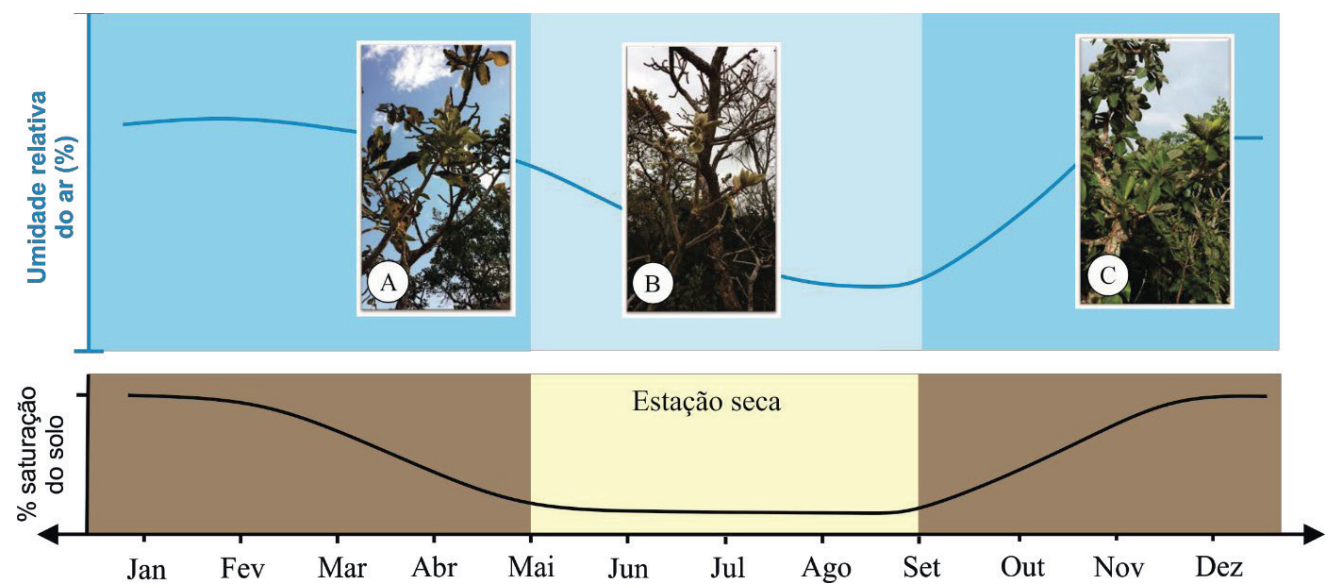

Figura 1. Representação esquemática da redução nos valores médios de umidade relativa do ar e da \% de saturação de água no solo (a $10 \mathrm{~cm}$ de profundidade) durante a estação seca na região da Estação Ecológica do Panga, uma das principais áreas de coleta do grupo. A estação seca estende-se por aproximadamente 5 meses, entre maio e setembro. As imagens (A), (B) e (C) mostram diferentes fases vegetativas de Aspidosperma tomentosum. Esta espécie inicia a perda de suas folhas a partir de março (A). Em junho e outubro ocorrem picos de brotação (B) que garantem folhas maduras (C) durante a estação chuvosa, e uma maior produtividade. Os dados de umidade relativa do ar foram retirados para os anos de 2019/2020 do INMET e a \% de saturação do solo foi medida no ano de 2017. Fotos Aspidosperma: Vitor Campana Martini.

Dentre as estratégias desenvolvidas pelas plantas do Cerrado, a perda das folhas durante os momentos de menor disponibilidade de água pode ser observada em várias espécies. Árvores e arbustos que perdem totalmente (espécies decíduas) ou parte de suas folhas (espécies brevidecíduas) no início da estação seca reduzem a perda de água por transpiração. Como observamos em algumas populações de Aspidosperma tomentosum (ver Figura 1) no Clube Caça e Pesca, e de Byrsonyma intermedia e B. coccolobifolia na Estação Ecológica do Panga, que perdem suas folhas, a brotação de novas folhas pode ocorrer durante a estação seca e início da estação chuvosa com intuito de recompor a atividade fotossintética e produzir matéria orgânica. É claro que a restrição hídrica sazonal, com perda das folhas e redução da atividade fotossintética, acaba também por prejudicar a produtividade da planta, levando muitas espécies vegetais a apresentarem, além da deciduidade foliar, uma taxa de crescimento sazonal bem ajustado à sazonalidade hídrica do Cerrado. Por outro lado, a maior parte das espécies vegetais (como observamos em Byrsonima verbascifolia) buscam por estratégias alternativas que não envolvem a perda de folhas para manutenção do seu status hídrico e de suas atividades fisiológicas, mesmo nos períodos de restrição hídrica. Elas optam por manter suas folhas ao longo de todo o ano e são conhecidas como perenes. Além da área foliar total reduzida, muitas destas espécies são isohídricas, ou seja, mantêm seu potencial hídrico foliar $\left(\Psi_{\text {fol }}\right)$ ao longo de todo ano, inclusive nos períodos de seca. Para tal, as plantas desenvolveram estratégias que reduzem a perda de água por transpiração, como um eficiente controle estomático. A condutância estomática depende de muitos fatores e, em geral, as plantas apresentam características morfológicas e ajustes fisiológicos que garantem um equilíbrio entre a disponibilidade de água e a perda de água por transpiração. Dessa forma, durante a estação seca, quando há menos água disponível para a reposição do que foi perdida por transpiração, a condutância estomática pode ser 
muitas vezes menor quando comparada à estação chuvosa. Normalmente, o processo de fechamento estomático envolve uma comunicação entre as folhas e o sistema radicular, que detecta rapidamente a redução na disponibilidade hídrica do solo, desencadeando ajustes osmóticos necessários ao fechamento estomático. Além disso, muitas espécies contêm folhas que podem apresentar um conjunto de atributos que aumentam a resistência foliar ao fluxo de água contribuindo para a conservação de água nos tecidos. Em um estudo com Dalbergia miscolobium e D. nigra, mostramos como as folhas destas espécies exibem plasticidade quanto à luminosidade em que crescem, com características foliares que levam à conservação de água quando em ambientes de alta luminosidade (Figura 2). Folhas com estômatos em alta densidade e posicionados na face abaxial (inferior) da folha, quando eficientemente controlados, garantem uma eficiente troca gasosa durante o período de chuvas. Tais estômatos podem, por sua vez, estar recobertos por câmaras supraestomáticas que aumentam ainda mais a resistência à saída de água. Além disso, outras estratégias como uma cutícula espessa e de constituição química altamente hidrofóbica, uma alta densidade de tricomas, a presença de criptas na epiderme ou mesmo o desenvolvimento de folhas revolutas podem aumentar a camada limite como uma resistência adicional e são encontradas em diversas outras espécies vegetais.

Um eficiente controle estomático para contenção da transpiração em resposta ao aumento da demanda evaporativa pode não ser suficiente para manter o status hídrico foliar durante a estação seca. Nestes casos, outros mecanismos associados ao controle estomático contribuem para a homeostase do potencial hídrico foliar $\left(\Psi_{\text {fol }}\right)$. Dentre estes, podemos citar aqui a remobilização de reservatórios internos de água, incluindo o caule, mudanças nos padrões de absorção de água, e variações na arquitetura hidráulica das plantas. As folhas representam uma forte resistência ao transporte contínuo de água, que segue um fluxo iniciado no solo, passando pela planta até atingir a atmosfera. Há relatos de que as folha de espécies arbóreas do Cerrado são vulneráveis ao embolismo, $\operatorname{com} \Psi_{\text {fol }}$ altamente negativo. A recuperação destes danos sugere mudanças decorrentes do controle osmótico celular, que envolvem a injeção de solutos nas células adjacentes aos feixes vasculares nos pecíolos. 


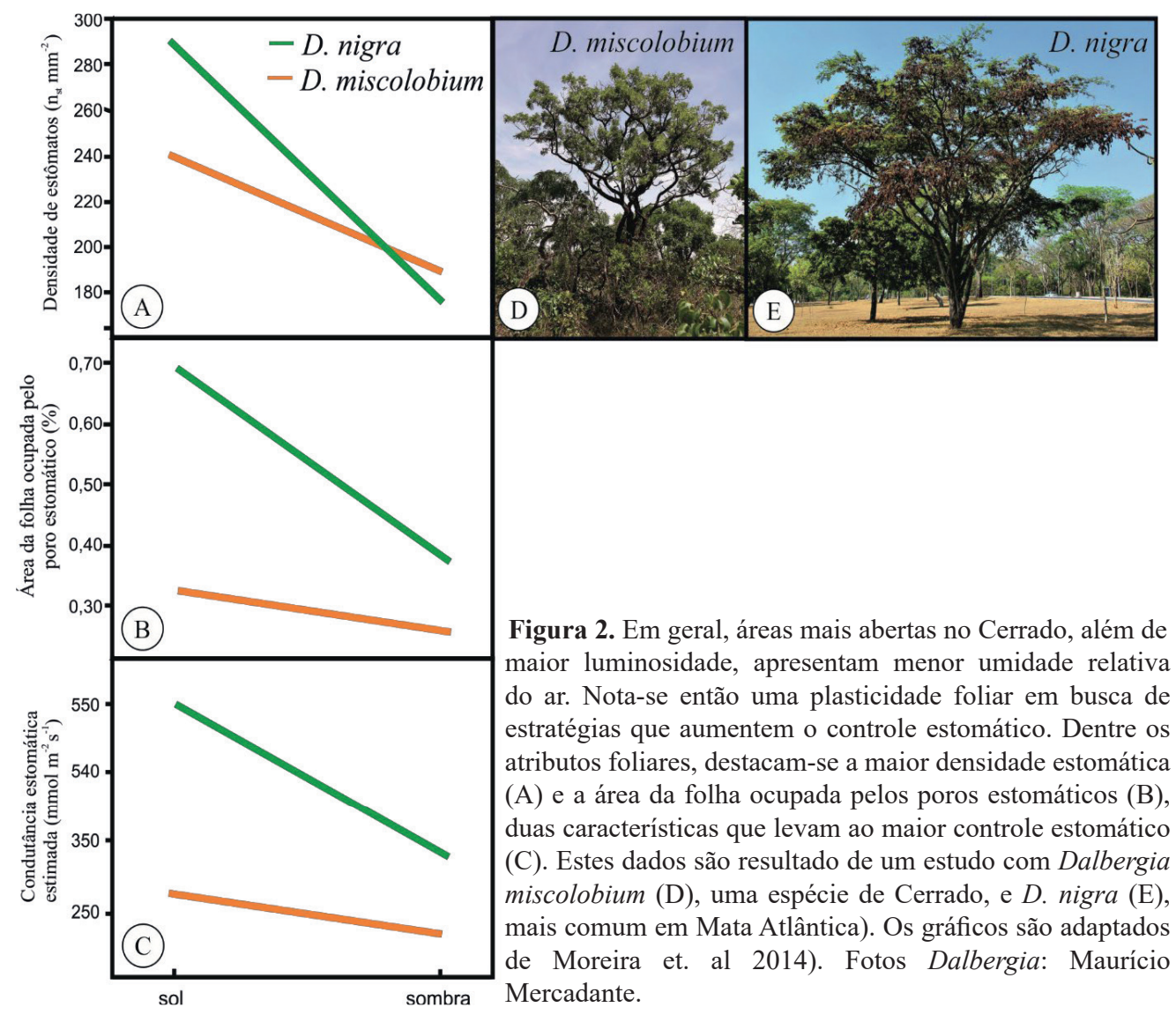

Apesar do caule e das folhas constituírem os órgãos vegetais acessíveis aos nossos olhos, as espécies podem canalizar o produto da fotossíntese expandindo seus sistemas radiculares em busca de água durante a estação seca. A manutenção de um sistema radicular longo e profundo apresenta alto custo energético para estas plantas, mas é uma das soluções para acesso aos recursos hídricos disponíveis nos lençóis freáticos do Cerrado. Acredita-se que boa parte das espécies arbóreas deste Bioma tenham mais que $50 \%$ de sua biomassa investida abaixo do solo, nos sistemas radiculares. Estes sistemas radiculares podem apresentar uma estrutura constituída por uma raiz principal profunda e um conjunto de raízes superficiais. Alguns trabalhos têm mostrado uma redistribuição da água entre estes sistemas radiculares. Nestes casos, durante a estação chuvosa, as raízes superficiais absorvem a água da chuva e transferem para a raiz principal, que a armazena nas regiões mais profundas do solo. Quando a estação seca chega, esta água é canalizada novamente até as raízes superficiais, num sistema de redistribuição que garante o suprimento de água para o fluxo contínuo nos vasos do xilema.

As savanas tropicais, incluindo o próprio Cerrado, são definidas por contínuos de cobertura graminosa entremeados por coberturas arbóreas descontínuas. Quanto mais abertas as savanas, mais dominante se torna o extrato graminoso. As gramíneas apresentam um sistema radicular superficial, o que torna este grupo altamente susceptível 
ao período de seca no Cerrado. Durante a estiagem, a maior parte das gramíneas tem sua biomassa aérea desidratada, sendo os recursos remobilizados para caules subterrâneos, os rizomas. No início das chuvas, os nutrientes são utilizados para a brotação de novos perfilhos. Entretanto, mesmo na presença de chuvas, grande parte das áreas dominadas pelas gramíneas no Cerrado apresenta solos com estrutura que favorece a percolação, com grande variação no potencial hídrico ao longo do dia. Nestes ambientes, as gramíneas $\mathrm{C}_{4}$ se tornaram dominantes e predominam nas savanas tropicais. $\mathrm{Na}$ Reserva Ecológica do Panga, realizamos um levantamento e foram identificadas 15 espécies de gramíneas, das quais apenas Echinolaena inflexa apresentou metabolismo $\mathrm{C}_{3}$. As demais espécies são plantas $\mathrm{C}_{4}$, assim denominadas por apresentarem metabolismo que difere do encontrado nas plantas comuns (que apresentam a conhecida via $\mathrm{C}_{3}$ ). Através da fixação do carbono atmosférico via fosfoenolpiruvato (PEP)-carboxilase formando um primeiro produto estável composto por quatro moléculas de carbono, elas separam espacialmente a entrada do $\mathrm{CO}_{2}$ no ciclo de Calvin através da ação da RuBisCO, a enzima responsável pela carboxilação e que geralmente se concentra na endoderme. Esta separação espacial reduz a fotorrespiração, aumentando o potencial de fixação de carbono destas espécies com relação às espécies $\mathrm{C}_{3}$ em ambientes quentes e abertos. Além disso, aumenta a eficiência do uso da água viabilizando o fechamento estomático nos horários de maior temperatura e menor umidade relativa do ar.

Apesar das formações florestais nas áreas de Cerrado apresentarem uma maior umidade do solo e do ar, é principalmente nestas áreas que se encontra um grupo de espécies que requerem outros tipos de especializações para absorção de água. $\mathrm{O}$ principal objeto de estudo do nosso grupo de pesquisa envolve plantas epífitas, ou seja, que crescem sobre outras em um ambiente onde, além da sazonalidade hídrica anual, devem lidar com uma variação diurna da umidade do ar, sua principal fonte de água. Estas plantas apresentam diversas estratégias que auxiliam na absorção e no armazenamento deste recurso. A presença de tricomas especializados na absorção de água (escamas) pelas bromélias (Figura 3), o velame nas raízes e a expressão do metabolismo CAM são exemplos que não podem deixar de ser citados. As escamas são encontradas em todas as espécies de bromélias, sendo uma estratégia eficiente para absorção de água. Estão distribuídas por toda a folha, podendo se concentrar em algumas regiões, como ocorre nas bromélias-tanque. Nestes casos, as escamas se concentram na região próxima ao tanque, maximizando o uso deste recurso. Estas bromélias apresentam uma organização das folhas em roseta capaz de reter a água da chuva no interior dos tanques formados. Conforme observado em nossos estudos com Aechmea distichantha, a idade e, portanto, o posicionamento das folhas dentro da roseta, determinam um maior investimento em tecidos armazenadores de água. A região da folha, próxima à base da roseta ou no ápice das folhas, também é determinante para o desenvolvimento dos tecidos, com maior investimento no tecido aquoso próximo ao tanque e do tecido clorofiliano próximo ao ápice foliar (que recebe mais luz para fotossíntese). Foram observadas variações inclusive em nível celular, com presença de pectinas de alta metil-esterificação no tecido de armazenamento de água, o que provavelmente proporciona elasticidade às células desse tecido.

Entre os estudos que merecem destaque neste tema encontram-se os que envolvem estratégias de absorção de água pelas raízes de epífitas. O velame consiste em uma epiderme morta que envolve as raízes de vários grupos de epífitas, como orquídeas, 
bromélias e aráceas. Na maioria das vezes é formado por inúmeras camadas celulares resultante de divisões celulares durante sua formação. Em um trabalho desenvolvido por nossa equipe e envolvendo 16 espécies de orquídeas foi mostrado que existe uma relação entre a espessura deste tecido e a capacidade de retenção de água. Além disso, o fato de não apresentarem conteúdo celular (já que estão mortas) e exibirem paredes celulares impregnadas por substâncias hidrofóbicas, como lipídios e lignina, ocorre um fluxo eficiente de água para o interior das raízes. Estes estudos indicaram que além da absorção de água, a manutenção de uma matriz péctica na parede celular do velame pode também ter uma relação direta com a captação de nutrientes minerais. Isso porque as pectinas apresentam uma carga negativa capaz de interagir com cátions e ânions carregados no fluxo de água.

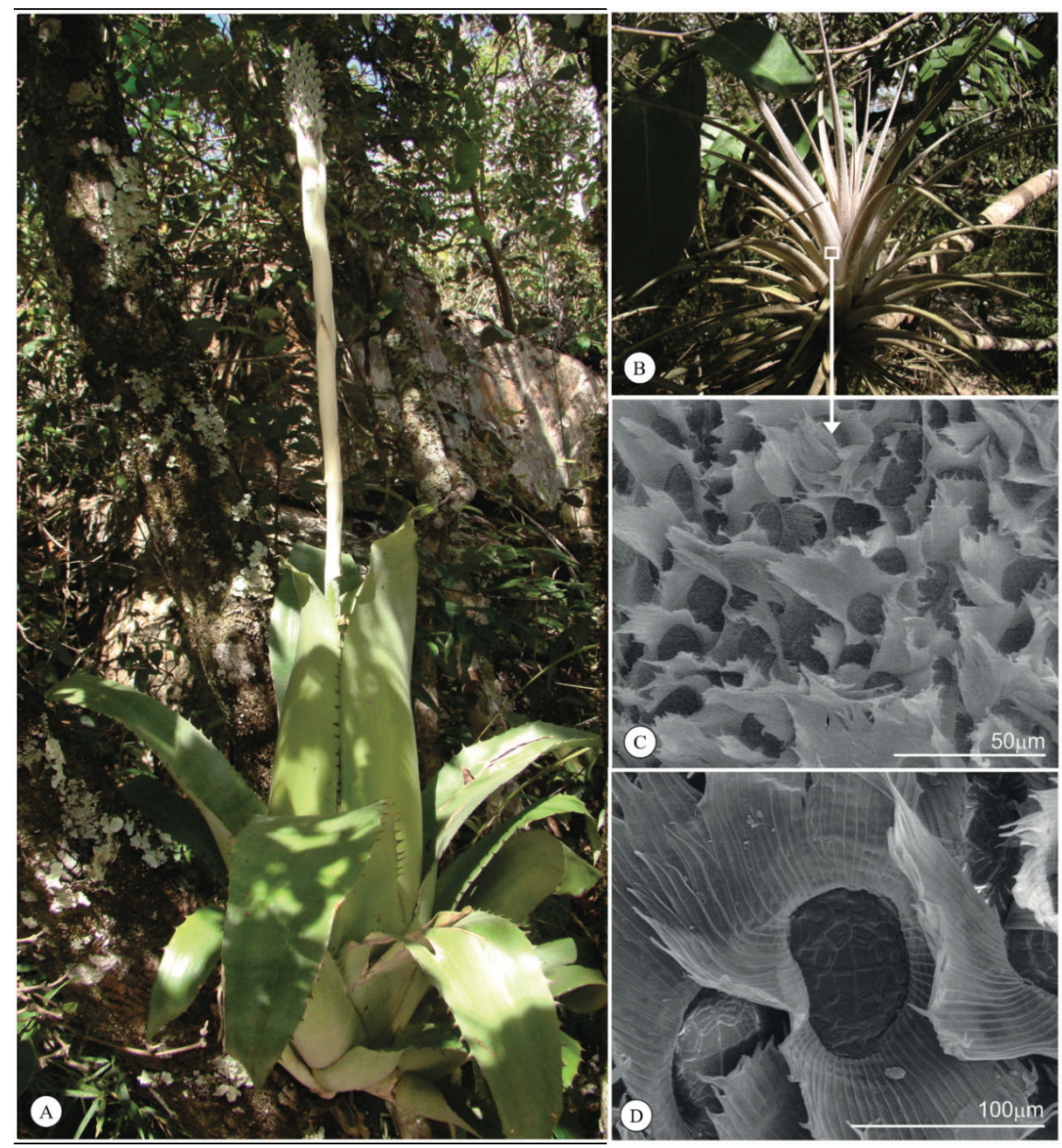

Figura 3. No Cerrado, existem mais de 256 espécies de bromélias, das quais 167 são endêmicas deste Bioma. Assim como as orquídeas e samambaias, muitas destas plantas são epífitas. Além da formação de tanques típicos de algumas espécies, a presença de tricomas peltados é uma característica exclusiva das bromélias e auxilia na absorção de água. Em (A) temos Aechmea distichantha, uma bromélia na qual a disposição de suas folhas forma um tanque capaz de armazenar água da chuva ou da umidade atmosférica. Em (B) temos Tillandsia stricta, uma espécie que não forma tanque. Mas, assim como as outras bromélias, as folhas de $T$. stricta apresentam na superfície grande quantidade de tricomas peltados, conhecidos como escamas (C). Em (D) podemos ver o detalhe de uma escama (C) e (D). Fotos em microscopia eletrônica de varredura. 
O metabolismo CAM aparece como outra estratégia para maior eficiência do uso da água, sendo amplamente encontrado em plantas epífitas e mesmo em algumas rupícolas (plantas que crescem sobre rochas, como nos afloramentos rochosos dos campos rupestres no Cerrado). Plantas com metabolismo CAM, em geral, são suculentas e apresentam estrutura morfológica que permite o armazenamento de água em seus tecidos ao longo de todo ano (conforme mostrado em nossos estudos com Bulbophyllum involutum e Vanilla bahiana), com células grandes e vacuoladas. O metabolismo CAM envolve, assim como nas plantas $\mathrm{C}_{4}$, a ação da PEP-carboxilase para fixação do $\mathrm{CO}_{2}$ atmosférico. Entretanto, aqui existe uma separação temporal; a abertura dos estômatos ocorre à noite, quando as temperaturas são mais amenas e a umidade relativa do ar é maior, reduzindo sensivelmente as taxas de transpiração e promovendo economia de água. Além disso, o $\mathrm{CO}_{2}$ atmosférico fixado na forma de ácidos orgânicos durante a noite, reduz o potencial hídrico destes órgãos no período de maior disponibilidade hídrica (início da madrugada) e aumenta a entrada de água. O efeito do metabolismo CAM sobre a capacidade de absorção de água por epífitas tem atualmente sido foco de estudo por nosso grupo.

Mais recentemente, alguns trabalhos tem mostrado a importância da absorção de água pelas folhas de plantas que crescem em áreas elevadas de Cerrado, onde comumente observa-se a presença de eventos de neblina. Nestas áreas, além da estação seca típica do Cerrado, nem há cursos de rios próximos ou lençois freáticos acessíveis às plantas. Desta forma, a absorção de água pelas folhas (FWU - foliar water uptake) torna-se uma importante fonte de recurso hídrico. Ela ocorre quando a água ultrapassa a superfície da folha em resposta ao gradiente de potencial hídrico causado pela diferença de pressão de vapor entre a atmosfera e o interior da folha, difundindo-se pelos tecidos foliares e promovendo sua hidratação. Embora a FWU represente uma pequena porção do teor de água que entra nas folhas em relação ao conteúdo total de água absorvido pelas raízes, essa absorção tem vários impactos sobre a fisiologia foliar: aumenta a hidratação das folhas e seu potencial hídrico, reduz a condutância estomática, aumenta a eficiência no uso da água e, portanto, melhora sua capacidade fotossintética. Muito pouco se conhece sobre este processo, e nada foi ainda descrito para espécies epífitas. Por isso, o tema tem sido assunto em nosso grupo de pesquisa.

\section{Sobrevivendo à passagem do fogo}

Acredita-se que a origem do Cerrado esteja associada à recente expansão de gramíneas $\mathrm{C}_{4}$ e seu potencial como combustível. A alta produtividade destas gramíneas, combinada com sua rápida desidratação na estação seca e a baixa taxa de decomposição destas plantas, as tornam combustíveis altamente inflamáveis, fazendo do fogo um agente frequente no Cerrado durante a estação seca. Sua ação nas áreas de Cerrado é tão significativa que, além de adaptações específicas das espécies, juntamente com propriedades do solo e a sazonalidade hídrica, a frequência do fogo é considerada um dos maiores determinantes para as formações abertas de vegetação do Cerrado.

Uma diversidade de características das plantas do Cerrado permite sua sobrevivência à passagem do fogo. Dentre elas, podemos citar a alocação de biomassa em órgãos subterrâneos e a presença de gemas que permitem a rebrota não apenas após a estiagem, mas também após o fogo. Podem ser consideradas ainda a presença 
de uma casca espessa que protege os tecidos internos, espessos meristemas terminais protegidos por estípulas que os tornam mais resistentes ao fogo, e estratégias fenológicas e reprodutivas, incluindo uma rápida maturidade e floração induzida no pós-fogo (Figura 4). Os trabalhos desenvolvidos por nosso grupo de estudo muito pouco abordam sobre o efeito do fogo em plantas do Cerrado. Entretanto, em um estudo envolvendo os alunos de pós-graduação e utilizando Vochysia cinnamomea como modelo, foi mostrada a resiliência destas plantas à passagem do fogo. A partir deste estudo, ficou evidente que as folhas jovens dessa espécie não apresentavam danos relativos ao potencial fotossintético no pós-fogo quando comparadas com folhas jovens de plantas que permaneceram em áreas que não foram atingidas pelo fogo.

Apesar da temperatura do fogo no Cerrado poder atingir até os $500^{\circ} \mathrm{C}$, no subsolo estas temperaturas não são tão acentuadas e causam pouco ou nenhum dano aos órgãos subterrâneos. Então, quando falamos de sistemas subterrâneos no Cerrado, falamos de uma diversidade morfológica com expressiva biomassa, que em alguns casos pode representar até $70 \%$ da biomassa vegetal na comunidade. Em algumas plantas, o sistema radicular pode atingir um diâmetro de mais de oito metros, de modo que alguns autores atribuam inclusive o termo "arvore subterrânea"! Além do sistema radicular profundo, a lignificação nos xilopódios protege do aumento da temperatura e sua estrutura anatômica, tanto radicular como caulinar, com grande número de gemas, confere alta capacidade de brotação.

\section{Condições limitantes do solo}

Embora a sazonalidade hídrica e a ação do fogo exerçam uma grande influência sobre a distribuição da vegetação e a ecofisiologia das plantas do Cerrado como um todo, fatores edáficos também são importantes. Entre estes, os mais relevantes são a fertilidade do solo (disponibilidade de nutrientes para as plantas) e sua profundidade efetiva, determinada pela presença de concreções no perfil do solo e profundidade do lençol freático em sua superfície. Fatores relacionadas à fertilidade do solo $(\mathrm{Ca}, \mathrm{Mg}, \mathrm{N}$ e P), teores de alumínio e textura são as variáveis mais estudadas. Estes atributos podem mostrar efeitos no crescimento de plantas que impactam a estrutura da comunidade por meio de seus efeitos sobre e/ou dentro das populações. Assim, estudos que verificam a relações solo $\times$ vegetação são extremamente relevantes, pois possibilitam maior entendimento dos processos que governam as comunidades vegetais e a distribuição de espécies. 


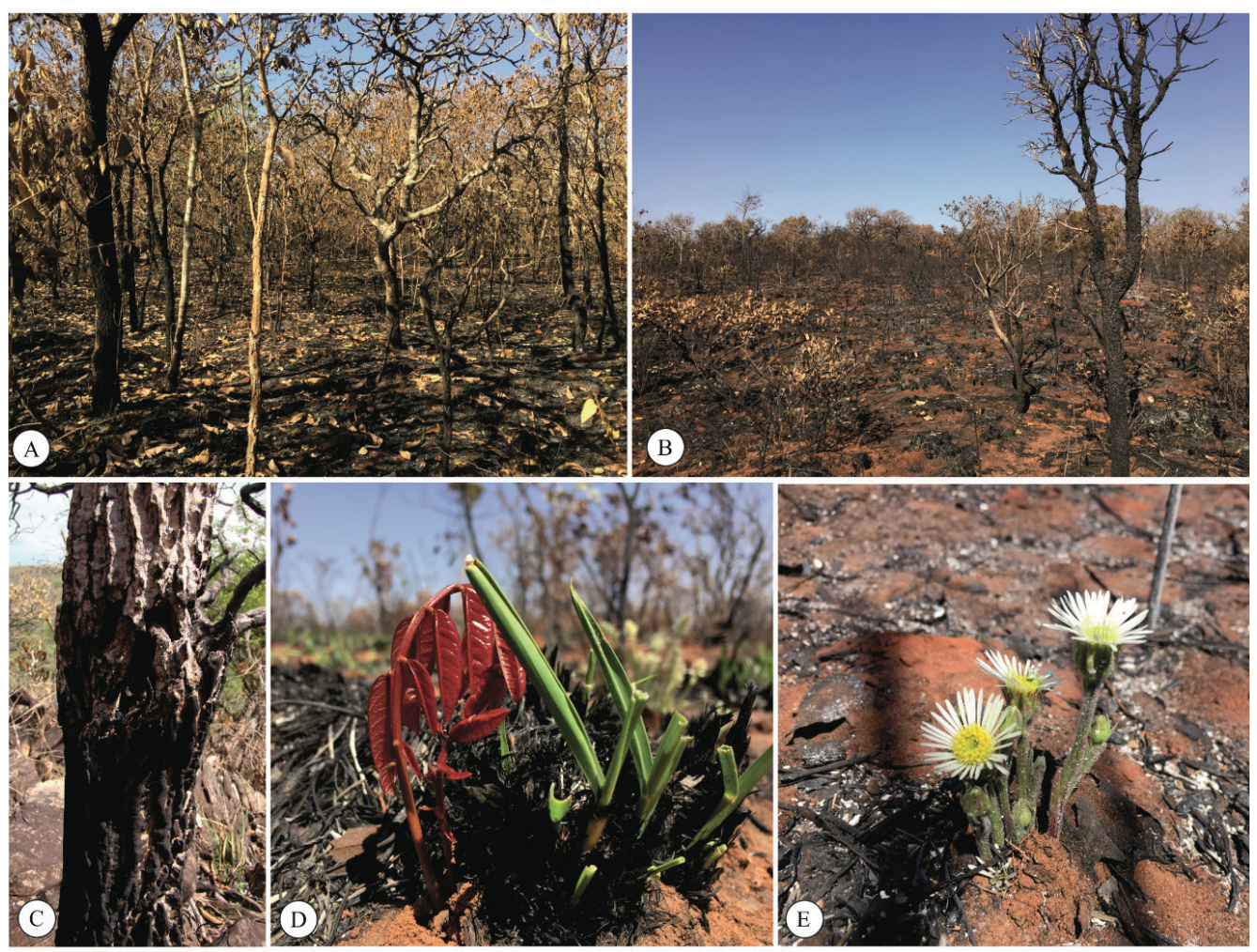

Figura 4. Área de cerrado na Reserva Ecológia do Panga, município de Uberlândia após queimada em 2017 (A-C) e 15 dias após a passagem do fogo (D e E). A reserva representa uma área de conservação dentro do sítio PELD-TMSG, sendo constituída por diferentes fitofisionomias. Em A) observa-se uma área de Cerrado sensu stricto e em B) uma área de campo sujo. Em C) podemos observar uma casca espessa que auxilia a proteção dos tecidos internos da planta. Em D) temos a brotação 15 dias após a passagem do fogo a partir de órgãos subterrâneos, e em E) a floração de uma margarida-do-cerrado (Inulopsis camporum (Gardner) (G.L.Nesom), uma estratégia apresentada também por outras espécies do Cerrado.

O Cerrado apresenta uma diversidade impressionante de tipos de solo, com propriedades significativamente diferentes; porém, vale a pena fazer uma série de amplas generalizações. Os latossolos são predominantes e ocupam mais de 50\% da região, sendo o restante constituído principalmente por neossolos, cambissolos e argissolos. Os solos arenosos também estão presentes, podendo cobrir até 15\% da área. A maioria dos solos de cerrado é bem drenada e frequentemente profunda. Sua textura é variável, mas a maioria é rica em argilas responsáveis pela maior parte do comportamento do solo, como características de troca iônica, retenção de água e adsorção de fosfato. Outras características comuns são sua acidez, com baixa capacidade de troca catiônica (apesar de um conteúdo de matéria orgânica moderado), altos níveis de saturação de alumínio (Al) e baixa disponibilidade de nutrientes. A maioria dos nutrientes derivados de rocha está em baixas concentrações e ligada em formas altamente recalcitrantes. Os solos do Cerrado são profundos e com vários horizontes, mas na sua porção superficial, a capacidade de troca cationica é muito baixa e a saturação de Al está acima de $50 \%$, o que pode ser considerado tóxico para a maioria das plantas, afetando diretamente os sistemas radiculares e inibindo indiretamente a captação de cálcio $(\mathrm{Ca})$ e fósforo $(\mathrm{P})$. 
A maioria dos solos do Cerrado possui conteúdo relativamente grande de matéria orgânica e, portanto, deposição de nitrogênio $(\mathrm{N})$. Porém, esses solos são geralmente deficientes em N, uma vez que este nutriente é lixiviado (os solos são altamente permeáveis e a intensidade das chuvas na estação chuvosa é alta) ou perdido na atmosfera durante os incêndios, dependendo da intensidade do fogo. As taxas lentas de mineralização desse nutriente durante a estação seca também contribuem para sua aparente baixa disponibilidade. A importância da limitação pelo $\mathrm{N}$ é bem evidenciada nas escalas individual e ecossistêmica, mas o $\mathrm{P}$ também contribui para a limitação da produtividade. As relações N:P foliares das espécies do Cerrado (valor médio de 18), reforçam a ideia de uma colimitação N-P nesse ambiente. No entanto, os valores estequiométricos dependem das necessidades metabólicas e, consequentemente, diferem entre os táxons, a vegetação e os tipos de tecidos, e entre plantas com idade ou estágio de vida contrastantes.

Com baixa disponibilidade de nutrientes e regime hídrico limitado, as especializações subterrâneas (como as micorrizas) são características-chave que permitem a sobrevivência das plantas. Estas dependem diretamente, portanto, do desempenho dos fungos micorrízicos para sobreviver, tornando a associação entre fungos e plantas um importante fator de resiliência a situações estressantes. Essa associação foi documentada para um grande número de plantas nativas da região, incluindo gramíneas, leguminosas como sene-do-campo (Cassia cathartica) e patade-vaca-do-Cerrado (Bauhinia holophylla), espécies arbustivas como a ata brava (Duquetia furfuraceae) e a carobinha (Jacaranda decurrens), e espécies arbóreas como o pequi (Caryocar brasiliense), a guabiroba-do-Cerrado (Campomanesia coerulea) e o buriti (Mauritia flexuosa). Essa associação entre plantas e fungos no Cerrado é tão importante que $67 \%$ das 79 espécies de fungos micorrízicos arbusculares encontradas nos biomas brasileiros foram identificadas no Cerrado. Em nossos estudos com orquídeas, é comum encontrarmos espécies com um tipo particular de micorrizas que formam aglomerados de hifas denominadas "pelotons" (Figura 5). Estas micorrizas instalam-se no córtex radicular e os "pelotons" mantém a conexão entre o ambiente e a planta. Quando necessário, a planta promove degradação dos "pelotons" em uma atividade altamente controlada para a manutenção da integridade celular e a absorção dos nutrientes liberados. 


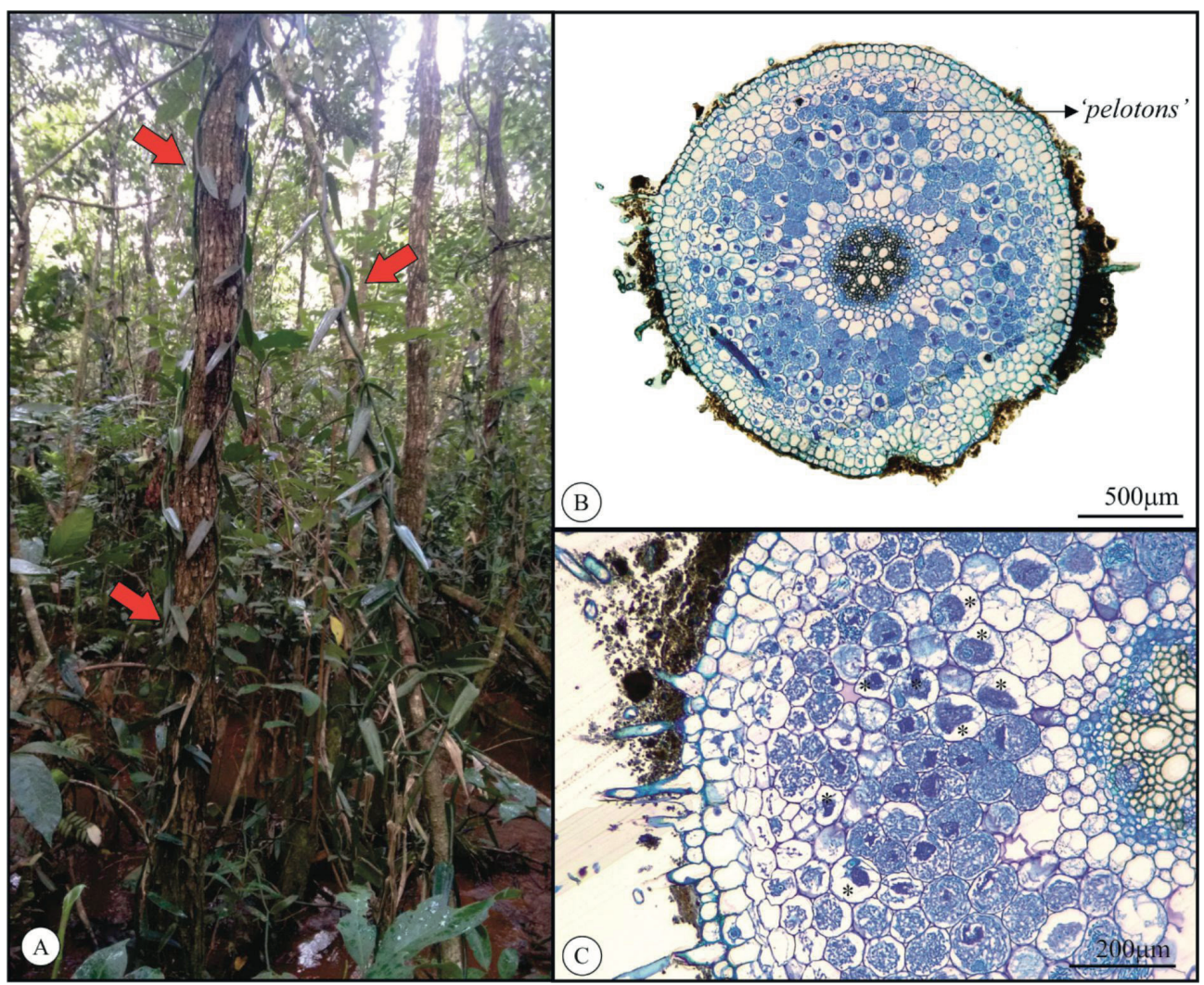

Figura 5. As Vanilla são orquídeas do gênero da baunilha. Este gênero é formado por hemiepífitas, ou seja, plantas que nascem no solo e crescem sobre o tronco de árvores em busca de luminosidade. Assumem então a condição de epífitas, podendo ou não se manter conectadas ao solo. Vanilla bahiana (A - setas) é uma espécie também encontrada no Cerrado e por isso alvo de estudo do nosso grupo de pesquisa. Ela apresenta raízes aéreas quando epífitas, e raízes que se conectam ao solo nas regiões mais próximas ao chão. As raízes terrestres apresentam uma alta taxa de infestação, frequentemente observada na forma de aglomerados de hifas denominados "pelotons" (B- observar a maioria das células). Quando necessário, a planta degrada estes "pelotons" (asteriscos no detalhe em C) e absorve os nutrientes liberados. B e C, fotos em microscopia óptica.

\section{Mudanças no uso da terra}

Do ponto de vista agronômico, o problema da baixa fertilidade dos solos do Cerrado se encontra principalmente na sua acidez e na alta disponibilidade de Al que acaba limitando a capacidade de troca catiônica. A maioria dos solos do Cerrado é muito profunda e bem drenada, com uma estabilidade muito boa dos microagregados, além de ocorrer sobre topografia nivelada ou suavemente ondulada com declives suaves (geralmente abaixo de 3\%). Portanto, embora não sejam naturalmente férteis agronomicamente falando, os solos do Cerrado possuem uma combinação de fatores que possibilitam a mecanização e são passíveis de fertilização. Com isso, aproximadamente 80 milhões de hectares de sua área já foram convertidos. Isso corresponde a cerca de $56 \%$ do total de terras adequadas para agricultura intensiva neste bioma, que é de aproximadamente 135 milhões de hectares (estimativa baseada nas propriedades físicas do solo e na topografia). As pastagens cultivadas (principalmente por Brachiaria spp.) são a atividade antrópica dominante, ocupando mais de 25\% desse bioma. Em Minas 
Gerais, as pastagens cultivadas se encontram principalmente na região do Triângulo Mineiro, onde apenas $25 \%$ da vegetação original ainda é preservada e se encontra de forma fragmentada. Isso está muito abaixo da porcentagem média de vegetação natural encontrada no estado: $41 \%$.

Outro grave problema relacionado à mudança do uso da terra diz respeito ao aumento da deposição de nitrogênio nos ecossistemas naturais através da intensificação do uso de fertilizantes agrícolas. A introdução antropogênica de nutrientes amplificou os ciclos globais de N e P em 100\% e 400\%, respectivamente, após a Revolução Industrial. Estima-se que a deposição atmosférica de $\mathrm{N}$ seja de aproximadamente $4 \mathrm{~kg} \mathrm{~N} \mathrm{Na}^{-1} \mathrm{ano}^{-1}$. As entradas de fósforo são substancialmente mais baixas, com a deposição atmosférica variando de 0,014 a 0,3 $\mathrm{kg} \mathrm{P} \mathrm{ha}^{-1}$ ano $^{-1}$. Essa deposição de nutrientes, especialmente $\mathrm{N}$, cresce anualmente e estima-se um aumento de 1 a $10 \mathrm{Kg} \mathrm{N} \mathrm{ha}^{-1}$ ao ano no Cerrado, com uma previsão para o ano de 2050 entre $25 \mathrm{Kg} \mathrm{N} \mathrm{ha}^{-1}$ (cenário otimista) e $50 \mathrm{Kg} \mathrm{N}^{-1}$ (cenário pessimista).

Diante deste contexto, uma das propostas dentro do PELD-TMSG envolve uma área experimental dentro da Reserva Ecológica do Panga. No experimento, $\mathrm{N}$ e mais recentemente $\mathrm{P}$, são anualmente acrescidos à uma área de cerrado $\left(50 \mathrm{~m}^{2}\right)$ desde 2007 , com intuito de acompanhar mudanças na estrutura da vegetação e detectar respostas ecofisiológicas que ajudem a compreender possíveis alterações nas populações. $\mathrm{O}$ aumento da deposição de nutrientes em ecossistemas naturais, juntamente com as mudanças no uso da terra e as mudanças climáticas, foi um importante determinante da perda de biodiversidade ao longo do século passado e está entre os três maiores condutores de mudanças na biodiversidade mundial até o ano de 2100 . No entanto, o crescimento de plantas nativas em ecossistemas de solos pobres quase nunca responde à adição de nutrientes, e essas plantas podem até experimentar toxicidade dos elementos adicionados. O aumento da disponibilidade de nitrogênio em áreas naturais, principalmente em regiões com baixa disponibilidade deste nutriente, pode afetar vários processos ecológicos em diferentes escalas temporais e espaciais. Dentre os principais efeitos que observamos, estão a produção de pigmentos e o rendimento fotossintético de algumas espécies, já que estes processos fisiológicos dependem diretamente do $\mathrm{N}$. A maior disponibilidade de nitrogênio também desempenha um papel importante no processo de invasões biológicas especialmente de gramíneas africanas. Em um trabalho em preparação, verificamos que as parcelas na área estudada com suplementação de $\mathrm{N}$ apresentaram maior entrada da espécie exótica Urochloa decumbens. Essas espécies invasoras podem obter vantagem sobre espécies nativas em áreas abertas e ensolaradas devido a seu ciclo reprodutivo e rebrota rápidos, à tolerância a herbivoria e ao alumínio, suas maiores taxas de fotossíntese e sua eficiência do uso de nutrientes, além de terem seu crescimento e dispersão fortemente responsivo à fertilidade do solo. Algumas espécies nativas, por serem mais raras, estariam mais ameaçadas devido ao tamanho reduzido de suas populações e apresentariam alta probabilidade de extinção local com esse possível aumento na entrada de espécies invasoras.

\section{Considerações finais}

A forte presença de árvores sempre-verdes no cerrado é provavelmente uma consequência de sua capacidade de extrair água de profundidades consideráveis durante a estação seca. Isso pode ocorrer porque a maioria dos solos do Cerrado é profunda e 
com boas características de retenção de água, como mencionado anteriormente. Além disso, estratégias para o eficiente controle estomático estão presentes e envolvem tanto ajuste osmótico quanto características morfológicas (como a densidade de estômatos). As árvores decíduas e brevidecíduas empregam uma estratégia ecofisiológica alternativa, que é uma redução nas necessidades de água por passarem um período sem folhas na estação seca. Isso permite uma maior alocação de recursos para a produção de raízes superficiais, o que, por sua vez, permite a ocorrência de taxas mais altas de captação de nutrientes. Em áreas florestais do Cerrado, mesmo com maior umidade, encontramos uma variedade de plantas epífitas que também sofrem pelas flutuações na disponibilidade de água. Estas plantas também apresentam estratégias específicas, como a presença de escamas nas bromélias e do velame nas orquídeas. Do ponto de vista fisiológico, foram citados o metabolismo $\mathrm{C}_{4}$, o metabolismo CAM e a absorção de água pelas folhas.

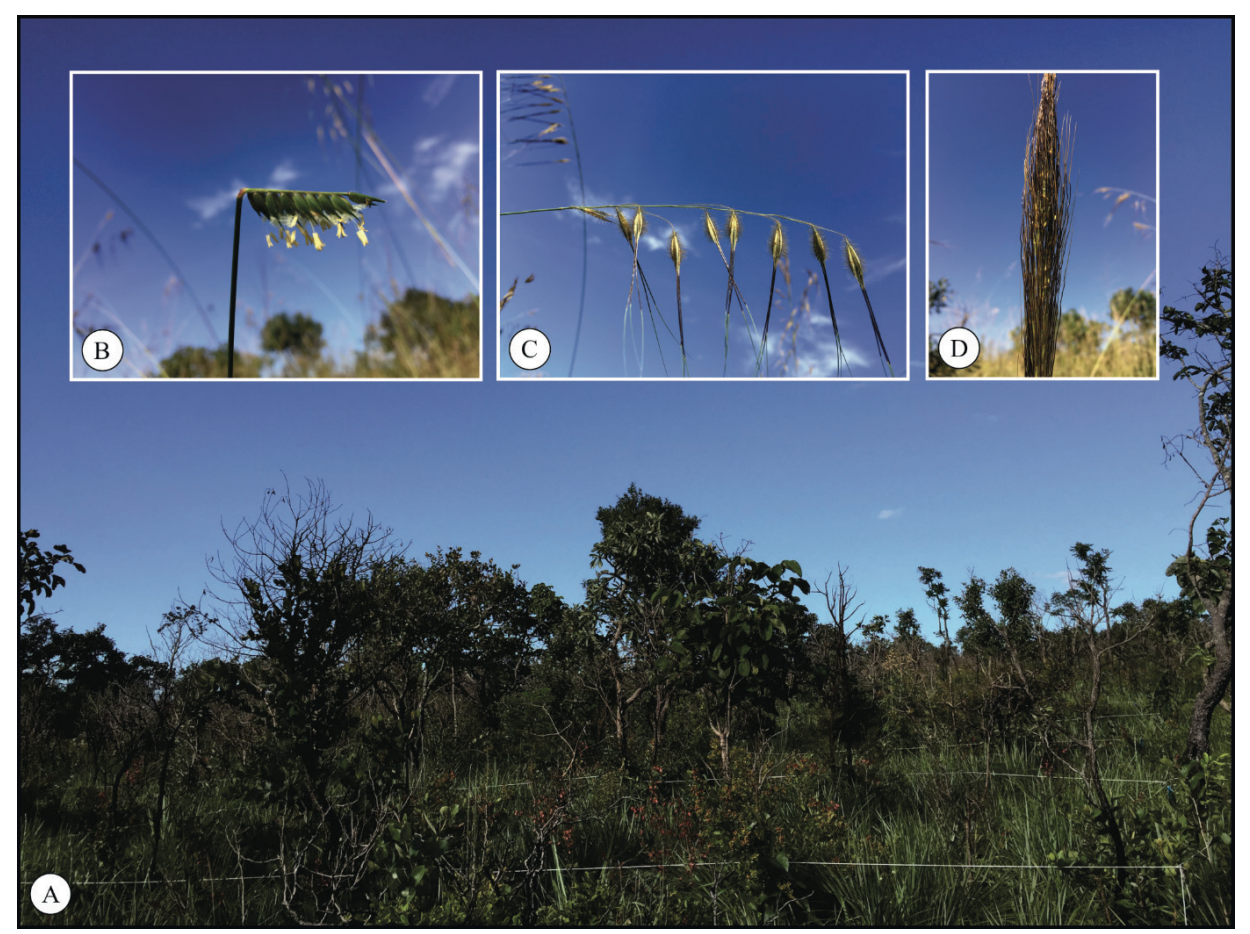

Figura 6. Dentro do PELD-TMSG, uma área experimental é acompanhada para avaliar respostas ecofisiológicas e mudanças na estrutura da vegetação a longo prazo decorrentes do enriquecimento de nitrogênio simulando o aumento da deposição atmosférica em virtude de atividades antrópicas como queima de combustíveis e fertilização em grande escala. Em (A) temos a área experimental dentro da Estação Ecológica do Panga, com algumas das espécies de gramíneas acompanhadas. Em (B) Echinolaena inflexa, (C) Tristachya leiostachya e (D) Schizachyrium sp.

Parece bastante provável que as características ecofisiológicas das árvores e gramíneas do Cerrado também contribuam para manter um ecossistema com baixa quantidade de $\mathrm{N}$ por meio de vários mecanismos, tais como as características esclerófilas das folhas de árvores (em particular das sempre-verdes): menor área foliar específica e baixo teor de nutrientes, mas também pela presença de níveis relativamente altos de lignina e fenóis, que servem para impor significantes restrições à mineralização do $\mathrm{N}$. 
Essa baixa mineralização de $\mathrm{N}$, juntamente com fatores como o fogo, provavelmente contribuiram para tornar o ecossistema do Cerrado, em certa medida, autossustentável.

\section{Para saber mais}

Abrahão A, Costa PB, Lambers H, Andrade SAL, Frankland Sawaya ACH, Ryan MH, Oliveira RS (2019) Soil types select for plants with matching nutrient-acquisition and -use traits in hyperdiverse and severely nutrient impoverished campos rupestres and cerrado in Central Brazilian J Ecol 107:1302-1316 doi: 10.1111/1365-2745.13111

Bucci SJ, Scholz FG, Goldstein G, Meizer FC, Franco AC, Zhang Y, Hao GY (2008) Water relations and hydraulic architecture in Cerrado trees: adjustments to seasonal changes in water availability and evaporative demand. Braz J Plant Physiol 20:233-245 doi: 10.1590/S1677-04202008000300007

Carvalho GH, Batalha MA, Silva IA, Cianciaruso MV, Petchey OL (2014) Are fire, soil fertility and toxicity, water availability, plant functional diversity, and litter decomposition related in a Neotropical savanna? Oecologia 175:923-935 doi: 10.1007/ s00442-014-2937-3

Franco AC, Rossatto DR, Silva LCR, Ferreira CS (2014) Cerrado vegetation and global change: the role of functional types, resource availability and disturbance in regulating plant community responses to rising $\mathrm{CO}_{2}$ levels and climate warming. Theor Exp Plant Physiol 26:19-38 doi: 10.1038/ncomms1191

Furley PA, Ratter JA (1988) Soil resources and plant communities of the central Brazilian cerrado and their development. J Biogeogr 15:97-108

Moreira ASFP, Queiroz ACL, Barros FV, Goulart MF, Lemos-Filho JP (2014) Do leaf traits in two Dalbergia species present differential plasticity in relation to light according to their habitat of origin? Aust J Bot 61:592-59 doi: 10.1071/BT13248

Simon MF, Pennington T (2012) Evidence for adaptation to fire regimes in the tropical savannas of the Brazilian Cerrado. Int J Plant Sci 173:711-723 doi 10.1086/665973 


\title{
CAPÍTULO 15
}

\section{POLINIZAÇÃO E REPRODUÇÃO DE PLANTAS DO CERRADO}

\author{
João C. F. Cardoso \\ Pietro K. Maruyama \\ Vinícius L.G. Brito \\ Bianca B. Rosa \\ Filipe de Deus \\ Paulo E. Oliveira
}

As plantas com flores (angiospermas) representam cerca de $90 \%$ de todas as espécies de plantas e dominam amplamente as formações vegetais, especialmente nas regiões tropicais do planeta. A razão desta diversidade e dominância parece estar na interdependência destas plantas com os polinizadores, especialmente insetos. Estes polinizadores permitem o transporte eficiente de pólen a longas distâncias, garantindo a reprodução sexuada destas plantas. Atualmente a maior diversidade das angiospermas é encontrada em florestas tropicais. Mas a diversidade vegetal é igualmente alta em ambientes tropicais não florestais (ATNF) ao redor do globo. Estes ambientes, especialmente as savanas tropicais, são menos carismáticos e têm historicamente recebido menos interesse das agências de fomento e iniciativas de conservação. Porém, as savanas tropicais cobrem $20 \%$ da superfície do planeta e contribuem com aproximadamente $30 \%$ da produtividade primária do planeta, isto é, quase um terço do carbono fixado e da fotossíntese global. Ao mesmo tempo, estas áreas abrigam $20 \%$ da população humana e a maior parte das áreas ativas para agropecuária no mundo. As savanas tropicais, que no Brasil formam o domínio do Cerrado, são ATNFs muito importantes ecológica-, econômica- e culturalmente. Este bioma é o segundo maior da América do Sul ocupando cerca de $22 \%$ do território brasileiro. O Cerrado é considerado um hotspot (bioma prioritário para conservação) uma vez que apresenta uma elevada riqueza de espécies, incluindo espécies exclusivas do bioma (endêmicas) e sofre uma drástica degradação de habitat. Na verdade, o Cerrado constitui a savana mais rica do mundo. É neste domínio que se insere a área focal de estudos do Programa Ecológico de Longa Duração "Triângulo Mineiro e Sudeste de Goiás" (PELD TMSG). Neste capítulo, apresentamos as características gerais dos processos reprodutivos das angiospermas e interação com polinizadores, realçando a importância destes processos para a biodiversidade da região. 


\section{Biologia reprodutiva de plantas do Cerrado}

Assim como em outras áreas tropicais, a maioria das plantas do Cerrado dependem de vetores bióticos para completar o seu ciclo reprodutivo. No processo de polinização, aproximadamente $90 \%$ das espécies tropicais dependem de vetores bióticos, uma vez que estas não somente têm flores chamativas que atraem tais vetores, mas também possuem mecanismos morfológicos e/ou fisiológicos que exigem o transporte de pólen entre plantas diferentes. Assim, o serviço dos polinizadores é indispensável para a reprodução dessas espécies. Além disso, mesmo em fisionomias mais abertas do Cerrado, onde algumas plantas herbáceas (especialmente gramíneas) são polinizadas pelo vento, existe o predomínio de espécies que dependem de animais para completar o ciclo reprodutivo.

No entanto, nem todas as espécies do Cerrado são dependentes de polinizadores. Algumas plantas apresentam mecanismos de reprodução autônomos, desde polinização espontânea/autônoma (autogamia) até mecanismos de multiplicação vegetativa (como gemação e rebrotação). A autopolinização autônoma ocorre quando plantas depositam pólen nas próprias flores, sem precisar de quaisquer agentes de polinização. Isso pode ocorrer em plantas com flores bissexuais (com órgãos masculinos e femininos, respectivamente anteras e estigmas) através da redução da distância entre os diferentes órgãos, permitindo assim a autodeposição. Estas alternativas reprodutivas incluem ainda mecanismos de apomixia, que é a formação de sementes sem que haja fecundação dos óvulos. A apomixia comumente resulta na formação de embriões que são menos variáveis geneticamente. Mas, mesmo nestes processos de apomixia, as sementes nem sempre são clones dos indivíduos parentais. A apomixia envolve recombinação e pode gerar variabilidade. Além disso, é muito comum ocorrer, concomitantemente à apomixia, eventos de reprodução sexuada num processo chamado de apomixia facultativa. Neste caso, os sacos embrionários não reduzidos ocorrem junto com outros sacos embrionários formados por meiose normal. Em outros casos, como na apomixia esporofítica, a formação dos embriões adventícios comumente depende de um endosperma formado após fertilização e reprodução sexuada, de maneira que embriões apomíticos e sexuados coexistam numa mesma semente (Figura 1).

De qualquer modo, estes processos de apomixia, descritos com frequência para plantas do Cerrado, permitem uma flexibilidade maior do processo reprodutivo, favorecendo a persistência e distribuição de espécies. Assim, a apomixia parece 1) diminuir a dependência das plantas de vetores bióticos, 2) ampliar o sucesso de formação de sementes, 3) permitir a origem uniparental de populações e 4) aumentar as chances de colonização de novas áreas após eventos ou períodos de limitação ambiental. Essa segurança reprodutiva pode ser importante também para plantas em situações de pressão ambiental ou por modificações resultantes da expansão da agricultura e outras atividades humanas. 


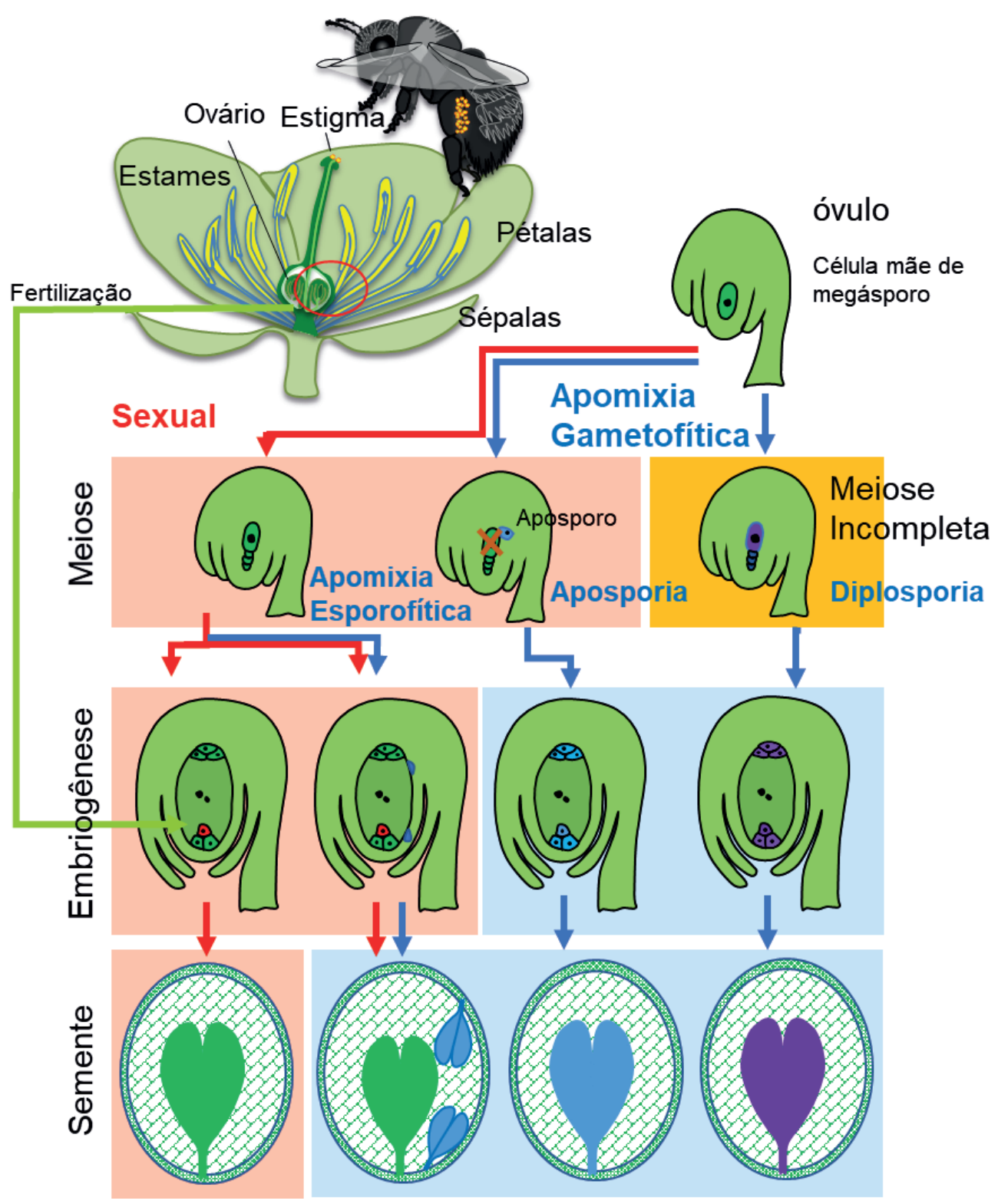

Figura 1. Sistemas de reprodução nas angiospermas. Nas flores, o processo sexual de formação das sementes normalmente envolve a meiose e formação de um saco embrionário haploide. A polinização e a fertilização pelos tubos polínicos dão origem a embriões geneticamente variáveis. Mas pode ocorrer a formação de embriões adventícios a partir de células do núcleo ou tegumentos, num processo denominado apomixia esporofítica. Estes embriões seriam basicamente clonais e podem coexistir com embriões sexuados numa mesma semente. O processo de meiose também pode ser suprimido por completo e uma das células do óvulo se desenvolver em um embrião. Este tipo de apomixia gametofítica denominada aposporia pode dar origem a um saco embrionário não reduzido e a sementes com embrião clonal. Mas a meiose em alguns casos pode ser incompleta, dando origem a um processo denominando diplosporia. Neste tipo de apomixia gametofítica, pode haver recombinação associada a fase I da meiose, mas a fase II é interrompida ou anômala, não ocorrendo a formação de um saco embrionário reduzido. A oosfera ou outras células deste saco embrionário podem dar origem a sementes com embriões que apresentam alguma variabilidade genética quando comparados com as plantas-mãe. 
$\mathrm{Na}$ verdade, muitas plantas invasoras e adaptadas às condições dos ambientes antropizados são apomíticas. Apesar de garantir a segurança reprodutiva sem depender de polinização biótica, mecanismos como a autopolinização espontânea e apomixia podem trazer consequências como redução da variabilidade genética da prole e depressão endogâmica, que se relaciona a perda de vigor das gerações futuras.

Apesar de algumas plantas apresentarem reprodução autônoma ou facilitada pela apomixia, a maioria requer polinização cruzada por meio do transporte de pólen entre indivíduos diferentes, e têm mecanismos que potencializam a alogamia (fertilização com pólen oriundo de diferentes flores/indivíduos). Se por um lado estas plantas são dependentes de polinizadores, por outro lado elas acumulam maior variação genética e parecem ter maior sucesso em ambientes heterogêneos como os do bioma Cerrado. Os gradientes de formações vegetais e a distribuição continental destas savanas favorece a adaptação dessas plantas a microambientes com diferenças na disponibilidade de água, nutrientes, luminosidade e até mesmo na densidade e intensidade de competição com outras plantas. Neste contexto, a reprodução sexuada provê a diversidade genética e adaptabilidade necessárias para as plantas da região. Apesar de durante muito tempo ter se acreditado que as plantas do Cerrado seriam limitadas por fatores abióticos, que restringiriam a capacidade de reprodução e forçariam a multiplicação vegetativa, a maioria das plantas desse bioma depende de polinizadores e requer polinização cruzada.

As plantas lenhosas de Cerrado são mais bem estudadas neste sentido. Essas parecem ter relações com grupos de árvores de florestas tropicais e compartilham com elas a grande diversidade de sistemas de polinização e mecanismos para promover polinização cruzada (alogamia). As árvores tropicais utilizam abelhas e outros animais para promover o transporte de pólen a grandes distâncias, as vezes mais do que uma dezena de quilômetros. Elas apresentam, ainda, mecanismos morfológicos ou fisiológicos para estimular a polinização cruzada. Por exemplo, espécies comuns e ecologicamente importantes no Cerrado pertencentes às famílias Rubiaceae, Erythroxylaceae e Turneraceae apresentam heterostilia. Nesse sistema floral, a polinização somente é possível entre indivíduos que possuem flores com morfologia e fisiologia diferentes (morfos), e não entre plantas semelhantes. Além da heterostilia, a dicogamia (liberação de pólen e receptividade estigmática em momentos diferentes) e a dioicia (produção de flores femininas e masculinas em indivíduos diferentes) são mecanismos extremos que obrigam fluxo de pólen entre flores. Mas as plantas podem ter mecanismos fisiológicos controlados geneticamente que são chamados de uma maneira geral de mecanismos de autoincompatibilidade. Estes mecanismos podem ser diferentes em termos de funcionamento, mas têm em comum o fato de impedirem a formação de frutos por autopolinização, evitando problemas de endogamia e depressão endogâmica, além de promover a variabilidade genética da progênie.

Estes mecanismos tornam as árvores tropicais dependentes de polinizadores e a suareprodução somente acontece se as flores forem capazes de atrair visitantes efetivos que consistentemente depositam o pólen em flores de outros indivíduos da mesma espécie. Assim, no processo de polinização mediada por polinizadores, os mecanismos de atração são fundamentais. Estes envolvem várias características que exploram diferentes aspectos sensoriais dos polinizadores, incluindo cheiros específicos, cores chamativas e morfologias florais. Além disso, recompensas florais estimulam as visitas e fidelizam os polinizadores, aumentando as chances de futuras visitas em diferentes 
flores. Estas recompensas são variadas e podem incluir partes florais, néctar, pólen, odor e até mesmo abrigo para diferentes tipos de visitantes. Enquanto besouros e outros organismos menos especializados utilizam partes florais e pólen como alimento, abelhas e vertebrados comumente utilizam o néctar e outros recursos produzidos pelas plantas.

As interações em ambientes tropicais comumente envolvem grupos de polinizadores que estão associados à grupos de plantas com características florais compatíveis. Estas guildas (grupos de organismos que usam um mesmo recurso na comunidade) de polinizadores e plantas são comuns no Cerrado, formando redes de interações que são distribuídas nas diferentes fisionomias e áreas geográficas do bioma. A estrutura das teias de interações pode ajudar a entender a resiliência destas interações e ajudar a prever como elas foram e serão afetadas por mudanças ambientais.

\section{Diversidade de sistemas de polinização}

Nossa área de estudos no Triângulo Mineiro e Sudeste de Goiás (TMSG) está situada na parte meridional do Cerrado, com temperaturas relativamente mais baixas e maior incidência de geadas. Isto pode explicar alguns aspectos intrínsecos do processo de reprodução das plantas desta região. Apesar das plantas lenhosas serem mais bem estudadas em termos reprodutivos no Cerrado brasileiro como um todo, nas áreas estudadas pelo PELD TMSG foram desenvolvidos estudos comunitários focados no componente herbáceo da vegetação. Os estudos foram realizados principalmente na Reserva Ecológica do Panga (REP) e no Parque Estadual da Serra de Caldas Novas (PESCAN), mas também em outras áreas da região, permitindo traçar um quadro geral das características reprodutivas das plantas bem como pensar como tais características podem ser utilizadas no desenvolvimento de estratégias de conservação.

Existe uma grande diversidade de sistemas de polinização nas formações vegetais do Triângulo Mineiro, Alto Paranaíba e Sudeste de Goiás, abrangidas pelo PELD TMSG (Figura 2). A importância relativa de cada sistema varia um pouco de área para área e cada sistema tem especificidades que influenciam a ecologia das plantas e as possibilidades de conservação. O entendimento do impacto dessas especificidades sobre a organização das comunidades da região exige uma descrição básica de cada sistema.

Como em outras áreas do Cerrado, as plantas lenhosas são predominantemente polinizadas por abelhas. As abelhas são os polinizadores bióticos mais comuns e, mesmo nas formações abertas onde a polinização pelo vento pode ser importante, a polinização por abelhas também é recorrente. Apesar da onipresença das abelhas melíferas (Apis mellifera) que foram introduzidas na região há menos de um século, a polinização por abelhas não é totalmente homogênea. As abelhas dependem quase que exclusivamente de flores para sobrevivência e reprodução, mas variam em tamanho e formas de organização social, além do tipo de recurso que procuram nas flores. Abelhas médias ou grandes são comumente solitárias e subsociais, forrageando solitariamente para encontrar a cada dia os recursos florais que utilizam. Neste grupo são incluídas abelhas de diferentes famílias/subfamílias. A maioria dessas abelhas, quando adultas, utilizam néctar como fonte de energia para o voo, e misturam pólen e outras recompensas florais, como óleo ou néctar, para a alimentação das larvas. Elas podem ainda coletar recursos florais como óleos e resinas utilizados para atração sexual e construção de 
ninhos. Estas abelhas podem ser mais generalistas ou mais especializadas nas flores que utilizam, mas comumente na região as guildas são estruturadas em função do recurso. Abelhas carpinteiras, do gênero Xylocopa, coletam principalmente pólen e néctar em flores diversas, que acumulam nos ninhos escavados em madeira morta. Elas podem ser polinizadoras de muitas espécies de plantas da região, tais como as paineiras-docampo (Eriotheca spp.), o pau-santo (Kielmeyera coriacea), as cássias (Cassia spp., Senna spp. e Chamaecrista spp.), e a lobeira (Solanum lycocarpum). Esses últimos dois tipos de plantas envolvem um mecanismo especializado onde o pólen se encontra aprisionado em anteras do tipo poricidas (com poros apicais por onde sai o pólen), sendo liberado apenas após a vibração das abelhas nas flores. Elas podem ser polinizadoras de algumas dezenas de plantas florindo numa mesma área. Outras abelhas grandes, como as da subfamília Centridinae são também solitárias e coletam recursos florais de várias espécies de plantas. Estas abelhas dependem de óleo para construção de ninhos e alimentação das larvas, e se especializam particularmente flores de murici (Byrsonima spp.) e outras plantas da família Malpighiaceae. Essas flores possuem glândulas na base do cálice que produzem óleo. Assim, apesar de coletarem pólen em flores também visitadas por Xylocopa e outras abelhas, as Centridinae são um exemplo de como uma guilda pode ser mais especializada na utilização de um recurso, nesse caso o óleo floral. 


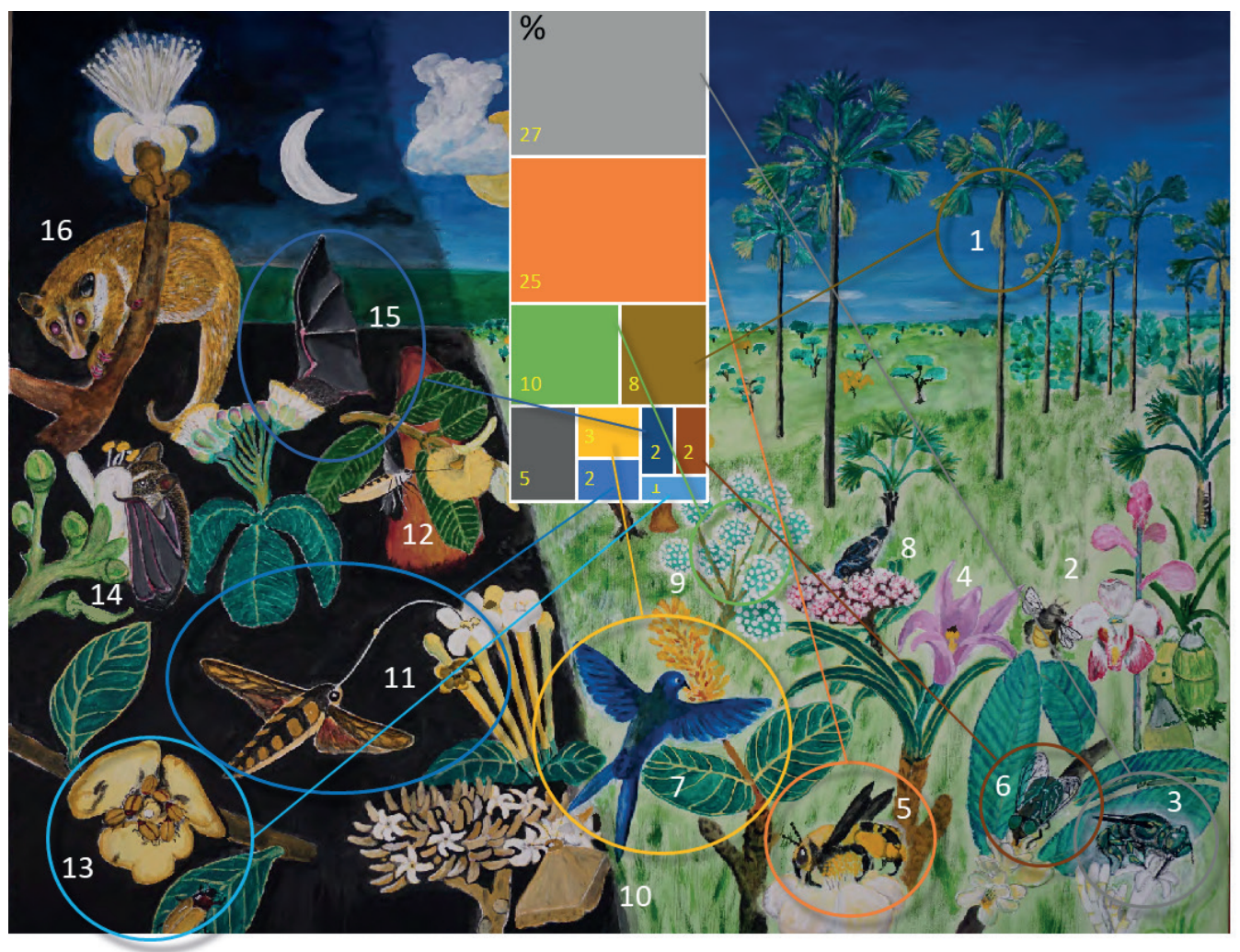

Figura 2. Sistemas de polinização em plantas do Cerrado do Triângulo Mineiro e Sudeste de Goiás. Ilustração da diversidade de sistemas de polinização e a frequência dos principais sistemas definidos para uma área de Cerrado da REP. 1. Muitas plantas são total ou parcialmente polinizadas pelo vento, tais como o buriti, palmeira típica de áreas de vereda que são também polinizadas por pequenos besouros. Gramíneas e outras plantas herbáceas também são polinizadas pelo vento. 2. Mas como em outras áreas de Cerrado, as plantas são predominantemente polinizadas por abelhas. Algumas não apresentam recompensa, como orquídeas do gênero Cyrtopodium, que são polinizadas por abelhas grandes por engano. 3. Outras plantas apresentam diferentes tipos de recompensa, como néctar em Psychotria spp. que atrai abelhas pequenas da tribo Euglossinae; 4. ou pólen em algumas Vellozia spp. que atraem abelhas pequenas eusociais. 5. Abelhas solitárias são polinizadores importantes, coletando néctar e pólen, como Centris sp. em Eriotheca pubescens. 6. Moscas de vários grupos compartilham a polinização de muitas plantas com abelhas pequenas. 7. Beija-flores são polinizadores especializados procurando exclusivamente néctar nas flores; 8. Passeriformes são os polinizadores mais importantes de Hortia brasiliana (Rutaceae). 9. Algumas plantas de cerrados da região são polinizadas por pequenos insetos, inclusive formigas no caso de algumas Eriocaulaceae. 10. Algumas plantas dependem de polinizadores de hábito noturno, como Aspidosperma macrocarpum, polinizada por mariposas pequenas de diversos grupos que pousam nas flores a procura de néctar. 11. Mariposas grandes são polinizadores muito importantes e especializados, visitando flores tubulares em pleno vôo e transferindo pólen a longas distâncias. 12. Mariposas da família Sphingidae são os principais polinizadores do pau-terra-grande (Qualea grandiflora), a árvore mais bem distribuída nos Cerrados brasileiros. 13. Outros visitantes noturnos comuns são besouros de vários grupos. Os araticuns (Annona spp.) são polinizados por um grupo especializado de besouros Cyclocephala spp. (ScarabeidaeDynastinae). 14. Morcegos também são importantes polinizadores noturnos, sendo alguns mais generalistas, utilizando néctar de maneira oportunista, como Carollia sp. em jatobá (Hymenaea stilbocarpa). 15. Outros morcegos como Glossophaga sp. são mais especializados, adejando como beija-flores para visitar flores de pequi (Caryocar brasiliense). 16. Pelo menos uma espécie de paineira (Pseudobombax tomentosum) que ocorre na região é polinizada por mamíferos não voadores como a cuíca (Caluromys lanatus). Vespas, não ilustradas no quadro, são polinizadores não especializados encontrados em $5 \%$ das espécies na área da REP. 
Muitas plantas podem simular recursos para atrair abelhas, especialmente abelhas solitárias, sem prover a devida recompensa. Por exemplo, algumas orquídeas do gênero Cyrtopodium, comuns em veredas do Triângulo Mineiro, dependem de visitas fortuitas de abelhas. Estas são atraídas pelas flores coloridas e possivelmente pelo cheiro, mas não encontram nenhum tipo de recompensa floral. O pólen nestas orquídeas é aglomerado em polinários com milhares de grãos, que não podem ser utilizados pela maioria das abelhas para aprovisionar os ninhos. Esses polinários possuem uma estrutura pegajosa e ficam aderidos às costas das abelhas, sendo então inteiramente depositados em outra flor na próxima visita. Apesar de pouco visitadas, pois as abelhas logo aprendem que não oferecem recurso algum, essas polinizações eventuais podem produzir frutos com milhares de sementes, o que compensa o sistema de polinização pouco efetivo. Além disso, devido a ausência de recurso, abelhas tendem a não visitar flores do mesmo indivíduo, promovendo assim polinização cruzada e elevada diversidade genética.

Ao contrário de outras regiões do globo, as abelhas grandes e solitárias são igualmente ou mais importantes que outras abelhas para a polinização das plantas do Cerrado. Porém, as abelhas pequenas são muito mais comuns. Ao contrário das abelhas médias e grandes, muitas das abelhas pequenas são também eussociais, apresentando ninhos organizados com muitas operárias não reprodutivas, que se dedicam à coleta de recursos florais. Estas abelhas comumente apresentam um mecanismo de recrutamento que permite às operárias visitantes florais orientarem as outras abelhas do ninho quanto à localização e disponibilidade de recursos. Além da espécie invasora Apis melifera, as abelhas sociais mais comuns são as espécies nativas da tribo Meliponinae, as abelhas sem ferrão. Elas também são eussociais e utilizam formas de recrutamento que parecem depender de marcas de odor deixadas por operárias na vegetação, de forma a guiar as parceiras de ninho. $\mathrm{O}$ recrutamento permite que estas abelhas eussociais reajam rapidamente a mudanças na oferta de recursos no ambiente. Em conformidade, existem algumas plantas que florescem explosivamente, produzindo milhares flores por um curto período. Esse tipo de recurso pode ser utilizado mais efetivamente pelas abelhas eussociais e possivelmente estas plantas têm a floração adaptada às características destas abelhas e vice versa. Apesar do recrutamento mobilizar colmeias inteiras para uma mesma espécie de planta, as abelhas eussociais não são necessariamente mais especializadas no uso de recursos do que as solitárias. Na verdade, ao longo do tempo, as abelhas eussociais podem inclusive usar mais tipos de recursos florais do que abelhas solitárias, e podem ser muito mais oportunistas no uso destes recursos.

Existem algumas abelhas pequenas que não são eussociais. Euglossinae, Halictidae e alguns grupos de abelhas pequenas são frequentes na região, visitando muitos grupos de plantas. Entretanto, a importância delas para a polinização é menos estudada, apesar de serem polinizadores exclusivos de algumas espécies. Aparentemente estas abelhas são mais especializadas no uso de outros recursos, procurando flores que oferecem perfumes, resinas e outras recompensas além de pólen e néctar. Mas muitas delas apresentam comportamento semelhante ao de abelhas solitárias médias e grandes.

Apesar das abelhas serem os mais importantes polinizadores na região, a diversidade de polinizadores encontrados no Cerrado é similar ao descrito para outros ambientes tropicais. Besouros são visitantes florais de muitas espécies de Annonaceae, incluindo os araticuns (Annona spp.), espécies que produzem frutos apreciados na região. Os besouros também são polinizadores importantes de aráceas e palmeiras, incluindo 
o buriti (Mauritia flexuosa), palmeira dióica (com indivíduos masculinos e femininos) típica de veredas e que depende de pequenos besouros para o transporte de pólen.

Vespas e moscas são também comuns visitando flores na região, mas comumente dividem as flores pequenas e generalistas que visitam com abelhas de pequeno porte. Borboletas são polinizadores menos importantes, associados principalmente a espécies da família Asteraceae, e comumente também dividem com abelhas pequenas as flores de néctar que visitam.

Mariposas noturnas, por outro lado, são polinizadores específicos de muitas espécies do Cerrado. Estas mariposas frequentemente visitam flores que se abrem a noite e mantêm o néctar protegido em tubos ou esporões que somente estes insetos de língua longa podem explorar. O tamanho do tubo floral separa as mariposas pequenas e com probóscides curtas daquelas da família Sphingidae, que podem ter probóscides de mais de $15 \mathrm{~cm}$ e são os únicos visitantes que conseguem obter néctar de flores de tubos longos como Tocoyena formosa e Macrosymphonia velame. Estas mariposas grandes são longevas e capazes de voar grandes distâncias, possivelmente acompanhando a oferta de recursos florais entre fisionomias e regiões do Cerrado. Por exemplo, a árvore mais bem distribuída no Cerrado, o pau-terra grande (Qualea grandiflora), é polinizada por mariposas Sphingidae que procuram néctar acumulado num esporão formado no cálice das flores.

Além de insetos, as plantas de Cerrado podem ser visitadas por vertebrados. Beija-flores são os mais conspícuos visitantes florais na região e são oportunistas e aparentemente visitam qualquer flor que ofereça néctar acessível, apesar de serem polinizadores primários de poucas plantas lenhosas. Beija-flores são polinizadores capazes de voar grandes distâncias e utilizar rotas de forrageamento previsíveis. Nas flores, eles se alimentam apenas de néctar, não utilizando pólen nem estruturas florais. Apesar de constituírem o grupo predominante de aves que visitam flores na região, alguns passeriformes procuram recursos florais com maior ou menor intensidade. A cambacica (Coereba flaveola), por exemplo, é um visitante comum e polinizador eventual em muitas flores de néctar. Entretanto, o caso de Hortia brasiliana, um arbusto comum no Triângulo Mineiro, é provavelmente o único na região onde há polinização quase exclusiva por passeriformes. Ao contrário dos beija-flores, que adejam nas flores e são capazes de polinizar em pleno voo, os passeriformes pousam nas grandes inflorescências de $H$. brasiliana e aparentemente transferem o pólen com suas pernas entre as pequenas flores.

Se durante o dia as aves são os principais vertebrados polinizadores das plantas de Cerrado, durante a noite muitas flores dependem dos morcegos para a polinização. Como no caso das aves, existem morcegos nectarívoros especializados capazes de realizar polinização como os beija-flores, adejando em frente às flores durante a visita. Por outro lado, alguns morcegos têm o comportamento de se pendurar nas flores. Árvores importantes na região, como o pequizeiro e o jatobá são polinizados por morcegos. Estes animais também visitam e polinizam flores de paineiras (Pseudobombax spp.). Entretanto, algumas dessas espécies podem ainda ser visitadas por mamíferos não voadores, especialmente marsurpiais como pequenas cuícas e gambás. Mamíferos não voadores são também visitantes e possivelmente polinizadores de outras espécies, incluindo holoparasitas (planta que retira todos seus nutrientes de outra planta hospedeira) da família Balanophoraceae. 


\section{Diversidade de sistemas de reprodução}

Adiversidade de sistemas de polinização entre as plantas da região está relacionada à dependência delas do transporte de pólen por vetores bióticos. Os estudos sobre comunidades de plantas mostraram que apenas uma pequena parte das espécies são autônomas em termos reprodutivos, ou seja, total ou majoritariamente independentes de polinizadores. Entre estas plantas, existem algumas espécies apomíticas, especialmente as Melastomataceae e Malvaceae, que têm sido mais bem estudadas. Mas é possível que muitas espécies de Asteraceae e Poaceae tenham mecanismos de reprodução autônoma via apomixia ou outras formas de reprodução vegetativa, mas ainda são pouco estudadas na região.

Entretanto, muitas plantas são autocompatíveis, especialmente aquelas de porte herbáceo, produzindo frutos e sementes viáveis após qualquer tipo de polinização. Algumas plantas herbáceas podem formar frutos e sementes por cleistogamia, isto é, possuem flores que nunca se abrem e são autopolinizadas. Entretanto, é comum que além das flores cleistógamas, essas espécies também possuam flores casmógamas, isto é, que se abrem normalmente, permitindo a reprodução alogâmica em paralelo à autopolinização. Em contraste com as plantas herbáceas, as plantas lenhosas são majoritariamente autoincompatíveis, exibindo mecanismos genéticos que reduzem as chances de autopolinização. Estes podem ser mecanismos clássicos que impedem o crescimento de tubos polínicos e fertilização. Entretanto, muitas destas plantas apresentam incompatibilidade de ação tardia, que é comum em plantas lenhosas tropicais de uma maneira geral. Nestas plantas, os tubos polínicos de autopolinização crescem normalmente e ocorre a fertilização, mas não há o desenvolvimento posterior de frutos e sementes, que somente ocorre via polinização cruzada.

Como mencionado anteriormente, plantas dioicas são um exemplo extremo da dependência da polinização, já que apresentam indivíduos com flores de apenas um sexo. A dioicia é mais comum em árvores tropicais e, na região do Cerrado, é mais frequente em florestas do que em formações abertas. Entretanto, é importante notar que muitas palmeiras de formações abertas, incluindo o buriti e outras espécies de pequeno porte, são dioicas ou funcionalmente dioicas, produzindo pelo menos durante algum tempo somente um tipo de flor em cada indivíduo.

De uma maneira geral, nos ambientes estudados no âmbito do PELD TMSG, os sistemas de reprodução são muito variados. Existe uma associação de sistemas mais flexíveis e menos dependentes de polinizadores com plantas herbáceas e formações abertas (como as campestres e savânicas), enquanto sistemas mais estritos e dependentes de polinizadores estão associados a formações florestais (Figura 3), apesar de exceções serem encontradas em ambos os casos.

\section{Redes de interações entre plantas e seus polinizadores}

A diversidade de sistemas de polinização e as características dos sistemas de reprodução descritos anteriormente implicam na interdependência entre animais polinizadores e plantas. Estas interações podem ser importantes para o entendimento da organização das comunidades e de como estas serão impactadas pelas mudanças ambientais em curso na região. 
O que temos observado para a nossa região de estudos é que as interações, como em outros ambientes do Cerrado, estão organizadas em guildas, envolvendo diferentes grupos de plantas e polinizadores. Uma forma de sintetizar e analisar a estrutura dessas comunidades é caracterizando a organização em redes de interações. Vários estudos realizados na REP e no PESCAN mostraram a estrutura destas guildas de plantas polinizadas por abelhas, mariposas e beija-flores. A base para estes trabalhos já estava sendo construída desde a década de 1980, com dados oriundos da REP, mas tais estudos foram revistos no âmbito do PELD TMSG e analisados usando abordagens mais atuais de redes de interações. Ao nível da comunidade, a rede entre plantas e polinizadores da região reflete a organização das guildas de polinizadores. Entretanto, também é possível observar que há grupos numerosos de plantas que estão associadas a distintos grupos funcionais de polinizadores (Figura 4).

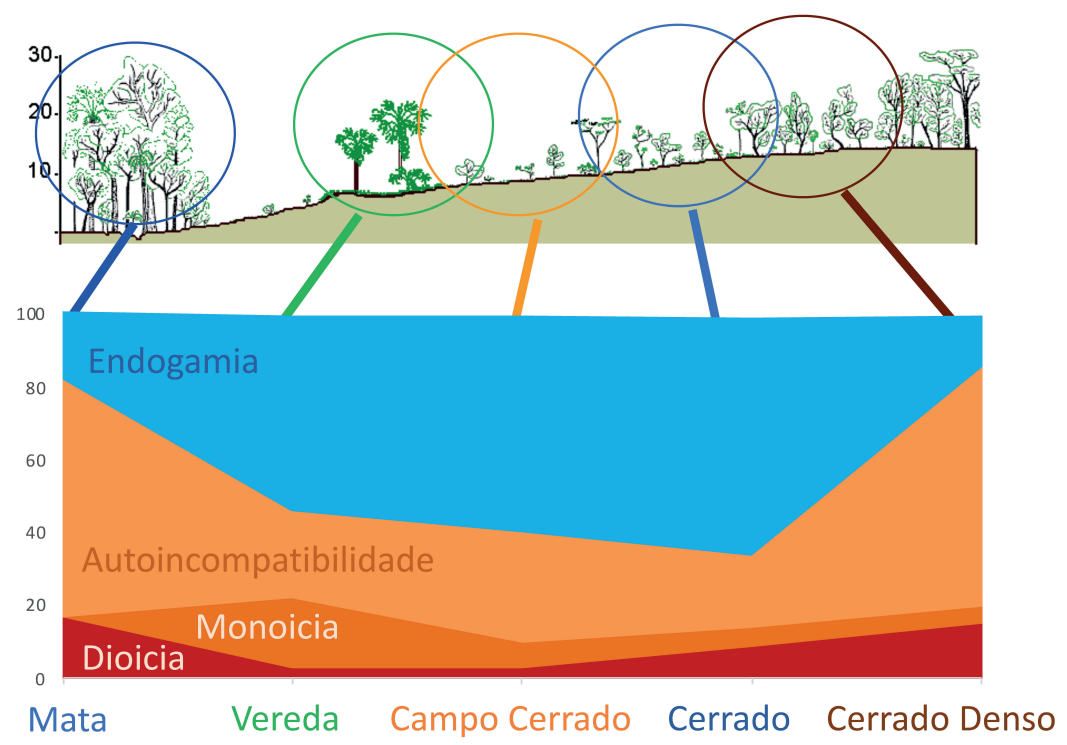

Figura 3. Sistemas de reprodução em diferentes fisionomias de Cerrado. Sistemas mais flexíveis e menos especializados são reunidos em Endogamia, uma vez que eles terminam permitindo reprodução uniparental. Autoincompatibilidade, dioicia e mesmo a separação das funções sexuais dentro do mesmo indivíduo (monoicia) são vistos como sistemas mais estritos, que dependem de serviços de polinização e resultam em alogamia.

Estudos conduzidos com guildas distintas ilustram alguns padrões. No caso das mariposas da família Sphingidae, algumas espécies visitam muitas plantas diferentes, enquanto algumas plantas são visitadas por muitas espécies de mariposas, sendo estes organismos mais generalistas. Essa estruturação forma um núcleo de espécies altamente conectadas. Por outro lado, existem mariposas que visitam poucas espécies de plantas e plantas que são visitadas por poucas espécies de mariposas, sendo estes organismos mais especialistas. Esse tipo de conformação caracteriza o que é conhecido como aninhamento, uma assimetria na distribuição das interações em que espécies generalistas interagem com generalistas e especialistas, enquanto as espécies especialistas interagem mais comumente apenas com as generalistas. Essa estrutura de rede tem implicações importantes sobre a dinâmica e a robustez contra distúrbios em comunidades ecológicas. 
É interessante que, nesse caso, a especialização morfológica também é assimétrica, isto é, as plantas morfologicamente mais especializadas apresentam corola tubular ou estruturas que limitam a visitação e o acesso ao néctar. Entretanto, as mariposas mais especializadas, com probóscides longas e capazes de visitar efetivamente tais plantas, têm um comportamento muitas vezes generalista, visitando tanto flores com tubos longos como flores com morfologia menos especializada. Apesar desta aparente assimetria, estudos indicam que existem ajustes fenológicos e morfológicos das mariposas com probóscides maiores com as plantas de flores com corola ou estruturas mais longas. Isto é, a época de floração das flores com corola ou estruturas longas e os padrões de migração e emergência das mariposas provavelmente aumentam as possibilidades de interações entre esses dois grupos mais especializados.

Estudos similares realizados com beija-flores indicam estruturas de redes de interações com características similares àquelas das mariposas. Beija-flores parecem ser oportunistas e usam néctar onde ele esteja disponível. Por possuírem tanto o bico quanto a língua longa, alguns beija-flores podem explorar uma variedade grande de flores e, por isso, são ecologicamente mais generalistas do que aqueles de bicos e línguas mais curtas. Estudos com beija-flores no Triângulo Mineiro mostram que as interações entre plantas e polinizadores são organizadas em módulos/compartimentos que refletem a morfologia e a utilização de diferentes fitofisionomias do Cerrado. Assim, beija-flores mais especializados (com bicos e línguas maiores) parecem estar mais ajustados e dependem de flores com estruturas mais longas que, num certo sentido, constituem um nicho exclusivo para tais aves. Ao mesmo tempo, espécies de beijaflores e plantas se distribuem de maneira heterogênea nas diferentes fitofisionomias, o que acaba determinando quais espécies de fato irão interagir (Figura 4).

Também é interessante notar que, apesar de tais padrões consistentes, existe uma alta taxa de turnover (troca) de espécies de plantas associadas a beija-flores em diferentes áreas de estudo do PELD TMSG, indicando a natureza dinâmica dessas interações no espaço e talvez no tempo. 

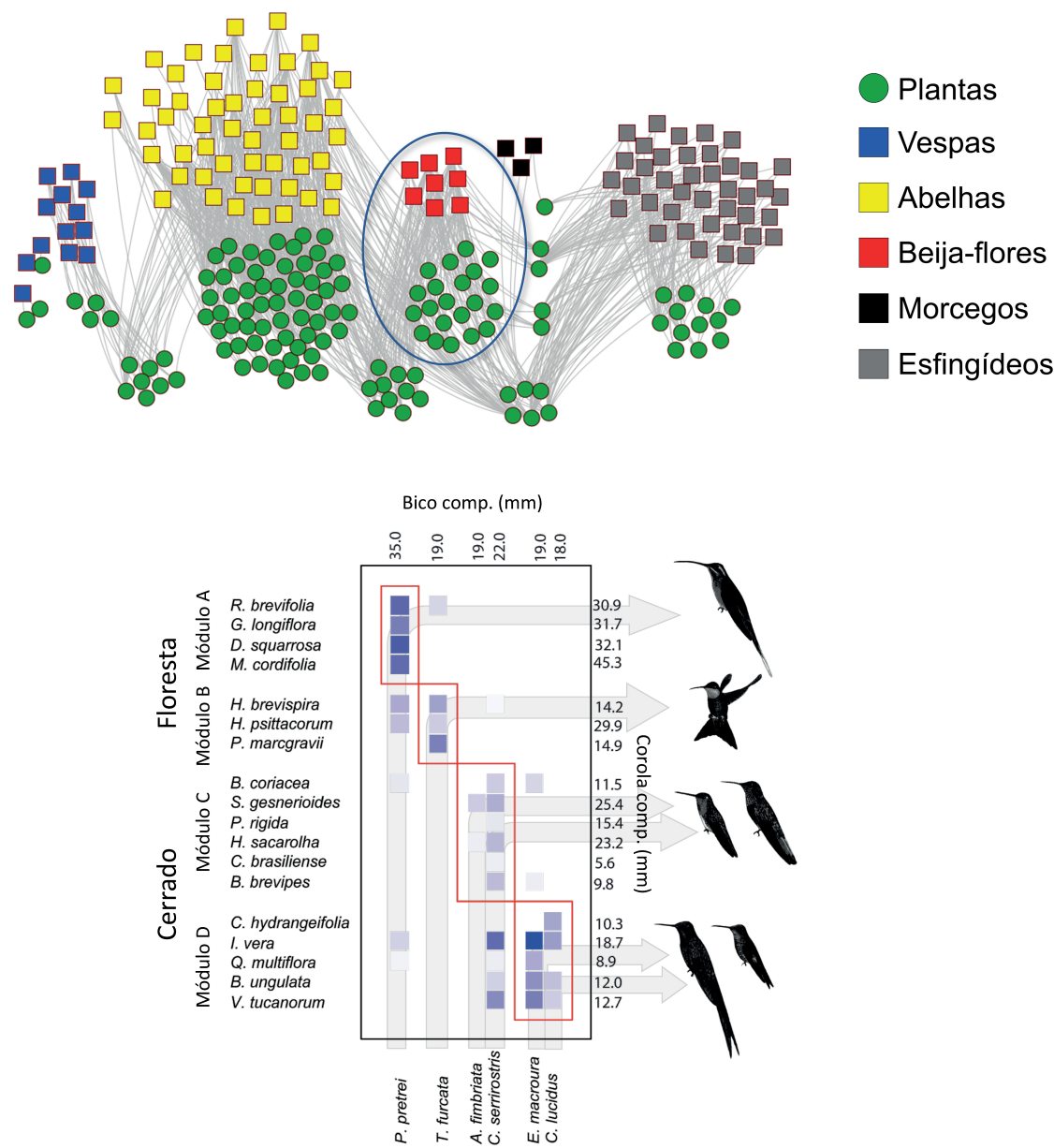

Figura 4. Redes de interações entre polinizadores e plantas na REP de dados compilados de diferentes estudos. A) Os sistemas de polinização são relativamente isolados, mas algumas espécies de plantas e polinizadores conectam as diferentes guildas. B) O detalhamento destas interações, como aquelas entre beija-flores e as plantas que eles visitam, mostram compartimentos/módulos associados a diferentes ambientes e ao comportamento dos polinizadores (adaptado de Maruyama et al. 2014. Biotropica 46: 740-747)

As redes de interações entre abelhas e plantas ainda não têm sido estudadas em ainda maior detalhe. O principal problema para estes estudos é documentar e quantificar as interações. Em alguns casos as interações entre abelhas e plantas podem envolver uma enorme diversidade de espécies. Por exemplo, um estudo com Matayba guianensis, uma arvoreta comum em áreas de cerrado do Triângulo Mineiro, resultou na coleta de um número recorde de 110 espécies de abelhas de diferentes espécies, todas polinizadores potenciais desta planta que apresenta flores pequenas e generalistas. As abelhas visitantes também variam muito entre áreas de estudo. Dessa maneira, a observação direta das interações entre abelhas e plantas exigiria um esforço muito maior do que o estudos de outras redes, especialmente porque a identificação das abelhas não é tão simples, rápida e direta.

A análise de cargas polínicas das abelhas pode ajudar na caracterização destas interações. A vantagem destes estudos é que eles permitem ter uma ideia de todas as 
plantas visitadas num período e não apenas das visitas observadas diretamente. Estes trabalhos foram feitos principalmente com abelhas solitárias das tribos Xylocopinae e Centridinae, mostrarando que elas visitam uma grande diversidade de plantas, tanto em busca de néctar como de outros recursos florais. Conhecendo os recursos oferecidos pelas plantas é possível ver que as abelhas visitam flores que oferecem apenas pólen ou óleo. Estes recursos são coletados especialmente para aprovisionar os ninhos. Estudos com Xylocopa sp. mostraram inclusive que o pólen presente no corpo das abelhas é diferente do pólen utilizado para o aprovisionamento dos ninhos. Algumas flores de Melastomataceae e Leguminosae parecem ser visitadas por Xylocopa sp. exclusivamente para aprovisionamento dos ninhos, pois estas plantas não oferecem néctar e o pólen aparece muito mais comumente que outros tipos de pólen no material acumulado nas células de cria. As análises da carga polínica permitem mostrar que tanto abelhas solitárias como sociais visitam plantas que tem disponibilidade de recursos florais diferentes no espaço e no tempo. Entretanto mais estudos são necessários para este grupo, especialmente considerando a sua importância como polinizadores de grande parte das plantas.

Outros tipos de polinização têm sido estudados na região, mas a organização das redes de interações e formação de guildas ainda são menos conhecidas. Morcegos são polinizadores de espécies importantes e em muitos casos compartilham flores com mariposas Sphingidae e outros polinizadores noturnos (Figura 4). Besouros mais especialistas na região, especialmente Dynastinae, são polinizadores de espécies de Annonaceae e Araceae. Por outro lado, pequenos besouros visitam ainda algumas espécies de palmeiras e são observados em outros tipos de flores consumindo pólen e partes florais de forma oportunista. Vespas, moscas e borboletas são polinizadores menos comuns e praticamente não foram estudados na região.

Estas redes de interações foram estudadas originalmente de maneira isolada, mas é possível tentar integrar as várias redes definidas para uma mesma área e analisar a sobreposição e importância relativa dos polinizadores e das plantas para o funcionamento dos serviços de polinização no âmbito da comunidade. A integração entre redes de polinizadores ainda carece de estudo detalhado. Entretanto, a compilação de dados para a REP mostrou que, apesar da baixa sobreposição nos sistemas de polinização, algumas espécies de plantas e polinizadores que provêm recursos e serviços de polinização interligam vários compartimentos da rede. Por exemplo, o pequizeiro (Caryocar brasiliense) apesar de associado primariamente à polinização noturna por morcegos, provê néctar para beija-flores e néctar e pólen para abelhas que visitam as flores durante o dia. O mesmo acontece com o pau-terra-grande $(Q$. grandiflora) com flores polinizadas por mariposas, mas que integram os recursos de outros grupos de polinizadores diurnos. Abelhas pequenas e beija-flores são visitantes florais generalistas e podem também usar recursos de flores associadas a outras guildas, porém sem necessariamente promover a polinização.

É importante notar que as formas de avaliação dos sistemas de polinização e das redes de interações raramente permitem quantificar a efetividade relativa de cada grupo de polinizador para uma dada planta e mesmo a importância dos recursos florais para um determinado grupo de polinizadores. Apesar de sabermos que existem diferenças marcadas na eficácia relativa dos serviços de polinização e na oferta de recursos florais, estudos neste sentido ainda são rudimentares. 


\section{Consequências ecológicas}

As características dos sistemas de polinização e reprodução envolvendo a dependência de polinização biótica e alternativas de reprodução autônoma e vegetativa, bem como a organização das teias de interações implicam em algumas consequências ecológicas e podem ajudar a definir estratégias de conservação.

A primeira consequência ecológica é a interdependência entre plantas e polinizadores para sobrevivência e reprodução. Em termos de conservação, nossos dados indicam que a maioria das plantas, especialmente as lenhosas, dependem dos serviços de polinização para formação de sementes, enquanto as espécies de polinizadores necessitam dos recursos florais para sobreviver e muitas vezes para reproduzir. Mesmo que alguns destes visitantes florais não dependam exclusivamente destes recursos, uma boa parte da energia e dos recursos que eles utilizam para sobrevivência é oferecido pelas plantas. Esta interdependência estrita parece ser característica de ambientes tropicais, como o de nossa região de estudos, sendo provavelmente um fator estruturador de comunidades biológicas. Apesar desta interdependência raramente envolver relações extremamente especializadas entre espécies ou grupos pequenos, ainda assim o déficit dos serviços de polinização pode implicar numa drástica cascata de consequências ecológicas e de conservação que serão discutidos a seguir. Entretanto, a principal consequência deste tipo de organização é a manutenção de níveis de diversidade local relativamente altos, comparáveis com formações florestais tropicais. Como em ambientes tropicais florestais, a interação entre plantas e polinizadores no Cerrado pode ser um dos fatores explicando a manutenção da biodiversidade.

Uma segunda consequência ecológica ligada aos sistemas de polinização é a complementaridade dos habitats no uso dos recursos florais. Dados relativos à polinização por beija-flores indicam que áreas específicas, tanto de cerrado como de florestas na região, raramente oferecem recursos florais em quantidade suficiente para manter populações residentes de beija-flores. Como estas aves utilizam majoritariamente néctar para manter suas necessidades calóricas, já definidas por estudos experimentais, é relativamente fácil quantificar a oferta de recursos e mesmo a quantidade de energia disponível numa determinada área através da amostragem da quantidade de açúcares presentes no néctar. Fragmentos de cerrado e florestas apresentam quantidade de energia que varia de área para área, mas que raramente é suficiente para manter um único beija-flor por fragmento. Isto significa que beija-flores têm que explorar áreas amplas para satisfazer suas necessidades energéticas diárias (Figura 5). Como a vegetação não é homogênea e existem diferenças nas espécies de plantas florindo nas diferentes fisionomias em diferentes épocas do ano, existe um mosaico de oferta de recursos florais que os beija-flores exploram. Isto implica na complexidade e complementaridade no uso de recursos que talvez ajude a explicar a organização das redes de interações.

É provável que estas mesmas características afetem outros sistemas de polinização. Mariposas grandes são móveis o suficiente para explorar recursos florais em áreas amplas de cerrado. Estudos no Brasil e em outras áreas tropicais mostraram que estes animais podem se deslocar por grandes distâncias em busca de recursos florais. Os cerrados do Triângulo Mineiro parecem atrair mariposas associadas a diferentes formações vegetais do Brasil, como florestas úmidas e formações secas de Caatinga e Chaco, funcionando talvez como um entroncamento no deslocamento 
destas mariposas. Abelhas grandes também exploram plantas em diferentes formações e se adaptam aos recursos florais disponíveis em diferentes áreas de cerrado. Abelhas carpinteiras (Xylocopa spp.) parecem nidificar ao longo do ano todo, mas os recursos florais disponíveis mudam claramente (Figura 6) e o pólen usado no aprovisionamento parece acompanhar tais mudanças. Estas observações e deduções a partir de dados comportamentais e reprodutivos sugerem que existe uma complementariedade de habitats na disponibilização de recursos florais que têm um impacto na movimentação de vários grupos de animais e provavelmente na persistência deles nestes ambientes.

Por fim, a organização das guildas provavelmente tem outra consequência ecológica que é a relativa redundância e resiliência destes sistemas frente a mudanças no tempo e no espaço. Esta pré-adaptação à heterogeneidade ambiental e às diferenças na diversidade entre áreas do Cerrado (diversidade beta) provavelmente habilitou plantas e polinizadores a ocupar amplas áreas do Cerrado numa escala continental. Por exemplo, a abelha carpinteira Xylocopa frontalis ocorre desde regiões meridionais do Cerrado até a América Central, provavelmente se ajustando as mudanças florísticas, fisionômicas e fenológicas das plantas que utiliza para forrageamento e aprovisionamento (Figura 6). Ao mesmo tempo, o pau-terra-grande ( $Q$. grandiflora) é provavelmente a árvore mais bem disseminada, ocorrendo em mais de $80 \%$ das áreas de cerrado já amostradas, desde o Paraná até o extremo norte do Brasil. Estudos feitos em diferentes áreas da região mostraram que há uma troca de espécies de plantas utilizadas por beija-flores de área para área, e isto parece estar associado à distância geográfica. Entretanto, essa substituição é aparentemente menor entre as plantas efetivamente usadas pelos beijaflores do que entre as espécies de plantas de uma maneira geral. A semelhança entre as plantas utilizadas por beija-flores na REP e no PESCAN, distantes ca. de $200 \mathrm{~km}$ entre si, é de $74 \%$. Já as espécies de beija-flores mudam menos na mesma escala geográfica estudada e de uma maneira geral as mesmas 7 a 10 espécies destas aves aparecem em cada uma das áreas.

A necessidade de ajuste a formações e elementos vegetais distribuídos numa escala continental talvez explique a própria estrutura das guildas de polinizadores. Estruturas aninhadas das redes de interações permitem a redundância necessária para ajustes locais e persistência de plantas e polinizadores. Como a maior parte destas plantas, especialmente as lenhosas, são obrigatoriamente alógamas, a sobrevivência e reprodução dos indivíduos e populações dependem da resiliência e funcionamento dos processos. 


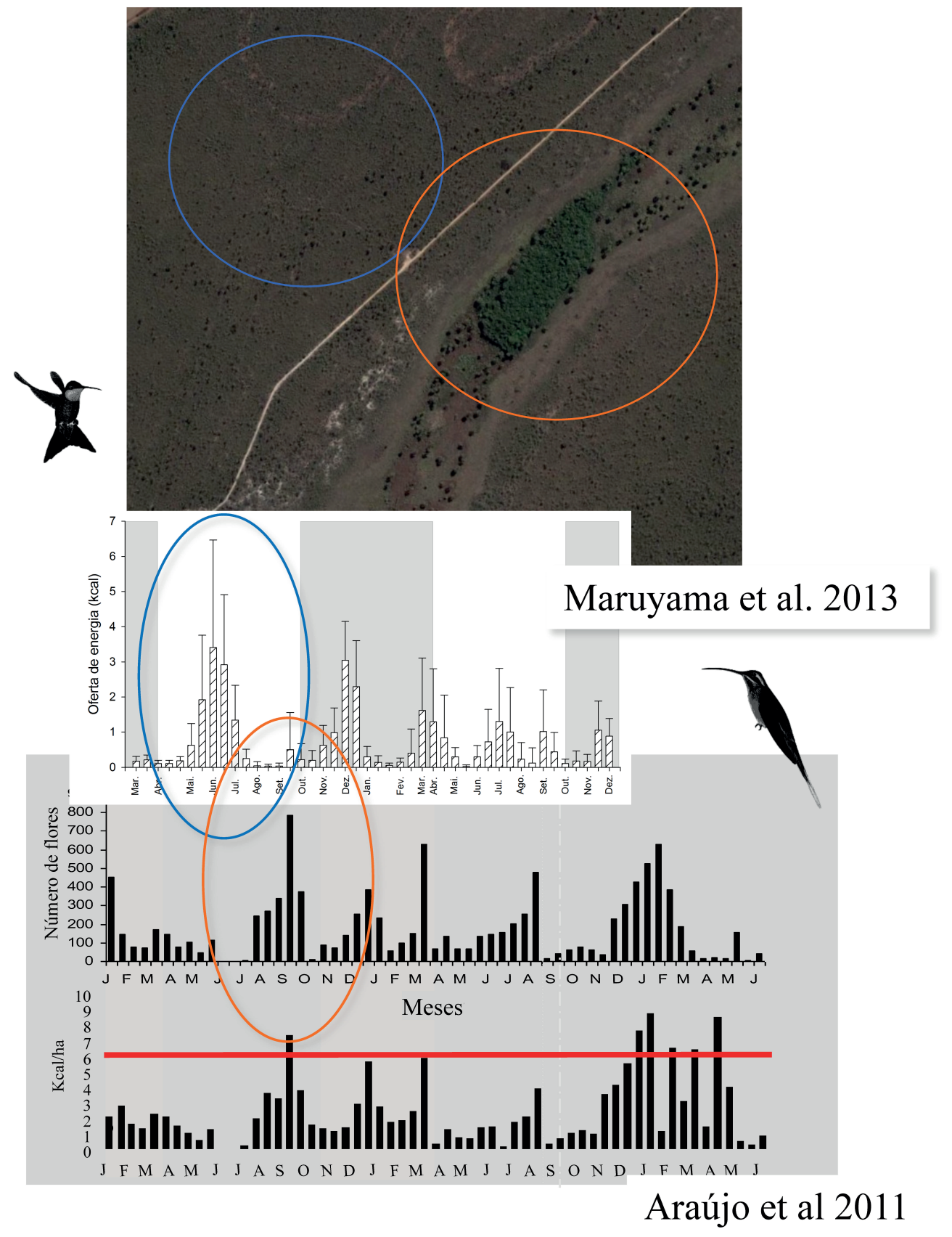

Figura 5. Oferta de recursos florais e complementaridade de habitats. Ambientes de cerrado sensu stricto (círculos azuis) e florestas (círculos laranja) que ocorrem de maneira contígua na reserva do Clube Caça e Pesca Itororó de Uberlândia (CCPIU) mostram ofertas de recursos aparentemente complementares. Os picos de oferta de energia presente no néctar ocorrem em épocas diferentes. A linha vermelha mostra a quantidade mínima de energia (por unidade de área) necessária para as necessidades de um beija-flor. Esta raramente é atingida nos ambientes estudados, implicando que os beija-flores têm que se deslocar entre ambientes mesmo durante os picos de oferta. (adaptados de Maruyama et al. 2013. Naturwissenschaften 100: 1061-1068 e Araújo et al. 2011. Flora 206: 827-835) 

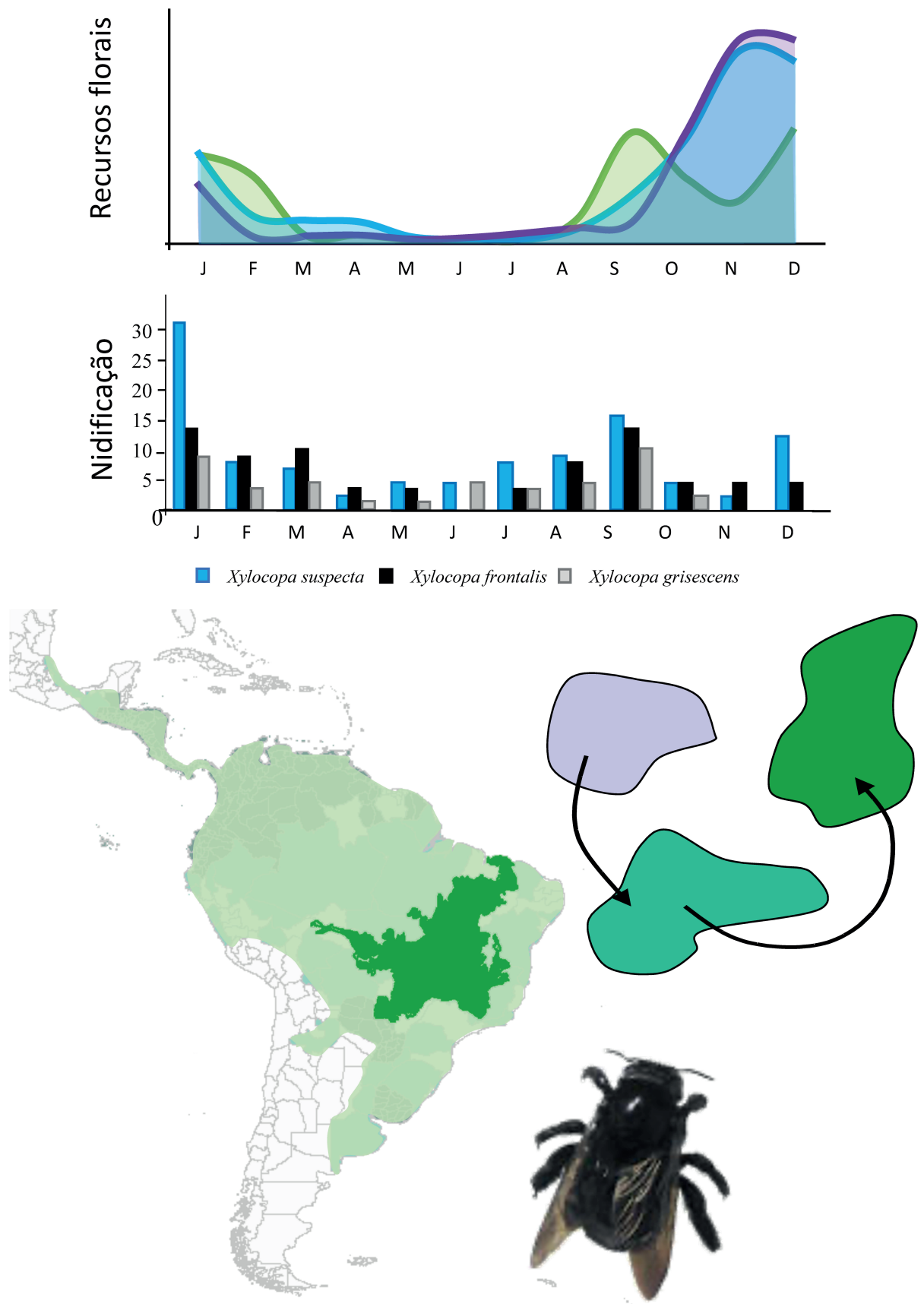

Figura 6. Oferta de recursos florais e distribuição de abelhas carpinteiras (Xylocopa spp.) Apesar de nidificarem durante todo o ano (nidificação indicada por ninhos ativos), a disponibilidade de recursos florais (indivíduos em floração) muda ao longo do tempo, exigindo que as abelhas se desloquem entre áreas. Além disso, a distribuição ampla destas abelhas, exemplificada por Xylocopa frontalis (área de distribuição, em verde claro, baseada em Moure, Urban \& Melo 2007 se sobrepõe amplamente à região do Cerrado, em verde mais escuro), exige que utilizem recursos florais muito diferentes de área para área. (Dados de recursos florias: Relatório PROBIO 2005. Nidificação: Camillo e Garófalo 1982. Revta.bras. biol. 42: 571-582). 
Neste sentido, as alternativas reprodutivas envolvendo reprodução vegetativa e apomixia podem ser formas de lidar com tal heterogeneidade. Vários grupos apresentam populações apomíticas e estes processos de reprodução uniparentais podem permitir a colonização e manutenção de populações em situações de limitação nos serviços de polinização. Um exemplo típico de tal situação são as plantas da espécie Miconia albicans, que são obrigatoriamente apomíticas e não produzem grãos de pólen viáveis. Dada a autonomia reprodutiva, o rápido crescimento e a alta plasticidade, estas plantas ocorrem em vários ambientes do Cerrado brasileiro, independente da diversidade dos polinizadores locais. Em um cenário futuro envolvendo mudanças climáticas, degradação de habitat e uso de pesticidas, os processos de polinização biótica podem ser prejudicados, o que permite uma vantagem para plantas apomíticas e autocompatíveis. Os potenciais impactos bem como mudanças temporais nos sistemas de polinização serão discutidos mais adiante.

\section{Impacto das mudanças e da deterioração ambiental}

Toda a base de conhecimento acumulada sobre a estruturação das relações entre plantas e polinizadores na região permite delinear estudos que acompanhem as consequências das mudanças ambientais em curso sobre estas inter-relações. Os dados de longo prazo mostram uma série de tendências nos últimos 20 ou 30 anos que podem subsidiar os processos de conservação

Mesmo ambientes preservados não deixam de se transformar ao lao longo do tempo. Um estudo das mudanças nos sistemas de polinização numa área da REP mostrou uma transformação não na diversidade, mas na distribuição e importância relativa dos sistemas de polinização. Protegida do fogo, a REP tem sofrido um processo de adensamento da vegetação lenhosa. Numa área específica da REP analisada na década de 1990 e vinte anos depois, houve um adensamento da vegetação lenhosa e uma mudança fisionômica clara, de um campo cerrado para um cerrado mais típico (Figura 7). Novas espécies de plantas lenhosas apareceram, algumas espécies se tornaram mais comuns e outras mais raras. Mesmo sem levar em conta as gramíneas, levantamentos similares mostraram uma mudança na importância de alguns sistemas de polinização e sistemas de reprodução das plantas. Apesar dessas mudanças não permitirem estabelecer uma tendência clara, o processo sucessional de 20 anos e o adensamento da vegetação lenhosa aumentou o número de espécies e de indivíduos dependentes da polinização por abelhas, sendo estas tanto abelhas grandes solitárias quanto abelhas pequenas. Houve ainda o aumento da diversidade de sistemas de polinização de uma maneira geral, mesmo em detrimento da redução na polinização pelo vento. Por fim, foi observado o aumento da proporção de sistemas de polinização por animais mais especializados e comumente associados a ambientes florestais, tais como mariposas, morcegos e beija-flores. Este aumento foi principalmente no número de espécies, que foram representadas por poucos indivíduos. Estas mudanças nos sistemas de polinização possivelmente continuarão associadas aos processos sucessionais e de adensamento da vegetação. 

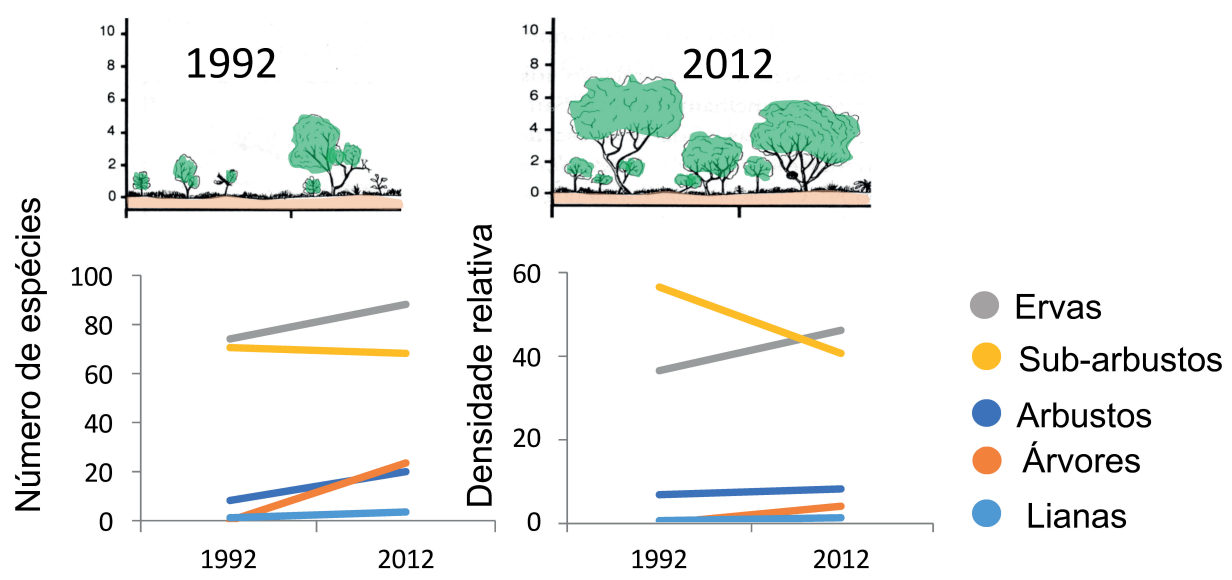

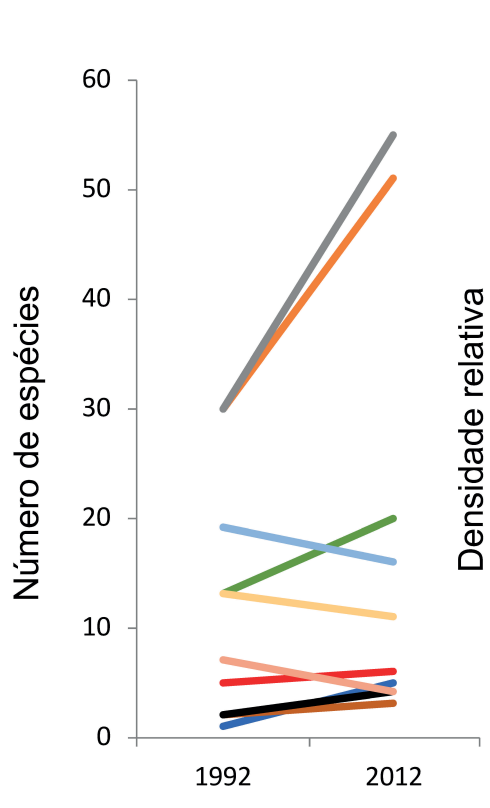

Espécies

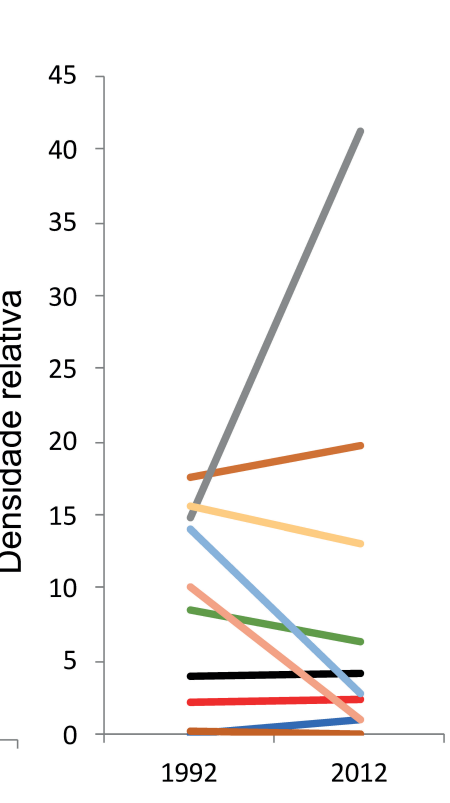

Abelhas

pequenas

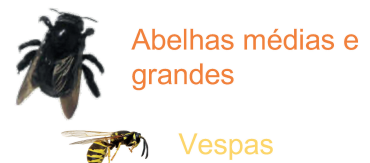

Fespas

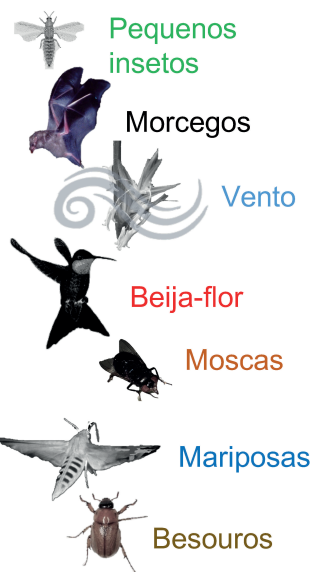

Indivíduos

Figura 7. Mudanças nos sistemas de polinização após 20 anos de processo sucessional. A proteção da área da REP contra fogo desde a década de 1980 levou a mudanças estruturais. A área de campo sujo deu lugar a áreas mais densas de cerrado, com mudanças na composição de espécies e indivíduos. A sucessão levou a mudanças na diversidade de sistemas de polinização, tanto em termos de espécies como indivíduos associados a cada sistema. (Deus \& Oliveira 2016. Braz. J. Bot. 39: 1051-1063).

Estudos semelhantes realizados em fragmentos de floresta semidecidual na região mostraram as relações dos sistemas de polinização e reprodução com o nível de perturbação. Estes fragmentos tiveram histórias de degradação distintas, que foram avaliadas usando diferentes indicadores, incluindo dados sobre o entorno e o histórico de perturbação. Analisando as espécies ocorrendo nestas áreas e os sistemas de polinização e reprodução, foi possível avaliar o impacto dos processos de fragmentação e degradação sobre a sustentabilidade dos serviços de polinização e sobre a capacidade 
de reprodução e persistência das plantas da área. Nossa hipótese era que o processo de degradação ambiental, como em outras áreas florestais brasileiras, levaria a uma exclusão de espécies dependentes de sistemas de polinização mais especializados. Em uma floresta Atlântica no Nordeste do Brasil, um estudo semelhante mostrou uma redução de sistemas especializados e até mesmo mudanças nos sistemas de reprodução predominantes, com o aumento de plantas autocompatíveis. Entretanto, os dados para os fragmentos florestais no Triângulo Mineiro não mostraram tendências neste sentido. $\mathrm{Na}$ verdade, a área possivelmente mais degradada e diferenciada em termos de polinização (Figura 8), abrigava espécies polinizadas por morcegos e mariposas que não eram encontradas em outros fragmentos. Isto não significa que a fragmentação e degradação não têm um impacto sobre os serviços de polinização, mas provavelmente este impacto vai ser sentido em períodos mais longos, erodindo as interações e diminuindo a capacidade de persistência de espécies mais especializadas nestes fragmentos florestais antropizados. Ainda, é possível que polinizadores como morcegos e mariposas, préadaptados a explorar recursos num ambiente originalmente organizado em mosaicos de fisionomias abertas e florestais, sejam resilientes o suficiente para lidar com a fragmentação antrópica e continuem provendo os serviços de polinização necessários para espécies de plantas na região. Estas observações continuadas possibilitadas pelos estudos de longa duração no âmbito do PELD podem dar respostas mais específicas para tais perguntas.

Figura 8 (página a seguir). Mudanças nos sistemas de polinização e perturbação ambiental. Porcentagens de espécies e indivíduos associados a diferentes sistemas de polinização em 10 áreas de florestas semideciduais. Neste estudo, plantas polinizadas por abelhas pequenas, vespas e moscas foram reunidos num só grupo. Polinização por beija-flores não foi registrada. Polinização por borboletas, apesar de menos comum em áreas de cerrado, foi encontrada em alguns fragmentos. A similaridade entre os fragmentos em termos de sistemas de polinização foi avaliada. Os fragmentos apresentam diferentes graus de perturbação ambiental indicados como uma nota ao lado da área de cada fragmento. Esta nota foi calculada a partir de vários parâmetros integrados de perturbação antrópica, tais como corte seletivo, sinais de queima e depósito de lixo, tanto na própria floresta como no entorno imediato. Em verde os fragmentos relativamente bem conservados, em amarelo aqueles com graus intermediários de conservação e em vermelho os menos conservados. (Dados de Deus et al. 2014. Biosc.J. 30: 1885-1902 e características dos fragmentos de Sérgio Faria Lopes 2010. Tese de doutorado). 


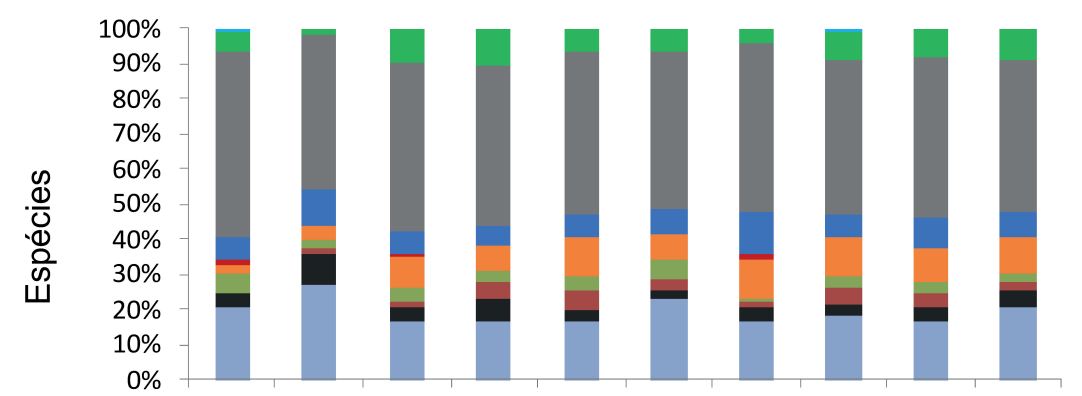

Vento

Pequenos

insetos

Abelhas,

Moscas e

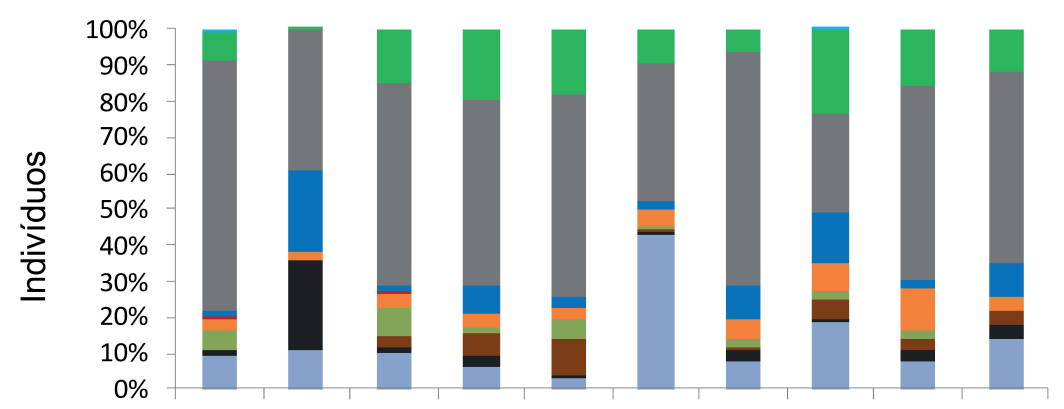

Vespas

Mariposas

Abelhas grandes

Borboletas

Besouros

Morcegos

Não ident.

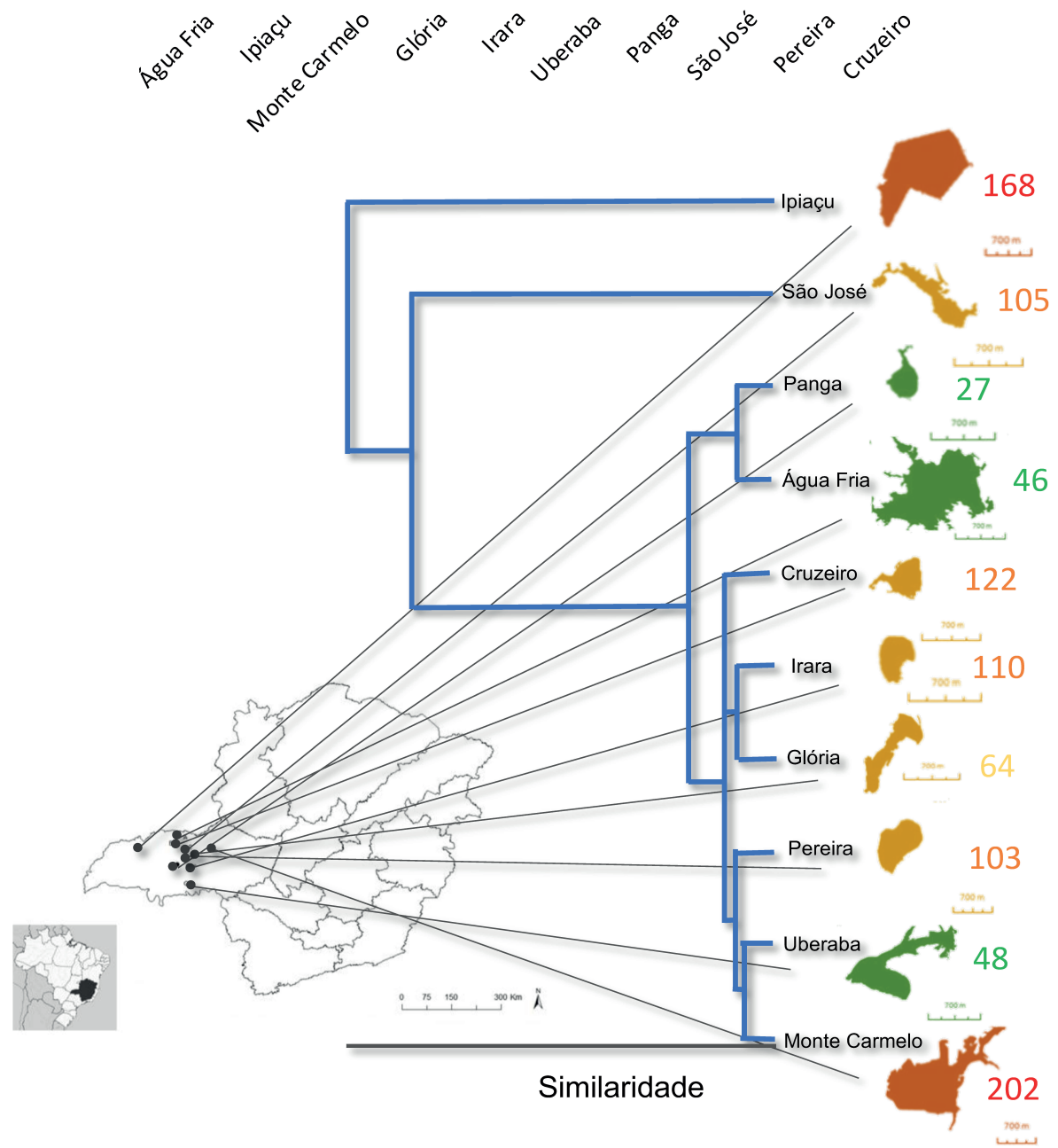




\section{Para saber mais}

Araújo FP, Barbosa AAA, Oliveira PE (2011) Floral resources and hummingbirds on an island of flooded forest in Central Brazil. Flora 206: 827-35 doi: 10.1016/j. flora.2011.04.001

Barbosa AAA, Sazima M (2008) Biologia reprodutiva de plantas herbáceo-arbustivas de uma área de campo sujo de cerrado. Cerrado: ecologia e flora (vol 1). pp. 291-318.

Cardoso JCF, Viana ML, Matias R, Furtado MT, Caetano APS, Consolaro H, Brito VLG (2018) Towards a unified terminology for angiosperm reproductive systems. Acta Bot Bras 32: 329-348 doi: 10.1590/0102-33062018abb0124

Carvalho AMC, Oliveira PE (2010) Estrutura da guilda de abelhas visitantes de Matayba guianensis Aubl.(Sapindaceae) em vegetação do cerrado. Oecol Aust 14: 4066 doi:10.4257/oeco.2010.1401.02

Deus FF, Oliveira PE (2016) Changes in floristic composition and pollination systems in a "Cerrado" community after 20 years of fire suppression. Braz J Bot 39: 1051-1063 doi: 10.1007/s40415-016-0304-9

Deus FF, Vale VS, Schiavini I, Oliveira PE (2014) Diversity of reproductive ecological groups in semideciduous seasonal forests. Biosc J 30: 1885-1902. http://www.seer.ufu. br/index.php/biosciencejournal/article/view/23072

Maruyama PK, Vizentin-Bugoni J, Oliveira GM, Oliveira PE, Dalsgaard B (2014) Morphological and spatio-temporal mismatches shape a neotropical savanna planthummingbird network. Biotropica 46: 740-747 doi: 10.1111/btp.12170

Maruyama PK, Oliveira G.M, Ferreira C, Dalsgaard B, Oliveira PE (2013) Pollination syndromes ignored: importance of non-ornithophilous flowers to Neotropical savanna hummingbirds. Naturwiss 100: 1061-1068 doi:10.1007/s00114-013-1111-9

Potascheff CDM, Brito VL, Galetto L, Sebbenn AM, Oliveira PE (2020) Nectar features, diurnal and nocturnal pollinators, and male fitness in Qualea grandiflora (Vochysiaceae). Plant Syst Evol 306: 3 doi:10.1007/s00606-020-01646-y

Rech AR, Agostini K, Oliveira PE, Machado IC (eds.) (2014). Biologia da polinização. Projecto Cultural, Rio de Janeiro. https://www.researchgate.net/publication/275831630_ Biologia_da_Polinizacao

Sazatornil FD, More,M, Benitez-Vieyra S, Cocucci AA, Kitching IJ, Schlumpberger BO, Oliveira PE, Sazima M, Amorim FW (2016) Beyond neutral and forbidden links: morphological matches and the assembly of mutualistic hawkmoth-plant networks. J Anim Ecol 85(6): 1586-1594 doi: 0.1111/1365-2656.12509

Yamamoto M, Oliveira PE., Gaglianone MC (2014) Uso sustentável e restauração da diversidade dos polinizadores autóctones na agricultura e nos ecossistemas relacionados: planos de manejo. MMA-Funbio, Rio de Janeiro. https://www.mma.gov. br/publicacoes/biodiversidade/category/57-polinizadores.html?start=20 



\title{
CAPÍTULO 16
}

\section{OS INSETOS HERBÍVOROS E SEU IMPACTO SOBRE A VEGETAÇÃO}

\author{
Alan N. Costa \\ Laura V. B. Silva \\ Jaqueline V. Silva \\ Paola P. Raupp
}

\begin{abstract}
Quando um animal consome parte de uma planta ou a planta inteira dizemos que ocorreu herbivoria. As diferentes partes de uma planta (folhas, caule, raízes, flores, frutos e sementes) podem ser consumidos por diferentes herbívoros, que podem ser classificados em relação à dieta vegetal que possuem (veja exemplos na Figura 1). Essa interação ecológica entre animais e plantas é parte essencial do funcionamento dos ecossistemas, porque é através desse processo que a energia e os nutrientes assimilados pelas plantas durante a fotossíntese chegam aos demais animais na cadeia alimentar. Além disso, devido ao ataque dos herbívoros, as plantas podem apresentar redução na sua sobrevivência, no seu crescimento e na sua reprodução. Assim, estudos ecológicos que avaliam os padrões de consumo dos herbívoros e seus potenciais efeitos sobre as plantas são essenciais para a compreensão da dinâmica da vegetação e o funcionamento de qualquer ecossistema.

Cada planta está exposta a diferentes espécies de herbívoros. Normalmente, quando falamos em herbívoros, lembramos dos grandes mamíferos presentes nas savanas africanas, como elefantes, zebras, antílopes e girafas. Sempre nos lembramos de citar também as vacas e cavalos, que são criados em grandes rebanhos nas fazendas espalhadas pelo mundo. Entretanto, além destes exemplos, existem muitos outros herbívoros, por vezes não tão chamativos aos nossos olhos. Como exemplos, podemos citar pequenos mamíferos (roedores e morcegos, principalmente) e grande parte das aves (mutuns, papagaios, canários, entre outros). Indo mais além, não podemos deixar de mencionar a infinidade de insetos que também consomem as plantas, como os gafanhotos, lagartas, besouros, formigas-saúvas e tantos outros insetos herbívoros que povoam o nosso planeta.

Dentre os animais, os insetos formam o grupo com maior diversidade no mundo, existindo uma grande riqueza de espécies (hoje, algo próximo de um milhão de espécies conhecidas, mas que pode ser muito maior). Os insetos também estão entre os animais mais numerosos da natureza e, sendo assim, pode-se supor que os insetos herbívoros consomem uma quantidade de material vegetal muito grande, talvez equivalente ou até mesmo superior àquela ingerida pelos grandes mamíferos herbívoros. A importância dos insetos e de seu impacto sobre o desenvolvimento das plantas pode ser facilmente percebido em lavouras por todo o mundo, sobretudo em função dos numerosos esforços e enormes investimentos realizados no controle de pragas, que em geral são insetos, a fim de reduzir os prejuízos a níveis aceitáveis.
\end{abstract}




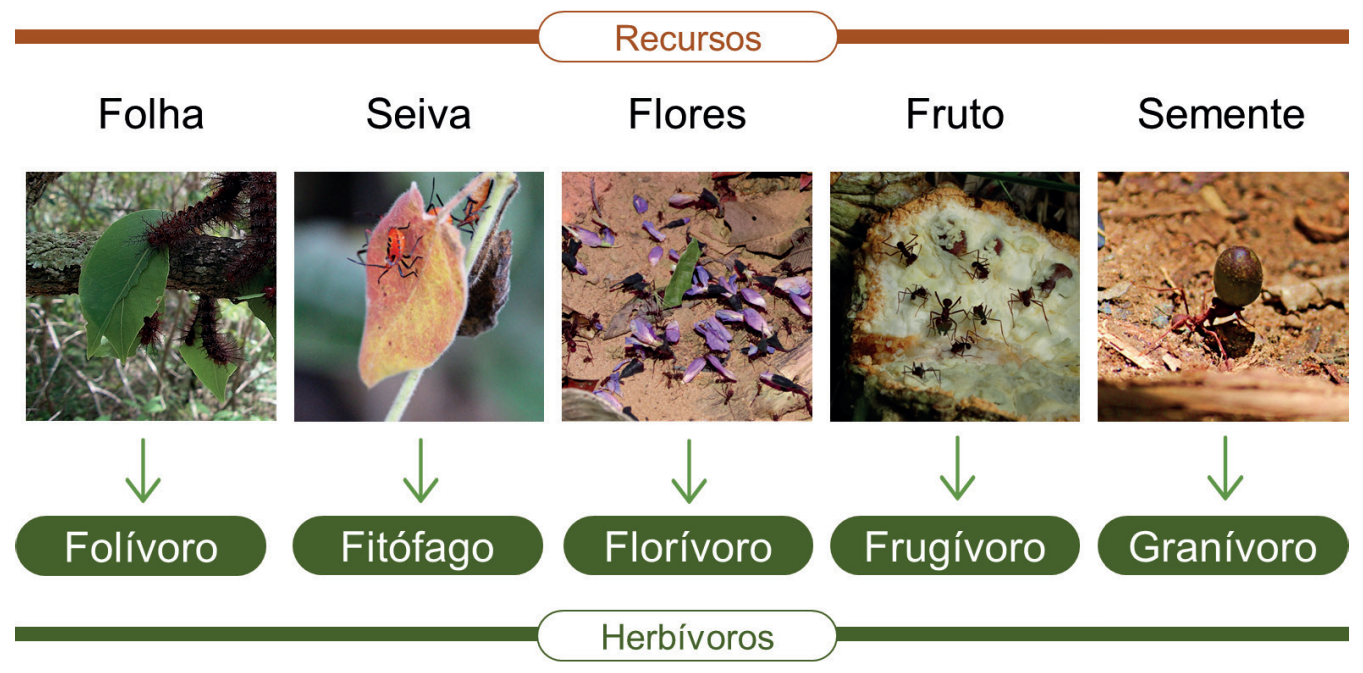

Figura 1: Exemplos de diferentes recursos vegetais consumidos por diferentes herbívoros. Fotos: Alan N. Costa e Jaqueline Vaz Silva.

Diversos estudos sobre os padrões de herbivoria e seus efeitos sobre a vegetação do bioma Cerrado têm sido desenvolvidos nas últimas décadas em remanescentes e reservas naturais presentes no Triângulo Mineiro e Sudeste de Goiás. As descobertas realizadas nesses estudos nos ajudam a entender qual o papel desempenhado pelos herbívoros no funcionamento desse bioma brasileiro, que infelizmente está hoje entre os ecossistemas mais devastados e ameaçados do nosso planeta.

\section{Importância dos insetos herbívoros no bioma Cerrado}

As savanas, vegetação predominante no bioma Cerrado, são ecossistemas caracterizados por uma "matriz" de gramíneas e outras herbáceas, entre as quais se distribuem de forma esparsa arbustos e pequenas árvores com casca grossa e caule retorcido (Figura 2). Esse tipo de vegetação é muito comum em regiões de clima tropical, ocupando quase $65 \%$ da área da África, 60\% da Austrália e 45\% da América do Sul. Décadas de pesquisa demonstraram que a vegetação das savanas africanas são reguladas por uma combinação de efeitos provenientes da abundância de chuvas e disponibilidade de nutrientes no solo, associada aos impactos de eventuais queimadas e das manadas de mamíferos herbívoros de grande porte. Em contraste, a reduzida densidade e diversidade de grandes mamíferos herbívoros observada nas savanas sulamericanas levou a hipótese de que a herbivoria não teria papel relevante na dinâmica da vegetação nestes ecossistemas. Porém, diversas evidências científicas recentes têm apontado que a importância da herbivoria nas savanas sul-americanas, principalmente aquela causada por insetos, tem sido subestimada. 


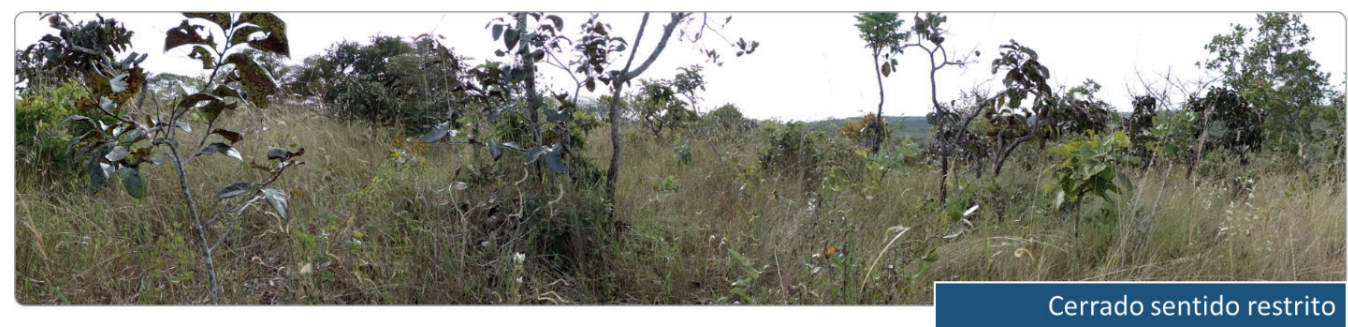

Figura 2: Vegetação savânica típica do bioma Cerrado no Sudeste de Goiás. Foto: Alan N. Costa.

Estudos realizados com o objetivo de quantificar os impactos dos herbívoros nas savanas da América do Sul são muito raros, apesar desses ecossistemas abrigarem uma comunidade diversa e abundante de insetos herbívoros. Em meio a tal diversidade, por exemplo, são encontradas várias espécies de formigas-cortadeirasde-folhas, popularmente conhecidas como formigas-saúvas (gênero Atta) e formigasquenquém (gênero Acromyrmex). As colônias destas formigas atuam como 'herbívoros generalistas', coletando material vegetal (folhas, flores e frutos) de uma grande diversidade de plantas. Contudo, o material coletado das plantas não é diretamente ingerido pelas formigas, mas transportado até o ninho e utilizado como substrato para o cultivo de um jardim de fungos, sendo este o verdadeiro alimento para as formigas da colônia. No caso das saúvas, as formigas operárias constroem grandes ninhos para abrigar colônias com milhões de indivíduos. Na construção desses ninhos, denominados sauveiros, as operárias escavam o solo e depositam a terra removida na superfície, formando enormes montes ou murundus de terra solta (Figura 3).
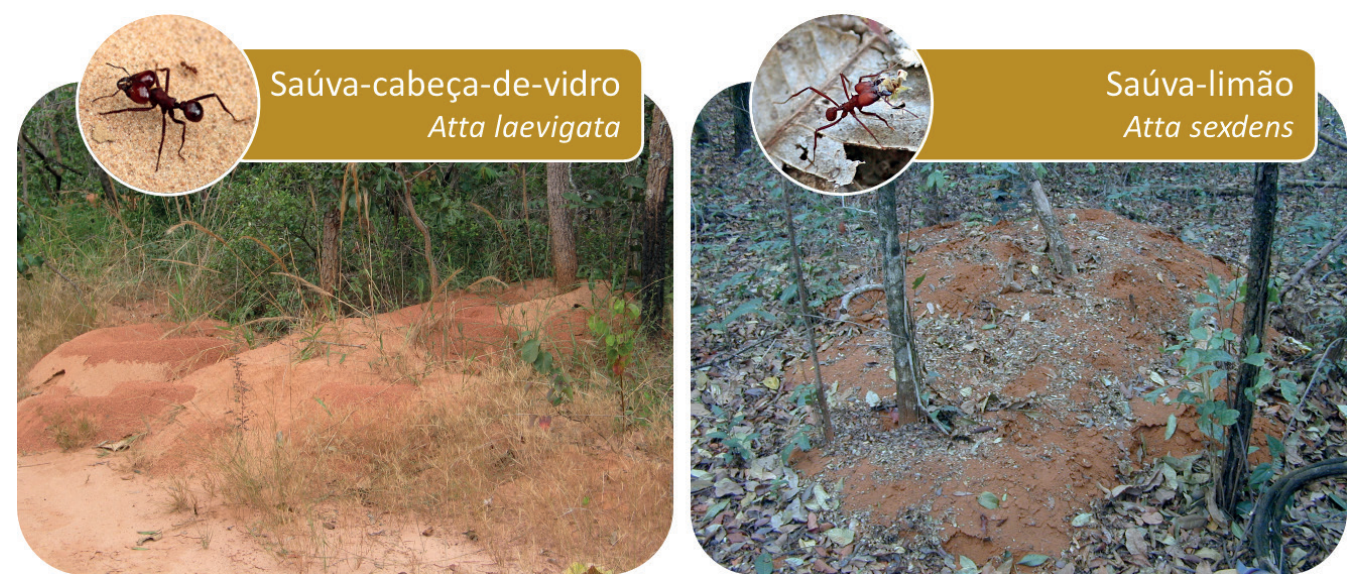

Figura 3: Monte de terra escavada (murundu) produzido pelas colônias de duas espécies de formigas saúvas bastante comuns em áreas do Cerrado. À esquerda ninho (também conhecido como sauveiro) em uma área de cerrado sensu stricto e à direita ninho em uma área de mata estacional. Fotos: Alan N. Costa e Jaqueline Vaz Silva. 
Os murundus dos ninhos das saúvas são elementos bem conhecidos na paisagem sul-americana, sendo encontrados facilmente tanto em ambientes naturais, como campos, savanas e florestas, quanto em lavouras e pastagens, ocorrendo até mesmo em jardins, praças e parques urbanos. Contudo, nosso conhecimento sobre a distribuição e a abundância de sauveiros em diversos ecossistemas ainda é limitado. Nossos estudos mostraram que os ninhos de saúvas são abundantes no Cerrado, podendo ser encontrados em uma densidade semelhante entre os diferentes tipos de vegetação ou fitofisionomias. Fizemos uma estimativa da quantidade de sauveiros adultos (murundu com área $>2$ m2) presentes em quatro grandes remanescentes de vegetação de cerrado, localizados no Triangulo Mineiro e Sudeste de Goiás. Nos quase 100 hectares amostrados foram encontrados 84 ninhos da espécie de formiga saúva-cabeça-de-vidro (Atta laevigata) e 40 ninhos da saúva-limão (Atta sexdens; Figura 3). A densidade média registrada foi aproximadamente 1,3 sauveiros por hectare, chegando a quase 7 sauveiros por hectare em certos locais. Esta densidade média de ninhos é similar àquela registrada em outros biomas, como Amazônia e Mata Atlântica (entre 0,5 e 1,5 sauveiros por hectare). Sabemos que os sauveiros são ninhos que podem chegar a grandes dimensões (existem registros de murundus com mais de $100 \mathrm{~m}^{2}$ de área), contendo colônias com milhões de operárias que podem cortar plantas a distâncias superiores a $100 \mathrm{~m}$ do ninho. Com base nestas informações, podemos questionar: Quanto uma única colônia de saúva pode cortar de material vegetal? Qual a porcentagem da produção de folhas é coletada por várias colônias de saúvas vivendo em um mesmo local? Outro de nossos estudos buscou responder à estas perguntas. Para isso, a atividade de forrageio de oito colônias da saúva-cabeça-de-vidro foi monitorada em área de cerrado sensu stricto na Reserva Ecológica do Panga, em Uberlândia, MG. Durante períodos de 24 horas de monitoramento, nos coletamos todos os fragmentos de plantas transportados até o ninho pelas operárias por três minutos, a cada duas horas. No laboratório, estes fragmentos foram secos em estufa e pesados. Com base nos números obtidos, estimamos que um único sauveiro seria capaz de cortar e carregar para o seu ninho entre 50 e $500 \mathrm{~kg}$ de material vegetal seco por ano, sendo que quanto maior o ninho (com base no tamanho do murundu), maior foi a quantidade de material coletado. Devido à alta densidade de sauveiros encontrada na área durante a realização do estudo (média de 4,8 ninhos por hectare), estimamos que as saúvas podem consumir anualmente cerca de $830 \mathrm{~kg}$ de material vegetal (peso seco) por hectare. Desse total, a porção de folhas $(560 \mathrm{~kg})$ correspondeu a aproximadamente $15 \%$ da biomassa foliar produzida pela vegetação lenhosa (isto é, arbustos e árvores) de uma área de cerrado sensu stricto durante um ano inteiro (Figura 4). 


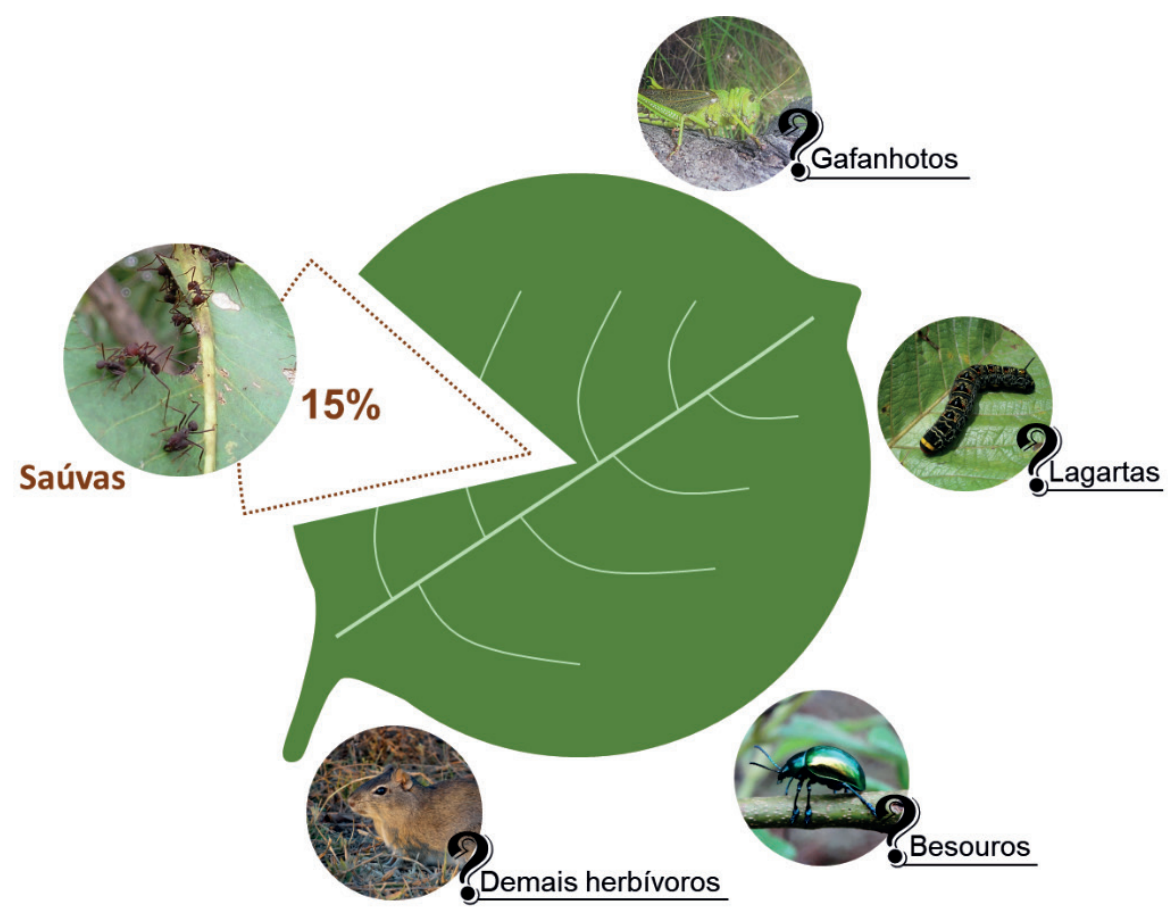

Figura 4: O consumo de folhas pelas saúvas pode chegar a 15\% do total produzido por arbustos e árvores no Cerrado. Para os demais herbívoros, ainda não existem estimativas precisas para cada tipo de organismo. Fotos: Jaqueline Vaz Silva e Alan N. Costa.

A remoção pelas saúvas de $15 \%$ da biomassa de folhas, à primeira vista, parece algo relativamente baixo, reforçando a ideia de que os herbívoros não seriam relevantes no Cerrado. Porém, é importante destacarmos dois pontos relevantes: primeiro, essa taxa de consumo é similar ao realizado por diversas espécies de antílopes nas savanas africanas, e segundo, a desfolha realizada pelas saúvas representa apenas parte do dano causado pelos herbívoros a vegetação. Não podemos nos esquecer que as plantas são simultaneamente danificadas por diferentes herbívoros, e não possuimos uma estimativa igualmente precisa do dano causado por gafanhotos, lagartas, besouros e tantos outros herbívoros existentes no Cerrado (Figura 4). Portanto, não podemos deixar de reconhecer que devido a abundância e diversidade desses organismos, seu consumo não deve ser insignificante, haja visto o exemplo das saúvas. Estas descobertas sugerem que os consumidores de plantas, principalmente os insetos, têm impactos ecológicos importantes (até então subestimados) sobre a estrutura e dinâmica da vegetação no Cerrado.

\section{Herbivoria ao longo do desenvolvimento da planta}

As plantas passam por diferentes estágios de desenvolvimento durante seu ciclo de vida. Tais estágios, em geral, podem ser representados por quatro fases distintas: semente, plântula, planta jovem e planta adulta. Nas duas primeiras fases, as plantas são especialmente suscetíveis ao ataque de herbívoros, pois este pode reduzir mais severamente as chances de sobrevivência. Isto é particularmente verdade para as 
sementes, que podem ser consumidas inteiramente por animais granívoros. O mesmo acontece com as plântulas, que são indivíduos jovens e relativamente dependentes das reservas energéticas provenientes da planta mãe. Por isso, a desfolha, mesmo que parcial, pode mais facilmente causar a morte em plântulas do que em plantas jovens e adultas.

Nosso conhecimento sobre o consumo de sementes e a desfolha de plântulas por herbívoros no Cerrado e seus potenciais efeitos sobre a vegetação nesse ecossistema ainda é reduzido, mas alguns estudos realizados na Reserva Ecológica do Panga, produziram dados interessantes. Experimentos de remoção de diásporos (isto é, sementes ou frutos) de seis espécies de árvores típicas de cerrado sensu stricto foram realizados para se determinar os padrões de consumo de sementes por insetos, pássaros e pequenos mamíferos. As espécies utilizadas nos experimentos foram Coussarea hydrangeifolia (Rubiaceae), Guapira graciliflora (Nyctaginaceae), Maprounea guianensis (Euphorbiaceae), Matayba guianensis (Sapindaceae), Siparuna guianensis (Siparunaceae) e Virola sebifera (Myristicaceae). Os pesquisadores registraram percentuais de consumo relativamente elevados, sendo que quase $57,5 \%$ dos 21.600 diásporos expostos foram removidos do solo após 48 horas de observação. Outro estudo de remoção de sementes realizado por nós nessa mesma reserva, com as mesmas espécies citadas no estudo anterior e mais outras seis, incluindo Cordiera myrciifolia (Rubiaceae), Brosimum gaudichaudii (Moraceae), Eugenia involucrata (Myrtaceae), Miconia albicans (Melastomataceae), Myrcia splendens (Myrtaceae) e Tapirira guianensis (Anacardiaceae), confirmou os resultados obtidos anteriormente.

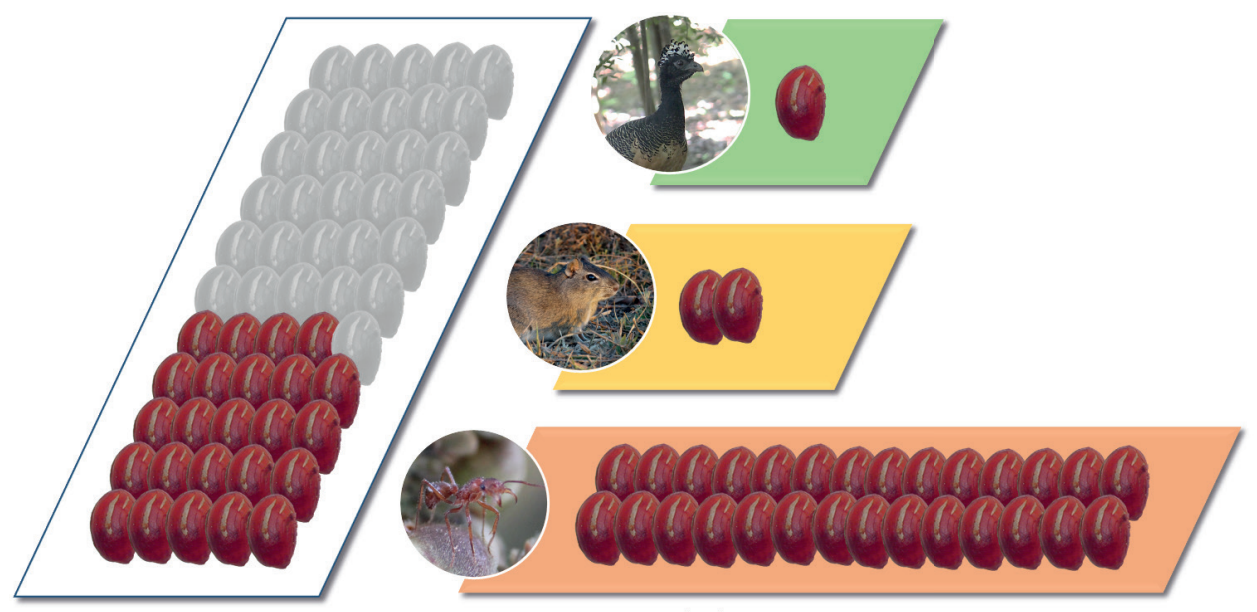

\section{Aproximadamente $55 \%$ dos diásporos foram removidos após 48 horas por insetos, pequenos mamíferos e aves}

Figura 5: Participação de diferentes animais na remoção de sementes e frutos de arbustos e árvores que caem no solo. A taxa de remoção em um período de 24 a 48 h é elevada, sendo as formigas, os principais predadores/dispersores secundários de sementes, seguido dos roedores e aves. Fotos: Alan N. Costa e Jaqueline Vaz Silva.

Nesse estudo observamos que $52,9 \%$ dos 5.080 diásporos expostos foram removidos após 24 horas (Figura 5). Ao se analisar separadamente as diferentes espécies de plantas estudadas, foi possível perceber que existe uma relação negativa entre o tamanho do diásporo e sua taxa de remoção. Demostrou-se também que as 
formigas removem muito mais diásporos do que as aves e os roedores (Figura 5), o que ajuda a explicar porque sementes e frutos menores foram os mais removidos.

Nos ecossistemas de florestas tropicais, ao observar as plântulas de arbustos e árvores, pode-se verificar que a grande maioria apresenta algum dano foliar, sendo estimado que as plântulas perdem em média $10 \%$ de sua área foliar para os herbívoros. Apesar dessa taxa de consumo médio aparentemente baixa, o ataque de herbívoros é indicado como uma das principais causas de morte em plântulas, respondendo por 30 a $40 \%$ da mortalidade registrada. No Cerrado, a desfolha em plântulas pode ser equivalente ou superior à observada em ambientes florestais. Em um estudo que realizamos na Reserva Ecológica do Panga, avaliamos o tipo e a quantidade de danos foliares em 1.600 plântulas de 13 espécies típicas de cerrado. Observamos que quase $72 \%$ das plântulas sofreram algum dano (Figura 6), especialmente por formigascortadeiras-de-folhas, gafanhotos, lagartas ou besouros. Com base em estimativas visuais da quantidade de área foliar removida por esses herbívoros, estimamos que a taxa média de dano foi próxima de $30 \%$. Esses resultados sugerem que a pressão de herbivoria sobre as plântulas é alta no Cerrado, podendo ser maior que a pressão registrada em florestas tropicais. Além disso, o impacto negativo dessa intensa desfolha sobre a sobrevivência das plântulas pareceu ser maior na fisionomia de cerrado ralo do que no cerrado denso, indicando a potencial interação entre os efeitos negativos da herbivoria com fatores ambientais como a seca. Estudos adicionais estão em andamento na Reserva Ecológica do Panga para avaliar esses fatores.
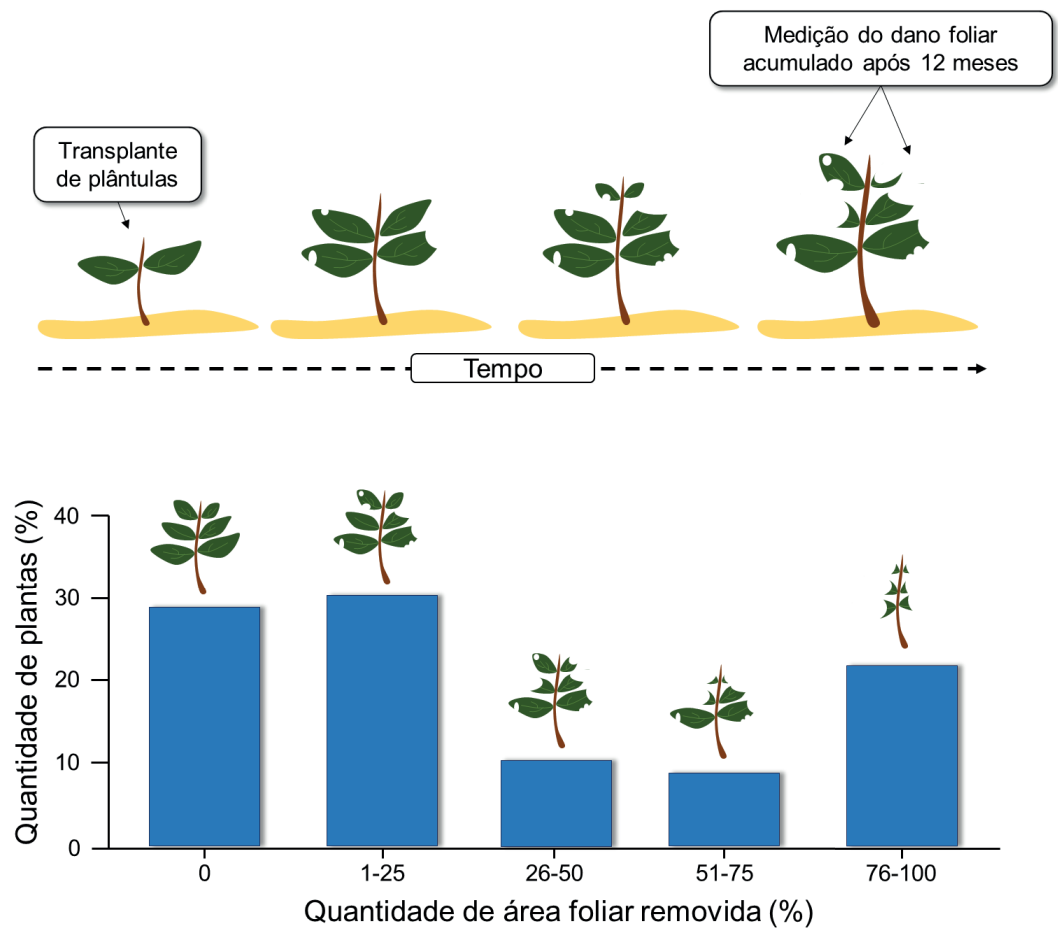

Figura 6: Metodologia e frequência de herbivoria medida em plântulas de espécie lenhosas na Reserva Ecológica do Panga, Uberlândia, MG. 
No Cerrado, também são raros estudos que objetivaram estimar os padrões gerais de herbivoria sobre plantas adultas no nível da comunidade, ou seja, que mediram a perda de área foliar em diferentes espécies de arbustos e árvores simultaneamente. Estudos realizados há mais de duas décadas indicam que as plantas adultas de espécies arbustivas e arbóreas tendem a perder entre 4 e 9\% da sua área foliar para os herbívoros. Contudo, tais valores podem estar subestimados, uma vez que esses estudos empregaram uma metodologia de coleta rápida de uma amostra de folhas presentes em plantas selecionadas previamente. Com isto, as folhas totalmente consumidas pelos herbívoros antes da seleção das plantas e coleta das amostras não foram consideradas nas análises.

A herbivoria em plantas adultas de espécies lenhosas também foi objeto de estudo na Reserva Ecológica do Panga e em outro remanescente de cerrado localizado em Catalão, GO. Adotando uma metodologia diferente daquela mencionada anteriormente, nesses dois estudos marcamos folhas jovens, ainda como botão foliar em estágio inicial de expansão, e medimos o dano foliar acumulado após 60 a 70 dias (Figura 7). Os resultados preliminares deste estudo apontam para uma taxa média de herbivoria entre 13 e 17\%. Esses valores são duas a quatro vezes maiores do que as estimativas registradas nos estudos anteriores. No monitoramento da taxa de herbivoria na Reserva Ecológica do Panga, nós repetimos a medição por três anos consecutivos e as estimativas de desfolha variaram entre 7 e $19 \%$ de acordo com o ano. Enquanto isso, no estudo realizado em Catalão, repetindo a mesma metodologia em quatro fitofisionomias diferentes, a estimativa de desfolha variou entre 14 e $18 \%$ de acordo com o tipo de vegetação. A comparação entre estes resultados indica que a pressão dos herbívoros sobre a vegetação é algo que tende a apresentar variação espaço-temporal, ou seja, pode variar entre diferentes fisionomias e locais, além de variar entre anos em um mesmo local.

É importante ressaltar que essas estimativas representam apenas a taxa geral de dano observado nas plantas, existindo grande variação na herbivoria entre plantas de diferentes espécies. Para algumas espécies, as plantas frequentemente apresentaram poucos danos em suas folhas, enquanto em outras as folhas foram muito danificadas pelos herbívoros (Figura 7). Essa variação na taxa de desfolha era esperada e ocorreu porque a qualidade das folhas, como alimento para os herbívoros, difere entre as espécies de plantas. Então, um questionamento emerge com a análise desses resultados: Qual o potencial impacto da herbivoria sobre as plantas e espécies mais danificadas? Outra pesquisa realizada também na Reserva Ecológica do Panga buscou responder essa pergunta analisando os efeitos da desfolha aplicada artificialmente em plantas de seis espécies de arbóreas de cerrado. Nesse estudo, as plantas das espécies estudas tiveram todas as suas folhas removidas em diferentes intervalos: a cada quatro meses para algumas (baixa frequência de desfolha) e a cada mês para outras (alta frequência de desfolha), enquanto que em um terceiro grupo as plantas não foram desfolhadas, servindo como grupo de controle. A desfolha artificial adotada nesse estudo seguiu os padrões de herbivoria realizados pelas saúvas na área de estudo. Os principais resultados encontrados pelos pesquisadores demonstram que a desfolha intensa e frequente pode reduzir a sobrevivência das plantas, além de diminuir o crescimento e a reprodução das plantas sobreviventes. 

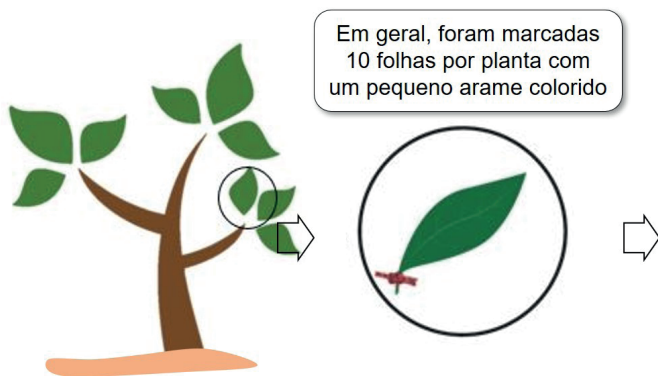

As folhas foram

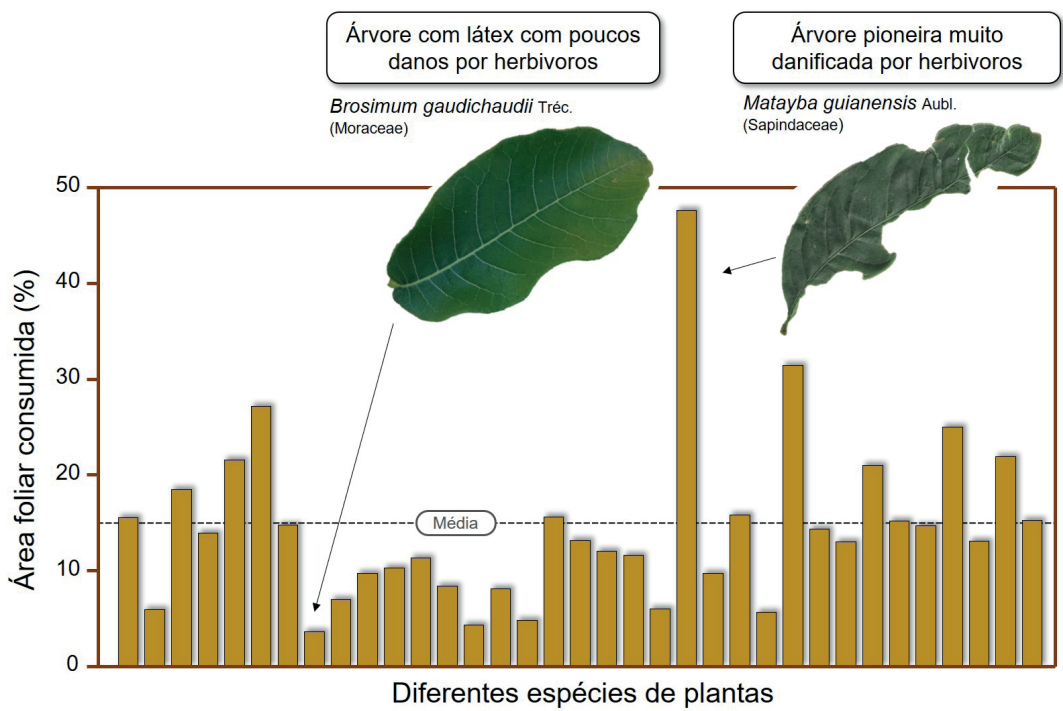

Figura 7: Método e taxas de herbivoria em plantas adultas de diferentes espécies de arbustos e árvores monitorados em remanescentes no cerrado no Triangulo Mineiro e sudeste de Goiás. Foto: Alan N. Costa.

\section{Estratégias anti-herbivoria das plantas: a defesa temporal ou fenológica}

Os herbívoros podem consumir parte do tecido vegetal e desencadear efeitos negativos nos processos metabólicos e fisiológicos das plantas, podendo prejudicar as chances de sobrevivência, seu crescimento ou mesmo sua reprodução. Contudo, as plantas não são organismos inertes ou passivos ao ataque de herbívoros. A contínua pressão seletiva imposta pela herbivoria impulsionou a evolução de defesas nas plantas. Essas estratégias anti-herbivoria podem ser fixas, sendo expressas independente de existir ou não o ataque de herbívoros, ou podem ser induzidas, sendo expressas quando ocorre o ataque. De tal modo, as plantas podem apresentar diversas estratégias físicas, químicas, biológicas e fenológicas contra os herbívoros.

As defesas físicas ou estruturais consistem em características para impedir o consumo de folhas, caules, flores e ou frutos. Por exemplo, a presença de espinhos e pelos (chamados de tricomas) sobre as folhas pode dificultar ou impedir a ação dos herbívoros. As defesas químicas são compostas por uma ampla variedade de substâncias, que podem inibir o consumo, dificultar a digestão e até causar intoxicação nos herbívoros. As defesas biológicas envolvem estratégias para atrair possíveis inimigos naturais dos herbívoros para a planta. Para tanto, as plantas podem liberar substâncias atrativas ou recompensar esses inimigos com comida e abrigo, o que os 
mantêm por perto. Por fim, as plantas também podem desenvolver defesas temporais ou fenológicas para escapar dos herbívoros. Esse escape temporal das plantas poderia ocorrer em duas situações. Primeiro, quando as plantas produzem novas folhas de forma sincronizada, ou seja, todas ao mesmo tempo, ocorrendo um excesso de folhas que permite que muitas escapem do ataque dos herbívoros. Segundo, quando as plantas concentram sua produção de novas folhas no período do ano com menor presença de herbívoros.

A herbivoria é uma relação ecológica que molda as comunidades vegetais em regiões tropicais e temperadas e pode ser influenciada pela sazonalidade climática. No Cerrado, há duas estações bem definidas, um inverno seco de maio a setembro e um verão chuvoso de outubro a abril. Essa alternância de estações seca e chuvosa pode influenciar os processos de crescimento e reprodução das plantas e, consequentemente, a oferta de alimento para os herbívoros. Em um dos trabalhos realizados na Reserva Ecologia do Panga, buscou-se investigar se as plantas de cerrado podem se valer da estratégia de fuga temporal ou fenológica dos herbívoros. Para testar essa hipótese foram medidas as taxas de herbivoria sobre arbustos e árvores em uma área de cerrado sensu stricto, em diferentes épocas do ano, para determinar se as plantas podem apresentar menos danos foliares ao concentrarem a produção de folhas jovens antes do início das chuvas, quando a ocorrência de herbívoros ainda pode ser baixa. Então, durante seis meses, foram monitoradas plantas de cinco espécies, sendo estas: Davilla elliptica. (Dilleniaceae), Neea theifera. (Nyctaginaceae), Piptocarpha rotundifolia (Asteraceae), Roupala montana. (Proteaceae) e Styrax ferrugineus (Styracaceae).

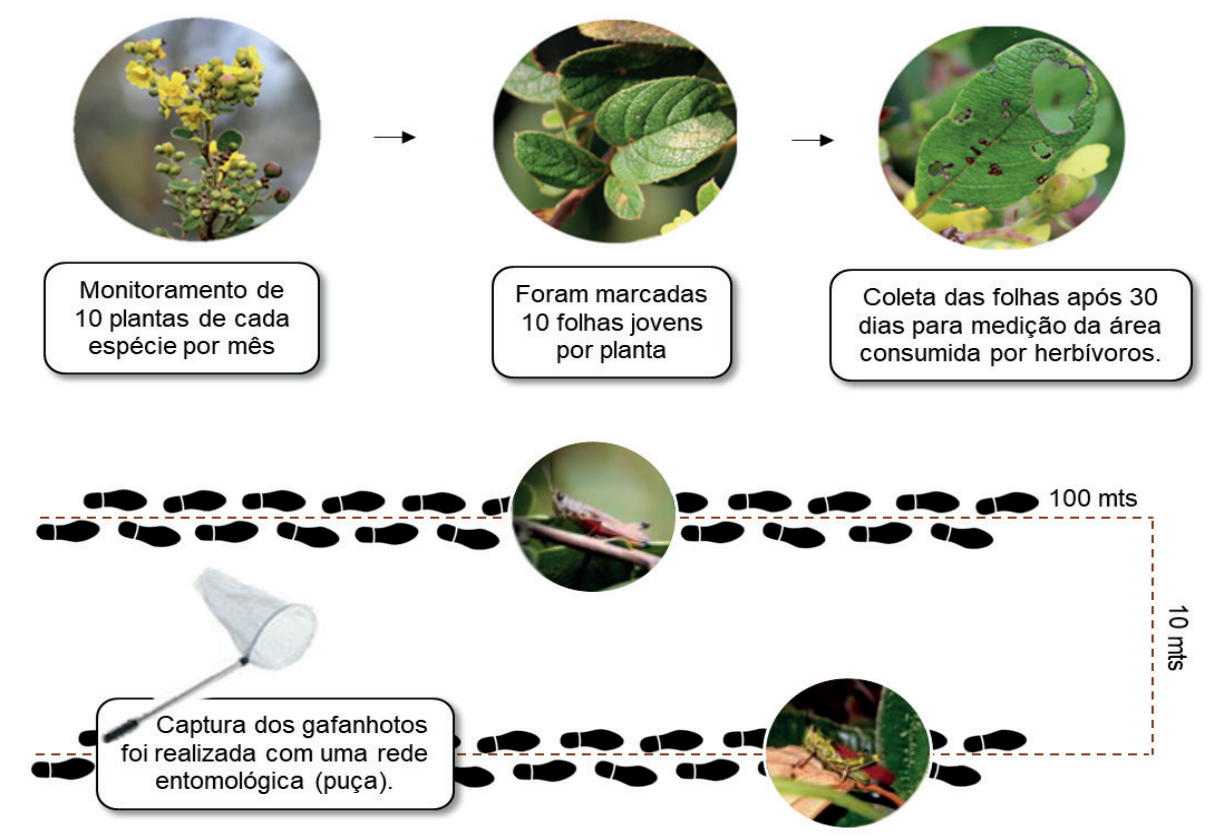

Figura 9: Metodologia utilizada para medir mensalmente a herbivoria em plantas no Cerrado e para captura de herbívoros no entorno das plantas monitoradas. Fotos: Jaqueline Vaz Silva. 
Essas espécies foram escolhidas entre as plantas que perdem todas as suas folhas durante a estação seca e produzem novas folhas antes do início das chuvas (plantas decíduas), plantas que perdem apenas parte das folhas durante a estação seca e produzem novas folhas mais intensamente durante a transição entre as estações seca e chuvosa (plantas brevidecíduas), e plantas que mantêm suas folhas durante todo o ano e produzem novas folhas durante grande parte da estação chuvosa (plantas sempre verdes). Para todas as cinco espécies foi medida a porcentagen de área foliar perdida nas folhas previamente marcadas no período do estudo. Além disso, foi avaliado se a variação mensal na taxa de herbivoria esteve correlacionada com a variação na abundancia de insetos herbívoros, como gafanhotos, capturados na área durante o estudo. A abundância de gafanhotos foi determinada por meio do método de captura direta, utilizando-se uma rede entomológica ou puçá (Figura 9).

De acordo com os resultados encontrados neste estudo, o dano causado nas plantas por herbívoros muda ao longo do tempo no Cerrado. Os menores danos foram registrados nos meses de outubro e novembro, época do início da estação chuvosa e baixa ocorrência de herbívoros. Contudo, a herbivoria se intensifica a partir do mês de dezembro, mantendo altas taxas de dano até o final da estação chuvosa. As maiores perdas de folhas das plantas foram registradas nos meses com maior abundância de gafanhotos. Com base nesses resultados é possível supor que o comportamento de antecipar e concentrar a produção de folhas jovens para um período anterior ao início das chuvas pode ser uma estratégia adotada por parte das espécies de plantas lenhosas do Cerrado para minimizar os danos causados por herbívoros.

\section{Interação entre herbivoria e fatores abióticos: efeito do fogo}

O resultado do ataque dos herbívoros sobre uma planta, ou seja, a quantidade de área foliar consumida, pode depender de fatores bióticos, como a qualidade das folhas, mas também de fatores abióticos, como as variações climáticas, disponibilidade de nutrientes no solo e a ocorrência de fogo. Esse último constitui um distúrbio frequente no Cerrado e que tem comprovada influência sobre a estrutura e a composição da vegetação desse bioma. O principal e imediato efeito do fogo é a morte de plantas sensíveis e rebrota vigorosa de plantas mais resistentes e adaptadas aos seus efeitos. Consequentemente, podemos supor que o fogo pode afetar as relações ecológicas existentes entre as plantas e seus consumidores, visto que a perturbação da vegetação pode levar a mudanças na disponibilidade e na qualidade das folhas. Entretanto, poucos estudos avaliaram a respostas dos herbívoros as mudanças causadas pelo fogo na vegetação de cerrado.

Um estudo realizado na Reserva Ecológica do Panga avaliou os efeitos do fogo nas taxas de danos causados por herbívoros e patógenos em espécies arbóreas. $\mathrm{O}$ estudo foi conduzido em uma área de cerrado sensu stricto parcialmente queimada após um incêndio de origem antrópica, que queimou parte da reserva. Para medir as taxas de dano foliar foram monitoradas 90 plantas de três espécies típicas de cerrado: Caryocar brasiliensis (Caryocaraceae), Qualea grandiflora (Vochysiaceae) e Xylopia aromatica (Annonaceae). As plantas foram aleatoriamente selecionadas ao longo de dois transectos de aproximadamente $600 \mathrm{~m}$, um estabelecido na área queimada e o outro na área não queimada mais próxima (Figura 10). Observou-se que o fogo afetou 
os padrões de produção de folhas pelas plantas das três espécies utilizadas no estudo e, consequentemente, as taxas de dano foliar. Nas espécies decíduas, como C. brasiliensis e $Q$. grandiflora, a produção de novas folhas ocorreu principalmente entre setembro e outubro, período que marca o final de estação seca e início da chuvosa. Porém, as árvores queimadas estenderam sua produção de novas folhas até o final da estação chuvosa, que ocorre entre março e abril. As plantas queimadas da espécie $X$. aromatica não produziram novas folhas nos três primeiros meses após o incêndio, período que foi o pico de produção de folhas pelos indivíduos não queimados desta espécie, enquanto nos meses seguintes foram produzidas mais folhas novas pelas árvores queimadas do que pelas árvores não queimadas.
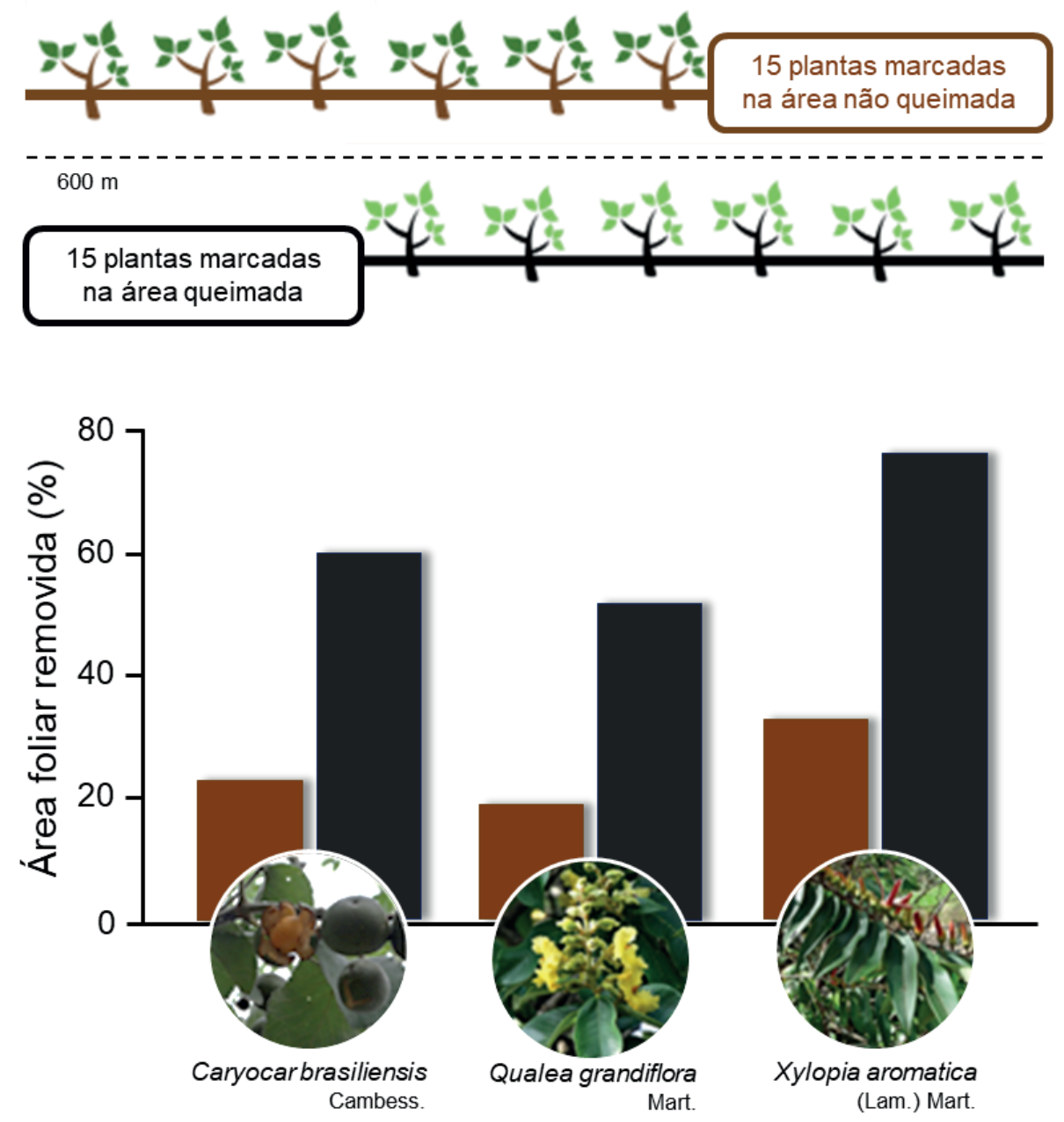

Figura 10: Metodologia e taxa de dano foliar registrada em árvores de três diferentes espécies no Cerrado. As plantas foram monitoradas em uma área de cerrado sensu strictoparcialmente perturbada pelo fogo. Fotos: Jaqueline Vaz Silva. 
As mudanças nos padrões de produção de folha tiveram efeito sobre as taxas de dano foliar, sendo que a herbivoria por insetos mastigadores, nas árvores afetadas pelo fogo foi pelo menos duas vezes maior que a herbivoria observada nas árvores não queimadas. Os principais danos nas árvores queimadas foram causados por insetos como formigas-cortadeiras-de-folhas, lagartas e gafanhotos. Como mencionado anteriormente, as formigas-cortadeiras-de-folhas são herbívoros importantes no Cerrado, e suas colônias não são afetadas diretamente pelo fogo porque seus ninhos são subterrâneos. Entretanto, essas formigas são sensíveis a mudanças na disponibilidade de recursos vegetais e direcionam seus esforços para áreas mais produtivas da vegetação. Sendo assim, devido ao impacto do fogo na produção e qualidade das folhas, as formigas parecem ter concentrado sua atividade de forrageio sobre as plantas presentes na área queimada, devido a maior disponibilidade de folhas jovens, que são seus recursos preferidos.

Porém, nem todos os herbívoros parecem ter se beneficiado da perturbação causada pelo fogo. Em geral, os demais tipos de dano foliar, que incluiu as perdas causadas por insetos galhadores, minadores, raspadores e por patógenos, tiveram padrões variados de resposta. Apesar dessa variação entre os diferentes herbívoros, no geral, a área foliar perdida pelas plantas afetadas pelo incêndio foi ainda duas a três vezes superior às perdas apresentadas pelas plantas presentes na área não queimada (Figura 10). Com base nesse padrão, que foi consistente entre as três espécies de árvore estudadas, podemos supor que o aumento da pressão de herbivoria sobre a vegetação de cerrado tende a ser o resultado mais provável após perturbações pelo fogo.

\section{Efeitos da herbivoria na vegetação: filtros ecológicos}

Semelhante ao que acontece em outros ecossistemas, as descobertas desses estudos sobre herbivoria desenvolvidos no Triângulo Mineiro e Sudeste de Goiás, demostram que tanto o consumo de sementes quanto a desfolha podem limitar o recrutamento de plantas de diversas espécies de cerrado. Então, podemos sugerir que os herbívoros atuam como filtros ecológicos, os quais as plantas devem superar ao longo das diferentes fases do seu ciclo-de-vida (Figura 11). No mais, como os resultados dos estudos citados demostraram, a remoção de sementes tende a diferir entre as espécies de plantas, sendo o mesmo verdadeiro para a quantidade de área foliar perdida por plantas jovens a adultas, onde algumas espécies são mais atacadas do que outras. Assim, as espécies menos consumidas teriam mais sucesso em superar os filtros ecológicos criados pelos herbívoros, ou seja, teriam mais indivíduos recrutados do que as espécies mais afetadas.

Como alguns resultados mostrados aqui também indicam, os efeitos da herbivoria podem ser afetados por fatores ambientais, como a estação seca e o fogo. Então, os filtros ecológicos causados pelos herbívoros, associados aos filtros ambientais exercidos pela sazonalidade climática, qualidade do solo e ocorrência do fogo, podem ser os fatores chave para explicar a variação na abundância e distribuição espacial das diferentes espécies de plantas ao longo da paisagem do Cerrado. 

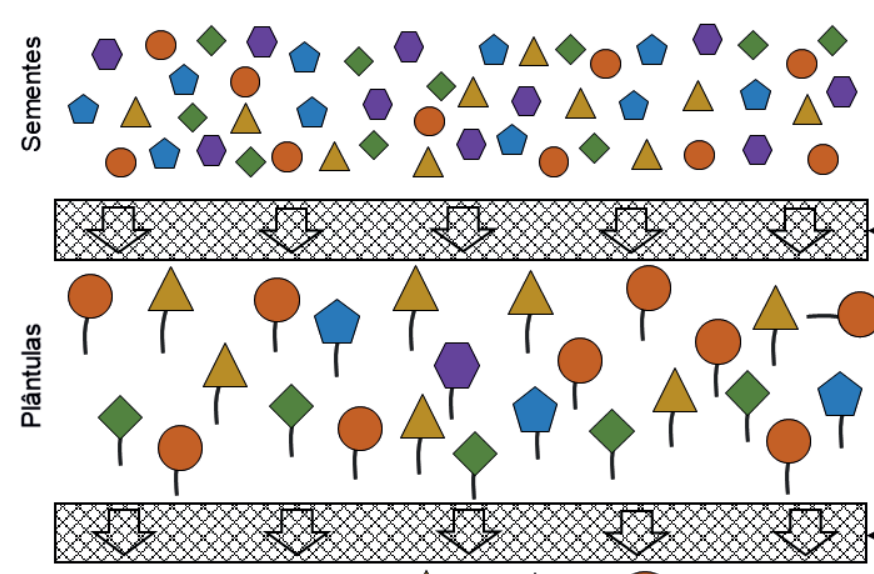

A predação de sementes e herbivoria podem atuar como FILTROS ECOLÓGICOS
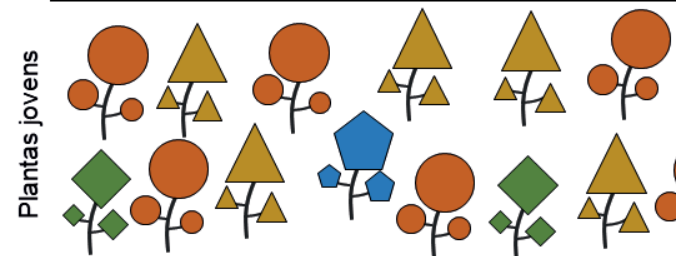

dificultando o estabelecimento de novas plantas ao longo
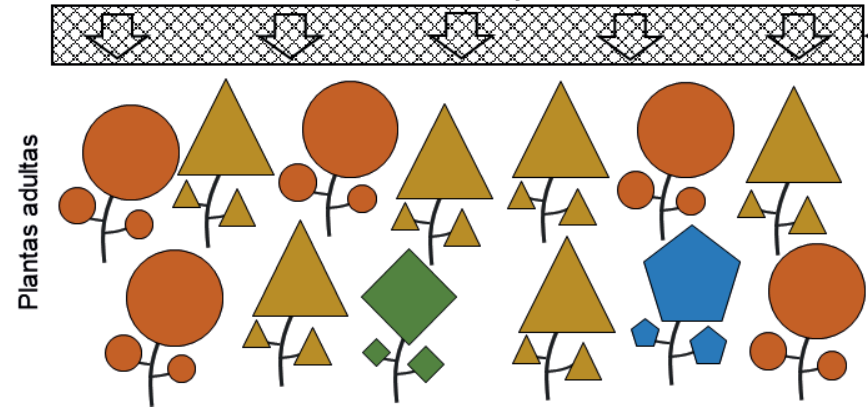

A diversidade de plantas que alcançariam a fase adulta seria então menor, em parte, devido ao impacto dos herbívoros.

Figura 11: Potenciais filtros ecológicos realizados pelos herbívoros ao longo das sucessivas etapas de desenvolvimento de plantas no Cerrado, desde a fase de semente até a fase de planta adulta.

\section{Considerações finais}

De modo geral, esses resultados ilustram como os herbívoros são importantes para a dinâmica da vegetação do Cerrado. Além disso, cabe ressaltarmos que esse bioma tem sido devastado desde as últimas décadas para a expansão agropecuária e urbana na região central do Brasil. Muitos herbívoros, como, por exemplo, algumas espécies de formigas-cortadeiras de folhas, podem ser favorecidos pela modificação da paisagem pelo homem. Com frequência se tem registrado o aumento das populações dessas formigas em ecossistemas perturbados ou ambientes antropizadas. Assim, com o aumento da abundância de herbívoros, podemos esperar o aumento significativo das taxas de consumo, o que pode trazer efeitos negativos para a vegetação e ampliar as perdas de diversidade dentro de uma paisagem já alterada e empobrecida. Portanto, entender os impactos da herbivoria, como esses efeitos interagem com fatores ambientais, e como os herbívoros respondem as mudanças induzidas pelo homem são essenciais para a realização de ações eficazes de manejo e conservação da vegetação remanescente do Cerrado. 


\section{Para saber mais}

Costa AN, Vasconcelos HL, Bruna EM (2017) Biotic drivers of seedling establishment in Neotropical savannas: selective granivory and seedling herbivory by leaf-cutter ants as an ecological filter. J Ecol 105:132-141 doi:10.1111/1365-2745.12656

Costa AN, Vasconcelos HL, Vieira-Neto EHM, Bruna EM (2008) Do herbivores exert top-down effects in Neotropical savannas? Estimates of biomass consumption by leafcutter ants. J Veg Sci 19:849-854 doi: 10.3170/2008-8-18461

Costa AN, Vasconcelos HL, Vieira-Neto EHM, Bruna EM (2019) Adaptive foraging of leaf-cutter ants to spatiotemporal changes in resource availability in Neotropical savannas. Ecol Entomol 44:227-238 doi:10.1111/een.12697

Costa AN, Vieira-Neto EHM (2016) Species turnover regulates leaf-cutter ant densities in environmental gradients across the Brazilian Cerrado. J Appl Entomol 140:474-478 doi: $10.1111 /$ jen. 12277

Ferreira A V, Bruna EM, Vasconcelos HL (2011) Seed predators limit plant recruitment in Neotropical savannas. Oikos 120:1013-1022 doi:10.1111/j.1600-0706.2010.19052.x Lopes CT, Vasconcelos HL (2011) Fire increases insect herbivory in a neotropical savanna. Biotropica 43:612-618 doi:10.1111/j.1744-7429.2011.00757.x 



\section{CAPÍTULO 17}

\section{O PROCESSO DE DECOMPOSIÇÃO DA SERAPILHEIRA}

Laura V. B. Silva

Heraldo L. Vasconcelos

Emilio M. Bruna

Em solos pobres em nutrientes, como é o caso de muitos ecossistemas tropicais, a produtividade e sustentabilidade do sistema dependem da ciclagem interna de nutrientes. A decomposição da serapilheira é um dos processos chave para a manutenção da fertilidade dos solos, principalmente naqueles pobres em nutrientes como é o caso dos solos de Cerrado. Entretanto, fatores naturais de controle do processo de decomposição podem ser afetados pelas alterações ambientais. A deposição atmosférica de nitrogênio $(\mathrm{N})$, por exemplo, está entre as principais ameaças para a conservação da biodiversidade do Cerrado, pois ela pode afetar o processo de decomposição e, consequentemente, a ciclagem de nutrientes. Neste capítulo, apresentaremos uma revisão sobre os principais fatores controladores do processo de decomposição, as estimativas globais da deposição de $\mathrm{N}$ previstas para a região geográfica do bioma Cerrado e os principais resultados obtidos no experimento de fertilização de longa duração desenvolvido na Reserva Ecológica do Panga em Uberlândia, MG.

\section{Decomposição da serapilheira}

A decomposição da serapilheira é a principal via de entrada de nutrientes em ecossistemas com solos pobres em nutrientes. Muito da produção primária acima do solo retorna ao solo como serapilheira. A maior parte dela é constituída principalmente de material vegetal como folhas, ramos, caules, flores e frutos, sendo o material foliar o mais expressivo em quantidade de nutrientes. Mediada por fatores bióticos e abióticos, a decomposição da serapilheira é resultado da transformação da matéria orgânica morta em dióxido de carbono, água e nutrientes. Isto se dá pela interação de três processos: lixiviação, fragmentação e alteração química. O primeiro corresponde a um processo abiótico em que há a remoção de compostos solúveis por ação da água. $\mathrm{O}$ segundo se refere a ação da fauna do solo, a qual irá reduzir o tamanho das partículas do material a ser decomposto, aumentando a área de exposição para a colonização de microrganismos. E, por último, a alteração química da matéria orgânica morta, que é primariamente uma conseqüência da atividade de bactérias e fungos, embora algumas reações químicas também ocorram espontaneamente no solo sem mediação microbial. A atuação desses processos envolve grande número e variedade de fatores, como parâmetros do clima, qualidade da serapilheira e microrganismos do solo que, em parte, determinam o processo de decomposição, e que variam de acordo com as condições locais e regionais.

Dentre os fatores climáticos, a temperatura e a precipitação são os mais importantes no controle da decomposição, pois influenciam o processo de lixiviação e, 
ao mesmo tempo, criam condições apropriadas para o estabelecimento e atuação dos microrganismos decompositores. Por causa da dependência desses fatores climáticos, a taxa de decomposição varia dramaticamente entre regiões climáticas, sendo mais lenta em florestas temperadas onde há baixas temperaturas, e mais alta em florestas tropicais, onde a alta temperatura e a precipitação aceleram a lixiviação e aumentam a atividade dos decompositores. Além disso, em regiões tropicais, em que esses fatores favorecem a decomposição, é possível que haja uma mudança na ordem dos fatores controladores do processo de decomposição. Assim, o clima deixaria de ser o principal determinante, fazendo da qualidade da serapilheira o principal controlador da taxa de decomposição.

O efeito da qualidade da serapilheira é evidente na taxa de decomposição, principalmente a quantidade de substâncias lixiviáveis e solúveis em água. Sob as mesmas condições climáticas, a velocidade de decomposição pode variar de acordo com a porcentagem de lignina, polifenóis, carbono, nitrogênio, fósforo e enxofre. Em particular, a concentração de nitrogênio e fósforo pode afetar a decomposição da serapilheira, especialmente em ecossistemas deficientes nestes nutrientes. Esses nutrientes são muito importantes para o crescimento microbiano, sendo que o processo de decomposição da serapilheira é mais rápido quando a concentração desses nutrientes é maior. Além da qualidade nutricional, a qualidade do carbono (referente ao tipo de ligações de carbono e a energia liberada por elas) também é bastante importante no processo de decomposição. A lignina tem forte influência sobre a decomposição da serapilheira. Ela apresenta uma das menores taxas de decaimento e, para que sua decomposição seja iniciada, é preciso da energia liberada durante a degradação de compostos de alta qualidade, como os açúcares.

Os nutrientes da serapilheira e concentrações de frações de carbono, como a lignina, têm sido identificados como indicadores de qualidade da serapilheira. A relação entre algumas dessas substâncias tem sido usada para explicar diferenças entre a velocidade de decomposição de materiais orgânicos. Alguns autores propõem que a primeira fase do processo de decomposição é regulada pelo conteúdo de nutrientes, enquanto a segunda fase pela lignina. A razão $\mathrm{C}: \mathrm{N}$ é um índice bastante utilizado como preditor da taxa de decomposição. Entretanto, alguns estudos têm mostrado que a quantidade inicial de lignina ou a razão lignina: $N$ ou lignina:P também são bons preditores do processo de decomposição, estando inversamente relacionados às taxas de decomposição.

Apesar da forte influência dos fatores climáticos e da qualidade da serapilheira, a decomposição éresultado primário da atividade dos microrganismos. Os microrganismos do solo são os principais agentes da ciclagem de nutrientes, pois são capazes de digerir quase todo o substrato encontrado no solo, utilizando a energia e os nutrientes para o seu próprio crescimento, incluindo compostos orgânicos complexos como a lignina e celulose. Fungos e bactérias são os principais responsáveis pela decomposição da serapilheira, e sua ação está diretamente relacionada com a qualidade nutricional do material a ser decomposto e como fatores climáticos, como temperatura e umidade, que são responsáveis por promover a atividade microbiana.

Parâmetros microbiológicos têm sido utilizados como importantes indicadores da qualidade de solo. Dentre os indicadores mais importantes da atividade microbiana estão a respiração do solo (que corresponde à liberação de $\mathrm{CO}_{2}$ pelos microrganismos, resultado da oxidação biológica de matéria orgânica a $\mathrm{CO}_{2}$ ), o carbono da biomassa 
microbiana do solo (definido como o componente vivo do solo excluindo a macrofauna e as raízes das plantas) e a atividade enzimática do solo. Por meio da avaliação destes indicadores, é possível avaliar as condições do solo para sustentar a produtividade de plantas e animais, mantendo e melhorando a qualidade do ar e da água, promovendo a saúde humana, animal e das plantas.

\section{Decomposição da serapilheira no Cerrado}

As savanas do Brasil Central, conhecidas como Cerrado, ocupam uma extensão de dois milhões de $\mathrm{km}^{2}$. Caracterizado por um mosaico de fisionomias vegetais, que inclui desde campos abertos até florestas densas, o Cerrado é um dos biomas terrestres de maior endemismo e diversidade de espécies. Estima-se que nesta região haja mais de 11.500 espécies de plantas, das quais aproximadamente 4.400 são endêmicas. É um ecossistema com distribuição marcadamente sazonal de precipitação e sua ocorrência se dá em solos intemperizados com alto conteúdo de alumínio e, consequentemente, baixo $\mathrm{pH}$ e disponibilidade de cálcio e magnésio. Além disso, é um sistema limitado pelas concentrações de nitrogênio $(\mathrm{N})$ e fósforo $(\mathrm{P})$ no solo.

No Cerrado, que tem solos pobres em nutrientes, a produtividade e a sustentabilidade do ecossistema dependem da ciclagem interna de nutrientes. As plantas do Cerrado apresentam mecanismos conservativos que minimizam a perda de nutrientes, como folhas escleromórficas e taxas de reabsorção alta para $\mathrm{P}$ e ocasionalmente também para $\mathrm{N}$, o que resulta na produção de uma serapilheira com elevada razão C:N e C:P. Isto acarreta uma baixa taxa de decomposição e mineralização e, assim, uma baixa disponibilidade de nutrientes no solo. Além disso, a forte sazonalidade da precipitação na região do Cerrado tem grande influência sobre os processos de decomposição e mineralização. Apesar da precipitação média anual ser relativamente alta, em torno de $1.500 \mathrm{~mm}$, ela é bastante sazonal o que determina que a decomposição e a mineralização ocorram primariamente durante a estação chuvosa.

\section{Atividades humanas: aumento da deposição atmosférica de $\mathrm{N}$ no Cerrado}

O aumento crescente da população humana e o desenvolvimento da agricultura e da atividade industrial têm se refletido em drásticas mudanças nos ciclos de nutrientes e na concentração de gases oxidados na atmosfera. Isto porque as atividades humanas têm provocado o aumento da emissão de $\mathrm{N}$ reativo $(\mathrm{Nr})$, que tem contribuído para alterar a ciclagem de nutrientes nos ecossistemas, principalmente devido ao impacto sobre a decomposição da serapilheira. O aumento da emissão de $\mathrm{Nr}$ no ambiente é causado principalmente pela queima de combustíveis fósseis e biomassa vegetal e pela aplicação de fertilizantes em grande escala. Com isso a quantidade de $\mathrm{N}$ fixado nos ecossistemas terrestres mais do que dobrou.

Historicamente, os aportes humanos de nitrogênio estavam concentrados nas regiões boreais ou temperadas do hemisfério norte. Entretanto, atualmente, $40 \%$ das aplicações globais de fertilizantes ocorrem nas regiões tropicais e subtropicais, e esta proporção deve aumentar dramaticamente nas próximas décadas. Segundo estimativas, em 40 anos, a taxa de deposição de nitrogênio será $50 \%$ maior na América Latina do que na América do Norte. Especificamente para o Brasil, tem sido registrado um aumento 
da entrada de $\mathrm{N}$ atmosférico nos ecossistemas terrestres em função principalmente da intensa atividade agrícola. Estima-se que para a região do Cerrado as deposições anuais de nitrogênio aumentem dos atuais $1-10 \mathrm{~kg} \mathrm{ha}^{-1}$ para até $50 \mathrm{~kg} \mathrm{ha}^{-1}$ por volta do ano 2050. Isto pode ter conseqüências dramáticas para estes ecossistemas, uma vez que as savanas tropicais da América Latina, entre as quais o Cerrado é a maior e mais diversa, são sistemas naturalmente limitados por nitrogênio.

Com o intuito de simular o cenário previsto de aumento da deposição atmosférica de $\mathrm{N}$ nos ecossistemas, alguns trabalhos têm realizado experimentos de adição de N. Os resultados mostram que a adição de $\mathrm{N}$ no solo pode mudar a concentração de nutrientes foliares, a disponibilidade de $\mathrm{N}$ no solo, a produção de biomassa e a diversidade de espécies. Porém, muito do que se sabe sobre a resposta dos ecossistemas, e em particular sobre o processo de decomposição ao enriquecimento de $\mathrm{N}$ no solo são resultados de experimentos de fertilização realizados em ecossistemas temperados. Uma revisão destes estudos indica que influência da adição de $\mathrm{N}$ sobre a decomposição é bastante variável, o que parece ser explicado ao menos em parte por variações na qualidade da serapilheira (conteúdo de $\mathrm{N}$ e lignina) e por diferenças na quantidade de $\mathrm{N}$ adicionado no solo (taxa de fertilização). Entretanto, não está claro se estes mesmos resultados se aplicam aos ecossistemas do Cerrado.

Alguns estudos mostram que muito do $\mathrm{N}$ atmosférico que entra nos sistemas tropicais é perdido por causa do aumento da taxa de nitrificação. Em consequência a este aumento na taxa de nitrificação e de perda de $\mathrm{N}$, há perda de cátions base e, por fim, diminuição do $\mathrm{pH}$ do solo, o que levaria à diminuição do estoque de carbono. Em experimento de fertilização em área de Cerrado localizada na parte central do Brasil, os pesquisadores mostraram que a adição de $\mathrm{N}$ no solo aumentou as concentrações de $\mathrm{N}$ nas folhas senescentes. Também foi observado que a fertilização com sulfato de amônia mudou o $\mathrm{pH}$ e a disponibilidade de $\mathrm{P}$ nas camadas mais profundas do solo.

Outro fator importante a ser considerado é a interação entre a sazonalidade da precipitação e deposição de N. Um estudo realizado na Reserva Ecológica do Panga mostrou que a adição de água levou a aumentos mais consistentes no crescimento e na reprodução de duas espécies de gramíneas nativas abundantes do Cerrado (Loudetiopsis chrysothrix e Tristachya leiostachya) do que a adição de nitrogênio ou do que a adição combinada de água e nitrogênio.

\section{Efeito da adição de $\mathrm{N}$ sobre a decomposição: um experimento de fertilização no Triângulo Mineiro}

Estudos experimentais no Cerrado sobre as respostas ecológicas a mudanças na quantidade de $\mathrm{N}$ depositados no solo ainda são poucos, embora este seja um dos biomas terrestres mais ameaçados pelo desmatamento. Os níveis de enriquecimento de $\mathrm{N}$ que representam a gama de deposições previstas para o bioma do Cerrado por volta de 2050 foram testados em um experimento na Reserva Ecológica do Panga, localizada a oeste do perímetro urbano do município de Uberlândia, em Minas Gerais. A reserva apresenta a maioria das fisionomias do Cerrado sendo o cerrado (sensu stricto) a vegetação dominante (Figura 1).

As 15 parcelas permanentes para realização do experimento de fertilização foram estabelecidas em área de cerrado ralo da reserva, mantendo uma distância mínima de 5 
$\mathrm{m}$ entre elas. Selecionadas aleatoriamente, um terço dessas parcelas recebeu ao longo de 5 anos o equivalente a $50 \mathrm{~kg}$ de $\mathrm{N}$ por hectare por ano (correspondente ao tratamento "alta adição de N"), outro terço das parcelas recebeu o equivalente a $20 \mathrm{~kg} \mathrm{~N}$ por hectare ano (correspondente ao tratamento "baixa adição de N"), enquanto que as parcelas restantes permaneceram como controles (sem adição de N) (Figura 2).

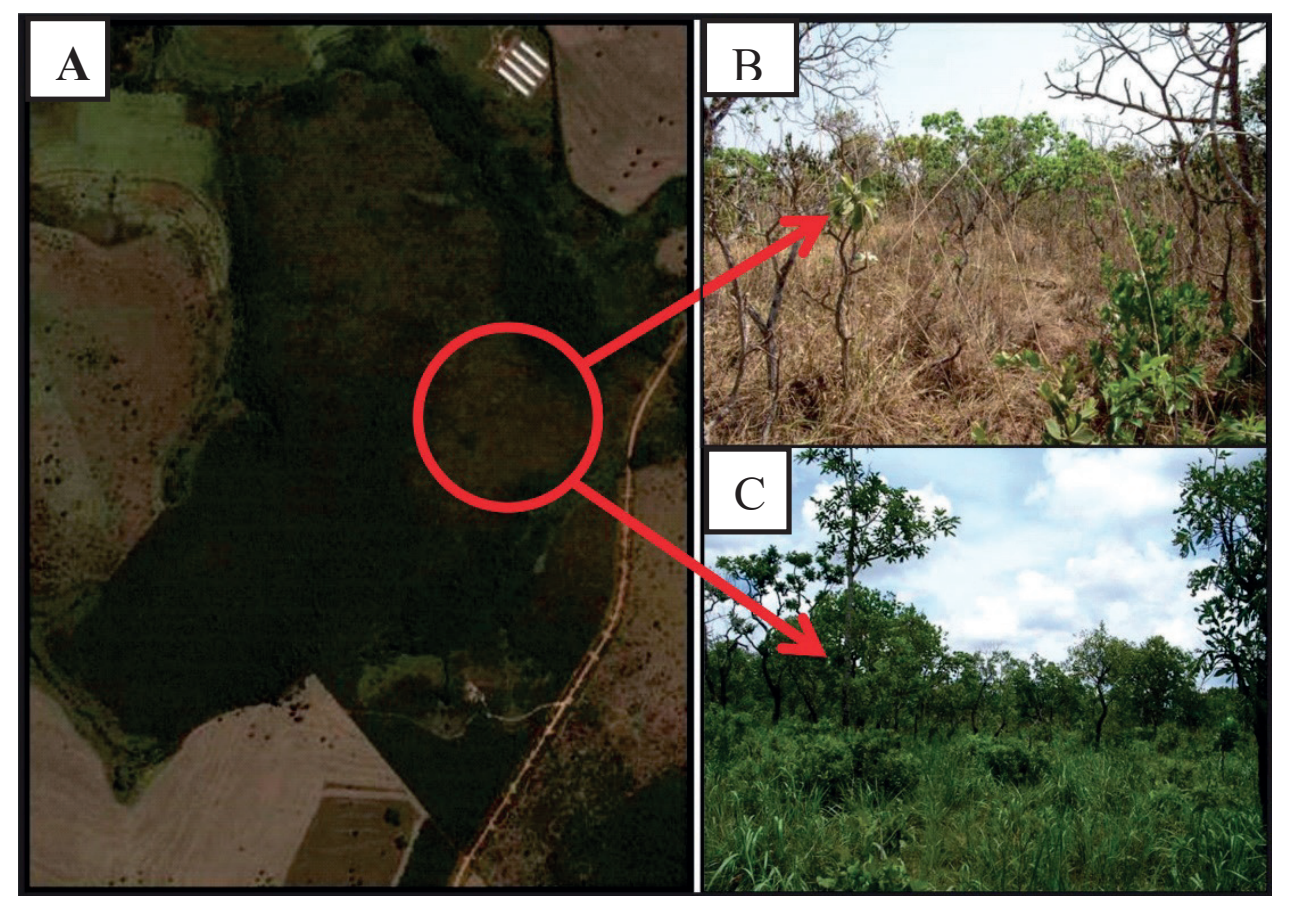

Figura 1. (A) Vista aérea da Reserva Ecológica do Panga e da área de cerrado ralo onde estão estabelecidas as parcelas experimentais de fertilização (B) na estação seca e na (C) estação chuvosa.

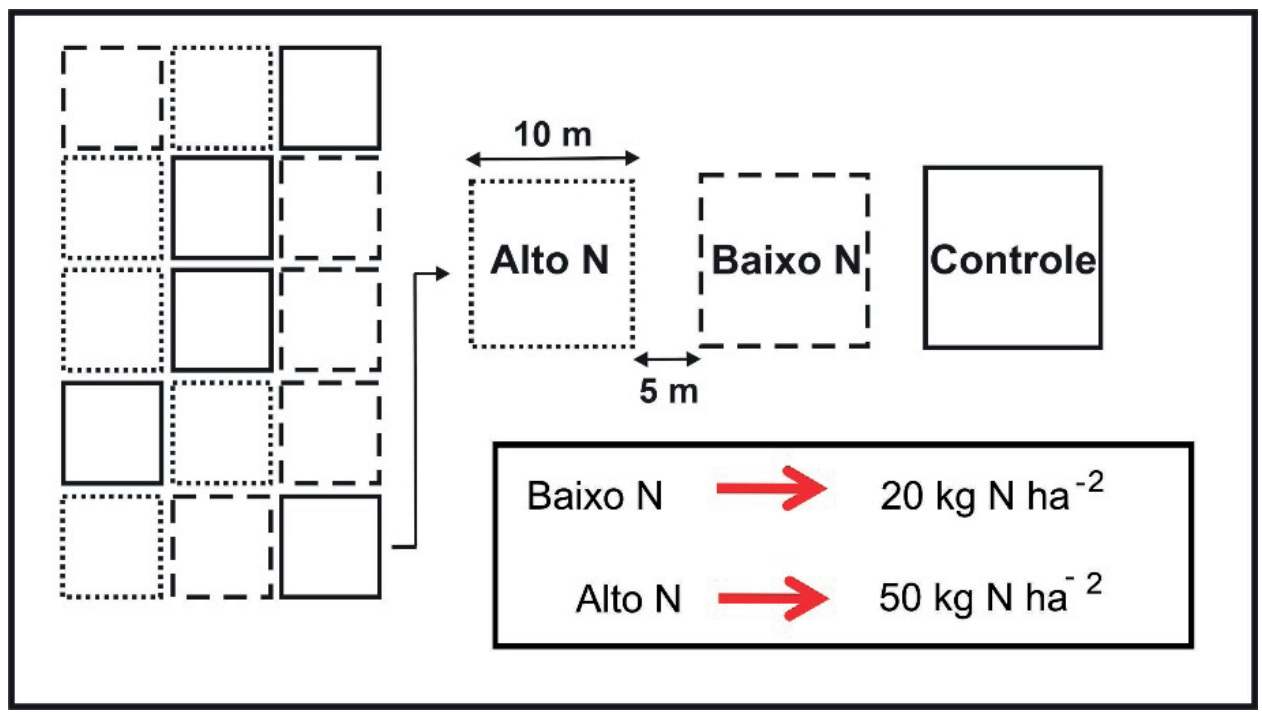

Figura 2. Mapa das parcelas experimentais onde o teor de nitrogênio foi manipulado. 
A fertilização teve início no segundo semestre de 2007. O nitrogênio foi adicionado na forma granular de nitrato de amônia $\left(\mathrm{NH}_{4} \mathrm{NO}_{3}\right)$, que é um fertilizante comumente usado na agricultura, e foi aplicado a lanço sobre a camada de serapilheira para evitar perturbação nas parcelas. A aplicação foi feita manualmente, seis vezes ao ano (três na estação chuvosa e três na seca) para minimizar perdas de $\mathrm{N}$ por denitrificação e lixiviação. Após dois anos de fertilização, iniciou-se a realização do experimento de decomposição utilizando o método de sacos de decomposição (Figura 3). A espécie escolhida para a confecção dos sacos de decomposição foi a espécie de gramínea Tristachya leiostachya Nees (Poaceae), que é muito comum na área de estudo. Para avaliar o efeito da adição de nitrogênio ao longo do tempo, este experimento foi repetido em três anos consecutivos: 2009, 2010 e 2011, durante a estação chuvosa, com início em novembro e término em março, visto que trabalhos anteriores na mesma área indicaram ser esse o período de maior decomposição do material.

Os resultados deste estudo mostraram que a serapilheira da gramínea Tristachya leiostachya coletadas em parcelas de alta adição de $\mathrm{N}$ decompôs mais rápido do que aquelas dos outros tratamentos. Além disso, em geral, a decomposição da serapilheira foi mais rápida nas parcelas que receberam adição elevada de $\mathrm{N}$ do que nas parcelas dos demais tratamentos. No entanto, estes efeitos foram variáveis entre os anos (Figura 3). Em 2009 observamos que, independente do tipo da serapilheira (coletada de plantas fertilizadas ou não), a decomposição foi mais rápida em parcelas submetidas à alta adição de N. Já em 2010, observamos uma inversão dos efeitos, onde a serapilheira coletada em parcelas de alta adição de $\mathrm{N}$ decompôs mais rápido que nas outras parcelas, independente do tipo de tratamento. Por fim, em 2011 não foi observado nenhum dos efeitos: tipo de serapilheira e tipo de tratamento das parcelas. Este efeito variado entre os anos foi atribuído a uma possível interação entre a adição de $\mathrm{N}$ e a precipitação. Isto porque de acordo com os dados de precipitação média anual, foi observado que, em geral, choveu mais em 2009 do que nos anos seguintes, principalmente se compararmos apenas os meses de novembro, dezembro e janeiro, período em que transcorreu o experimento.

Determinamos a concentração de $\mathrm{N}$ nas folhas mortas de plantas crescendo em cada um dos tratamentos para avaliar o efeito da adição de $\mathrm{N}$ na qualidade da serapilheira. Os resultados mostraram que adição de $\mathrm{N}$ aumentou a concentração de $\mathrm{N}$ na serapilheira, sendo que a serapilheira coletada em parcelas de alto $\mathrm{N}$ apresentou maior concentração de N (Figura 4). Apesar disso, no primeiro ano do experimento de decomposição (2009) - ao contrário dos demais (2010 e 2011) - não foi detectada uma maior taxa de decomposição da serapilheira oriunda das parcelas de alto $\mathrm{N}$. Isto indica que a adição de $\mathrm{N}$ afetou o processo de decomposição não apenas por mudar a qualidade da serapilheira, mas provavelmente também por fornecer aos microrganismos decompositores um nutriente limitante para eles por meio da adição de $\mathrm{N}$ no solo. Evidência a favor desta afirmação é que a decomposição da serapilheira é resultado primário da atividade de microrganismos decompositores, e estes requerem nutrientes da serapilheira em decomposição ou do solo ao redor. 


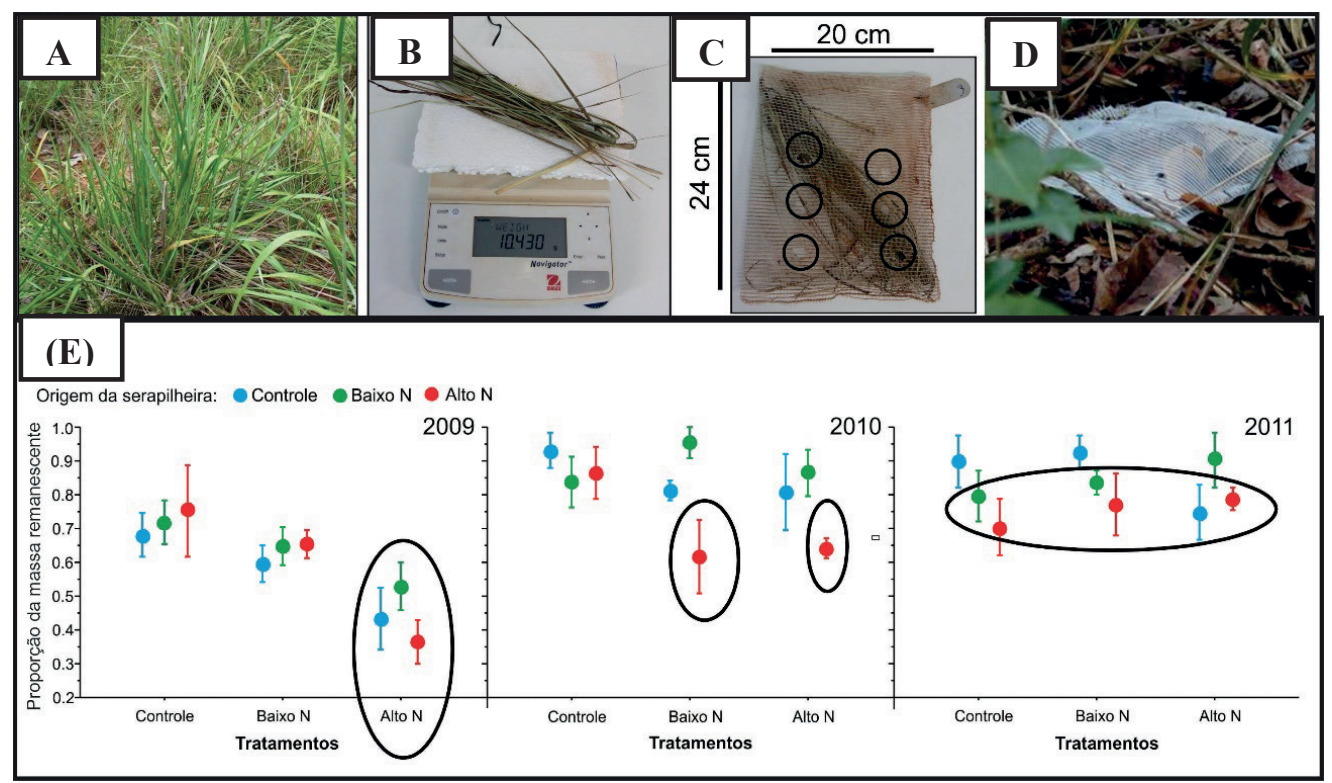

Figura 3. (A) Tristachya leiostachya, espécie comum no local de estudo; (B) Pesagem da serapilheira; (C) e (D) Saco de decomposição; (E) Diferenças na taxa de decomposição da serapilheira da gramínea Tristachya leiostachya nas parcelas submetidas à alta adição de $\mathrm{N}\left(50 \mathrm{~kg} \mathrm{~N} \mathrm{ha}^{-2}\right.$ ano $\left.^{-1}\right)$, baixa adição $(20 \mathrm{~kg}$ $\mathrm{N} \mathrm{ha}^{-2}$ ano $^{-1}$ ) e sem adição de $\mathrm{N}$ nos anos de 2009, 2010 e 2011.

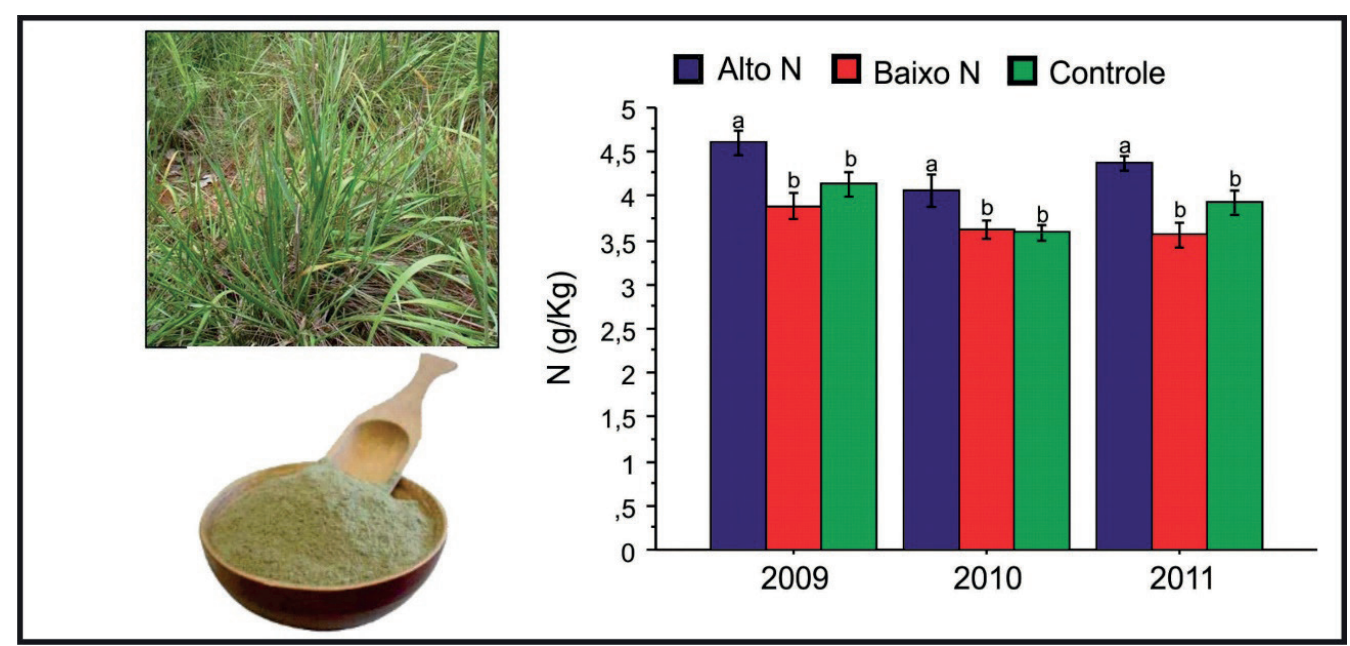

Figura 4. Concentração de nitrogênio na serapilheira produzida por Tristachya leiostachya em parcelas submetidas à alta $\left(50 \mathrm{~kg} \mathrm{~N} \mathrm{ha}^{-2}\right.$ ano $\left.^{-1}\right)$, baixa $\left(20 \mathrm{~kg} \mathrm{~N} \mathrm{ha}^{-2}\right.$ ano $\left.^{-1}\right)$ ou sem adição de $\mathrm{N}$ nos anos de 2009 , 2010 e 2011. Os valores são a média \pm erro padrão da média $(n=10)$.

Para determinar o efeito da adição de $\mathrm{N}$ sobre a atividade microbiana também foram feitas análises da qualidade do solo $\left(\mathrm{NH}_{4}\right.$ do solo) e parâmetros microbiológicos do solo (carbono da biomassa microbiana, respiração microbiana do solo, quociente metabólico - $\mathrm{qCO}_{2}$, atividade das enzimas $\beta$-glicosidase e urease). Baseado em estudos anteriores, era esperado que em sistemas limitados por $\mathrm{N}$ a adição de $\mathrm{N}$ no solo ao longo do tempo favoreceria a alocação de $\mathrm{N}$ pelos microrganismos para aumentar a produção e atividade dos microrganismos do solo. Entretanto, a análise de qualidade 
do solo e parâmetros microbiológicos medidos em 2011, quatro anos após o início do experimento, mostrou não haver diferenças entre os tratamentos de adição de $\mathrm{N}$. Este resultado foi coerente com o fato de que, ao menos neste, ano não foi encontrada diferenças na taxa de decomposição entre parcelas sujeitas a diferentes níveis de adição de N (Figura 5).

\section{Implicações para a conservação}

A importância do reaproveitamento de nutrientes que se dá pela decomposição da serapilheira é evidente em vegetações que se mantém em ecossistemas com baixa fertilidade dos solos, como as vegetações savânicas do Cerrado. Os resultados do experimento de decomposição, conduzidos em parcelas com aumento simulado na taxa de deposição atmosférica de $\mathrm{N}$ previstas para o Cerrado em 2050 -- sendo $20 \mathrm{~kg}$ $\mathrm{ha}^{-1}$ ano $^{-1} \mathrm{o}$ cenário mais otimista e $50 \mathrm{~kg} \mathrm{ha}^{-1}$ ano $^{-1}$ o mais pessimista -- mostrou que, sob o cenário mais pessimista, a adição de $\mathrm{N}$ afeta o processo de decomposição, que é o processo fundamental para a contínua ciclagem de nutrientes, pois influencia a fertilidade dos solos.

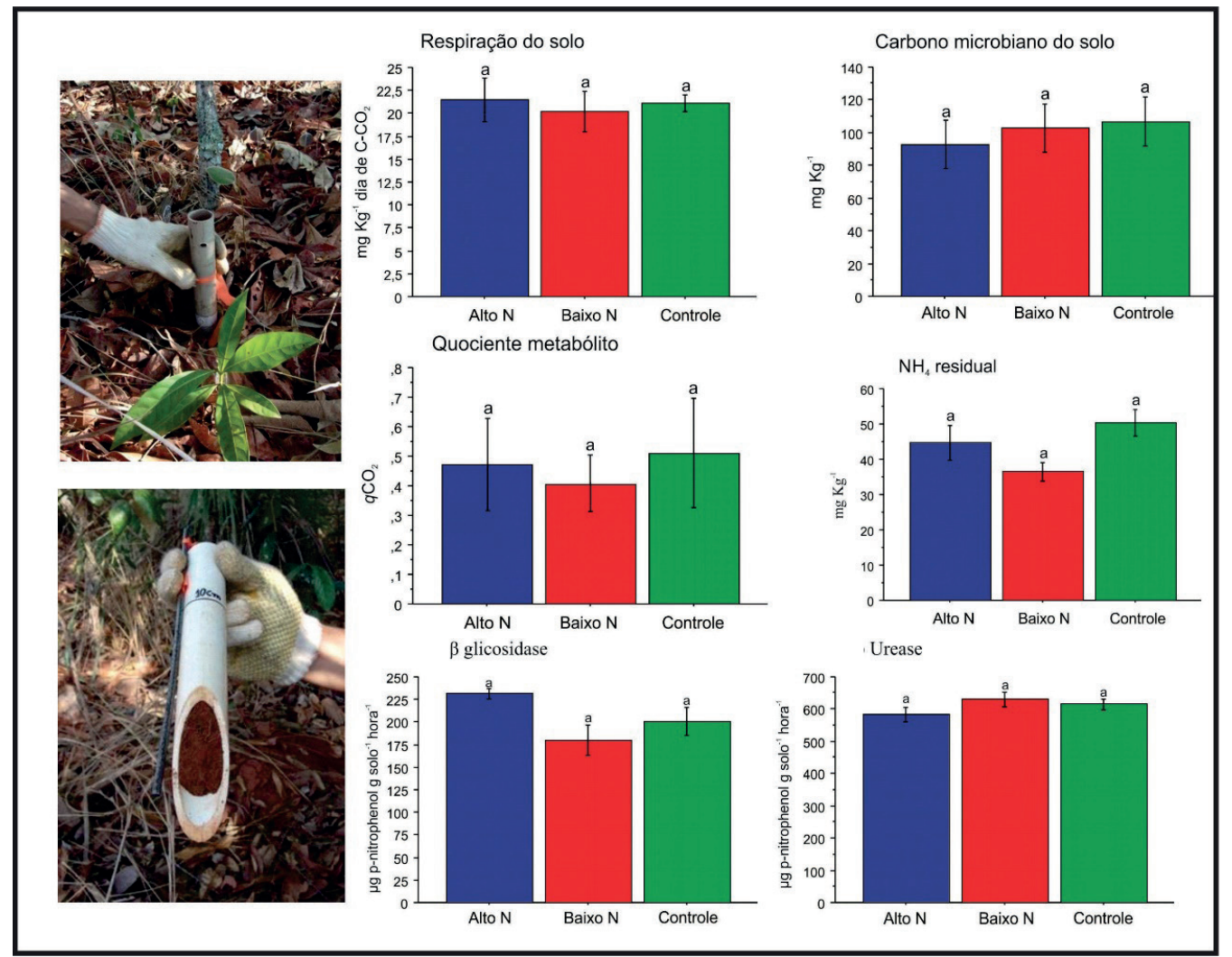

Figura 5. Respiração do solo (A), carbono da biomassa microbiana (B), quociente metabólico (C) e NH4 residual no solo (D) coletado nas parcelas submetidas à alta adição de $\mathrm{N}(50 \mathrm{~kg} \mathrm{~N}$ ha-1 ano-1), baixa adição (20 kg N ha-1 ano-1) ou sem adição de $\mathrm{N}$ (n=20 para cada tratamento). As amostras do solo foram coletadas em março de 2011. Os valores são a média \pm EP (erro padrão da média.). 
Os resultados aqui apresentados reforçam que a vegetação savânica do Cerrado é limitada pela disponibilidade deste elemento uma vez que o aumento da disponibilidade de N no solo aumentou a sua concentração nas folhas. Por outro lado, a atividade microbiana não mostrou respostas ao aumento da deposição $\mathrm{N}$ ao longo do tempo. Isto indica que a atividade microbiana do solo tende a ser mais sensível a outros fatores, como a disponibilidade de água (via precipitação), do que a adição de $\mathrm{N}$ no solo. Evidência em favor a esta afirmação é de que uma possível interação entre a precipitação e o efeito da adição de $\mathrm{N}$ sobre a atividade microbiana já foi observada em estudos conduzidos em ecossistemas temperados; porém, para o Cerrado ainda há pouco conhecimento sobre esta interação mesmo sabendo que tanto a água quanto o $\mathrm{N}$ são recursos determinantes para atividade microbiana do solo. Dessa forma, avaliar em longo prazo a decomposição e o conteúdo de nutrientes sobre os solos de cerrado pode refletir a capacidade produtiva do solo e o seu potencial de recuperação em consequência das modificações que poderão ocorrer devido a alterações ambientais.

\section{Para saber mais}

Bustamante MMC, Medina E, Asner GP, Nardoto GB, Garcia-Montiel DC. (2006). Nitrogen cycling in tropical and temperate savannas. Biogeochemistry 79: 209-237 doi:/10.1007/s10533-006-9006-X

Bustamante, MMC, de Brito DQ, Kozovits AR, Luedemann G, de Mello TRB, Pinto AS, Munhoz CBR, Takahashi, FSC (2012) Effects of nutrient additions on plant biomass and diversity of the herbaceous-subshrub layer of a Brazilian savanna (Cerrado). Plant Ecol 213: 795-808 doi:10.1007/s11258-012-0042-4

Chapin III, F. S., Matson, P. A. \& Mooney, H. A., (2002). Principles of terrestrial ecosystem ecology. 423p Springer, USA.

Copeland SM, Bruna EM, Silva LVB, Mack MC, Vasconcelos HL. (2012). Short-term effects of elevated precipitation and nitrogen on soil fertility and plant growth in a Neotropical savanna. Ecosphere 3: 31-51 doi:10.1890/ES11-00305.1

Knorr M, Frey SD, Curtis PS. (2005). Nitrogen additions and litter decomposition: a meta-analysis. Ecology 86:3252-3257 doi:10.1890/05-0150

Galloway JN, Townsend AR, Erisman JW, Bekunda M, Cai Z, Freney JR, Martinelli LA, Seitzinger SP, Sutton MA. (2008). Transformation of the nitrogen cycle: recente trends, questions and potential solutions. Science 320: 889-892 doi:10.1126/science.1136674

Jacobson TKB, Bustamante MMC, Kozovits AR. (2011). Diversity of shrub tree layer, leaf litter decomposition and $\mathrm{N}$ release in a Brazilian Cerrado under $\mathrm{N}, \mathrm{P}$ and $\mathrm{N}$ plus $\mathrm{P}$ additions. Environ Pollut 159: 2236-2242 doi:10.1016/j.envpol.2010.10.019

Kozovits AR, Bustamente MMC, Garofalo CR, Bucci S, Franco AC, Goldstein G, Meinzer FC. (2007). Nutrient resorption and patterns of litter production and decomposition in a Neotropical savanna. Funct Ecol 21:1034-1043 doi:10.1111/j.13652435.2007.01325.x

Silva LVB, Vasconcelos HL, Mack M, Ferreira A, Bruna EM. (2020). Effects of experimental nitrogen enrichment on soil properties and litter decomposition in a Neotropical savanna, Austral Ecology (no prelo). 


\section{REGÊNCIA E ARTE \\ E D I T O R A \\ Diagramação * Impressão * Consultoria \\ Publicação de ebooks}

(34) 98859-69840

E-mail: regenciaearte@gmail.com www.regenciaearte.com.br 


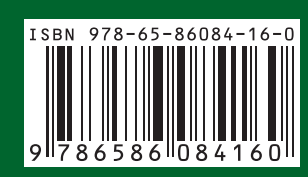

